JUAN FRANCISCO TEMOCHE ESQUIVEL

\title{
AVALIAÇÃO DA INFLUÊNCIA DO CHOQUE TÉRMICO NA ADERÊNCIA DOS REVESTIMENTOS DE ARGAMASSA
}

Tese apresentada à Escola Politécnica da Universidade de São Paulo para obtenção do título de Doutor em Engenharia.

São Paulo

2009 
JUAN FRANCISCO TEMOCHE ESQUIVEL

\section{AVALIAÇÃO DA INFLUÊNCIA DO CHOQUE TÉRMICO NA ADERÊNCIA DOS REVESTIMENTOS DE ARGAMASSA}

Tese apresentada à Escola Politécnica da Universidade de São Paulo para obtenção do título de Doutor em Engenharia.

Área de Concentração:

Engenharia de Construção Civil

Orientadora:

Prof $^{a}$. Dra ${ }^{a}$. Mércia M. S. B. Barros

São Paulo, 2009 
Este exemplar foi revisado e alterado em relação à versão original, sob responsabilidade única do autor e com a anuência de seu orientador.

São Paulo, de agosto de 2009.

Assinatura do autor

Assinatura do orientador

FICHA CATALOGRÁFICA

Temoche Esquivel, Juan Francisco

Avaliação da influência do choque térmico na aderência dos revestimentos de argamassa / J.F. Temoche Esquivel. -- ed.rev. -- São Paulo, 2009.

$262 \mathrm{p}$.

Tese (Doutorado) - Escola Politécnica da Universidade de São Paulo. Departamento de Engenharia de Construção Civil.

1. Revestimentos de fachadas 2. Argamassa I. Universidade de São Paulo. Escola Politécnica. Departamento de Engenharia de Construção Civil II. t. 
Aos meus pais Fernando e Juana e aos meus irmãos A Isis, minha filha, um anjo que chegou na minha vida... 


\section{AGRADECIMENTOS}

Ao concluir esta tese quero expressar meu agradecimento ao criador e a todas as pessoas e instituições que contribuíram direta e indiretamente em diferentes momentos desta longa jornada.

À Prof. Dra. Mércia M. S. B. Barros pela orientação muito competente e objetiva e pelo constante apoio para o desenvolvimento deste trabalho e nos momentos decisivos desta etapa.

Ao Prof. Dr. Sabbatini pelos ensinamentos e pelo incentivo para iniciar o curso de pós aqui na Poli.

Ao Prof. Dr. Vanderley John, pelo apoio a este trabalho, as sugestões e opiniões apontadas no exame de qualificação.

Aos professores Francisco Cardoso, Silvio Melhado, Ubirací Souza, Luiz Sérgio Franco do TGP, pelos ensinamentos e sugestões para o desenvolvimento do trabalho.

Ao Prof. Dr. Helio Greven pelas contribuições dadas durante o exame de qualificação.

Aos professores Antonio Figueiredo, Silvia Selmo, Kai Uemoto, Maria Alba Cincotto, Rafael Pileggi pelas oportunas sugestões nas oportunidades que surgiram.

Aos professores Ruy Pauletti, Ricardo França, João Della Bella pela ajuda e os ensinamentos e sugestões durante a etapa de desenvolvimento da modelagem numérica.

Aos participantes do Consitra e em especial a Fábio Campora, Luiz Enrique Ceotto, Elza, e todos os participantes pelas sugestões e discussões durante as reuniões mensais.

Ao prof. Dr. Telmo Deifeld pela ajuda e desenvolvimento dos modelos para analise com elementos finitos.

Ao Dr. Rubens Ramires pela ajuda na montagem dos equipamentos de aquisição de sinais e no desenvolvimento do programa de interface no Labview.

Aos amigos da pós da sala Buraco Negro onde este trabalho começou a ser desenvolvido, Maurício Resende, Amaury Siqueira, Rosiany, Maria Júlia, Luciana, Max Junginger, Fábia Marcondes, Alexandre Brites pela troca de idéias e sugestões e pelos momentos de alegria. Aos atuais usuários da Buraco Negro, Ricardo, Jamil, Renato. Aos amigos da Asteróide, Heitor, Fabiana, Juarez, Antonio Acácio, Odair, Flávio Maranhão, Cláudio pelos momentos compartilhados seja no esporte seja nos momentos de alegria.

Aos amigos da microestrutura, ao grande Cléber, sempre prestativo e modesto, da mesma forma ao César, Waleska, Fábio, Heloísa, Andrea.

Ao pessoal dos laboratórios que sempre foram prestativos e colaboradores, Reginaldo, Mario, Adilson, Talita, e em especial a Renata.

A Fátima, Denise da secretaria da pós e a Patrícia, Edson, Rogério sempre prontos para ajudar a resolver problemas de informática. 
Às bibliotecárias Leo, Vilma e Fátima e à Engrácia Maria Bartuciotti pelo competente apoio e assistência amiga.

À Flávio Munhoz da ABCP pela ajuda com a produção dos substratos de concreto., Ao Dr. Wayne Assis pelas dicas no trabalho experimental

Aos estagiários que muito me ajudaram na hora de botar as mãos na massa, Júlio Spalanzani e Rafael Zillig.

Ao CNPq pela concessão da bolsa de doutorado e os auxílios para apresentação de trabalhos em congressos

Ao Consitra pelo apoio no programa experimental e as discussões nas reuniões do projeto.

Aos amigos de sempre Hugo, Danidtza, Mario, Marco, Jorge Risco, Wellington, Cecília, Leslie, Ramona, Zêzinho, Abelardo, Hélcio. 


\section{RESUMO}

Neste trabalho enfoca-se o efeito da variação térmica na degradação da aderência de revestimentos de argamassa.

Dentre os diversos fatores que condicionam a aderência dos revestimentos de argamassa, destaca-se aqui o cenário crítico definido pela presença de macrodefeitos na interface revestimento-base e também pela intensidade com que ocorre a variação de temperatura, encontrando-se uma situação extrema quando da ocorrência do choque térmico.

Assim, o objetivo desta pesquisa é avaliar, de maneira experimental, o efeito de sucessivos ciclos de choque térmico na resistência de aderência de revestimentos de argamassa, em duas situações limites de taxa de macro-defeitos no contato entre o revestimento e a base e para duas distintas argamassas.

Para dar suporte ao trabalho experimental foi elaborado um modelo computacional paramétrico, utilizando modelagem com elementos finitos. Com ele foi possível obter a distribuição de temperaturas, bem como as deformações e tensões geradas no revestimento, variando-se a intensidade do contato revestimento-base e alterandose as características da argamassa de revestimento. A partir de então, definiram-se as variáveis de maior influência e a geometria dos corpos prova, bem como as condições de contorno a serem utilizadas no programa experimental.

O programa experimental foi desenvolvido em duas etapas: uma etapa piloto e outra definitiva. Para sua realização foram desenvolvidos e construídos os equipamentos para execução e controle dos ensaios cíclicos de choque térmico.

Finalmente, foram realizados ensaios de resistência de aderência do revestimento e avaliados os efeitos de cada uma das variáveis estudadas, empregando-se suporte estatístico.

Pelos resultados pode-se comprovar que os macro-defeitos na interface revestimento-base provocam diminuição na resistência de aderência a qual é agravada quando da ocorrência de cíclicos choques térmicos, ocorrendo a situação mais crítica para os revestimentos com maior módulo de elasticidade.

Palavras chave: revestimentos de argamassa, choque térmico, tensões térmicas, macro-defeitos de interface, resistência de aderência. 


\begin{abstract}
The present study focus on thermal variation effects on mortar rendering bonding degradation.

Among the variety of factors that condition the bonding of mortar renderings, a critic scenario can be defined by the existence of interface macro-flaws between mortar rendering and substrate, and by the thermal variation intensity in the extreme situation of thermal shock.

This research aims to experimentally evaluate the effects of continuous thermal shock cycles on the bonding strength of mortar renderings in two macro-flaw rate extreme situations in the contact surface between mortar rendering and substrate for two types of mortar.

A parametric model based on finite element analysis has been developed to support the experimental work, which allowed ascertaining temperature profile as well as stress and strain distribution in the mortar rendering by changing the macro-flaws rate and mortar rendering properties. As a result, one could define the variables with higher influence and test panel geometry, as well as the boundary conditions to be used in the experimental program.
\end{abstract}

The experimental program has been performed first in pilot scale and then in a definite stage, which required designing and building of equipment for the execution and control of cyclic thermal shock laboratory tests.

Furthermore, bond strength tests have been performed on the mortar rendering samples, and effects of variables have been analyzed by using statistical help.

Results have shown that the existence of interfacial macro-flaws decreases bond strength values between mortar rendering and substrate, and this scenario worsens under thermal shock. Mortar renderings with higher Young's modulus (E) are more affected.

Key words: mortar renderings, thermal shock, thermal stresses, interfacial macroflaws, bond strength. 


\section{LISTA DE FIGURAS}

Figura 1-1: Variação da temperatura do ar na Estação Climática da EPUSP - 16 de jan. 2003

Figura 2-1: Modelos de zona de transição pasta-agregado (Breton et al., 1993)

Figura 2-2: Zona de transição entre pasta e grão de areia para argamassa com 28 dias. Fonte:

Diamond e Kjellsen (2007).

Figura 2-3: Interface base-revestimento com argamassa de cimento e areia (1:3 em volume) aplicada sobre substrato cerâmico - figura ampliada 20 vezes empregando-se lupa estereocópica (CARASEK, 1996).

Figura 2-4: Seção transversal de corpo de prova (a) e análise da imagem da interface de um quadrante selecionado na seção transversal (b) Fonte: ANTUNES (2005).

Figura 2-5: Processos de transferência de calor nos revestimentos externos no período diurno.

Figura 2-6: Processos de transferência de calor nos revestimentos externos no período noturno.

Figura 2-7: Variação da condutividade térmica de concreto, argamassa e pasta de cimento em função da idade (a), e variação da condutividade térmica de concreto em função da relação a/c e do conteúdo de umidade das amostras (b). Fonte: Kim et al (2003)...........56

Figura 2-8: Variação do módulo de elasticidade secante da argamassa em função da temperatura. Fonte: Fu et al (2004).

Figura 3-1: Distribuição de temperatura e tensões em uma placa resfriada na superfície .....

Figura 3-2: Ilustração do sólido modelado. Para a modelagem em elementos finitos foi considerada a seção transversal limitada para área ABCD. Fonte: Collin e Rowcliffe (2000).

Figura 3-3: Distribuição de temperaturas e tensões na seção ABCD do sólido modelado (a) e variação das tensões ao longo do tempo na línea $\mathrm{AB}$ do sólido da Figura anterior.

Figura 3-4: Deformação térmica requerida para iniciar a propagação da fissura em função do comprimento da fissura e da densidade de fissuras (N). Fonte: Hasselman (1969) ..........73

Figura 3-5: Comprimento da fissura em função da diferença de temperatura no choque térmico. Fonte: Hasselman (1969).

Figura 3-6: Variação da resistência em função da severidade do choque térmico. Fonte: Hasselman (1969)

Figura 3-7: Classificação de materiais cerâmicos pelo critério de falha controlado pela sua tenacidade. (LU e FLECK, 1998)..

Figura 3-8: Variação de temperatura que resulta no choque térmico em revestimentos externos

Figura 3-9: Esquema de análise do choque térmico no revestimento de argamassa com a temperatura inicial da fase interna da vedação mantida constante $T_{i}$ e com $T_{i}>T_{\text {: }}$

Figura 3-10: Esquema mostrando a flexão provocada por tensões de origem térmica

Figura 3-11: Variação da temperatura da parede (corpo de prova) com diminuição de temperatura atingindo valores abaixo de $0^{\circ} \mathrm{C}$. 
Figura 3-12: Influência dos ciclos de aquecimento e resfriamento na resistência de aderência do revestimento cerâmico.

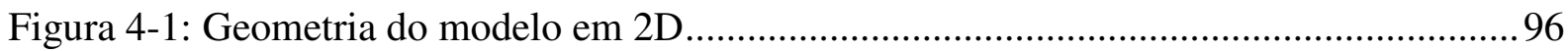

Figura 4-2: Geometria dos elementos PLANE13 e PLANE55 do Ansys ................................96

Figura 4-3: Malha de elementos finitos e condições de contorno consideradas para a análise numérica.

Figura 4-4: Geometria do Modelo 3D: substrato - 300mm x400mm x100mm e revestimento $300 \mathrm{~mm} \times 400 \mathrm{~mm} \times 30 \mathrm{~mm}$.....

Figura 4-5: Geometria dos elementos finitos utilizados

Figura 4-6: (a) Tipo de malha considerada e condições de contorno e (b) carregamento térmico

Figura 4-7: Modelo 2D com 35\% de macro-defeitos.

Figura 4-8: Geometria e distribuição de macro-defeitos (7\% e 42\%) no modelo tridimensional

Figura 4-9: Variação da posição e comprimento do macro-defeito e sua influência na distribuição de temperaturas

Figura 4-10: Geometria dos modelos com o início dos macro-defeitos de interface na borda do bloco

Figura 4-11: Geometria dos modelos com o início dos macro-defeitos de interface a $2 \mathrm{~mm}$ da borda do bloco

Figura 4-12: Geometria dos modelos com o início dos macro-defeitos de interface a $4 \mathrm{~mm}$ da borda do bloco

Figura 4-13: Geometria dos modelos com o primeiro macro-defeito de interface a $6 \mathrm{~mm}$ da borda.

Figura 4-14: Diferentes taxas de macro-defeitos uniformemente distribuídos: a) 0\%, b) 7\%, c) $14 \%$, d) $21 \%$, e) $28 \%$, f) $35 \%$, g) $42 \%$

Figura 4-15: Geometrias dos modelos com 0,20 m de comprimento 103

Figura 4-16: Geometrias dos modelos com $0,50 \mathrm{~m}$ de comprimento 103

Figura 4-17: Geometrias dos modelos com 1,00 m de comprimento.................................... 103

Figura 4-18 - Geometrias dos modelos com 2,00 m de comprimento................................... 103

Figura 4-19 - Geometrias dos modelos com 4,00 m de comprimento.................................. 103

Figura 5-1: Atividades Programa Experimental .................................................................... 105

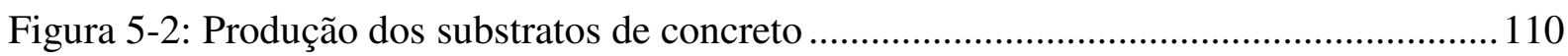

Figura 5-3: Cura das bases de concreto por imersão, durante os 6 dias seguintes à desenforma feita com 1 dia.

Figura 5-4: Argamassadeira de eixo horizontal e projetor de argamassa tipo "caneca" empregados no preparo da argamassa e na sua aplicação, respectivamente.

Figura 5-5: Imagem de macro-defeitos de interface base-revestimento de argamassa para identificação do defeito típico a ser empregado no programa experimental. 
Figura 5-6: Geometria e distribuição de macro-defeitos (7\% e 42\%), no modelo tridimensional, utilizados na simulação matemática.

Figura 5-7: Reprodução de macro-defeitos de interface com a) borracha adesiva, e b) silicone

Figura 5-8: (a) Tela para impressão de macro-defeitos e (b) gabarito metálico para correção dos macro-defeitos resultantes da serigrafia.

Figura 5-9: Reprodução dos macro-defeitos sobre a superfície do substrato. 116

Figura 5-10: Efeito dos macro-defeitos simulados na interface base-revestimento. Imagem com aumento de $13 x$ (a) e 20x (b)

Figura 5-11: Caixa de madeira para isolamento lateral dos corpos de prova. 118

Figura 5-12: Impermeabilização das laterais dos corpos de prova para evitar a infiltração de água no período de resfriamento.

Figura 5-13: Montagem de suporte para colocação dos corpos de prova

Figura 5-14: Calha utilizada para coleta de água no período de resfriamento

Figura 5-15: (a) Painel para aquecimento dos corpos de prova em funcionamento; (b) distribuição de número de lâmpadas por corpo de prova; (c) posicionamento na frente do suporte

Figura 5-16: (a) Estrutura montada para realização dos ensaios de choque térmico; (b) momento de resfriamento dos corpos de prova....

Figura 5-17: (a) Estrutura para resfriamento no início do período; (b) coleta da água em calha para posterior evacuação.

Figura 5-18: a) Equipamento de aquisição de sinais e (b) formato de interface do programa de aquisição de sinais.

Figura 5-19: Montagem de sistema de aquisição de temperaturas e instalação dos sensores nos corpos de prova.

Figura 5-20: Diferenças de temperatura superficial do corpo de prova a temperatura ambiente (a), no momento do aquecimento (b) e após um minuto do resfriamento (c).

Figura 5-21: Equipamentos de controle da temperatura nos corpos de prova........................ 128

Figura 5-22: Ensaios de absorção capilar na superfície dos substratos .

Figura 5-23: Gabarito para aplicação do revestimento e chapisco no gabarito lateral do revestimento

Figura 5-24: a) Colocação dos materiais secos na argamassadeira e b) colocação e bandeja perfurada para adição da água.

Figura 5-25: Ensaio de squeeze-flow na definição do teor de água para as argamassas........ 131

Figura 5-26: Tempo utilizado na seqüência de mistura da argamassa .

Figura 5-27: Transporte (a) e projeção de argamassa e (b) proteção dos corpos de prova adjacentes

Figura 5-28: Acabamento superficial dos corpos de prova empregando-se desempenadeira de madeira. 
Figura 5-29: Condições de secagem dos corpos de prova: a) filme de polietileno cobrindo a superfície do revestimento; (b) porta de entrada da câmara úmida em que serão acondicionados os corpos de prova durante 28 dias

Figura 5-30: Cura térmica dos corpos de prova de referência.

Figura 5-31: Termopares colados na superfície do revestimento (a) e detalhe da proteção à passagem de água nas bordas da fita adesiva utilizadas.

Figura 5-32: (a) Ensaio do choque térmico com resfriamento da câmara isolante; (b) e aceleração da secagem superficial por convecção.

Figura 5-33: (a) Corte dos corpos de prova com aspiração dos resíduos; e (b) colagem das pastilhas de alumínio.

Figura 5-34: Realização do ensaio de resistência de aderência à tração (a) e registro da forma de ruptura (b) .

Figura 6-1: Distribuição de temperaturas em modelos 2D e 3D para: a) revestimento com $\mathrm{E}=$ $2 \mathrm{GPa}$ e b) revestimento com $\mathrm{E}=15 \mathrm{GPa}$.

Figura 6-2: Variação do gradiente temperatura entre a superfície do revestimento e sua interface com a base em função da espessura do revestimento.

Figura 6-3:Tensões normais, segundo a direção Y em modelos 2D para módulos de elasticidade do revestimento de a) $2 \mathrm{GPa}$ e b) $15 \mathrm{GPa}$.

Figura 6-4:Tensões normais, segundo a direção $\mathrm{Z}$ em modelos 3D para módulos de elasticidade do revestimento de a) $2 \mathrm{GPa}$ e b) $15 \mathrm{GPa}$

Figura 6-5: Perfil de temperaturas para o modelo 2D com $42 \%$ de macro-defeitos e revestimento com módulo de elasticidade de $15 \mathrm{GPa}$.

Figura 6-6: Distribuição de tensões normais verticais em a) modelo 2D com taxa de macrodefeitos de interface de 42\%; e b) modelo 3D com 7\% de taxa de macro-defeitos

Figura 6-7:Resultados da simulação para avaliação dos deslocamentos nos corpos com espessura de substrato de $2,5 \mathrm{~cm}$, sendo o revestimento de $3,0 \mathrm{~cm}$ e módulo de elasticidades de a) $2 \mathrm{GPa}$ e b) $15 \mathrm{Gpa}$.

Figura 6-8:Resultados da simulação de um quarto do modelo em 3D para os deslocamentos verticais nos corpos com espessura de substrato de $10 \mathrm{~cm}$, sendo o revestimento de 3,0cm e módulo de elasticidades de a) $2 \mathrm{GPa}$ e b) $15 \mathrm{GPa}$.

Figura 6-9:Distribuição de tensões normais em $\mathrm{Z}$ em 1/4 de modelos tridimensionais e na superfície de interface do revestimento (afastado da base), mostrando a com base de 100 mm de espessura e módulo de: a) 2 GPa e b) 15 GPa......

Figura 6-10: (a) Perfil de temperaturas em revestimentos com 25 e $50 \mathrm{~mm}$ de espessura e (b) gradiente de temperatura resultante entre a superfície e a interface em função da espessura do revestimento.

Figura 6-11: Comparativo das tensões principais máximas $\left(S_{1}\right)$ para modelos com duas espessuras, dois valores de módulo de elasticidade e três taxas de macro-defeitos de interface.

Figura 6-12: Tensões normais verticais e de cisalhamento, para o caso de revestimento com $25 \mathrm{~mm}$ de espessura e módulo de elasticidade de $15 \mathrm{GPa}$. 
Figura 6-13: Detalhe das tensões normais verticais para revestimentos com espessura de 25 $\mathrm{mm}$ e $50 \mathrm{~mm}$ e com módulo de deformação de $2 \mathrm{GPa}$.

Figura 6-14: Detalhe das tensões de cisalhamento para revestimentos com módulos de elasticidade de 2 e $15 \mathrm{GPa}$ e com espessura de a) $25 \mathrm{~mm}$ e b) $50 \mathrm{~mm}$.

Figura 6-15:Variação da temperatura na interface em função da variação da taxa de macrodefeitos: (a) para 4 espessuras de revestimento (b) para a espessura de $25 \mathrm{~mm}$.

Figura 6-16: Variação das máximas tensões normais verticais em função da taxa de macrodefeitos e variando a espessura do revestimento de $25 \mathrm{~mm}$ a $62,5 \mathrm{~mm}$ para revestimento com módulo de elasticidade de a) $2 \mathrm{GPa}$ e b) $15 \mathrm{GPa}$

Figura 6-17: Variação das máximas tensões de cisalhamento em função da taxa de macrodefeitos e variando a espessura do revestimento de $25 \mathrm{~mm}$ a $62,5 \mathrm{~mm}$ para revestimento com módulo de elasticidade de a) $2 \mathrm{GPa}$ e b) $15 \mathrm{GPa}$

Figura 6-18: Variação das máximas tensões de cisalhamento em função do comprimento do macro-defeito e da sua proximidade à borda do modelo, para revestimento com módulo de elasticidade de 2 e $15 \mathrm{GPa}$.

Figura 6-19:Simulação de choque térmico em prisma de argamassa bi-engastado

Figura 6-20: Valores de tensão térmica máxima para argamassas com diferentes módulos de elasticidade para diferentes faixas de variação de temperatura.

Figura 6-21: Valores de tensão térmica máxima com fator de atenuação para argamassas com diferentes módulos de elasticidade para diferentes faixas de variação de temperatura.. 160

Figura 6-22:Distribuição granulométrica da areia.

Figura 6-23: Percentagem volumétrica dos constituintes das argamassas utilizadas no experimento

Figura 6-24: Curvas de carga versus deslocamento obtidas no ensaio de squeeze-flow para as argamassas utilizadas no experimento: S/AIA e C/AIA .

Figura 6-25: Relação entre o módulo de elasticidade e as propriedades mecânicas das argamassas utilizadas no programa experimental

Figura 6-26: a) Corte do revestimento para extração de prismas para ensaios mecânicos e b) ensaio de tração na flexão em prisma extraído do revestimento .....

Figura 6-27: Distribuição dos corpos de prova no painel de ensaio

Figura 6-28: Distribuição média de temperaturas nos ensaios de choque térmico para as combinações: a) $0 \%$ S/AIA; b) $0 \%$ C/AIA; c) 35\% S/AIA, e d) 35\% C/AIA

Figura 6-29:Temperaturas superficiais nas 4 combinações nos primeiros $15 \mathrm{~min}$. do aquecimento.

Figura 6-30: Temperaturas superficiais para as 4 combinações entre os 15 min e $3 \mathrm{~h}$ do aquecimento

Figura 6-31: Temperaturas superficiais para as 4 combinações no período do choque térmico entre as $3 \mathrm{~h}$ e $4 \mathrm{~h}$ do ensaio.

Figura 6-32: Distribuição de temperaturas superficiais para as 4 combinações no primeiro ciclo de choque térmico. 
Figura 6-33: Temperaturas médias nas interfaces base-revestimento dos corpos de prova no período de aquecimento e resfriamento para as combinações 0\% S/AIA, 0\% C/AIA, 35\% S/AIA e $35 \%$ C/AIA.

Figura 6-34: Temperaturas nas interfaces base-revestimento dos corpos de prova no período inicial de aquecimento até os 15 minutos $0 \%$ S/AIA,e $0 \%$ C/AIA, 35\% S/AIA e $35 \%$ C/AIA

Figura 6-35: Temperaturas nas interfaces base-revestimento dos corpos de prova no período dedos 15 minutos até $3 \mathrm{~h}$ de aquecimento para as combinações: 0\% S/AIA, 0\% C/AIA, $35 \%$ S/AIA e $35 \%$ C/AIA.

Figura 6-36: Temperaturas nas interfaces base-revestimento dos corpos de prova no período de aquecimento e resfriamento para as combinações 35\% S/AIA e 35\% C/AIA.

Figura 6-37:Gradientes de temperatura entre a superfície e interface do corpo de prova das combinações a) $0 \%$ S/AIA e b) $0 \%$ C/AIA

Figura 6-38: Gradientes de temperatura entre a superfície e interface do corpo de prova da combinação $35 \%$ S/AIA

Figura 6-39: Comparativo dos valores médios de resistência de aderência de todos os fatores analisados.

Figura 6-40:Variação da resistência de aderência em função do efeito principal: (a) choque térmico, (b) $0 \%$ taxa de macro-defeitos e (c) incorporação de ar.

Figura 6-41: Resistência de aderência em função da taxa de resfriamento na superfície e interface dos corpos de prova

Figura 6-42: Relação entre os valores de resistência de aderência dos revestimentos submetidos ao choque térmico e o produto do valor do módulo de elasticidade e do coeficiente de dilatação térmica do revestimento.

Figura 6-43: Variação do módulo de elasticidade dos prismas de revestimento extraídos dos corpos de prova ensaiados.

Figura 6-44: Variação da resistência à compressão dos prismas de revestimento extraídos dos corpos de prova ensaiados. 186

Figura 6-45: Variação da resistência à tração na flexão dos prismas de revestimento extraídos dos corpos de prova ensaiados 


\section{LISTA DE TABELAS}

Tabela 2-1:Coeficientes de dilatação térmica de vários tipos de agregado e pasta de cimento46

Tabela 2-2: Variação da condutividade térmica com a idade de argamassa com relação a/c= 0,40. Adaptada de Kim et al. (2003)

Tabela 2-3: Calor específico de pasta de cimento em J/kg ${ }^{\circ} \mathrm{C}$, adaptado de Marshall (1972). 57

Tabela 2-4: Calor específico de alguns agregados de acordo a sua composição. Fonte: Marshall (1972)

Tabela 2-5: Valores de módulo de elasticidade segundo a classificação MERUC. Fonte: Blanchard (2003)

Tabela 2-6: Valores de resistência à tração segundo a classificação MERUC para argamassas

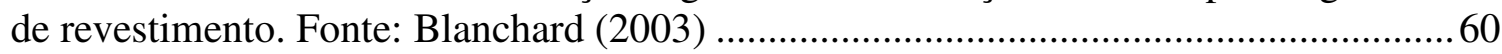

Tabela 3-1: Ensaios de choque térmico para componentes do edifício.................................... 88

Tabela 3-2: Parâmetros dos métodos de ensaio propostos por diferentes autores e normas técnicas

Tabela 4-1: Propriedades mecânicas dos materiais empregadas na simulação computacional.

Tabela 4-2: Propriedades térmicas dos materiais empregadas na simulação computacional...95

Tabela 5-1: Variáveis do arranjo experimental

Tabela 5-2: Características da base ou substrato 110

Tabela 5-3: Parâmetros definidos para o ensaio de choque térmico .....

Tabela 5-4: Ensaios de caracterização dos materiais utilizados e do revestimento. 136

Tabela 6-1: Propriedades mecânicas consideradas no modelo. 158

Tabela 6-2: Caracterização dos materiais constituintes da argamassa

Tabela 6-3: Caracterização da argamassa em estado fresco com teor de água de 16\% em massa de materiais secos.

Tabela 6-4: Resultados dos ensaios mecânicos realizados na argamassa de revestimento e base de concreto.

Tabela 6-5: Resultados dos ensaios mecânicos realizados nos prismas extraídos dos corpos de

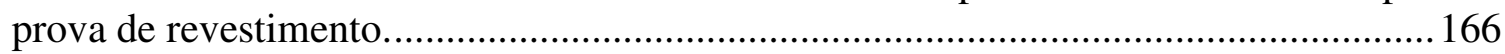

Tabela 6-6: Valores médios de resistência de aderência à tração (MPa) 178

Tabela 6-7: Resultados obtidos da análise de variância ANOVA das resistências de aderência.

Tabela 6-8: Analise de variância ANOVA para avaliar o efeito dos fatores e as interações entre fatores.

Tabela 6-9: Tipos de ruptura produzidas nos ensaios de resistência de aderência. 


\section{SUMÁRIO}

1 INTRODUÇÃO

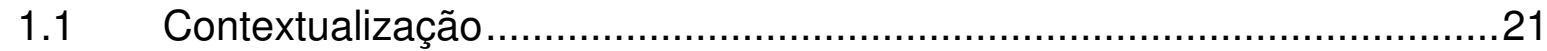

1.2 Justificativa

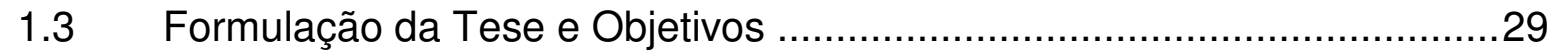

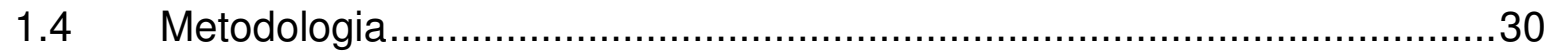

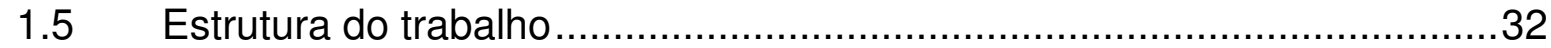

2 FATORES QUE INFLUENCIAM A VARIAÇÃO NA ADERÊNCIA DOS REVESTIMENTOS DE ARGAMASSA ..........................................................34

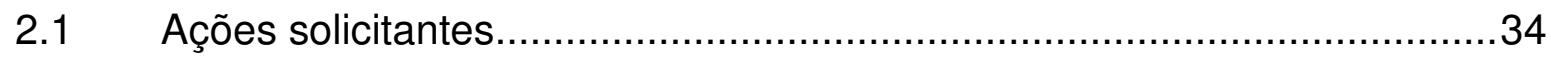

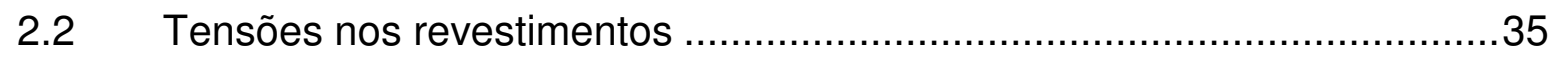

2.2.1 Mecanismo de aderência em bases porosas....................................38

2.2.2 Características da interface base-camada de revestimento ................40

2.3 Comportamento do revestimento frente à variação de temperatura. ........44

2.3.1 Diferença entre coeficientes de dilatação térmica.................................45

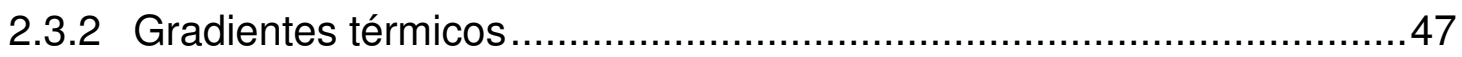

2.3.3 Modelos para determinação das tensões térmicas..............................49

2.3.3.1 Determinação do perfil de temperaturas ............................................51

2.3.3.1.1 Formulação do balanço de energia para o revestimento ...........51

2.3.3.2 Análise mecânica .........................................................................52

2.4 Fatores de influência nas tensões de origem térmica nos revestimentos .53

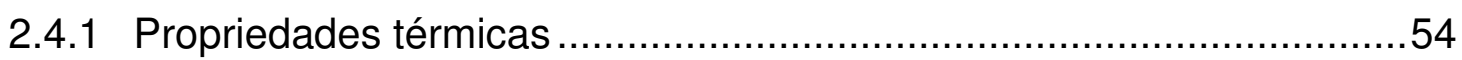

2.4.1.1 Coeficiente de expansão térmica .......................................................54

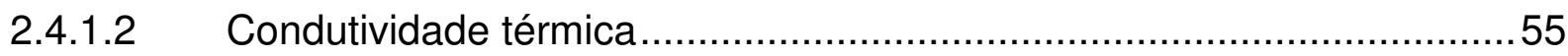

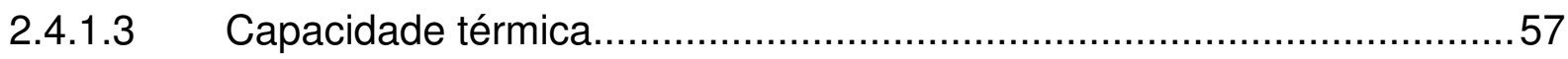

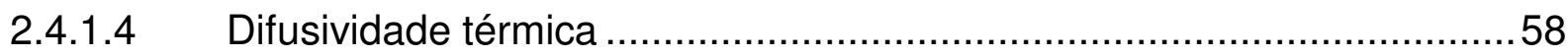

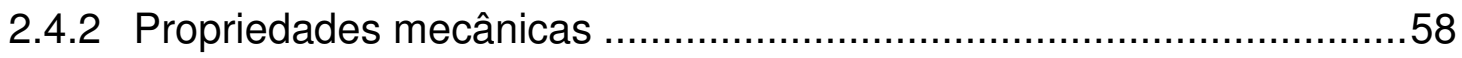

2.4.2.1 Módulo de elasticidade - E ........................................................ 58

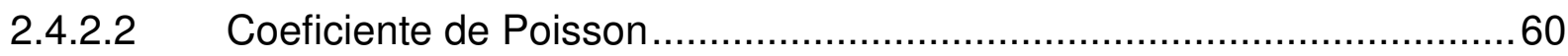

2.4.2.3 Resistência - tensão de ruptura .......................................................60

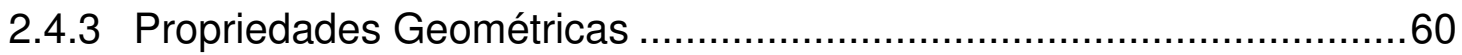

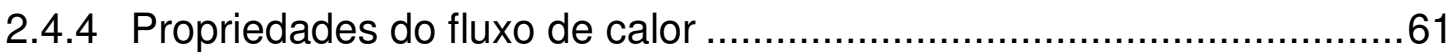




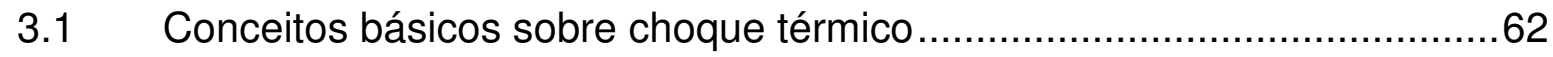

3.2 Modelos para avaliação do choque térmico em sólidos ...........................65

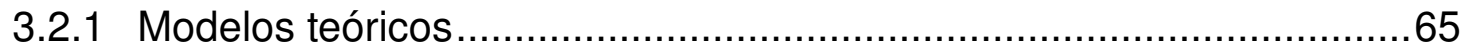

3.2.1.1 Critério de resistência ao choque térmico ………….........................66

3.2.1.2 Critério de propagação de fissuras................................................... 71

3.2.2 Modelos de abordagem experimental.......................................... 77

3.3 Análise do potencial de aplicação dos modelos teóricos para sólidos às

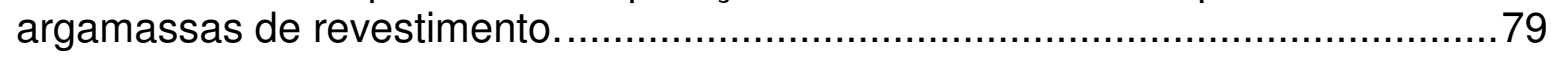

3.3.1 Avaliação teórica do choque térmico em revestimentos ......................81

3.3.1.1 Variáveis relativas à variação de temperatura que influem no choque térmico.

3.3.1.2 Variáveis relativas ao comportamento mecânico do revestimento....... 85

3.3.2 Métodos de avaliação experimental de choque térmico em revestimentos.

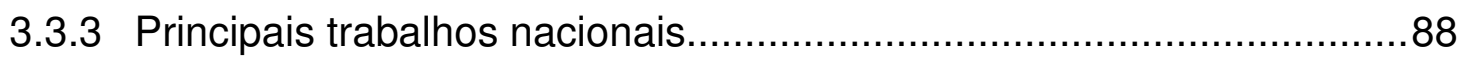

3.3.4 Principais parâmetros considerados nos métodos de ensaio de choque térmico

4 SIMULAÇÃO COMPUTACIONAL PARA AVALIAÇÃO DO REVESTIMENTO DE ARGAMASSA FRENTE À VARIAÇÃO TÉRMICA ……................................92

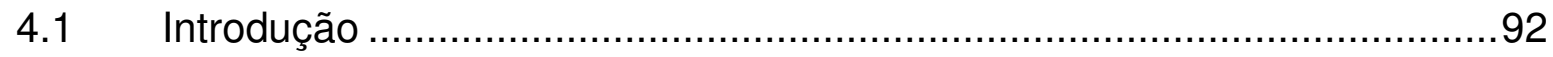

4.2 Modelos que empregam o método de elementos finitos .........................93

4.3 Desenvolvimento do modelo numérico para o revestimento ......................93

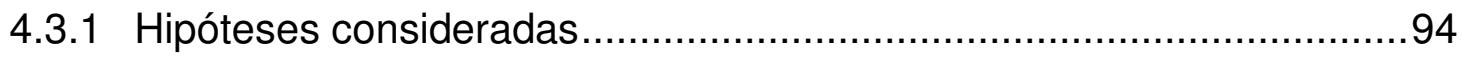

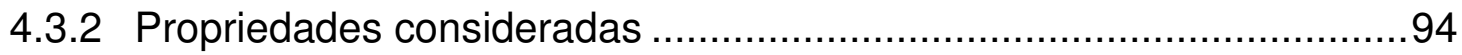

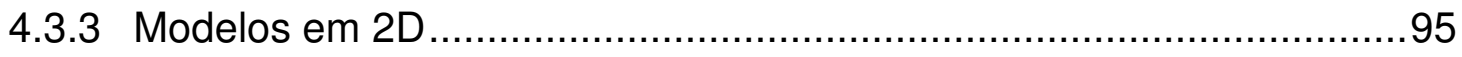

4.3.3.1 Geometria 95

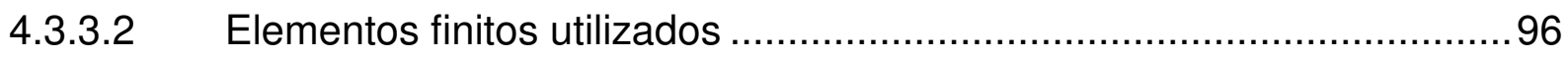

4.3.3.3 Tipo de malha e condições de contorno ...............................................96

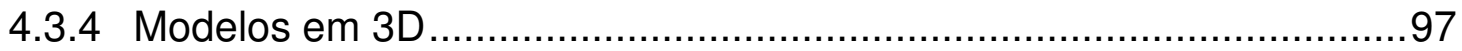

$\begin{array}{lll}\text { 4.3.4.1 Geometria } & 97\end{array}$

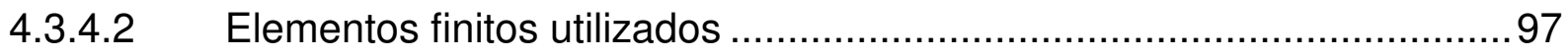

4.3.4.3 Tipo de malha e condições de contorno ..............................................98 
4.4 Simulação dos macro-defeitos .99

$\begin{array}{lll}\text { 4.4.1.1 Geometria } & 99\end{array}$

4.4.1.2 Posição do macro-defeito ..............................................................100

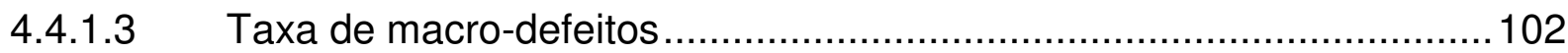

4.5 Análise para definição das dimensões dos corpos de prova....................102

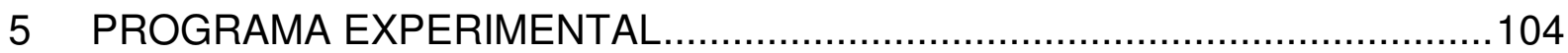

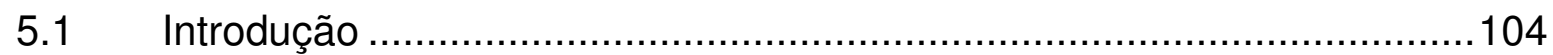

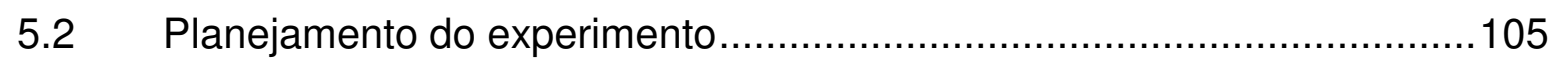

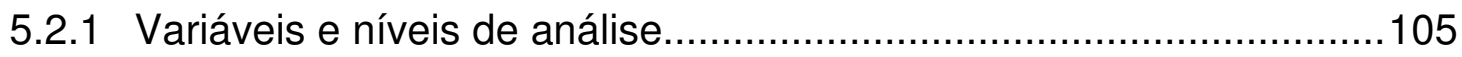

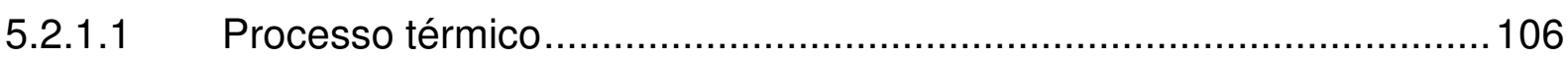

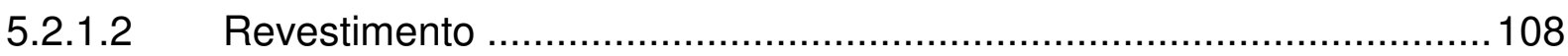

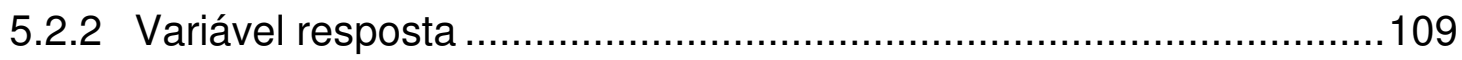

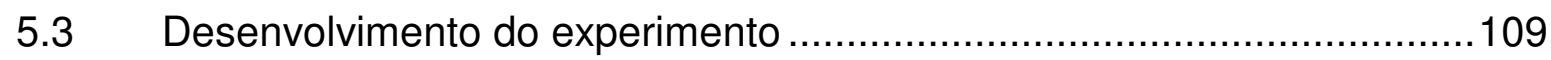

5.4 Materiais e equipamentos utilizados ..................................................109

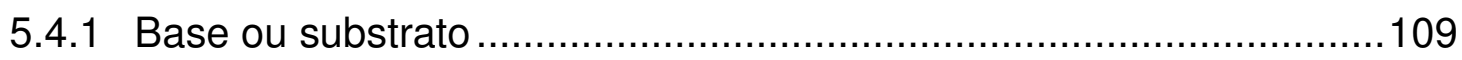

5.4.2 Revestimento de argamassa ......................................................111

5.4.3 Simulação de macro-defeitos de interface base-revestimento ...........113

5.4.4 Parâmetros dos ensaios de choque térmico .......................................116

5.4.5 Montagem do ensaio de choque térmico ........................................117

5.4.5.1 Suporte dos corpos de prova ………................................................

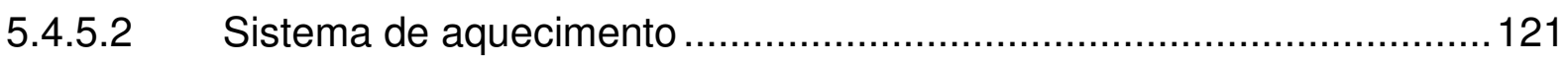

5.4.5.3 Sistema de resfriamento ........................................................... 122

5.4.5.4 Materiais e equipamentos para registro e controle do ensaio de choque

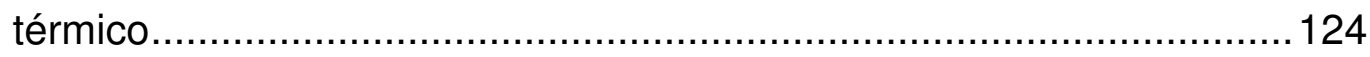

5.4.5.4.1 Atividades de calibração ......................................................126

5.4.5.4.2 Parâmetros de Controle do ensaio .......................................... 127

5.5 Produção dos corpos de prova do revestimento …..............................128

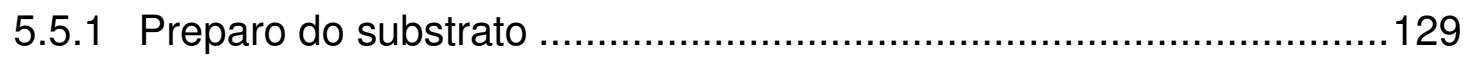

5.5.2 Mistura da argamassa para revestimento ....................................130

5.5.3 Aplicação da argamassa no substrato ........................................... 131

5.5.4 Acabamento superficial do revestimento .......................................132

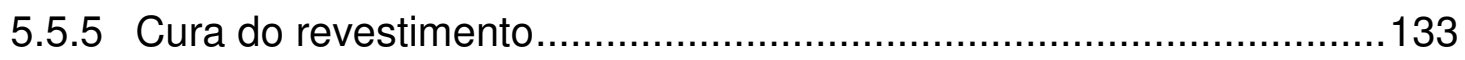


5.5.6 Instrumentação dos corpos de prova...............................................135

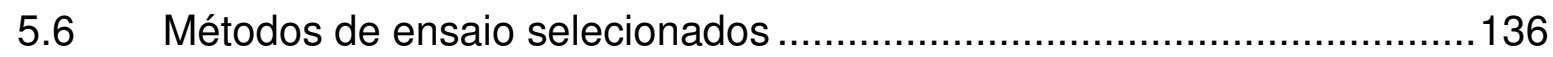

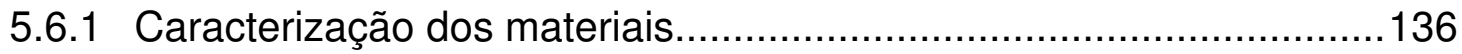

5.6.2 Ensaios cíclicos de choque térmico ……..................................... 137

5.6.3 Ensaios de avaliação da resistência de aderência ...........................138

5.6.3.1 Corte do revestimento para o ensaio de resistência de aderência.......138

5.6.3.2 Avaliação da resistência de aderência ..............................................139

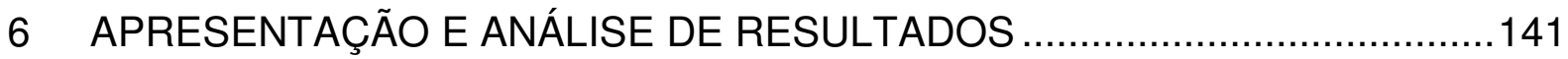

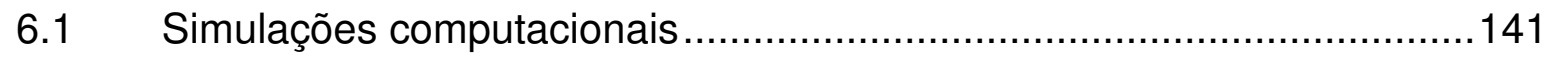

6.1.1 Variáveis de influência no desenvolvimento das tensões térmicas no

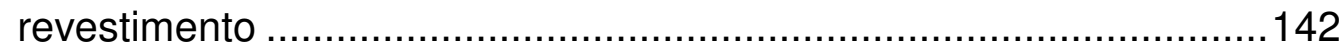

6.1.2 Simulações para definição das características do corpo de prova ....146

6.1.2.1 Definição da espessura do substrato .............................................146

6.1.2.2 Definição da espessura do revestimento.........................................148

6.1.2.3 Dimensões laterais dos corpos de prova.........................................150

6.1.3 Definição das características dos macro-defeitos de interface

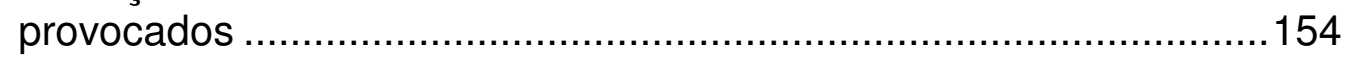

6.2 Simulações realizadas com modelos de choque térmico ........................157

6.3 Resultados do Programa experimental .............................................160

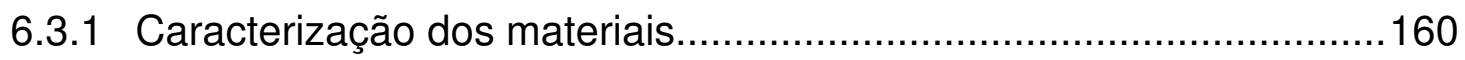

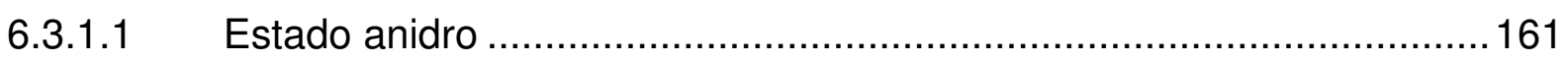

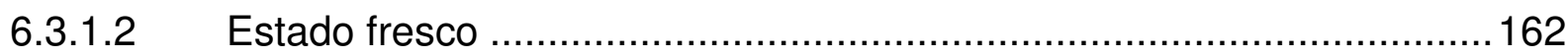

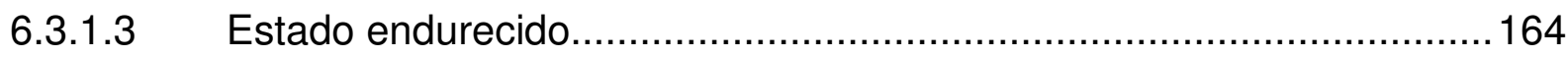

6.3.2 Distribuição das temperaturas nos ensaios de choque térmico .........167

6.3.2.1 Temperaturas na superfície dos revestimentos................................. 168

6.3.2.2 Temperatura na interface base-revestimento ....................................173

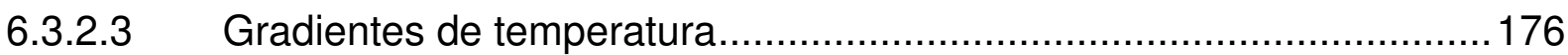

6.3.3 Resistência de aderência.........................................................178

6.3.4 Forma de ruptura nos ensaios de resistência de aderência ..............181

6.3.5 Influência do conteúdo de umidade ............................................. 182

6.4 Influência das características do choque térmico na resistência de aderência do revestimento. 
6.5 Influência das propriedades mecânicas da argamassa para revestimento

na resistência de aderência.

6.5.1 Variação das propriedades mecânicas dos revestimentos em função do choque térmico 185

7 CONCLUSÕES E SUGESTÕES PARA TRABALHOS FUTUROS ..................188

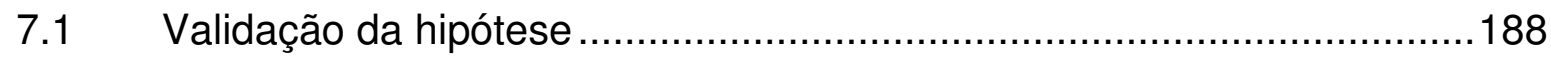

7.2 Considerações sobre a metodologia experimental. ..............................189

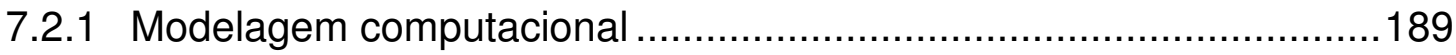

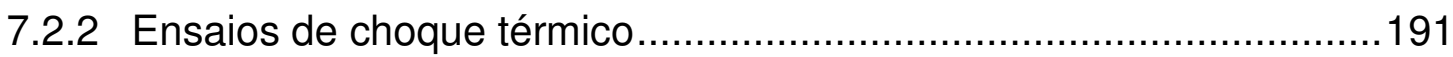

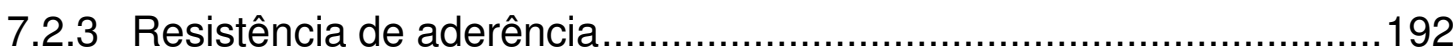

7.3 Considerações sobre aplicações práticas para projetos de revestimento de

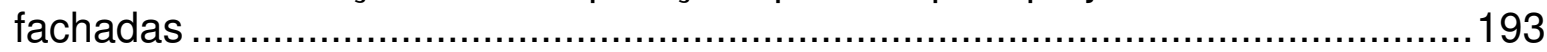

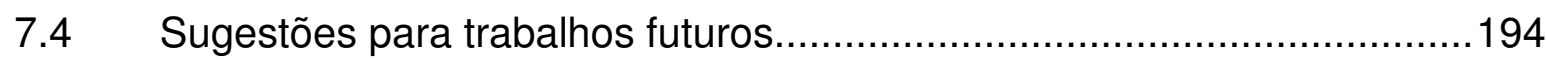

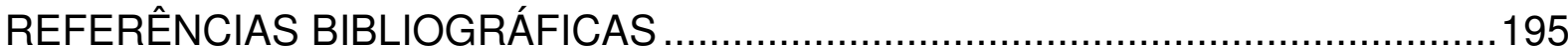

APÊNDICE A - CONCEITOS BÁSICOS SOBRE TRANSFERÊNCIA DE CALOR .214

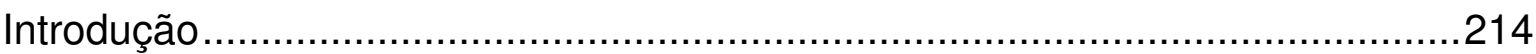

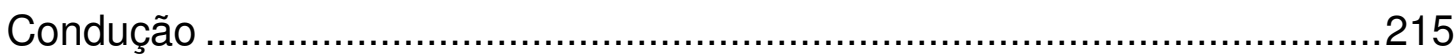

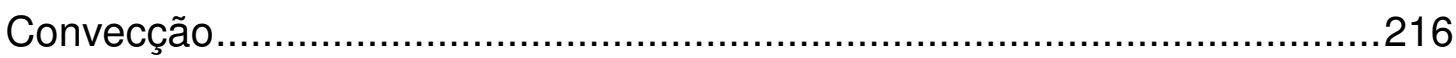

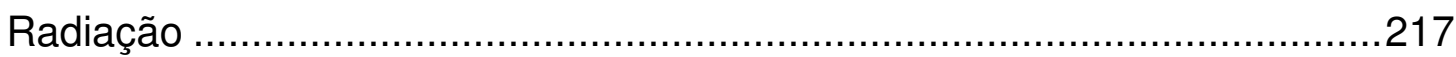

APÊNDICE B: DADOS DE LEVANTAMENTOS DE CAMPO …...........................219

APÊNDICE C - PROGRAMA EXPERIMENTAL PILOTO ......................................220

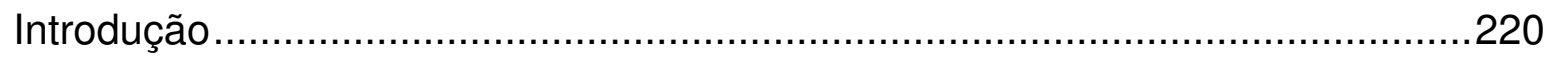

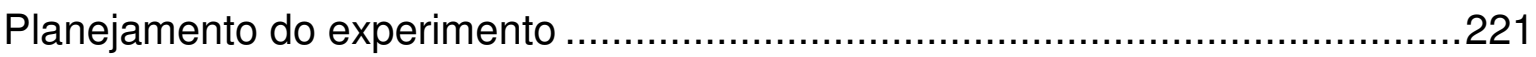

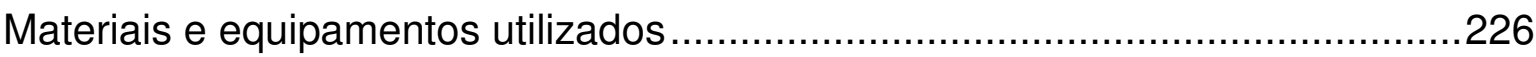

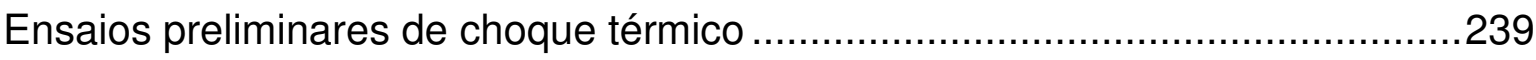

ANEXO A - MODELO PARA CALCULO DE TENSÕES TÉRMICAS EM SISTEMAS

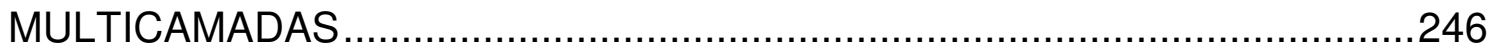

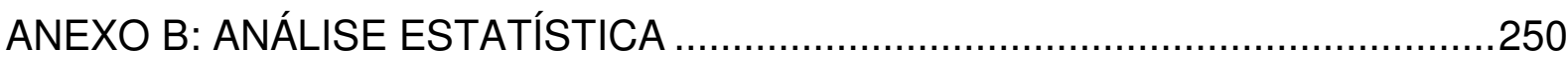

ANEXO C: ANÁLISE GRANULOMÉTRICA DA AREIA.......................................262 


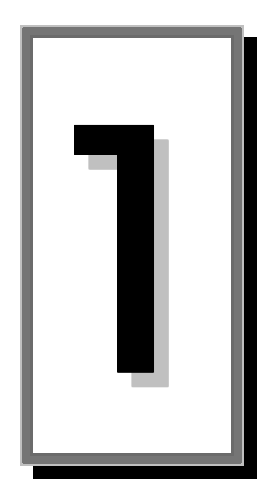

\section{INTRODUÇÃO}

\subsection{Contextualização}

No cenário de crescimento vivido nos últimos anos pelo setor da Construção Civil brasileira, um dos aspectos de destaque foi a discussão sobre o desempenho das edificações, alimentada pelo processo de elaboração e posterior publicação da norma brasileira de desempenho voltada aos edifícios habitacionais de até cinco pavimentos (ABNT, 2008).

Com o objetivo de se parametrizar o desempenho dos elementos e subsistemas dos edifícios, desde antes da década de 1980, muitas pesquisas têm sido desenvolvidas com o intuito de traduzir as necessidades dos usuários em requisitos de desempenho, de forma que possam ser mensuráveis objetivamente pelo estabelecimento de critérios adequados a cada situação de utilização.

Trata-se, pois, de uma tarefa complexa que passa pela definição da metodologia de avaliação de um determinado subsistema do edifício ou mesmo de uma sua parte.

Dentre os diversos importantes subsistemas, os revestimentos de fachadas, têm sido foco de várias pesquisas no Brasil, principalmente em decorrência dos problemas patológicos apresentados em diversas regiões do país, os quais têm levado tanto o meio acadêmico como a indústria de materiais e componentes e empresas construtoras a investir recursos visando à sua solução. Exemplos recentes de iniciativas envolvendo todos esses agentes são os projetos Comunidade da 
Construção $^{1}$ e Consitra $^{2}$, os quais estão voltados principalmente ao estudo dos revestimentos aderidos de argamassas de base cimentícias, os quais estão entre as tecnologias tradicionais mais utilizadas na Construção Civil brasileira.

A utilização do revestimento aderido de argamassa é verificada principalmente em vedações verticais constituídas usualmente pelos elementos estruturais de concreto armado associados à alvenaria de blocos de concreto, cerâmicos, de concreto celular ou sílico-calcário, tanto no interior como na fachada dos edifícios. São utilizados, ainda, nas vedações horizontais, particularmente na camada de contrapiso. Em ambas as situações, auxiliam os vedos a atingir os níveis de desempenho exigidos.

Quando utilizados em fachada de edifícios, aparecem como camada de regularização ou acabamento, como constatado por Temoche (2002) cuja pesquisa permitiu concluir que na cidade de São Paulo, por exemplo, a totalidade dos edifícios residenciais estudados possuía revestimentos de argamassa em fachada, seja como acabamento em conjunto com a pintura ou como base para revestimentos cerâmicos.

Diversos são os materiais e métodos construtivos empregados para produção desses revestimentos; porém, independentemente deles, o que se busca é que o revestimento de fachada atenda às exigências dos usuários, ou seja, que cumpram as funções para as quais foram especificados e projetados, ou seja, que apresentem o desempenho requerido.

A norma de desempenho hoje disponível (NBR 15575-4 - ABNT, 2008) é uma referência importante, mas não parametriza todos os elementos do edifício. Há um enfoque para a fachada como um todo, mas não há abordagem específica do revestimento; por isto, há ainda um longo percurso a se percorrer.

No caso específico do revestimento de argamassa, segundo a Agence Qualité Construction (1995), o seu desempenho é condicionado por três exigências básicas:

\footnotetext{
${ }^{1}$ Comunidade da Construção é um movimento liderado pela Associação Brasileira de Cimento Portland com o objetivo de aumentar a competitividade e melhorar o desempenho dos sistemas à base de cimento por meio da difusão das melhores práticas. (ABCP, 2002)

${ }^{2}$ Consitra é a sigla do Consórcio Setorial para Inovação da Tecnologia de Revestimentos de Argamassa que integrando vários agentes da cadeia produtiva têm com objetivo comum, desenvolver, no âmbito dos revestimentos de argamassa, novas tecnologias pautadas por atributos como: confiabilidade, produtividade, durabilidade e custo compatível com o mercado nacional.
} 
aderência à base, estanqueidade à água de chuva e durabilidade, as quais lhe permitirão cumprir suas funções junto à vedação vertical.

Pode-se dizer que durabilidade é uma propriedade condicionada pela manutenção do desempenho exigido do revestimento ao longo da sua vida útil; portanto, perda de aderência ou ausência de estanqueidade são situações que comprometem a durabilidade do revestimento.

É preciso destacar que a durabilidade do revestimento está associada ainda a outros fatores, como por exemplo, a manutenção da estética ao longo da vida útil, o que depende também das ações de manutenção realizadas no revestimento durante este período.

Estudar a durabilidade do revestimento de argamassa implica em analisar, segundo Haagenrud (2004), os fatores de degradação devidos aos diferentes agentes atuantes tais como os citados pela norma ISO 6241- E (ISO, 1984): mecânicos; eletromagnéticos; térmicos; químicos e biológicos. Estes fatores atuam no revestimento de maneira aleatória e não uniforme, podendo solicitá-lo simultaneamente ou não. Além disso, a durabilidade está condicionada também à resposta dada pelo revestimento às ações desses agentes que, por sua vez, depende de variáveis como características da argamassa, do método de aplicação, das condições da base e ambientais durante e após a produção do revestimento e das ações de manutenção do mesmo.

Sendo o revestimento um sistema constituído por camadas interligadas aderidas à uma base, seu desempenho depende também da efetiva área de contato entre a argamassa e a base, usualmente denominada "extensão de aderência", um conceito introduzido por Palmer e Parsons ${ }^{3}$, citados por Boyton e Gutschick (1964).

Fica, pois, evidente que se trata de uma análise complexa. Por isto, na abordagem do presente trabalho busca-se isolar alguns fenômenos, estudando-se apenas a degradação mecânica a que os revestimentos estão sujeitos ao longo da sua vida útil, uma vez que esta degradação usualmente afeta tanto a aderência do revestimento à sua base, como também a sua estanqueidade, propriedades fundamentais para a durabilidade do revestimento.

\footnotetext{
${ }^{3} \mathrm{O}$ conceito de extensão de aderência foi utilizado segundo Boyton e Gutschick (1964) na publicação de Palmer, L. A e Parsons, D. A. intitulada "Study of the properties of mortars and brick and their relation to bond" em 1934.
} 
A degradação mecânica dos revestimentos de argamassa ocorre devido às solicitações a que são submetidos ao longo de sua vida útil e que resultam num processo de propagação de microfissuras, seja na superfície, no corpo do revestimento ou na interface com a base. Quando a fissuração se concentra na superfície e no corpo da argamassa, de forma geral, compromete-se a estanqueidade do revestimento. Ao se concentrar na interface, a aderência do revestimento também fica comprometida. Por conseguinte, a durabilidade do revestimento pode ser reduzida (JOHN, 2003).

Um dos agentes de degradação mecânica dos materiais de base cimentícia, reconhecido amplamente na literatura, é a temperatura, sobretudo porque sua variação provoca, inevitavelmente, tensões de tração, que são as mais prejudiciais devido à baixa resistência à tração das argamassas.

A variação de temperatura a que podem ser submetidos os revestimentos de argamassa depende das condições de uso e de exposição do edifício. Quando de uso industrial, por exemplo, em determinados ambientes internos essas variações podem atingir uma ou várias centenas de ${ }^{\circ} \mathrm{C}$; por outro lado, podem ocorrer situações em que as temperaturas atingem valores negativos $\left(<0^{\circ} \mathrm{C}\right)$.

Quando o uso é residencial ou comercial, usualmente os revestimentos estão sujeitos à variação de temperatura do meio ambiente e, neste caso, podem ocorrer variações de dezenas de graus principalmente na sua superfície.

Como destacado, essa variação de temperatura provocará tensões no revestimento aderido, as quais são usualmente denominadas tensões térmicas ${ }^{4}$.

Além do estado de tensões provocado pelo gradual aumento ou diminuição da temperatura, existe ainda uma situação crítica que depende da velocidade (taxa) com que ocorre a variação. Se a temperatura do ambiente a que está exposto o material cimentício variar rapidamente ${ }^{5}$, será produzido um gradiente entre a superfície do corpo e seu interior, o que pode provocar tensões de elevada magnitude, fenômeno denominado de choque térmico.

\footnotetext{
${ }^{4}$ Neste trabalho denominam-se tensões térmicas no material, aquelas geradas pela restrição à livre deformação causada por uma variação de temperatura.

${ }^{5}$ Aqui novamente o termo "rapidamente" dependerá das condições de exposição consideradas, já que se é considerado o uso industrial essa velocidade de variação pode ser de centenas de ${ }^{\circ} \mathrm{C}$ por segundos ou milésimos de segundos. Por outro lado se é considerada exposição ao meio ambiente essa velocidade pode ser de dezenas de ${ }^{\circ} \mathrm{C}$ por minuto ou por hora, por exemplo.
} 
Este tema é bastante estudado na ciência dos materiais, principalmente para materiais frágeis os quais, ao serem submetidos a altas temperaturas (centenas de ${ }^{\circ}$ C) e, posteriormente, a uma rápida queda de temperatura (em muitos casos frações de segundos) podem sofrer conseqüentes danos por choque térmico, inclusive fratura catastrófica. Segundo Lu e Fleck (1998), apesar de ser um assunto antigo e de existir vasta literatura sobre o tema, os modelos teóricos existentes não são capazes de definir a resistência ao choque térmico de diversos materiais.

Nos revestimentos expostos ao meio ambiente, essa situação crítica ocorre quando a variação (principalmente diminuição) da temperatura superficial é rápida, gerando gradientes de temperatura no revestimento e conseqüentemente, tensões e deformações na superfície e no corpo do revestimento e na sua interface com a base. Este efeito ocorre, por exemplo, quando após um período de forte insolação, que pode fazer com que a superfície do revestimento atinja entre 70 e $80^{\circ} \mathrm{C}$, ocorre uma chuva intensa $\left(\sim 20^{\circ} \mathrm{C}\right)$ provocando uma queda da temperatura superficial entre $50^{\circ} \mathrm{C}$ a $60^{\circ} \mathrm{C}$ em poucos minutos. Este fenômeno, com essa faixa de variação de temperatura, é denominado “choque térmico" tanto pela Agence Qualité Construction (1995) e como pela ASTM D1079-02 (ASTM, 2002).

A avaliação do efeito de tensões térmicas em revestimentos tem seguido duas abordagens: uma em que se analisam as tensões térmicas empregando-se simulação matemática e outra utilizando modelos experimentais.

Internacionalmente, apesar de existirem diversas instituições com vasta pesquisa sobre revestimentos de argamassa, tais como o CSTB, na França e o LNEC, em Portugal, e também, da existência de diversos periódicos que abordam o tema como - Cement \& Concrete Research ou Cement and Concrete Composites, são praticamente inexistentes os trabalhos enfocando o choque térmico com modelos numéricos em sistemas multicamadas para materiais cimenticios.

Há sim alguns trabalhos correlatos como os de Kristensen e Hansen (1994) que mostraram, com auxílio de modelos teórico e experimental, que pastas de cimento apresentavam fissuras quando submetidas a choque térmico com variação de temperatura de apenas $30^{\circ} \mathrm{C}$, situação que é possível de ocorrer em revestimentos de edifícios no Brasil, dadas às suas condições climáticas. 
Além disso, algumas contribuições foram registradas nos trabalhos de Bazant; Chern e Thonguthai (1981); Bowman (1995); Zhu e Guan, (1997); Obied et al., (2000); Abreu (2004), os quais empregaram modelagem por elementos finitos para análise das tensões térmicas em revestimentos.

Nos trabalhos publicados por Hayashi; Aoyama e Matsuyama, (1993); Tam et al. (1993); CSTB (1999) avaliou-se experimentalmente o efeito do choque térmico em revestimentos, utilizando como parâmetro a resistência de aderência do revestimento após o choque térmico. Por sua vez, Mohd Zain; Yusof e Matsufuji, (1999) e Lion et al. (2005) avaliaram experimentalmente o efeito da variação de temperatura utilizando como parâmetro a variação da permeabilidade à àgua. Além desses o trabalho de Jingyao e Chung (2002) avaliou a degradação mecânica de argamassas de revestimento após serem submetidos a variação de temperatura.

No Brasil, trabalhos que seguem a modelagem matemática também foram encontrados, com destaque para os de Fiorito (1994); Saraiva (1998); Silva et al. (1999); Saraiva, Bauer e Bezerra (1999) e Bortoluzzo (2000). Autores como Geyer e Greven (1994); Siqueira; Cincotto e John (1995); Roman et al. (2000); Miranda e Selmo (2003); Crescêncio e Barros (2003) seguiram a abordagem experimental. Destaca-se, porém, que nenhum deles conclui por um modelo de comportamento do revestimento frente à variação de temperatura e que para o número de ciclos utilizado nos trabalhos de Geyer e Greven (1994) e Crescêncio e Barros (2003), o choque térmico promoveu o aumento da resistência de aderência em algumas das situações analisadas.

Tendo em vista as lacunas de conhecimento que ainda pairam sobre o tema choque térmico em revestimentos de argamassa de fachadas de edifícios, bem como sobre as conseqüências desse choque na resistência de aderência do revestimento à base, será este o enfoque do presente trabalho.

\subsection{Justificativa}

Episódios como o acidente nas obras da Estação de Pinheiros do Metrô (FOLHA ONLINE, 2007) trazem à discussão a responsabilidade dos profissionais da Construção Civil nos projetos e na execução de obras que virão a ser parte do patrimônio construído da sociedade, as quais devem ser entregues em condições de desempenho e durabilidade adequadas às condições de solicitação durante sua vida 
útil. E no contexto atual, em que o tema da construção sustentável se transformou em uma exigência fundamental no setor da construção, a especificação e uso racional e consciente dos recursos naturais que demanda o setor ganharam maiores dimensões.

Quando o tema é revestimento de fachadas, muitas situações estão vinculadas a problemas, passando-se pela perda da estética da fachada e, por conseqüência, da diminuição do valor do imóvel, chegando-se a graves acidentes, inclusive fatais, devido à queda de revestimentos por perda de aderência. Jornais diários nacionais têm registrado muitos e freqüentes casos desse tipo, com danos físicos e materiais, tais como os noticiados pela Agência JB em 19/07/2007:

"Reboco do teto do Maracanã cai, mas ninguém se fere".

Relatos sobre acidentes semelhantes também foram feitos por pesquisadores estrangeiros como Hayashi et al., 1993 (Japão); Guan e Alum, 1997 (Singapura) somando-se, assim a diversos trabalhos no âmbito nacional, tais como os de Medeiros, 1999; Silva (2001); Campante (2001); Consitra (2003); Fontenelle e Moura (2004) e Dumêt (2006), que deixam em evidência a atualidade e quantidade de problemas referidos à perda de aderência de revestimentos de fachada em diferentes regiões do Brasil.

Diante desses fatos, nos quais as responsabilidades pelo ocorrido não ficam claramente definidas, e resgatando-se as informações registradas pelo autor a partir de diversas visitas que fez a obras na etapa de execução do revestimento externo, acredita-se que muitos dos problemas com esses revestimentos decorrem da falta de domínio do processo de produção e da ausência de especificações de projeto suficientemente claras, que permitam uma produção dentro de adequados parâmetros de desempenho.

Assim, pode-se afirmar que o domínio científico da tecnologia de produção desses revestimentos em fachadas de edifícios de múltiplos pavimentos apresenta lacunas que são evidenciadas, sobretudo, pela freqüente ocorrência de problemas patológicos, notadamente, as fissuras e os destacamentos.

Uma dessas lacunas é o entendimento do comportamento desses revestimentos quando expostos à variação repentina de temperatura, assunto que ganha relevância em países como o Brasil onde as características climáticas podem 
apresentar situações de variação de temperatura do ar extremas. A obtenção de dados sobre variação da temperatura em curto espaço de tempo não é simples, uma vez que a maior parte de dados é originada em medidas de temperatura atmosférica em estações climáticas que fornecem valores médios e extremos (INMET, 2007). Dados de temperatura do ar coletados na Estação Climática da EPUSP6, apresentados na Figura 1-1 mostram que uma diminuição rápida da temperatura em $10^{\circ} \mathrm{C}$ pode atingir taxas em torno de $0,5^{\circ} \mathrm{C} / \mathrm{min}$, no início da precipitação.

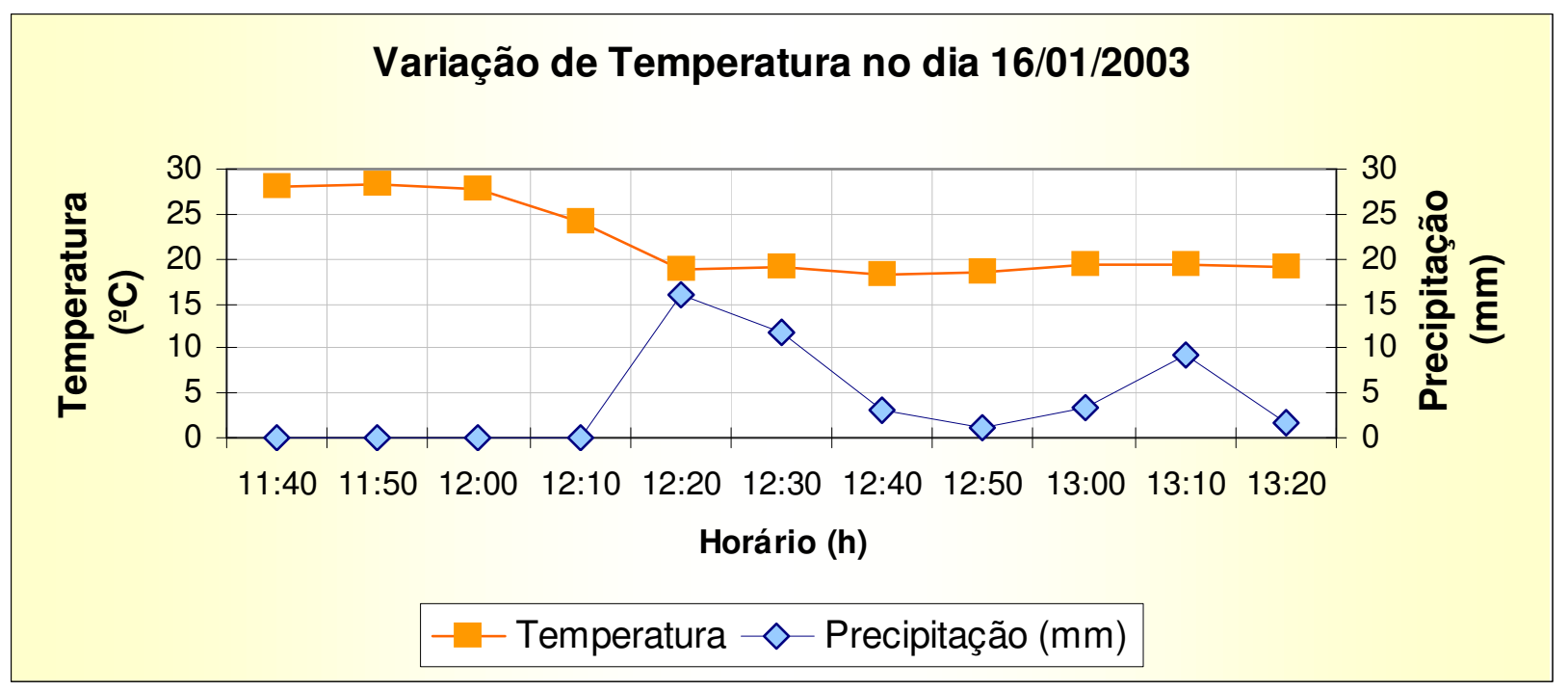

Figura 1-1: Variação da temperatura do ar na Estação Climática da EPUSP - 16 de jan. 2003

Entretanto, Haagenrud (2004) lembra que a relação entre a temperatura do ambiente, a temperatura na superfície e no interior do revestimento é bastante complexa.

Uma cuidadosa consulta bibliográfica em sítios específicos da internet, em instituições de pesquisas nacionais e internacionais e em periódicos científicos permitiu constatar que os investimentos em pesquisa estão focados no estudo dos materiais constituintes da argamassa e na própria argamassa, geralmente, em condições de temperatura constante. Porém, o revestimento se faz a partir da aplicação da argamassa sobre uma determinada base e sob determinadas condições de execução, inclusive com variação de temperatura, e são reduzidas as pesquisas que abordam estes fatores e quando o fazem, não há enfoque para a variação de temperatura.

\footnotetext{
${ }^{6}$ EPUSP é a Escola Politécnica da Universidade de São Paulo.
} 
A análise dos principais trabalhos publicados sobre o tema mostra que o Brasil é responsável por uma parte significativa das pesquisas publicadas no mundo sobre argamassas, com mais de 300 artigos publicados na série de sete Simpósios Brasileiros de Tecnologia de Argamassas ocorridos desde 1995 até 2007; entretanto, raras são as pesquisas referentes ao comportamento termo-mecânico do revestimento de argamassa ou às suas propriedades térmicas básicas.

Da mesma forma, os poucos trabalhos que se ocupam em analisar o efeito do choque térmico nos revestimentos, tais como os de Geyer e Greven (1994), Collantes (2000), Paes (2000), Miranda e Selmo (2003), Crescêncio e Barros (2003), já citados, estão embasados em resultados experimentais que não podem ser generalizados, pois não buscaram entender o fenômeno em si, avaliando somente as suas conseqüências, a partir das diferentes variáveis.

É neste contexto que se insere o presente trabalho que visa avançar a fronteira do conhecimento investigando-se mais profundamente o efeito da variação térmica no comportamento mecânico dos revestimentos de fachada, particularmente em relação à sua resistência de aderência.

\subsection{Formulação da Tese e Objetivos}

As premissas consideradas para formulação da tese neste trabalho são:

A aderência dos revestimentos de argamassa ao longo da sua vida útil é condicionada por fatores associados a:

materiais constituintes da argamassa de revestimento (tipo e teor de aglomerante, tipo de agregado e sua distribuição granulométrica, aditivos e adições, teor de água, etc.);

características da base ou substrato (rugosidade, porosidade, absorção de água, rigidez);

características do processo de produção do revestimento (reologia da argamassa, mistura dos materiais, condições de aplicação);

características de exposição do revestimento, quando da sua execução e ao longo da sua vida útil; 
área efetiva de contato entre a argamassa e a base que pode ser quantificada pela taxa de defeitos de interface ${ }^{7}$.

mantendo-se constantes a composição da argamassa de revestimento, sua base, o processo de produção do revestimento e as tensões originadas pela movimentação da base, a degradação da aderência do revestimento ao longo da sua vida útil é condicionada por duas variáveis: a intensidade das tensões e deformações de origem térmica geradas pela variação rápida de temperatura; e a presença de macro-defeitos na interface base-revestimento; ou seja, quanto maior a taxa de macro-defeitos na interface quando da execução do revestimento, maior será o dano em função das tensões térmicas geradas.

A partir dessas premissas, a hipótese pode ser assim enunciada:

"A degradação da aderência dos revestimentos de argamassa é intensificada pelo efeito de sucessivos choques térmicos e também pela presença de elevada taxa de macro-defeitos na interface base-revestimento quando da sua execução, desde que mantidos constantes os demais fatores que também condicionam a aderência do revestimento de argamassa".

Para que esta hipótese possa ser comprovada, o objetivo a ser atingido ao longo deste trabalho é:

Avaliar, de forma experimental, o efeito de sucessivos ciclos de choque térmico na resistência de aderência do revestimento de argamassa em duas situações limites de taxa de macro-defeitos de aderência na interface base-revestimento.

\subsection{Metodologia}

A escolha do tema da tese decorreu do trabalho desenvolvido pelo autor no seu programa de mestrado que permitiu constatar inúmeras ocorrências de problemas patológicos em revestimentos de fachada, particularmente a perda de aderência (TEMOCHE, 2002).

Para o desenvolvimento do tema escolhido, e para atingir os objetivos propostos procedeu-se a uma primeira etapa de revisão bibliográfica de trabalhos anteriores sobre o tema. O levantamento bibliográfico esteve orientado ao estudo de:

\footnotetext{
${ }^{7}$ Com suporte em ferramenta de análise de imagens, Antunes (2005) desenvolveu uma técnica para quantificação da área de contato entre argamassa de revestimento e a base expressando-a na forma de taxa de defeitos.
} 
trabalhos que têm como objetivo estudar o comportamento dos revestimentos de argamassa frente à variação de temperatura, as principais variáveis consideradas e as formas de avaliação utilizadas;

trabalhos que visam estudar a influência das propriedades térmicas de compósitos cimentícios no seu comportamento mecânico;

trabalhos teóricos e experimentais cujo objetivo é o entendimento do fenômeno do choque térmico e dos principais fatores que influenciam nos efeitos produzidos por esse fenômeno em materiais e componentes construtivos;

trabalhos experimentais que visam descrever o comportamento de materiais e componentes de base cimentícia submetidos a choque térmico;

trabalhos que identificam e analisam os principais métodos de avaliação experimental dos efeitos do choque térmico.

Paralelamente a estas pesquisas, foi realizado o levantamento de métodos de ensaio de choque térmico em materiais e componentes a partir de documentos normativos nacionais e internacionais, assim como em outros documentos que, mesmo que não constituam normas, sugerem diversos procedimentos ou critérios para avaliar experimentalmente o fenômeno em questão.

Para o levantamento bibliográfico do estado da arte do tema foram pesquisados bancos de dados como ISI, Compendex, Scopus, CSA Illumina, Crossref search, Cahiers do CSTB, publicações do SBTA, etc.

A partir da revisão bibliográfica foram escolhidas as variáveis a serem analisadas na segunda etapa desta metodologia referida ao desenvolvimento do trabalho experimental. Foram também definidos os procedimentos materiais e equipamentos necessários para a simulação experimental do choque térmico.

Para ajudar na definição do programa experimental, particularmente na definição do tamanho e formato dos corpos de prova e nas condições de contorno dos corpos de prova, foi realizada uma simulação numérica do fenômeno termo-mecânico. Para isto, buscou-se apoio de um especialista em modelagem do Departamento de Estruturas e Geotécnica da EPUSP, o qual, auxiliado por este autor e utilizando o programa de simulação ®Ansys, cedido pelo laboratório de Mecânica Computacional da Escola, desenvolveu um modelo computacional. Para as simulações iniciais o 
modelo foi alimentado com dados extraídos da bibliografia. As características da modelagem computacional são detalhadas no capítulo 4.

\subsection{Estrutura do trabalho}

Esta tese está estruturada em oito capítulos, sendo este primeiro relativo à introdução e contextualização da pesquisa. Inclui-se neste capítulo a justificativa do trabalho, seus objetivos e metodologia seguida, bem como a estrutura do trabalho.

No capítulo 2 são discutidos os fundamentos teóricos que permitem entender como ocorre a variação de temperatura nos revestimentos e a forma como essa variação provoca tensões térmicas nos revestimentos de fachada. São também apresentados resumidamente modelos teóricos de avaliação e discutidos os principais fatores que têm influência no desenvolvimento das tensões térmicas nos revestimentos.

No capítulo 3 é apresentado e discutido o conceito de choque térmico e analisado o seu efeito nos revestimentos; são apresentados também os modelos teóricos e experimentais utilizados para a avaliação do fenômeno.

No capítulo 4 é apresentada a forma como foi realizada a simulação computacional que deu suporte na definição do programa experimental, com destaque para as hipóteses consideradas, as condições de contorno e os elementos utilizados na simulação.

No capítulo 5 é apresentado o planejamento experimental, os materiais e os métodos utilizados na realização dos ensaios. No capítulo 6 são apresentados os resultados das simulações realizadas e os resultados do programa experimental. Os resultados dos ensaios, bem como o tratamento e a forma de análise desses resultados.

No capítulo 6 são apresentados os resultados e com suporte nas ferramentas da estatística e realizada a análise dos mesmos tanto das simulações numéricas como do programa experimental, contrastando as tendências observadas com os resultados encontrados na literatura.

No capítulo 7 é verificada a comprovação das hipóteses apresentadas na tese e cumprimento do objetivo proposto, sendo apresentadas também as conclusões do trabalho, com as sugestões de temas para continuação da pesquisa. 
Finalmente, apresenta-se o conjunto de referências bibliográficas utilizadas, os apêndices e os anexos do trabalho. 


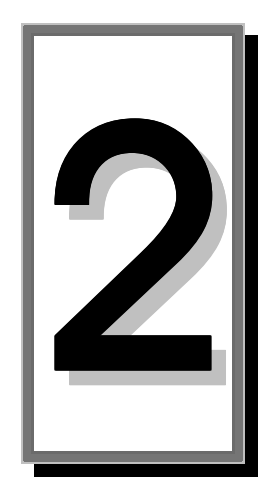

\section{FATORES QUE INFLUENCIAM A VARIAÇÃO NA ADERÊNCIA DOS REVESTIMENTOS DE ARGAMASSA}

\subsection{Ações solicitantes}

Entre as diversas categorias de revestimentos de argamassa à base de aglomerantes hidráulicos, os de base cimentícia são utilizados em muitos paises como camada de proteção da estrutura e vedação e, ao mesmo tempo, como acabamento decorativo. Amplamente difundidos no Brasil, quando utilizados em vedações verticais exteriores são aplicados sobre uma base ou substrato porosos que, usualmente, são constituídos pela alvenaria de vedação ou estrutura de concreto. Geralmente são moldados in loco e constituídos fundamentalmente por uma ou mais camadas de argamassa aderidas à base.

Apesar da sua longa tradição de uso e da ampla pesquisa sobre os revestimentos de argamassa, alguns aspectos relativos ao seu desempenho, particularmente seu comportamento mecânico, ainda não foram completamente estudados.

Para manter o nível de desempenho esperado ao longo da sua vida útil, o revestimento deverá resistir tanto a solicitações que surgem desde as primeiras idades como aquelas que, no seu estado endurecido, são promovidas pelos agentes de degradação atuando, geralmente, de forma simultânea.

Essas solicitações poderão afetar o desempenho do revestimento com diversos graus de gravidade. É possível que se tenha desde o aparecimento de manchas na sua superfície, fissuração no corpo ou superfície do revestimento ou até sua fratura 
e perda de aderência, com o risco de queda, com conseqüências agravadas para edifícios altos.

Dentre as solicitações que condicionam o comportamento mecânico dos revestimentos de argamassa estão aquelas que the introduzem tensões e deformações. Tais solicitações, segundo a Agence Qualité Construction (1995) devem-se a dois fatores: à movimentação da base (alvenaria ou estrutura), muitas vezes incompatível com o revestimento, e a movimentação provocada pelas condições ambientais. Destacam-se dentre estas últimas: as de origem higroscópica; as de origem térmica devido à radiação solar, notadamente a variação de temperatura (sazonal ou rápida), e as provocadas pelo vento.

Todas essas deformações, ao serem restringidas pela aderência do revestimento à sua base, são traduzidas em tensões que o solicitarão, as quais, dependendo da sua magnitude, podem superar a resistência mecânica do revestimento, causando desde fissuração localizada até a sua perda de aderência. Aqui reside a importância de se analisar a origem dessas tensões e a forma de atenuá-las.

\subsection{Tensões nos revestimentos}

O revestimento externo aderido é um subsistema do edifício constituído por várias camadas sobrepostas, aplicadas sobre base ou substrato porosos. De modo geral, os revestimentos de argamassa de fachadas são constituídos ao menos, pelas camadas de preparo de base (chapisco) e por uma camada de argamassa de revestimento.

A ocorrência de tensões neste conjunto começa desde as primeiras idades. Tão logo a argamassa é aplicada sobre a base (usualmente mais rígida) e ainda no estado plástico, e considerando ela como um fluido com comportamento pseudo-plástico, ela deve possuir tensão de escoamento superior à de cisalhamento provocada pelo peso próprio do volume de argamassa aplicada para evitar diminuição da área de contato entre a argamassa e a base. Durante a secagem, período em que ocorre o processo de hidratação do cimento, o revestimento está sujeito a variações de volume resultantes de vários fenômenos que ocorrem durante esse processo e geralmente resultam na retração do revestimento. Essa retração produz tensões internas no revestimento ao longo do tempo e é agravada pela restrição imposta pela aderência à base ou suporte. 
Além disso, as próprias condições ambientais durante a secagem podem vir a provocar tensões indesejáveis ao revestimento.

A importância do estudo do fenômeno da retração por secagem em revestimentos tem levado diversos autores a propor modelos de comportamento que, de acordo com Veiga (2001), ainda não permitem descrever a distribuição de tensões devidas à retração por secagem no revestimento (considerada restringida), devido à complexidade e multiplicidade de fatores que influenciam nesse fenômeno.

Contudo, autores como Joisel (1961) apresentam valor de retração de argamassas de 0,08\%, semelhante aos 0,06\% apresentados por Fiorito (1994) e por Kopschitz et al. (1997) para argamassas de cimento e areia e de cimento, cal e areia, aos 28 dias de idade. No trabalho de Kopschitz et al. (1997) em que se analisou exclusivamente argamassas de cimento, cal e areia, foram comparados os valores de resistência à tração na flexão de corpos de prova aos 28 dias com as tensões estimadas a partir das deformações resultantes por retração na mesma idade, calculadas a partir da utilização da relação entre módulo elástico e deformação específica, sendo verificado que essa tensão calculada era, em média, seis vezes maior que a resistência à tração por flexão atingida pelas argamassas. A explicação dos autores para essa contradição entre tensões atuantes maiores do que a resistência de argamassas comumente utilizadas em revestimentos foi atribuída ao fenômeno de relaxação.

Uma vez atingido o estado endurecido, as tensões continuam a solicitar o revestimento de forma muito variável e, conforme destaca Fiorito (1994), elas podem se compensar ou se somar, gerando esforços máximos no revestimento.

Dentre as deformações oriundas da movimentação da base, Fiorito (1994) destaca a deformação lenta da estrutura de concreto sobre a qual foi aplicado o revestimento e o recalque das fundações. A estas deformações Goldberg (1998) acrescenta a retração da estrutura de concreto, as movimentações por cargas acidentais (vento, sismos) e deformação elástica da estrutura sob cargas iniciais.

A quantificação dessas deformações não é simples e varia de situação para situação; entretanto, Goldberg (1998) menciona que a retração da estrutura de concreto armado em um edifício pode variar de 0,025\% a 0,1\% e que a deformação permanente da estrutura pode atingir valores de $0,065 \%$ da altura do edifício. 
O comportamento mecânico de revestimentos com várias camadas no estado endurecido tem sido analisado com o auxílio de alguns modelos analíticos.

Toakley e Waters (1973) analisaram teoricamente o problema das tensões no revestimento como um problema de flambagem de uma placa aderida sobre uma base rígida, sem restrição nos extremos e com carregamento considerado de forma simplificada, uniaxial. Com essas considerações e analisando o comportamento de um revestimento cerâmico, esses autores afirmaram que o nível de tensões atingido devido à tração na superfície e contração na interface com a base é relativamente baixo, estimando valores abaixo de 0,1 MPa. Todavia, salientam que se a resistência de aderência é fraca ou muito baixa, a perda de aderência do revestimento ocorrerá mesmo com a incidência de tensões reduzidas.

Para Ignatiev e Chatterji (1992) as tensões nos revestimentos de argamassa concentram-se na interface, devido ao grau de restrição à movimentação, promovido pela aderência entre a base comumente de módulo maior e o revestimento com módulo menor, sendo relevantes fatores como a diferença entre os módulos de elasticidade da camada de revestimento e a base, a sua espessura e seu grau de fissuração devido à retração por secagem da argamassa.

Kovler e Frostig (1998) analisam três modelos de avaliação das tensões de tração normais ao revestimento, concluindo, em oposição a Ignatiev e Chatterji (1992), que a espessura do revestimento praticamente não influencia no valor das tensões. Por outro lado, confirmam que para minorar a probabilidade de fissuração normal ao revestimento é necessário utilizar argamassas com módulo de elasticidade baixo e diminuir as deformações por retração na secagem, procurando o equilíbrio entre uma diminuição na rigidez das argamassas utilizadas e uma adequada resistência mecânica.

A limitação dos modelos propostos está nas simplificações adotadas para cada caso analisado não sendo possível generalizar um único modelo.

Como alternativa grande parte dos trabalhos tem optado pela avaliação experimental da aderência do revestimento, principal parâmetro de desempenho, cuja avaliação tem sido feita por meio de um ensaio que procura avaliar a aderência do revestimento à sua base. 
A aderência dos revestimentos tem sido medida segundo diversas normas internacionais, avaliando-se, principalmente, a resistência de aderência à tração normal. Há também iniciativas que avaliam a resistência de aderência ao cisalhamento (Collantes e Franco, 1995; Roman et al., 2003 e Crescêncio, 2003); no entanto, a dificuldade de realização de tal avaliação tem restringido os ensaios às pesquisas laboratoriais, não havendo método de ensaio completamente definido.

No Brasil, a ABNT NBR 13749 (1995) especifica como parâmetro de aceitação de revestimentos de argamassa inorgânica uma resistência de aderência à tração maior ou igual a 0,3 $\mathrm{MPa}$, para revestimentos em fachadas de edifícios com idades iguais ou superiores aos 28 dias. Os valores da resistência de aderência são obtidos por meio de ensaios de arrancamento -"pull-off"- de corpos de prova (circulares ou quadrados) da camada de revestimento, conforme a ABNT NBR 13528 (1995). Entretanto, com unicamente esse parâmetro não é possível garantir a durabilidade dos revestimentos, uma vez que dependendo das condições de exposição ao longo da sua vida útil, um revestimento com maior resistência de aderência inicial em um pano de fachada com determinada orientação, por exemplo, pode ter vida útil inferior a outro revestimento do mesmo tipo com menor aderência inicial mas com orientação mais favorável.

Considerando-se que a aderência é um dos fatores que condiciona a durabilidade do revestimento, é fundamental entender os fatores que condicionam essa importante propriedade do revestimento, o que será discutido na seqüência.

\subsubsection{Mecanismo de aderência em bases porosas}

Diversos autores como Détriché e Grandet (1981); Sabbatini (1984); Lejeune (1985); Dupin, Détriché e Maso (1988); Selmo (1989); Addleson (1992); Carasek (1996); Veiga (2001) destacam a aderência como o principal mecanismo de interação entre o revestimento de argamassa e a base, sendo a responsável pela estabilidade das camadas do revestimento.

A aderência é um assunto longamente estudado, principalmente entre a argamassa de assentamento e as unidades de alvenaria e existem pesquisas sobre os fatores que condicionam esse mecanismo há mais de 60 anos.

Segundo Grandet (1973) e Dupin, Détriché e Maso (1988) a aderência revestimentosubstrato é o resultado da interação entre a rede de cristais hidratados do cimento 
presente na argamassa em contato com a superfície do substrato e com seus poros capilares.

Os fatores que governam a aderência do revestimento ao substrato são, segundo Détriché e Maso (1986): as características da argamassa e de seus materiais constituintes; as características da base; a interação base-revestimento; as características da aplicação e as condições ambientais durante e após a aplicação.

No que se refere às características da argamassa que influenciam na aderência dos revestimentos, Détriché e Maso (1986) destacam a proporção e tipo do aglomerante, a granulometria e forma dos grãos do agregado utilizado, que no estado fresco da argamassa lhe proporcionarão características reológicas adequadas para maximizar a extensão de aderência. Cardoso; Pileggi e John (2005) destacam a importância das características reológicas da argamassa no momento do contato inicial, argamassa-base, no momento da conformação sobre o substrato quando do sarrafeamento e do próprio desempeno.

Dentre as características da base que interferem na aderência estão sua própria natureza (tipo de base), sua função na vedação vertical e suas características físicas como a absorção superficial, porosidade e rugosidade, conforme é destacado por Bauer (2008), Carasek (1996) e Candia (1998).

O processo de mistura da argamassa e de seu lançamento manual ou mecânico (projeção) sobre a base são determinantes na obtenção da uma adequada aderência conforme enfatizam Carasek (1996); Brea (1999); Antunes, John e Pileggi (2005); Duailibe, Cavani e Oliveira (2005), porque delas também dependerá a área de contato efetivo na interface base-revestimento denominada extensão de aderência que, quanto maior, maior será o potencial de aderência à base, conforme já fora destacado por Anderegg (1942). Dito de outra forma, a presença de macrodefeitos na interface base-revestimento promove a diminuição da aderência como destacado por Antunes (2005).

Somados a esses fatores, Coutinho (1954) e Détriché e Maso (1986) destacam que as condições ambientais e de cura do revestimento também interferem no mecanismo de aderência, pois durante o processo de secagem da camada de revestimento ocorre retração da argamassa devido à perda de água que, por sua vez, origina uma variação volumétrica que é restringida pela aderência inicial à base, 
resultando no surgimento de tensões de tração na argamassa que se forem suficientemente altas, podem comprometer a aderência do revestimento.

Coutinho (1954) já destacava que a variação volumétrica no processo de hidratação do cimento na argamassa de revestimento é inerente ao material cimentício e que o importante é minimizar o efeito dos fatores que governam a retração na secagem.

Analisando-se o revestimento no nível microscópico (na escala de $\mu \mathrm{m}$ ), ele possuirá, além dos cristais hidratados do cimento e agregados, poros, bolhas de ar e uma determinada quantidade de microfissuras localizadas principalmente nas interfaces pasta-agregado e entre agregados (WITTMANN, 1983). Essas microfissuras presentes no revestimento constituem-se em pontos de concentração de tensões que potencializam o efeito das solicitações externas ao revestimento ao longo de sua vida útil.

Por outro lado, fazendo-se uma análise no nível macroscópico (na escala de mm), as descontinuidades supracitadas, presentes no corpo do revestimento poderão ser incrementadas por regiões em que não foi obtido um contato efetivo ao longo da interface base-revestimento, resultando em defeitos que minoram a extensão de aderência do revestimento e que serão denominados daqui a diante macro-defeitos de acordo com o trabalho de Antunes (2005).

\subsubsection{Características da interface base-camada de revestimento}

A microestrutura dos revestimentos de argamassa de base cimentícia é formada devido ao processo de hidratação do cimento. Inicialmente, a partir da mistura de água e cimento há a formação de um gel que, devido às reações químicas produzidas, cresce dos contornos dos grãos do cimento para fora envolvendo os agregados e formando uma rede de produtos da hidratação, entre 4 e 6 horas desde o início da mistura água-cimento (METHA e MONTEIRO, 1994; BAZANT e KAPLAN, 1996). Nesse processo são geradas áreas de transição entre os materiais que constituem a argamassa (agregados e pasta), que surgem na forma de poros capilares, arestas de grãos (grãos de cimento não hidratados ou agregados), bolhas de ar, água adsorvida nos poros, microfissuras devidas à retração na secagem (COUTINHO, 1954).

Breton et al. (1993) mostram alguns dos modelos desenvolvidos para identificar as características da zona de transição entre a pasta e os agregados os quais 
apresentam como característica principal uma porosidade maior do que no resto da pasta, conforme mostrado na Figura 2-1.

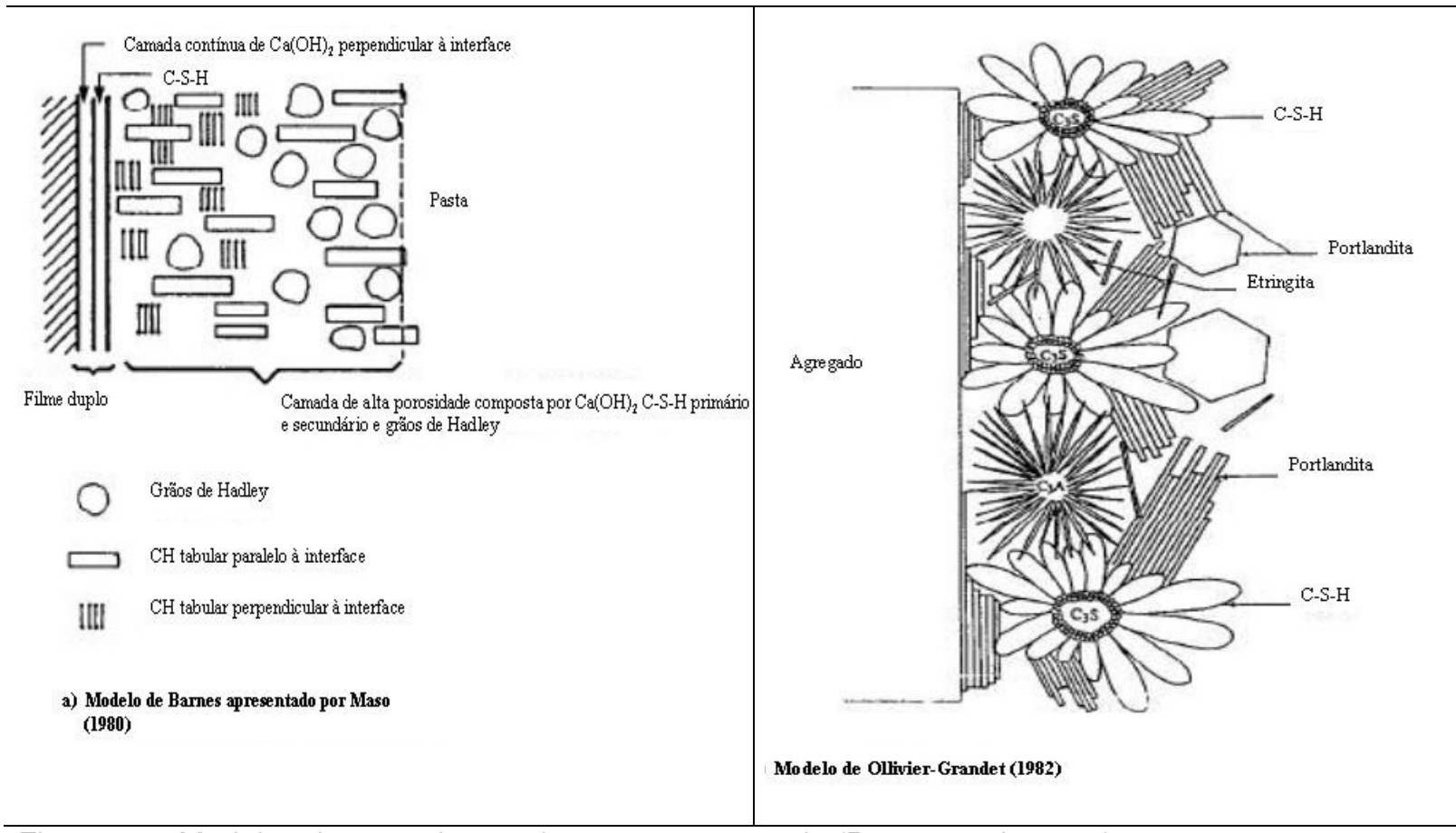

Figura 2-1: Modelos de zona de transição pasta-agregado (Breton et al., 1993)

Essas micro-descontinuidades na interface pasta agregado são mostradas por Diamond e Kjellsen (2007) em imagens realizadas com microscópio eletrônico de varredura (MEV) para argamassa com 28 dias de idade e relação água/cimento de 0,40 . Na imagem mostrada na Figura 2-2 são destacadas regiões de menor densidade na proximidade do contorno do agregado (indicadas por setas).

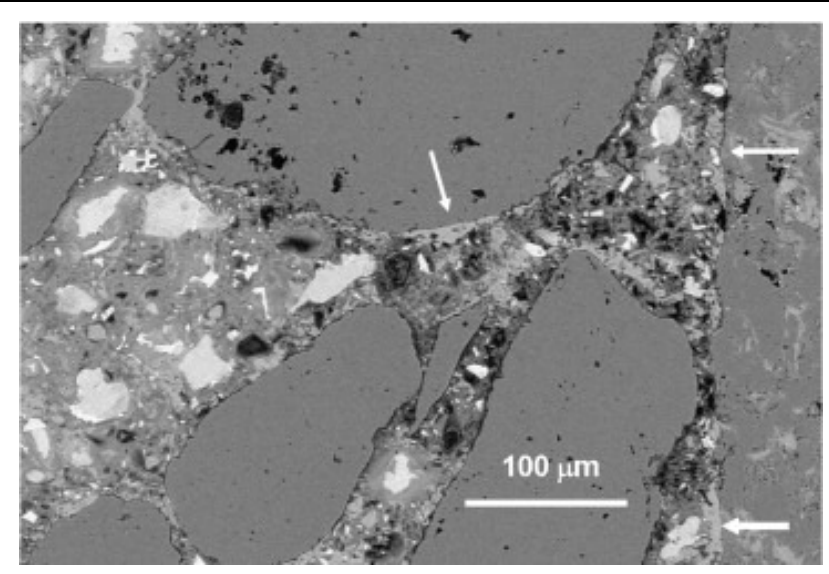

Figura 2-2: Zona de transição entre pasta e grão de areia para argamassa com 28 dias. Fonte: Diamond e Kjellsen (2007)

Observando o revestimento de argamassa em uma escala macro, não é possível identificar as descontinuidades na interface pasta agregado, mas é possível verificar 
que elas existem também na superfície de contato interfacial base-revestimento. Tais descontinuidades são mostradas por Carasek (1996) que, com a ajuda de uma lupa estereoscópica (Figura 2-3), comprovou sua existência para argamassas e bases de diferentes características.

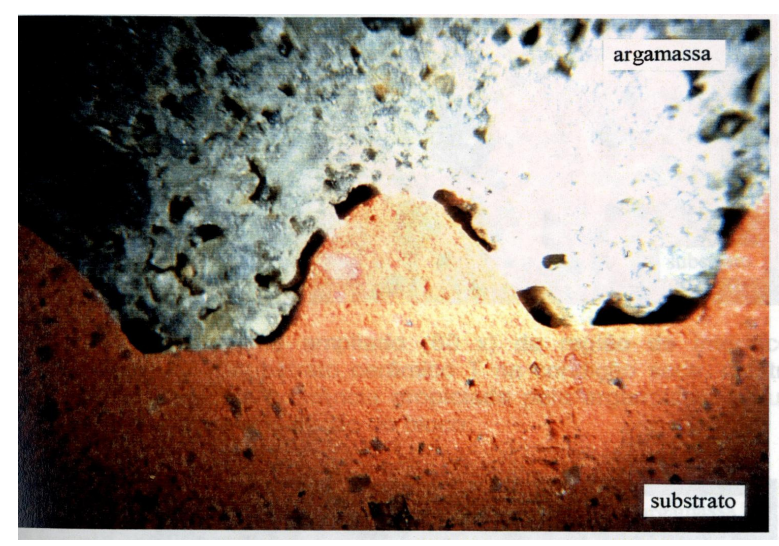

Figura 2-3: Interface base-revestimento com argamassa de cimento e areia (1:3 em volume) aplicada sobre substrato cerâmico - figura ampliada 20 vezes empregando-se lupa estereocópica (CARASEK, 1996).

Apesar de Carasek (1996) ter identificado estas descontinuidades de interface, ao longo de quase 10 anos nenhum estudo aprofundado do tema foi realizado. O tema é retomado por Antunes (2005) que, estudando o efeito da energia de lançamento, quantificou as descontinuidades na região da interface base-revestimento.

Essa autora, com ajuda de uma câmera digital e de uma ferramenta de análise de imagem, obteve imagens para seções transversais de corpos de prova de revestimento de argamassa aplicados sobre substrato padronizado de concreto, com o objetivo de quantificar as áreas de interface base-revestimento em que o contato era deficiente (descontinuidades), como é mostrado na Figura 2-4

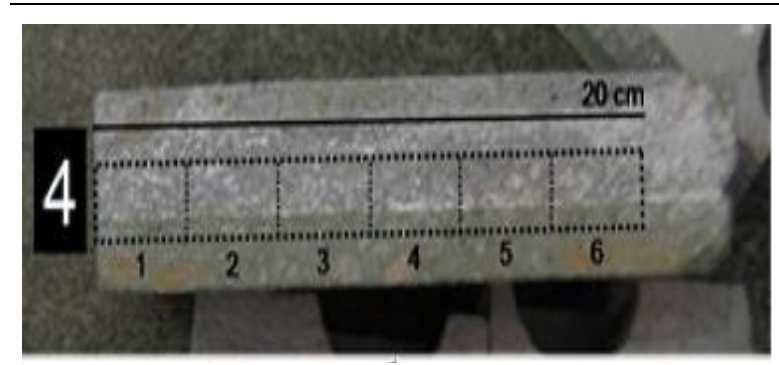

a)

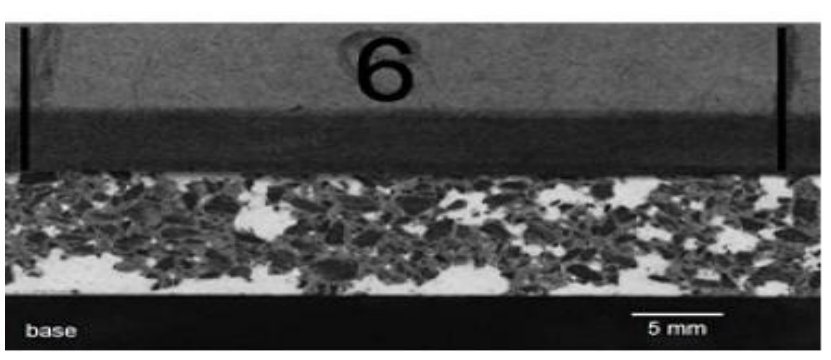

b)

Figura 2-4: Seção transversal de corpo de prova (a) e análise da imagem da interface de um quadrante selecionado na seção transversal (b) Fonte: ANTUNES (2005). 
Através da análise de imagens (Figura 2-4b), Antunes (2005) quantificou razão entre a taxa de macro-defeitos (macro-flaws) e a área total da interface denominando a essa relação de taxa de macro-defeitos de interface. Porém, essa aproximação considerou constante a seção do macro-defeito, situação que não ocorreu quando analisadas outras seções transversais do mesmo tipo de revestimento, sendo assim necessária a estimação de um valor médio.

No trabalho de Antunes (2005) foram estudadas 16 argamassas de revestimento. Para um mesmo lote de argamassa produzida industrialmente e tomando-se como referência a massa seca, variou: o teor de água de mistura (13\% e 15\%); o teor de aditivo incorporador de ar $(0 \%$ e $0,01 \%$, resultando em argamassas que variaram nos casos estremos entre $7,4 \%$ e 19,4\% respectivamente) e a altura de lançamento da argamassa sobre o substrato (1 m e $2 \mathrm{~m}$ ). Para a avaliação dos macro-defeitos, foram analisadas cerca de quatrocentas imagens de seções transversais, obtendose valores de taxa de defeitos que variaram desde $7 \%$ até $42 \%$. Essa variação na extensão de aderência dos revestimentos analisados foi evidenciada pela introdução de pasta de gesso na região da interface (Figura 2-4b). Os resultados assim obtidos foram comparados com os de resistência de aderência dos revestimentos verificando-se que os maiores valores de resistência de aderência correspondiam às placas cujas seções transversais apresentaram menores taxas de defeitos na análise de imagens.

Como uma etapa preliminar do presente trabalho, buscando-se conhecer a influência dos macro-defeitos de interface na distribuição de tensões no revestimento e na região da interface, o autor, em parceria com um especialista em elementos finitos, fazendo uso de um modelo numérico, simularam o revestimento aplicado a substrato de concreto com diferentes taxas de macro-defeitos circulares na superfície interfacial. O conjunto foi submetido unicamente a um gradiente de temperatura. Como resultado dessa simulação verificou-se que os fatores determinantes no nível de tensões são:

a restrição imposta pelos diferentes graus de movimentação térmica do revestimento e de sua base;

a posição do macro-defeito em relação à borda do revestimento ou a uma discontinuidade presente no mesmo, por exemplo, uma junta ou uma fissura (TEMOCHE et al., 2007). 
A partir dessas colocações fica evidente que tanto as tensões geradas no revestimento pela variação de temperatura como os macro-defeitos inerentes à sua produção condicionam seu comportamento mecânico e de modo particular sua resistência de aderência que, por sua vez, é umas das condições para sua durabilidade.

Portanto, para melhor entender as solicitações geradas na presença de um gradiente térmico serão abordadas na seqüência as tensões de origem térmica.

\subsection{Comportamento do revestimento frente à variação de temperatura.}

Todos os materiais apresentam uma variação dimensional quando varia a temperatura no meio em que se encontram. Essa variação pode produzir expansão quando a temperatura aumenta ou retração quando diminui e a propriedade que governa essa variação dimensional é denominada coeficiente de dilatação térmica $(\alpha)$. Quando há restrição à livre movimentação do material, surgem tensões que segundo Kingery (1955); Gatewood (1957); Timoshenko, Goodier (1968), são denominadas tensões térmicas.

O efeito das tensões térmicas em materiais de base cimentícia tem sido estudado principalmente em duas escalas: macroscópica e microscópica.

Na escala macroscópica Weidlinger (1964) já destacava a importância de se analisar o efeito da diferença entre as temperaturas externa e interna no edifício. Em locais onde a temperatura externa do ar pode aumentar ou diminuir muito em relação à temperatura de conforto térmico (entre $19^{\circ} \mathrm{C}$ e $25^{\circ} \mathrm{C}$ ) no interior do ambiente, são utilizados materiais de isolamento térmico para manter a temperatura interna na faixa de conforto.

Por sua vez, o BRE (1979) explica que nos componentes, geralmente unidos por ligações mecânicas ou químicas, as tensões devidas à restrição à movimentação por variação de temperatura ocorrem devido à diferença entre os seus coeficientes de expansão térmica, as quais se somam as descritas por Weidlinger (1964).

Os trabalhos de Saemann e Washa (1957), Castillo e Durrani (1990) apresentam uma abordagem macroscópica quanto ao efeito das tensões térmicas em concretos e argamassas. Após a aplicação de um carregamento térmico, os autores avaliam a resistência à compressão e o módulo de elasticidade dos materiais cimentícios analisados. 
No nível microscópico, autores como Wittmann (1983); Maekawa; Ishida e Kishi (2003); Fu (2003); William; Rhee e Xi (2005), dentre outros têm avaliado a degradação causada pelas tensões térmicas em concretos considerando a diferença de expansão térmica entre suas fases (pasta e agregados).

Diferentes autores, dentre os quais Neville (1982); PCA (1982); Wittmann (1983); Mehta e Monteiro (1994); Bazant e Kaplan (1996) e Fu (2003), coincidem em destacar três causas para a degradação dos materiais cimenticios devido a tensões térmicas: incompatibilidade de deformações térmicas de seus constituintes, decomposição dos produtos de hidratação e, pressão interna dos poros.

As duas últimas são significativas somente a altas temperaturas (várias centenas de @C). Segundo Bazant e Kaplan (1996), a decomposição dos produtos de hidratação ocorre a partir de $105^{\circ} \mathrm{C}$ e a pressão interna dos poros é significativa a temperaturas superiores a esta.

Para o caso dos revestimentos de argamassa em fachadas de edifícios sujeitos à variação de temperatura torna-se importante a primeira das causas incompatibilidade de deformações térmicas - dada à diferença entre os coeficientes de expansão térmica da pasta e dos agregados miúdos e aos efeitos dos gradientes térmicos, ambos abordados na seqüência.

\subsubsection{Diferença entre coeficientes de dilatação térmica}

Autores como Neville (1982); Mehta e Monteiro (1994) e a publicação da PCA (1982) destacam que os valores médios de expansão térmica de concretos e argamassas variam com o tipo de agregado utilizado em função da rocha-mãe que lhe dá origem.

$\mathrm{Na}$ Tabela 2-1 são registrados valores de coeficientes de dilatação térmica de diferentes agregados e do coeficiente de dilatação térmica de pasta de cimento. Pelos dados desta tabela é possível inferir que ao se utilizar agregados cuja origem seja o granito ou o calcário, por exemplo, pode-se ter uma grande diferença entre o coeficiente de dilatação térmica do agregado e o da pasta de cimento, o que certamente influenciará no comportamento do revestimento frente à variação de temperatura. 
Tabela 2-1:Coeficientes de dilatação térmica de vários tipos de agregado e pasta de cimento

\begin{tabular}{l|l|l}
\hline \multicolumn{1}{c|}{$\begin{array}{c}\text { Tipo de agregado } \\
\text { miúdo }\end{array}$} & \multicolumn{2}{c}{ Coeficiente de dilatação linear $\left(\times \mathbf{1 0}^{-\mathbf{6}^{\mathbf{0}}} \mathbf{C}^{-1}\right)$} \\
\hline & Neville (1982) & Metha: Monteiro (1994) \\
\hline Granito & $1,8-11,9$ & 8,0 \\
\hline Quartzo & - & $11,0-12,0$ \\
\hline Calcário & $0,9-12,0$ & 5 \\
\hline Basalto & $3,6-9,7$ & 7,0 \\
\hline Escória & 9,2 & 9,0 \\
\hline Pasta de cimento & $11-16$ & - \\
\hline
\end{tabular}

Apesar da grande diferença que pode resultar entre os coeficientes de expansão térmica da pasta e de agregados, Neville (1982) esclarece que o movimento diferencial entre pasta e agregado por temperatura é influenciado também por forças como a devida à retração na secagem da pasta e que dentro de certos limites de temperatura a diferença entre coeficientes de dilatação térmica entre pasta e agregado tem sua importância diminuída frente à retração que ocorre na pasta.

Segundo a PCA (1982), a diferença entre coeficientes de expansão térmica dos constituintes de concretos e argamassas tem mostrado certa correlação com a redução da durabilidade desses materiais quando submetidos a carregamento térmico. Esta constatação é confirmada por Venecanin (1990) que, em trabalho experimental, analisou o efeito das diferenças entre os coeficientes de dilatação térmica dos agregados e da pasta de cimento para temperaturas que atingiram até $65^{\circ} \mathrm{C}$ num extremo e até $-20^{\circ} \mathrm{C}$ no outro, considerando nesse caso também o efeito do congelamento da umidade nos corpos de prova. Em ambas as situações, foi verificada degradação de concretos devido à intensa fissuração.

No que se refere às argamassas, é usual estabelecer valores médios para seu coeficiente de dilatação térmica que, segundo Fiorito (1994), giram em torno de 10$12 \times 10^{-6}{ }^{\circ} \mathrm{C}^{-1}$. Experimentalmente, Saraiva (1998), Melo (2002) e, posteriormente, Childs (2007) obtiveram valores semelhantes para diferentes composições de argamassas em que foram variados o teor de aglomerante e o tipo de agregados. $O$ coeficiente de expansão térmica das argamassas que avaliaram variou de 10 a $13 \mathrm{x}$ $10^{-6}{ }^{\circ} \mathrm{C}^{-1}$. 


\subsubsection{Gradientes térmicos}

Os gradientes de deformação ocorrem quando a temperatura ao longo das dimensões de um corpo atinge diferentes valores provocando deformações diferenciais que, se restringidas, provocam tensões neste corpo.

$\mathrm{Na}$ escala macroscópica esses gradientes ocorrem nos vedos externos e, por conseqüência, nos revestimentos, uma vez que existe uma diferença entre as temperaturas das faces externa e interna da vedação vertical. Essa variação de temperatura assimétrica (em relação ao eixo paralelo às faces) produz um momento fletor.

Acrescenta-se a isto que a temperatura na face externa da vedação varia permanentemente, de acordo com as flutuações de temperatura que podem ser diárias, por estação ou anuais, enquanto a temperatura da face interna da mesma dependerá do calor gerado pelas condições de uso e da parcela de calor transferido através do corpo do revestimento desde o exterior.

Diariamente, a radiação solar promove o aquecimento superficial do revestimento durante o dia e à noite ocorre o seu resfriamento devido à emissão térmica. Essa variação cíclica geralmente descreve uma curva senoidal, que pode ter seus limites máximo e mínimo - variáveis, dependendo da estação do ano (verão ou inverno). Essa variação cíclica de temperaturas associada às tensões e deformações produzidas em cada ciclo pode desencadear um processo de fadiga do revestimento, principalmente no seu mecanismo de aderência comprometendo desta forma sua durabilidade.

A variação de temperatura (diárias, mensais ou anuais) no revestimento é governada por processos periódicos e permanentes de transferência de calor, os quais podem ser representados como exemplificado na Figura 2-5 e Figura 2-6 para período diurno e período noturno. 


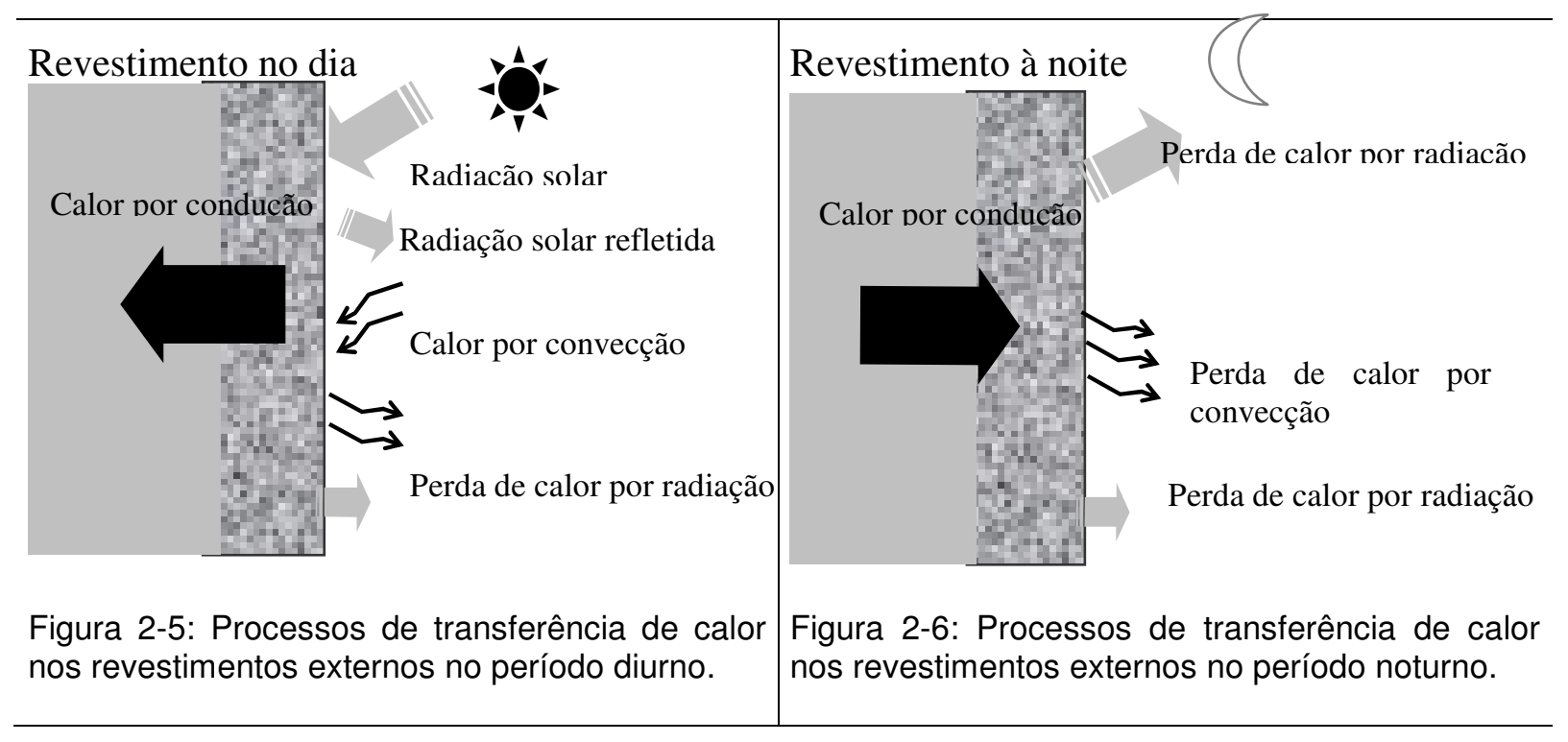

Internacionalmente, diferentes autores têm estudado 0 efeito dos gradientes térmicos tanto no concreto como em estruturas produzidas com ele, empregando abordagens teóricas e experimentais.

Analisando condições de uso de usinas nucleares nos Estados Unidos, Elgaaly (1988) desenvolveu curvas com valores máximos possíveis de gradientes térmicos para paredes, vigas e lajes de concreto considerando uma deformação limite, em função de parâmetros de projeto como resistência à compressão do concreto $\left(f_{c k}\right)$ e área de aço. Partiu da hipótese simplificadora de uma distribuição de temperatura linear e simulou um gradiente de temperatura através do elemento analisado também linearmente.

Vecchio e Sato (1990), em trabalho experimental, mostram que a rigidez da estrutura, governa o efeito dos gradientes térmico e que a diferença de temperatura entre superfícies opostas é o fator dominante no surgimento dos gradientes térmicos.

Empregando abordagem teórica, Timoshenko; Goodier (1970) propõem um modelo analítico para cálculo das tensões internas devidas a um gradiente térmico para um sólido cilíndrico homogêneo e isotrópico. Modelos semelhantes tinham sido anteriormente propostos por Gatewood (1957) e por Boley e Weiner (1960) para placas homogêneas com distribuição de temperatura assimétrica.

Infelizmente, esses modelos são aplicáveis somente a materiais homogêneos, o que não ocorre com o revestimento de argamassa. Por isto, muitos pesquisadores têm direcionado suas pesquisas para escalas microscópica ou até mesoscópica; há, 
ainda, aqueles que realizam suas análises considerando ambas as escalas e, por isto mesmo denominada análise multi-escala.

$\mathrm{Na}$ escala microscópica os gradientes são originados pela heterogeneidade do revestimento de argamassa, uma vez que tanto no seu corpo como na interface com a base (área de contato) a presença de ar ou água nos poros, a pasta, as microfissuras ou os agregados promovem esses gradientes devido às suas diferentes propriedades térmicas.

Muitos dos modelos teóricos para abordagem do efeito mecânico de tensões térmicas na microestrutura de compósitos cimentícios estão focados no estudo da degradação de concretos a altas temperaturas.

Utilizando um modelo multi-escala, William; Rhee e Xi (2005) apresentam uma análise do processo de dano termomecânico em materiais heterogêneos como o concreto. Na mesma linha, Fu et al. (2007) apresentam um método para modelar a fissuração por gradiente térmico em compósitos de base cimentícia, considerando a heterogeneidade do meio submetido a altas temperaturas para componentes de concreto.

Verifica-se, assim, que não há ainda uma abordagem de consenso para a determinação do nível de tensões de origem térmica em materiais de base cimentícia e que em geral, a abordagem numérica é complementada pela avaliação experimental.

\subsubsection{Modelos para determinação das tensões térmicas}

Diversos autores têm analisado as tensões térmicas em sólidos, principalmente na escala macroscópica, dentre os quais Gatewood (1957); Boley e Weiner (1960); Benham e Hoyle (1964); Manson (1966), Timoshenko e Goodier (1968), Hasselman (1970b), BRE (1979), Lu e Fleck (1998) e Collin e Rowcliffe (2000) os quais apresentam soluções analíticas gerais para diferentes geometrias e condições de contorno.

Esses autores salientam que, devido à complexidade de análise para algumas situações, é fundamental a adoção de hipóteses simplificadoras para a resolução do problema. Em função disto, vários modelos propostos não consideram a interação entre os efeitos das ações térmicas, higroscópicas e mecânicas. 
Nos materiais cimentícios, sabe-se que seu comportamento mecânico é influenciado pelas tensões decorrentes do perfil térmico que também influencia a cinética da hidratação do cimento. Esta, por sua vez, como destacado por Saemann e Washa (1957), afeta a evolução das propriedades mecânicas do revestimento. Além disso, embora com menor impacto, o comportamento mecânico do revestimento, sobretudo a fissuração resultante, cria descontinuidades que afetam a transferência de calor no revestimento.

Somado a isto, sabe-se também que o conteúdo de umidade nos materiais cimentícios, em razão da sua inerente porosidade, pode promover tensões internas quando o material está saturado ou quando há diminuição no conteúdo de umidade, além das alterações nos processos de transferência de calor gerados pelos gradientes de umidade, como destacado por Obied et al. (1999).

Observa-se, portanto, que os fenômenos somados resultam em comportamento bastante complexo dos materiais cimentícios, acrescentando o fato de que quando é analisado o revestimento, os modelos devem ser adaptados para análise de sistemas em camadas. Possivelmente por isto, como salientado, não se encontrou modelo de análise específico que leve em conta todas estas interações.

Apesar da dificuldade de se ter modelos adequados de análise, alguns avanços têm sido obtidos com o auxílio das simulações computadorizadas. Maekawa; Ishida e Kishi (2003) apresentam um modelo computacional em multi-escala combinando características micro-estruturais e macroscópicas do concreto para descrever aspectos do seu comportamento mecânico. Mabrouk; Ishida e Maekawa (2004) propuseram um modelo computacional em multi-escala para predizer 0 comportamento do concreto em curtas idades. Nessas abordagens, a microestrutura do compósito cimentício é simulada estatisticamente, descrevendo a distribuição de poros, agregados e pasta sendo necessária a adoção de hipóteses simplificadoras tais como considerar o sólido analisado composto por uma matriz com inclusões (agregados particulados) e defeitos de dois tipos: poros e fissuras; ou assumir os estados de tensão tri-axial como bi-axiais; ou considerar a pasta material homogêneo e isotrópico como era já destacado por Zaitsev (1983).

Neste trabalho, cujo foco é experimental e para o qual se busca nos modelos teóricos suporte para balizar o experimento, serão destacados unicamente os modelos que abordam o fenômeno das tensões de origem térmica no nível 
macroscópico e que sejam adequados às características geométricas do revestimento.

Autores como Gatewood (1957); Boley e Weiner (1960); Manson (1966), Timoshenko e Goodier (1968) apresentam modelos gerais de análise de tensões térmicas utilizando a abordagem macroscópica para diferentes geometrias básicas. A análise nesses modelos é dividida em duas partes: uma análise térmica, para determinar a distribuição de temperaturas no corpo; e uma análise mecânica, para o cálculo das tensões e deformações resultantes.

\subsubsection{Determinação do perfil de temperaturas}

A análise térmica é realizada para se obter o perfil de temperaturas no sólido o qual é definido a partir dos modelos de transferência de calor dos quais é apresentada uma síntese no Apêndice $A$.

Inicialmente é necessário estabelecer as condições de contorno, as quais estão relacionadas com a geometria definida para representar o revestimento, as propriedades dos materiais constituintes do revestimento e a forma como ocorre o fenômeno térmico, ou seja, se em regime permanente ou transiente, para posteriormente formular o balanço de energia que será abordado na seqüência.

\subsection{Formulação do balanço de energia para o revestimento}

Como o foco do presente trabalho está na interface base-revestimento, a face da base oposta à interface é considerada com temperatura constante.

$\mathrm{Na}$ superfície externa do revestimento haverá um ganho de calor enquanto a temperatura no seu interior for menor do que a externa. Durante o dia o ganho é por radiação, devido à exposição à radiação solar que, através de ondas eletromagnéticas, atinge a superfície do revestimento, havendo uma parcela refletida (albedo) e outra absorvida.

A quantidade de calor absorvida é medida pela absortância do material (número adimensional), que é influenciada notadamente pela cor nos materiais opacos, variando desde valores mínimos de 0,2 a 0,5, para superfícies com cores claras; até 0,7 a 0,9, para superfícies com cores escuras (Lamberts et al., 1997).

No balanço de energia na superfície externa do revestimento, à quantidade de calor absorvida por radiação deve-se acrescentar o ganho ou a perda por convecção 
provocado pela maior ou menor agitação das moléculas do ar em contato com a superfície do revestimento, que deve equilibrar o fluxo de calor em direção ao interior do revestimento mais o calor interno do mesmo.

Portanto, o balanço de energia em um determinado instante (regime permanente) é expresso pela Equação 2-1:

$$
\rho . c \frac{\partial T}{\partial t}=q^{\prime \prime}{ }_{c o n v}+q^{\prime \prime}{ }_{r a d}-q^{\prime \prime}{ }_{c o n d}
$$

Equação 2-1

Onde:

$\rho=$ densidade do meio continuo (revestimento)

c = calor específico do meio contínuo;

$\partial \mathrm{T} / \partial \mathrm{t}=$ taxa de variação da temperatura no tempo;

$q "{ }^{\prime \prime}$ onv = taxa de variação do fluxo de calor por convecção;

$q_{\text {rad }}^{\prime \prime}$ taxa de variação do fluxo de calor por radiação;

$q^{\prime \prime}{ }_{\text {cond }}=$ taxa de variação do fluxo de calor por condução.

Os fluxos de calor por condução, convecção e radiação podem ser obtidos utilizando a Equação A 3, a Equação A 4, e a Equação A 5, apresentadas no Apêndice 1, definindo se a análise será uni, bi ou tri-direcional.

\subsubsection{Análise mecânica}

Para proceder à análise mecânica do revestimento submetido à variação de temperatura, é necessário adotar o modelo numérico que melhor represente o problema. É necessária a formulação de algumas hipóteses como condições de contorno, as quais se referem às leis de comportamento estabelecidas no problema, às condições de equilíbrio, à geometria analisada, às propriedades intrínsecas dos materiais analisados, ou à ocorrência de um ou no máximo dois fenômenos de cada vez. As condições de contorno adotadas para que se proceda à análise mecânica deverão ser condizentes com o tipo de análise térmica realizada.

A maioria dos trabalhos que analisam o comportamento mecânico dos revestimentos de argamassa considera que seus materiais constituintes são contínuos, homogêneos e isotrópicos, assumindo um comportamento elástico linear, com o qual é possível utilizar os modelos da termo-elasticidade. 
De acordo com a geometria do revestimento externo em que sua superfície é bastante extensa em relação à sua espessura, a análise da distribuição das tensões pode ser simplificada supondo um estado plano de deformações, uma vez que em uma seção transversal do revestimento podem ser representadas de maneira bidimensional as tensões atuantes, considerando que ao longo do eixo perpendicular à seção transversal não há variação das deformações geradas. Assim, a geometria do revestimento poderia ser analisada como um sólido laminar constituído por um conjunto de camadas aderidas à base.

Dentre os modelos que atendem esses requisitos estão o de Saul (1969); Olsen e Ettenberg (1977); Hsueh e Evans (1985) e Hsueh (2002) que têm analisado as tensões geradas por uma variação de temperatura na superfície externa de um sistema com múltiplas camadas.

O modelo analítico proposto por Hsueh e Evans (1985) para cálculo de tensões de origem térmica para sistemas elásticos de dupla camada foi ampliado para múltiplas camadas por Hsueh (2002). O detalhamento desse modelo é apresentado no Anexo A desta tese.

Uma ferramenta comumente utilizada para a resolução de modelos mais sofisticados, por exemplo, para análise de transferência de calor bidirecional e estado tri-axial de tensões é o Método dos Elementos Finitos - MEF que tem ajudado a minimizar os esforços computacionais requeridos ao longo das modelagens (BOWMAN e BANKS, 1996; GOLDBERG, 1998; LU e FLECK, 1998; OBIED et al., 2000; COLLIN e ROWCLIFFE, 2000).

Contudo, os modelos simplificados apresentados permitem mostrar certas tendências e identificar os fatores que têm maior influência no desenvolvimento das tensões de origem térmica nos revestimentos. Por esta razão, neste trabalho, os métodos que envolvem os elementos finitos, mais sofisticados, não serão aprofundados.

\subsection{Fatores de influência nas tensões de origem térmica nos revestimentos}

De acordo com os modelos apresentados, determinados fatores exercem um papel de destaque no desenvolvimento de tensões de origem térmica nos revestimentos, os quais podem estar vinculados a propriedades térmicas e mecânicas do revestimento ou a características do carregamento como, por exemplo, as 
propriedades do fluxo de calor ou a configuração geométrica do revestimento, na forma de camadas.

Em relação às propriedades térmicas dos materiais cimentícios, propostos por diferentes referências bibliográficas, Marshall (1972) recomenda sua utilização com extremo cuidado uma vez que as condições para sua determinação têm influência nos valores obtidos, além das mesmas variarem com a idade, temperatura e umidade do elemento ou componente.

\subsubsection{Propriedades térmicas}

As principais propriedades térmicas que condicionam a resposta mecânica de revestimentos de argamassa, quando submetidos a uma fonte de calor são: o coeficiente de expansão térmica, a condutividade térmica e a capacidade térmica e, associada a essas duas últimas, a difusividade térmica, os quais serão brevemente discutidos a seguir.

\subsubsection{Coeficiente de expansão térmica}

Refere-se à variação volumétrica ou linear do revestimento para cada grau Celsius $\left({ }^{\circ} \mathrm{C}\right)$ de variação da temperatura. No caso da variação do comprimento em materiais isotrópicos, geralmente é denominado coeficiente de dilatação térmica linear. Como o revestimento de argamassa é composto de pasta aglomerante e agregado miúdo que possuem diferentes coeficientes de dilatação térmica, como mostrado na Tabela 2-1, é comum adotar-se um valor médio para esse coeficiente.

Além disso, o coeficiente de dilatação térmica da argamassa varia de acordo com o tipo de areia empregada na composição e também em função da litologia do grão, como é descrito pela PCA (1982) e também apresentado na Tabela 2-1. O PCA acrescenta que o principal fator que afeta o coeficiente de dilatação do agregado e, portanto da argamassa, é a proporção de quartzo no agregado. Assim, quanto maior o conteúdo de quartzo no agregado, maior o coeficiente de dilatação térmica e viceversa.

Outro fator determinante no valor do coeficiente de dilatação térmica dos revestimentos de argamassa é o seu conteúdo de umidade, como destacado por Marshall (1972); Emanuel; Hulsey (1977) e pelo PCA (1982). Um revestimento seco poderá ter um coeficiente de dilatação térmica $10 \%$ maior do que um que se encontre saturado. 
A PCA (1982) sugere que a relação água/cimento na argamassa também teria influência na variação do coeficiente de dilatação térmica citando como exemplo medições em concretos de dois meses de idade em que aqueles produzidos com relação água/cimento de 0,50 resultaram com coeficientes de dilatação térmica $16 \%$ maiores do que concretos com relação água/cimento de 0,70 .

Do ponto de vista teórico, existem na literatura alguns modelos como o de Hobbs (1971) ou Venecanin (1980) para determinação do coeficiente de dilatação térmica da argamassa de revestimento em função dos coeficientes de dilatação térmica da pasta e dos agregados, do módulo de Young de ambos, da concentração do volume dos agregados dentre outros parâmetros.

\subsubsection{Condutividade térmica}

Segundo Incropera, DeWitt (1990), a condutividade térmica é uma propriedade de transporte que indica a taxa de transferência de energia calorífica mediante 0 processo de difusão e depende da estrutura física da matéria. Em geral, a condutividade térmica de um sólido é maior do que a de um líquido, que por sua vez é maior que a de um gás.

A importância desta propriedade na análise das tensões térmicas em revestimentos está no fato de que ela pode alterar a velocidade do fluxo de calor no revestimento diminuindo a geração de gradientes térmicos. Entretanto, sua medição experimental demanda atenção especial.

A partir de trabalho experimental, Ganjian; Thinker; Cabrera (1994) propõem um modelo para predição da condutividade térmica de vários tipos de concretos em função da sua densidade e porosidade obtendo valores de condutividade térmica que variaram entre 0,63 e $2,86 \mathrm{~W} / \mathrm{m}$. ${ }^{\circ}$, mostrando uma faixa de variação relativamente estreita.

Por outro lado, Ramazan (2003) atribui o incremento da condutividade térmica de materiais como o concreto e, por analogia, a argamassa, ao seu conteúdo de umidade quando a água toma o lugar do ar que ocupa os poros do material. Afirma isto devido a maior condutividade térmica da água (25 vezes) em relação à condutividade térmica do ar.

Kim et al. (2003) realizaram um estudo experimental para identificar os fatores de maior influência na variação da condutividade térmica de concretos, argamassas de 
reparo e pasta de cimento em que analisaram os seguintes fatores: idade, relação água/cimento, tipo de cimento e adições, fração do volume de agregado, temperatura e condições de umidade do corpo de prova.

Dos resultados apresentados por Kim et al. (2003) verifica-se que a variação da condutividade térmica da argamassa de reparo ensaiada, saturada a $20^{\circ} \mathrm{C}$ é praticamente independente da idade, como é mostrado na Tabela 2-2:

Tabela 2-2: Variação da condutividade térmica com a idade de argamassa com relação $a / c=0,40$. Adaptada de Kim et al. (2003)

\begin{tabular}{l|l|l}
\hline \multicolumn{1}{c|}{ Tipo de material } & \multicolumn{1}{c|}{ Idade } & \multicolumn{1}{c}{ Condutividade térmica } \\
\cline { 3 - 3 } & & \multicolumn{2}{c}{$\mathbf{( W / \mathbf { m } ^ { \mathbf { } } \mathbf { C } )}$} \\
\hline $\begin{array}{l}\text { Argamassa de reparo de } \\
\text { cimento e areia na } \\
\text { relação }(1: 1,4 \text { em massa) }\end{array}$ & 3 dias & 2,091 \\
\cline { 2 - 3 } & 7 dias & 2,068 \\
\cline { 2 - 3 } & 14 dias & 2,103 \\
\cline { 2 - 3 } & 28 dias & 2,068 \\
\hline
\end{tabular}

Por essa pesquisa, os autores identificaram que a relação água/cimento e o tipo de cimento utilizado governam a variação da condutividade térmica das argamassas. $\mathrm{Na}$ Figura 2-7a é apresentado o gráfico que mostra o decréscimo dos valores da condutividade térmica em função do incremento da relação a/c e a influência da temperatura e umidade nesses valores.

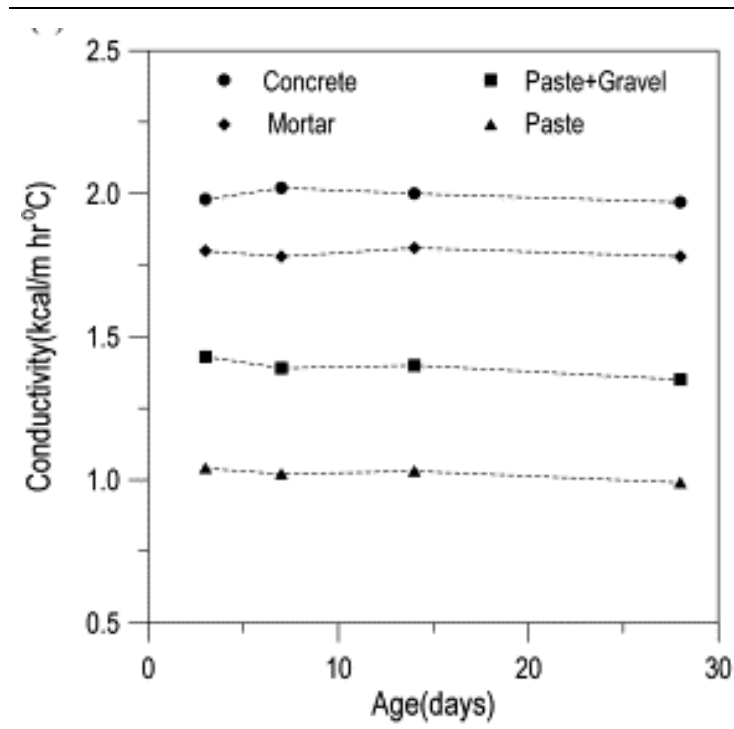

a)

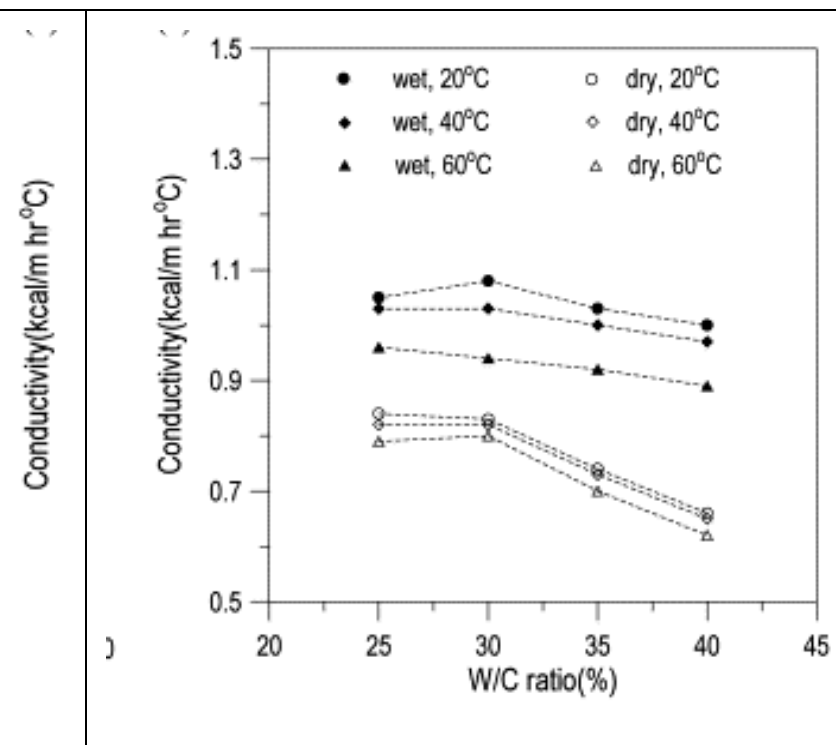

b)

Figura 2-7: Variação da condutividade térmica de concreto, argamassa e pasta de cimento em função da idade (a), e variação da condutividade térmica de concreto em função da relação a/c e do conteúdo de umidade das amostras (b). Fonte: Kim et al (2003). 
Dos resultados apresentados observa-se que a variação da condutividade térmica em argamassas de revestimento é relativamente baixa e como era esperado, seu incremento depende do conteúdo de umidade do revestimento, o qual tende a diminuir com o aumento da temperatura, promovendo assim um decréscimo da condutividade térmica que, segundo Incropera, DeWitt (1990), torna-se relevante somente para variações de temperatura acima dos $100^{\circ} \mathrm{C}$.

\subsubsection{Capacidade térmica}

É uma medida da quantidade de energia requerida para produzir a elevação de uma unidade de temperatura de um material (J/Ko ) (KINGERY, 1970). Usualmente é mais utilizado o calor específico (c) que representa a capacidade térmica por unidade de

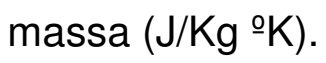

A partir do trabalho experimental de Verbeck e Helmuth, citados por Marshall (1972), é apresentada a Tabela 2-3, com valores de calor específico para pasta de cimento, a várias temperaturas e duas relações água/cimento.

Tabela 2-3: Calor específico de pasta de cimento em J/kg ${ }^{\circ} \mathrm{C}$, adaptado de Marshall (1972).

\begin{tabular}{|c|c|c|}
\hline \multirow{2}{*}{$\begin{array}{c}\text { Temperatura } \\
{ }^{\circ} \mathrm{C}\end{array}$} & \multicolumn{2}{|c|}{ Relação água / cimento } \\
\hline & 0,25 & 0,60 \\
\hline 21 & 1109,502 & 1590,984 \\
\hline 34 & 1159,744 & 1708,214 \\
\hline 43 & 1268,600 & 1904,994 \\
\hline 54 & 1423,512 & 2114,334 \\
\hline 65 & 1674,720 & 2428,344 \\
\hline
\end{tabular}

Pode ser observado que o aumento do calor específico devido ao aumento da temperatura ou da relação água/cimento ocorre em uma faixa relativamente pequena.

Quanto à influência do tipo de agregado esta parece ser mínima de acordo com os dados apresentados por Marshall (1972) mostrados na Tabela 2-4:

Tabela 2-4: Calor específico de alguns agregados de acordo a sua composição. Fonte: Marshall (1972)

\begin{tabular}{l|l}
\hline \multicolumn{1}{c|}{ Agregado } & \multicolumn{1}{c}{ Calor específico $\left(\mathbf{J} / \mathbf{k g}^{\mathbf{o}} \mathbf{C}\right)$} \\
\hline Quartzo & 732,69 \\
\hline Granito & 715,94 \\
\hline Dolomítico & 803,87 \\
\hline Argiloso & 845,73 \\
\hline Basaltico & 766,18 \\
\hline
\end{tabular}




\subsubsection{Difusividade térmica}

Segundo Incropera, DeWitt (1990), esta propriedade mede a capacidade de um material de conduzir energia térmica em relação à sua capacidade para armazenála. Ou seja, é relação entre a condutividade térmica $(k)$ do material e o produto da sua densidade pela sua capacidade térmica por unidade de massa (calor específico) - $\rho$ x c (produto denominado capacidade térmica volumétrica), apresentando como unidades $\mathrm{m}^{2} / \mathrm{s}$.

Materiais de baixa difusividade retardam sua resposta às variações do seu ambiente térmico, tardando mais tempo em atingir o equilíbrio térmico.

Apesar dos poucos dados disponíveis sobre difusividade térmica de materiais cimenticios, Marshall (1972) apresenta uma faixa de variação dessa propriedade para concreto entre $0,00186 \mathrm{~m}^{2} / \mathrm{h}$ (para agregado basáltico) e $0,00744 \mathrm{~m}^{2} / \mathrm{h}$ (para agregado quartzoso). Esse autor explica ainda que a difusividade térmica do concreto diminui com o aumento da temperatura, uma vez que o aumento da temperatura leva ao aumento do calor específico (Tabela 2-3).

\subsubsection{Propriedades mecânicas}

É importante destacar que nos modelos de análise mecânica apresentados anteriormente é assumido que os materiais são elásticos e cumprem a lei de Hooke. Kingery (1955) lembra que para materiais frágeis, essas hipóteses são válidas quando a alteração do valor do módulo é muito pequena, vale dizer, para pequenos intervalos de variação de temperatura, o que ocorre usualmente com os revestimentos de fachada. Para altos valores de variação de temperatura, geralmente considerados a partir de $100^{\circ} \mathrm{C}$, ocorre a relaxação do material no contorno dos grãos e as deformações dão origem ao fluxo plástico ou viscoso.

\subsubsection{Módulo de elasticidade - E}

O módulo de elasticidade da argamassa de revestimento é uma das propriedades mais importantes para sua caracterização já que é um parâmetro que indica seu grau de rigidez frente a um determinado nível de tensões.

Comumente é obtido como o resultado da relação entre a tensão aplicada em um corpo e a deformação específica produzida por esta tensão, conforme explicado por Callister (2000). 
Para o caso das argamassas de revestimento existem vários métodos de ensaio que empregam distintos formatos de corpos de prova e diferentes formas de determinação o que tem resultado na impossibilidade de comparação entre os resultados de diferentes autores conforme é destacado por Bastos (2003).

A discussão sobre a variação dos valores encontrados na literatura para o módulo de elasticidade da argamassa de revestimento não faz parte do escopo deste trabalho; por isto, será apresentada apenas a faixa de valores encontrados para diferentes tipos de argamassas. Nesse sentido pode-se citar a classificação MERUC ${ }^{8}$ estabelece os valores apresentados na Tabela 2-5:

Tabela 2-5: Valores de módulo de elasticidade segundo a classificação MERUC. Fonte: Blanchard (2003)

\begin{tabular}{l|l}
\hline \multicolumn{1}{c|}{ Tipo de argamassa } & \multicolumn{1}{|c}{\begin{tabular}{c}
\multicolumn{1}{c}{ Módulo de Elasticidade (E) } \\
MPa
\end{tabular}} \\
\hline 2 & 3500 a 7000 \\
\hline 3 & 5000 a 10000 \\
\hline 5 & 7500 a 14000 \\
\hline
\end{tabular}

Por outra parte cabe destacar que a variação de temperatura influencia no módulo de elasticidade de concretos e argamassas como tem sido verificado desde trabalhos como o de Saemann; Washa (1957) até trabalhos recentes como o de Fu et al. (2004). Estes últimos confirmam que aumento da temperatura promove um decréscimo do módulo para altas temperaturas como mostrado na Figura 2-8:

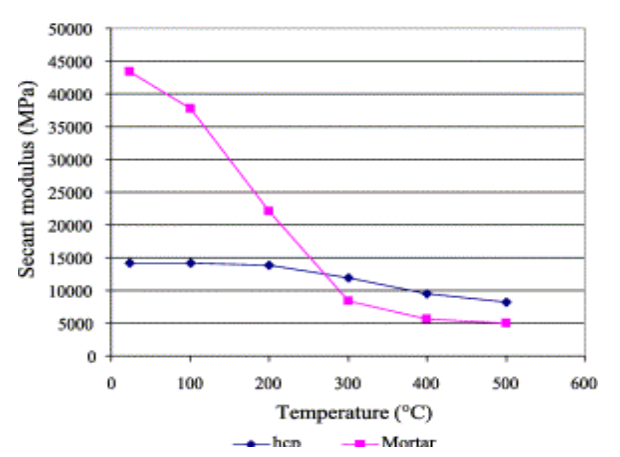

Figura 2-8: Variação do módulo de elasticidade secante da argamassa em função da temperatura. Fonte: Fu et al (2004).

\footnotetext{
${ }^{8}$ Esta classificação da norma francesa estabelece quatro tipos de argamassa de revestimento em função das suas seguintes propriedades: massa volumétrica aparente $(M)$; módulo de elasticidade $(E)$; resistência à tração $(R)$; retenção de água $(U)$ e, capilaridade $(C)$ (BLANCHARD, 2003)
} 


\subsubsection{Coeficiente de Poisson}

O coeficiente de Poisson (v) é uma propriedade elástica dos materiais definida pela relação entre a deformação longitudinal e a deformação transversal (CALLISTER, 2000). Araújo Junior (2004) determinou experimentalmente o coeficiente de Poisson para argamassas de revestimento obtendo valores menores $(0,16,0,12,0,07)$ do que 0,2 , valor teórico assumido para argamassas e concretos segundo Callister (2000)

\subsubsection{Resistência - tensão de ruptura}

Para materiais de base cimentícia como o concreto ou argamassa de revestimento, as tensões mais indesejáveis são as de tração e as de cisalhamento. Já a sua resistência à compressão é alta em relação às outras duas.

Como referência, apresenta-se, na Tabela 2-6, os valores de resistência à tração na flexão considerados na classificação MERUC, que são obtidos a partir de ensaios de de corpos de prova $4 \times 4 \times 16\left(\mathrm{~cm}^{3}\right)$.

Tabela 2-6: Valores de resistência à tração segundo a classificação MERUC para argamassas de revestimento. Fonte: Blanchard (2003)

\begin{tabular}{l|l}
\hline \multicolumn{1}{c|}{ Tipo de argamassa } & \multicolumn{1}{c}{\begin{tabular}{c}
\multicolumn{1}{c}{ Resistência à tração na flexão $(\mathbf{R})$} \\
$\mathbf{M P a}$
\end{tabular}} \\
\hline 2 & 1,0 a 2,0 \\
\hline 3 & 1,5 a 2,7 \\
\hline 4 & 2,0 a 3,5 \\
\hline 5 & 2,7 a 4,5 \\
\hline
\end{tabular}

\subsubsection{Propriedades Geométricas}

O revestimento externo de argamassa geralmente apresenta uma seção retangular com duas dimensões (comprimento e largura) muito maiores do que sua espessura. Embora no revestimento externo de um edifício, essa espessura possa apresentar seções variáveis devido às irregularidades da base ou substrato e à diferença de prumos entre os pavimentos, é freqüente considerar sua seção retangular.

Quanto à espessura, a NBR 7200 (ABNT, 1998) especifica uma espessura mínima de $25 \mathrm{~mm}$, entretanto esse valor em canteiros de obra pode ser mais elevado, como constatado por Souza et al. (1999) em pesquisa sobre produtividade na execução de 
revestimentos de argamassa em fachada registrando valores de espessura variando de 19 a $76 \mathrm{~mm}$.

Deve ser lembrado que segundo Ignatiev e Chatterji (1992) a espessura do revestimento influencia no nível de tensões atingido por ele, portanto é fator a ser considerado.

\subsubsection{Propriedades do fluxo de calor}

A evolução das tensões térmicas é influenciada pela taxa de aquecimento ou de resfriamento com que ocorre o fluxo térmico (KINGERY, 1955). Na superfície externa dos revestimentos os fluxos térmicos são gerados principalmente pelas condições ambientais tal como a radiação solar durante o dia e são potencializados ou atenuados em função das propriedades térmicas do revestimento.

Em relação à transferência de calor no revestimento por radiação e convecção, a maior variabilidade ocorre devido à faixa de valores que pode atingir o coeficiente convectivo "h" que pode variar até quatro ordens de grandeza dependendo do grau de turbulência em que se encontre o fluido no momento do resfriamento como será abordado no capítulo seguinte referido ao choque térmico. 


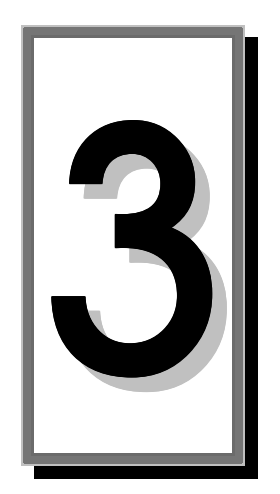

\section{CHOQUE TÉRMICO NOS REVESTIMENTOS DE ARGAMASSA}

\subsection{Conceitos básicos sobre choque térmico}

Em diversas aplicações da engenharia há situações que implicam em severas tensões térmicas, sendo necessária a seleção de materiais e componentes adequados. Para suportar essas condições de trabalho, além das propriedades do material são determinantes as características do fluxo de calor, particularmente a velocidade com que a variação de temperatura ocorre.

Quando a variação de temperatura é muito rápida, a taxa de carregamento no material é alta; portanto, a propagação das deformações de origem térmica no material dependerá da velocidade de resposta do mesmo, até atingir o equilíbrio.

A analogia desse fenômeno com o do choque ou colisão de dois sólidos tem permitido denominar ao efeito dessa rápida variação de temperatura como choque térmico, definido por Kingery (1955); Gatewood (1957) e Manson (1966) como "um fenômeno produzido por uma variação de temperatura rápida e transiente em um sólido, cujo resultado é um estado de tensões térmicas".

Essa definição genérica de choque térmico permite incluir nela uma diversidade de possibilidades. As características do fenômeno como: velocidade com que ocorre a variação de temperatura - minutos, frações de segundos; o meio em que ocorre líquido ou gasoso; a faixa de variação de temperatura - poucos ${ }^{\circ} \mathrm{C}$ ou centenas de ○C; o tipo de variação - aumento também denominado "upshock" ou diminuição também denominada "downshock"; direção do fluxo de calor - da superfície do sólido para seu centro ou no sentido contrário; formas de transferência de calor atuantes 
(condução, convecção, radiação) precisam ser definidas para uma melhor análise do fenômeno.

$\mathrm{Na}$ ciência dos materiais, por exemplo, esse fenômeno é extensamente estudado há mais de 50 anos, principalmente para materiais frágeis; e, de acordo com Jin; Mai (1995), geralmente refere-se a variações de temperatura severas (centenas de ${ }^{\circ} \mathrm{C}$ ), como pode ser verificado nos trabalhos de Kingery (1955); Buessem (1955); Manson (1966); Hasselman (1969); Nied (1987); Andersson; Rowcliffe (1996) ou Lu; Fleck (1998). Além disso, as taxas com que são produzidos os choques térmicos mencionados são também variáveis.

A resposta do material ao choque térmico também está condicionada às suas condições de contorno. Se houver restrições externas à livre deformação do sólido, o estado de tensões será agravado; se a exposição ao fluxo de calor é simétrica em toda a superfície do sólido, a transferência de calor ocorrerá até se atingir o equilíbrio térmico, isto é, a temperatura será a mesma em todo o sólido.

Quando o choque térmico é por resfriamento, conforme explica Kingery (1960), a superfície do sólido atingirá rapidamente a nova temperatura $\left(T_{s}\right)$ e irá retrair; porém, será restringida pelo seu interior que continuará na temperatura inicial $\left(\mathrm{T}_{\mathrm{i}}\right)$. Com isto, é gerado um gradiente térmico, surgindo tensões de tração na superfície e compressão no centro do sólido (Figura 3-1).

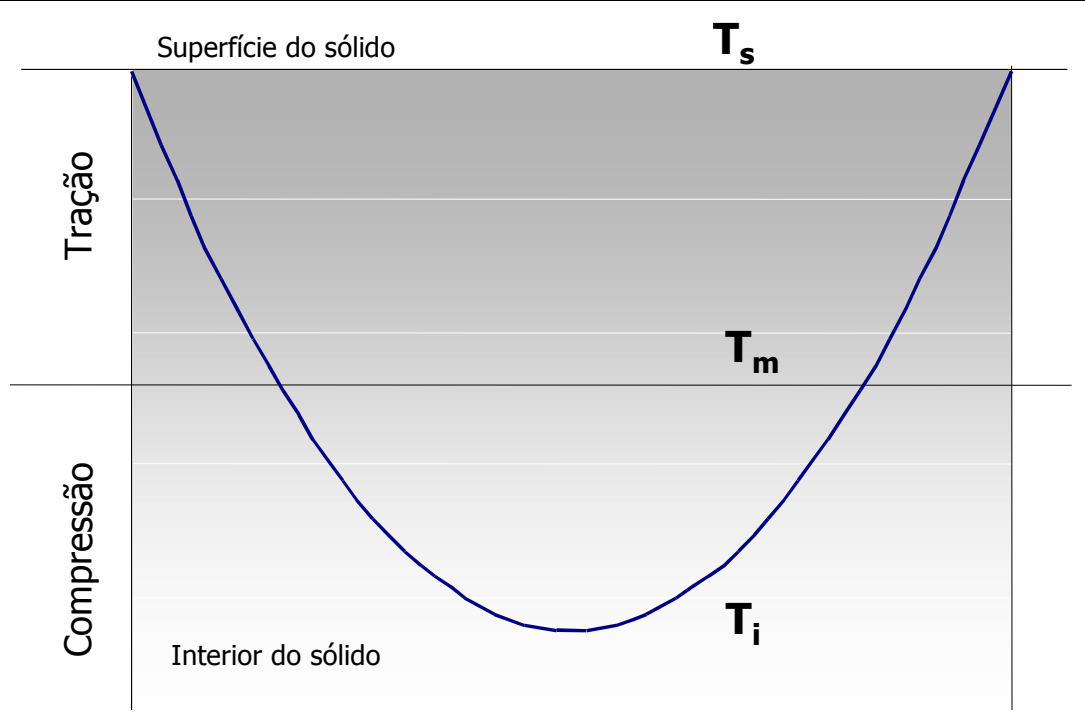

Figura 3-1: Distribuição de temperatura e tensões em uma placa resfriada na superfície 
Explica, ainda esse autor, que quando as superfícies de um sólido, exposto a um ambiente de menor temperatura, são resfriadas a uma taxa constante, a distribuição de temperaturas resultante é parabólica. O grau de deformação do sólido é dependente da sua temperatura média $\left(T_{m}\right)$; portanto, a tensão em qualquer ponto dependerá da diferença de temperatura entre esse ponto e a $T_{m}$.

No caso dos materiais cerâmicos, Kingery (1955) destaca que as tensões de tração geradas na superfície do sólido pelo choque térmico podem atingir valores que superem a resistência à tração do material, resultando na fratura do mesmo.

Para os materiais e componentes de construção são também diversas as situações em que o fenômeno pode ocorrer, seja pela exposição ao meio ambiente (ciclos de gelo e degelo, períodos de aquecimento solar seguidos de períodos de chuva), ou pelas diversas condições de uso (fornos industriais, pisos, saunas, etc.) ou, inclusive, em casos de incêndios.

Nos cenários em que a variação de temperatura é produzida pela exposição ao meio ambiente, a situação mais crítica vinculada à diminuição de temperatura (tensões de tração) pode ocorrer durante o dia para uma faixa de variação de temperatura limitada a algumas dezenas de ${ }^{\circ} \mathrm{C}$, e a taxa de variação de temperatura está na casa dos ${ }^{\circ} \mathrm{C} /$ minuto, se considerada a temperatura do ar como mostrado anteriormente na Figura 1-1. Nessas situações o fenômeno também é denominado choque térmico por autores como Agence Qualité Construction (1995) ou ASTM (2002).

Goldberg (1998) explica que se essa variação refere-se à temperatura superficial do componente construtivo, podendo-se atingir cerca de $60^{\circ} \mathrm{C}$.

Para os componentes construtivos geralmente a exposição ao choque térmico no meio ambiente é assimétrica e os fluidos mais comuns que promovem o resfriamento são o ar e água.

Além dos fatores anteriormente mencionados que exercem influência no comportamento do revestimento frente ao choque térmico, Coble e Kingery (1955) explicam que quando existem defeitos no material, sejam eles microfissuras ou poros, o transiente térmico originado pelo choque térmico provoca tensões nãolineares, concentradas nas extremidades desses defeitos. Nessas situações,

\footnotetext{
${ }^{9}$ Deve-se lembrar que nos materiais cerâmicos a resistência à tração é bastante menor que a sua resistência à compressão, assim como ocorre nos materiais de base cimentícia.
} 
conforme explicam Hasselman (1969), Nied (1987), Jin e Mai (1995), Lu e Fleck (1998) e Kerezsi e Price (2002), a exposição contínua a choques térmicos pode desencadear a propagação progressiva ou generalizada de defeitos, provocando uma degradação da resistência mecânica do material e, finalmente, o seu colapso.

Com o intuito de entender o efeito do choque térmico nos materiais, diversos pesquisadores têm proposto modelos que retratem as conseqüências provocadas pelo fenômeno e os fatores de maior influência, alguns dos quais serão abordados na seqüência.

\subsection{Modelos para avaliação do choque térmico em sólidos}

\subsubsection{Modelos teóricos}

Kingery (1960); Hasselman (1969); Biswas (1973) ressaltam a existência de duas teorias que explicam a falha por choque térmico em materiais cerâmicos. A primeira está relacionada à ocorrência da fratura, quando a resistência mecânica do material é superada e a segunda refere-se à propagação das fissuras que é promovida pela energia elástica armazenada no momento da fratura.

A primeira abordagem (ocorrência de fratura) é baseada em modelos de termoelasticidade, pelos quais, segundo Baroody e Simons e Duckworth (1955) e Hasselman (1970), qualquer problema de fratura de origem térmica pode ser entendido a partir de três elementos básicos: distribuição de temperatura; tensões resultantes e resistência do material.

No que diz respeito à distribuição interna de temperatura no sólido, Callister (2000) enfatiza que ela depende de:

- seu tamanho;

- sua forma;

- sua condutividade térmica;

- magnitude, direção e duração do fluxo de calor; e

- taxa de variação da temperatura.

Além disso, distribuições não uniformes de temperatura, no interior do sólido, gerarão gradientes térmicos na sua estrutura interna e conseqüentemente tensões. 
A determinação da distribuição de temperaturas no sólido dependerá da clara definição das condições de contorno para depois formular a equação de balanço de energia conforme descrito no item 2.3.3.1.1.

A partir do cálculo das temperaturas é possível a determinação das tensões utilizando modelos como os propostos por Boley e Weiner (1960) para diversas geometrias básicas.

A resistência ao choque térmico de um material não pode ser estimada precisamente porque não é uma propriedade intrínseca do material, podendo variar com o tamanho do sólido, com o tipo de tensão, com a taxa de carregamento e com outras condições de aplicação da tensão, por exemplo, as características do fluxo de calor.

A segunda abordagem - propagação das fissuras - conforme destaca Hasselman (1969), não considera o início do processo de fratura, mas aborda a extensão da propagação das fissuras e a resultante mudança no comportamento físico do material. Isto é avaliado através de ensaios em que o material é submetido a choques térmicos, geralmente por resfriamento e, após um número determinado de ciclos de exposição, são avaliadas as alterações em propriedades como massa, resistência mecânica, permeabilidade ou módulo elástico.

Essa abordagem foca o estudo das propriedades do material que afetam a propagação das fissuras.

\subsubsection{Critério de resistência ao choque térmico}

Este critério estabelece que o início da fratura do material submetido a um choque térmico ocorre quando as tensões atingidas no sólido superam sua resistência mecânica que, para o caso dos materiais de base cimentícia, analisados neste capítulo, diz respeito à resistência à tração do sólido.

Partindo de um sólido prismático homogêneo e isotrópico, é determinado o perfil de temperaturas em cada ponto e, para o cálculo das tensões, é considerado um sistema bidimensional e, como cenário crítico, a total restrição à deformação do prisma. Para esse caso, o modelo para o cálculo da máxima tensão térmica, proposto por Timoshenko e Goodier (1968), é apresentado na Equação 3-1: 


$$
\sigma_{y}=\sigma_{z}=\frac{E \alpha \cdot\left(T_{\text {sup }}-T_{\text {int }}\right)}{(1-v)}
$$

Onde:

$\sigma_{\mathrm{y}}=\sigma_{\mathrm{z}}=$ tensão de tração normal (MPa)

$\mathrm{T}_{\text {sup }}=$ temperatura superficial $(\stackrel{\circ}{ } \mathrm{C})$

$\mathrm{T}_{\text {int }}=$ temperatura interna no centro do corpo $\left({ }^{\circ} \mathrm{C}\right)$

$\mathrm{E}=$ módulo de elasticidade do material $(\mathrm{MPa})$

$\alpha=$ coeficiente de expansão térmica

$v=$ coeficiente de Poisson

Assim, quando a tensão de tração $(\sigma)$ atingir a tensão crítica de ruptura $\left(\sigma_{c}\right)$, ou seja $\sigma=\sigma_{c}$, a fratura do material ocorre e inicia-se a propagação da fissura.

Em estudos posteriores, Manson (1966) propôs uma fórmula semi-empírica para incluir um fator da atenuação térmica $\left(\psi^{-1}\right)$ na Equação $3-1$, em função das condições térmicas dependentes do tempo, o qual é calculado a partir do coeficiente de transferência de calor não-dimensional $(\beta)$, denominado número de Biot, resultando na Equação 3-2:

$$
\sigma=\frac{\psi \cdot E \cdot \alpha \cdot\left(T_{\text {sup }}-T_{\text {int }}\right)}{(1-v)}
$$

Equação 3-2

Onde:

$\psi=$ fator de atenuação das tensões térmicas

$\sigma=$ tensão de tração normal (MPa)

$\mathrm{T}_{\text {sup }}=$ temperatura superficial $\left({ }^{\circ} \mathrm{C}\right)$

$\mathrm{T}_{\text {int }}=$ temperatura interna no centro do corpo; $\left({ }^{\circ} \mathrm{C}\right)$

$\mathrm{E}=$ módulo de elasticidade do material (MPa)

$\alpha=$ coeficiente de expansão térmica $\left({ }^{\circ} \mathrm{C}^{-1}\right)$

$v$ = coeficiente de Poisson

O referido fator introduz no cálculo das tensões o número de Biot, conforme indicado na Equação 3-3:

$$
\Psi^{-1}=1,5+\frac{3,25}{\beta}-0,5 \exp \left[-\frac{16}{\beta}\right]
$$

\section{Onde:}


$\Psi=$ Parâmetro de atenuação da tensão térmica

$\beta=$ Número de Biot

Por sua vez o número de Biot $(\beta)$ é um número adimensional que proporciona uma medida da queda de temperatura no sólido em relação à diferença de temperaturas entre a superfície do sólido e o fluido e é definido pela Equação 3-4:

$$
\begin{array}{l|l}
\beta=\frac{h L}{k} & \text { Equação 3-4 }
\end{array}
$$

Onde:

$\beta=$ número de Biot

$\mathrm{h}=$ coeficiente de transferência de calor por convecção (energia que sai do corpo por unidade de diferença de temperatura entre a atmosfera e a superfície do mesmo) $\left(\mathrm{W} / \mathrm{m}^{2} . . \mathrm{.} \mathrm{C}\right)$

$\mathrm{L}=$ espessura característica do material analisado, geralmente definida como o volume do sólido dividido pela sua área superficial $(\mathrm{m})$

$k=$ coeficiente de condutividade térmica $\left(\mathrm{W} / \mathrm{m} .{ }^{\circ} \mathrm{C}\right)$

O significado físico do número de Biot também é interpretado como a relação entre duas resistências térmicas. Quando um sólido aquecido é inserido em um fluido a menor temperatura, é produzido um fluxo de calor que sai do sólido. Esse fluxo experimenta duas resistências, uma pelo próprio material do sólido e outra pelo fluido em contato na superfície do sólido. Se a resistência térmica imposta pelo fluido é maior que aquela imposta pelo sólido, $\beta<1$ (ou seja, alta condutividade térmica do material), e se a resistência térmica do material é maior que a do fluido, $\beta>1$.

Para Manson (1966), $\beta$ é uma das principais variáveis a serem determinadas para se estimar as tensões na superfície de um material frágil de seção retangular e de pouca espessura.

Esse autor demonstrou em um gráfico entre tensão máxima não-dimensional e o coeficiente de transferência de calor não-dimensional $(\beta)$ que para valores pequenos de $\beta$ há uma relação quase linear com os valores da tensão máxima nãodimensional, enquanto que para valores muito maiores de $\beta$, essa correlação se torna assintótica.

Utilizando essa relação e assumindo alguns valores como desprezíveis, Manson (1966) mostrou que a temperatura de equilíbrio que produz a tensão de ruptura na superfície pode ser expressa aproximadamente pela

Equação 3-5 e pela 
Equação 3-6:

\begin{tabular}{lll}
\hline$R=T_{\max }=\frac{k \sigma_{r} 3,25 \cdot(1-v)}{E \cdot \alpha \cdot h L}$ & Para pequenos valores de $\frac{h L}{k}$ & Equação 3-5 \\
\hline$R=T_{\max }=\frac{\sigma_{r} \cdot(1-v)}{E . \alpha}$ & Para valores muito grandes de: $\frac{h L}{k}$ & Equação 3-6
\end{tabular}

Onde:

$\mathrm{R}=\mathrm{T}_{\max }=$ variação de temperatura para produzir tensão máxima $\left({ }^{\circ} \mathrm{C}\right)$

$\mathrm{k}=$ coeficiente de condutividade térmica $\left(\mathrm{W} / \mathrm{m} \cdot{ }^{\circ} \mathrm{C}\right)$

$\sigma_{\mathrm{r}}=$ tensão de ruptura $(\mathrm{Pa})$

$v=$ coeficiente de Poisson

$\mathrm{E}=$ módulo de elasticidade $(\mathrm{Pa})$

$\alpha=$ coeficiente de dilatação térmica $\left({ }^{\circ} \mathrm{C}^{-1}\right)$

$\mathrm{h}=$ coeficiente de transferência de calor convectiva $\left(\mathrm{W} / \mathrm{m}^{2} .{ }^{\circ} \mathrm{C}\right)$

$\mathrm{L}=$ espessura do material analisado $(\mathrm{m})$

A partir dos modelos anteriores, Gatewood (1957); Manson (1966) indicam que as expressões (k. $\left.\sigma_{\text {ruptura }} / E . \alpha\right)$ e ( $\left.\sigma_{\text {ruptura }} / E . \alpha\right)$ são denominados parâmetros do choque térmico e permitem ter uma idéia da resistência relativa ao choque térmico para diferentes materiais frágeis.

A condutividade térmica do componente pode gerar duas situações. Uma baixa condutividade concentrará as tensões de compressão (queda rápida de temperatura) perto da superfície externa do revestimento, desde que o tempo de duração do choque térmico seja suficientemente longo, enquanto a parte interna do componente não é significativamente afetada. Por outro lado, uma alta condutividade promoverá uma propagação e fluxo de saída do calor rapidamente através do revestimento (queda rápida de temperatura) e a tensão na sua superfície poderá ser menor em determinado momento; porém, uma região maior no centro do componente estará em alta tensão devido aos gradientes gerados no interior. Pickles e Field (1996) destacam que o tempo de duração do choque térmico é determinante, já que se o ciclo de variação for muito curto não haverá tempo suficiente para a propagação do calor e a condutividade deixa de ser importante na análise. Em função disso, não se pode afirmar que o aumento da condutividade gera necessariamente um aumento na resistência ao choque térmico. 
Jin e Mai (1995) afirmam que a severidade do choque térmico corresponde a um valor infinito do número de Biot e que as tensões térmicas são menos severas na condição de um resfriamento gradual que equivale a um número de Biot finito, o qual resulta em uma degradação menos severa.

Utilizando modelagem por elementos finitos, Collin e Rowcliffe (2000) simularam um sólido cilíndrico de $6 \mathrm{~mm}$ de radio e $4 \mathrm{~mm}$ de altura submetido a choque térmico resfriado simetricamente, como pode ser observado na Figura 3-2.

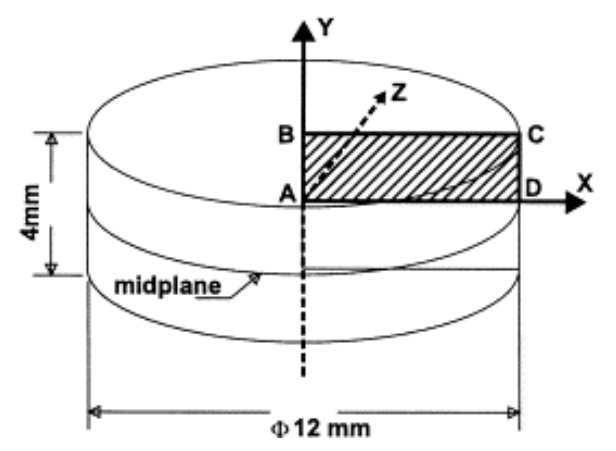

Figura 3-2: llustração do sólido modelado. Para a modelagem em elementos finitos foi considerada a seção transversal limitada para área ABCD. Fonte: Collin e Rowcliffe (2000).

O resultado dessa modelagem (Figura 3-3 a) mostra o gradiente de temperaturas provocado pelo choque térmico de $160^{\circ} \mathrm{C}$ e a região de concentração das tensões de tração na superfície externa do sólido.
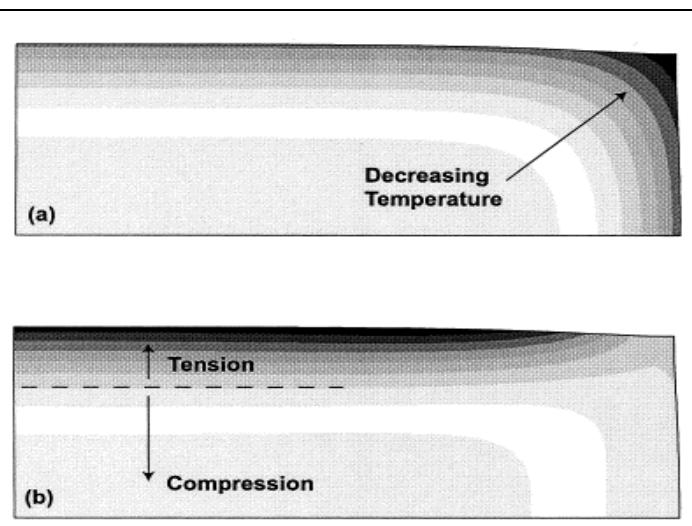

a)

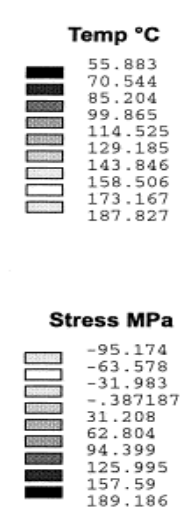

89.186

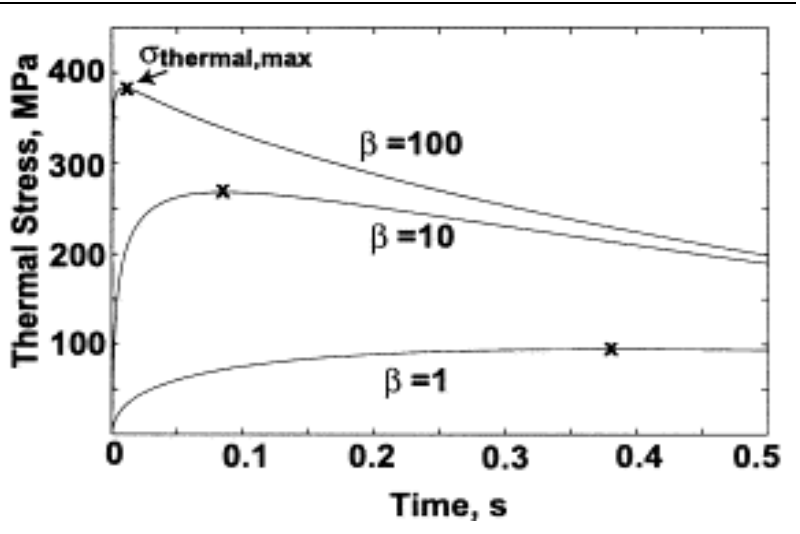

b)

Figura 3-3: Distribuição de temperaturas e tensões na seção ABCD do sólido modelado (a) e variação das tensões ao longo do tempo na línea $A B$ do sólido da Figura anterior.

A Figura 3-3 b apresenta o desenvolvimento das tensões provocadas pelo choque térmico de $160^{\circ} \mathrm{C}$ dentro dos primeiros cinco décimos de segundos, mostrando a 
influência da grandeza do número de Biot que quanto maior, mais alto o nível de tensões. Para esta modelagem foram considerados valores de 1, 10 e 100 para o número de Biot, deixando em evidencia o crescimento exponencial das tensões.

\subsubsection{Critério de propagação de fissuras}

Entre as principais limitações do critério de resistência ao choque térmico, Hasselman (1963) destaca que ele está baseado na análise das propriedades que afetam a nucleação da fratura e que, em contraposição a muitas aplicações industriais, essa nucleação e iniciação da fratura é menos importante do que o grau de degradação provocado pelo choque térmico, em termos de perda de resistência, por exemplo. Isto porque muitos dos materiais utilizados na indústria possuem microdefeitos (poros, contornos de grão, micro-fissuras, etc) que lhes são inerentes, e a propagação desses defeitos devidos às cargas mecânicas torna-se de maior interesse.

Dessa forma, Hasselman $(1963 ; 1969)$ utilizou a teoria da mecânica da fratura, proposta por Griffith (1920), para analisar as propriedades que governam a propagação das fissuras após sua nucleação para materiais submetidos a choque térmico.

A teoria proposta por Griffith (1920) para explicar a falha de materiais frágeis defende que para a propagação de uma fissura é necessária a criação de energia superficial, a qual é fornecida pela liberação de energia de deformação que acompanha a relaxação do campo de tensões gerado no extremo de uma fissura, na medida em que a fissura avança. $O$ aumento da fissura ocorrerá quando a liberação de energia de deformação for suficiente para promover o aumento na energia superficial.

Essa energia superficial é denominada por Hasselman (1969) de "energia superficial efetiva", e resulta ao comparar os diferentes mecanismos de dissipação de energia que tendem a interromper a propagação da fissura. Segundo esse autor, a "energia superficial efetiva - ( $\left.\gamma_{\text {efectiva }}\right)$ " resulta da soma da energia termodinâmica livre, da energia dissipada por deformação inelástica no extremo da fissura e, da energia dissipada pela deformação plástica de uma fina camada superficial nas novas superfícies geradas na fissura. 
Para o modelo proposto por Hasselman (1969), foi considerado um sólido uniformemente resfriado com uma variação de temperatura $(\Delta T)$ e sem a presença de outras forças externas, com suas superfícies externas rigidamente restringidas para gerar um estado tri-axial de tensões e que contém defeitos na forma de microfissuras de formato circular, distribuídas uniformemente pelo material, de acordo com o valor "N" que representa o número de fissuras por unidade de volume. É assumido também que as fissuras se propagam simultaneamente, sendo a variação de temperatura crítica para gerar a instabilidade das fissuras $\Delta$ Tc conforme Equação 3-7:

$$
\Delta T_{c}=\left[\frac{\pi \gamma_{\text {efectiva }}(1-2 v)^{2}}{2 E_{0} \alpha^{2}\left(1-v^{2}\right)}\right]^{1 / 2}\left[1+\frac{16\left(1-v^{2}\right) N l^{3}}{9(1-2 v)}\right] \cdot l^{-1 / 2} \quad \text { Equação 3-7 }
$$

Onde:

$\Delta \mathrm{T}_{\mathrm{C}}=$ variação de temperatura crítica $\left({ }^{\circ} \mathrm{C}\right)$;

$\pi_{\mathrm{i}}=$ constante pi;

$\gamma_{\text {efectiva }}=$ energia superficial efetiva;

$v=$ coeficiente de Poisson;

$\mathrm{E}_{0}=$ módulo de elasticidade do material livre de fissuras $(\mathrm{Pa})$;

$\alpha=$ coeficiente de dilatação térmica do material $\left({ }^{\circ} \mathrm{C}^{-1}\right)$;

$\mathrm{N}$ = número de fissuras por unidade de volume;

$\mathrm{I}$ = comprimento da fissura $(\mathrm{m})$

A partir desse modelo, Hasselman (1969) mostra que a variação da temperatura crítica $\left(\Delta \mathrm{T}_{\mathrm{c}}\right)$ com o incremento do comprimento da fissura atinge uma região de instabilidade entre dois valores desse comprimento conforme Figura 3-4: 


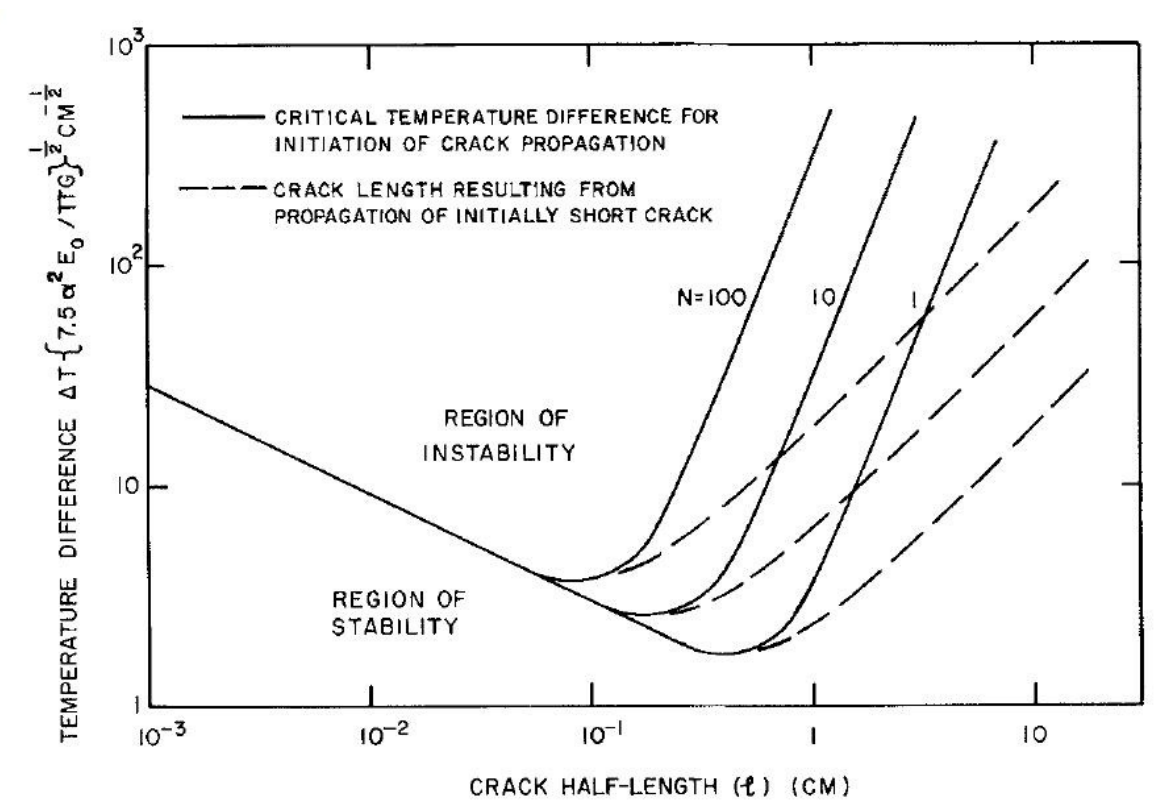

Figura 3-4: Deformação térmica requerida para iniciar a propagação da fissura em função do comprimento da fissura e da densidade de fissuras (N). Fonte: Hasselman (1969)

Analisando o modelo proposto por Hasselman, Kingery (1960) explica que para fissuras iniciais pequenas (à esquerda do valor mínimo) a taxa de liberação de energia após o início da propagação da fissura excede a energia superficial de fratura, e a energia excedente é transformada em energia cinética da fissura em movimento. Quando a fissura atinge o comprimento provocado pela $\Delta T c$, ela ainda possui energia cinética e continuará se propagando até que a energia de deformação seja igual à energia superficial de fratura total. Essa condição é representada pelos comprimentos finais da fissura mostrados em linha tracejada na Figura 3-4, que também permite observar que esses comprimentos finais da fissura são subcríticos em relação à $\Delta T_{c}$ necessária para seu início. Finalmente Kingery (1960) salienta que em contraposição às fissuras de pequeno comprimento, aquelas com comprimento inicial à direita do valor mínimo de $\Delta \mathrm{T}_{\mathrm{c}}$ (na parte inferior na Figura 3-4) propagam-se de maneira quase estática.

Para materiais que possuem fissuras com pequeno comprimento inicial, este variará em função da severidade do choque térmico de acordo com a Figura 3-5. 


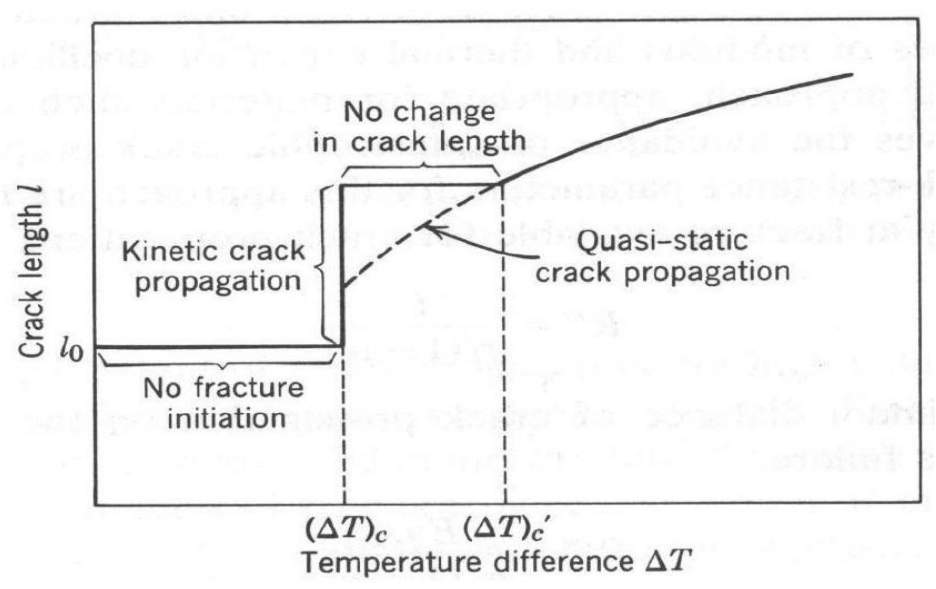

Figura 3-5: Comprimento da fissura em função da diferença de temperatura no choque térmico. Fonte: Hasselman (1969)

A variação correspondente na resistência do material em função da severidade do choque térmico também é mostrada esquematicamente por Hasselman (1969) na Figura 3-6. Aqui, para tensões menores do que as requeridas para iniciar a fratura, o valor da resistência do material é estável. Quando é atingida a tensão crítica para a $\Delta T_{c}$, as fissuras se propagam rapidamente e a resistência sofre uma queda abrupta. Nesse momento as fissuras tornam-se subcríticas e, portanto, não há variação na resistência do material, sendo necessário um acréscimo nas tensões atingidas através de um novo $\Delta \mathrm{T}_{\mathrm{c}}{ }^{\prime}$.

No caso de choques térmicos mais severos $\left(\Delta \mathrm{T}_{\mathrm{c}}>\Delta \mathrm{T}_{\mathrm{c}}{ }^{\prime}\right)$, as fissuras se propagarão quase estaticamente com a correspondente queda na resistência do material.

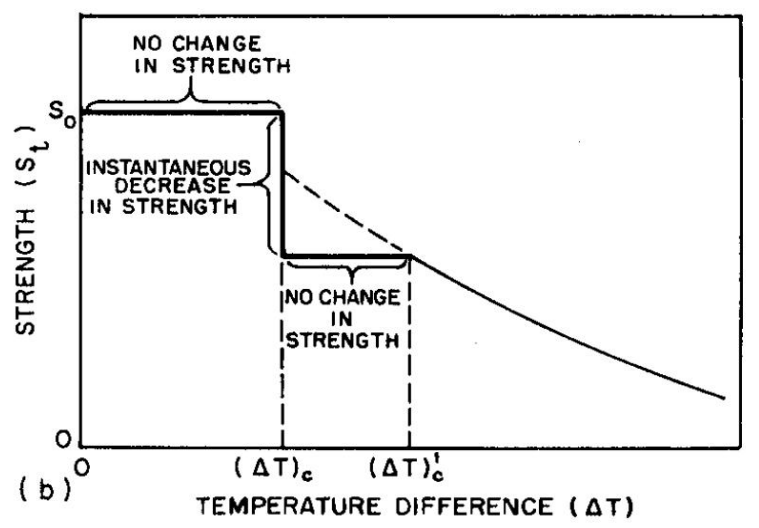

Figura 3-6: Variação da resistência em função da severidade do choque térmico. Fonte: Hasselman (1969) 
Em estudos posteriores, a teoria de Griffith (1921) foi reformulada em termos de tensões, sendo introduzido o conceito de fator de intensidade de tensões $\left(K_{1}\right)$, calculado de acordo com a Equação 3-8:

$$
K_{I}=Y \sigma \sqrt{\pi a}
$$

Equação 3-8

Onde:

$K_{I}=$ fator de intensidade de tensões em MPa. $(m)^{1 / 2}$;

$\mathrm{Y}=$ fator adimensional que caracteriza a geometria do sólido;

$\sigma=$ tensão remota aplicada ao componente (neste caso tensão devida ao choque térmico) (MPa);

$a=$ comprimento da fissura $(m)$.

Além disso, foi introduzida como propriedade do material a tenacidade à fratura $\left(\mathrm{K}_{\mathrm{IC}}\right)$, que resulta quando $\mathrm{K}_{\mathrm{I}}$ atinge seu valor crítico. Esta propriedade descreve a habilidade do material para resistir à fratura e, para sua determinação, é necessário conhecer as características de uma de suas fissuras (comprimento e coordenadas), além das características geométricas do sólido, como pode ser observado na Equação 3-8.

Outra reformulação à teoria de Griffith surgiu da verificação de que os materiais, em especial os cerâmicos, não apresentam um comportamento totalmente frágil; por isto, é necessário acrescentar nos modelos anteriores à energia superficial, a energia devida à deformação plástica, conforme destaca Collins (1980).

O desenvolvimento de modelos de predição da propagação de fissuras tem envolvido diversos pesquisadores cujas abordagens aparecem em trabalhos recentes que avaliam o grau de degradação provocado pelo choque térmico.

Jin e Mai (1995), Lu e Fleck (1998), Collin e Rowcliffe (2000), Chapuliot et al. (2005) e Reytier et al. (2006) destacam o critério da mecânica da fratura como sendo o mais apropriado para avaliar o choque térmico em materiais porosos.

Lu e Fleck (1998) desenvolveram um modelo para classificação de diversos materiais de acordo com a sua resistência ao choque térmico, por resfriamento rápido ("cold shock"), utilizando como critério de falha o valor da tenacidade do material. Nessa análise, considerou-se a existência de uma fissura dominante com 
características conhecidas e que a falha ocorreria quando o fator de intensidade de tensões $\left(\mathrm{K}_{\mathrm{l}}\right)$ é máximo, ou seja, quando é atingido o valor de $\mathrm{K}_{\mathrm{IC}}$.

Dois foram os cenários críticos estabelecidos: o primeiro refere-se à máxima queda de temperatura que um sólido pode resistir na situação extrema de perfeita transferência de calor, ou seja quando $\beta=\infty$; e o segundo refere-se à outra situação crítica em que $\beta \leq 1$.

Para o primeiro cenário o modelo deduzido resultou na Equação 3-9.

$$
\Delta T=A_{1} \frac{K_{I C}}{E \alpha \sqrt{\pi H}} \quad \text { Equação 3-9 }
$$

Onde:

$\Delta \mathrm{T}=$ variação de temperatura crítica $\left({ }^{\circ} \mathrm{C}\right)$;

A1= Constante estimada aproximadamente em 4,5

$\mathrm{K}_{\mathrm{IC}}=$ fator de intensidade de tensões em MPa. $(\mathrm{m})^{1 / 2}$;

$\mathrm{E}=$ módulo de elasticidade do material $(\mathrm{MPa})$;

$\alpha=$ coeficiente de dilatação térmica do material $\left({ }^{\circ} \mathrm{C}^{-1}\right)$;

$\pi_{\mathrm{i}}=$ constante $\mathrm{pi} ;$

$\mathrm{H}=$ metade da espessura do sólido considerado $(\mathrm{m})$.

Para o segundo cenário, o modelo considerado é apresentado na Equação 3-10.

$$
\Delta T=A_{2} \frac{K_{I C}}{E \alpha \sqrt{\pi H}} \frac{1}{\beta} \equiv A_{2} \frac{K_{I C}}{E \alpha \sqrt{\pi H}} \frac{k}{h H} \quad \text { Equação 3-10 }
$$

Onde: 
$\mathrm{A}_{2}=$ Constante estimada aproximadamente em 9,5;

$\beta$ = número de Biot;

$h$ = coeficiente de transferência de calor por convecção;

$\mathrm{k}=$ coeficiente de condutividade térmica

Desta forma, foram classificados diferentes materiais cerâmicos em um gráfico, considerando a variação de suas propriedades e utilizando como eixos de coordenada $\mathrm{k} \mathrm{K} \mathrm{K}_{\mathrm{IC}} / \mathrm{E}_{\alpha}$ e $\mathrm{K}_{\mathrm{IC}} / \mathrm{E} \alpha$, conforme Figura 3-7

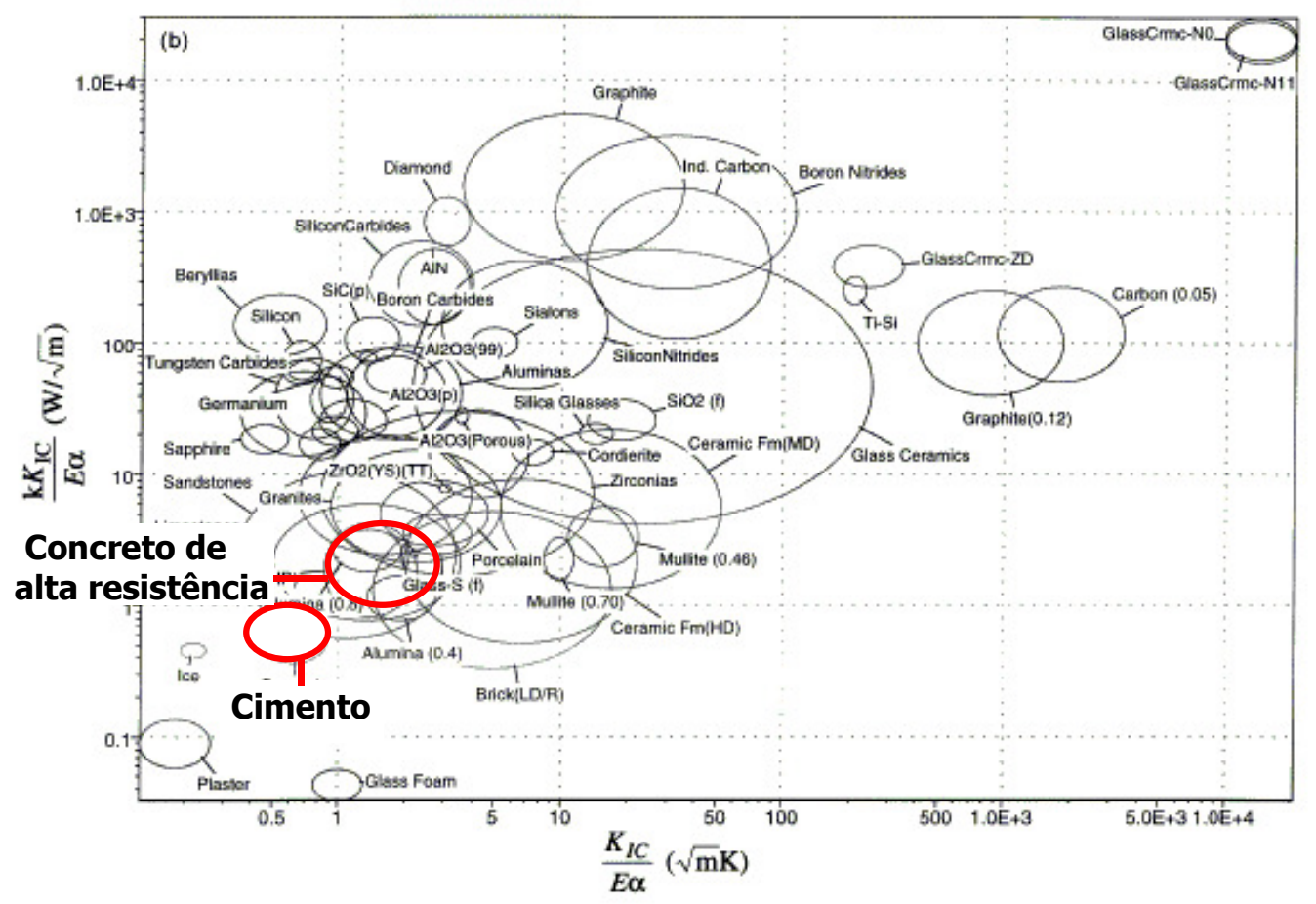

Figura 3-7: Classificação de materiais cerâmicos pelo critério de falha controlado pela sua tenacidade. (LU e FLECK, 1998).

\subsubsection{Modelos de abordagem experimental}

Os ensaios de choque térmico são realizados, segundo Buessem (1955), para dar suporte à predição de falha mecânica de um material, quando a variação de temperatura é rápida. Entretanto, os resultados desses ensaios estão limitados porque cinco das propriedades que influenciam o comportamento do sólido frente ao choque térmico - resistência mecânica, módulo de elasticidade, coeficiente de Poisson, coeficiente de expansão térmica e condutividade térmica- sofrem influência 
da temperatura. Desta forma, os resultados dos ensaios permitem avaliar somente 0 grau de degradação das propriedades mecânicas do material.

De maneira geral, Kingery (1955) classifica os modelos experimentais de choque térmico em função da forma como o gradiente térmico é simulado, por exemplo, aquecimento ou resfriamento rápido, ou ciclos de variação de temperatura e; pela forma como é avaliada a resistência do material em função das tensões térmicas geradas na exposição ao choque térmico, isto é, pela perda de peso, pela perda de resistência, pelo decréscimo nas propriedades elásticas do material.

Enfatiza ainda esse autor que a resistência ao choque térmico não é uma propriedade intrínseca do material e sim uma interação entre determinadas propriedades térmicas e mecânicas do material e as condições de contorno em que ocorre o choque térmico.

Um dos ensaios de laboratório mais utilizados na análise dos efeitos do choque térmico é o "quenching test", que prevê o resfriamento do material previamente aquecido simetricamente, geralmente por imersão em água na temperatura ambiente. Após cada choque, em que o valor da variação de temperatura vai sendo incrementada se tornando mais crítica, são medidas as resistências mecânicas residuais do material ensaiado. Quando o material experimenta uma drástica queda na sua resistência mecânica, é registrada a variação de temperatura em que isto ocorreu, ficando estabelecido o parâmetro "R", que representa a variação de temperatura máxima que o material pode resistir sem que ocorra uma queda drástica na sua resistência mecânica.

Analisando o efeito da variação da temperatura da água utilizada no resfriamento nos ensaios de choque térmico em alumina, Becher (1981) destaca a forte influência do coeficiente de transferência de calor por convecção (h). Esse autor explica que quando o resfriamento é realizado com água a $22^{\circ} \mathrm{C}$ os valores da variação de temperatura $\left(\Delta \mathrm{T}_{\mathrm{c}}\right)$ se mostraram independentes das propriedades da alumina e da espessura do corpo de prova, enquanto que quando a temperatura da água utilizada para o resfriamento aumentava até $100^{\circ} \mathrm{C}$, a variação de temperatura $\left(\Delta \mathrm{T}_{\mathrm{c}}\right)$, mostrou uma forte dependência com a espessura do corpo de prova, para choques térmicos em que a faixa de queda de temperatura era maior a $250^{\circ} \mathrm{C}$. 
No intuito de melhor representar as condições reais de uso dos materiais aplicados, foi utilizado, segundo indicam Kingery (1955); Buessem (1955), o método de ensaio ASTM C-38 (ASTM, 1949), atualmente fora de vigência, no qual era simulado um painel produzido com tijolos refratários e era mantido aquecido em uma temperatura determinada e em seguida resfriado rapidamente com ar e água. Cabe destacar que esse ensaio foi proposto inicialmente já na década dos anos 20.

\subsection{Análise do potencial de aplicação dos modelos teóricos para sólidos às argamassas de revestimento.}

Os revestimentos verticais de argamassa internos ou externos não apresentam, geralmente, condições de uso em que as variações de temperatura atinjam valores acima de $70^{\circ} \mathrm{C}$, a menos que se trate de situações fora do comum, como é o caso do revestimento em uma edificação em processo de incêndio, por exemplo.

Nas condições de exposição ao meio ambiente dos revestimentos externos, as situações extremas que poderiam promover um choque térmico estão no período diurno quando a temperatura superficial do revestimento atinge os valores máximos e pode ocorrer um período de precipitação. A queda de temperatura no período noturno não costuma ocorrer em altas taxas.

De acordo com Duffie e Beckman (1991), a energia recebida da radiação solar por unidade de tempo (potência), em uma área unitária perpendicular à direção da propagação da luz é em média $1367 \mathrm{~W} / \mathrm{m}^{2}$. Porém, essa radiação é atenuada pela influência de vários fatores até atingir um determinado ponto na superfície terrestre, dentre eles: latitude, estação do ano, hora do dia, condições do céu e condições atmosféricas. Desta forma, o aumento de temperatura na superfície do revestimento apresenta constante variação de caráter aleatório em função dos fatores mencionados, sendo igualmente variáveis sua duração e diferença de temperatura provocada.

Na situação em que as condições são favoráveis à máxima insolação possível, pode ocorrer também uma diminuição de temperatura em um período de tempo relativamente curto, provocada pela presença de nebulosidade, forte vento e inclusive o início de precipitação.

Tendo em vista que são inúmeras as variáveis que determinam as variações de temperatura no meio ambiente, considerou-se definir "choque térmico", a partir da 
definição genérica dada pela ASTM D1079-02 (ASTM, 2002), como o fenômeno produzido quando a diminuição da temperatura superficial na face externa do revestimento, havendo atingido seu valor máximo $\left(70^{\circ} \mathrm{C}\right)$, ocorre rapidamente (em poucos minutos) devido ao início de um evento de precipitação (água aproximadamente a $20^{\circ} \mathrm{C}$ ) diminuindo a temperatura superficial do revestimento em cerca de $50^{\circ} \mathrm{C}$.

A determinação do valor da temperatura superficial do revestimento para uma superfície vertical pode ser realizada de acordo com modelos de transferência de calor por radiação com suporte em dados climáticos reais para o local de análise. No caso da cidade de São Paulo, tais dados quais podem ser encontrados na publicação de Goulart, Lamberts e Firmino (1998).

A temperatura superficial do revestimento poderia atingir valores próximos aos $70^{\circ} \mathrm{C}$, de acordo com a cor da superfície do revestimento conforme descrito por Bansal; Garg e Kothari (1992).

A diminuição da temperatura superficial do revestimento começa, a rigor, no momento em que a nebulosidade que antecede a um período de precipitação cobre o céu, impedindo a passagem da radiação solar. Essa diminuição é acelerada no início da precipitação em que a superfície recebe o impacto do fluido que está com uma temperatura menor, estimada em valores próximos aos $20^{\circ} \mathrm{C}$. As trocas de calor são aceleradas na presença da água que satura a superfície do revestimento. O maior gradiente gerado ocorrerá entre a superfície do revestimento e sua interface com a base

Neste trabalho, a face oposta à interface base-revestimento (área interna segundo a Figura 3-8), está sendo considerada com temperatura constante $(\Delta T=0)$, no valor mínimo de temperatura de conforto térmico dentro de um ambiente interno $(T=$ $\left.20^{\circ} \mathrm{C}\right)$ 


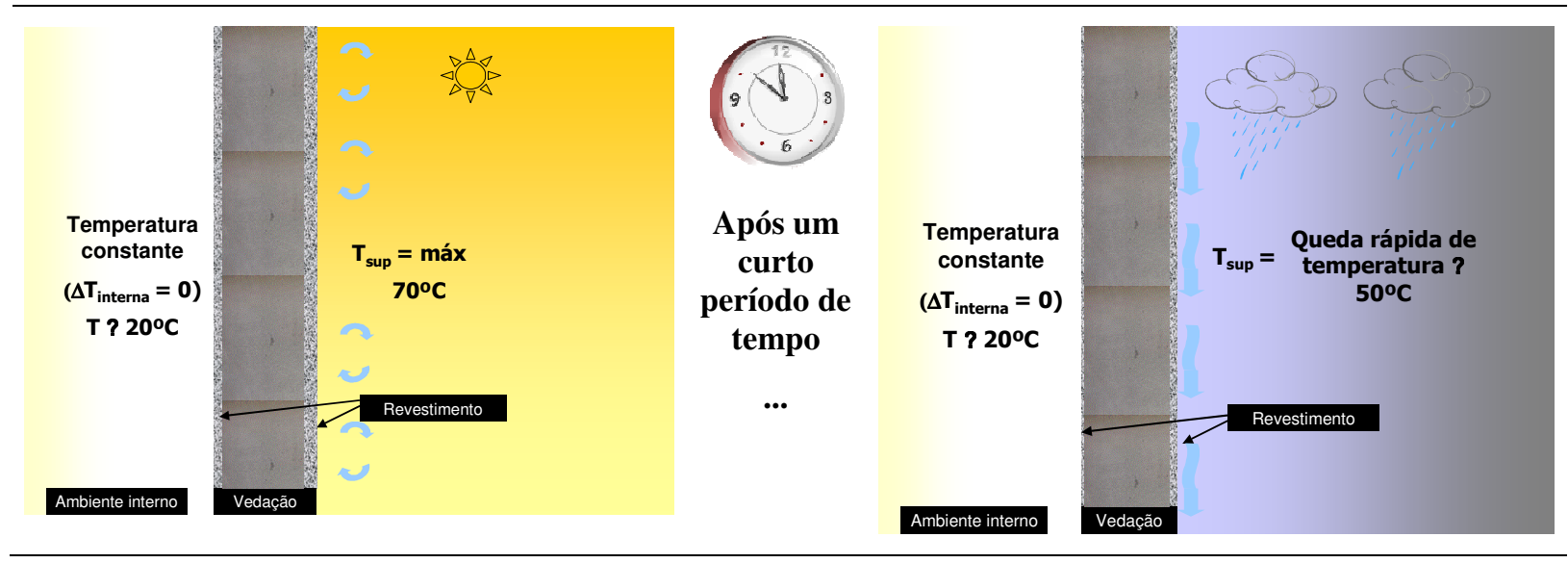

Figura 3-8: Variação de temperatura que resulta no choque térmico em revestimentos externos.

\subsubsection{Avaliação teórica do choque térmico em revestimentos}

A busca de um modelo que permita avaliar o comportamento dos revestimentos de fachada perante determinados fenômenos é o objetivo de muitos trabalhos. $O$ efeito provocado pelas variações na temperatura e no conteúdo de umidade desses revestimentos bem como a repercussão no comportamento mecânico podem ser avaliadas geralmente de forma isolada ou considerando a interação entre os três fenômenos físicos; essa última opção é a mais escassa na literatura, e obriga estabelecer simplificações, por exemplo, nas características dos materiais constituintes ou na geometria do compósito (sistema multicamada).

A avaliação do choque térmico em revestimentos parte então da definição clara das propriedades e características do componente do fenômeno analisados e da formulação das hipóteses simplificadoras.

O revestimento de argamassa é um compósito poroso de base cimentícia de uma ou mais camadas aplicadas em estado plástico sobre uma base ou substrato. Seu comportamento mecânico depende em grande medida do mecanismo de aderência discutido no item 2.2.1 desenvolvido desde o contato inicial com a base e durante a secagem.

Os inúmeros fatores que condicionam o desenvolvimento da aderência com destaque para as características dos materiais utilizados na produção da argamassa, o próprio processo de aplicação e as características intrínsecas da base sobre a qual é aplicado podem ser considerados adequadamente controlados. Todavia, na etapa de secagem do revestimento, após as primeiras horas da sua produção, produz-se o fenômeno da retração da pasta, como foi comentado no item 
2.2.2, que, ao ser restringida, inclusive pela aderência à base, promove tensões que, quando superam a resistência à tração da argamassa, resultam em microfissuras no interior do revestimento. O fenômeno da retração é complexo e é difícil determinar o nível de microfissuração atingido por sua causa, como o explica Coutinho (1954).

Contudo, é possível atenuar o risco de fissuração proveniente da retração na secagem nas primeiras idades controlando-se algumas variáveis externas como a umidade relativa, a temperatura e a velocidade do vento do ambiente em que se encontra o revestimento como é explicado por Veiga (2001). Umidades relativas de cerca de $90 \%$ podem atenuar o grau de retração do revestimento nas primeiras idades, ganhando importância na medida que passa o tempo o módulo de elasticidade do revestimento e sua capacidade de relaxação de tensões, proveniente da microfissuração, como enfatiza Veiga (2001).

Como se sabe a umidade ambiente em que se encontra o revestimento afeta seu comportamento mecânico. De acordo com Obied, Munajed e Abdenour (2000), a variação das propriedades térmicas (dilatação térmica, condutividade térmica, difusividade térmica) e mecânicas (módulo de elasticidade, coeficiente de Poisson) do revestimento de argamassa sofrem alteração significativa somente a partir de $80 \%$ de umidade relativa do ambiente em que se encontra o revestimento.

O grau de saturação do revestimento torna-se, então, um fator determinante na hipótese de se considerar constantes suas propriedades térmicas e mecânicas na análise do efeito do choque térmico. Por outro lado, para atingir o cenário crítico com o máximo gradiente de temperatura, a temperatura superficial do revestimento deve ter atingido o mais alto valor possível. Nestas condições, o conteúdo de umidade no revestimento pode ter diminuído bastante devido à evaporação produzida pelo aumento de temperatura. Assim, no instante do choque térmico (primeiros segundos) após o início do resfriamento a influência do conteúdo de umidade na superfície do revestimento será relativamente menor e se tornando importante na medida em que o revestimento fique saturado, função do coeficiente de absorção capilar do revestimento.

Desta forma, se é assumido um baixo conteúdo de umidade no revestimento, na análise do efeito mecânico do choque térmico, nos primeiros instantes do resfriamento, as propriedades mecânicas e térmicas poderiam ser consideradas constantes. 
A partir dessa premissa pode-se considerar o revestimento aderido sobre uma base rígida cujas seções transversais podem ser descritas pelo formato de uma placa aderida a outra e ambas com comprimento infinito, como mostrado na Figura 3-9.

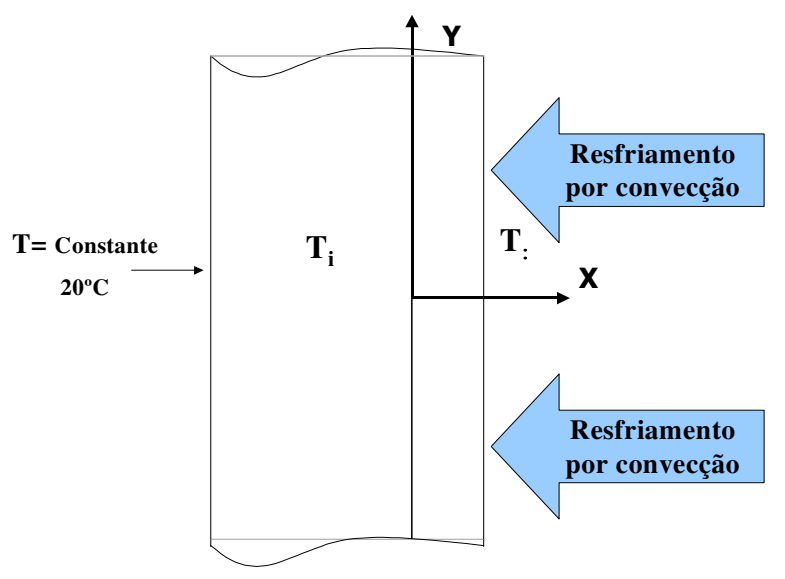

Figura 3-9: Esquema de análise do choque térmico no revestimento de argamassa com a temperatura inicial da fase interna da vedação mantida constante $T_{i}$ e com $T_{i}>T_{\text {: }}$

O cálculo das temperaturas, após o início do resfriamento em cada ponto do revestimento e da sua interface com a base, pode ser realizado utilizando a equação de balanço de energia, obtendo-se as temperaturas para cada intervalo de tempo.

Em termos de deformações e suas respectivas tensões, a análise pode ser realizada utilizando o modelo de Hsueh (2002), para o caso de um revestimento de uma única camada aderido sobre uma base, que é submetido a carregamento térmico (variação de temperatura) de forma assimétrica, mantendo-se constante a temperatura da face não exposta do conjunto, como mostrado na Figura 3-10
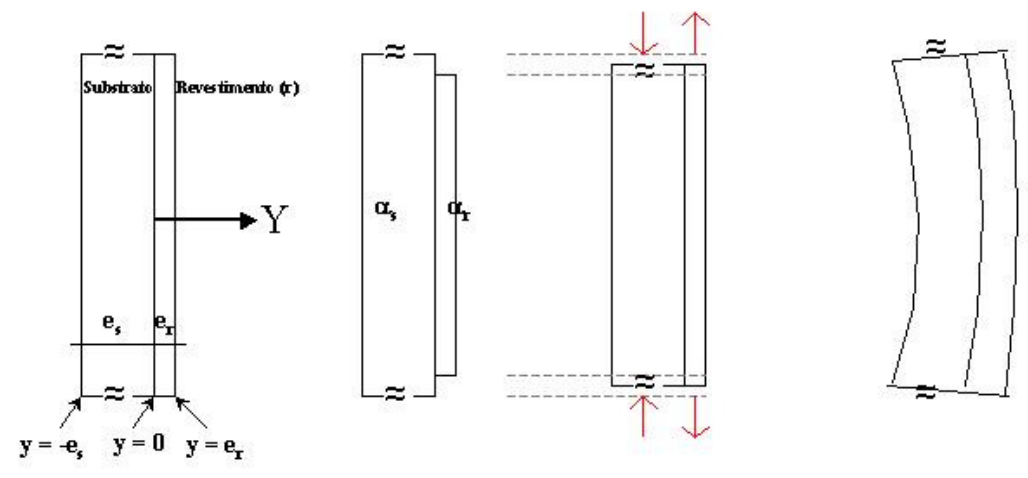

Sem carregamento

Sem restrição

Com restrição

Flexão induzida pelas tensōes assimétricas

Figura 3-10: Esquema mostrando a flexão provocada por tensões de origem térmica 
A análise das tensões de origem térmica em sistemas de múltiplas camadas tem sido desenvolvida nos trabalhos de Brown e Erdogan (1968); Matysiak (1989) e Kaczynski (1993), dentre outros autores.

Dentro da abordagem da propagação de fissuras é possível também estimar o grau de deterioração causado pelas tensões, o qual varia de material para material e pode compreender desde o surgimento de uma fissura, a propagação de fissuras existentes no material ou até a ruptura do material.

A flutuação das tensões produzidas por este carregamento pode incrementar o processo de dano progressivo no revestimento de argamassa pelo crescimento e propagação das microfissuras pré-existentes no corpo e na interface do revestimento. Em função destas características, a recomendação de Lu; Fleck (1998) é aplicar como critério de ruptura a situação em que a fissura pré-existente de maior comprimento se propaga, ou seja, quando o fator de intensidade da tensão máxima atinge o valor da tenacidade à fratura $\left(\mathrm{K}_{\mathrm{IC}}\right)$ da argamassa.

A formação da fissura e a sua propagação têm um papel importante no desempenho do revestimento de argamassa, tanto porque pode comprometer sua resistência mecânica como sua estanqueidade.

Segundo Hillerborg; Modéer; Peterson (1976) existem vários métodos de análise da mecânica da fratura para abordar o problema de fissuração em materiais de base cimentícia, dentre os quais o do fator de intensidade de tensão (K); e o do balanço de energia.

$\mathrm{Na}$ abordagem pelo fator de intensidade de tensão $(\mathrm{K})$ são estudadas as tensões próximas ao extremo da fissura, as quais atingem valores altíssimos. Quando K atinge o valor crítico $\mathrm{K}_{\mathrm{c}}$, a fissura se propaga.

$\mathrm{Na}$ abordagem do balanço de energia, assume-se que uma certa quantidade de energia Gc é absorvida pela formação de uma unidade de área da superfície da fissura. Quando a fissura se propaga, certa quantidade de energia de deformação armazenada é liberada. A fissura se propaga quando a energia liberada é igual ou maior do que a energia absorvida.

De acordo com o modelo de fissura fictícia desenvolvido por Hillerborg (1985) para estudar o material concreto, a energia de fratura (Gf), a resistência a tração crítica 
$\left(\sigma_{t, c r}\right)$ e a relação entre a carga e a deflexão descrevem completamente as características da fratura.

Dentro dessa abordagem, Menou et al. (2006) avaliaram experimentalmente a influência de ciclos de aquecimento (atingindo temperaturas máximas de 120, 250 e $\left.400^{\circ} \mathrm{C}\right)$ e resfriamento em vários materiais de base cimentícia, verificando a mudança na sua energia de fratura, resistência à tração e módulo elástico.

Uma das conclusões a que chegaram esses autores foi que a degradação de origem térmica nesses materiais, dentre eles argamassa de alta resistência utilizada em reparos, promoveu o incremento da sua energia de fratura em cerca de $50 \%$, explicando esse aumento na geração de uma superfície de fissuras mais tortuosa. Por outro lado, verificaram que a exposição à temperatura deixou os materiais cimenticios testados mais dúcteis e menos resistentes.

\subsubsection{Variáveis relativas à variação de temperatura que influem no choque térmico}

Além das propriedades que influenciam nas tensões por choque térmico, apresentadas na Equação 3-1, Lu; Fleck (1998) destacam outras como de grande importância tais como: a condutividade térmica, um parâmetro considerado central na resposta do material ao choque térmico; a difusividade térmica; o coeficiente de transferência convectiva de calor; a geometria do corpo; e finalmente, a duração do choque térmico.

Como mostrado por Collin e Rowcliffe (2000) na Figura 3-3 valores altos do número de Biot $(\beta)$ geram as máximas tensões de tração na superfície do sólido, e a magnitude das tensões aumenta com o incremento do número de Biot.

\subsubsection{Variáveis relativas ao comportamento mecânico do revestimento}

A resistência às tensões térmicas do revestimento de argamassa é influenciada principalmente pelas seguintes propriedades das camadas constituintes: módulo de elasticidade, resistência à tração, coeficiente de expansão térmica, coeficiente de Poisson, tenacidade à fratura.

\subsubsection{Métodos de avaliação experimental de choque térmico em revestimentos}

Como representações da estrutura do edifício, de seus componentes ou parte deles, os modelos experimentais são construídos, geralmente, em escala reduzida para 
testar determinados fenômenos. Segundo Gajanan et al. (1983), os modelos experimentais devem ser encarados como um complemento para os modelos analíticos e ganham importância quando as condições de contorno adotadas no modelo numérico são demasiado simplificadas.

A simulação do choque térmico produzido por variação climática foi utilizada por Hayashi et al. (1993) para avaliarem seu efeito na aderência de revestimentos cerâmicos externos. Esses autores produziram paredes de concreto, de dimensões $3 \mathrm{~m} \times 2 \mathrm{~m}$, revestidas com placas cerâmicas $(60 \mathrm{~mm} \times 108 \mathrm{~mm})$. O conjunto era, então, submetido a aquecimento produzido com ar quente (convecção) durante 3 horas, até atingir uma temperatura superficial de cerca de $80^{\circ} \mathrm{C}$; em seguida, a superfície do revestimento era resfriada com jatos de água, durante 1 hora, promovendo uma queda de temperatura de mais de $60^{\circ} \mathrm{C}$, conforme pode ser visualizado na Figura 3-11. Nesta figura, percebe-se o gradiente térmico produzido entre as camadas do revestimento no inicio do resfriamento e sua estabilização e prolongação por mais de 16 horas, até atingir uma temperatura aproximada de $25^{\circ} \mathrm{C}$ negativos.

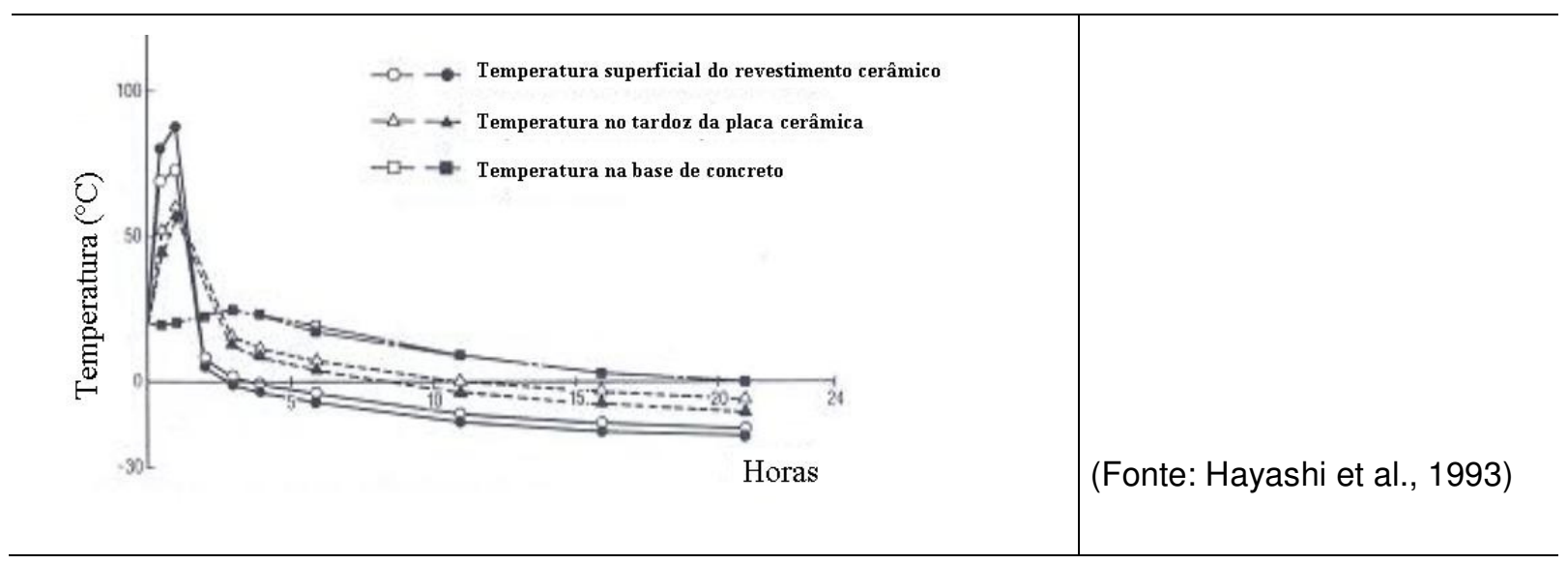

Figura 3-11: Variação da temperatura da parede (corpo de prova) com diminuição de temperatura atingindo valores abaixo de $0^{\circ} \mathrm{C}$..

Esses autores realizaram de 30 a 100 ciclos de choque térmico para dois tipos de base (concreto comum e concreto celular) e durante a execução de cada ciclo foram monitoradas, através de extensômetros elétricos, as deformações na superfície do revestimento. Após esses ciclos, foi avaliada a resistência à tração do revestimento. Os autores constataram a relação proporcional entre as deformações de origem térmica e os gradientes de temperatura. Igualmente, verificaram que os valores de resistência de aderência para a base de concreto comum decrescem, 
acompanhando uma curva exponencial, com o aumento dos ciclos de choque térmico, conforme Figura 3-12 enquanto que para o concreto celular há a conservação da resistência ao longo dos ciclos:

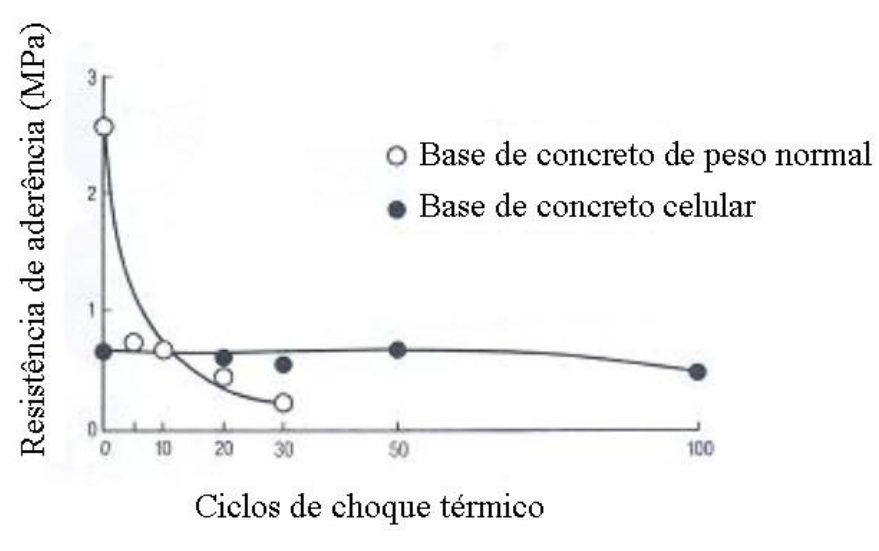

(Fonte: Hayashi et al., 1993)

Figura 3-12: Influência dos ciclos de aquecimento e resfriamento na resistência de aderência do revestimento cerâmico.

Com outro tipo de abordagem Tam et al. (1993) simularam a carga produzida pela variação de temperatura em um revestimento através de um ensaio mecânico. Nessa pesquisa foram produzidos corpos de prova com $410 \mathrm{~mm} \times 205 \mathrm{~mm} \times 75 \mathrm{~mm}$ constituídos por uma base de concreto sobre a qual, ainda no estado fresco, foram assentadas placas cerâmicas (190 mm x $90 \mathrm{~mm} \times 9 \mathrm{~mm}$ ). Nesses corpos de prova foi aplicada ciclicamente carga de compressão excêntrica simulando assim a carga térmica na superfície e na interface dos revestimentos. Esta abordagem coincide com a afirmativa de autores como Manson (1966) que defendem que dentro de determinadas limitações as relações matemáticas que governam a análise da fadiga por tensões de origem térmica são similares às que governam a fadiga por tensões de origem mecânica.

As cargas cíclicas foram aplicadas por uma prensa Instron sobre o corpo de prova, orientado na sua maior dimensão (coincidente com a direção longitudinal das placas cerâmicas). O eixo de aplicação da carga teve uma excentricidade de $12,5 \mathrm{~mm}$ da superfície externa da placa cerâmica e as deformações eram monitoradas na superfície das placas (via sensores), até atingir o valor calculado para uma deformação superficial devida a uma tensão térmica.

Com dados de predições para variação média de temperaturas diárias em Singapura, foram realizados testes mecânicos simulando 20, 50 e 100 anos de 
exposição com um ciclo de carga térmica diário (7.300, 18.250 e 36.500 ciclos de carga mecânica respectivamente). Posteriormente, através de ensaios de resistência de aderência à tração direta e ao cisalhamento, foi verificado um maior grau de deterioração na resistência de aderência à tração, para simulações de 100 anos.

Além dos trabalhos anteriormente destacados, a partir do estudo de normas internacionais e a partir de trabalhos de outros pesquisadores foram encontrados métodos de ensaio para simular o choque térmico, os quais são sintetizados na Tabela 3-1.

Tabela 3-1: Ensaios de choque térmico para componentes do edifício

\begin{tabular}{|c|c|c|c|}
\hline Instituição & Código & Nome & Ano \\
\hline CSTC & Façades & Performance du batiment. Durabilite. Choc thermique. & 1980 \\
\hline UEAtc & & $\begin{array}{l}\text { Guide technique UEAtc pour } 1 \text { 'agreement des systèmes d'isolation } \\
\text { exterieure des façades avec enduits mineraux }\end{array}$ & 1992 \\
\hline CSIRO & $\begin{array}{l}\text { AS/NZS } \\
4284-95\end{array}$ & Wall Evaluation Test method - SIROWET & 1995 \\
\hline IPT & & Método de Ensaio de choque térmico & 1998 \\
\hline $\begin{array}{l}\text { Roman et } \\
\text { al. }\end{array}$ & $\begin{array}{l}\text { ENTAC } \\
2000\end{array}$ & Método utilizando câmara climática com 120 ciclos & 2000 \\
\hline EOTA & TR 010 & Exposure procedure for artificial weathering & 2000 \\
\hline \multirow[t]{2}{*}{$\mathrm{EN}$} & EN 13687-2 & $\begin{array}{l}\text { Products and systems for the protection and repair of concrete } \\
\text { structures - Test methods - Determination of thermal compatibility } \\
\text { - Part 2: Thunder-shower cycling (thermal shock). }\end{array}$ & 2002 \\
\hline & $\begin{array}{l}\text { EN 1367- } \\
5: 2002\end{array}$ & $\begin{array}{l}\text { Tests for thermal and weathering properties of aggregates. } \\
\text { Determination of resistance to thermal shock }\end{array}$ & 2002 \\
\hline EOTA & TR 011 & Exposure procedure for accelerated ageing by heat & 2003 \\
\hline
\end{tabular}

\subsubsection{Principais trabalhos nacionais}

No Brasil, os primeiros registros da utilização de ensaios de simulação de choque térmico em componentes do edifício podem ser encontrados em um relatório técnico publicado pelo IPT na década de 80. No entanto a completa descrição do método somente aparece em publicação em 1998 (IPT, 1998), e posteriormente no projeto de Normas de desempenho de edifícios residências de até 5 pavimentos (ABNT, 2007). Nesse método é simulado o aquecimento por radiação (com lâmpadas incandescentes) sobre um corpo de prova na forma de painel de 1,20m x $2,00 \mathrm{~m}$ até atingir uma temperatura superficial de $80^{\circ} \mathrm{C}$, controlada com termopares. O painel é mantido com essa temperatura durante uma hora, promovendo-se, em seguida, o resfriamento via jato de água (simulação da chuva) até atingir uma 
temperatura superficial de $20^{\circ} \mathrm{C}$. Usualmente realizam-se 10 ciclos de ensaio, durante os quais verifica-se o surgimento de fissuras no revestimento.

Quando simulados revestimentos verticais, o parâmetro utilizado para avaliar o efeito do choque térmico têm sido a resistência de aderência à tração normal residual no revestimento. Seguindo esse método de ensaio, Geyer; Greven (1994) submeteram painéis revestidos com placas cerâmicas a ciclos de choque térmico obtendo diferenças pouco significativas entre os painéis ensaiados a 10 ciclos e os não expostos. Por outra parte, Siqueira (1995) verificou em modelos físicos de revestimento de argamassa e revestimento cerâmico que, após a ciclagem, nos corpos de prova com revestimento cerâmico, todas as rupturas deram-se na argamassa colante.

Mais recentemente Miranda; Selmo (2000) realizaram o ensaio em painéis revestidos com argamassa com agregados à base de resíduos de construção e demolição reciclados, verificando a degradação do revestimento através do surgimento de fissuras na superfície do revestimento. Da mesma forma, Crescêncio; Barros (2003) ensaiaram painéis revestidos com argamassa decorativa monocamada, utilizando também argamassa de revestimento industrializada (referência). Para esse último revestimento, após aplicação de 10 ciclos de choque térmico, as autoras constataram seu efeito negativo na resistência de aderência à tração, principalmente quando a base era com blocos cerâmicos, atingindo uma queda de mais de $70 \%$ nessa resistência no caso mais crítico, quando comparada com a referência (revestimento sem aplicação do choque térmico). Por outro lado, quando a base foi a estrutura de concreto, essa resistência de aderência aumentou em $50 \%$.

Nos trabalhos citados não houve controle de variáveis como a umidade relativa do ar durante a realização do ensaio ou propriedades térmicas dos materiais do revestimento, como também não foram apresentados valores das deformações e tensões.

ROMAN et al. (2000) analisaram experimentalmente a influência das variações higrotérmicas cíclicas na resistência de aderência dos revestimentos cerâmicos, propondo um método de ensaio com a utilização de uma câmara climática. O corpo de prova - um painel $(0,91 \mathrm{~m} \times 0,91 \mathrm{~m})$, constituído por uma base de blocos cerâmicos, uma camada de emboço, argamassa colante, placas cerâmicas e rejunte 
- foi preparado no interior de um caixilho metálico encaixado na porta da câmara climática, ficando a face revestida voltada para o seu interior. Essa face foi, então, submetida a ciclos de temperatura e umidade, através de variações controladas no interior da câmara, sendo a face não revestida submetida às condições de laboratório.

Após 120, 240 e 360 ciclos higrotérmicos foram realizados ensaios de resistência de aderência à tração, tendo esse autores concluído que existe uma diminuição dessa resistência após 120 ciclos de temperatura e umidade, e que a ruptura do revestimento foi principalmente nas interfaces emboço/argamassa e na interface argamassa colante/placa cerâmica.

\subsubsection{Principais parâmetros considerados nos métodos de ensaio de choque térmico}

De maneira geral, segundo a EN60068-2-14 (EN, 2000), os efeitos do ensaio do choque térmico estão determinados pelos seguintes parâmetros:

máximo e mínimo valores de temperatura entre os quais ocorre a variação rápida;

os tempos de condicionamento (aquecimento/resfriamento) do corpo de prova durante o ensaio que, por sua vez, dependem da inércia térmica dos corpos de prova;

a taxa de variação entre a temperatura máxima e a mínima;

o número de ciclos;

os valores de transferência de calor para o corpo de prova e deste para o ambiente.

Além disso, Buessem (1955) destaca que é importante determinar a dependência da temperatura das cinco propriedades físicas do material que sempre aparecem em um choque térmico, propondo o seguinte agrupamento:

- fatores que definem as condições do choque térmico: variação de temperatura entre o sólido e o meio de resfriamento (água, por exemplo);

- fatores de geometria do sólido, com a dimensão da metade da espessura característica do sólido;

- fatores que definem as propriedades do material. 
A partir das normas a que se teve acesso identificaram-se os equipamentos propostos para os ensaios, as faixas de temperatura utilizadas em cada um deles, o número de ciclos proposto e também o tempo de duração de cada ciclo, os quais estão sintetizados na Tabela 3-2:

Tabela 3-2: Parâmetros dos métodos de ensaio propostos por diferentes autores e normas técnicas

\begin{tabular}{|l|l|l|l|l|l|}
\hline $\begin{array}{c}\text { Norma / } \\
\text { Método }\end{array}$ & \multicolumn{1}{|c|}{ Equipamento } & $\begin{array}{l}\text { Temperatura } \\
\text { Mínima }\left({ }^{\circ} \mathbf{C}\right)\end{array}$ & $\begin{array}{l}\text { Temperatura } \\
\text { Máxima }\left({ }^{\circ} \mathbf{C}\right)\end{array}$ & $\begin{array}{l}\text { Número } \\
\text { de ciclos }\end{array}$ & $\begin{array}{l}\text { Tempo de } \\
\text { duração do } \\
\text { ciclo }\end{array}$ \\
\hline EN 1367-5 & Molhagem e secagem & & & & \\
\hline EN 13687-2 & $\begin{array}{l}\text { Em aparelho durante 5 h 45 } \\
\text { min. e simulação de chuva 15 } \\
\text { min. }\end{array}$ & $21 \pm 2$ & $60 \pm 10$ & $\begin{array}{l}\text { PrEN1504 } \\
-2\end{array}$ & 6 horas \\
\hline CSTC & Aparelho & $15-20$ & 80 & $>10$ & 1 h. 10 min. \\
\hline UEAtc 1992 & Aparelho & $16 \pm 5$ & 50 & 80 & 8 horas \\
\hline UEAtc 1999 & Aparelho & $23 \pm 2$ & 70 & 140 & 6 horas \\
\hline Silva et al. & Câmara climática & 18 & 68 & 120 & 3 horas \\
\hline IPT & $\begin{array}{l}\text { Painel radiante e simulação de } \\
\text { chuva }\end{array}$ & 20 & 80 & 10 & 4 horas \\
\hline
\end{tabular}




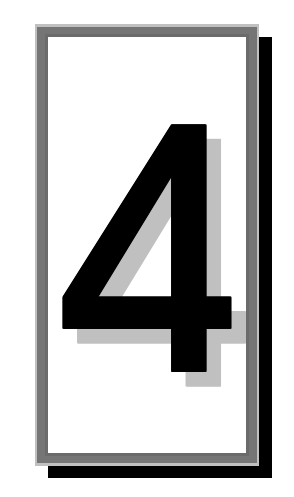

\section{SIMULAÇÃO COMPUTACIONAL PARA AVALIAÇÃO DO REVESTIMENTO DE ARGAMASSA FRENTE À VARIAÇÃO TÉRMICA}

\subsection{Introdução}

O desenvolvimento das ferramentas de simulação computacional para a resolução de problemas físicos de aplicação na engenharia tem ajudado no avanço do entendimento do comportamento de sistemas complexos.

No campo da construção civil essas ferramentas têm auxiliado principalmente na identificação dos fatores de influência no comportamento de diferentes sistemas a um custo e tempo relativamente menores quando comparados com o desenvolvimento de modelos físicos em escala real para avaliação experimental.

A complexidade do estudo do comportamento em uso de revestimentos de fachada tem despertado o interesse de diversos pesquisadores no mundo motivando-os à utilização das ferramentas de simulação computacional para análise do comportamento mecânico desses revestimentos, como apontado por Bowman e Banks (1996).

Segundo a literatura disponível, a ferramenta de simulação computacional mais utilizada o estudo de revestimentos e em geral de materiais de base cimenticia é a simulação pelo método de elementos finitos, como pode ser constatado nos trabalhos de Bazant; Chern e Thonguthai (1981); Zhu e Guan, (1997); Obied et al., (2000); Bowman e Banks (2003); Abreu (2004) e cujas características principais serão abordadas na seqüência. 


\subsection{Modelos que empregam o método de elementos finitos}

Este método de análise numérico é definido por Zienkiewicz (1980) como um procedimento geral de discretização de problemas contínuos descritos por expressões definidas matematicamente.

Desta maneira, a aproximação de um problema relativo a um meio contínuo (com um número infinito de graus de liberdade) se realiza dividindo-o em um número finito de partes (elementos). Cada um desses elementos é conectado ao outro através dos denominados 'nós' e o comportamento desse conjunto (elementos e nós) é determinado a partir das propriedades e quantidades físicas (carregamento térmico, mecânico, etc.) atribuídas ao conjunto.

A solução do sistema completo resulta da junção dos elementos seguindo as mesmas regras aplicadas aos problemas discretos tipo (com um número finito de graus de liberdade). Assim, uma vez que a malha sobre o domínio tenha sido determinada, o comportamento de uma variável desconhecida é aproximado em cada elemento por funções contínuas expressas em termos dos valores nodais da variável (valores atribuídos aos nós permitem o cálculo dos valores nos elementos).

Em problemas do meio continuo em que as variáveis são temperatura, tensão e deformação geralmente são obtidas soluções analíticas com um número infinito de valores, porque são funções de um número infinito de pontos. Desta forma, o método dos elementos finitos torna-se uma ferramenta adequada para lidar com este tipo de problema, já que permite obter soluções aproximadas de equações diferenciais parciais obtidas em problemas complexos. Esta técnica não aproxima equações diferenciais diretamente, como no cálculo diferencial, mas elabora uma rotina que permite a solução através de integrais.

\subsection{Desenvolvimento do modelo numérico para o revestimento}

O objetivo do modelo numérico desenvolvido para este trabalho foi dar suporte na etapa da definição do programa experimental em dois aspectos:

na identificação das variáveis de maior influência no estado de tensões térmicas provocado pela variação de temperatura que ocorria em um bloco que simulava um revestimento de argamassa aplicado sobre uma base de concreto; e na definição das características, principalmente a geometria dos corpos de prova, mais adequadas para serem utilizadas no programa experimental. 
Assim, foi elaborado um modelo paramétrico que representava parte de um revestimento externo o qual era submetido a uma variação de temperatura na face do revestimento, sendo analisadas a distribuição de tensões e de temperaturas no conjunto.

Para o desenvolvimento do modelo contou-se com a parceria de um especialista do Departamento de Estruturas e Fundações da EP-USP, sendo viabilizada a utilização do software Ansys ${ }^{\circledR}$ (2005) com o método dos Elementos Finitos (MEF), através do Laboratório de Mecânica Computacional (LMC) desse departamento.

\subsubsection{Hipóteses consideradas}

Para realização das simulações, os materiais foram considerados contínuos, homogêneos e isotrópicos, com um comportamento elástico-linear e foi admitido um estado plano de deformações em coincidência com os trabalhos de BenAmor (1996) e Abreu (2001).

O único carregamento considerado foi o resultante da variação de temperatura e não foram consideradas tensões residuais devidas à retração por secagem da argamassa nem aquelas provocadas pela forca da gravidade.

Inicialmente considerou-se modelos bidimensionais (2D) e, posteriormente, foram desenvolvidos alguns modelos tridimensionais (3D) para confirmação dos resultados da análise bidimensional.

Todas as análises realizadas foram estáticas e como variável adicional às propriedades dos materiais estudou-se também a influência de falhas na interface entre o substrato e o revestimento. As falhas foram introduzidas pela supressão dos elementos finitos na região do modelo.

\subsubsection{Propriedades consideradas}

As propriedades mecânicas dos materiais (Tabela 4-1) foram levantadas a partir dos trabalhos de BenAmor (1996), Silva et al. (1999), Obeid, Mounajed e Abdenour (2000), Abreu (2001), Bowman e Banks (2003) e em trabalhos publicados no V SBTA (2003). 
Tabela 4-1: Propriedades mecânicas dos materiais empregadas na simulação computacional.

\begin{tabular}{l|l|l|l}
\hline \multicolumn{1}{c|}{ Camada } & \multicolumn{1}{c|}{$\begin{array}{c}\text { Módulo de Elasticidade } \\
(\mathbf{G P a})\end{array}$} & \multicolumn{1}{c|}{$\begin{array}{c}\text { Coeficiente de } \\
\text { Poisson }\end{array}$} & \multicolumn{1}{c}{$\begin{array}{c}\text { Densidade } \\
\left(\mathbf{k g} / \mathbf{m}^{\mathbf{3}}\right)\end{array}$} \\
\hline Revestimento & 2 e 15 & 0,2 & 1800 \\
\hline $\begin{array}{l}\text { Substrato } \\
\text { (concreto) }\end{array}$ & 25 & 0,2 & 2400 \\
\hline
\end{tabular}

Para as propriedades térmicas dos materiais (Tabela 4-2) foram considerados os dados apresentados nos trabalhos de Marshall (1972); PCA (1982), Granjian, Thinker e Cabrera (1994), Fiorito (1994), Saraiva (1998), Melo (2002) e Kim et al. (2003).

Tabela 4-2: Propriedades térmicas dos materiais empregadas na simulação computacional.

\begin{tabular}{l|l|l|l}
\hline \multicolumn{1}{c|}{ Camada } & \multicolumn{1}{|c|}{$\begin{array}{c}\text { Condutividade } \\
(\mathbf{W} / \mathbf{m K})\end{array}$} & \multicolumn{1}{|c|}{$\begin{array}{c}\text { Calor específico } \\
\mathbf{( J / k g ~ K )}\end{array}$} & $\begin{array}{c}\text { Coeficiente de } \\
\text { expansão térmica } \\
\left({ }^{\mathbf{0}} \mathbf{C}^{-1}\right)\end{array}$ \\
\hline Revestimento & de 0.5 a 1.7 & 900 & $8^{*} 10^{-6}$ \\
\hline Substrato (concreto) & de 0.6 a 1.8 & 1000 & $12^{*} 10^{-6}$ \\
\hline
\end{tabular}

Cabe destacar que em um dos modelos foi avaliada a influência no nível de tensões da variação da condutividade térmica do revestimento, variando de 0.6 a $1.8 \mathrm{~W} / \mathrm{mK}$, intercalados por incrementos de $0.2 \mathrm{~W} / \mathrm{mK}$. Variou-se também a espessura do revestimento, de 25 a $62,5 \mathrm{~mm}$, intercalados por intervalos de $12,5 \mathrm{~mm}$.

\subsubsection{Modelos em 2D}

\subsubsection{Geometria}

Os modelos considerados preliminarmente têm a forma da Figura 4-1. Inicialmente foi considerada uma espessura do substrato de $2,5 \mathrm{~cm}$ e comprimento de $50 \mathrm{~cm}$, ou seja, as dimensões do substrato padrão especificado pela ABNT NBR 14082 (1998) para ensaios de argamassas colantes. A espessura do revestimento foi de $3 \mathrm{~cm}$ (espessura média do revestimento).. Essas dimensões foram redefinidas posteriormente.

Para que se pudesse considerar a ocorrência de falhas na interface, foi criada uma camada intermediária, com as propriedades do revestimento. 


\section{Revestimento}

\section{Base}

Figura 4-1: Geometria do modelo em 2D

\subsubsection{Elementos finitos utilizados}

Usou-se, nesta simulação numérica, os elementos finitos PLANE13 (análise estática) e PLANE55 (análise transiente) do ANSYS. A Figura 4-2 mostra as geometrias destes elementos.

Figure 13.1 PLANEl3 Geometry

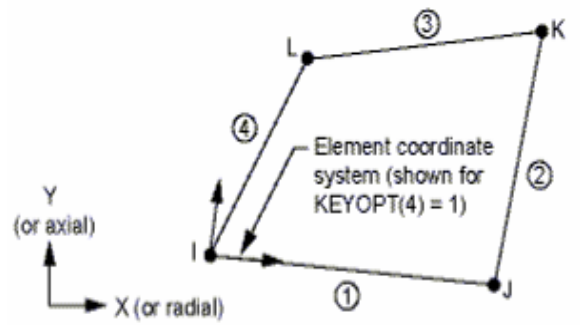

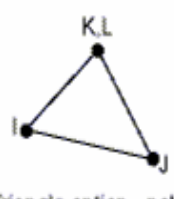

(Triangle option - not recommended for structural applications)
Figure 55.1 PLANE55 Geometry

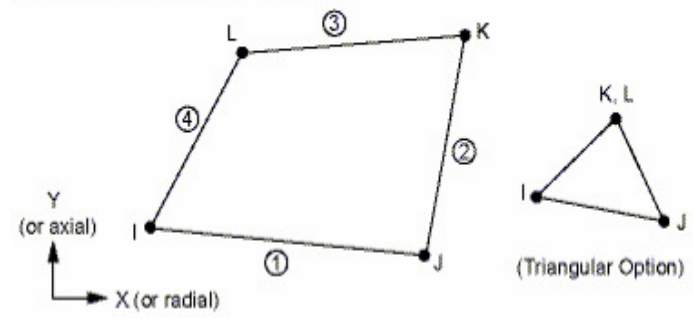

Figura 4-2: Geometria dos elementos PLANE13 e PLANE55 do Ansys

\subsubsection{Tipo de malha e condições de contorno}

A Figura 4-3 mostra a malha de elementos finitos e as condições de contorno consideradas.

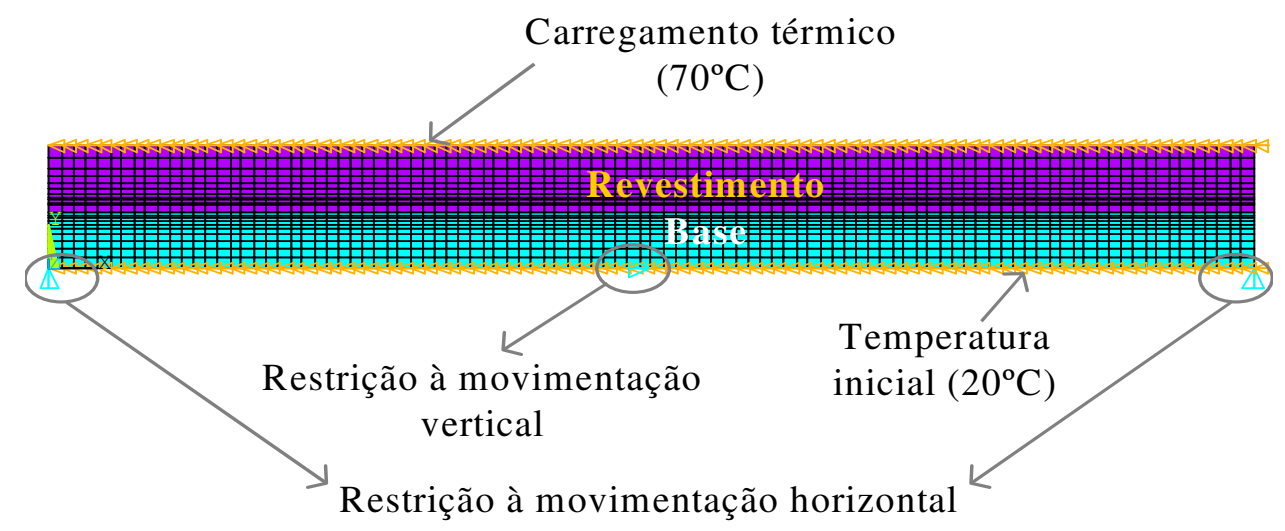

Figura 4-3: Malha de elementos finitos e condições de contorno consideradas para a análise numérica. 
A dimensão dos elementos definidos pela malha foi variada com a altura, em cada uma das camadas, de forma a apresentar elementos menores nas proximidades da interface.

As vinculações foram definidas para impedir apenas os movimentos de corpo rígido do modelo deixando-o livre para quaisquer deformações que viessem ocorrer. Nos extremos inferiores foi impedida a movimentação no eixo $Y$ o no centro foi impedida a movimentação no eixo $X$.

\subsubsection{Modelos em 3D}

\subsubsection{Geometria}

A partir dos resultados da simulação para o modelo em 2D, discutidos no item 6.1.12, alguns parâmetros foram redefinidos para a realização dos modelos 3D. Um desses parâmetros foi a espessura do substrato que passou a ser $10 \mathrm{~cm}$, bem como as suas demais dimensões, sendo $\mathrm{lx}=40 \mathrm{~cm}$ e ly $=30 \mathrm{~cm}$. e que foram consideradas em todos os modelos posteriores. Os modelos considerados têm a forma da Figura 4-4.

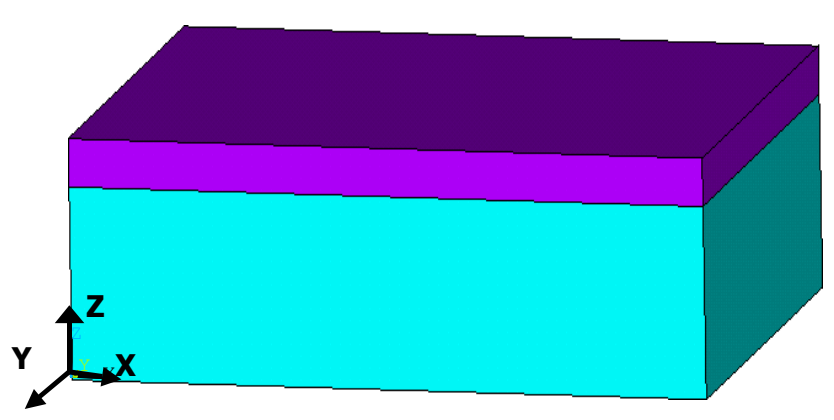

Figura 4-4: Geometria do Modelo 3D: substrato $-300 \mathrm{~mm} \times 400 \mathrm{~mm} \times 100 \mathrm{~mm}$ e revestimento $300 \mathrm{~mm}$ x400mm x30mm

No modelo 3D, também foi criada uma camada intermediária entre o revestimento e a base, a qual possuía as mesmas propriedades do revestimento, para que se pudesse considerar a ocorrência dos macro-defeitos na interface.

\subsubsection{Elementos finitos utilizados}

Nesta simulação numérica foram utilizados os elementos finitos SOLID226 (análise estática) do ANSYS, mostrados na Figura 4-5 


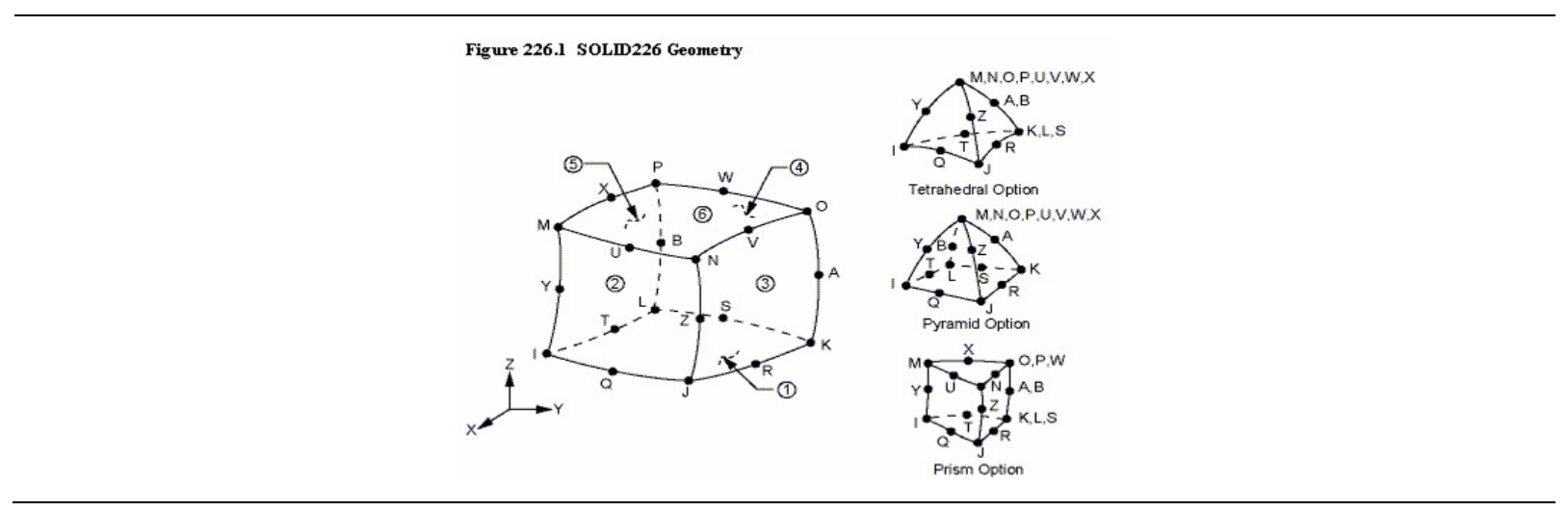

Figura 4-5: Geometria dos elementos finitos utilizados

A análise estática consistiu da aplicação de uma temperatura de $20 \stackrel{\circ}{\mathrm{C}}$ na face inferior (face externa do substrato) e de uma temperatura de $70^{\circ} \mathrm{C}$ na face superior (face exterior do revestimento) do modelo, considerando-se que a temperatura inicial do modelo era a mesma aplicada na face inferior.

\subsubsection{Tipo de malha e condições de contorno}

As dimensões dos elementos definidos pela malha foi variada com a altura, em cada uma das camadas, de forma a apresentar elementos menores nas proximidades da interface.

As vinculações foram definidas para impedir apenas os movimentos de corpo rígido do modelo deixando-o livre para quaisquer deformações que viessem ocorrer. Nos extremos inferiores foi impedida a movimentação no eixo $\mathrm{Y}$ e no centro foi impedida a movimentação no eixo $X$ como mostrado na Figura 4-6a.

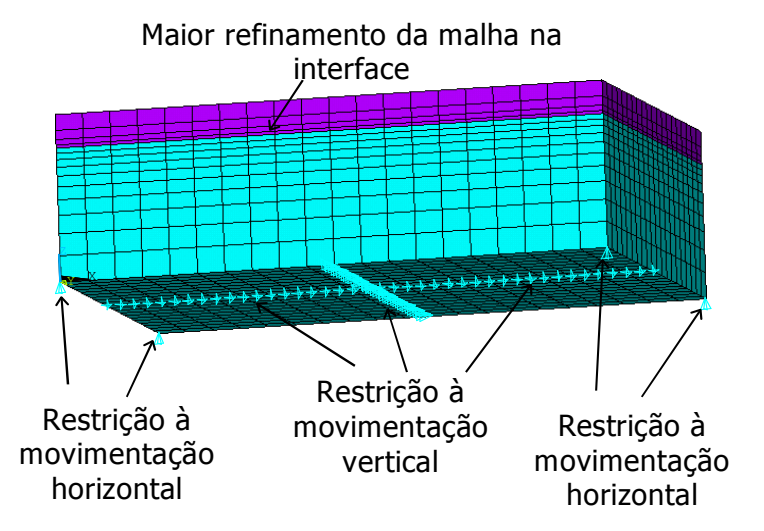

a)

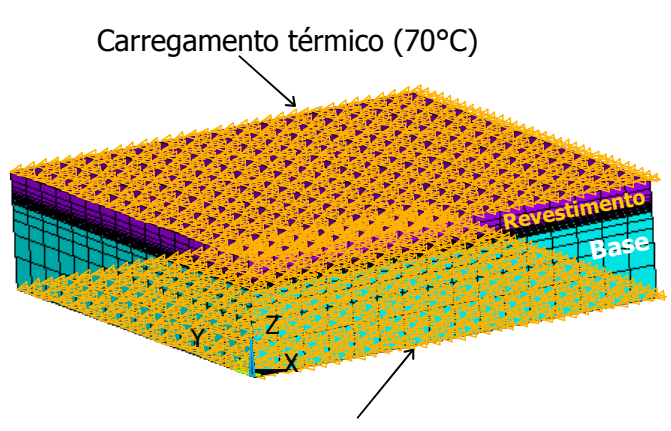

Temperatura constante $\left(20^{\circ} \mathrm{C}\right)$

b)

Figura 4-6: (a) Tipo de malha considerada e condições de contorno e (b) carregamento térmico 


\subsection{Simulação dos macro-defeitos}

\subsubsection{Geometria}

Tanto no modelo bidimensional como no tridimensional foi definido um defeito com uma altura de $1 \mathrm{~mm}$ e um comprimento de $8 \mathrm{~mm}$ no caso do modelo 2D e uma calota circular com $8 \mathrm{~mm}$ de diâmetro no caso do modelo 3D.

Estas dimensões foram obtidas das imagens apresentadas por Antunes (2005), utilizando a escala gráfica para determinar a dimensão na situação mais crítica.

No modelo 2D o defeito foi representado retirando um elemento da malha e deixando-se o espaço vazio, como observado na Figura 4-7 que mostra uma taxa de macro-defeitos de $35 \%$.

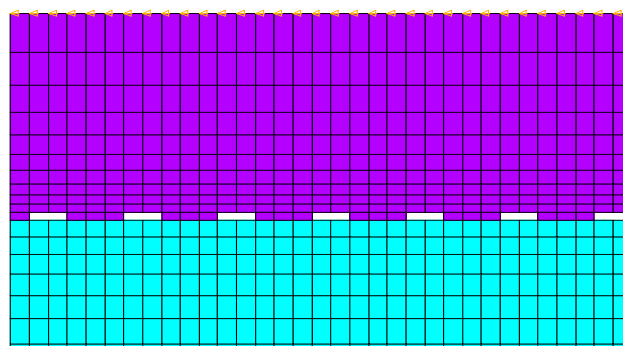

Figura 4-7: Modelo 2D com 35\% de macro-defeitos.

No modelo 3D, o macro-defeito volumétrico foi criado com o formato apresentado na Figura 4-8a, em que se mostra o volume correspondente aos macro-defeitos que estão sobre a superfície do substrato correspondentes a 7\%. Na Figura 4-8b é mostrado o volume ocupado pelos macro-defeitos na camada de revestimento e 0 afastamento entre si, no caso em que se considera que a área das falhas corresponde a $42 \%$ da área da interface entre os materiais.

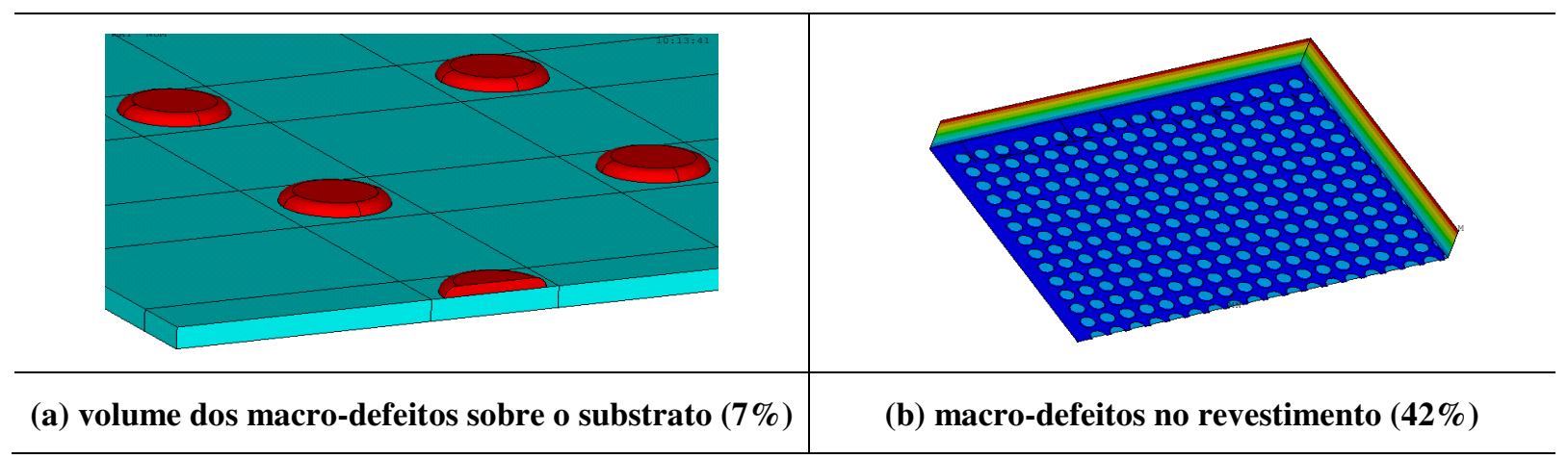

Figura 4-8: Geometria e distribuição de macro-defeitos (7\% e 42\%) no modelo tridimensional 


\subsubsection{Posição do macro-defeito}

Para determinar a posição dos macro-defeitos foram realizados modelos 2D, nos quais foi variada a posição e o comprimento do macro-defeito para avaliar seu efeito na distribuição de temperaturas (Figura 4-9).

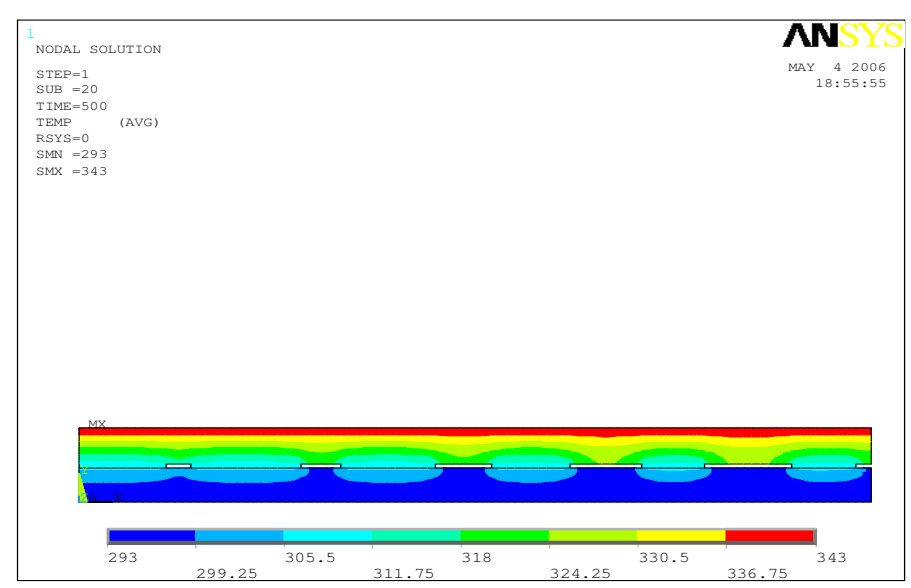

Figura 4-9: Variação da posição e comprimento do macro-defeito e sua influência na distribuição de temperaturas

Havendo sido definida uma distribuição uniforme dos macro-defeitos na interface base-revestimento, foi avaliada a variação da posição do primeiro macro-defeito em relação à borda do bloco para três valores de comprimento do macro-defeito: $2 \mathrm{~mm}$, $4 \mathrm{~mm}$ e $6 \mathrm{~mm}$.

A Figura 4-10 mostra as geometrias consideradas nos modelos em que o início dos macro-defeitos na interface base-revestimento encontrava-se na borda do bloco modelado ( $d=0 \mathrm{~mm})$. Para cada simulação a espessura da base (cor azul) foi mantida constante em $0,10 \mathrm{~m}$. e a camada de revestimento (cor roxa) com espessura de $0,30 \mathrm{~m}$.

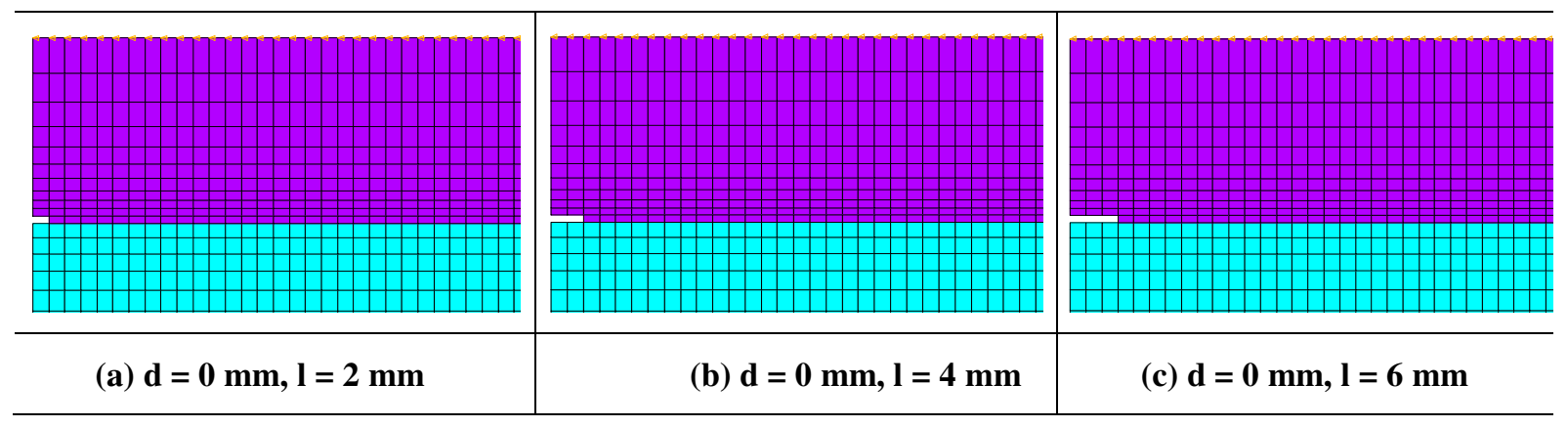

Figura 4-10: Geometria dos modelos com o início dos macro-defeitos de interface na borda do bloco 
A Figura 4-11 mostra as geometrias consideradas nos modelos em que o primeiro dos macro-defeitos na interface base-revestimento encontrava-se a $2 \mathrm{~mm}$ da borda $(\mathrm{d}=2 \mathrm{~mm})$.

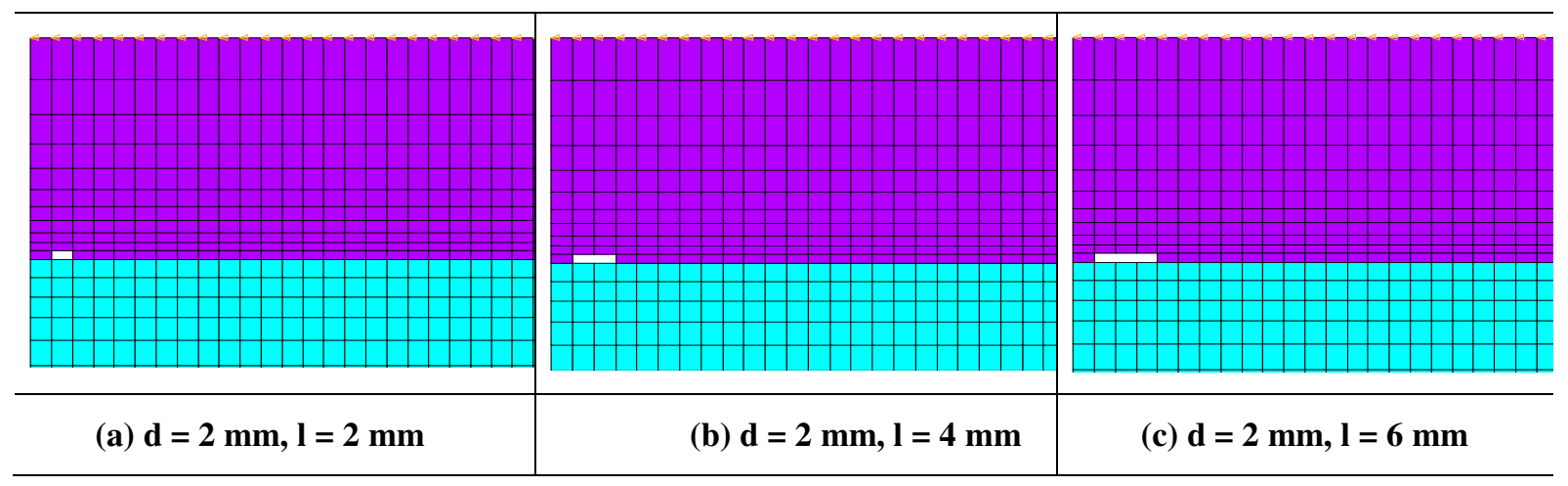

Figura 4-11: Geometria dos modelos com o início dos macro-defeitos de interface a $2 \mathrm{~mm}$ da borda do bloco

A Figura 4-12 mostra as geometrias consideradas nos modelos em que o primeiro dos macro-defeitos na interface base-revestimento encontrava-se a $4 \mathrm{~mm}$ da borda do bloco modelado $(\mathrm{d}=4 \mathrm{~mm})$.

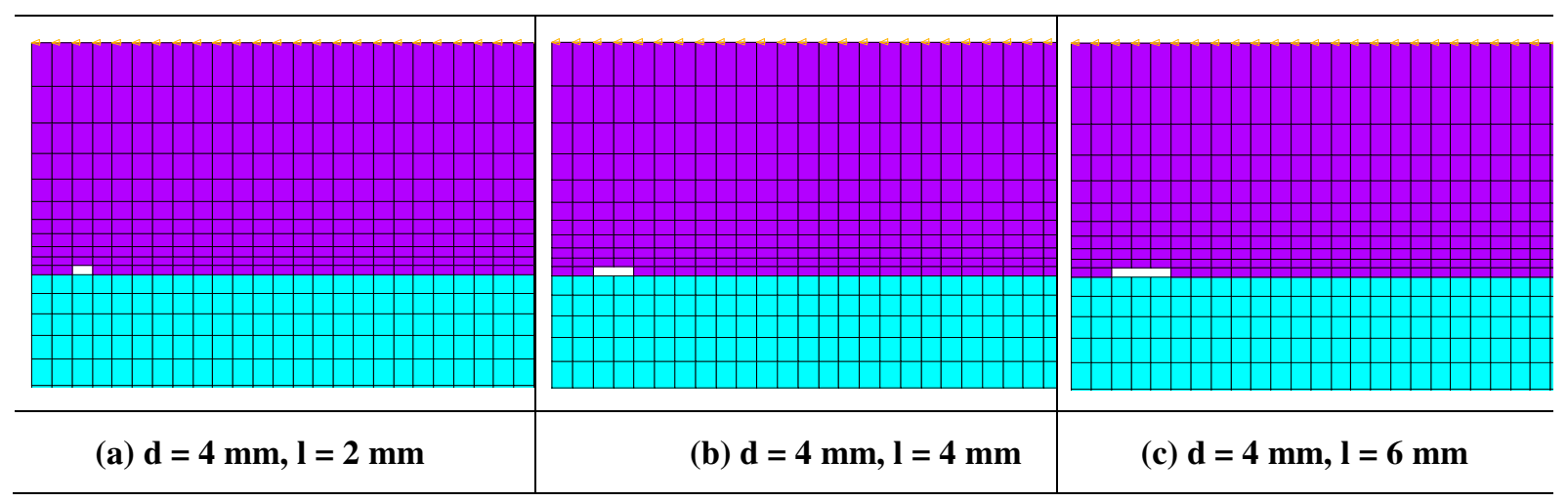

Figura 4-12: Geometria dos modelos com o início dos macro-defeitos de interface a $4 \mathrm{~mm}$ da borda do bloco

As geometrias consideradas nos modelos em que o primeiro dos macro-defeitos na interface base-revestimento encontrava-se a $6 \mathrm{~mm}$ da borda do bloco modelado (d=6) são apresentados na Figura 4-13: 


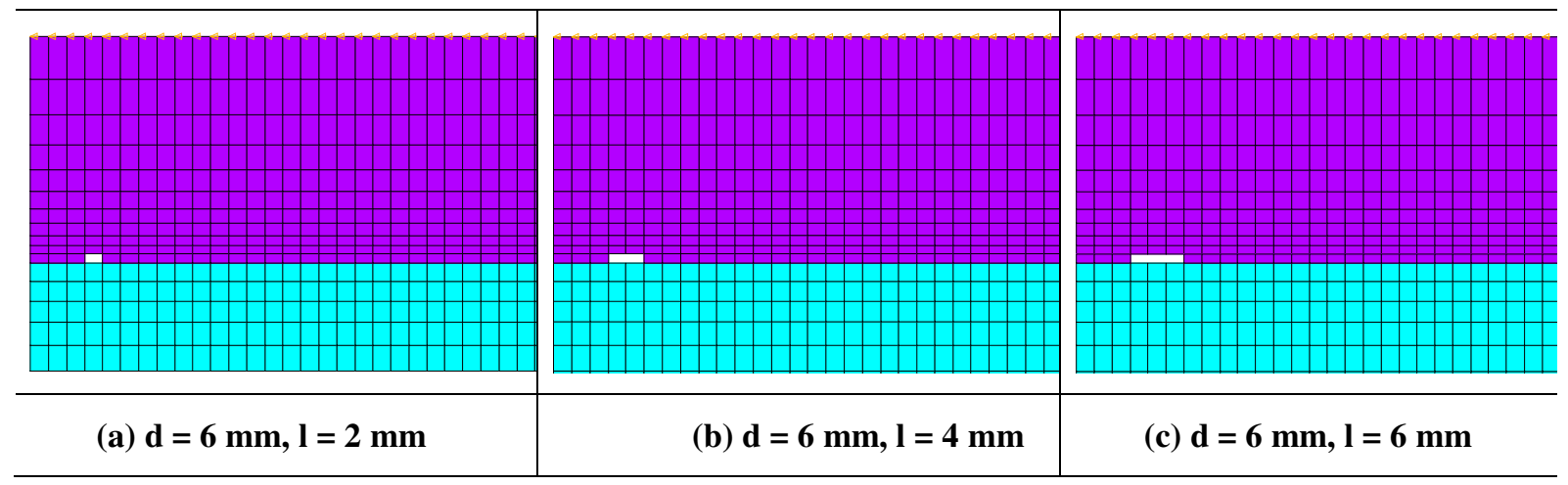

Figura 4-13: Geometria dos modelos com o primeiro macro-defeito de interface a $6 \mathrm{~mm}$ da borda.

\subsubsection{Taxa de macro-defeitos}

Nas análises 2D foram consideradas diferentes taxas de macro-defeitos: $0 \%, 7 \%$, $14 \%, 21 \%, 28 \%, 35 \%$ e $42 \%$ as quais são apresentadas na Figura 4-14

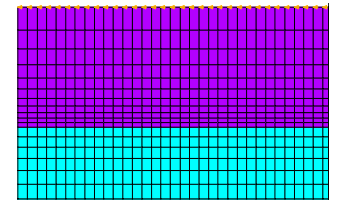

a)

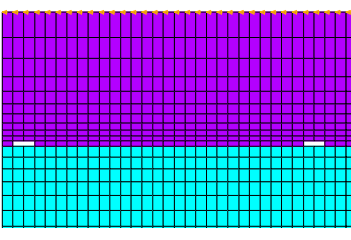

b)

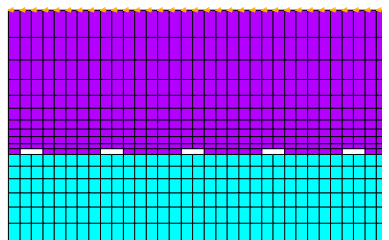

e)

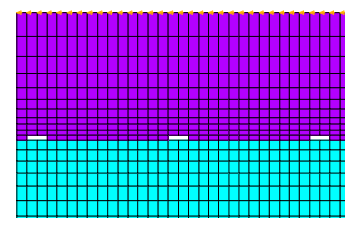

c)

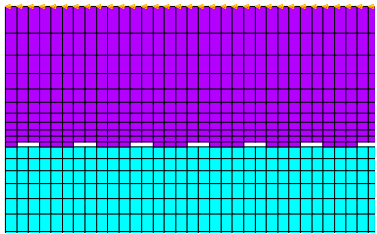

f)

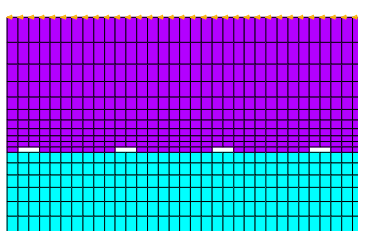

d)

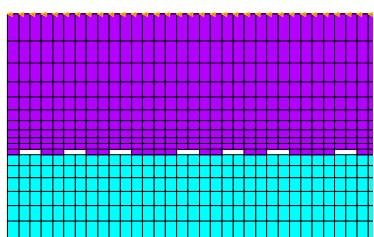

g)

Figura 4-14: Diferentes taxas de macro-defeitos uniformemente distribuídos: a) 0\%, b) $7 \%$, c) $14 \%$, d) $21 \%$, e) $28 \%$, f) $35 \%$, g) $42 \%$

\subsection{Análise para definição das dimensões dos corpos de prova.}

Para determinação do comprimento e largura mais adequados para o corpo de prova a ser ensaiado no programa experimental, foram realizadas várias simulações em 2D, com a espessura do substrato do bloco fixada em $10,0 \mathrm{~cm}$ e com dois valores para a espessura do revestimento: 2,5 e 5,0 cm. Com estas duas espessuras foram realizados modelos em que foi variado o comprimento do bloco nas seguintes medidas: 0,20 m (Figura 4-15), 0,50 m (Figura 4-16), 1,00 m (Figura 4-17), 2,00 m (Figura 4-18). e 4,00 m (Figura 4-19). 


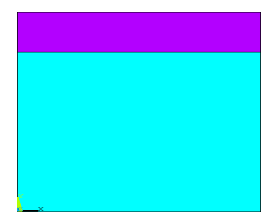

(a) revestimento com $2,5 \mathrm{~cm}$ de espessura

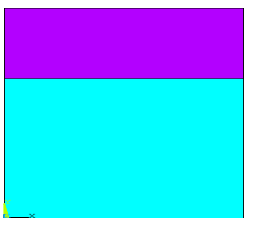

(b) revestimento com $5,0 \mathrm{~cm}$ de espessura

Figura 4-15: Geometrias dos modelos com 0,20 m de comprimento

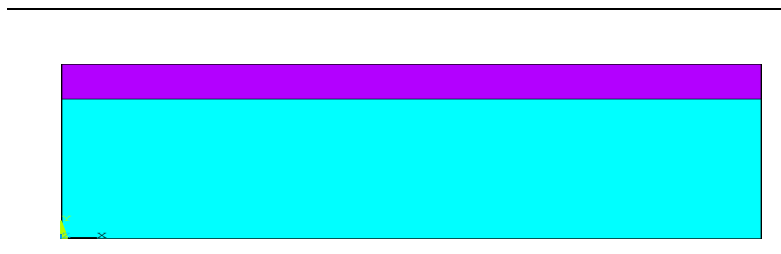

(a) revestimento com $2,5 \mathrm{~cm}$ de espessura

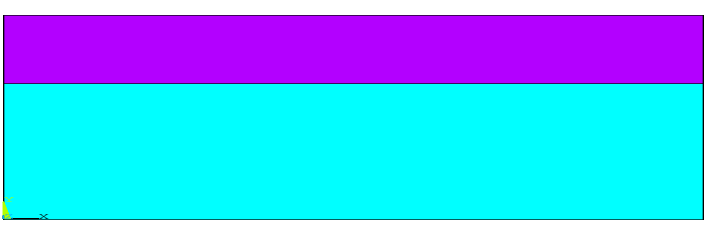

(b) revestimento com $5,0 \mathrm{~cm}$ de espessura

Figura 4-16: Geometrias dos modelos com 0,50 m de comprimento

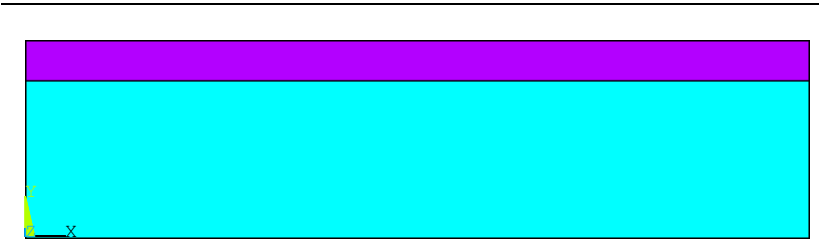

(a) revestimento com $2,5 \mathrm{~cm}$ de espessura

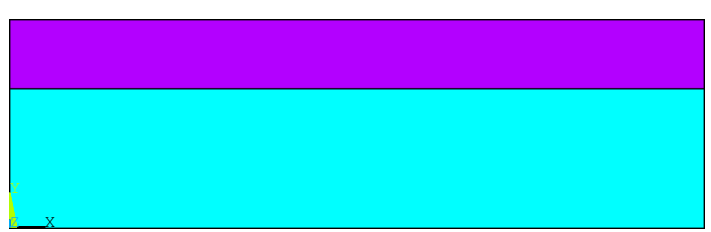

(b) revestimento com $5,0 \mathrm{~cm}$ de espessura

Figura 4-17: Geometrias dos modelos com 1,00 m de comprimento

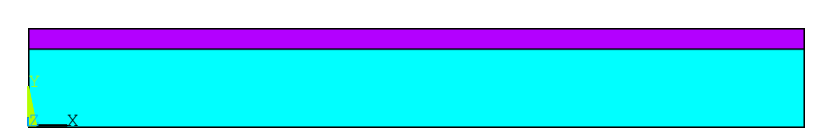

(a) revestimento com $2,5 \mathrm{~cm}$ de espessura

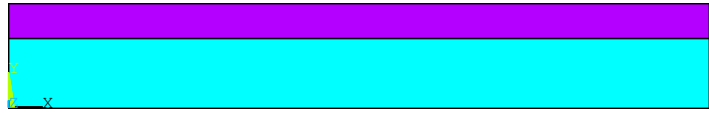

(b) revestimento com 5,0 $\mathrm{cm}$ de espessura

Figura 4-18 - Geometrias dos modelos com 2,00 m de comprimento

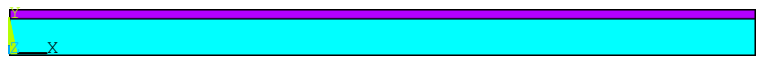

(a) revestimento com $2,5 \mathrm{~cm}$ de espessura

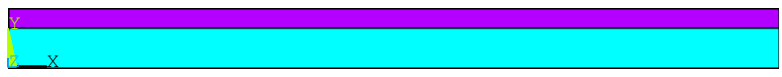

(b) revestimento com $5,0 \mathrm{~cm}$ de espessura

Figura 4-19-Geometrias dos modelos com 4,00 m de comprimento

Os resultados das simulações realizadas são apresentados no capítulo 6, junto com a análise dos resultados e os detalhes da definição dos corpos de prova utilizados no programa experimental são apresentados no capítulo seguinte. 


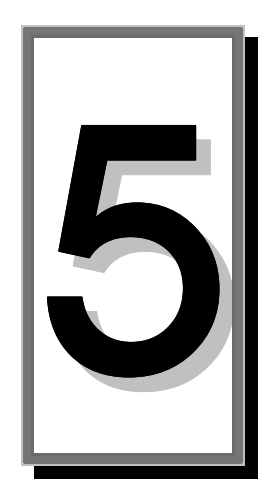

\section{PROGRAMA EXPERIMENTAL}

\subsection{Introdução}

Este programa experimental teve o intuito de verificar a hipótese de que sucessivos choques térmicos degradam a aderência revestimento-base dos revestimentos de argamassa, principalmente, em função das suas condições iniciais de aderência ao substrato, quando a extensão de aderência é limitada.

O desenvolvimento do experimento foi realizado em duas etapas: um programa piloto, cujos detalhes e principais resultados são apresentados no Apêndice $C$ desta tese e, o programa definitivo que foi reajustado a partir das limitações verificadas no piloto.

A seleção de cada um dos fatores ou variáveis analisados, bem como os materiais e métodos utilizados neste programa experimental estiveram alinhados com os objetivos da tese de forma a isolar convenientemente algumas variáveis, fato que reduziu o número de argamassas avaliadas.

A seqüência de atividades realizadas no programa experimental, conforme apresentado na Figura 5-1, tiveram suporte na informação levantada na revisão bibliográfica e também nos resultados obtidos no modelo numérico apresentado no capítulo 4. 


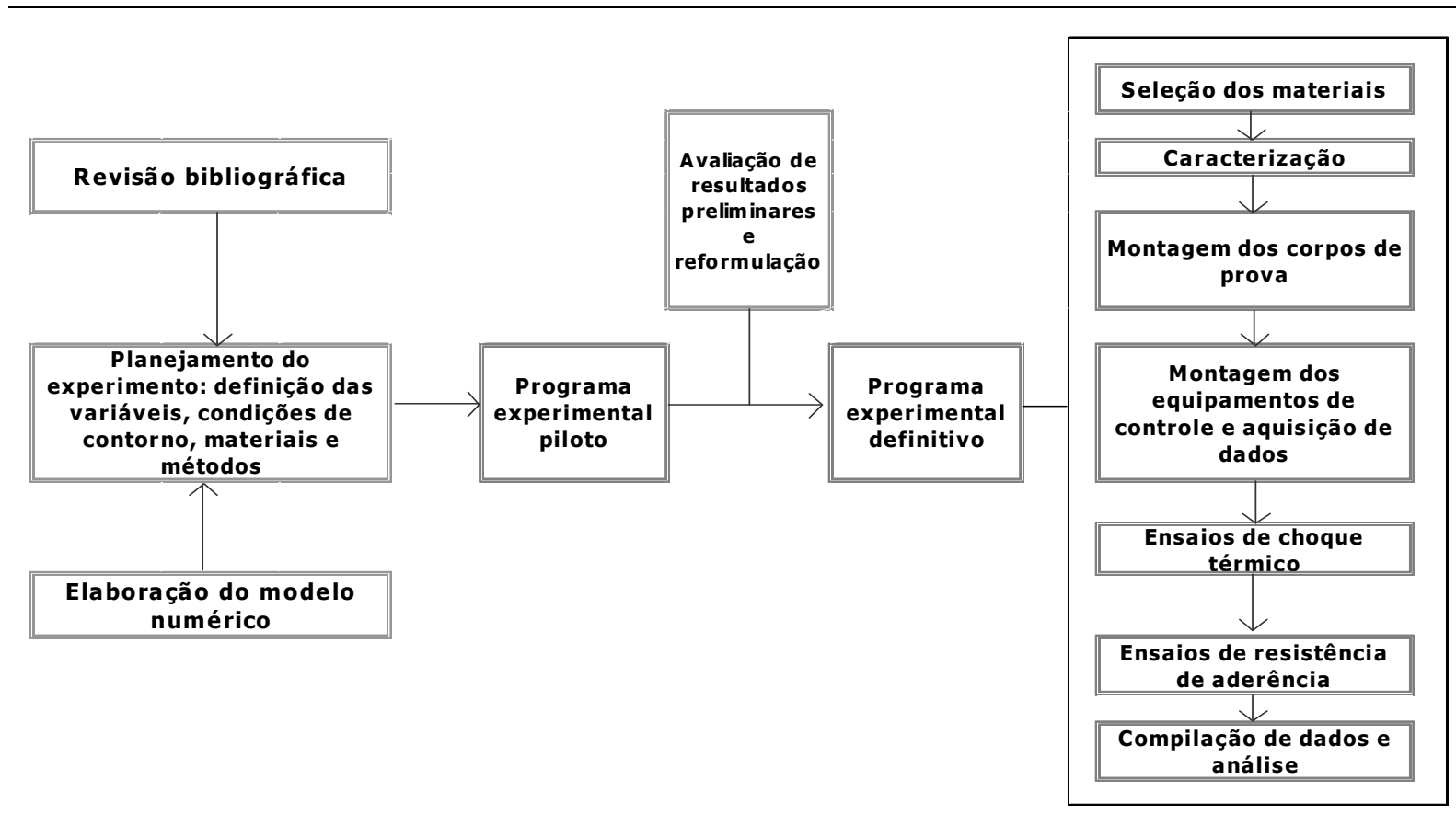

Figura 5-1: Atividades Programa Experimental

Objetivando aperfeiçoar a utilização de recursos disponíveis para o desenvolvimento deste trabalho foram consideradas no planejamento do experimento as ferramentas estatísticas que permitissem a obtenção de um número de ensaios que não comprometessem a confiabilidade dos resultados.

As atividades experimentais foram desenvolvidas principalmente nas instalações dos Laboratórios do Departamento de Engenharia de Construção Civil da Escola Politécnica da USP $\left(\mathrm{CPqDCC}^{10}\right)$.

\subsection{Planejamento do experimento}

Para atingir os objetivos propostos no programa experimental, foi empregado um planejamento fatorial $2^{n}$ e em cada uma das etapas do programa experimental foi considerada também a aleatorização dos procedimentos seguidos.

\subsubsection{Variáveis e níveis de análise}

O efeito do choque térmico sobre materiais e componentes construtivos é avaliado experimentalmente submetendo-se corpos de prova a um período de aquecimento e, posteriormente a um resfriamento rápido, geralmente com água ou ar. Posteriormente, são avaliadas as modificações geradas pelo choque térmico no

${ }^{10}$ CPqDCC é o Centro de Pesquisa e Desenvolvimento da Construção Civil da Escola Politécnica da Universidade de São Paulo. 
corpo de prova, sejam elas fissuras superficiais ou alteração das suas propriedades físicas.

Para os revestimentos de argamassa em fachada os fatores que têm influência no efeito do choque térmico podem ser classificados em dois grupos: aqueles relativos ao processo térmico que produz a variação rápida de temperatura e aqueles relativos às características do revestimento e da base sobre a qual estão aplicados e que condicionam sua resposta perante a solicitação térmica. Portanto, foram analisadas e definidas as variáveis nesses dois grupos conforme apresentado na seqüência:

\subsubsection{Processo térmico}

O processo térmico a que foi exposto o revestimento foi definido como variável, e foram considerados dois níveis: um processo térmico extremo com choque térmico e outro processo térmico em condições ambientais de laboratório (sem choque térmico).

Para produzir o choque térmico por resfriamento (downshock), foi necessário definir algumas características do processo térmico previamente ao início do choque, tais como: seu tempo de duração, a taxa de variação de temperatura, as formas de transferência de calor atuantes no processo, a direção do fluxo de calor e o número de ciclos de choque térmico.

No revestimento foi provocada uma diminuição da sua temperatura superficial após um período de aquecimento, utilizando água a temperatura ambiente para o resfriamento, mantendo constantes as outras variáveis mencionadas.

Com base nos parâmetros utilizados em métodos de ensaio de choque térmico propostos em normas internacionais e na literatura disponível, os quais são apresentados na Tabela 3-2, verificou-se a necessidade de definir melhor algumas informações, tais como: a temperatura superficial máxima atingida pelo revestimento no aquecimento e a temperatura mínima no resfriamento, de forma a adequar as características do ensaio às particularidades climáticas próprias do local, que para o caso deste trabalho é a cidade de São Paulo.

Assim sendo, foram consultados dados climáticos para São Paulo, os quais geralmente estão referidos à temperatura do ar, umidade relativa, intensidade da radiação solar e precipitação em estações climáticas em diferentes lugares da 
cidade, pelo qual foi necessário cruzar informações sobre diminuição da temperatura do ar e ocorrência simultânea de eventos de precipitação.

Consultando as informações publicadas pelo DAEE ${ }^{11}$ (2004) foi possível constatar uma concentração de eventos de precipitação nos meses de dezembro, janeiro e fevereiro, como mostrado na Figura 5.2. Com essa informação foi concentrada a análise dos dados climáticos nesses meses para os dados climáticos a que se teve acesso dos anos 2003, 2004, 2005 e 2006.

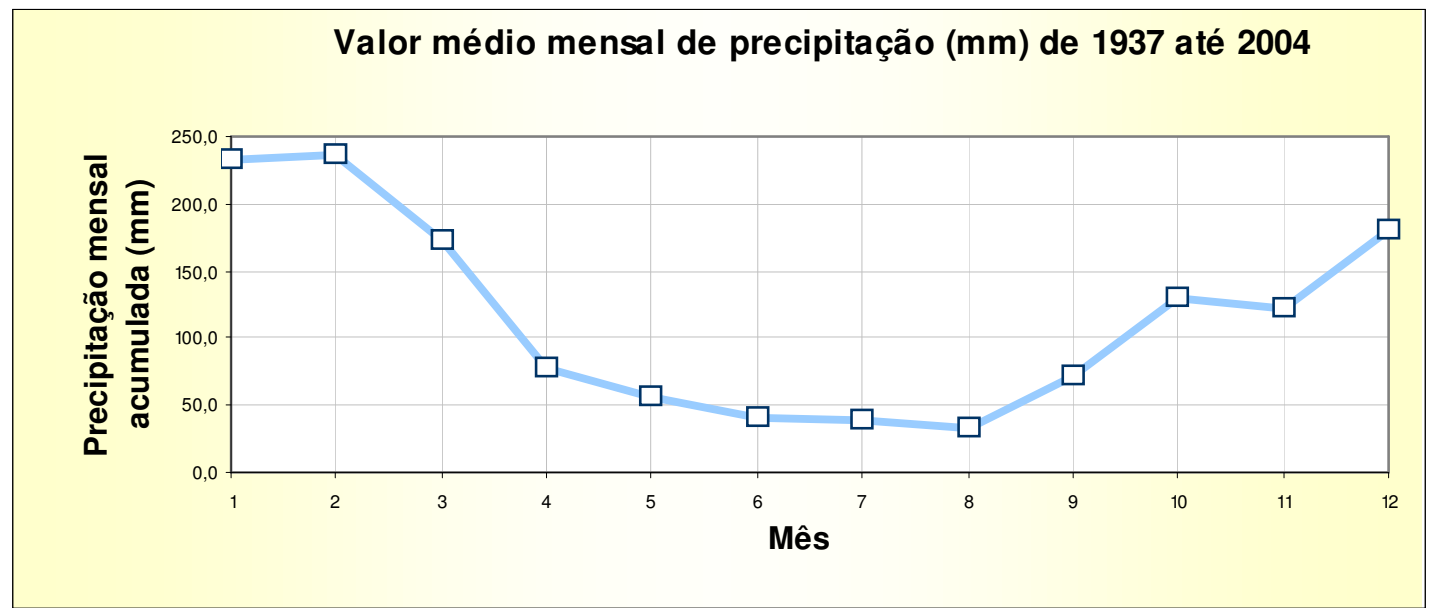

Figura 5.2: Variação anual dos valores médios de precipitação mensal acumulada desde 1937 até 2004

Paralelamente foram realizadas medições de temperatura superficial de revestimento externo para observar os valores atingidos em situações diferentes.

Os principais dados desses levantamentos estão apresentados no Apêndice B deste trabalho.

Da análise dos trabalhos nacionais em que é simulado choque térmico emrevestimentos - dentre eles os de Geyer e Greven (1994); Siqueira, Cincotto e John (1995); Roman et al. (2000) Candia (2001); Miranda e Selmo (2003); Crescêncio e Barros (2003); e Vilató (2004) - observou-se a utilização do procedimento de ensaio especificado pelo IPT (1998), com algumas variantes no caso de Candia (1999), com exceção do trabalho de Roman et al. (2000) que utilizaram uma câmara climática para simular o ciclos higrotérmicos.

${ }^{11}$ DAEE é a sigla do Departamento de Águas e Energia Elétrica do Estado de São Paulo 


\subsubsection{Revestimento}

A resposta do revestimento às solicitações provocadas pelo choque térmico pode ser avaliada verificando-se a alteração nas suas características superficiais ou propriedades físicas. Neste trabalho definiu-se focar a avaliação na aderência do revestimento, por ser esta uma das principais propriedades que condiciona seu desempenho.

Por sua vez, conforme discutido anteriormente, a aderência do revestimento é condicionada por diversos fatores, dentre os quais foram avaliadas a rigidez do revestimento, pelo módulo de elasticidade da argamassa, o qual é particularmente determinante no estado de tensões térmicas; e as condições iniciais de aderência do revestimento à base, avaliadas pela presença de macro-defeitos de interface e quantificada pela taxa de macro-defeitos, conforme descrito por Antunes (2005).

O módulo de elasticidade é uma propriedade que indica a capacidade de deformação que o revestimento pode apresentar. Sua influência no desempenho do revestimento é destacada em trabalhos experimentais como os de Godoy e Barros (1999) e Bastos (2003). Também Candia (2001) identificou em ensaios de choque térmico sobre revestimentos de argamassa que o aumento do módulo de elasticidade das argamassas de revestimento influi negativamente na resistência de aderência após o choque térmico. Todos esses resultados experimentais são coerentes com os modelos teóricos para choque térmico apresentados no capítulo 3 . Portanto, foram escolhidos dois valores extremos de módulo de elasticidade da argamassa, a partir dos trabalhos de Temoche et al. (2007); Silva; Barros; Monte (2008).

Para estabelecer os dois níveis de rigidez no revestimento foi considerada a utilização de aditivo incorporador de ar na argamassa para revestimento de forma a controlar o módulo de elasticidade e a condutividade térmica do revestimento.

A outra variável estudada nesta tese e relacionada às características de aplicação da argamassa para revestimento foi a presença de macro-defeitos na interface baserevestimento. De acordo com Antunes (2005) existe uma correlação acima de 70\% entre a taxa de macro-defeitos e a resistência de aderência do revestimento. Com o intuito de trabalhar com cenários extremos, definiram-se dois níveis de avaliação: 0 primeiro em que, teoricamente, a taxa de macro-defeitos é mínima e outra em que 
os macro-defeitos foram provocados deliberadamente em uma taxa de $35 \%$ da superfície da interface. Como apresentado no capítulo 4, na modelagem computacional foram simulados também outros valores de taxa de macro-defeitos (7\% e 42\%) encontrados por Antunes (2005); porém, não foram reproduzidos experimentalmente pelas dificuldades de realização de tal feito no tempo disponível para a sua realização.

Assim, as variáveis estudadas e os níveis de análise na matriz de planejamento estão apresentados na Tabela 5-1.

Tabela 5-1: Variáveis do arranjo experimental

\begin{tabular}{l|l|l|l}
\hline \multirow{2}{*}{ Tipo de argamassa } & $\begin{array}{l}\text { Taxa de macro- } \\
\text { defeitos de } \\
\text { Interface provocados }\end{array}$ & Sem choque térmico & 30 ciclos de choque térmico \\
\cline { 2 - 4 } & $\mathrm{e}=30 \mathrm{~mm}$ & $\mathrm{e}=30 \mathrm{~mm}$ \\
\hline Argamassa sem AIA & $0 \%$ & $1 \ldots$ & 5 \\
\cline { 2 - 5 } & $35 \%$ & 2 & 6 \\
\hline Argamassa com AIA & $0 \%$ & 3 & 7 \\
\cline { 2 - 4 } & $35 \%$ & 4 & 8 \\
\hline
\end{tabular}

\subsubsection{Variável resposta}

O principal parâmetro utilizado na literatura para avaliar a aderência dos revestimentos de argamassa é o ensaio de resistência de aderência à tração normal, que foi definido como variável resposta no trabalho.

\subsection{Desenvolvimento do experimento}

No programa experimental definitivo constam a definição dos materiais a serem utilizados e seus ensaios de caracterização, as técnicas e equipamentos empregados na produção dos corpos de prova e a montagem e equipamentos desenvolvidos para os ensaios de choque térmico.

\subsection{Materiais e equipamentos utilizados}

\subsubsection{Base ou substrato}

Como o substrato de aplicação do revestimento não deveria ser uma variável, optouse pela sua produção junto a um especialista, no caso, a Associação Brasileira de Cimento Portland (ABCP) que produz costumeiramente as bases de substrato

\footnotetext{
${ }^{12}$ Para as argamassas dosadas com Aditivo Incorporador de Ar foi adotada a nomenclatura Com AIA ou c/AIA e para as argamassas sem aditivo a nomenclatura Sem AIA ou s/AIA.
} 
padrão para ensaios de argamassas colantes. As características definidas para esses substratos são apresentadas na Tabela 5-2:

Tabela 5-2: Características da base ou substrato

\begin{tabular}{|c|c|c|c|c|}
\hline Material & Dimensões (m) & $\begin{array}{c}\text { Módulo de } \\
\text { elasticidade - E } \\
\text { (GPa) }\end{array}$ & $\begin{array}{c}\text { Densidade } \\
\left(\mathrm{kg} / \mathrm{cm}^{3}\right)\end{array}$ & Características superficiais \\
\hline Concreto & $\begin{array}{l}0,30 \times 0,40 \times \\
0,10\end{array}$ & 25 & 2.400 & $\begin{array}{l}\text { características superficiais } \\
\text { semelhantes às do substrato padrão } \\
\text { definido pela norma ABNT NBR } \\
14082^{13} \text {. }\end{array}$ \\
\hline
\end{tabular}

Os materiais utilizados na produção dos substratos de concreto foram: cimento Portland CP II E (ABNT NBR 11578); brita № 1; areia e aditivo dispersante para concreto.

O equipamento utilizado para mistura do concreto foi uma betoneira de 120 I e na moldagem dos substratos foram utilizadas fôrmas de madeira compensada. Para 0 adensamento foi utilizada uma mesa vibratória e o acabamento superficial foi desempenado grosso, conforme mostrado na Figura 5-2:

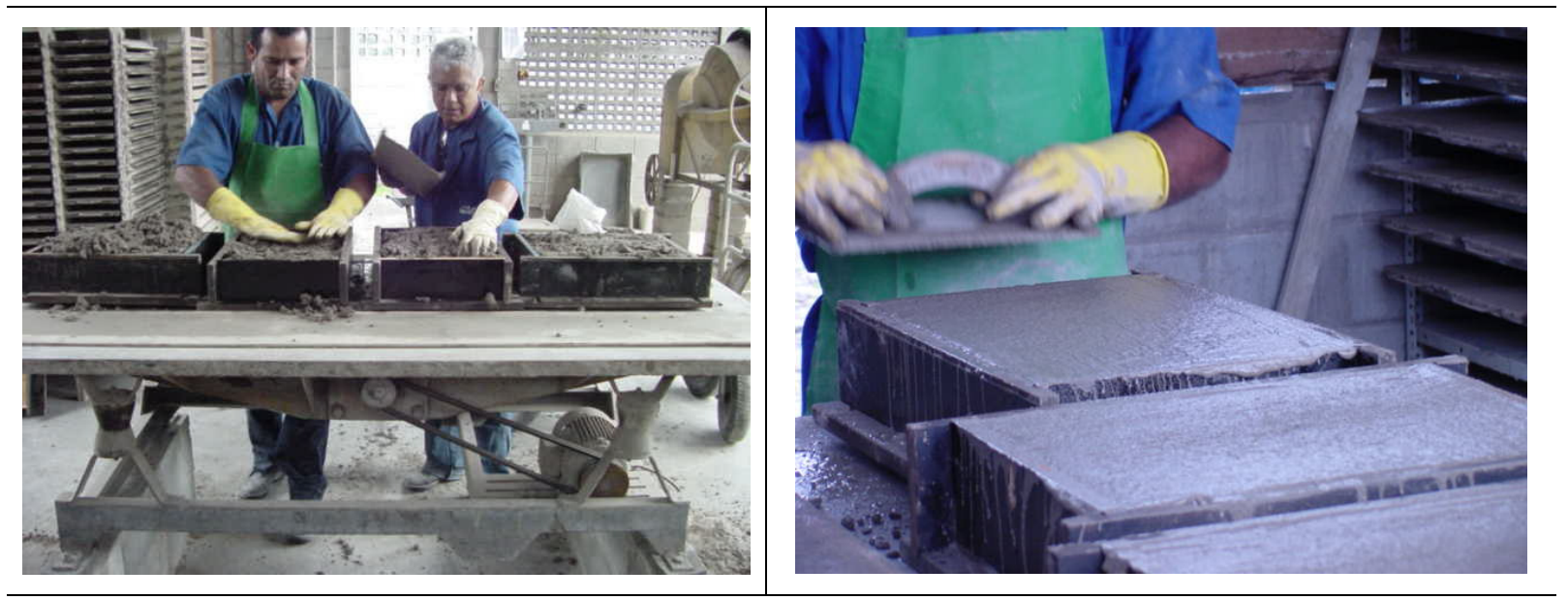

Figura 5-2: Produção dos substratos de concreto

A cura foi realizada durante 28 dias sendo o primeiro dia no molde, seis dias imerso na água, conforme mostrado na Figura 5-3 e 21 dias ao abrigo das intempéries.

\footnotetext{
${ }^{13} \mathrm{O}$ concreto para o substrato-padrão deve ser executado com cimento Portland, areia e pedrisco, com relação água:cimento de 0,45 a 0,50 e consumo mínimo de cimento de $400 \mathrm{~kg} / \mathrm{m} 3$. Como traço indicativo (em massa), sugere-se 1:2,58:1,26. O acabamento final deve ser feito com desempenadeira de madeira e cura deve ser feita durante 28 dias, sendo o primeiro dia no molde, seis dias imerso na água e 21 dias ao abrigo das intempéries.
} 


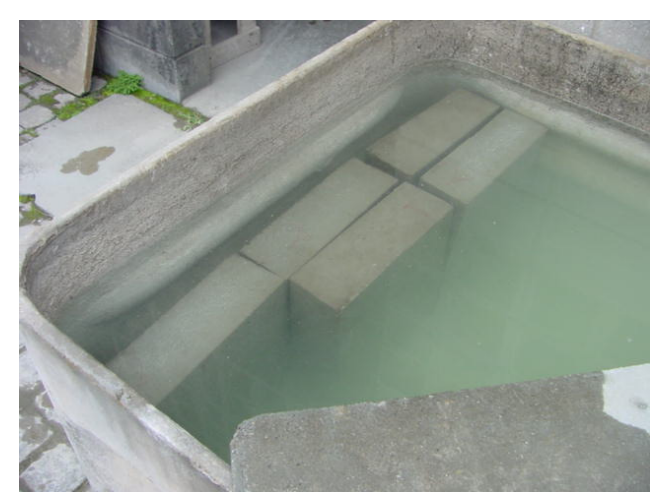

Figura 5-3: Cura das bases de concreto por imersão, durante os 6 dias seguintes à desenforma feita com 1 dia.

\subsubsection{Revestimento de argamassa}

Os fatores que condicionam a aderência do revestimento que dizem respeito à argamassa estão vinculados aos materiais utilizados e ao processo de produção da argamassa, à sua posterior aplicação no substrato e às condições ambientais durante a aplicação e durante a secagem do revestimento.

Diante das diversas possibilidades de produção da argamassa e objetivando diminuir as variáveis fora de controle, foi decidido manter constante o tipo de argamassa, optando pela sua dosagem em laboratório com um único tipo de aglomerante e agregado, bem como um único teor de água. Assim, para se obter o segundo tipo de argamassa, com características distintas, foi utilizado um aditivo incorporador de ar na dosagem.

Desta forma, foram utilizadas duas argamassas para revestimento. A primeira dosada na proporção 1:4, em volume de materiais secos sem aditivos e a segunda com adição de incorporador de ar. O teor de aglomerante e do agregado (em massa) e o teor de água ( $16 \%$ da massa dos materiais secos) foram mantidos constantes.

A proporção 1:4 em volume, apesar de não ser comum para revestimento externo, salvo obras de recuperação de concreto, permitiu potencializar o efeito do módulo de elasticidade na ocorrência das tensões térmicas; e a adição de incorporador de ar na segunda argamassa permitiu diminuir a sua densidade e, por conseqüência, a condutividade térmica do revestimento, devido à baixa condutividade térmica do ar $\left(0,025 \mathrm{~W} / \mathrm{m}^{\circ} \mathrm{K}\right)$ e também seu módulo de elasticidade, permitindo valores desta propriedade mais próximos aos valores das argamassas freqüentemente utilizadas em revestimento externo. 
Os materiais utilizados para produção do revestimento de argamassa e suas proporções são apresentados na Tabela 5-4:

Tabela 5.3. Dosagem da argamassa utilizada.

\begin{tabular}{|c|c|c|c|}
\hline Materiais & $\begin{array}{l}\text { Massa dos materiais secos } \\
(\mathrm{kg}) \text { utilizados para } \\
\text { produção de } 20 \text { litros de } \\
\text { argamassa (uma batelada) }\end{array}$ & $\begin{array}{l}\text { Proporção unitária } \\
\text { em massa (kg) }\end{array}$ & $\begin{array}{c}\text { Relação } \\
\text { a/c }\end{array}$ \\
\hline $\begin{array}{l}\text { Cimento Portland CP II F } \\
\text { (ABNT NBR 11578) }\end{array}$ & 5,177 & 1 & \multirow{4}{*}{0,93} \\
\hline $\begin{array}{l}\text { areia quartzosa proveniente } \\
\text { de leito de rio. }\end{array}$ & 29,818 & 5,759 & \\
\hline $\begin{array}{l}\text { aditivo incorporador de ar a } \\
\text { base de laurilsulfato de sódio } \\
(0,00125 \% \text { da massa de } \\
\text { materiais secos) }\end{array}$ & 0,000437 & 0,00008 & \\
\hline Água & 5,599 & 1,08 & \\
\hline
\end{tabular}

A espessura do revestimento também tem influência no seu comportamento mecânico, uma vez que o aumento da espessura do revestimento diminui o nível de tensões na interface base-revestimento, fato que foi confirmado também pelo modelo numérico (item 6.1.2.2) em coincidência com trabalhos como o de Bortoluzzo (2000). Entretanto, neste trabalho optou-se pelo cenário mais crítico, ou seja, aquele do revestimento com a menor espessura média que representasse o valor mais freqüente em obra.

Assim, a espessura do revestimento foi definida em $30 \mathrm{~mm}$, que é um valor acima do mínimo recomendado pela norma ABNT NBR 7200 (1998) e que foi registrado pelo pesquisador em diversas visitas a obras na cidade de São Paulo. Da mesma forma, esse valor coincide com a espessura média de revestimentos de argamassa encontrada por Souza et al. (1999) e por Paliari, Souza e Andrade (2001) e o utilizado no trabalho de Antunes (2005).

O equipamento utilizado para produção e homogeneização da argamassa para revestimento foi uma argamassadeira de eixo horizontal marca Consolid modelo $\mathrm{MH}$ 80 com capacidade de 50 litros, comumente utilizado em obras na cidade de São Paulo. Para produção do revestimento foi utilizado um projetor de argamassa marca ANVI (tipo caneca) conectado a um sistema de ar comprimido que permitisse atingir uma pressão de aplicação de 100 psi. Ambos os equipamentos são mostrados na Figura 5-4 


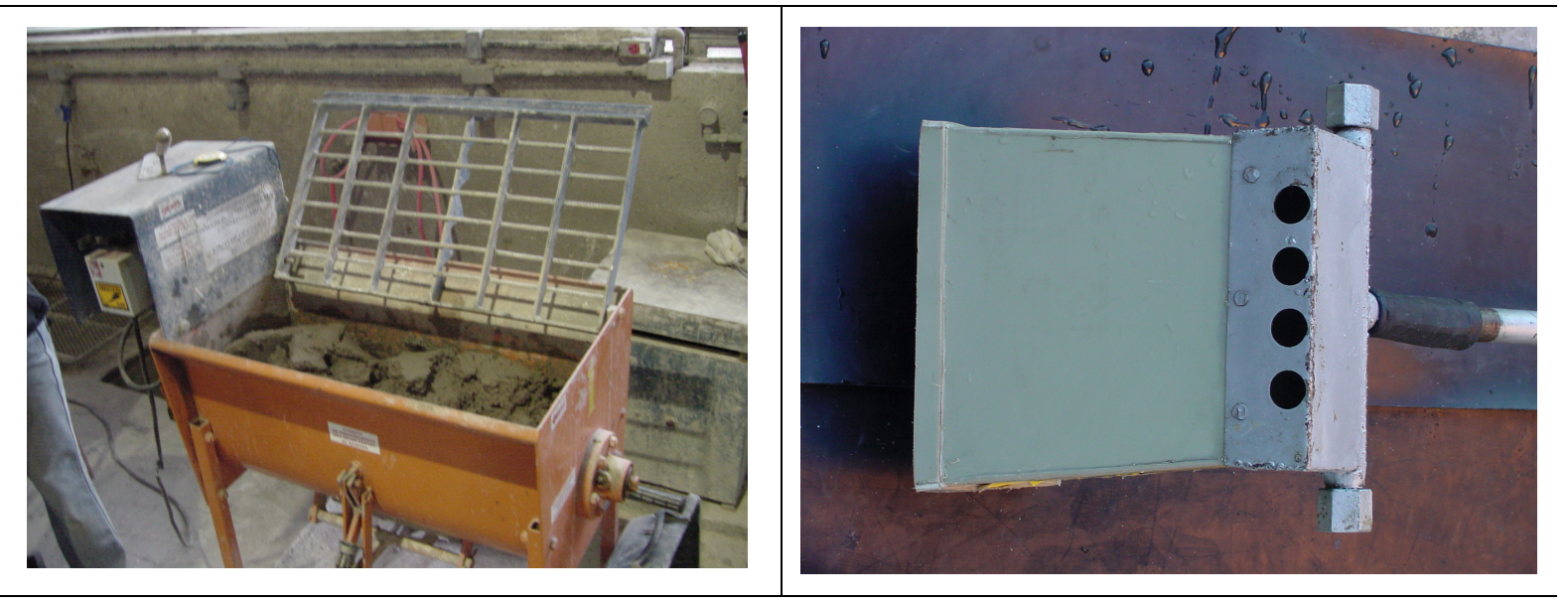

Figura 5-4: Argamassadeira de eixo horizontal e projetor de argamassa tipo "caneca" empregados no preparo da argamassa e na sua aplicação, respectivamente.

As condições de secagem do revestimento foram também controladas de forma a evitar a fissuração por retração na secagem, mantendo os corpos de prova do revestimento em ambiente saturado (em câmara úmida) até os 28 dias após a moldagem dos revestimentos. Este procedimento visou potencializar a aderência do revestimento ao seu substrato.

\subsubsection{Simulação de macro-defeitos de interface base-revestimento}

Para simulação dos macro-defeitos de aderência na interface base-revestimento inicialmente foi definida a geometria e as dimensões do defeito típico, para que se pudesse realizar sua reprodução. Isto foi realizado a partir das análises de imagem de macro-defeitos apresentadas por Antunes (2005) como, por exemplo, o mostrado na Figura 5-5:

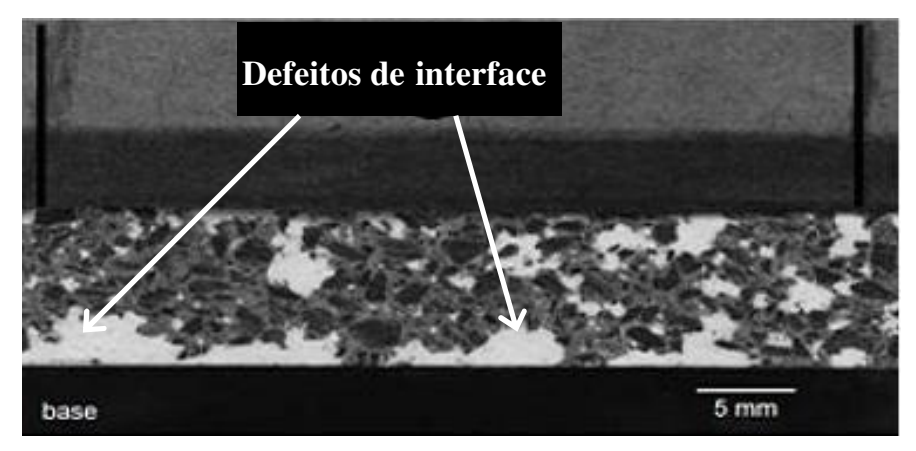

Fonte: Antunes (2005)

Figura 5-5: Imagem de macro-defeitos de interface base-revestimento de argamassa para identificação do defeito típico a ser empregado no programa experimental.

Utilizando a escala gráfica nas imagens foi definido um defeito com formato de calota circular com $8 \mathrm{~mm}$ de diâmetro e $1 \mathrm{~mm}$ de altura, imersa no revestimento e 
aderida ao substrato. A Figura 5-6a mostra em vermelho o volume correspondente às falhas que estão sobre a superfície do substrato, correspondentes a $7 \%$ e na Figura 5-6b é mostrada somente a camada de revestimento separada da base com destaque para o volume ocupado pelas falhas nessa camada e o afastamento entre si, no caso em que se considera que a área das falhas corresponde a $42 \%$ da área da interface entre os materiais.

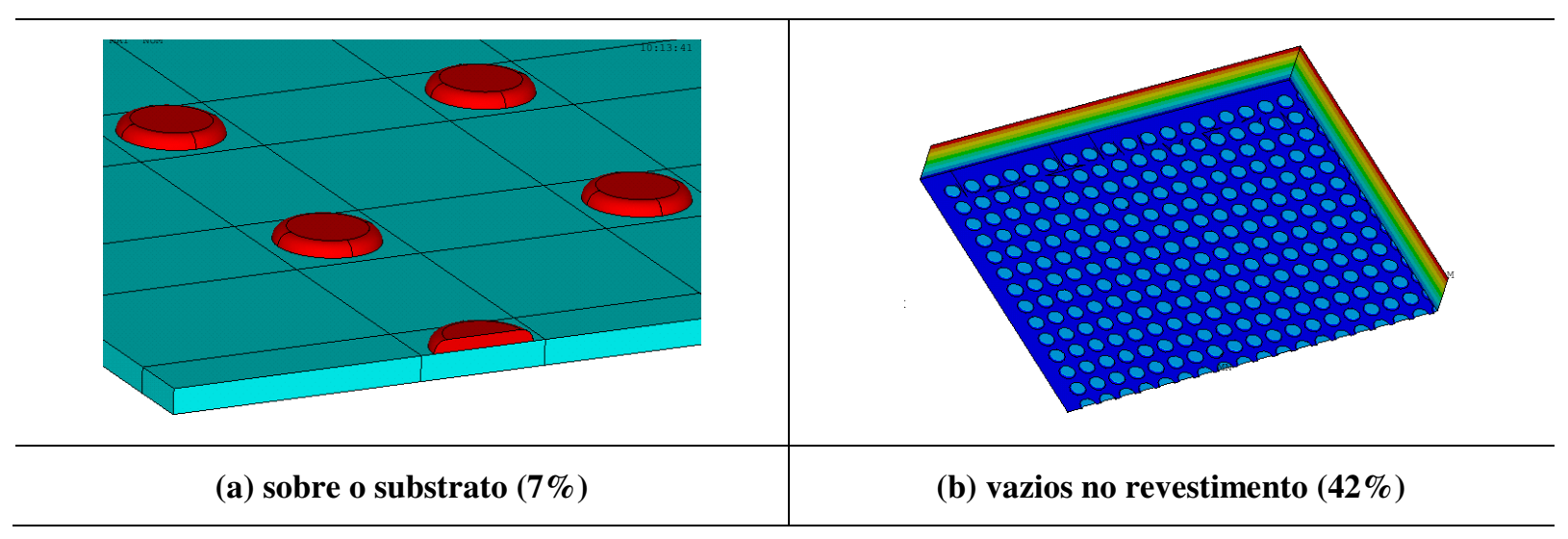

Figura 5-6: Geometria e distribuição de macro-defeitos (7\% e 42\%), no modelo tridimensional, utilizados na simulação matemática.

Desta forma partiu-se para simulação dos macro-defeitos sobre a superfície rugosa e porosa dos substratos produzidos. Testes preliminares foram realizados com silicone e com adesivos à base de borracha procurando reproduzir uma distribuição regular desses macro-defeitos de interface. O resultado da utilização desses materiais na criação dos macro-defeitos não foi adequado como mostrado na Figura $5-8$

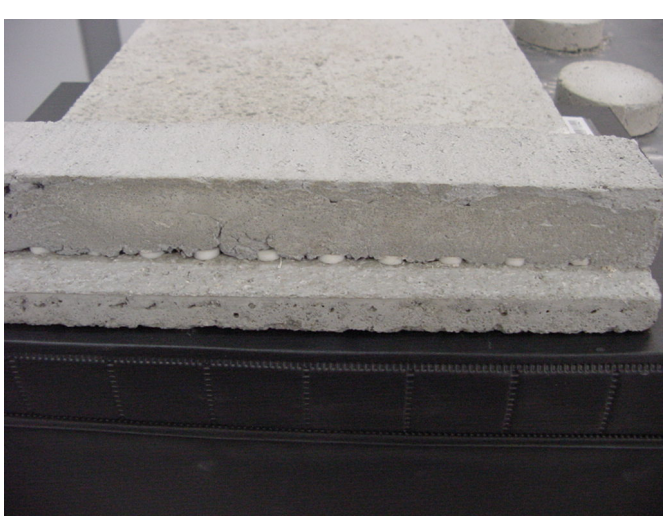

a)

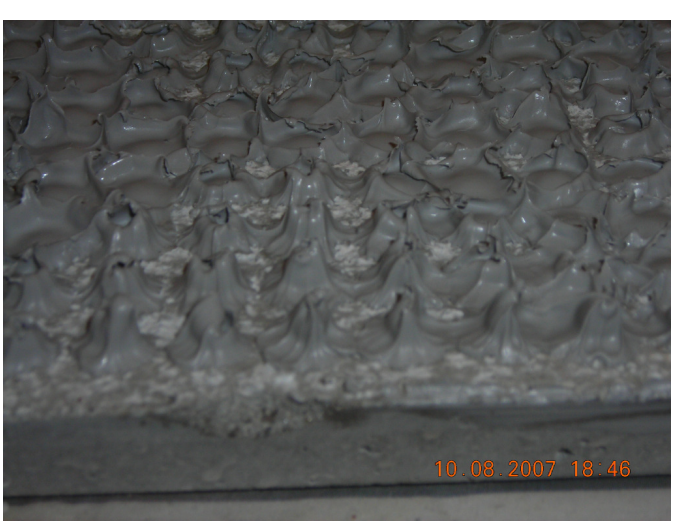

b)

Figura 5-7: Reprodução de macro-defeitos de interface com a) borracha adesiva, e b) silicone 
Como o resultado do uso desses materiais não foi satisfatório, foi testada uma tinta à base de emulsão acrílica expansível usada para impressão serigráfica (geralmente sobre tecidos de algodão ou mistos) e que expande com calor formando acabamento alto relevo.

Para aplicação da serigrafia foi utilizada uma tela com o desenho dos macro-defeitos distribuídos em filas e colunas, de acordo com a Figura 5-8a. O resultado da aplicação da tinta sobre a base não foi satisfatório devido à rugosidade da superfície que não permitia um acabamento homogêneo e no caso da maior taxa (42\%) a proximidade dos macro-defeitos simulados entre si provocava a junção entre um defeito e outro após a segunda e terceira aplicações da serigrafia. A solução para este problema foi a redução da taxa de macro-defeitos ao valor de $35 \%$ da superfície da interface, valor que também foi analisado no modelo computacional e, paralelamente, a produção de um gabarito (Figura 5-8b) em chapa de aço de $1 \mathrm{~mm}$ de altura perfurada de acordo com a distribuição dos macro-defeitos que, apoiado na superfície da base ou substrato, permitiu corrigir as imperfeições da aplicação com serigrafia.

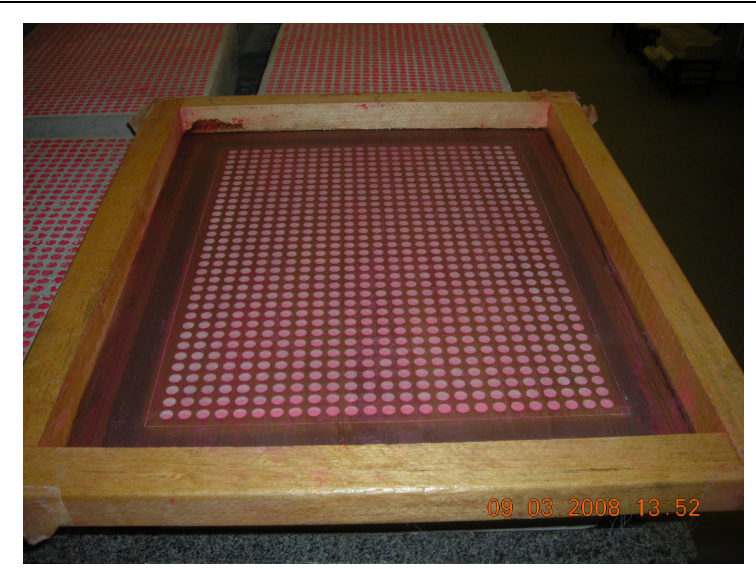

a)

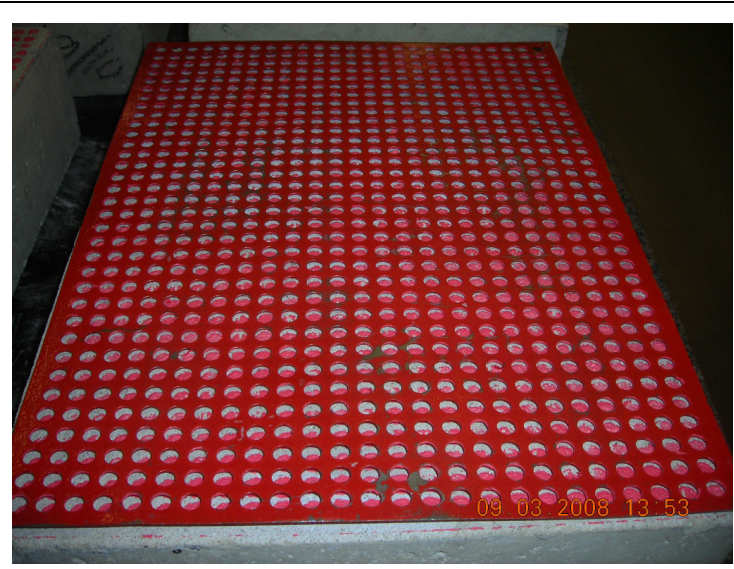

b)

Figura 5-8: (a) Tela para impressão de macro-defeitos e (b) gabarito metálico para correção dos macro-defeitos resultantes da serigrafia.

O resultado da impressão dos macro-defeitos para a taxa de $35 \%$ é mostrado na Figura 5-9. O uso da tinta expansível com aumento de temperatura ajudou a obter o volume com a espessura aproximada de $1 \mathrm{~mm}$ definida anteriormente. 

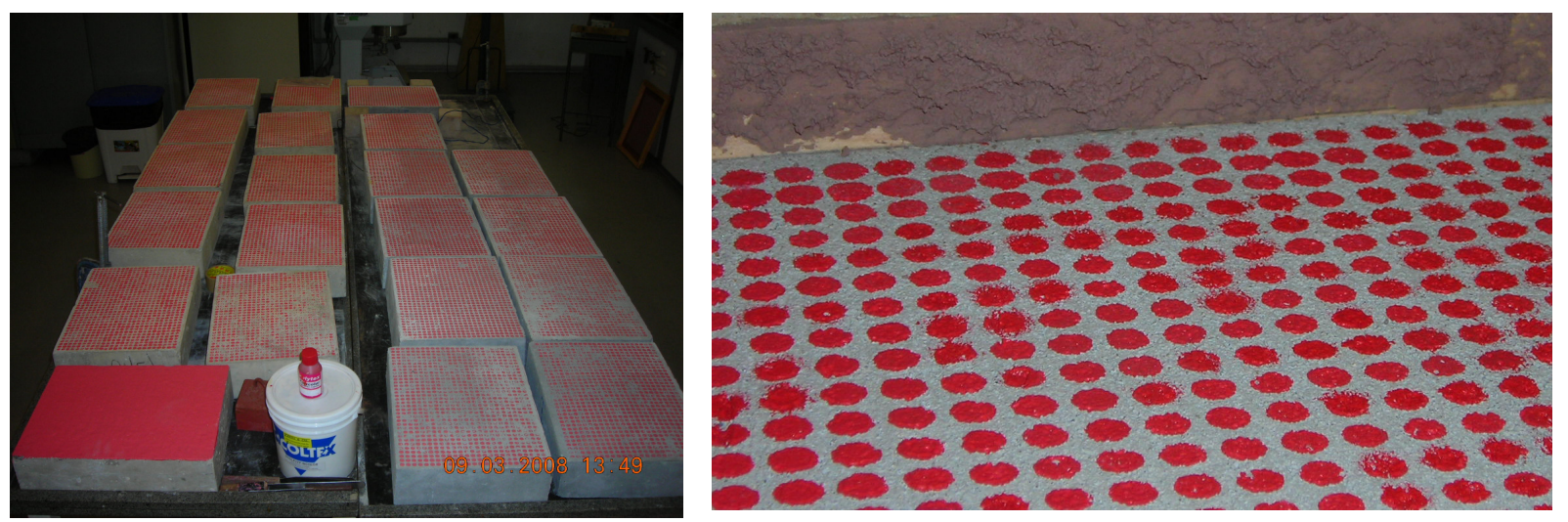

Figura 5-9: Reprodução dos macro-defeitos sobre a superfície do substrato

O resultado da simulação dos macro-defeitos pode ser avaliado a partir seções transversais dos corpos de prova produzidos no programa experimental piloto conforme é mostrado na Figura 5-10. A inclusão dos círculos com tinta acrílica expansível provocou a formação de vazios de ar na interface base-revestimento e evitou o contato entre a argamassa para revestimento (material na parte superior) e a base de concreto.

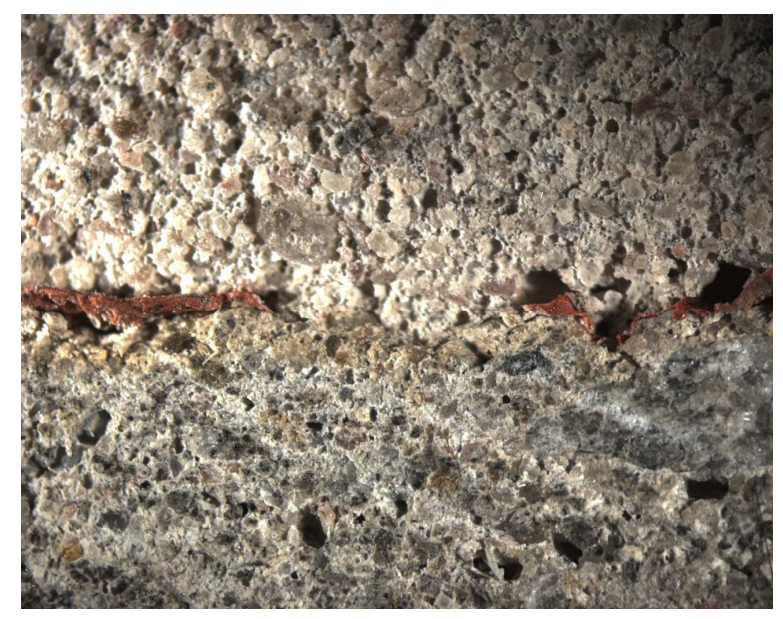

a)

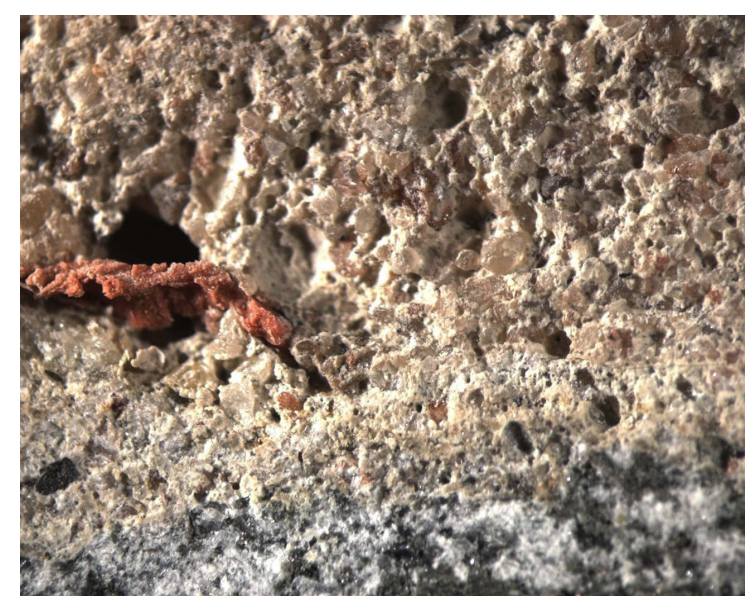

b)

Figura 5-10: Efeito dos macro-defeitos simulados na interface base-revestimento. Imagem com aumento de $13 \times$ (a) e 20x (b)

\subsubsection{Parâmetros dos ensaios de choque térmico}

A partir dos métodos de ensaio reunidos na Tabela 3-1, foram selecionados aqueles possíveis de serem realizados com os equipamentos disponíveis, dentre eles os métodos especificados pelo CSTC (CSTC, 1980), UEAtc (UEAtc, 1992 e 1999), pelo IPT (IPT,1998) e pela norma EN 13687-2 (EN, 2002). 
Da análise desses métodos e dos trabalhos citados na bibliografia com destaque para os citados em 5.2 foram escolhidos os parâmetros apresentados na Tabela 5-3

Tabela 5-3: Parâmetros definidos para o ensaio de choque térmico

\begin{tabular}{|c|c|c|}
\hline Parâmetro de ensaio & Valores definidos no ensaio & Referência \\
\hline Temperatura superficial máxima & $70^{\circ} \mathrm{C}$ & UEAtc 1999 \\
\hline Temperatura superficial mínima & $23^{\circ} \mathrm{C}$ (ambiente) & UEAtc 1999 \\
\hline Tempo de aquecimento & $3 \mathrm{~h}$ & IPT (1998) \\
\hline $\begin{array}{l}\text { Tempo de permanência na } \\
\text { temperatura máxima }\end{array}$ & $1,5 \mathrm{~h}$ & \\
\hline Tempo de resfriamento & $1 \mathrm{~h}$ & IPT (1998) \\
\hline Forma de aquecimento & $\begin{array}{l}\text { Painel radiante com } 96 \text { lampadas } \\
\text { incandescentes com potencia de } 150 \mathrm{~W}\end{array}$ & \\
\hline Forma de resfriamento & $\begin{array}{l}\text { Jato de água na superfície do } \\
\text { revestimento provocado por aspersores. }\end{array}$ & IPT (1998) \\
\hline Número de ciclos & 30 & EN 13687-2 \\
\hline Duração do ciclo & $4 \mathrm{~h}$ & IPT (1998) \\
\hline Controle de temperatura & $\begin{array}{l}\text { Controlador automático liga/desliga } \\
\text { montado neste trabalho }\end{array}$ & \\
\hline Registro de temperaturas & Termopares tipo "t" & \\
\hline
\end{tabular}

Para o cenário considerado neste trabalho adotou-se a temperatura superficial máxima de $70^{\circ} \mathrm{C}$ provocada por aquecimento por radiação. Este valor foi escolhido a partir de valores extremos citados por Goldberg (1998) e medições de temperatura superficial realizadas, pelo autor, em revestimentos expostos nas quatro orientações na Torre do Laboratório de Sistemas Prediais da EPUSP, durante os meses de janeiro e fevereiro de 2005 (Apêndice B).

Quanto ao valor da temperatura de resfriamento do revestimento esta foi definida de acordo com os valores das referências normativas para testes de choque térmico, considerando que o choque seria produzido com água à temperatura ambiente, pois segundo Hasselman (1969) e Becher (1981) é o método mais freqüente nestes testes. Assim o valor definido foi de $20^{\circ} \mathrm{C}$ a $23^{\circ} \mathrm{C}$.

Esses parâmetros foram comparados também com medições realizadas pelo autor em levantamento de campo e na Estação climática da EPUSP.

\subsubsection{Montagem do ensaio de choque térmico}

O ensaio de choque térmico prevê um período de aquecimento e posteriormente um período de resfriamento provocado por água aplicada sobre os corpos de prova. No laboratório do CPqDCC, contava-se unicamente com um painel móvel para produzir o aquecimento por radiação; portanto, foi necessário desenvolver o restante dos 
dispositivos para realização do ensaio, dentre eles o suporte para colocação dos corpos de prova, o sistema de resfriamento com água e o sistema de controle e monitoramento do ensaio.

De acordo com as condições de contorno estabelecidas para os corpos de prova no choque térmico, a variação de temperatura devia ser provocada unicamente na face externa do revestimento, mantendo-se isoladas as laterais e a face posterior da base, devendo esta última ser mantida a temperatura constante. Com tal propósito, foram fabricadas molduras de madeira (material de baixa condutividade térmica), com dimensões tais que o corpo de prova coubesse dentro, deixando-se exposta a face do revestimento (Figura 5-11).
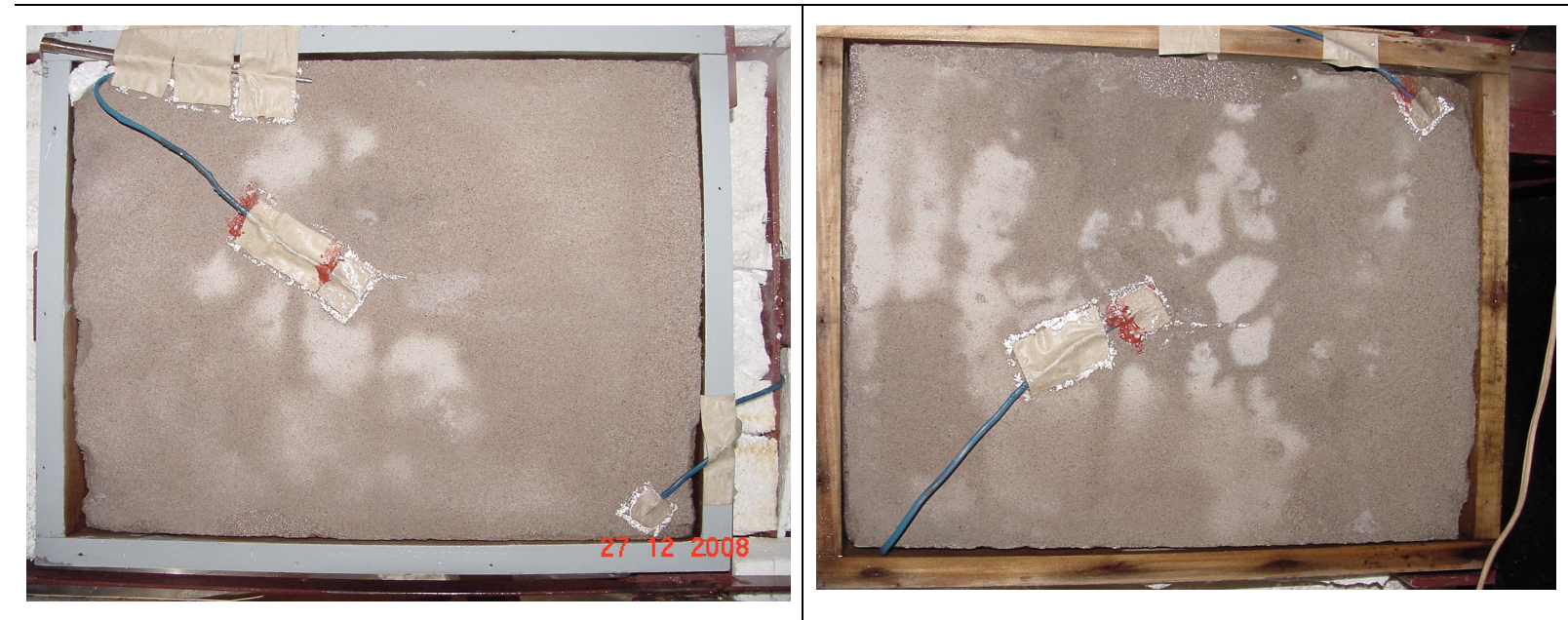

Figura 5-11: Caixa de madeira para isolamento lateral dos corpos de prova

Para garantir um fluxo de calor constante, os procedimentos seguidos em cada um dos ciclos de aquecimento foram padronizados, e para garantir homogeneidade na absorção do calor os outros fatores determinantes na absortividade como a cor da superfície ou seu acabamento superficial (INCROPERA, DeWITT, 1990) também foram mantidos constantes.

Para melhor isolar as laterais dos corpos de prova contra a absorção de água durante o período de resfriamento, problema detectado no programa piloto, foi aplicado um verniz impermeabilizante nas laterais de cada um dos corpos de prova (Figura 5-12). 


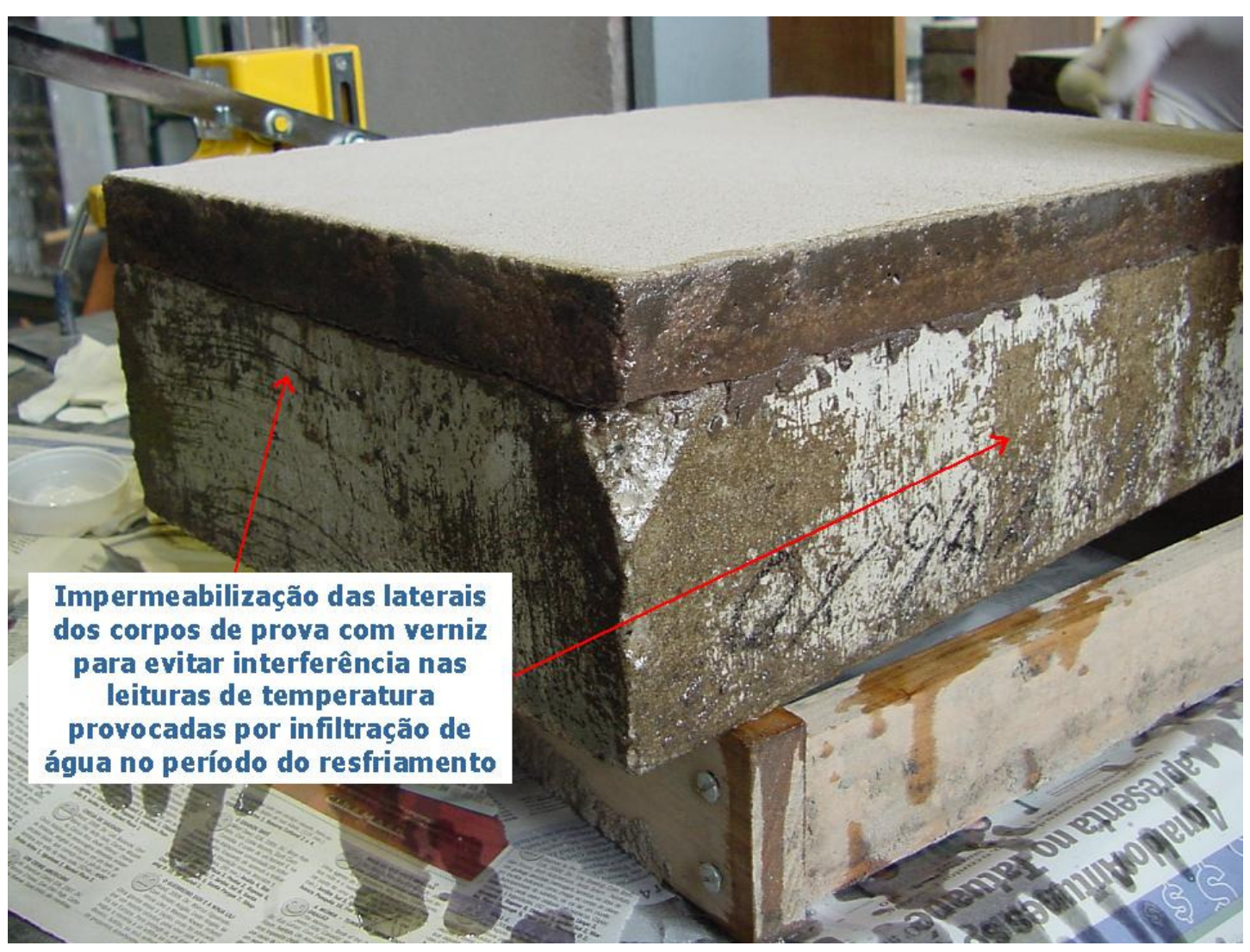

Figura 5-12: Impermeabilização das laterais dos corpos de prova para evitar a infiltração de água no período de resfriamento.

\subsubsection{Suporte dos corpos de prova}

O suporte dos corpos de prova devia atender aos seguintes requisitos:

ter uma largura menor do que a largura do painel de aquecimento, ou seja, com largura menor a $1,30 \mathrm{~m}$;

suportar a carga de 8 corpos de prova, isto é, em torno de 400 kg, e ser móvel;

ter sobre a superfície dos corpos de prova um elemento de proteção que impedisse a passagem de água para a parte posterior do conjunto;

permitir a criação de uma câmara de isolamento na face posterior dos corpos para manter a temperatura em torno dos $20^{\circ} \mathrm{C}$.

Assim, foi produzido um suporte com perfis metálicos soldados, conforme mostrado na Figura 5-13 a, para o posicionamento de até 8 corpos de prova. O requisito de impedimento da passagem de água para a parte posterior foi solucionado com uma porta fixada com dobradiças metálicas na lateral do suporte e abas de madeira para 
ajudar a atingir a largura do painel de aquecimento, como é mostrado na Figura 5-13b.

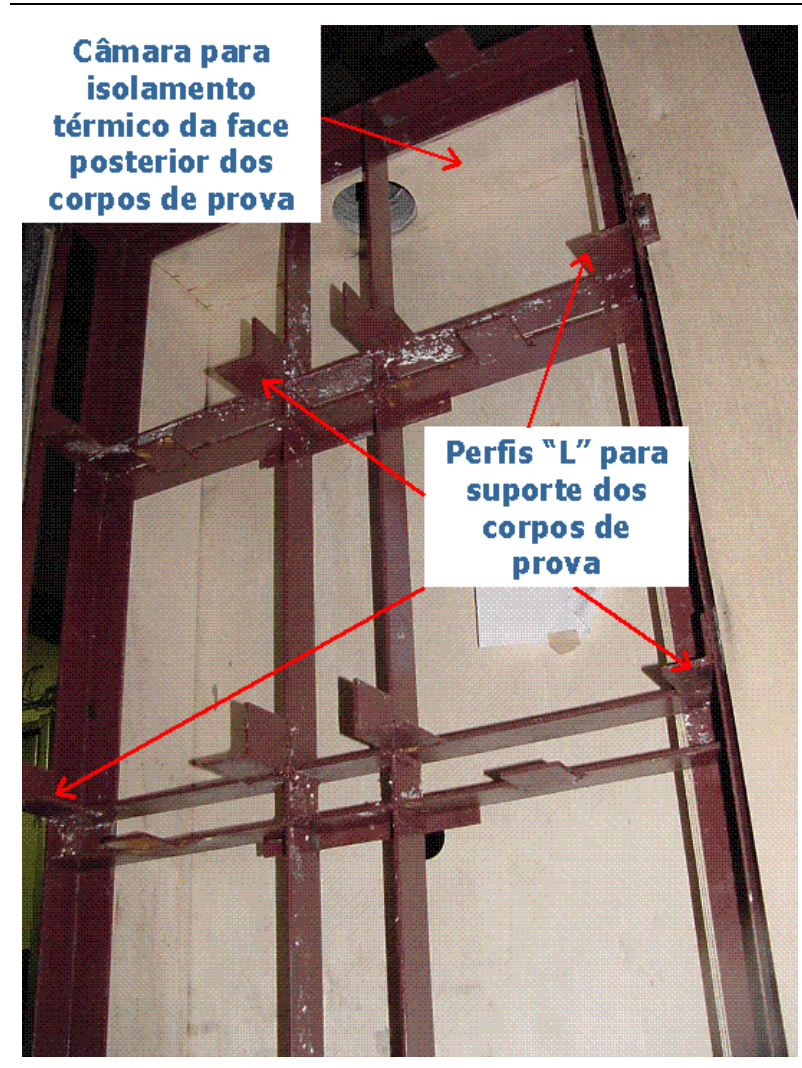

a)

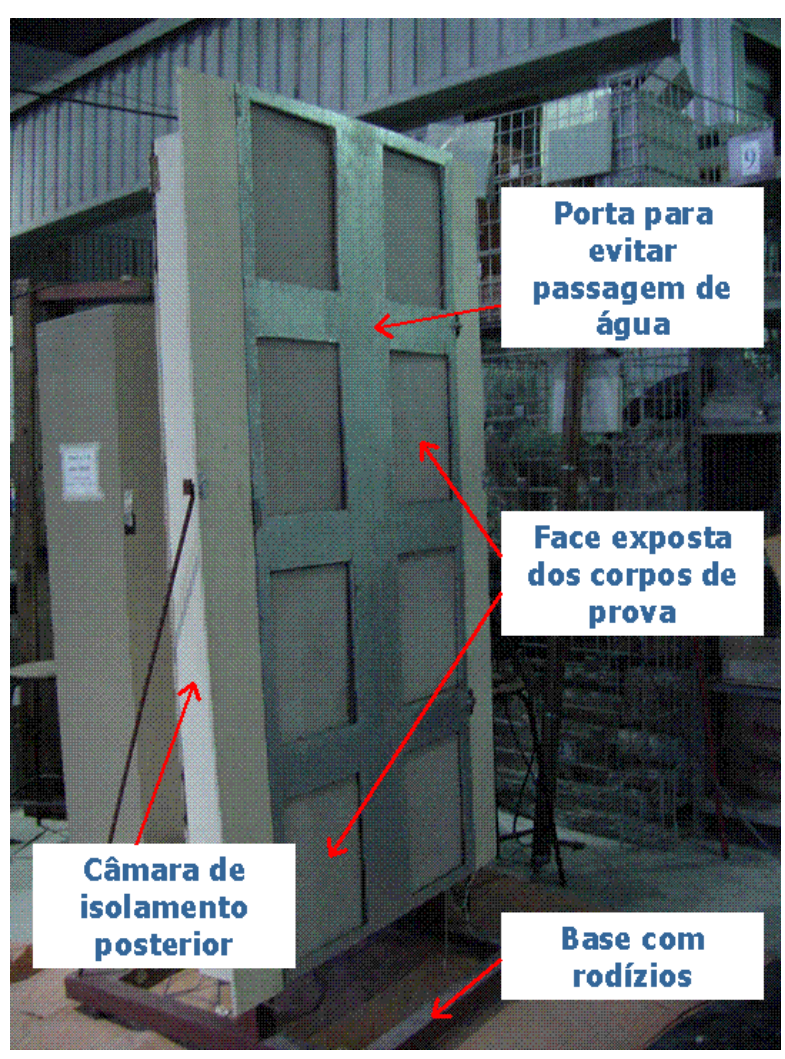

b)

Figura 5-13: Montagem de suporte para colocação dos corpos de prova

Para manter a temperatura controlada em torno dos $23^{\circ} \mathrm{C}$ na face posterior dos corpos de prova, um equipamento de ar condicionado portátil foi conectado à câmara, através de um duto circular na parte superior da mesma, como pode ser visto na Figura 5-13 a.

O suporte devia permitir também a instalação do sistema de resfriamento e de um depósito para coleta da água. A coleta de água foi realizada com uma calha preparada especialmente para o suporte, mostrada na Figura 5-14. 


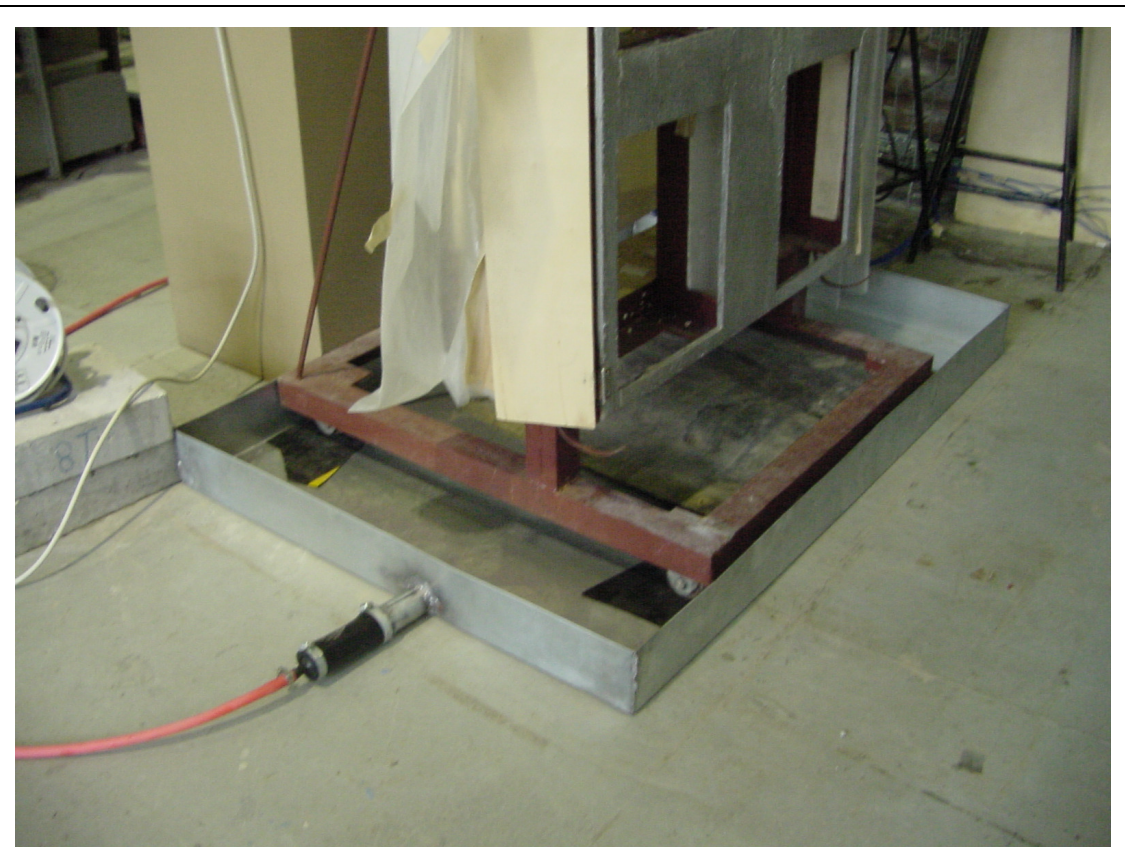

Figura 5-14: Calha utilizada para coleta de água no período de resfriamento

O escoamento da água coletada no ensaio foi conectado através de mangueira à rede de esgoto do laboratório. No programa piloto buscou-se recircular a água utilizada para o resfriamento; no entanto a temperatura da água após o contato com os corpos de prova ficava elevada o que inviabilizava a sua recirculação. Para os seu reaproveitamento deveria existir um reservatório para que pudesse ser utilizado em ciclos posteriores. Porém, por falta de espaço no laboratório tal reservatório não pode ser construído. No entanto, esta deve ser uma melhoria a ser feita posteriormente no equipamento de ensaio.

\subsubsection{Sistema de aquecimento}

Para produzir o aquecimento superficial nos corpos de prova foi utilizado um equipamento constituído por um painel de 1,30 m x 2,30 m com suporte móvel, composto por 98 lâmpadas incandescentes de $150 \mathrm{~W}$ cada uma, conforme mostrado na Figura 5-15a.

A partir da distribuição das lâmpadas no painel foi dimensionado o suporte para posicionar os corpos de prova de forma a que cada um deles tivesse a incidência direta de 6 lâmpadas, ou seja 900 W. Essa distribuição pode ser observada na Figura 5-15b.

No programa experimental piloto foi verificado que havia uma diminuição da temperatura superficial nos corpos de prova localizados perto dos extremos do 
painel, em relação aos localizados na parte central que foi atribuída a perdas de calor por radiação e convecção nas bordas. Por este motivo, no programa experimental definitivo os corpos de prova ocuparam uma largura menor do que a largura do painel, sendo reservada uma fileira inteira de lâmpadas além das bordas do suporte dos corpos de prova. Além disso, buscando-se evitar a perda de calor, instalou-se abas laterais de compensado (Figura 5-15b) com a dimensão necessária para atingir a largura total de $1,30 \mathrm{~m}$ do painel.

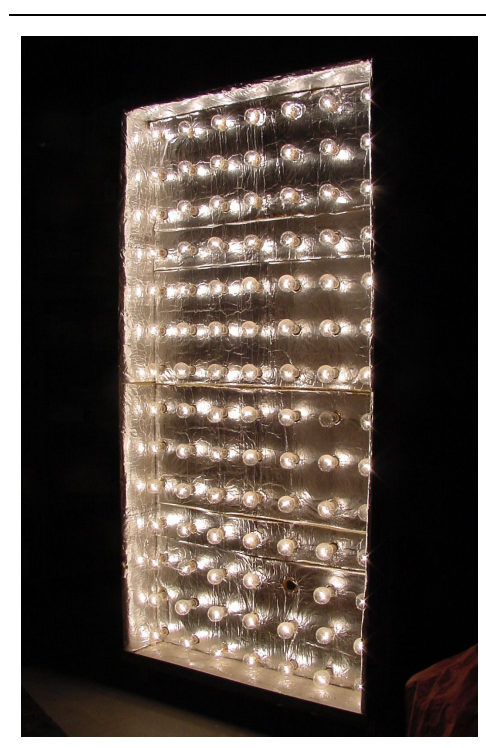

a)

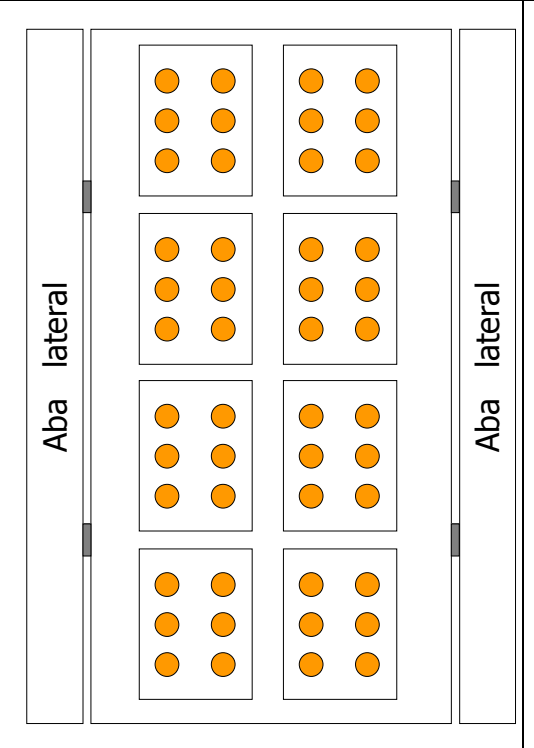

b)

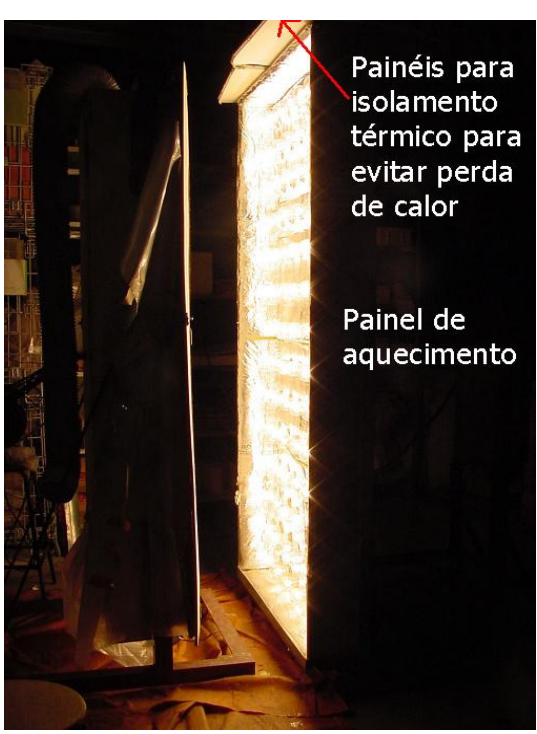

c)

Figura 5-15: (a) Painel para aquecimento dos corpos de prova em funcionamento; (b) distribuição de número de lâmpadas por corpo de prova; (c) posicionamento na frente do suporte

Além das abas laterais do suporte, também buscando-se evitar perdas de calor no período do aquecimento, foram utilizadas placas isolantes na parte superior do painel como pode ser observado na Figura 5-15c.

O aquecimento foi realizado com lâmpadas incandescentes sobre os corpos de prova até atingir a temperatura superficial especificada nos parâmetros do ensaio $\left(70^{\circ} \mathrm{C}\right)$. O controle de temperatura foi realizado por um termopar instalado na superfície do revestimento e conectado a um sistema de liga/desliga que comandava o quadro geral dos circuitos das lâmpadas no painel.

\subsubsection{Sistema de resfriamento}

Para promover o resfriamento da superfície do revestimento foi necessário montar um sistema de fornecimento, circulação e evacuação de água. Esse sistema 
precisava ser móvel; desta forma, uma mangueira de $\varnothing 1 / 2$ " foi fixada por meio de abraçadeiras sobre um pórtico de madeira (Figura 5-16a). A distância entre os dois elementos verticais do pórtico coincidia com a distância entre os eixos das duas colunas de corpos de prova no suporte (Figura 5-16b).

Para simular a chuva sobre a superfície do revestimento foram utilizados aspersores fixados na mangueira de forma a se ter dois aspersores por corpo de prova ${ }^{14}$, alinhados no seu eixo, como pode ser constatado na Figura 5-16b. Foi utilizada água da rede pública, conectada por mangueira ao sistema descrito, garantindo-se, assim, o fornecimento constante de água durante todo o período do ensaio.

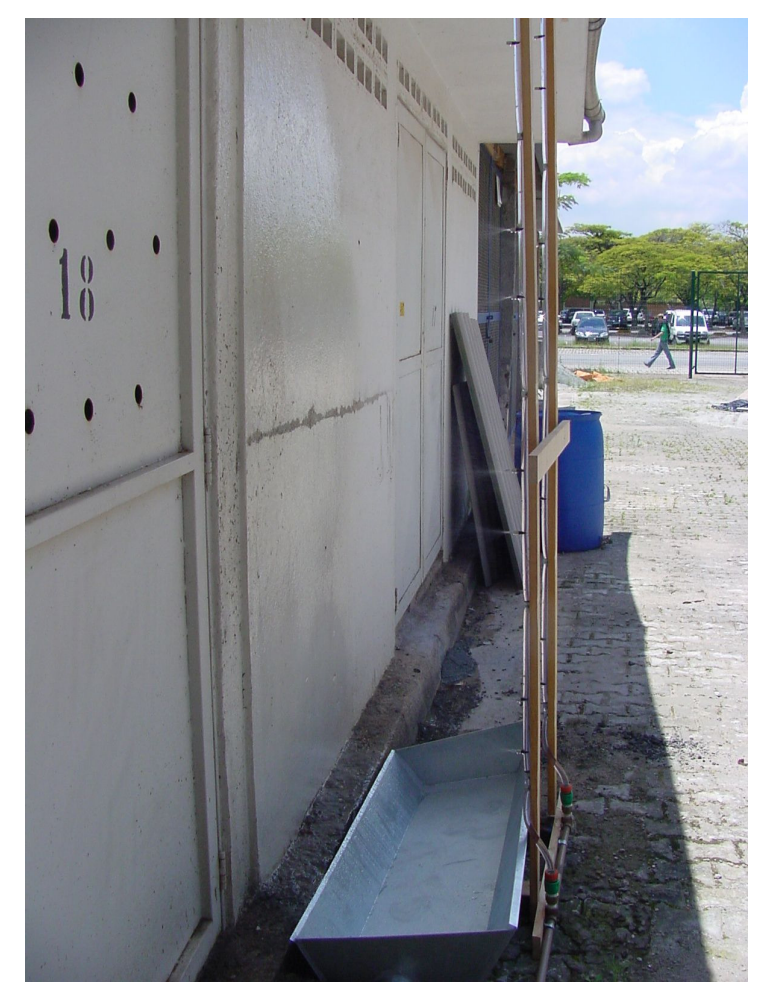

a)

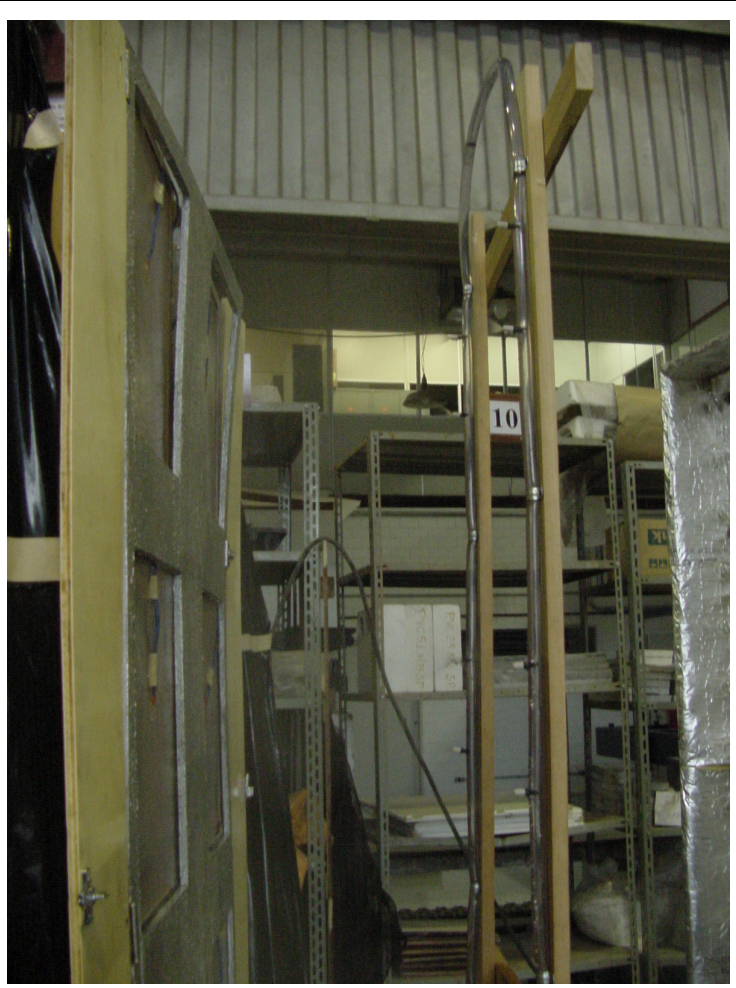

b)

Figura 5-16: (a) Estrutura montada para realização dos ensaios de choque térmico; (b) momento de resfriamento dos corpos de prova

A coleta da água foi realizada por calha com bocal de saída conectado à rede pública de drenagem.

\footnotetext{
${ }^{14}$ A definição de dois aspersores por corpo de prova foi feita a partir de teste preliminar que permitiu verificar que dois aspersores eram suficientes para molhar toda a superfície do corpo de prova.
} 
Para o início do resfriamento, após a terceira hora de aquecimento, o procedimento adotado para colocação da estrutura de simulação da chuva foi manual. Faltando cinco minutos para o fim do período de aquecimento, a estrutura era conectada à mangueira que,por sua vez, era conectada à rede de água do laboratório. Após o desligamento das lâmpadas, o painel radiante era afastado da superfície dos corpos de prova, ao mesmo tempo em que era colocada a estrutura de simulação de chuva (Figura 5-17 ${ }^{\mathrm{a}}$ ); na seqüência, abria-se a válvula de controle para a passagem de água no sistema. Uma vez iniciado o período de resfriamento, a água era coletada e evacuada pela calha colocada na parte inferior do suporte (Figura 5-17 b).

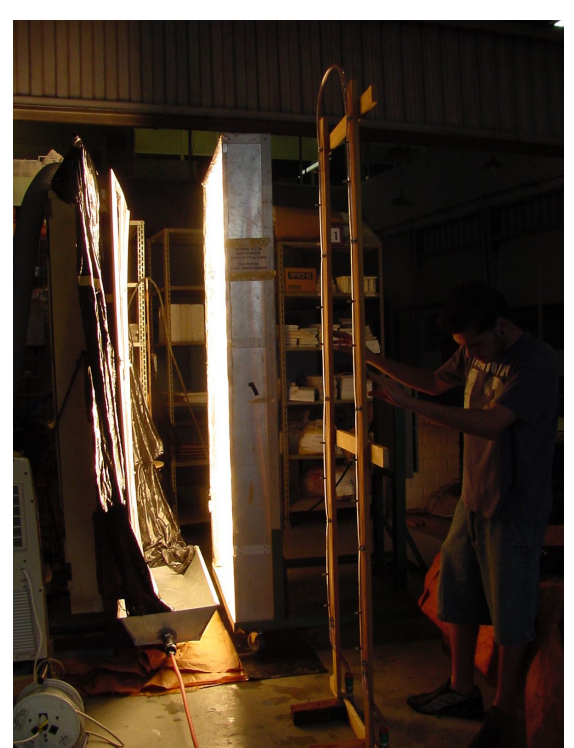

a)

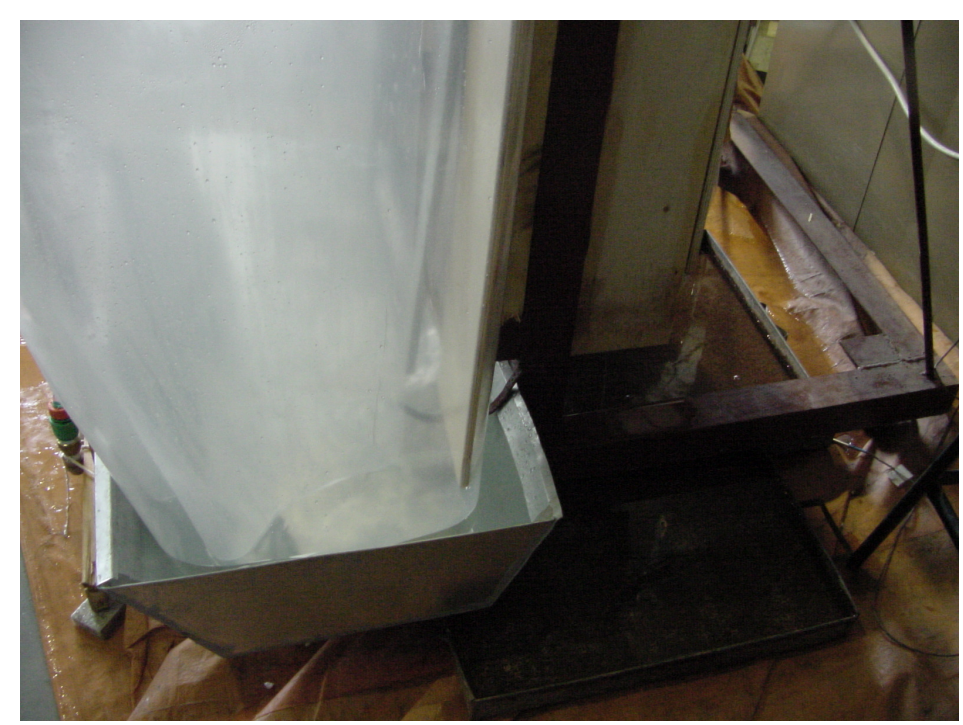

b)

Figura 5-17: (a) Estrutura para resfriamento no início do período; (b) coleta da água em calha para posterior evacuação.

\subsubsection{Materiais e equipamentos para registro e controle do ensaio de choque térmico}

Para o sistema de aquisição de temperaturas durante os ensaios de choque térmico foram utilizados:

a) Cabo de compensação para termopar tipo T; e

b) Equipamento de aquisição de sinais marca National (Figura 5-18a). O equipamento consta de um módulo de amplificação de sinais (Módulo SCXI 1000) e um bloco terminal SCXI 1300 com 32 canais de leitura para medição das temperaturas. 
Este equipamento possui também um sistema de medição de deformações a partir de sensores denominados extensômetros elétricos (strain gage). Estes sensores foram utilizados para determinação de outras propriedades (módulo de Poisson) dos materiais utilizados.

O programa de interface utilizado foi o "Labview", versão 8.1 com uma rotina especificamente desenvolvida para leitura simultânea de temperaturas e deformações, cuja tela de saída é apresentada na Figura 5-18b.

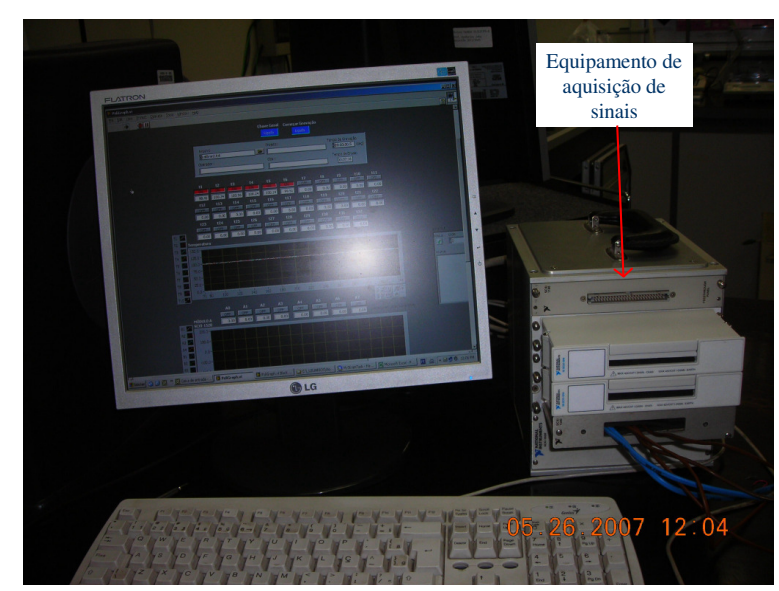

a)

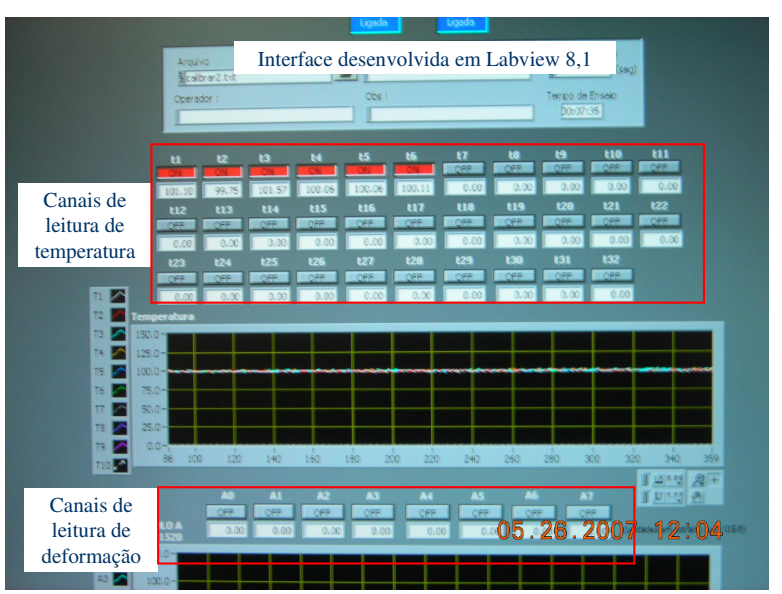

b)

Figura 5-18: a) Equipamento de aquisição de sinais e (b) formato de interface do programa de aquisição de sinais.

Nos ensaios foram utilizados 30 canais de aquisição de temperaturas e um canal para ser utilizado como temperatura de referência (junção fria).

Concluídos os pormenores de instalação do sistema de aquisição, foi possível realizar a conexão de cada um dos sensores (termopares) utilizados para coleta de dados de temperatura na placa de aquisição (Figura 5-19a). Posteriormente, cada um dos 30 termopares conectados à placa foi conectado nos corpos de prova sendo sua instalação pela parte posterior do suporte, sendo necessária a passagem dos termopares pela câmara de isolamento (Figura 5-19b).

Por fim cada termopar foi colado em cada um dos 8 corpos de prova: na superfície externa do revestimento foram colados 14 termopares em total (Figura 5-19c) utilizando uma fita adesiva resistente à temperatura; no interior do corpo de prova na altura da interface base-revestimento 8 termopares e na face posterior do corpo de prova (substrato de concreto) 8 termopares. 


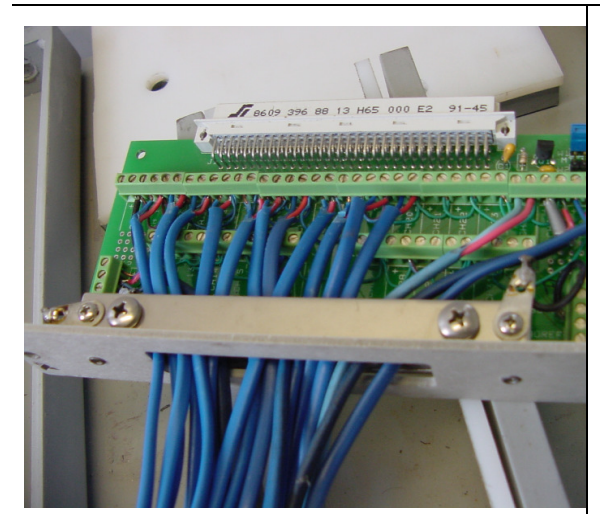

a)

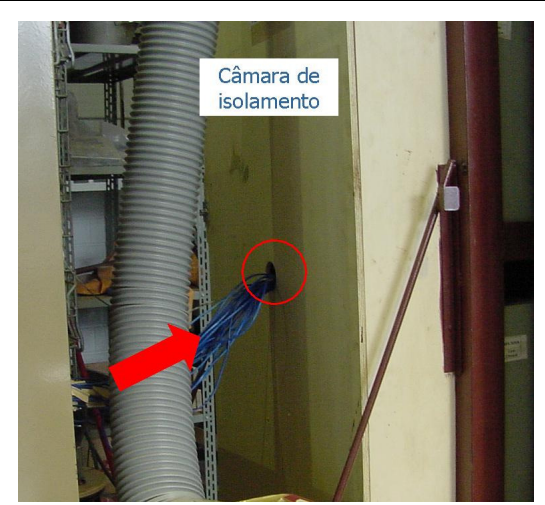

b)

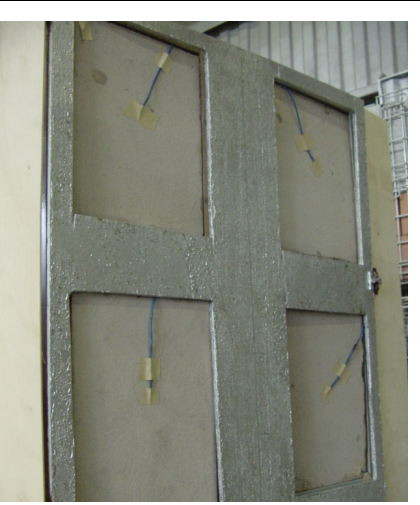

c)

Figura 5-19: Montagem de sistema de aquisição de temperaturas e instalação dos sensores nos corpos de prova

\subsection{Atividades de calibração}

Com o propósito de identificar fontes de erro experimental e buscar formas de atenuá-lo, antes de iniciar os ensaios foram realizados testes de calibração dos equipamentos utilizados na medição de temperaturas identificando-se a necessidade de realizar correções nas leituras dos canais do equipamento de aquisição.

Uma das fontes de erro identificada foi a própria rede de alimentação de energia que apresentava contínuas oscilações, pelo que foi necessário proceder ao aterramento do sistema para atenuar as flutuações nas leituras.

Outra fonte de erro nas leituras era provocada por diferença de leituras entre os próprios canais do equipamento, sendo necessário realizar correções no programa de interface com o equipamento de aquisição (Labview).

Para verificar a homogeneidade no aquecimento dos corpos de prova foram realizados testes em que eram aquecidos corpos de prova semelhantes aos do ensaio de choque térmico para identificar a homogeneidade na forma de aquecimento promovida pelo painel.

A Figura 5-20a mostra como, no estado de equilíbrio à temperatura ambiente, a variação da temperatura superficial para o corpo de prova é mínima. Já no período do aquecimento a variação da temperatura na superfície começou a variar atingindo cerca de $4^{\circ} \mathrm{C}$ de diferença entre o ponto central e as bordas, ficando evidentes as perdas de calor pelas bordas (Figura 5-20b). Finalmente no momento do resfriamento a variação promovida foi maior nos primeiros minutos do resfriamento tendendo a diminuir e se estabilizar no tempo como apresentado na Figura 5-20c. 


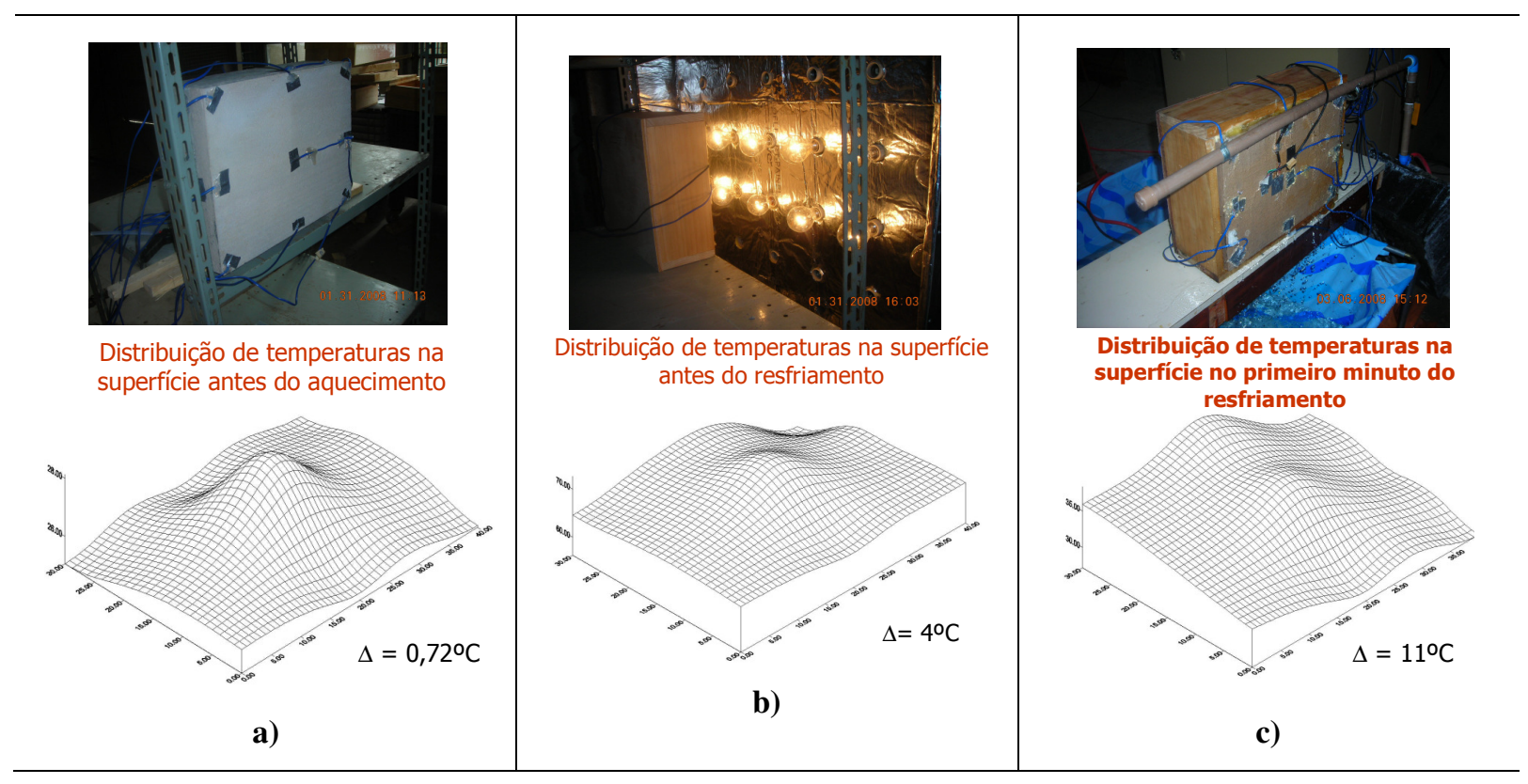

Figura 5-20: Diferenças de temperatura superficial do corpo de prova a temperatura ambiente (a), no momento do aquecimento (b) e após um minuto do resfriamento (c).

\subsection{Parâmetros de Controle do ensaio}

Os parâmetros controlados nos ciclos de choque térmico foram a temperatura atingida na superfície do revestimento e o tempo de duração de cada um dos períodos do ensaio (aquecimento, resfriamento e espera entre um ensaio e outro).

No programa experimental piloto o controle desses parâmetros foi realizado manualmente e mostrou-se ineficiente devido às variações atingidas entre um ciclo e outro seja quanto aos tempos de início e fim do ensaio seja quanto às temperaturas superficiais máximas atingidas;por isto, foi decidida sua automação para a etapa do programa experimental definitivo.

Para automatizar esse controle foi desenvolvido um equipamento de liga/desliga composto por um relé programável, um contator elétrico conectado a um controlador de temperatura e um temporizador que comandavam o funcionamento do quadro do painel utilizado para o aquecimento (Figura 5-21a).

A configuração do funcionamento do sistema através do relé programável permitiu gerar um programa em que os parâmetros de temperatura, tempo de ensaio e inclusive número de ciclos podem ser modificados facilmente.

Os parâmetros de configuração do programa utilizado são: a temperatura máxima atingida e seus limites de erro, também configuráveis; o tempo de duração do 
período de aquecimento; a duração do período de resfriamento; e o número de ciclos para o ensaio, considerando o ciclo como um período de aquecimento e um período de resfriamento (4 horas), conforme pode ser apreciado na Figura 5-21b.

A Figura 5-21c mostra o sistema de controle automático de temperaturas em operação junto ao sistema de aquisição de sinais.

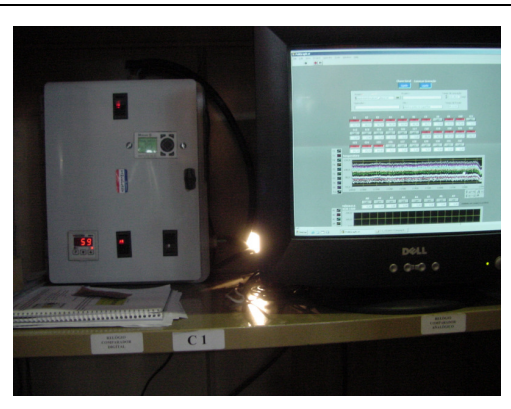

a)

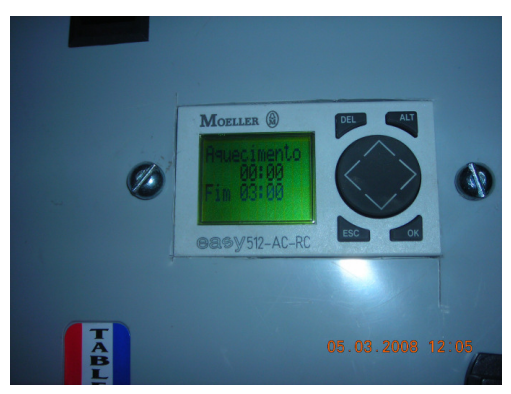

b)

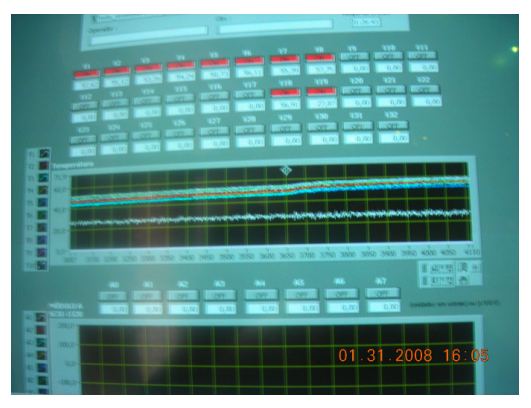

c)

Figura 5-21: Equipamentos de controle da temperatura nos corpos de prova

O controlador de temperatura monitora as temperaturas atingidas na superfície do revestimento empregando-se, para isto, um termopar independente do termopar do sistema de aquisição que também foi colado na superfície de um dos corpos de prova. O controle dos limites de temperatura no aquecimento foi configurado para manter ligado o sistema enquanto a temperatura no termopar de controle não ultrapassasse $70+2^{\circ} \mathrm{C}$. O mesmo deveria ligar o sistema se a temperatura atingisse $70-2^{\circ} \mathrm{C}$.

Quando o ensaio atingia 3 horas do ciclo de aquecimento o sistema era desligado automaticamente, sendo iniciado o período de resfriamento cuja duração era de 1 hora. Após o termino do ciclo foi definido um período de descanso que dependia do tempo que o corpo de prova necessitava para atingir o equilíbrio térmico nas condições iniciais do ensaio.

O controle da temperatura da água de resfriamento foi realizado somente nos primeiros ensaios, coletando água do sistema de água do laboratório em um reservatório, porém ela não foi constante ao longo dos trinta ciclos de ensaio devido a que dependia da temperatura ambiente variando dos $21^{\circ} \mathrm{C}$ até os $24^{\circ} \mathrm{C}$.

\subsection{Produção dos corpos de prova do revestimento}

A forma de produção dos revestimentos de argamassa é um fator de influência na aderência potencial do revestimento. Fatores como o preparo da base, a forma de 
mistura da argamassa, a forma de aplicação sobre o substrato, o acabamento superficial dado ao revestimento e a sua forma de cura fazem parte do processo de produção dos revestimentos e não podem ser negligenciados.

De acordo como o objetivo desta tese, esses fatores não fazem parte das variáveis de análise e para tanto foram adotados procedimentos padronizados na produção dos corpos de prova pautados nos resultados de pesquisas que estudaram a influencia desses fatores na aderência dos revestimentos, selecionando os procedimentos que ajudassem a maximizar essa aderência.

\subsubsection{Preparo do substrato}

A produção dos substratos foi padronizada conforme explicado em 5.4.1, de forma a obter características superficiais e de absorção capilar (Figura 5-22) semelhantes as do substrato padrão conforme especificado na norma ABNT NBR 14082 (1998).

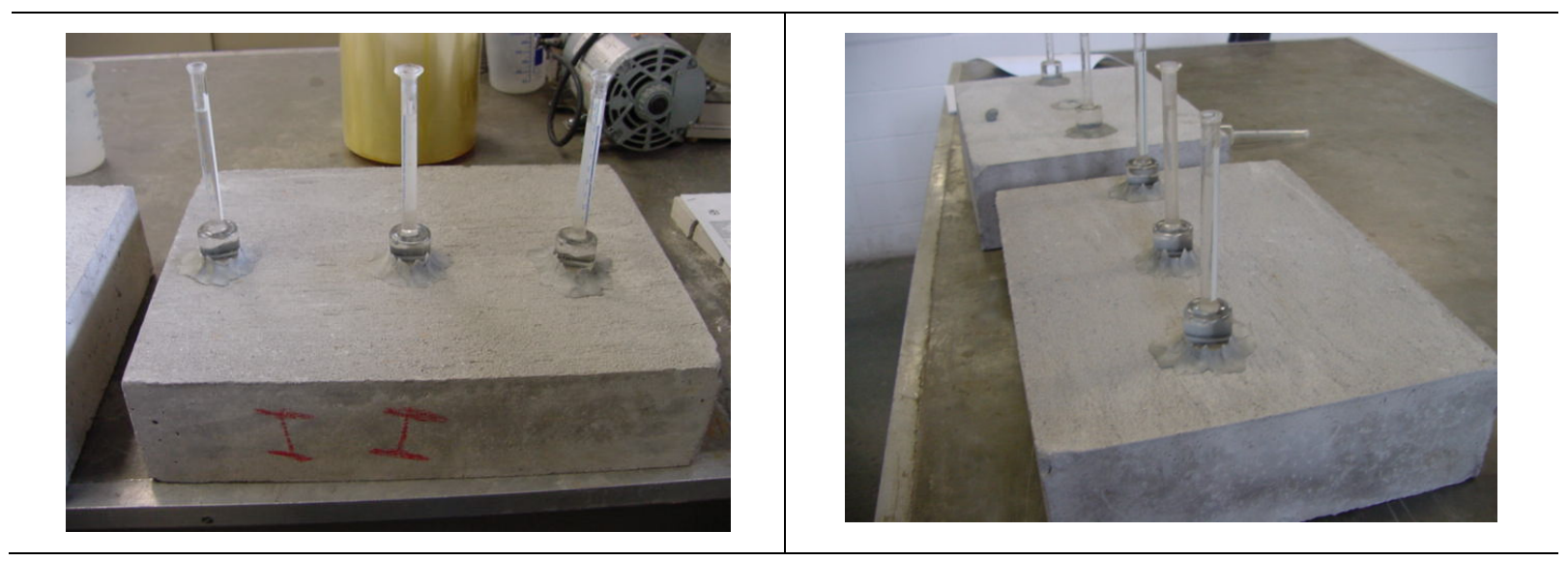

Figura 5-22: Ensaios de absorção capilar na superfície dos substratos

Antes da aplicação da argamassa, as faces dos substratos que seria revestida e aquelas onde foi aplicada a tinta para simulação dos macro-defeitos de interface foi limpa com escova de aço. Esses últimos substratos foram guardados após a aplicação da tinta para evitar sujidades na superfície a ser revestida.

Para garantir a obtenção da espessura definida de $30 \mathrm{~mm}$ foi confeccionado um gabarito de madeira e fixado nas laterais do substrato antes da aplicação da argamassa, conforme pode ser apreciado na Figura 5-23a.

Para melhor reproduzir as características de restrição à livre movimentação do revestimento moldado, foi aplicado chapisco industrializado na superfície interna dos gabaritos de todos os corpos de prova. Este procedimento visou promover a 
aderência do revestimento às laterais do gabarito (Figura 5-23 b), de modo que se restringisse o potencial de retração do revestimento.

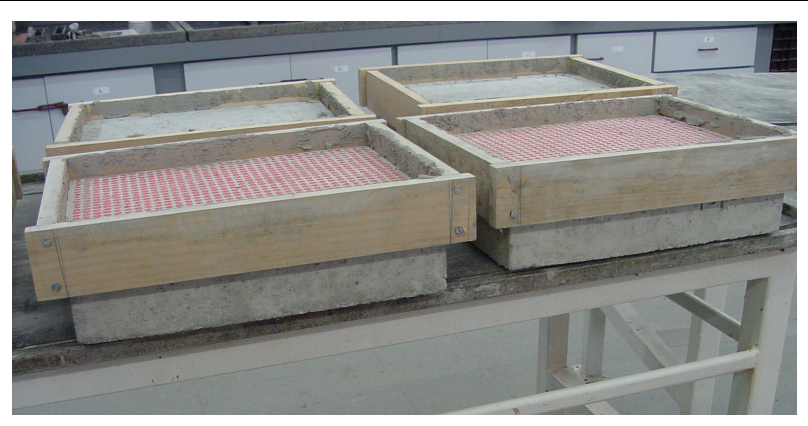

a)

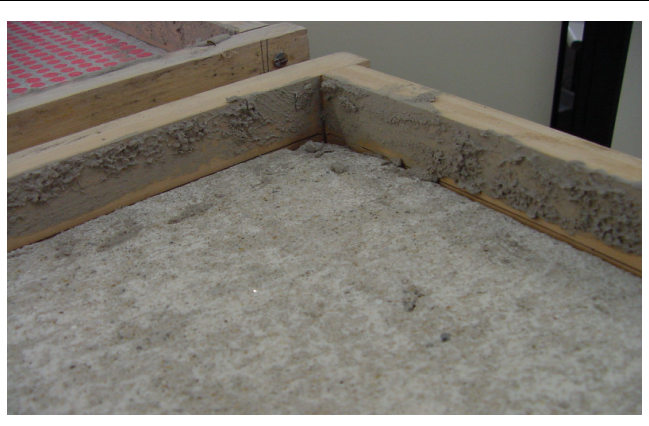

b)

Figura 5-23: Gabarito para aplicação do revestimento e chapisco no gabarito lateral do revestimento

\subsubsection{Mistura da argamassa para revestimento}

A, mistura da argamassa foi realizada com controle da seqüência e tempo de mistura, bem como, da quantidade de água utilizada. De acordo com as recomendações de Antunes (2005) para a seqüência de mistura, foram colocados, em primeiro lugar, os materiais secos (Figura 5-24a) e, posteriormente, a água correspondente ao teor de $16 \%$ em relação à massa seca (Figura 5-24b).

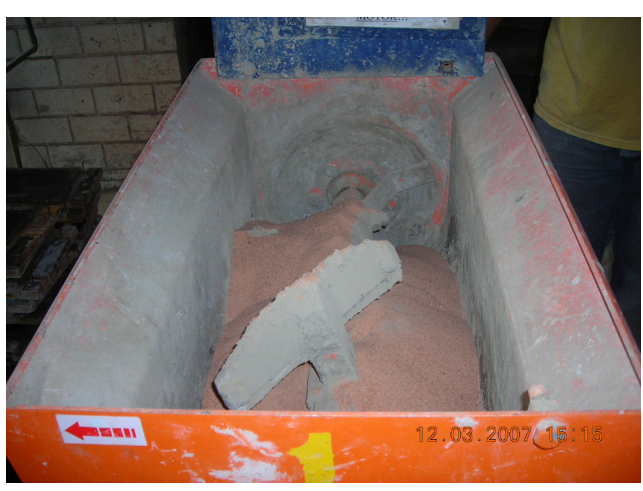

a)

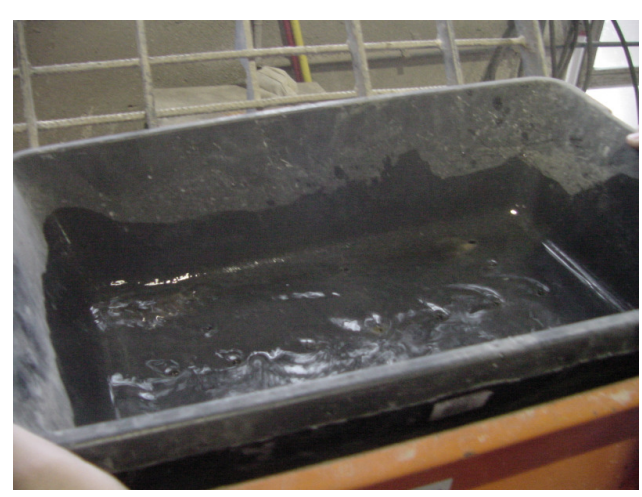

b)

Figura 5-24: a) Colocação dos materiais secos na argamassadeira e b) colocação e bandeja perfurada para adição da água.

Para definição do teor de água foram realizados testes preliminares com o propósito de avaliar as características reológicas da argamassa empregando-se o ensaio de squeeze-flow, descrito por Cardoso, Pileggi e John (2005).

Segundo esses autores, o ensaio simula o lançamento da argamassa no substrato e a posterior compressão realizada pelo pedreiro, e consiste na aplicação de um 
carregamento de compressão uniaxial sobre uma amostra cilíndrica de argamassa no estado fresco entre duas placas paralelas. Avaliando o deslocamento vertical da amostra em função do carregamento aplicado é possível comparar, dentre outros parâmetros, o comportamento da argamassa para diferentes teores de água.
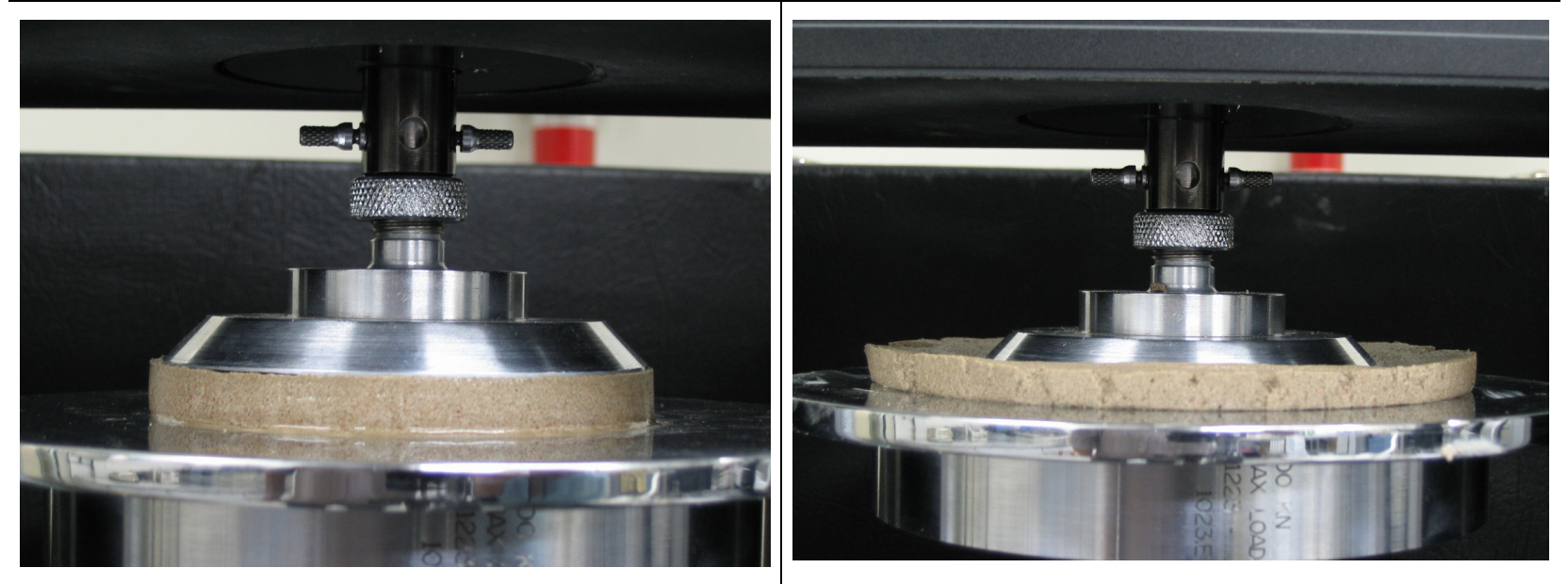

Figura 5-25: Ensaio de squeeze-flow na definição do teor de água para as argamassas.

A seqüência de mistura dos materiais e o tempo utilizado para a mesma foram os recomendados por Antunes (2005) e são mostrados na Figura 5-26:

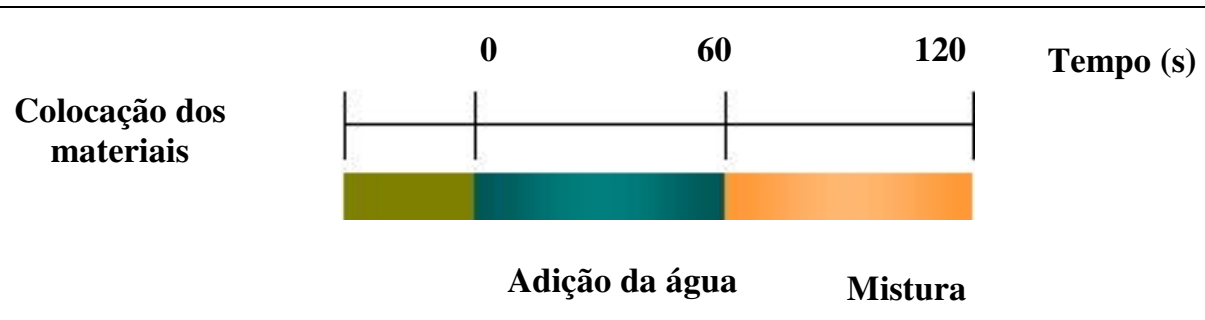

Figura 5-26: Tempo utilizado na seqüência de mistura da argamassa

Para manter uma vazão constante de água na mistura foi utilizada uma bandeja perfurada (Figura 5-24b) na qual era despejada toda a água e contabilizado o tempo que demorava em vazar pela bandeja, sendo obtida uma vazão de 74,3 g/s.

\subsubsection{Aplicação da argamassa no substrato}

O processo de aplicação também é um fator condicionante na obtenção da máxima aderência; portanto, a escolha do procedimento de aplicação evitou a aplicação 
manual, para não introduzir variáveis fora do controle na produção dos corpos de prova. De forma a padronizar a aplicação da argamassa foi selecionada a projeção mecânica com spray a ar comprimido que além de compatível com as práticas utilizadas em canteiros de obra, conforme destacado por Fernandes et al. (2007), também permite um melhor controle da energia de aplicação e aumento da produtividade, com resultados favoráveis na resistência de aderência em relação à aplicação manual, conforme avaliado em trabalho de Duailibe, Cavani e Oliveira (2005).

Após a mistura da argamassa foi realizado seu transporte até o lugar da aplicação. A argamassa foi projetada sobre os substratos posicionados na horizontal (Figura 5-27a) com equipamento de projeção marca Anvi, com pressão constante de 100 psi.. No programa experimental piloto a projeção foi realizada com os substratos na posição vertical; entretanto, depois da avaliação dos resultados de resistência de aderência daqueles corpos de prova, optou-se pela posição horizontal (Figura 5-27a) para se potencializar a aderência, evitando-se a influência negativa da gravidade no resultado final.

Como pode ser observado também na Figura 5-27b teve-se o cuidado de se proteger os corpos de prova adjacentes àquele em que era realizada a projeção.

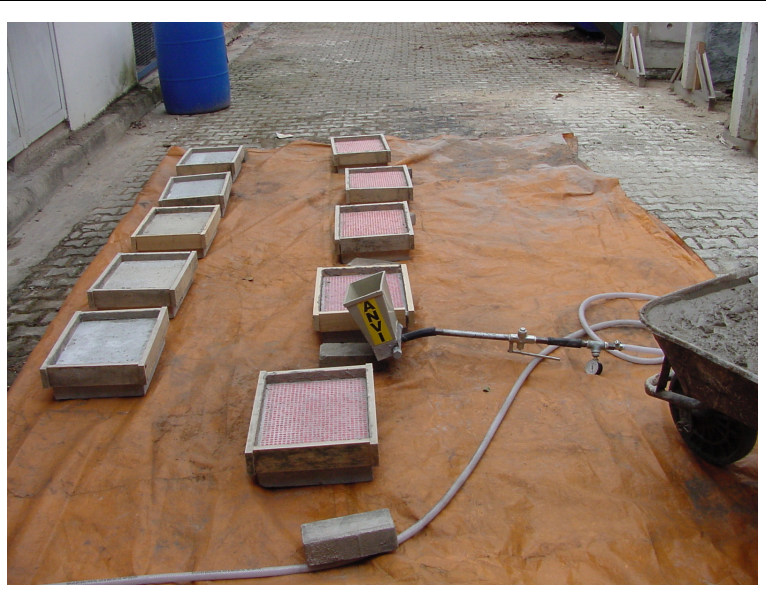

a)

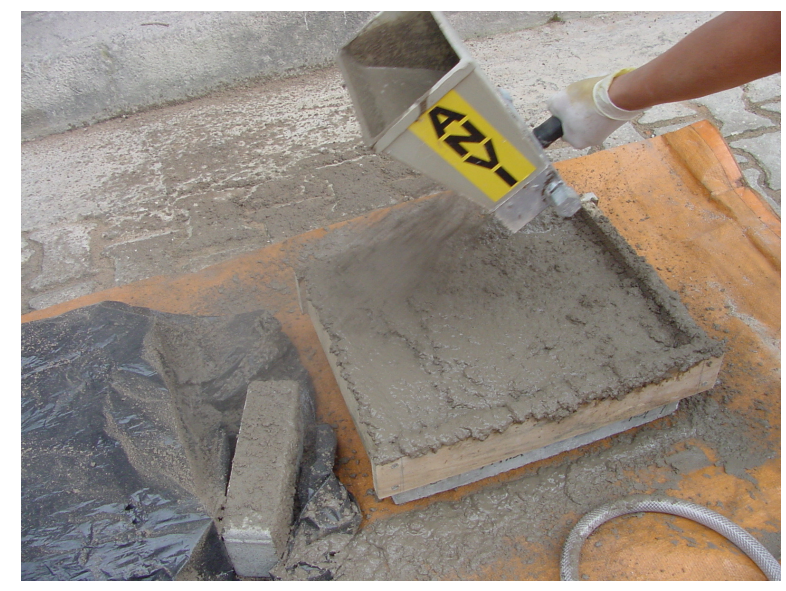

b)

Figura 5-27: Transporte (a) e projeção de argamassa e (b) proteção dos corpos de prova adjacentes

\subsubsection{Acabamento superficial do revestimento}

De acordo com o objetivo desta tese a avaliação é focada na aderência da interface base-revestimento, razão pela qual a resistência superficial do revestimento deveria 
ser maximizada para evitar rupturas na superfície do revestimento. Para isto, foi necessário escolher a técnica de acabamento superficial mais apropriada, sendo o acabamento desempenado o recomendado, segundo o trabalho de Temoche et al. (2005). Desta forma, após o período de puxamento da argamassa, todas os corpos de prova foram desempenados utilizando desempenadeira de madeira (Figura 5-28).

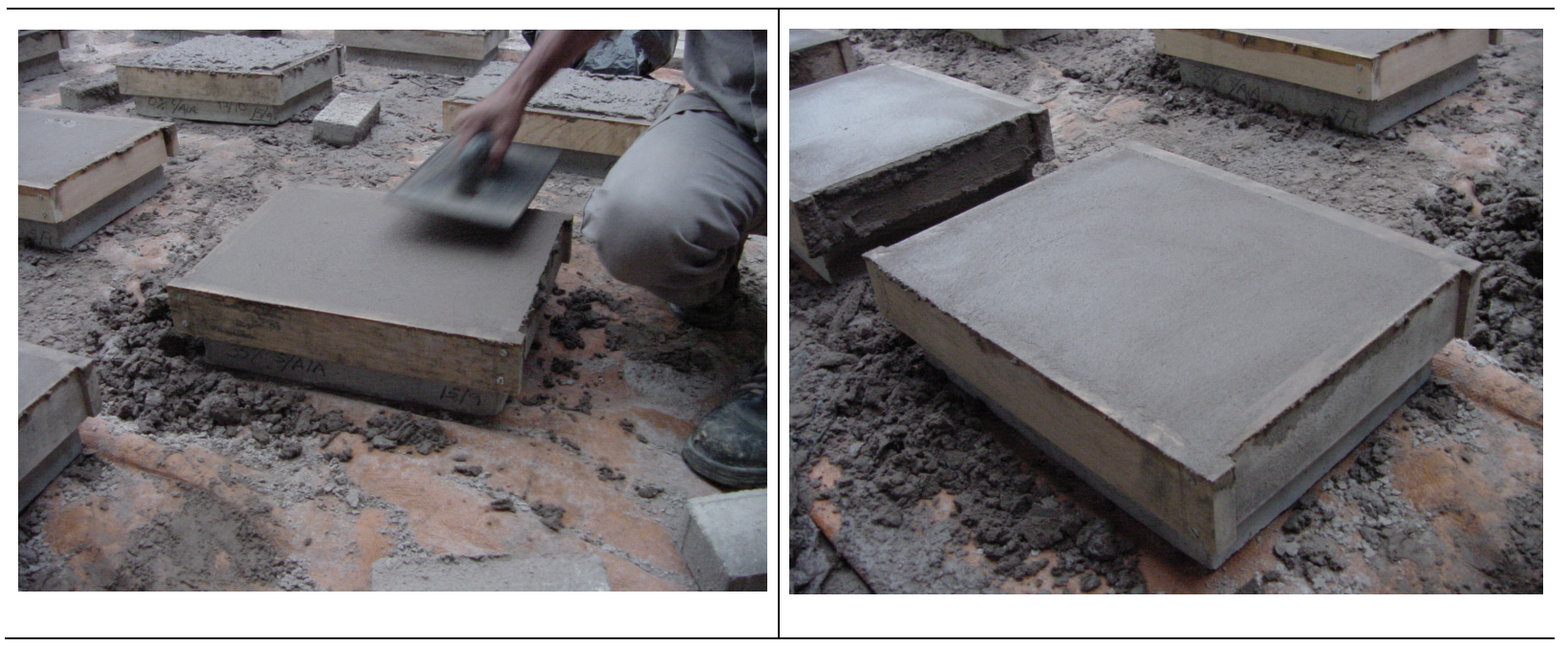

Figura 5-28: Acabamento superficial dos corpos de prova empregando-se desempenadeira de madeira.

\subsubsection{Cura do revestimento}

O processo de secagem do revestimento de argamassa é também um fator relevante no desenvolvimento das suas propriedades mecânicas, conforme destacado por Coutinho (1954), Veiga (2001) e Bastos (2001) dentre outros autores.

Desta forma para otimizar as condições ambientais durante a secagem do revestimento, os corpos de prova foram cobertos com plástico (Figura 5-29a) para evitar perda de água e levados à câmara úmida durante 28 dias para garantir seu estado de saturação na temperatura de 23ํㅡ (Figura 5-29b). 


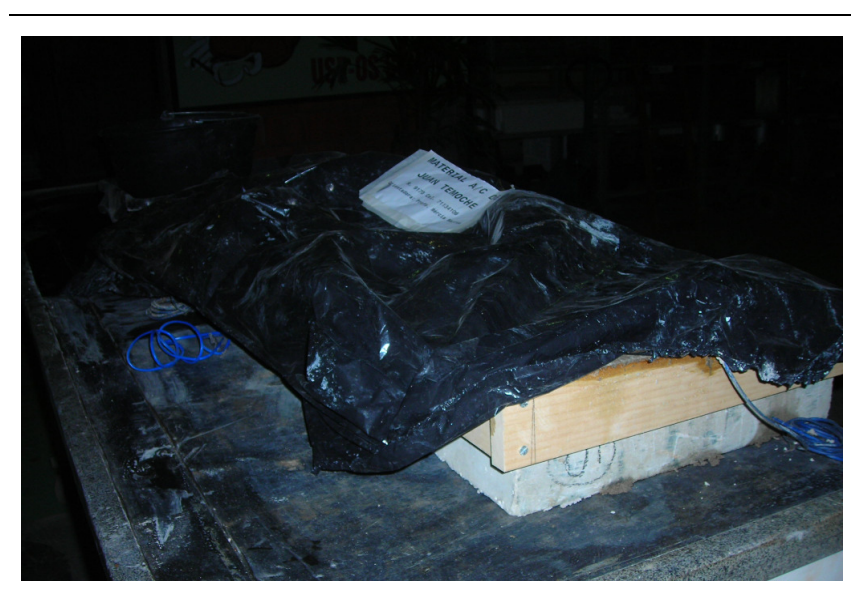

a)

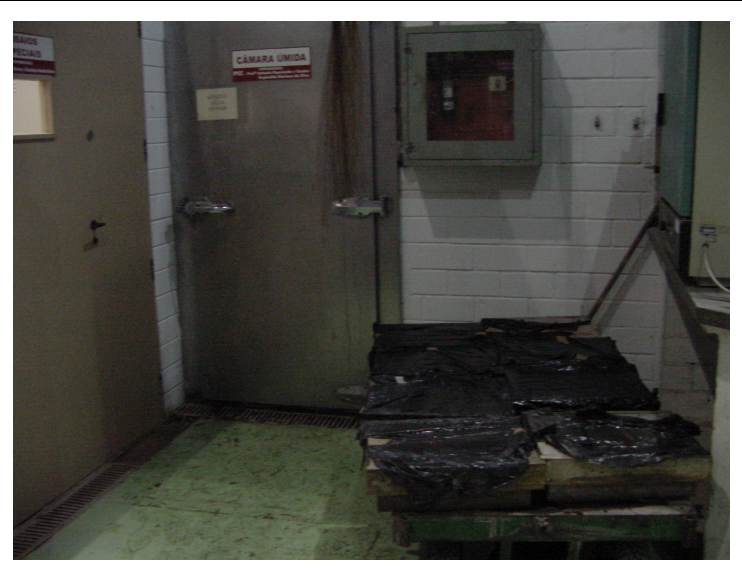

b)

Figura 5-29: Condições de secagem dos corpos de prova: a) filme de polietileno cobrindo a superfície do revestimento; (b) porta de entrada da câmara úmida em que serão acondicionados os corpos de prova durante 28 dias.

Após os 28 dias, os corpos de prova foram colocados no laboratório em condições de temperatura e umidade controladas até o início dos ensaios de choque térmico.

A partir da análise dos resultados do programa experimental piloto foi levantada a hipótese de que o choque térmico poderia estar auxiliando na cura dos corpos de prova ensaiados introduzindo a variável do ganho de resistência mecânica devido à exposição ao aumento de temperatura.

A relação entre temperatura, tempo e aceleração do ganho de resistência em materiais cimentícios tem sido estudada por Carino e Tank (1992) e também por Camarini e Cincotto (1995).

Utilizando o conceito de "tempo equivalente" introduzido por Carino e Tank (1992) é possível converter um intervalo de cura a qualquer temperatura a um intervalo equivalente na temperatura de referência. Assim, foram calculados o tempo e a temperatura necessários para atingir o ganho de "maturidade" provocado pelos choques térmicos nos corpos de prova ensaiados. Esse período resultou em 96 horas à temperatura de $40^{\circ} \mathrm{C}$ (Figura 5-30). Desta forma, todos os corpos de prova de referência foram colocados em caixas plásticas com água em câmara térmica durante 4 dias à temperatura de $40^{\circ} \mathrm{C}$, no mesmo período em que os corpos de prova submetidos ao choque térmico eram ensaiados. 


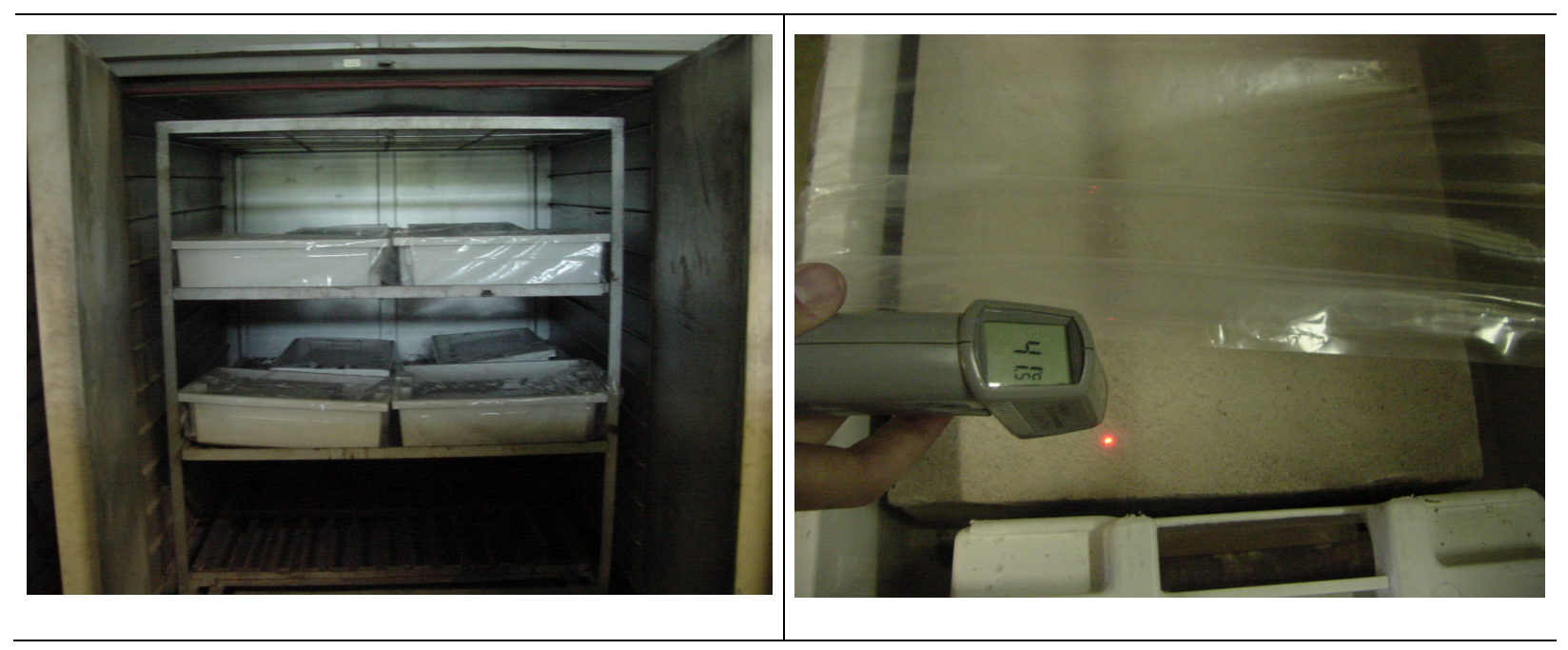

Figura 5-30: Cura térmica dos corpos de prova de referência

\subsubsection{Instrumentação dos corpos de prova}

Para a aquisição dos dados de temperatura ao longo dos ensaios de choque térmico, no programa definitivo foram colados termopares tipo "T" na superfície do revestimento (Figura 5-31a), na sua interface base-revestimento e na face posterior dos corpos de prova (substrato de concreto). Os termopares da interface baserevestimento foram colocados imediatamente antes da realização do ensaio de choque térmico; portanto, após o endurecimento do revestimento. Para isto, utilizouse uma furadeira com broca de comprimento maior do que $10 \mathrm{~cm}$. Este procedimento foi alterado em relação ao programa experimental piloto porque lá se verificou a influência negativa na aderência do cabo do termopar que era estendido desde a borda até o centro do corpo de prova.

Os demais termopares foram fixados da mesma forma que no programa experimental piloto.

Para evitar a interferência da água nas leituras de temperatura no período de resfriamento com água, optou-se por proteger as bordas da fita adesiva usada para colar os termopares com silicone resistente à temperatura (Figura 5-31b). 


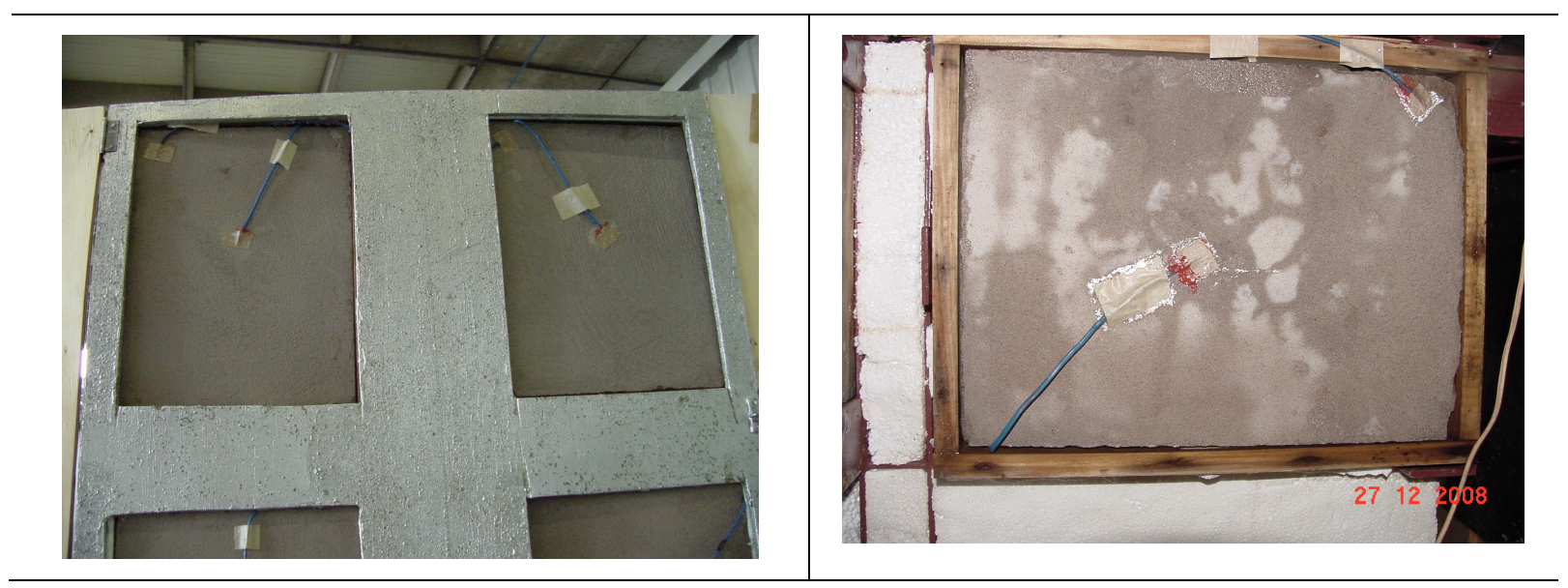

Figura 5-31: Termopares colados na superfície do revestimento (a) e detalhe da proteção à passagem de água nas bordas da fita adesiva utilizadas.

\subsection{Métodos de ensaio selecionados}

\subsubsection{Caracterização dos materiais}

Os materiais constituintes da argamassa foram caracterizados no estado anidro, fresco e no estado endurecido. A Tabela 5-4 apresenta o resumo dos ensaios utilizados para caracterização das argamassas.

Tabela 5-4: Ensaios de caracterização dos materiais utilizados e do revestimento

\begin{tabular}{|c|c|c|c|}
\hline Material & Ensaio & № de repetições & Referência normativa \\
\hline & Estado anidro & & \\
\hline \multirow{2}{*}{ Cimento } & Massa específica & 3 & NBR NM 23/01 \\
\hline & Granulometria a laser & & \\
\hline \multirow{3}{*}{ Areia } & Massa unitária & 3 & NBR7251 ABNT, 1982) \\
\hline & Massa específica & 3 & Picnometria \\
\hline & Granulometria a laser & & \\
\hline & Estado Fresco & & \\
\hline \multirow{4}{*}{ Argamassa } & Squeeze flow & 1 & (MIN; ERWIN, JENNINGS, 1994) \\
\hline & Densidade de massa & 3 & NBR 13278 (ABNT, 2005) \\
\hline & Retenção de água - & & NBR 13277 (ABNT, 2005) \\
\hline & $\begin{array}{l}\text { Determinação do teor de ar } \\
\text { incorporado - }\end{array}$ & 3 & NBR 13278 (ABNT, 2005) \\
\hline & Estado endurecido & & \\
\hline \multirow{7}{*}{$\begin{array}{l}\text { Argamassa de } \\
\text { revestimento }\end{array}$} & Resistência à tração na flexão & 6 & NBR 13279 (ABNT, 2005) \\
\hline & Resistência à compressão & 6 & NBR 13279 (ABNT, 2005) \\
\hline & $\begin{array}{l}\text { Módulo de Elasticidade - Método } \\
\text { do ultrasom - }\end{array}$ & 6 & BS 1881 Part:209 (BSI, 1990) \\
\hline & $\begin{array}{l}\text { Densidade de massa aparente no } \\
\text { estado endurecido - }\end{array}$ & 3 & NBR 13280 (ABNT, 2005) \\
\hline & Coeficiente de dilatação térmica & 3 & (ASTM C531, 2000) \\
\hline & Coeficiente de poisson - & 3 & ASTM E132 (ASTM 2004) \\
\hline & Termogravimetria & 1 & \\
\hline \multirow{2}{*}{ Revestimento } & Resistencia de aderência à tração & 6 & NBR15258 (ABNT, 2005) \\
\hline & Choque térmico & 30 & \\
\hline
\end{tabular}


O ensaio de termogravimetria $(\mathrm{TG})^{9}$ foi realizada para obter informações sobre a composição e estabilidade da argamassa endurecida comparando as amostras que foram submetidas ao choque térmico com as amostras de referência após a elevação de temperatura. Procurou-se verificar se na faixa de temperatura em que se produz o choque térmico ocorre dissociação térmica de alguma espécie química dentro das argamassas.

\subsubsection{Ensaios cíclicos de choque térmico}

O número de ciclos definido para os ensaios de choque térmico foi de 30 , em coincidência com a recomendação normativa da EN 13687-2.

Após a verificação do tempo necessário para restabelecimento das condições iniciais de temperatura nos corpos de prova, principalmente na interface baserevestimento, foi definida a realização de pelo menos dois ciclos de choque térmico por dia. A possibilidade de atingir a temperatura inicial do ensaio na interface foi favorecida pela aceleração da perda de calor provocada pela câmara de isolamento na face posterior dos corpos de prova conectada ao equipamento de ar condicionado, como pode ser apreciado na Figura 5-32a e também pela ventilação promovida na superfície dos corpos de prova após finalização de cada ciclo como pode ser observado na Figura 5-32b.

A ventilação mecânica promovida na superfície dos corpos de prova foi realizada de maneira a distribuir o tempo de ventilação em cada corpo de prova de forma homogênea durante o período de uma hora.

\footnotetext{
${ }^{9}$ A termogravimetria (TG) é uma técnica de análise térmica bastante empregada que consiste em aquecer (ou resfriar) uma amostra a uma taxa geralmente constante, e medir a variação de sua massa. No experimento proposto foi utilizada uma termobalança Nezstch TG 209 (LM).
} 


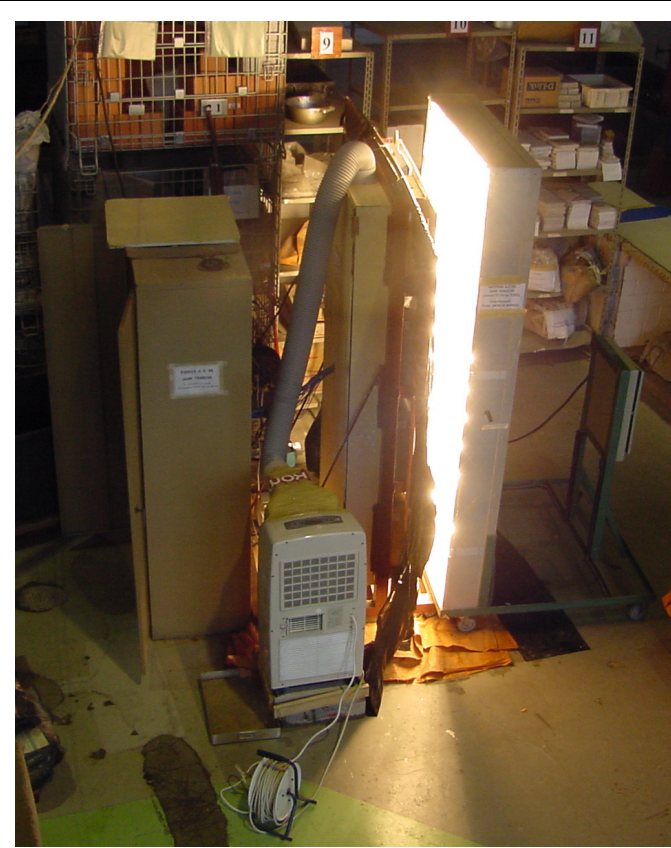

a)

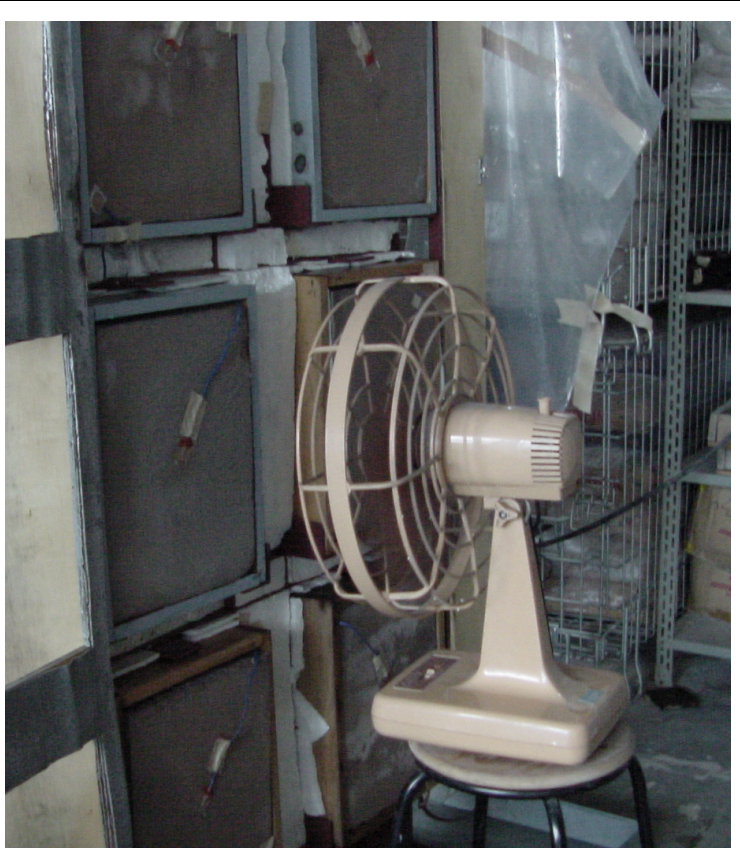

b)

Figura 5-32: (a) Ensaio do choque térmico com resfriamento da câmara isolante; (b) e aceleração da secagem superficial por convecção

\subsubsection{Ensaios de avaliação da resistência de aderência}

A influência dos ciclos de choque térmico na aderência do revestimento foi avaliada através de ensaios de resistência de aderência à tração normal, de acordo com a ABNT NBR 13528 (1995), após cada conjunto de ensaios cíclicos, isto é, após os 30 ciclos, deixando-se os corpos de prova em repouso por mais um dia antes do inicio dos ensaios de resistência de aderência.

Cabe destacar que nos corpos de prova de referência (não submetidos ao choque térmico), em mesmo número que os corpos de prova ensaiados, os ensaios de resistência de aderência foram realizados na mesma data.

\subsubsection{Corte do revestimento para o ensaio de resistência de aderência}

Foram realizados cortes com uma serra copo de $50 \mathrm{~mm}$ de diâmetro a qual foi adaptada a uma furadeira de bancada fixada em suporte vertical como pode ser observado na Figura 5-33a. Para padronizar os cortes e evitar os macro-defeitos de corte que pudessem ser causados pelo atrito durante a operação, foi utilizado um aspirador de pó durante todo o tempo do corte. 


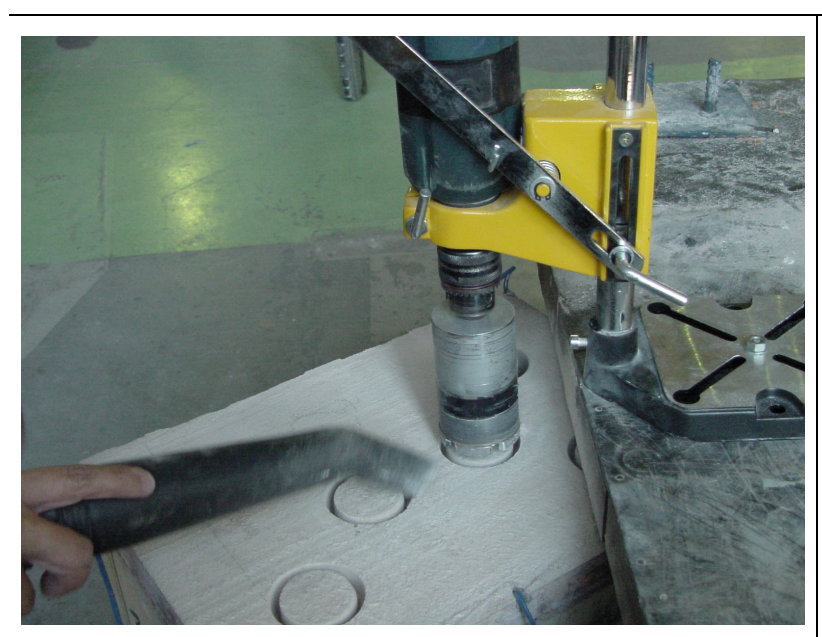

a)

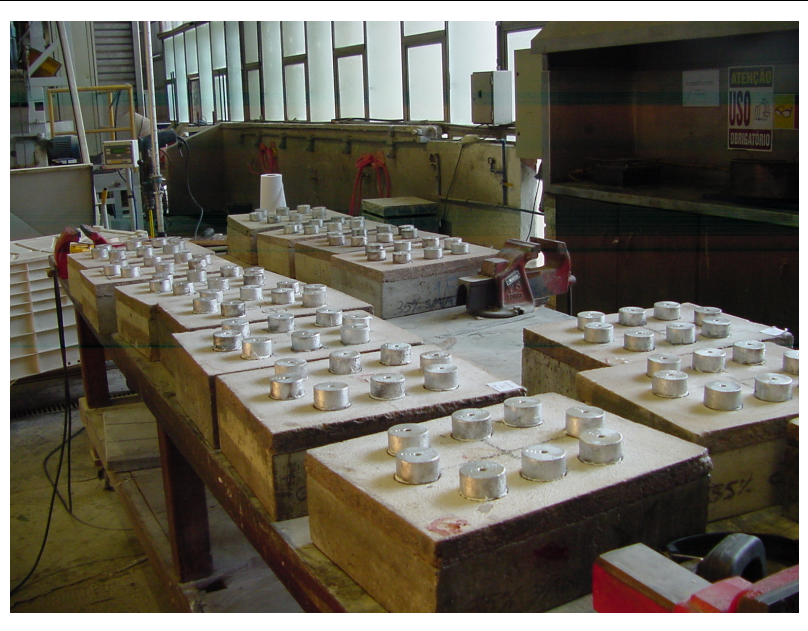

b)

Figura 5-33: (a) Corte dos corpos de prova com aspiração dos resíduos; e (b) colagem das pastilhas de alumínio.

Depois de realizados os cortes no revestimento as pastilhas de alumínio utilizadas no ensaio foram coladas com adesivo de poliéster deixando secar até o dia seguinte.

\subsubsection{Avaliação da resistência de aderência}

A realização dos ensaios de resistência de aderência à tração foi feita de acordo com as recomendações da ABNT NBR 13528 (1995) sendo registradas as informações de carga de ruptura, diâmetro da seção do cilindro extraído no arrancamento e forma de ruptura (adesiva ou coesiva).

$\mathrm{Na}$ Figura 5-34a é mostrada a forma de realização do ensaio em ambiente de laboratório e na Figura 5-34b são mostrados corpos de prova após o ensaio.

Cabe destacar que os ensaios foram realizados a seco e para determinar o teor de umidade médio das placas foram utilizados os cilindros de argamassa extraídos dos arrancamentos sendo separada imediatamente a parte da pastilha de alumínio colada e levados o restos de revestimento em sacos plásticos vedados até a câmara térmica. Antes da sua colocação na mesma foi registrada a massa de cada corpo de prova. Este procedimento foi repetido durante vários dias até encontrar Constancia de massa. Desta forma foi determinado o teor de umidade do revestimento no momento do ensaio. 


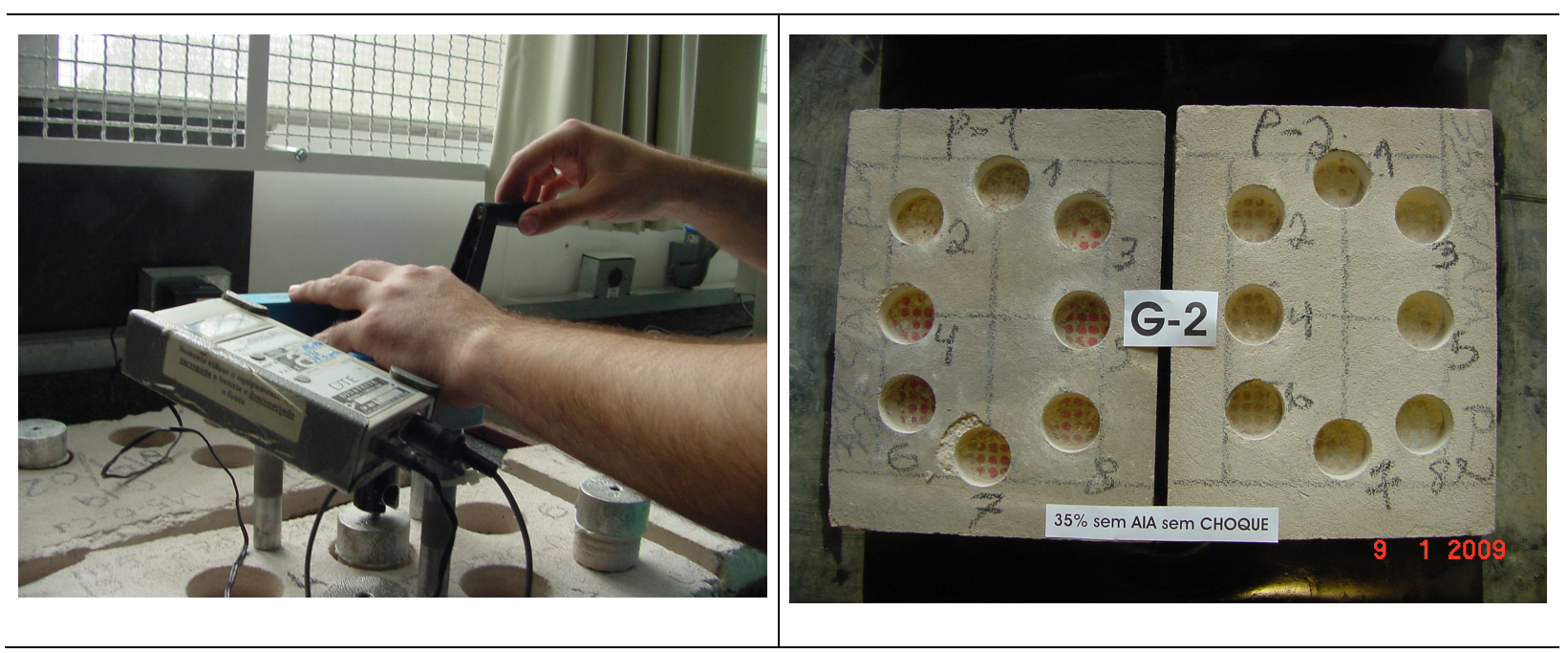

Figura 5-34: Realização do ensaio de resistência de aderência à tração (a) e registro da forma de ruptura (b) 


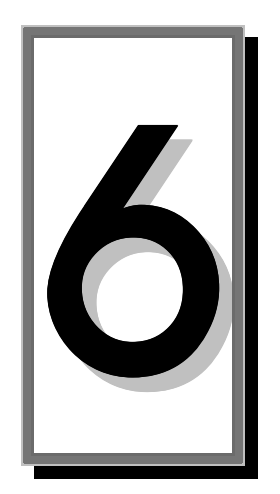

\section{APRESENTAÇÃO E ANÁLISE DE RESULTADOS}

Neste capítulo são apresentados os resultados das simulações computacionais e dos ensaios do programa experimental realizados. A discussão dos resultados da modelagem é realizada na seqüência da sua apresentação. Para a análise dos resultados obtidos na parte experimental e os efeitos dos fatores avaliados foi realizada a análise de variância (ANOVA).

A análise inicial é feita em relação a cada fator avaliado para, posteriormente, identificar a sinergia entre estes fatores, identificando-se aqueles que têm mais influência na degradação da resistência de aderência dos revestimentos de argamassa.

\subsection{Simulações computacionais}

Conforme destacado no capítulo 4, os resultados das simulações computacionais ajudaram na identificação das variáveis de maior influência no estado de tensões térmicas e deram suporte para a definição da geometria dos corpos de prova do programa experimental.

De acordo com os modelos de tensões térmicas apresentados nos capítulos 2 e 3 tanto o módulo de elasticidade como o coeficiente de dilatação térmica dos materiais analisados exercem influência no aumento das tensões, bem como a variação de temperatura a que são submetidos. Somados a esses fatores, Ignatiev e Chatterji (1992), Fiorito (1994) e Bortoluzzo (2000) destacam também a influência da espessura do revestimento no nível de tensões térmicas atingido, pelo que inicialmente foi avaliado também esse fator. 
Para as condições de contorno simuladas nos modelos numéricos detalhadas no capítulo 4 (4.3.3.3 e 4.3.4.3), a variação de temperatura foi promovida na face externa do revestimento $\left(70^{\circ} \mathrm{C}\right)$ enquanto que a face oposta do modelo simulado manteve-se com temperatura fixa $\left(20^{\circ} \mathrm{C}\right)$. Quanto ao coeficiente de dilatação térmica observou-se que tanto a base de concreto como o revestimento de argamassa possuem valores de coeficiente de dilatação térmica próximos dependentes do tipo de agregados utilizados, pelo que a diferença dentre eles foi mantida constante em todas as simulações. Os fatores variados foram o módulo de elasticidade da argamassa, a espessura do revestimento e a taxa de macro-defeitos na interface base-revestimento, conforme as propriedades descritas na Tabela 4-1 e Tabela 4-2 do capítulo 4.

\subsubsection{Variáveis de influência no desenvolvimento das tensões térmicas no revestimento}

Para se ter uma idéia de como as simulações auxiliaram na identificação das principais variáveis, apresenta-se, na seqüência, os tipos de resultados gráficos que se obteve, os quais serão posteriormente utilizados para as análises dessas variáveis.

Para a simulação do perfil térmico considerou-se uma distribuição linear de temperatura através da espessura do revestimento. Na Figura 6-1 é mostrado o perfil de temperaturas no conjunto base-revestimento em modelo $2 D$ e $3 D$, diferenciando as faixas de temperatura através das cores apresentadas.

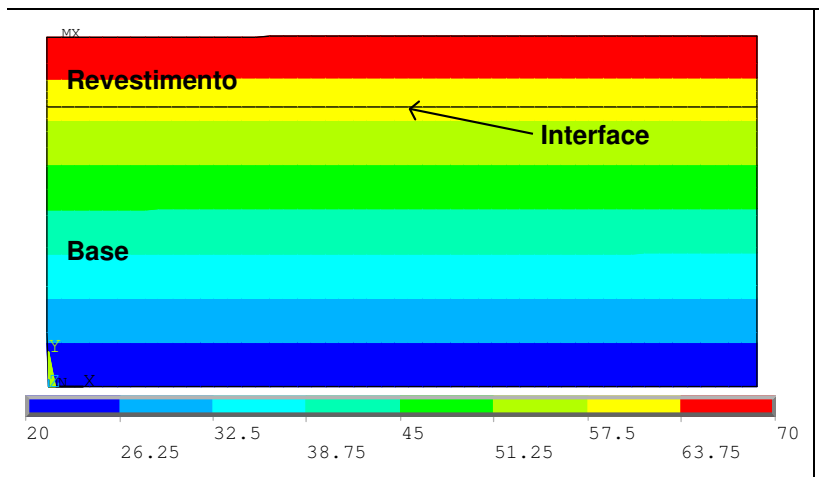

a)

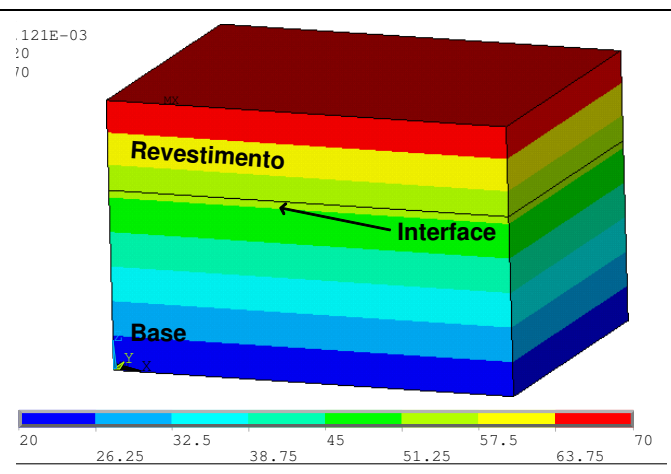

b)

Figura 6-1: Distribuição de temperaturas em modelos 2D e 3D para: a) revestimento com $E=2 G P a$ e b) revestimento com $\mathrm{E}=15 \mathrm{GPa}$.

Como o painel simulado representa uma parte de um revestimento com uma superfície muito maior, foi possível assumir as laterais do painel perfeitamente 
isoladas, sem perdas ou ganhos de calor. Assim sendo, a distribuição de temperaturas é independente do comprimento e da largura do corpo de prova.

Analisando o gradiente de temperatura produzido entre a superfície do revestimento e sua interface com a base (Figura 6-2), verifica-se que com o aumento da espessura (de $25 \mathrm{~mm}$ a $50 \mathrm{~mm}$ ) o gradiente produzido aumenta em cerca de $60 \%$, promovendo também um incremento proporcional na resistência térmica do revestimento. Todavia o aumento da espessura do revestimento pode-se tornar em fator negativo na aderência do revestimento à base, como destacado no capítulo 2 . Por outro lado constatou-se também que a variação do módulo de elasticidade não teve influência nenhuma no gradiente analisado.

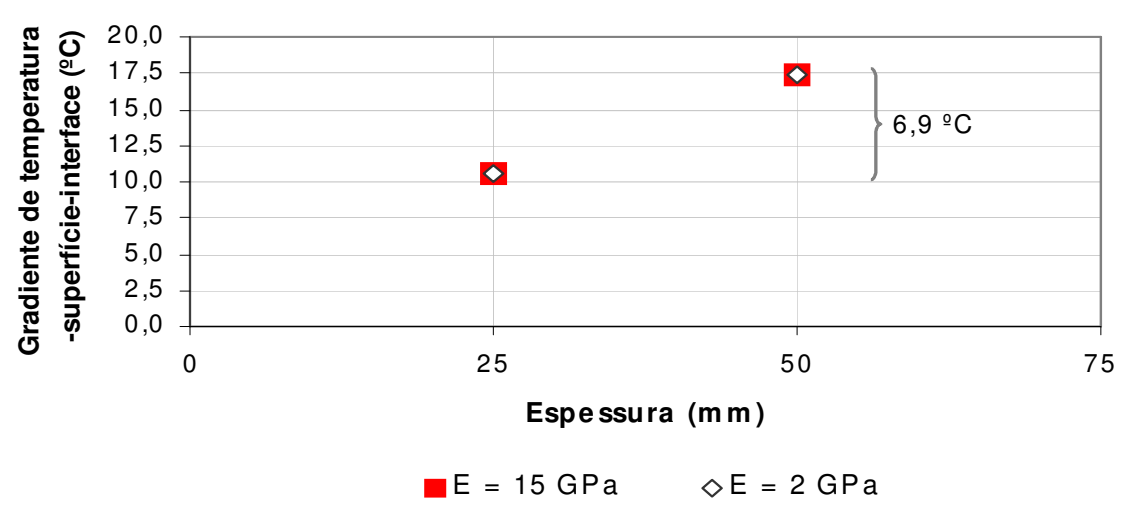

Figura 6-2: Variação do gradiente temperatura entre a superfície do revestimento e sua interface com a base em função da espessura do revestimento.

A partir dessa distribuição de temperaturas e condições de contorno definidas, foi calculada a distribuição de tensões no bloco modelado tanto no modelo bidimensional como no tridimensional. Visto que o foco do trabalho está na avaliação do efeito das tensões na aderência do revestimento, em ambos os modelos foram destacadas as tensões normais ao plano da interface base-revestimento e as de cisalhamento no mesmo plano.

Na Figura 6-3 é apresentado o resultado gráfico em 2D da distribuição de tensões para dois blocos com revestimentos de módulos de elasticidade de 2GPa e 15GPa e espessura constante $(25 \mathrm{~mm})$. Em ambos os gráficos é representada uma das metades do bloco cortado no eixo de simetria (centro). A variação de tensões é representada através de cores, sendo a cor azul indicativa das máximas tensões de compressão e a vermelha indicativa das máximas tensões de tração no bloco simulado. 


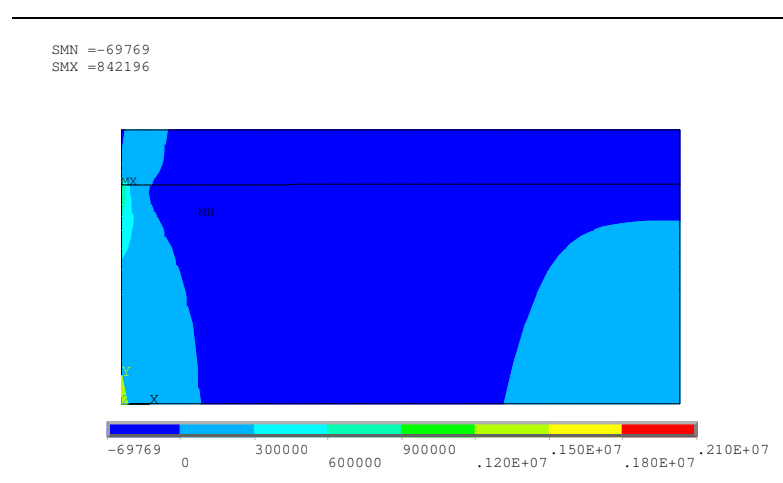

a)

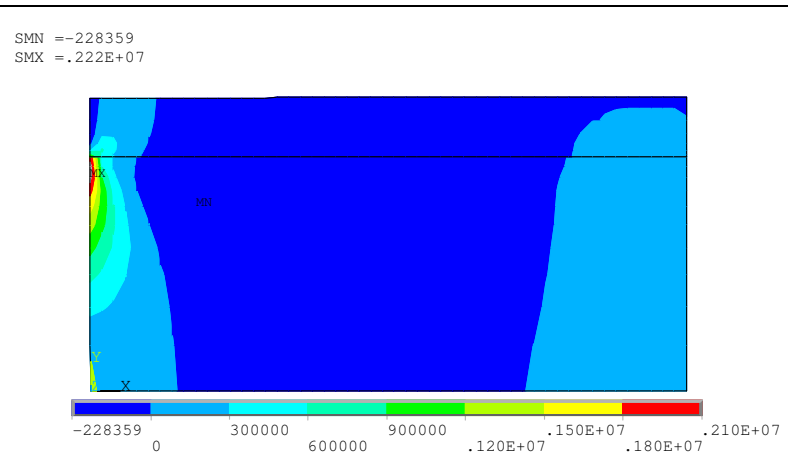

b)

Figura 6-3:Tensões normais, segundo a direção $Y$ em modelos 2D para módulos de elasticidade do revestimento de a) $2 \mathrm{GPa}$ e b) $15 \mathrm{GPa}$

Observa-se na Figura 6-3 a que para o revestimento com baixo módulo as tensões na base e no revestimento são principalmente de compressão com uma região de tensões de tração próxima à borda e concentração dessas tensões na interface com a base. Já na Figura 6-3 b, o aumento do módulo gera maiores tensões de tração na base na proximidade da interface, concentradas na borda do bloco.

Quando a análise é realizada em 3D (Figura 6-4), em cujo caso é apresentado um quarto do bloco cortado por dois eixos de simetria ( $X$ e $Y$ ), observa-se também um aumento no nível de tensões no bloco cujo revestimento possui um módulo de 15 GPa (Figura 6-4 b), com as maiores tensões localizadas perto na interface na região da borda.

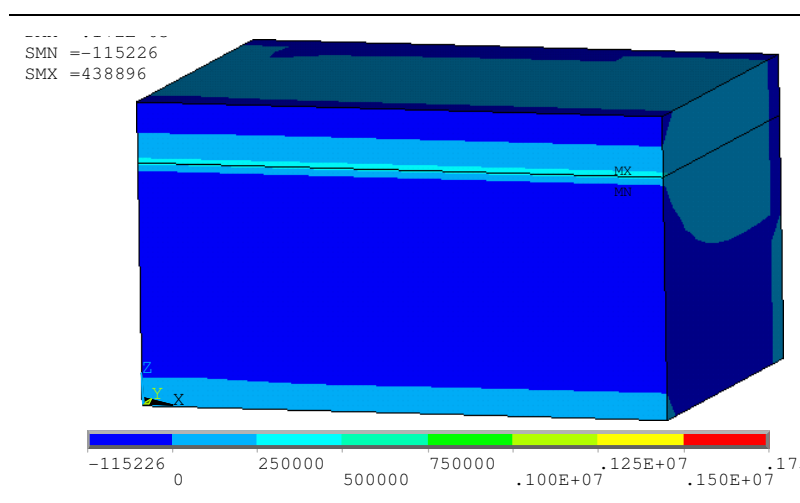

a)

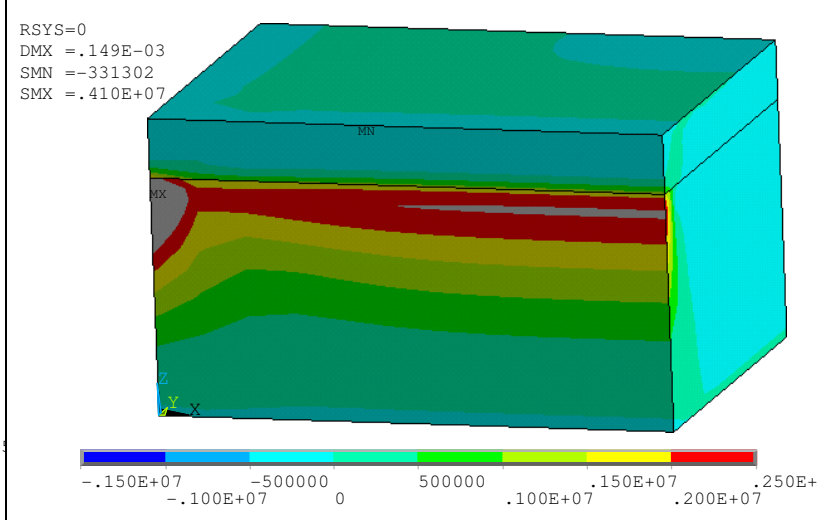

b)

Figura 6-4:Tensões normais, segundo a direção Z em modelos 3D para módulos de elasticidade do revestimento de a) $2 \mathrm{GPa}$ e b) $15 \mathrm{GPa}$

De forma semelhante ao modelo em 2D, a Figura 6-4 a, permite observar que as tensões predominantes tanto na base como no revestimento são de compressão e 
que a região submetida a tração cresce com o aumento do módulo de elasticidade do revestimento (Figura 6-4 b). Isto ocorre apesar dos gradientes serem os mesmos em toda a superfície da interface base-revestimento.

A influência da introdução dos macro-defeitos tanto no perfil de temperaturas como na distribuição de tensões foi avaliada simulando macro-defeitos na interface baserevestimento como mostrado no item 4.4 (capítulo 4). Na Figura 6.5 pode ser observada graficamente a distribuição de temperaturas nos modelos 2D (Figura 6-5 a) e 3D (Figura 6-5 b) para revestimentos com o mesmo módulo de elasticidade e a mesma espessura, verificando-se que a inclusão dos macro-defeitos não altera a distribuição de temperaturas.

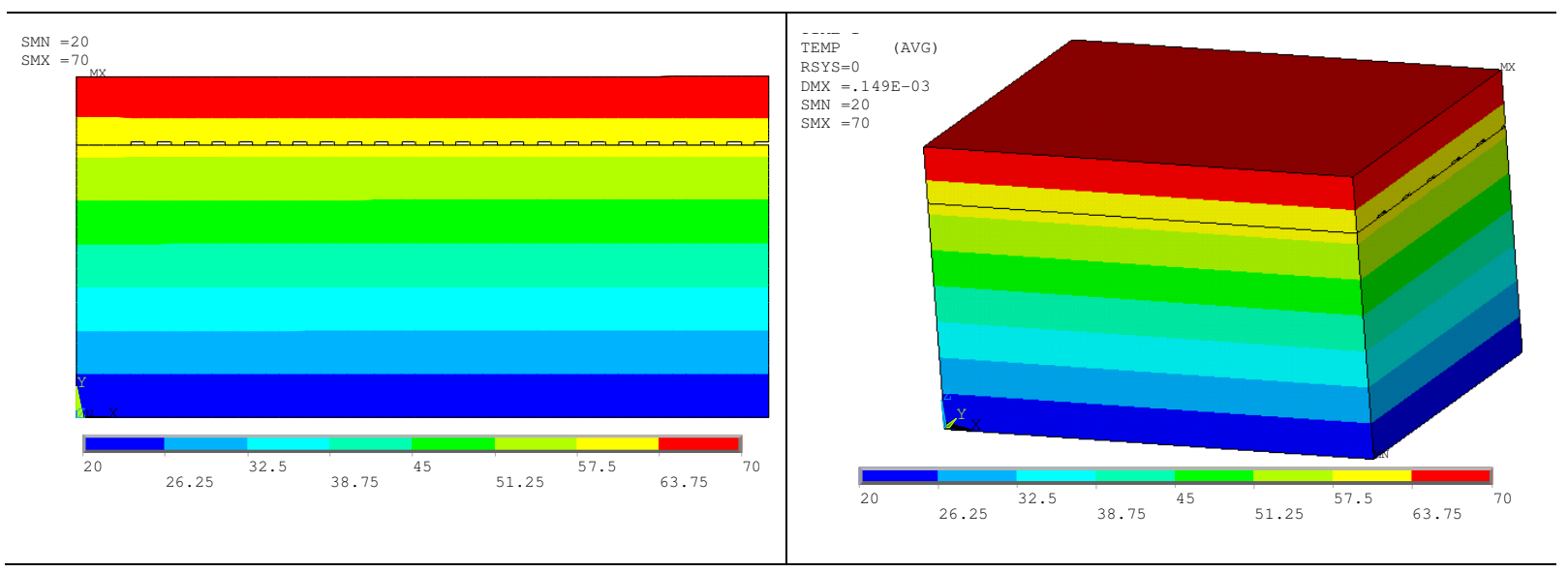

Figura 6-5: Perfil de temperaturas para o modelo 2D com 42\% de macro-defeitos e revestimento com módulo de elasticidade de $15 \mathrm{GPa}$.

Pode ser destacado a partir da Figura 6-5 que a variação da taxa de macro-defeitos não repercutiu de forma determinante no perfil de temperaturas, afetando principalmente a região da interface.

A Figura 6-6a apresenta a distribuição de tensões em um modelo 2D considerando uma taxa de macro-defeitos de interface de $42 \%$, e um revestimento de $25 \mathrm{~mm}$ de espessura e módulo de elasticidade de 15 GPa, enquanto que a Figura 6-6 b mostra distribuição de tensões em bloco 3D simulando um revestimento de $25 \mathrm{~mm}$ de espessura, módulo de elasticidade de15 GPa, e taxa de macro-defeitos de 7\%. 


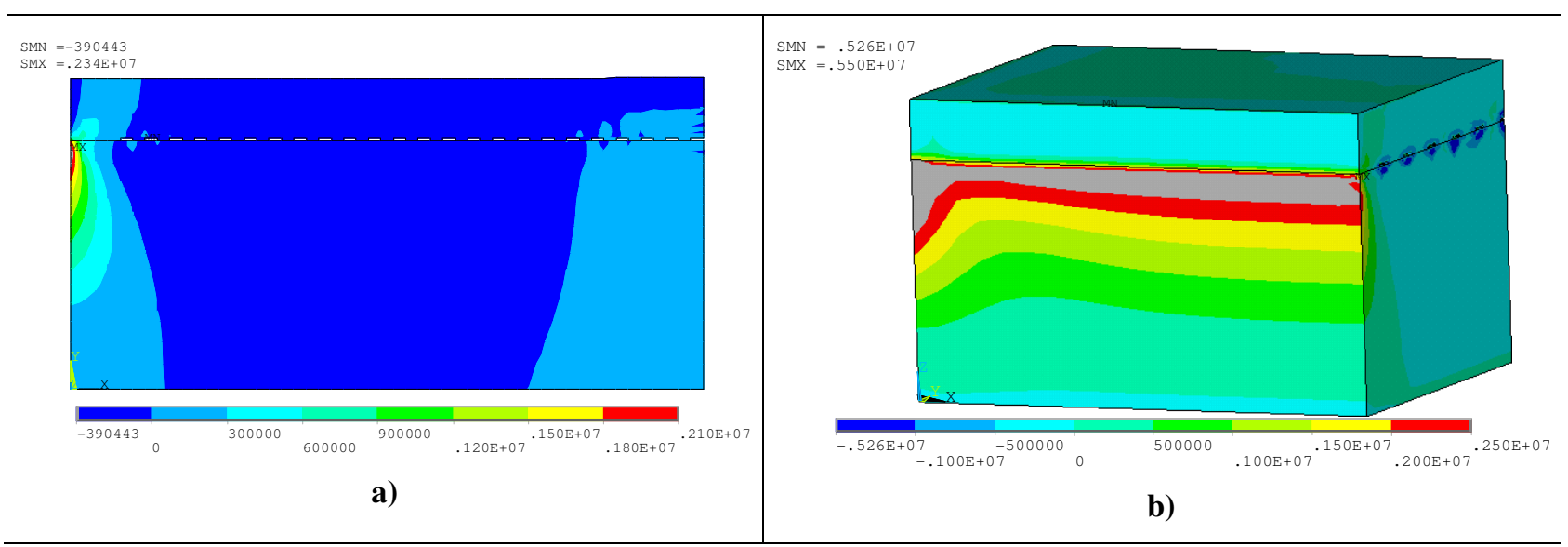

Figura 6-6: Distribuição de tensões normais verticais em a) modelo 2D com taxa de macro-defeitos de interface de $42 \%$; e b) modelo 3D com $7 \%$ de taxa de macro-defeitos

Verifica-se que a distribuição de tensões com a inclusão dos macro-defeitos de interface praticamente não é alterada quando comparados modelos 2D (Figura 6-3b e Figura 6-6a), surgindo regiões pontuais de perturbação das tensões ao longo da interface, o que poder ser observado comparando a Figura 6-6b e Figura 6-4b.

A partir da análise desses resultados gerais pôde-se realizar a análise para definição das dimensões do corpo de prova para o trabalho experimental. Para isto, a análise foi focada unicamente na região da interface base-revestimento, selecionando os elementos do modelo da camada intermediária criada na interface, como explicado no item 4.4 (capítulo 4), o que será discutido na seqüência.

\subsubsection{Simulações para definição das características do corpo de prova}

\subsubsection{Definição da espessura do substrato}

Como a base ou substrato do revestimento é um dos fatores mantidos constantes nesta tese, procurou-se, a partir das simulações com um modelo bidimensional, encontrar uma dimensão para a espessura da base que a mantivesse praticamente indeformável ao ser solicitada por variação de temperatura. Inicialmente foi considerado um corpo de prova com a espessura do substrato padrão utilizado em ensaios de revestimento cerâmico $(25 \mathrm{~mm})$ e especificado pela ABNT NBR 14082 (1998), como indicado em 5.4.1. Entretanto, essa reduzida espessura não proporcionou rigidez suficiente ao corpo de prova para minimizar seu deslocamento vertical perante o carregamento térmico, principalmente nos extremos do bloco simulado, como pode ser observado na Figura 6-7. 


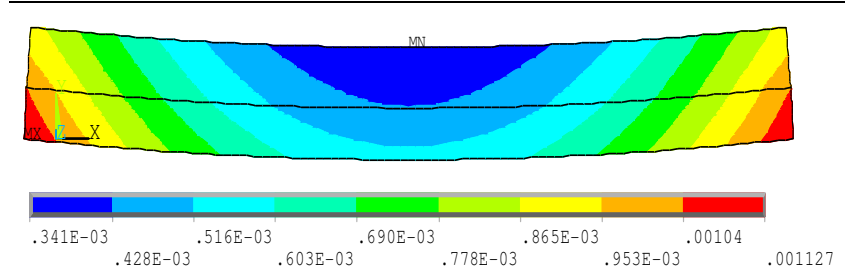

a)

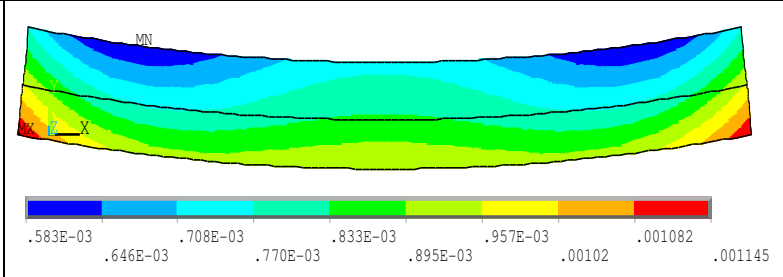

b)

Figura 6-7:Resultados da simulação para avaliação dos deslocamentos nos corpos com espessura de substrato de 2,5 cm, sendo o revestimento de $3,0 \mathrm{~cm}$ e módulo de elasticidades de a) $2 \mathrm{GPa}$ e b) 15 Gpa.

Como aquele corpo de prova não atendia a premissa de reduzido deslocamento, foram realizadas simulações variando a espessura do substrato até a dimensão que promovesse deslocamento vertical mínimo (Figura 6-8). Para a definição da espessura da base foi considerada, ainda, a facilidade de manipulação dos corpos de prova. Com isso, definiu-se espessura de $10 \mathrm{~cm}$, verificando que o deslocamento vertical do corpo de prova simulado era menor a $1 \mathrm{~mm}$ na parte central, em especial para o revestimento com módulo de elasticidade de 2 GPa (Figura 6-8a).

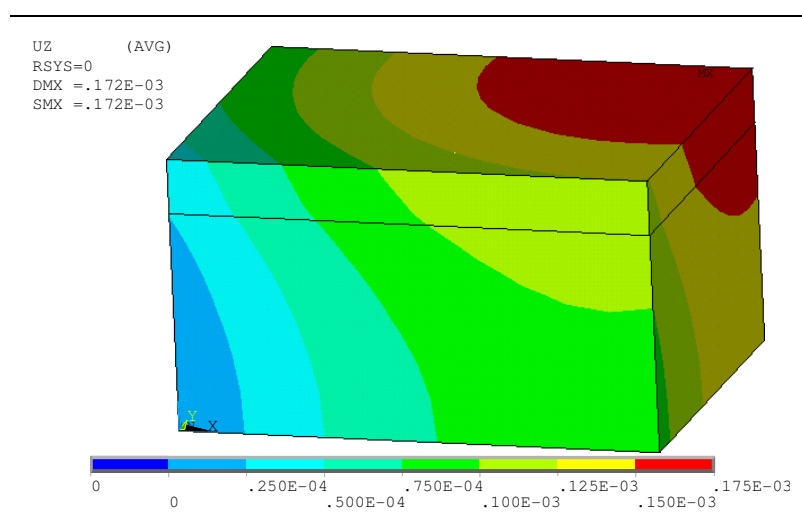

a)

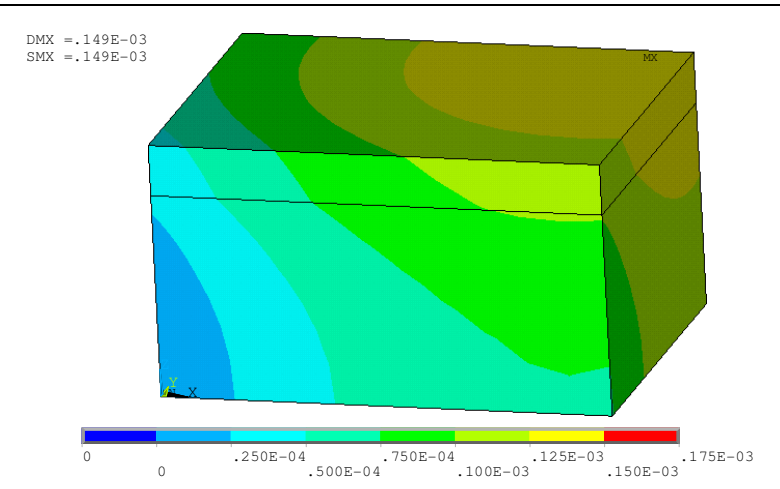

b)

Figura 6-8:Resultados da simulação de um quarto do modelo em 3D para os deslocamentos verticais nos corpos com espessura de substrato de $10 \mathrm{~cm}$, sendo o revestimento de $3,0 \mathrm{~cm}$ e módulo de elasticidades de a) $2 \mathrm{GPa}$ e b) $15 \mathrm{GPa}$.

Além dos deslocamentos verticais, a escolha da espessura da base do painel levou em conta também a distribuição de tensões normais ao plano da interface para se ter distribuição de tensões mais homogênea. Na Figura 6-9 são apresentados, a título de exemplo, os modelos tridimensionais de tensões normais na direção $Z$ do modelo 3D, apresentando $1 / 4$ do modelo tirando proveito da simetria do mesmo, para revestimento com módulo de elasticidade de $2 \mathrm{GPa}$, espessuras de revestimento de $30 \mathrm{~mm}$ e espessura da base de $100 \mathrm{~mm}$. 


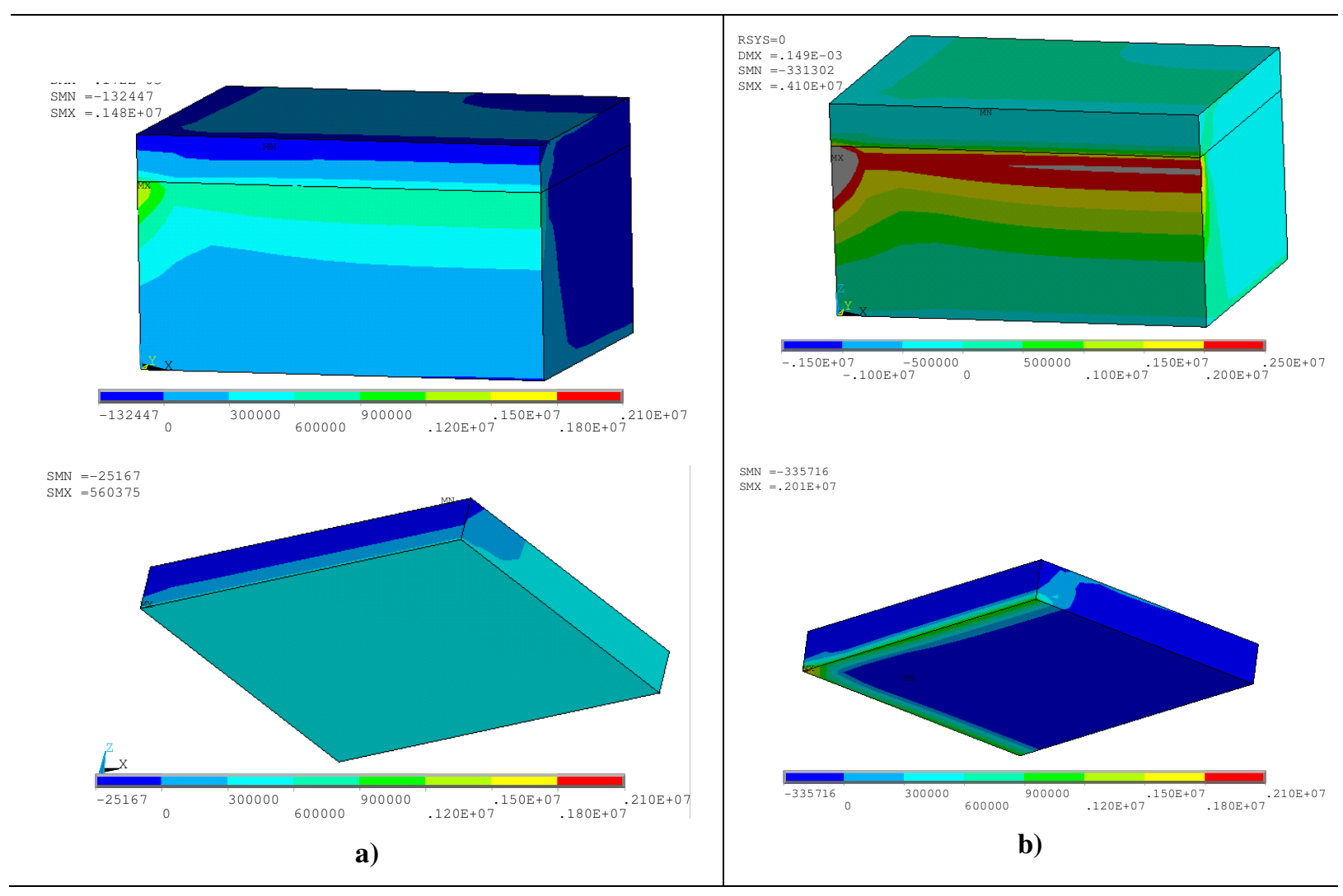

Figura 6-9:Distribuição de tensões normais em Z em 1/4 de modelos tridimensionais e na superfície de interface do revestimento (afastado da base), mostrando a com base de $100 \mathrm{~mm}$ de espessura e módulo de: a) $2 \mathrm{GPa}$ e b) $15 \mathrm{GPa}$.

Pode ser observada uma distribuição uniforme de tensões na região da interface para o revestimento de menor módulo (2GPa) e uma região de concentração de tensões de tração nas bordas para o revestimento com módulo maior (15 GPa), comparando a Figura 6-9a e Figura 6-9b.

Com este resultado foi possível definir o tamanho do corpo de prova, limitando-se a região possível de se fazer as avaliações de resistência de aderência. Nesta região, longe das bordas, o efeito do carregamento térmico parece ser mais homogêneo, não apresentando zonas de perturbação.

\subsubsection{Definição da espessura do revestimento}

Os perfis de temperaturas correspondentes a modelos com revestimentos de $25 \mathrm{e}$ $50 \mathrm{~mm}$ de espessura, sem considerar macro-defeitos de interface, mostraram diferenças no gradiente provocado entre a superfície do revestimento e sua interface com a base, conforme mostrado na Figura 6-10.

Ao aplicar carregamento térmico na superfície externa com $70^{\circ} \mathrm{C}$, o gradiente produzido até a interface foi em torno dos $10,5^{\circ} \mathrm{C}$ para a espessura de revestimento 
de $25 \mathrm{~mm}$, valor que subiu para $17,4^{\circ} \mathrm{C}$ quando a espessura foi elevada a $50 \mathrm{~mm}$. (Figura 6-10b).

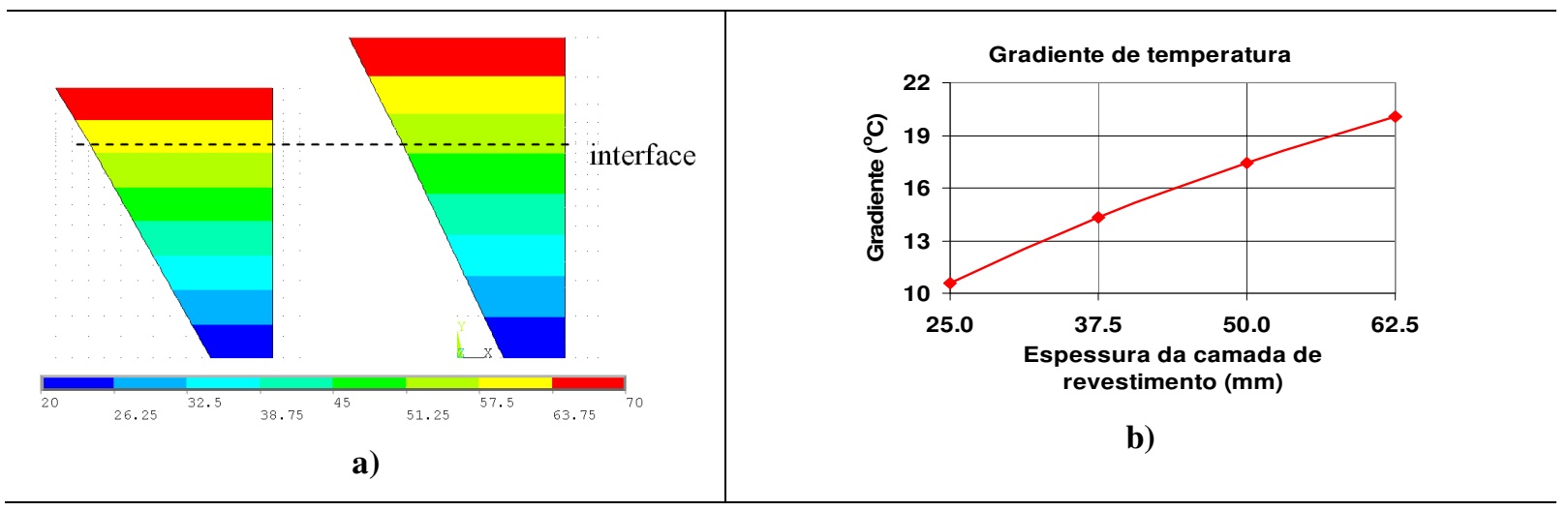

Figura 6-10: (a) Perfil de temperaturas em revestimentos com 25 e $50 \mathrm{~mm}$ de espessura e (b) gradiente de temperatura resultante entre a superfície e a interface em função da espessura do revestimento.

A variação do módulo de elasticidade do revestimento de argamassa (2GPa e 15GPa) altera de forma inexpressiva o perfil de temperatura. Por outro lado, como era esperado, há uma clara influência da espessura do revestimento na temperatura atingida na interface base-revestimento.

Quando são avaliadas as tensões produzidas, em função da variação da espessura do revestimento e do módulo de elasticidade, verifica-se o efeito mais importante do módulo no aumento das tensões.

Considerando, por exemplo, os valores máximos das tensões principais $\left(\mathrm{S}_{1}\right)$ obtidos nas simulações é obtido o gráfico mostrado na Figura 6-11:

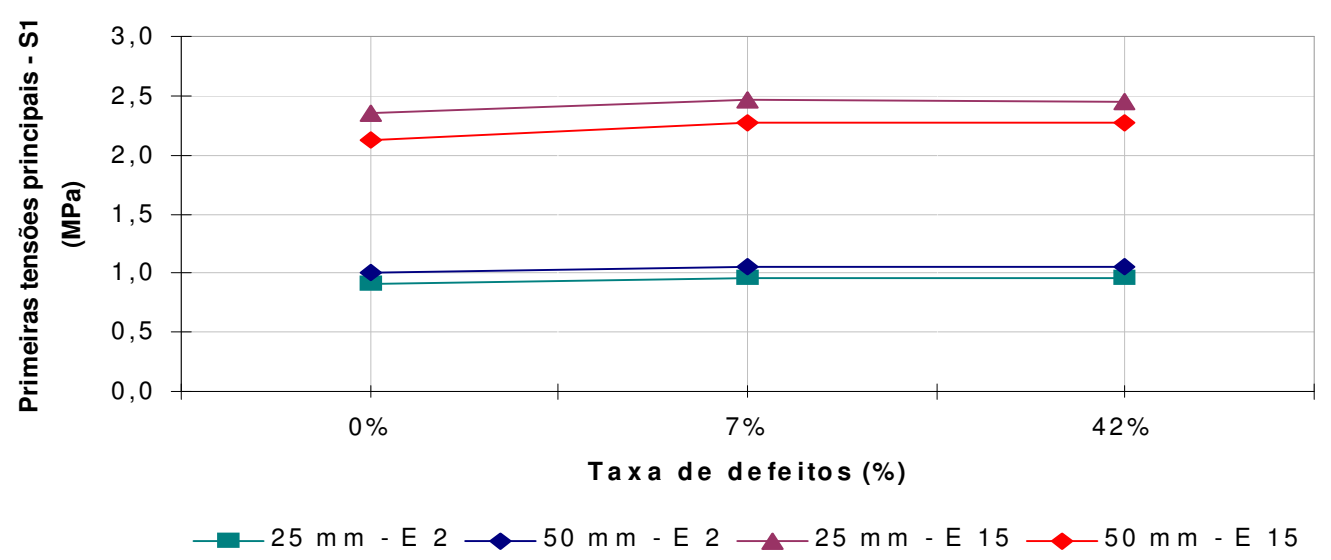

Figura 6-11: Comparativo das tensões principais máximas $\left(\mathrm{S}_{1}\right)$ para modelos com duas espessuras, dois valores de módulo de elasticidade e três taxas de macro-defeitos de interface. 
Verifica-se com esses resultados que o cenário mais crítico se apresenta sempre nos modelos em que o revestimento possui alto módulo ( $E=15 \mathrm{GPa})$, sendo mais crítico aquele com a menor espessura. No entanto, as variações não são proporcionais nem ao aumento do módulo nem à diminuição da espessura. Esse comportamento também é observado quando analisadas as tensões normais verticais e de cisalhamento no modelo, como mostrado na seqüência.

\subsubsection{Dimensões laterais dos corpos de prova}

Uma das preocupações na definição das dimensões do corpo de prova foi sua representatividade em termos do comprimento do painel de revestimento simulado e a respectiva distribuição das tensões.

Desta forma, foram modelados painéis sem a introdução de macro-defeitos com comprimento variando entre 0,20m e 4,0m. A Figura 6-12a mostra a distribuição das tensões normais verticais e na Figura 6-12b são mostradas as de cisalhamento ao longo da interface, em função da distância da borda da placa, para modelos com revestimento de $25 \mathrm{~mm}$ de espessura e com módulo de elasticidade de $15 \mathrm{GPa}$, considerada a situação mais crítica, ou seja, de maiores tensões atuantes.

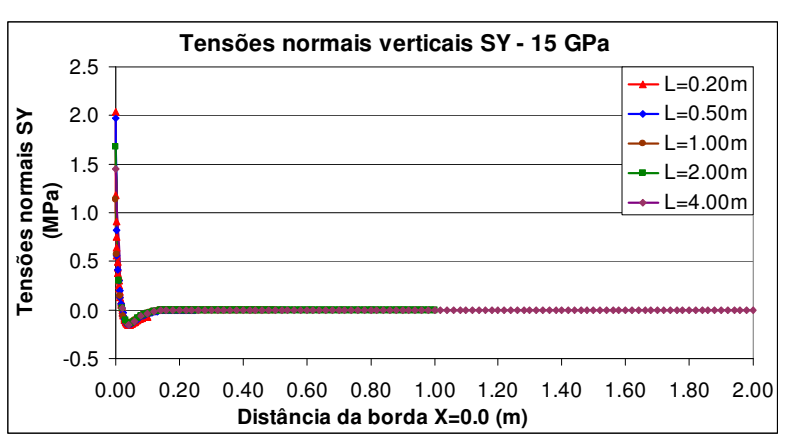

a) Tensões normais verticais (SY)

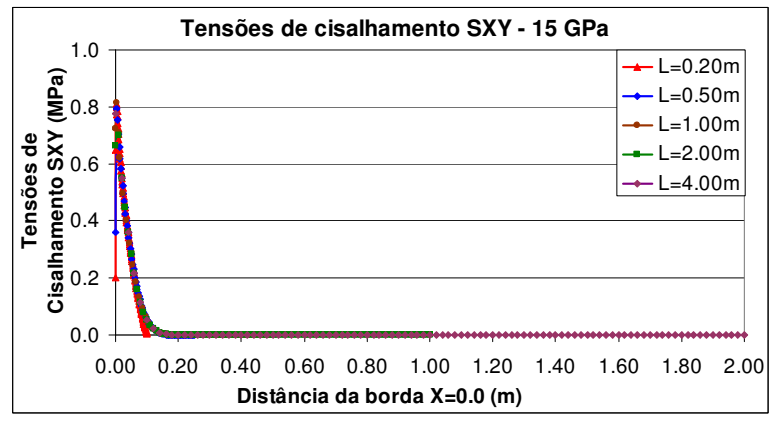

(b) Tensões de cisalhamento (SXY)

Figura 6-12: Tensões normais verticais e de cisalhamento, para o caso de revestimento com $25 \mathrm{~mm}$ de espessura e módulo de elasticidade de $15 \mathrm{GPa}$.

Verifica-se que a concentração dos maiores valores de tensão ocorre nas bordas do modelo até uma distância de, aproximadamente, $10 \mathrm{~cm}$ da borda do modelo. A partir dessa distância mínima da borda observa-se uma estabilização na variação das tensões. Esse comportamento é independente do comprimento do painel analisado e ocorre tanto para as tensões normais verticais como para as de cisalhamento. Isto se aproxima da análise realizada por Bortoluzzo (2000) e com as observações de autores como Veiga (2003) e Pagnussat et al. (2003) que referenciam a maior 
intensidade de fissuração e/ou desplacamento do revestimento junto de uma borda livre ou próximo às juntas do revestimento, o qual confirma a coerência do modelo desenvolvido nessa etapa do trabalho.

Observando com maior detalhe as proximidades das bordas, na faixa limitada pelos $20 \mathrm{~cm}$ próximos à borda do modelo, na Figura 6-13 são mostradas as distribuições de tensões normais verticais na interface base-revestimento, para os casos de revestimento com 25 mm e módulos de elasticidade de 2 e 15 GPa (Figura 6-13a) e revestimento com 50mm de espessura e módulos de elasticidade de 2 e 15 GPa (Figura 6-13b).

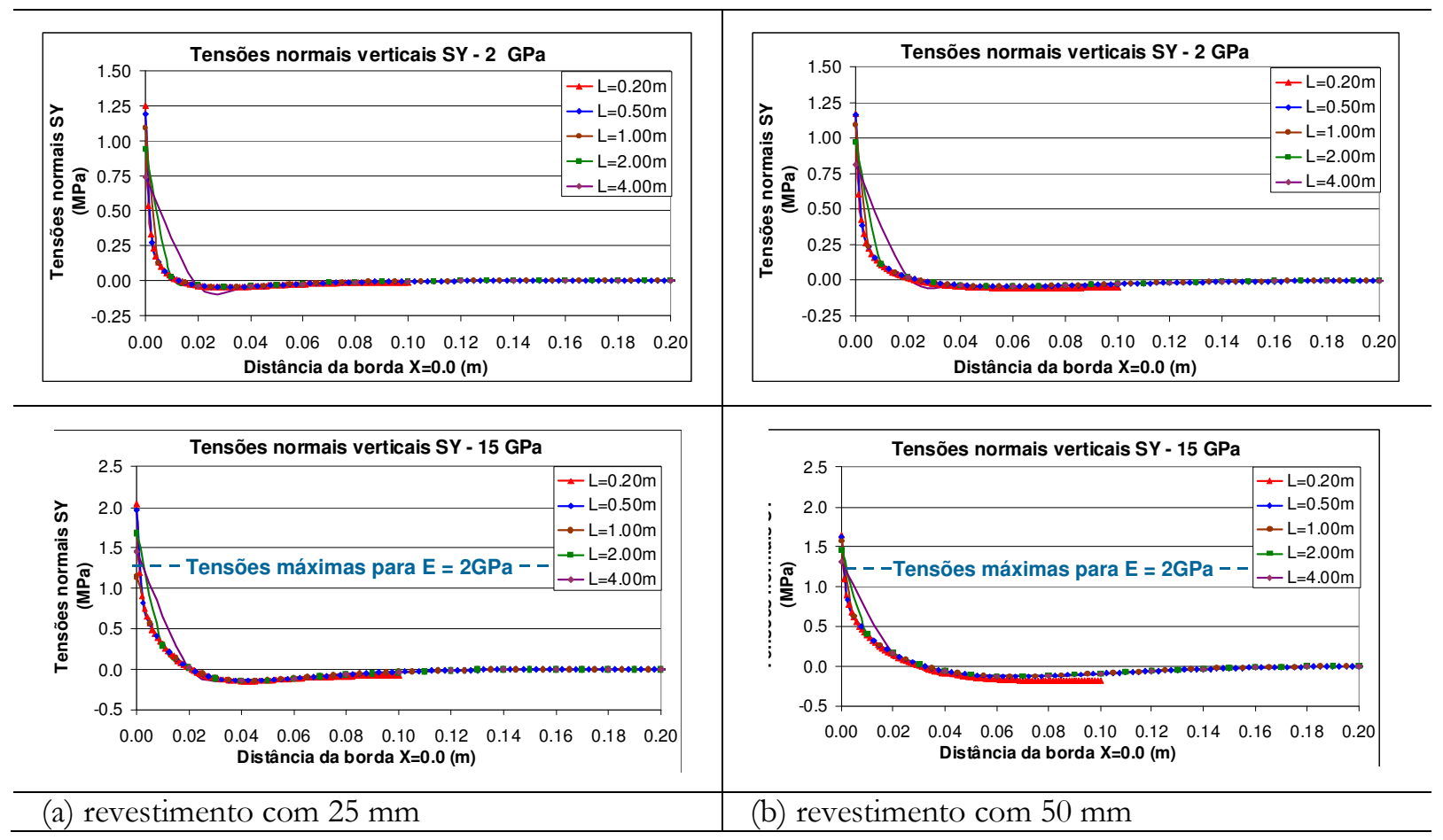

Figura 6-13: Detalhe das tensões normais verticais para revestimentos com espessura de $25 \mathrm{~mm}$ e 50 $\mathrm{mm}$ e com módulo de deformação de $2 \mathrm{GPa}$.

Verifica-se que para os revestimentos com módulo menor (2 GPa), o aumento da espessura do revestimento não é tão relevante na diminuição das tensões normais (4\%) como para os revestimentos de alto módulo (15 GPa) em que essa diminuição atinge cerca de $25 \%$ no nível de tensões. Por outro lado, quando a variação é do módulo de elasticidade, seu incremento até $15 \mathrm{GPa}$ pode significar um aumento no nível de tensões de aproximadamente 60\% para revestimento de pouca espessura (25 $\mathrm{mm}$ ) e de 30\% para revestimento de espessura maior $(50 \mathrm{~mm})$. Igualmente verifica-se que a faixa de abrangência dessa concentração de tensões é até $10 \mathrm{~cm}$ a partir da borda do modelo, independentemente do módulo de elasticidade, da 
espessura do revestimento e das dimensões laterais do modelo; ou seja, é possível afirmar que, independentemente das características intrínsecas do revestimento, as máximas tensões normais verticais concentram-se junto à borda do revestimento.

A Figura 6-14 apresenta as tensões de cisalhamento na interface com a base do revestimento com módulo de elasticidade de 2GPa e 15 GPa e comprimentos de bloco de 0,20 $\mathrm{m}$ até 4,0 $\mathrm{m}$, considerando a região compreendida entre a borda do bloco até $20 \mathrm{~cm}$ de distancia dela, para revestimentos de $25 \mathrm{~mm}$ (Figura 6-14a) e 50 $\mathrm{mm}$ de espessura (Figura 6-14b).

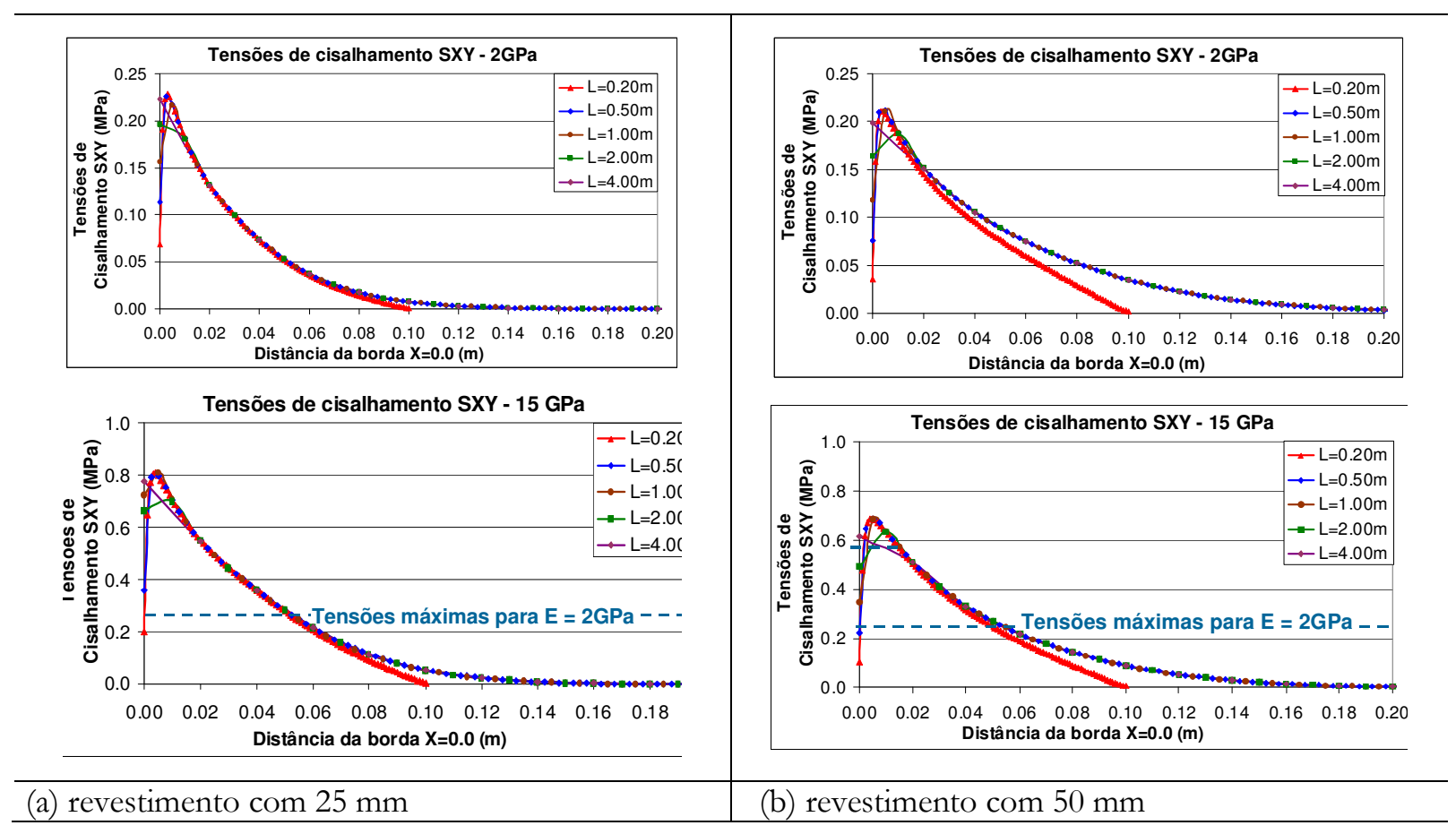

Figura 6-14: Detalhe das tensões de cisalhamento para revestimentos com módulos de elasticidade de 2 e $15 \mathrm{GPa}$ e com espessura de a) $25 \mathrm{~mm}$ e b) $50 \mathrm{~mm}$.

O efeito de atenuação das tensões máximas de cisalhamento pelo aumento da espessura do revestimento de $25 \mathrm{~mm}$ para $50 \mathrm{~mm}$ é de cerca de $13 \%$ para o revestimento de menor módulo (E 2 GPa), e de cerca de14\% para o revestimento de módulo maior ( $\mathrm{E}=15 \mathrm{GPa})$.

Por outro lado, o aumento das máximas tensões de cisalhamento devido ao incremento do módulo de elasticidade do revestimento de 2 GPa para 15 GPa, é de aproximadamente $330 \%$, mostrando ser um fator de maior influência do que a variação de espessura.

Contudo, os valores mais significativos estão também na faixa de até $10 \mathrm{~cm}$ a partir da borda do modelo), independentemente do módulo de elasticidade, da espessura 
do revestimento e das dimensões laterais do bloco. Destaca-se que refinando-se a malha de elementos finitos foi possível verificar que as tensões de cisalhamento diminuem drasticamente a pequena distância das bordas, como pode ser visto nos gráficos da Figura 6-14 (alerta-se que os gráficos de 2GPa e 15GPa estão com escalas diferentes). Observa-se, que como esperado, as máximas tensões de cisalhamento não ocorrem na borda do modelo, mas sim a uma pequena distância desta.

A análise dos gráficos da Figura 6-14 permite concluir, ainda, que quando são feitas juntas no revestimento para alívio das tensões é gerada uma borda e as tensões máximas de cisalhamento não ocorrem na junta e sim no próprio revestimento pouco antes da junta, a qual é uma região debilitada pela própria execução da junta, onde não se consegue uma compactação adequada, sendo esta uma região bastante propensa ao aparecimento de problemas de destacamento do revestimento e, por isto mesmo, uma região a ser melhor cuidada tanto no momento do projeto quanto da execução do revestimento.

Com os resultados obtidos da simulação e considerando-se a facilidade de manuseio dos corpos de prova definiram-se as suas dimensões para o programa experimental, adotando-se comprimento de 0,40 m e largura de 0,30 m. Com estas dimensões não se teria perturbações nas tensões devido a efeitos de borda, não haveria grande dificuldade de manuseio dos corpos de prova e haveria superfície adequada para realização dos ensaios de resistência de aderência.

As constatações relativas à concentração das maiores tensões normais e de cisalhamento em regiões muito próximas às bordas do pano do revestimento permitem reafirmar, com certeza, as recomendações sobre os cuidados necessários nessas regiões na etapa de aplicação do revestimento, principalmente quanto à obtenção de uma maior extensão de aderência (mínima taxa de macro-defeitos) e um adensamento adequado, para atenuar o posterior efeito das tensões de origem térmica. 


\subsubsection{Definição das características dos macro-defeitos de interface provocados}

Os efeitos produzidos pela introdução de macro-defeitos na interface baserevestimento foram analisados no perfil de temperaturas resultante e no campo de tensões na interface.

A inclusão dos macro-defeitos na interface base-revestimento, como mostrado na Figura 6-15, segundo o modelo, afetou muito pouco a temperatura resultante na camada de contato entre esses materiais em relação ao efeito provocado pela variação de espessura do revestimento como já observado na Figura 6-2. A variação do gradiente de temperatura entre a face superior do modelo e a interface esteve entre $+0,4 \%$ e $+2,2 \%$, correspondentes a $7 \%$ e $42 \%$ de macro-defeitos, respectivamente, avaliando diferentes espessuras de revestimento (Figura 6-15a).

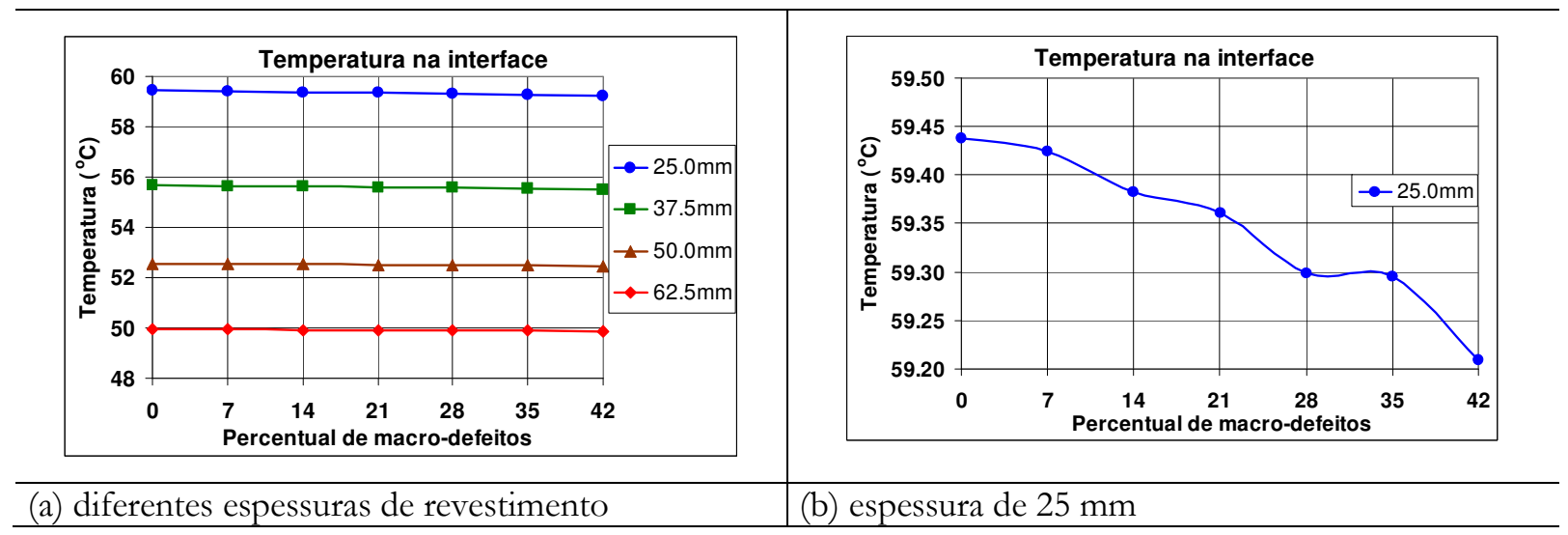

Figura 6-15:Variação da temperatura na interface em função da variação da taxa de macro-defeitos: (a) para 4 espessuras de revestimento (b) para a espessura de $25 \mathrm{~mm}$.

Entretanto, a inclusão dos macro-defeitos na interface base revestimento promoveu um aumento no campo de tensões. A Figura 6-16 mostra a variação dos valores das máximas tensões normais verticais obtidos neste estudo variando a taxa de macrodefeitos, comparando-os com os valores correspondentes obtidos sem a consideração do macro-defeito. 


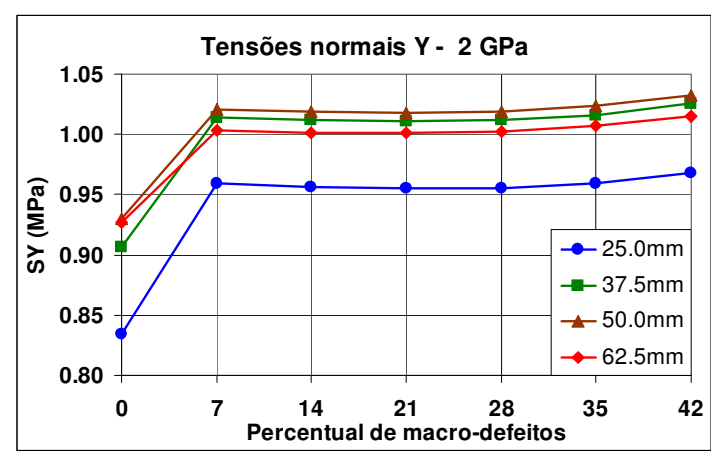

a)

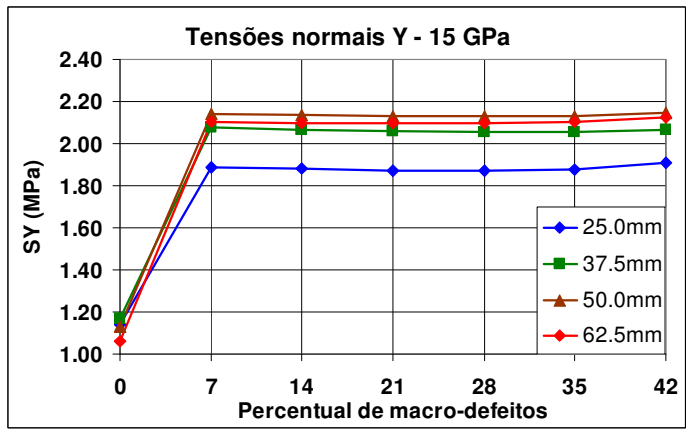

b)

Figura 6-16: Variação das máximas tensões normais verticais em função da taxa de macro-defeitos e variando a espessura do revestimento de $25 \mathrm{~mm}$ a $62,5 \mathrm{~mm}$ para revestimento com módulo de elasticidade de a) $2 \mathrm{GPa}$ e b) $15 \mathrm{GPa}$.

Observa-se na Figura 6-16 que a inclusão dos macro-defeitos, mesmo que em pequena taxa, incrementa os valores das tensões normais máximas e que esse aumento é mais importante quando o módulo é maior (Figura 6-16b) praticamente dobrando os valores das máximas tensões em relação ao revestimento sem macrodefeitos de interface. A partir desta pequena taxa, até próximo de $30 \%$ não há variação nas tensões originadas, sendo que a partir daí (35\%) há mais um incremento nas tensões, ainda que menos expressivo.

Para avaliar o efeito da inclusão dos macro-defeitos de interface nas tensões de cisalhamento, a Figura 6-17 apresenta a variação dos valores das máximas tensões de cisalhamento obtidos nesta simulação variando a taxa de macro-defeitos, comparando-os com os valores correspondentes ao revestimento sem macrodefeitos de interface.
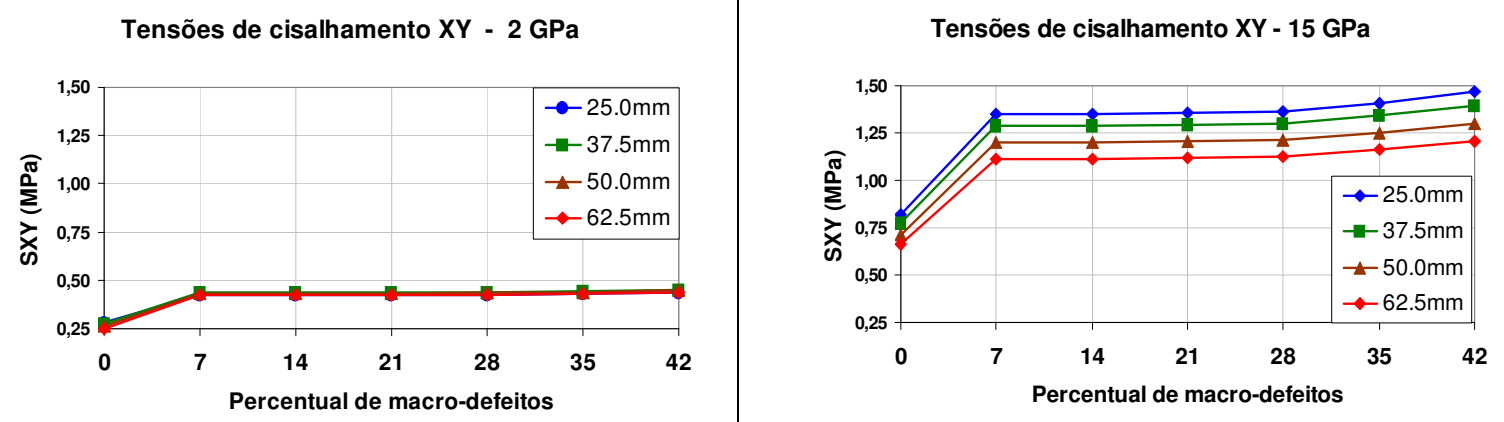

Figura 6-17: Variação das máximas tensões de cisalhamento em função da taxa de macro-defeitos e variando a espessura do revestimento de $25 \mathrm{~mm}$ a $62,5 \mathrm{~mm}$ para revestimento com módulo de elasticidade de a) $2 \mathrm{GPa}$ e b) $15 \mathrm{GPa}$. 
Observa-se na Figura 6-17a que a inclusão dos macro-defeitos, produz um incremento nas tensões que representa quase o dobro das máximas tensões atingidas sem macro-defeitos de interface, com pouca influência do aumento da taxa de macro-defeitos, até o valor avaliado (42\%) e igualmente com inexpressiva influência da variação da espessura do revestimento. De forma parecida observa-se na Figura 6-17b que a inclusão dos macro-defeitos de interface inclusive em pequena taxa (7\%) também provoca um aumento nas tensões máximas quase em $100 \%$ principalmente para a menor espessura de revestimento $(25 \mathrm{~mm})$ em relação ao revestimento sem macro-defeitos de interface.

Todos os resultados obtidos consideram o primeiro macro-defeito localizado a $4 \mathrm{~mm}$ da borda, e todos os macro-defeitos com $8 \mathrm{~mm}$ de comprimento.

$\mathrm{Na}$ definição da geometria do macro-defeito provocado na interface, foram realizadas simulações em que foi variada a dimensão longitudinal do macro-defeito desde $4 \mathrm{~mm}$ até $12 \mathrm{~mm}$ e a sua posição relativa à borda do modelo. Buscou-se, com isto, avaliar o efeito do tamanho e posição do macro-defeito de interface no nível de tensões atingidas no instante da maior temperatura na superfície do revestimento $\left(70^{\circ} \mathrm{C}\right)$, como é apresentado na Figura 6-18 para as tensões de cisalhamento para revestimentos de $2 \mathrm{GPa}$ e $15 \mathrm{GPa}$, considerando como situação crítica o revestimento com menor espessura $(25 \mathrm{~mm})$.

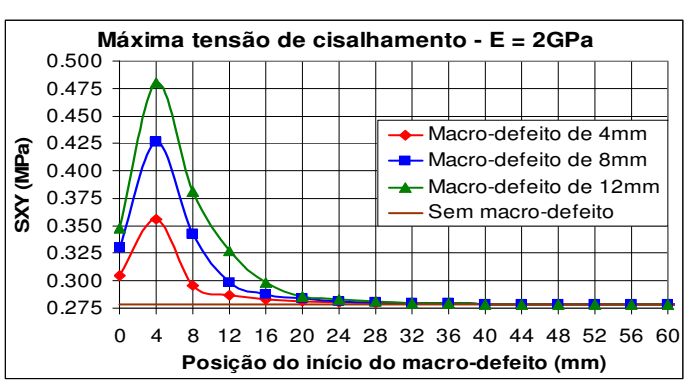

a)

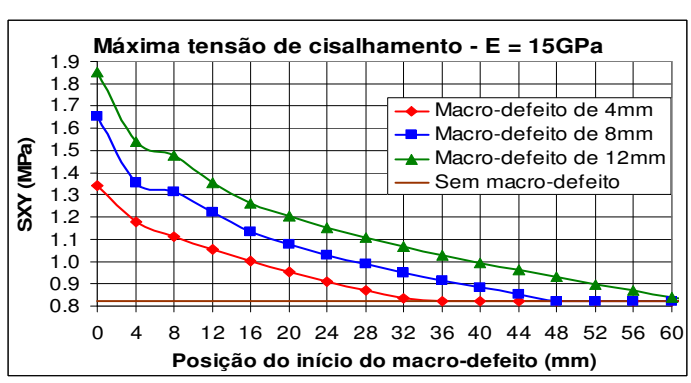

b)

Figura 6-18: Variação das máximas tensões de cisalhamento em função do comprimento do macrodefeito e da sua proximidade à borda do modelo, para revestimento com módulo de elasticidade de 2 e $15 \mathrm{GPa}$.

Analisando os gráficos da Figura 6-18, observa-se que o aumento das máximas tensões de cisalhamento na proximidade da borda provocado pelo incremento do módulo de elasticidade de 2GPa para 15 GPa e pela inclusão de macro-defeitos de interface ainda pode ser potencializado com o incremento do comprimento do 
macro-defeito quando esse estiver localizado mais próximo da borda.Para o revestimento de menor módulo (2GPa) se a localização do primeiro defeito é a partir dos $20 \mathrm{~mm}$ da borda, o efeito do comprimento do mesmo perde importância no incremento do nível de tensões térmicas como pode ser observado na Figura 6-18a, enquanto que se o módulo do revestimento for maior (15 GPa), a influência do comprimento do macro-defeito na elevação das tensões se estende até cerca de 60 $\mathrm{mm}$ da borda.

Observa-se, ainda, que no caso do revestimento de $15 \mathrm{GPa}$ as máximas tensões de cisalhamento ocorrem muito mais próximas da borda, antes de diminuir. Essa diminuição pode ser apreciada na Figura 6-18a e não é visível no modelo com revestimento de $15 \mathrm{GPa}$ (Figura 6-18b), possivelmente pela falta de refinamento na malha de análise.

A partir dos resultados das simulações realizadas pode-se afirmar que na produção dos revestimentos deve-se buscar sempre a menor taxa de defeitos de interface possível (macro-defeitos). Isto pode ser realizado a partir do emprego de uma argamassa de revestimento com adequada reologia em função das condições de aplicação e das próprias características da base, e com técnicas de execução do revestimento que garantam o máximo da compactação das camadas, principalmente nas bordas, encontros de paredes e na execução de juntas no revestimento. Deficiências ou descontinuidades no plano de contato entre a camada de argamassa e a base, podem resultar em elevação das tensões decorrentes da variação de temperatura.

\subsection{Simulações realizadas com modelos de choque térmico}

A partir de simulações realizadas utilizando os modelos para avaliação de tensões térmicas devido ao choque térmico (Equação 3-1), buscou-se identificar a variação de temperatura crítica que provocaria tensões para atingir a resistência à tração de argamassa para revestimento. Cabe destacar que os modelos identificados são válidos para sólidos de geometria regular e a análise realizada é bidimensional.

Assim, foi simulado um prisma de argamassa para revestimento engastado em ambos extremos, com uma espessura definida em $6 \mathrm{~cm}$. para simular o dobro da espessura média de revestimento utilizada no programa experimental (Figura 6-19). 
Esse prisma foi submetido a variações de temperatura de $50^{\circ} \mathrm{C}, 40^{\circ} \mathrm{C}, 30^{\circ} \mathrm{C}$ e $20^{\circ} \mathrm{C}$, sendo calculados os valores de tensão máxima produzidos.

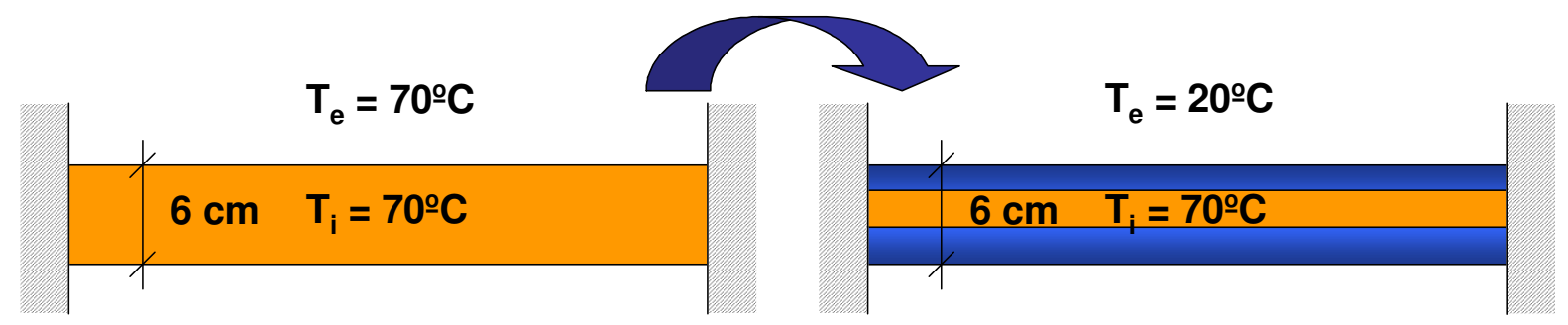

Figura 6-19:Simulação de choque térmico em prisma de argamassa bi-engastado

Buscou-se com isto simular o choque térmico produzido pela diferença de temperatura entre a superfície do revestimento e sua interface com a base representando a temperatura da parte central do prisma com a temperatura da interface do revestimento, para assim poder chegar mais próximo ao que seria o comportamento do revestimento.

As propriedades consideradas na simulação são apresentadas na Tabela 6-1. Foram considerados dois valores extremos de módulo de elasticidade e para os coeficientes de Poisson, de dilatação térmica e condutividade térmica foram considerados valores constantes. O coeficiente de convecção foi considerado no seu maior valor para as condições de contorno analisadas.

Tabela 6-1: Propriedades mecânicas consideradas no modelo

\begin{tabular}{l|l|l}
\hline \multicolumn{3}{c}{ Propriedades mecânicas da argamassa para revestimento } \\
\hline Módulo de Elasticidade $(\mathrm{GPa})$ & 2,0 & 18,0 \\
\hline Coeficiente de Poisson & 0,2 & 4,5 \\
\hline Resistência à tração na flexão $(\mathrm{MPa})$ & 1,0 \\
\hline \multicolumn{1}{c}{ Propriedades térmicas da argamassa para revestimento } \\
\hline Coeficiente de expansão térmica $\left({ }^{\circ} \mathrm{C}^{-1}\right)$ & $12 \times 10^{-6}$ \\
\hline Condutividade $\left(\mathrm{W} / \mathrm{m}^{\circ} \mathrm{K}\right)$ & 0,7 \\
\hline Coeficiente convectivo de transferência de calor $\left(\mathrm{W} / \mathrm{m}^{2}{ }^{\circ} \mathrm{C}\right)$ & 100 \\
\hline
\end{tabular}

De acordo com as tensões por choque térmico obtidas, mostradas na Figura 6-20, argamassas com altos valores de módulo de elasticidade acentuam o efeito da diferença de temperaturas no nível de tensões atingidas. 


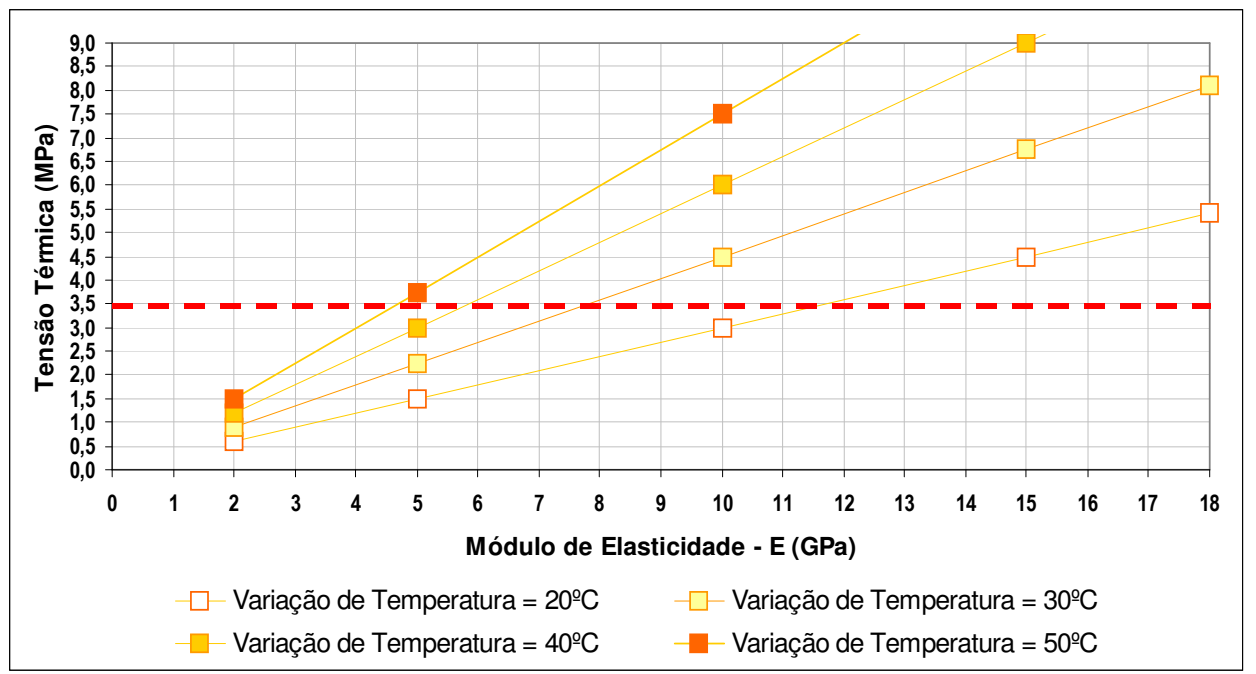

Figura 6-20: Valores de tensão térmica máxima para argamassas com diferentes módulos de elasticidade para diferentes faixas de variação de temperatura.

A maneira de exemplo, na Figura 6-20 é marcado com linha tracejada vermelha um valor máximo de referência $(3,5 \mathrm{MPa})$ para resistência à tração (por tração diametral ou por tração na flexão) de argamassa para revestimento encontrado em trabalhos experimentais publicados por pesquisadores brasileiros para diferentes traços de argamassas utilizadas para revestimento (SBTA, 2005). Nas condições de contorno estabelecidas (Figura 6-19), segundo esse limite, choques térmicos de até $20^{\circ} \mathrm{C}$ poderiam ser críticos para argamassas com módulos acima de $10 \mathrm{GPa}$, enquanto que para argamassas com módulos de até 4,5 GPa, permitiriam choques térmicos de até $50^{\circ} \mathrm{C}$ sem atingir o limite máximo de resistência à tração da argamassa. Porém, cabe destacar aqui que o valor médio das resistências à tração para corpos de prova de argamassa para revestimento, encontradas nos trabalhos supracitados foi de $0,7 \mathrm{MPa}$, o qual limita a faixa de variação de temperatura no choque térmico a $20 \stackrel{\circ}{ } \mathrm{C}$.

Entretanto, nos modelos de choque térmico é considerado freqüentemente um fator de atenuação (Equação 3-3) levando em conta as condições térmicas dependentes do tempo e introduzindo o número de Biot.

Com o fator de atenuação e considerando o coeficiente de convecção " $h$ " mais crítico que, segundo Stoecker e Jones (1985), para convecção livre com água pode ser considerado o valor de $100 \mathrm{~W} / \mathrm{m}^{2}{ }^{\circ} \mathrm{C}$, podem ser calculadas as tensões por choque térmico, como mostrado na Figura 6-21. Neste caso, a faixa de variação de 
temperatura que passa a ser crítica para valores de módulo de elasticidade acima de $15 \mathrm{MPa}$ é de $30^{\circ} \mathrm{C}$.

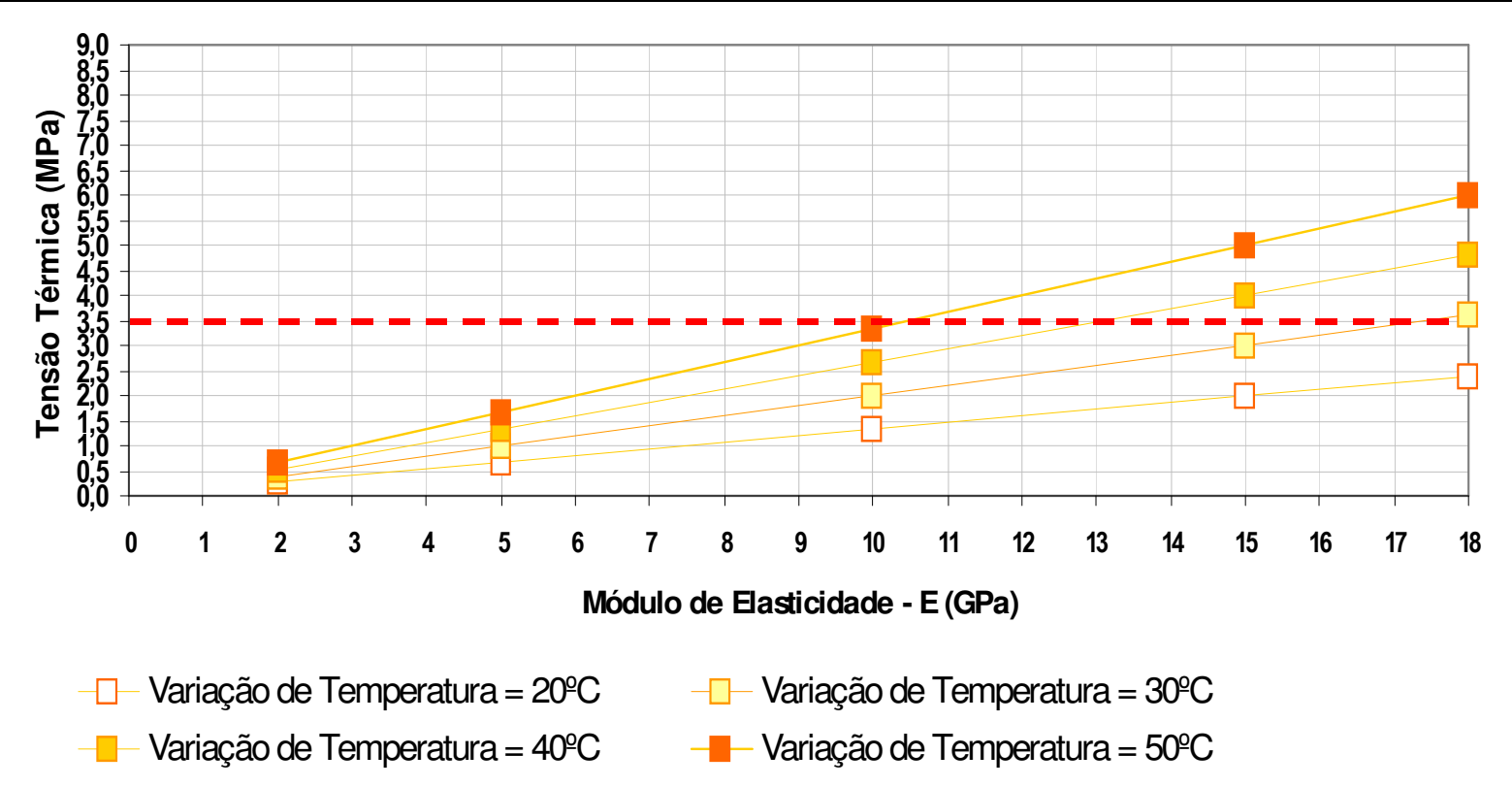

Figura 6-21: Valores de tensão térmica máxima com fator de atenuação para argamassas com diferentes módulos de elasticidade para diferentes faixas de variação de temperatura.

A partir desses resultados, mesmo com todas as limitações da simulação matemática, é possível afirmar que uma adequada resistência ao choque térmico de argamassas para revestimento dependerá de altos valores de resistência à tração e baixos valores de módulo de elasticidade (preferencialmente abaixo de $10 \mathrm{GPa}$ ).

Entretanto, é preciso lembrar que o revestimento é aplicado em camadas sobre uma base e a forma como ocorre o choque térmico na sua superfície é assimétrica; portanto, o modelo anteriormente utilizado não representa completamente a realidade do sistema; infelizmente, porém, não foi identificado na literatura disponível um modelo que representasse adequadamente o fenômeno em revestimentos de argamassa.

\subsection{Resultados do Programa experimental}

\subsubsection{Caracterização dos materiais}

Os materiais constituintes da argamassa (cimento e areia) foram caracterizados no estado anidro. Para a argamassa, foram realizados ensaios de caracterização no estado fresco e posteriormente no estado endurecido. 


\subsubsection{Estado anidro}

De acordo com o objetivo do trabalho o tipo de aglomerante e de agregado foi mantido constante, sendo selecionados para sua caracterização os ensaios de massa unitária e de densidade real, os quais permitiram realizar a dosagem em massa da argamassa. Os resultados dessas propriedades para o cimento utilizado (CPII F) e a areia de cava são apresentados na Tabela 6-2.

Tabela 6-2: Caracterização dos materiais constituintes da argamassa

\begin{tabular}{l|l|l}
\hline \multicolumn{1}{c|}{ Material } & \multicolumn{2}{|c|}{ Massa unitária NBR 7251 (ABNT, } \\
$\mathbf{1 9 8 2})$ & $\begin{array}{c}\text { Densidade Real - Picnometria de Gás } \\
\text { (g/cm3) }\end{array}$ \\
\hline Cimento CPII F $\left(\mathrm{g} / \mathrm{cm}^{3}\right)$
\end{tabular}

Como é destacado por Carneiro (1999) e Bauer e Sousa (2005) e Comunidade da Construção (2005), a granulometria do agregado miúdo tem influência nas proporções do aglomerante e da quantidade de água da mistura, e conseqüentemente no desenvolvimento das propriedades mecânicas do revestimento. Assim, foi realizada a caracterização granulométrica da areia utilizada no programa experimental como mostrado na Figura 6-22.

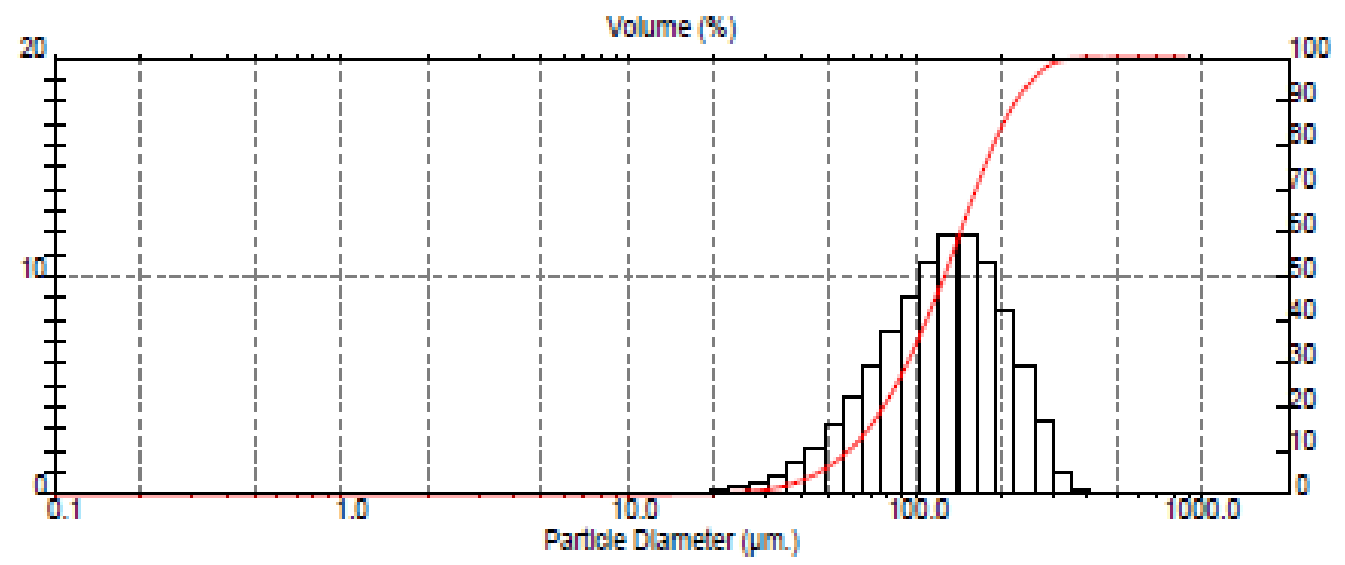

Figura 6-22:Distribuição granulométrica da areia.

Na Figura 6-22 pode-se observar que os tamanhos dos grãos da areia utilizada apresentaram uma distribuição granulométrica contínua e sem excesso de finos, os quais poderiam promover um maior consumo de água de amassamento e um potencial aumento da retração por secagem na argamassa. 


\subsubsection{Estado fresco}

São apresentados na Tabela 6-3 os resultados da caracterização das argamassas no estado fresco. O teor de água determinado para as argamassas foi de $16 \%$ em massa de materiais secos.

Tabela 6-3: Caracterização da argamassa em estado fresco com teor de água de $16 \%$ em massa de materiais secos.

\begin{tabular}{l|l|l|l}
\hline \multirow{2}{*}{ Propriedade } & \multirow{2}{*}{ Método de ensaio } & Tipo de argamassa \\
\cline { 3 - 4 } & & $1: 4$ sem AIA & $1: 4$ com AIA \\
\hline Densidade no estado fresco & NBR 13278 & 1,99 & 1,65 \\
\hline Teor de ar incorporado $(\%)$ & NBR 13278 & 5,20 & 21,74 \\
\hline Carga max. em $0,1 \mathrm{~mm}(\mathrm{~N})$ & Squeeze Flow & 3,52 & 10,41 \\
\hline Carga max. em 1,5 mm (N) & Squeeze Flow & $* 15$ & 31,23 \\
\hline Carga max. em 2,5 mm (N) & Squeeze Flow & - & 35,99 \\
\hline Índice de penetração $(\mathrm{mm})$ & Dropping-ball & 7,13 & 10,92 \\
\hline
\end{tabular}

Com os valores do teor de ar incorporado, as massas do aglomerante e agregado e as densidades reais do aglomerante e agregado (Tabela 6-2) foi calculada a distribuição volumétrica (\%), no estado fresco, dos materiais constituintes das argamassas utilizadas no experimento, conforme mostrado na Figura 6-23:

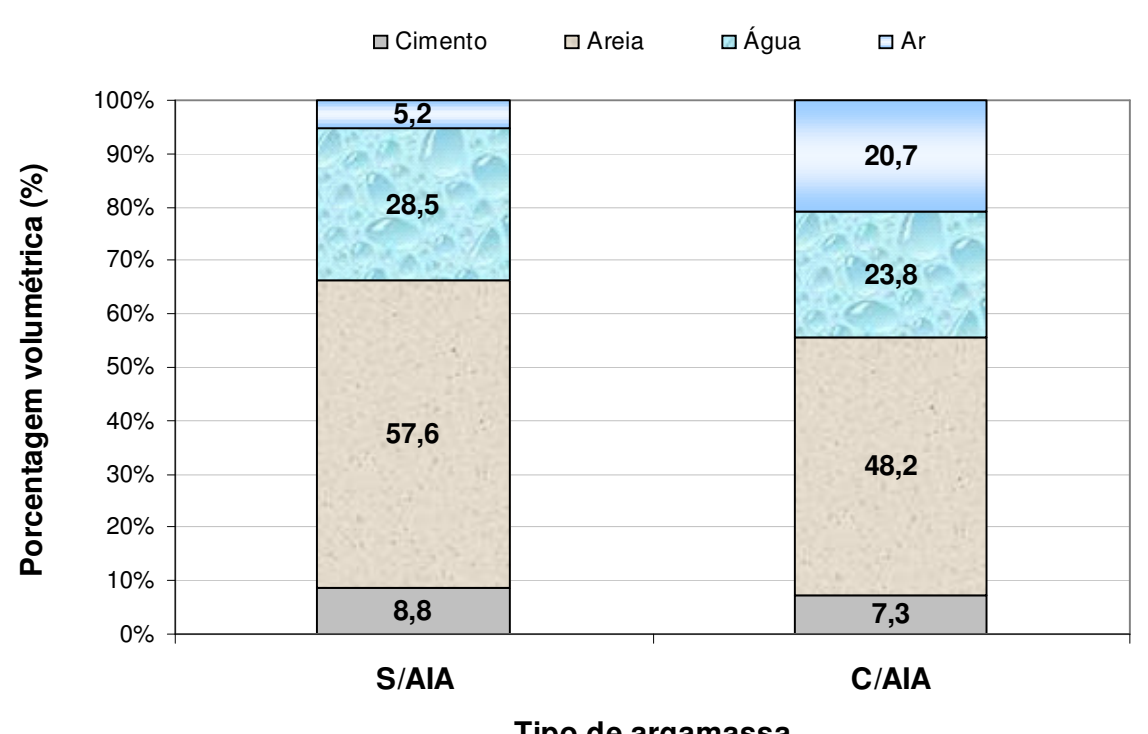

Tipo de argamassa

Figura 6-23: Percentagem volumétrica dos constituintes das argamassas utilizadas no experimento

Verifica-se na Figura 6-23 que apesar de que as duas argamassas foram produzidas com a mesma massa de cimento e areia a inclusão do incorporador de ar modificou a distribuição em volume das argamassas resultantes.

\footnotetext{
${ }^{15}$ A carga para $1,5 \mathrm{~mm}$ de deformação superou a carga máxima da célula de carga ( $\left.1 \mathrm{kN}\right)$ utilizada no ensaio
} 
O ensaio denominado squeeze-flow, cujas características tem sido detalhadas no trabalho de Cardoso; Pileggi e John (2005) permite obter um indicativo da facilidade de espalhamento das argamassas na etapa de aplicação através da medida do esforço necessário para comprimir o material entre duas placas paralelas gerando deformações por cisalhamento e deslocamento do material. Segundo Antunes (2005) a facilidade de espalhamento da argamassa no estado fresco está relacionada com o potencial de macro-defeitos de interface que podem ser gerados e que prejudicam a aderência do revestimento. Assim este ensaio foi utilizado com o intuito de se ter um indicador para ajudar na obtenção de uma adequada extensão de aderência, uma vez que os macro-defeitos avaliados no experimento foram gerados intencionalmente.

Os valores do ensaio de squeeze-flow mostrados na Tabela 6-3 indicam que a inclusão do incorporador de ar permitiu um espalhamento maior da argamassa com cargas abaixo de $1 \mathrm{kN}$. O perfil descrito por ambas as argamassas no ensaio de squeeze flow é apresentado na Figura 6-24

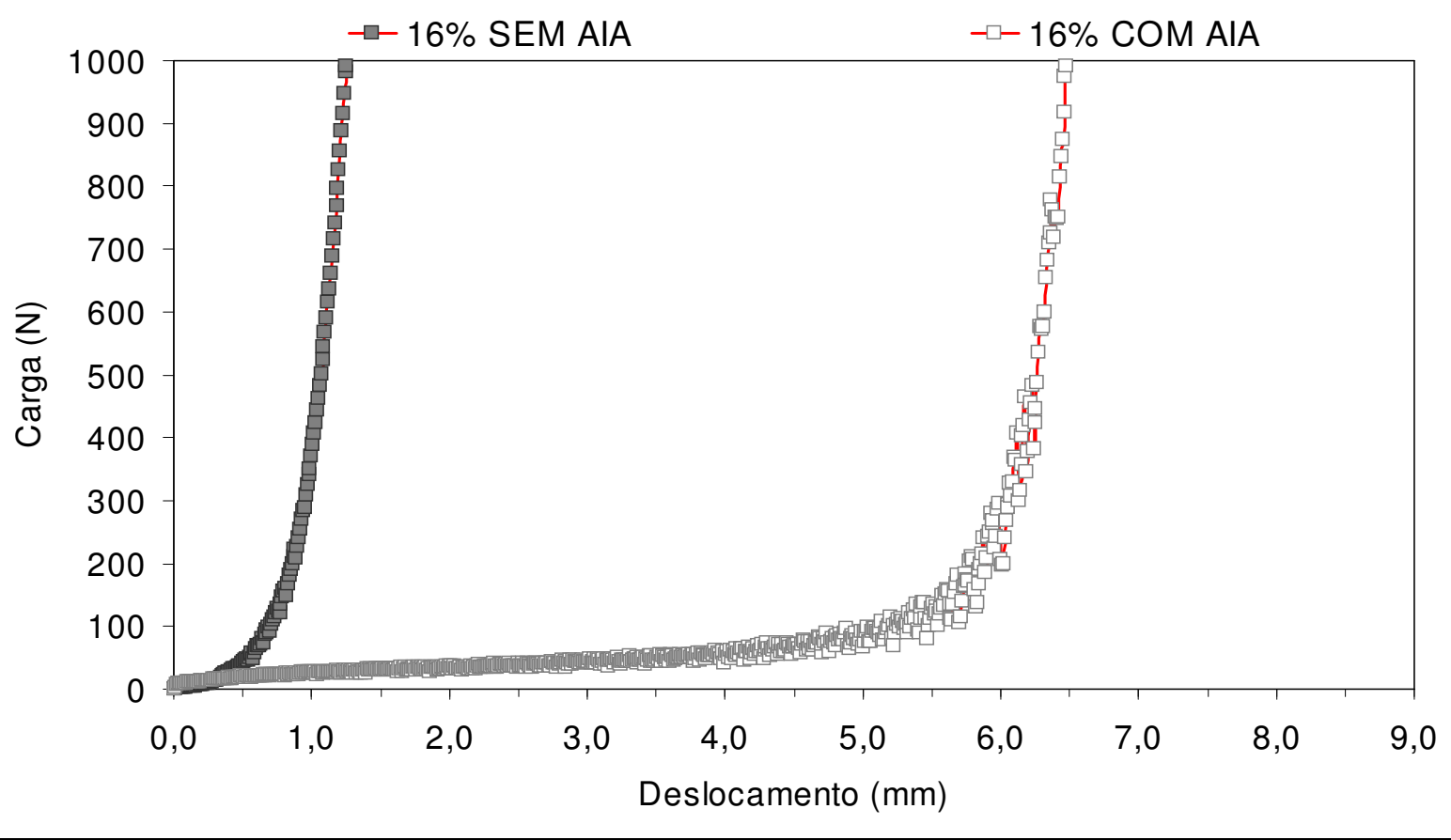

Figura 6-24: Curvas de carga versus deslocamento obtidas no ensaio de squeeze-flow para as argamassas utilizadas no experimento: S/AIA e C/AIA.

Pode-se observar na Figura 6-24 uma clara diferença entre as duas argamassas quanto à sua facilidade espalhamento na superfície do substrato, sendo a inclusão do incorporador de ar o fator que favoreceu o melhor espalhamento da argamassa 
com a indicação 16\% C/AIA. Entretanto o enrijecimento da argamassa $16 \%$ S/AIA para os mesmos níveis de carga pode ser explicado pelo atrito gerado nos constituintes da argamassa em função do maior volume de agregados presentes na argamassa.

\subsubsection{Estado endurecido}

De acordo com os procedimentos de ensaio definidos na Tabela 5-4, foram obtidos os resultados para as propriedades físicas e mecânicas das argamassas utilizadas os quais são apresentados na Tabela 6-4:

Tabela 6-4: Resultados dos ensaios mecânicos realizados na argamassa de revestimento e base de concreto.

\begin{tabular}{|c|c|c|c|c|c|c|}
\hline Material & $\begin{array}{l}\text { Módulo } \\
\text { (E) } \\
\text { (MPa) }\end{array}$ & $\begin{array}{l}\text { Densidade } \\
\text { aparente } \\
\left(\mathrm{kg} / \mathrm{m}^{3}\right)\end{array}$ & $\begin{array}{l}\text { Resistência à } \\
\text { tração na } \\
\text { flexão (MPa) }\end{array}$ & $\begin{array}{l}\text { Resistência à } \\
\text { compressão } \\
(\mathrm{MPa})\end{array}$ & $\begin{array}{l}\text { Coeficiente de } \\
\text { dilatação térmica } \\
\mathrm{m} / \mathrm{m}^{\circ} \mathrm{C}^{-1}\end{array}$ & $\begin{array}{l}\text { Coefiente de } \\
\text { Poisson }\end{array}$ \\
\hline $\begin{array}{l}\text { Argamassa 1:4 } \\
\text { sem AIA } \\
\text { (prisma) }\end{array}$ & $\begin{array}{l}18491 \\
\text { (ultrasom) }\end{array}$ & 1995,9 & 4,039 & 14,76 & $10,6 \times 10^{-6}$ & 0,18 \\
\hline $\begin{array}{l}\text { Argamassa 1:4 } \\
\text { com AIA } \\
\text { (prisma) }\end{array}$ & $\begin{array}{l}11094 \\
\text { (ultrasom) }\end{array}$ & 1651,6 & 2,353 & 6,53 & $9,3 \times 10^{-6}$ & 0,18 \\
\hline \multirow{2}{*}{$\begin{array}{l}\text { Substrato de } \\
\text { Concreto }\end{array}$} & $\begin{array}{l}29200 \\
\text { (secante) }\end{array}$ & \multirow[t]{2}{*}{-} & \multirow[t]{2}{*}{-} & \multirow[t]{2}{*}{46,30} & \multirow[t]{2}{*}{ - } & \multirow[t]{2}{*}{0,22} \\
\hline & $\begin{array}{l}40144 \\
\text { (ultrasom) }\end{array}$ & & & & & \\
\hline
\end{tabular}

Os valores obtidos para o módulo de elasticidade e resistência mecânica das duas argamassas mostraram-se coerentes com a densidade e teor de ar incorporado de cada uma delas como apresentado na Figura 6-25. 


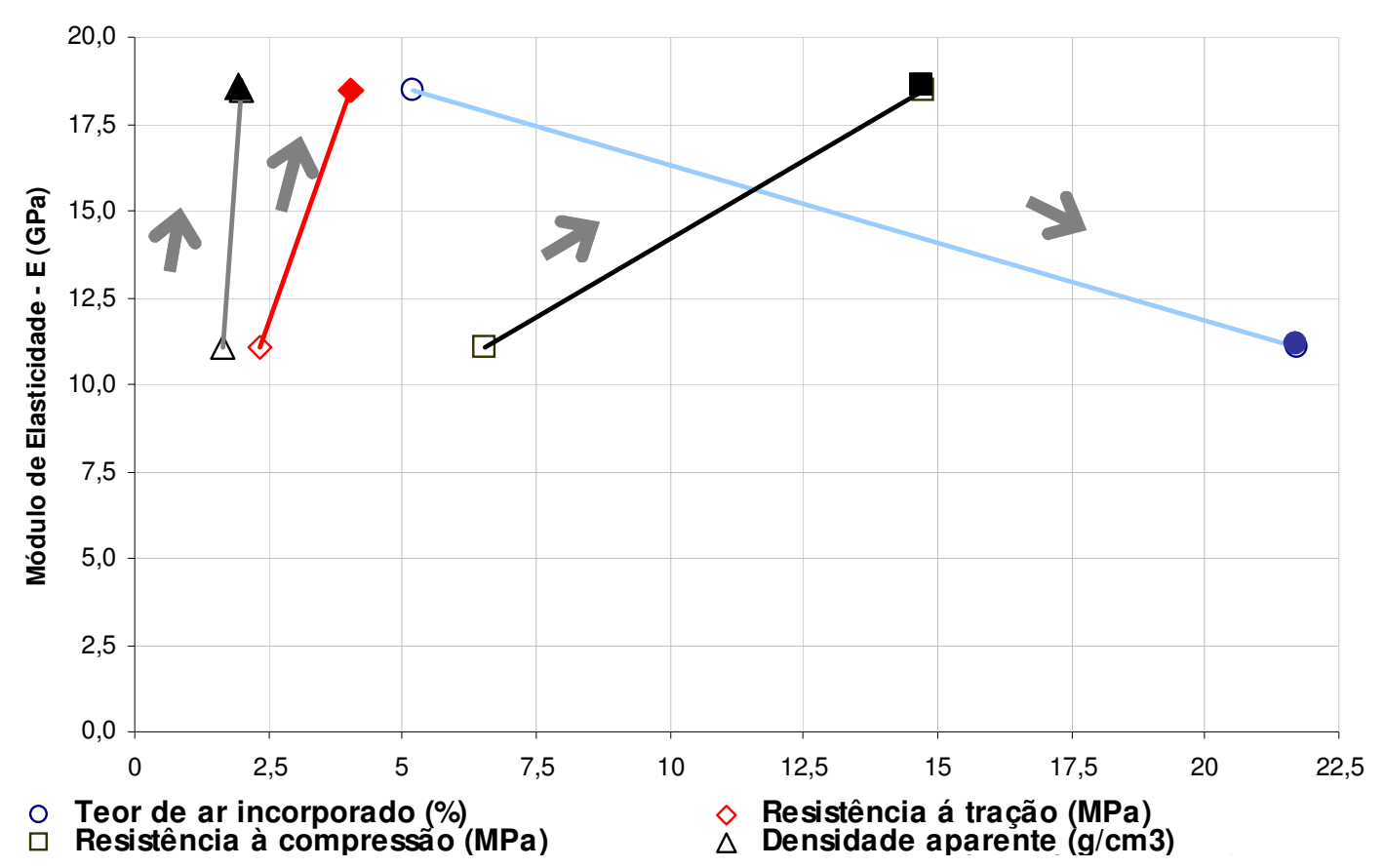

Figura 6-25: Relação entre o módulo de elasticidade e as propriedades mecânicas das argamassas utilizadas no programa experimental

As duas argamassas utilizadas no programa experimental mostraram propriedades mecânicas diferenciadas e a inclusão do incorporador de ar promoveu a diminuição do módulo de elasticidade e as resistências à compressão e tração das argamassas. Entretanto com a diminuição do valor do módulo não se atingiu o valor mínimo utilizado na etapa das simulações (2GPa). Deve ser destacado porém, que a definição desse valor mínimo foi a partir de valores levantados na literatura nos quais o valor módulo de elasticidade estático à compressão é determinado experimentalmente conforme o procedimento da ABNT, NBR 8522 (2003).

Por outro lado, observa-se que os valores de módulo de elasticidade obtidos pelo método do ultra-som estão acima de $10 \mathrm{GPa}$, o qual coloca as duas argamassas analisadas em situação crítica de acordo com a Figura 6-21. Porém, deve ser lembrado que os valores de modulo de elasticidade críticos recomendados referemse às condições de contorno em que há restrição total à movimentação, hipótese que não se aplica ao revestimento ensaiado, cuja restrição à movimentação é dada principalmente pela aderência do revestimento à base.

A partir dos corpos de prova do revestimento preparado para os ensaios de choque térmico foram extraídos prismas do revestimento com dimensões de $30 \mathrm{~mm}$ (espessura) $\times 40 \mathrm{~mm} \times 160 \mathrm{~mm}$, como mostrado na Figura 6-26 a, para avaliar a 
variação das propriedades como densidade aparente, módulo de elasticidade e resistências mecânicas (Figura 6-26 b) dessas argamassas em relação às propriedades obtidas através dos prismas moldados.
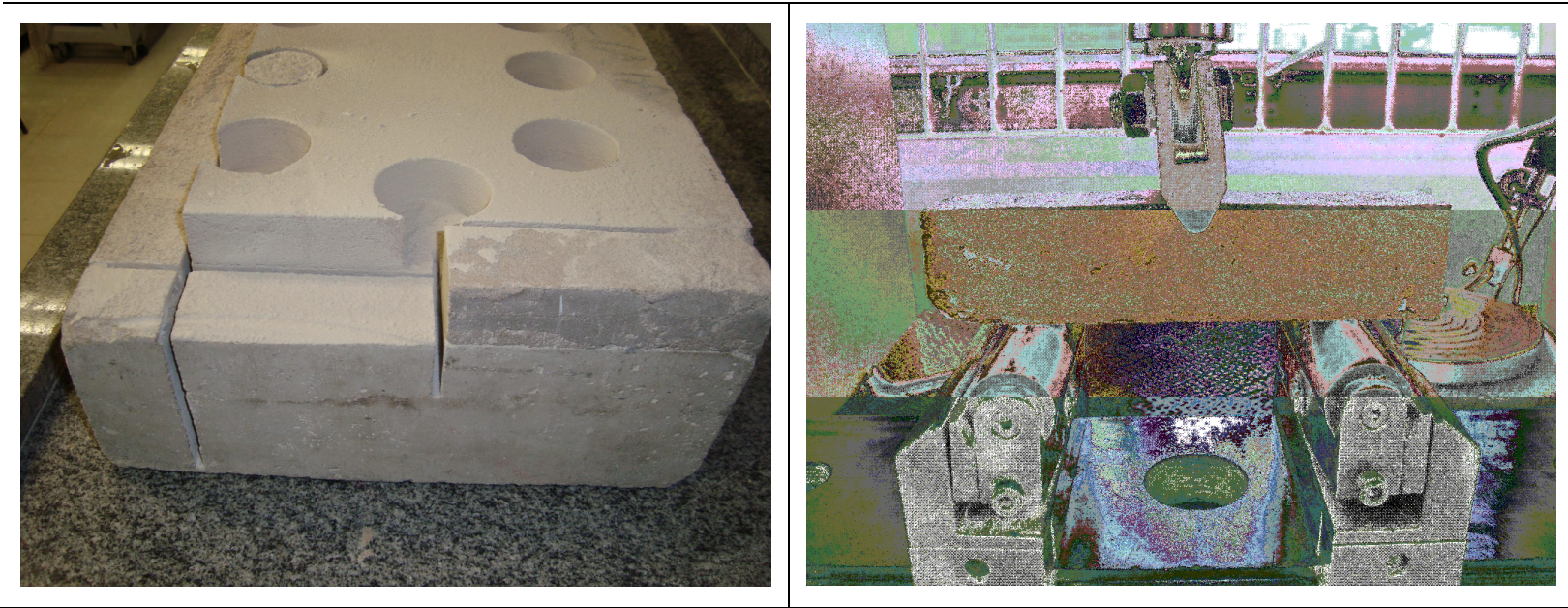

Figura 6-26: a) Corte do revestimento para extração de prismas para ensaios mecânicos e b) ensaio de tração na flexão em prisma extraído do revestimento

Os resultados obtidos a partir dos prismas extraídos do revestimento com e sem macro-defeitos de interface mas que não foram submetidos aos ciclos de choque térmico são apresentados na Tabela 6-1

Tabela 6-5: Resultados dos ensaios mecânicos realizados nos prismas extraídos dos corpos de prova de revestimento.

\begin{tabular}{l|l|l|l|l}
\hline Material & $\begin{array}{l}\text { Módulo (E) } \\
(\mathrm{MPa})\end{array}$ & $\begin{array}{l}\text { Densidade } \\
\text { aparente }\left(\mathrm{kg} / \mathrm{m}^{3}\right)\end{array}$ & $\begin{array}{l}\text { Resistência à tração na } \\
\text { flexão }(\mathrm{MPa})\end{array}$ & $\begin{array}{l}\text { Resistência à } \\
\text { compressão (MPa) }\end{array}$ \\
\hline $\begin{array}{l}\text { Prisma extraido } \\
\text { de revestimento } \\
0 \% \mathrm{~S} / \text { AIA }\end{array}$ & 19532 & 1,941 & 3,01 & 6,83 \\
\hline $\begin{array}{l}\text { Prisma extraido } \\
\text { de revestimento } \\
0 \% \mathrm{C} / \text { AIA }\end{array}$ & 18605 & 1,822 & 2,67 & 4,57 \\
\hline $\begin{array}{l}\text { Prisma extraido } \\
\text { de revestimento } \\
35 \% \text { S/ AIA }\end{array}$ & 20342 & 1,943 & 4,06 & 6,10 \\
\hline $\begin{array}{l}\text { Prisma extraido } \\
\text { de revestimento } \\
35 \% \text { C/ AIA }\end{array}$ & 16593 & 1,801 & 2,61 & 5,97 \\
\hline
\end{tabular}

Observa-se uma variação em relação aos valores obtidos na moldagem dos prismas para o valor do módulo de elasticidade, sendo maiores os valores de módulo dos prismas extraídos do revestimento. Entretanto para as resistências à compressão e tração na flexão os valores obtidos com os prismas moldados são maiores. $\mathrm{Na}$ comparação da densidade aparente houve muito pouca variação. 


\subsubsection{Distribuição das temperaturas nos ensaios de choque térmico}

A apresentação dos resultados é para cada uma das 4 combinações de corpos de prova que foram submetidos ao choque térmico:

- $0 \%$ de taxa de macro-defeitos de interface e argamassa sem aditivo incorporador de ar (0\% S/AIA);

- $0 \%$ de taxa de macro-defeitos de interface e argamassa com aditivo incorporador de ar (0\% C/AIA);

- $35 \%$ de taxa de macro-defeitos de interface e argamassa sem aditivo incorporador de ar (35\% S/AIA);

- $35 \%$ de taxa de macro-defeitos de interface e argamassa com aditivo incorporador de ar (35\% C/AIA)

O registro das temperaturas nos corpos de prova, realizado com termopares permitiu obter leituras na parte central da superfície, interface e face posterior de cada corpo de prova mantendo um alinhamento perpendicular ao plano da superfície do corpo de prova.

Os corpos de prova (16 cps) foram submetidos ao choque térmico durante 30 ciclos em dois grupos, pois o suporte comporta oito corpos de prova em cada bateria de ensaios (Figura 6-27a)

Desta forma foi possível ensaiar duas combinações de cada corpo de prova em cada ciclo de choque térmico (Figura 6-27b) sendo obtidas duas curvas da distribuição de temperaturas.

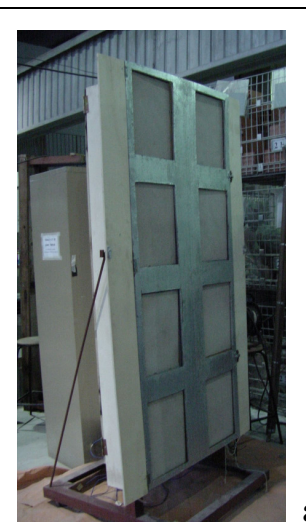

a)

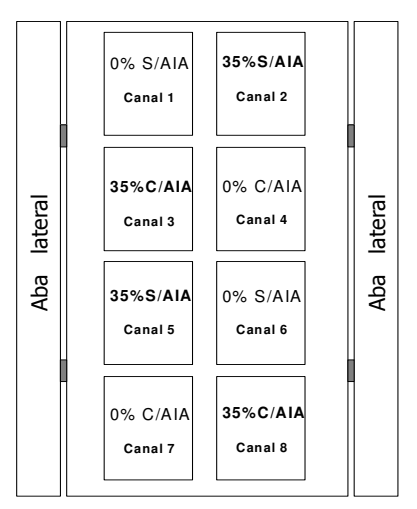

b)

Figura 6-27: Distribuição dos corpos de prova no painel de ensaio 
O intervalo entre as leituras de temperatura foi definido no programa de aquisição (Labview) em 5 segundos. Os termopares registraram temperaturas na parte central da superfície, interface e face posterior de cada corpo de prova.

\subsubsection{Temperaturas na superfície dos revestimentos}

A Figura 6-28 apresenta os valores médios da evolução das temperaturas na superfície dos corpos de prova, nos 30 ciclos de choque térmico, para as combinações: 0\% S/AIA (Figura 6-21a) 0\% C/AIA (Figura 6-21b), 35\% S/AIA (Figura 6-21c) 35\% C/AIA (Figura 6-21d), no período completo do ensaio, ou seja 3 horas de aquecimento e 1 hora de resfriamento.

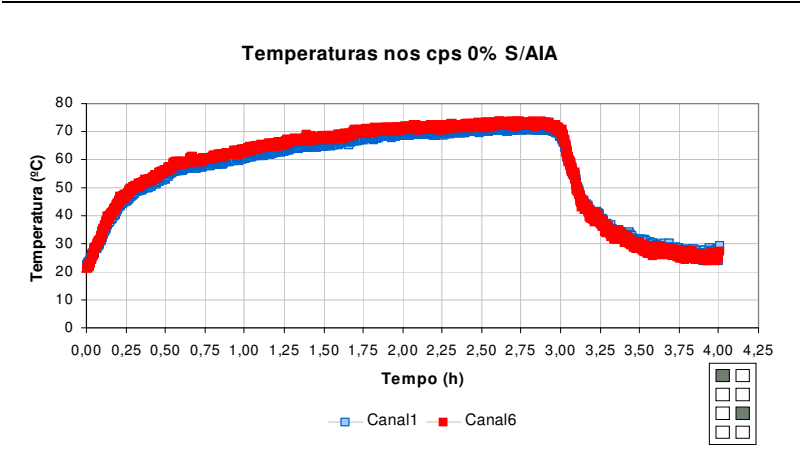

a)

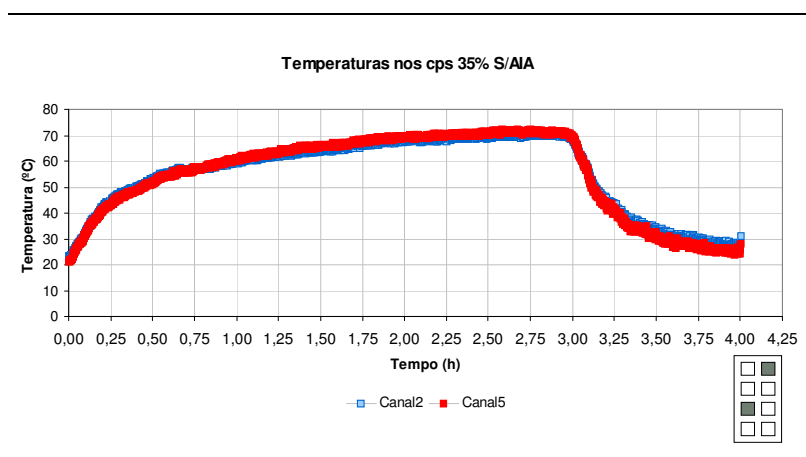

c)

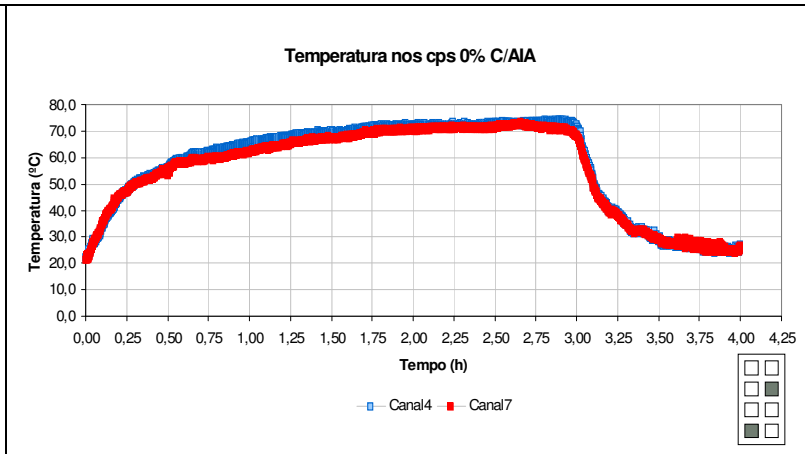

b)

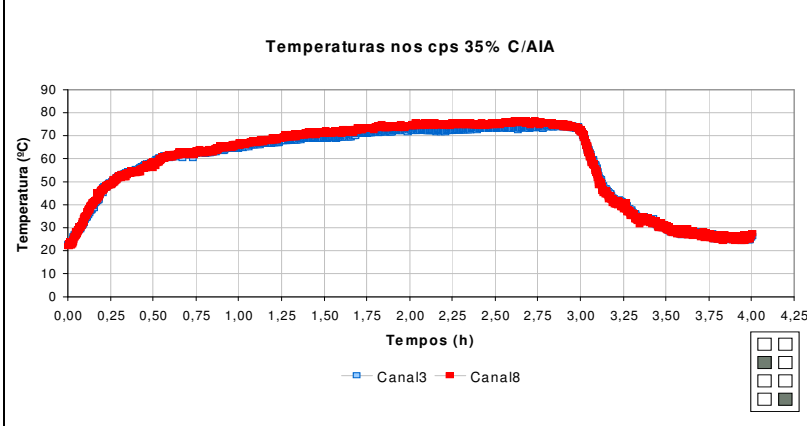

d)

Figura 6-28: Distribuição média de temperaturas nos ensaios de choque térmico para as combinações: a) $0 \%$ S/AIA; b) $0 \%$ C/AIA; c) 35\% S/AIA, e d) $35 \%$ C/AIA

Os gráficos mostram distribuição de temperaturas na superfície bastante semelhantes para as quatro combinações e com muito pouca variação em função de posição do corpo de prova no painel. Podem ser observados em cada curva três trechos: um inicial com uma velocidade de aquecimento maior no início do ensaio partindo da temperatura ambiente do laboratório (em torno de $23^{\circ} \mathrm{C}$ ) até aproximadamente os primeiros quinze minutos; um segundo trecho com menor velocidade de aquecimento até atingir o patamar de $70^{\circ} \mathrm{C}$ e um terceiro trecho 
(choque térmico) em que é promovida a diminuição da temperatura superficial dos corpos de prova.

Para avaliar o efeito dos fatores que diferenciavam cada uma das combinações a Figura 6-29 apresenta a variação da temperatura superficial das quatro combinações no período dos 15 minutos iniciais do aquecimento.

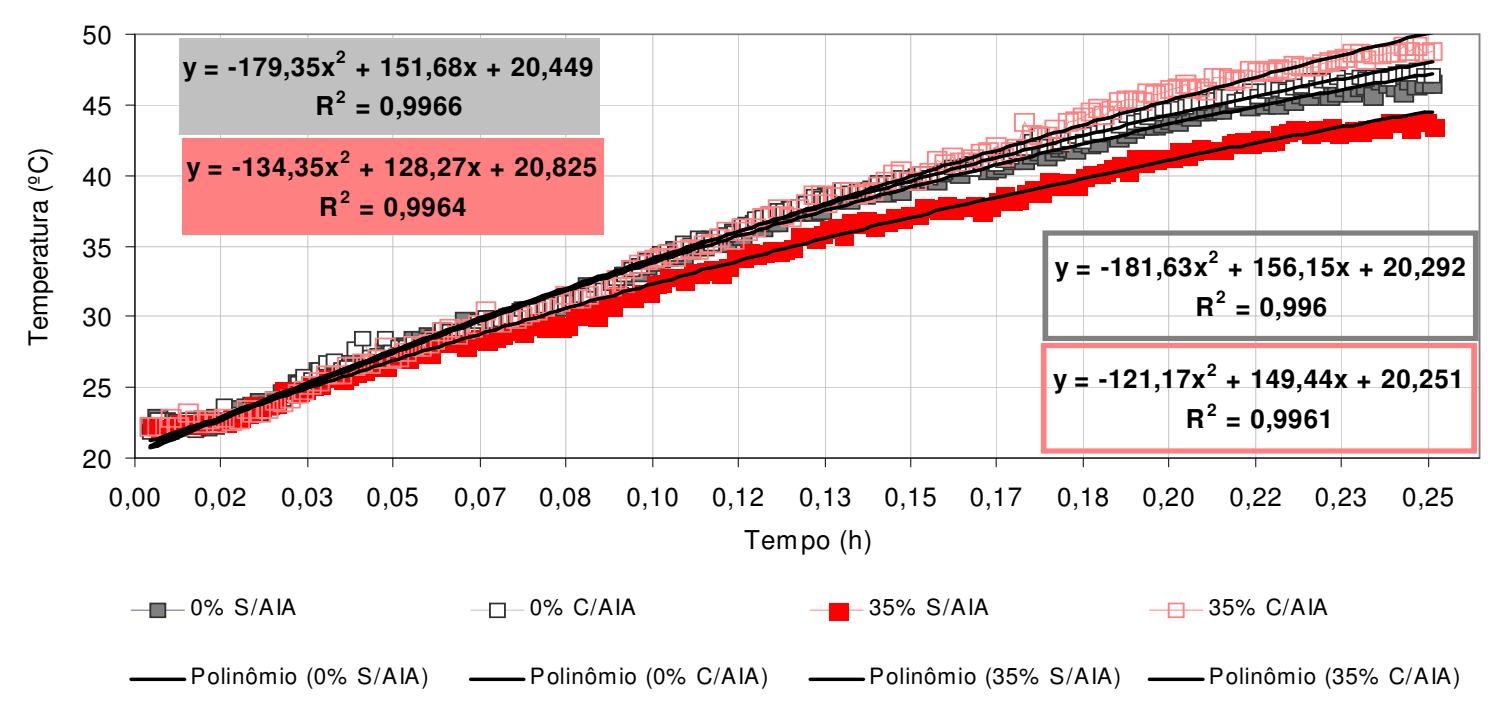

Figura 6-29:Temperaturas superficiais nas 4 combinações nos primeiros $15 \mathrm{~min}$. do aquecimento.

Observa-se que nos minutos iniciais não há diferença de taxa de aquecimento dentre os revestimentos correspondentes as quatro combinações. Essa diferença começa a aparecer após de aproximadamente dez minutos de iniciado o aquecimento para o revestimento com $35 \%$ de macro-defeitos de interface e S/AIA que vai ficando com uma taxa de aquecimento menor do que as outras combinações. Enquanto que para a combinação de $35 \%$ de macro-defeitos de interface C/AIA a taxa de aquecimento vai se mostrando ligeiramente maior. De acordo os perfis de temperatura descritos na Figura 6-29, como era esperado a presença dos macro-defeitos de interface não interfere na variação da temperatura superficial como ocorre com a inclusão do incorporador de ar.

Finalmente, a Figura 6-29 mostra também que a distribuição de temperaturas apresenta boas correlações com funções quadráticas.

Na Figura 6-30 apresenta a distribuição de temperaturas superficiais para as quatro combinações, mostrando o período compreendido entre os $15 \mathrm{~min}$ iniciais e as $3 \mathrm{~h}$ do aquecimento. 
Mantendo o comportamento observado nos $15 \mathrm{~min}$ iniciais a distribuição de temperaturas para a combinação 35\% S/AIA permanece com a menor taxa de aquecimento, isto é, levou mais tempo para atingir a temperatura de $70^{\circ} \mathrm{C}$. Em geral, esse tempo foi de 1,5 horas aproximadamente para as outras três combinações.

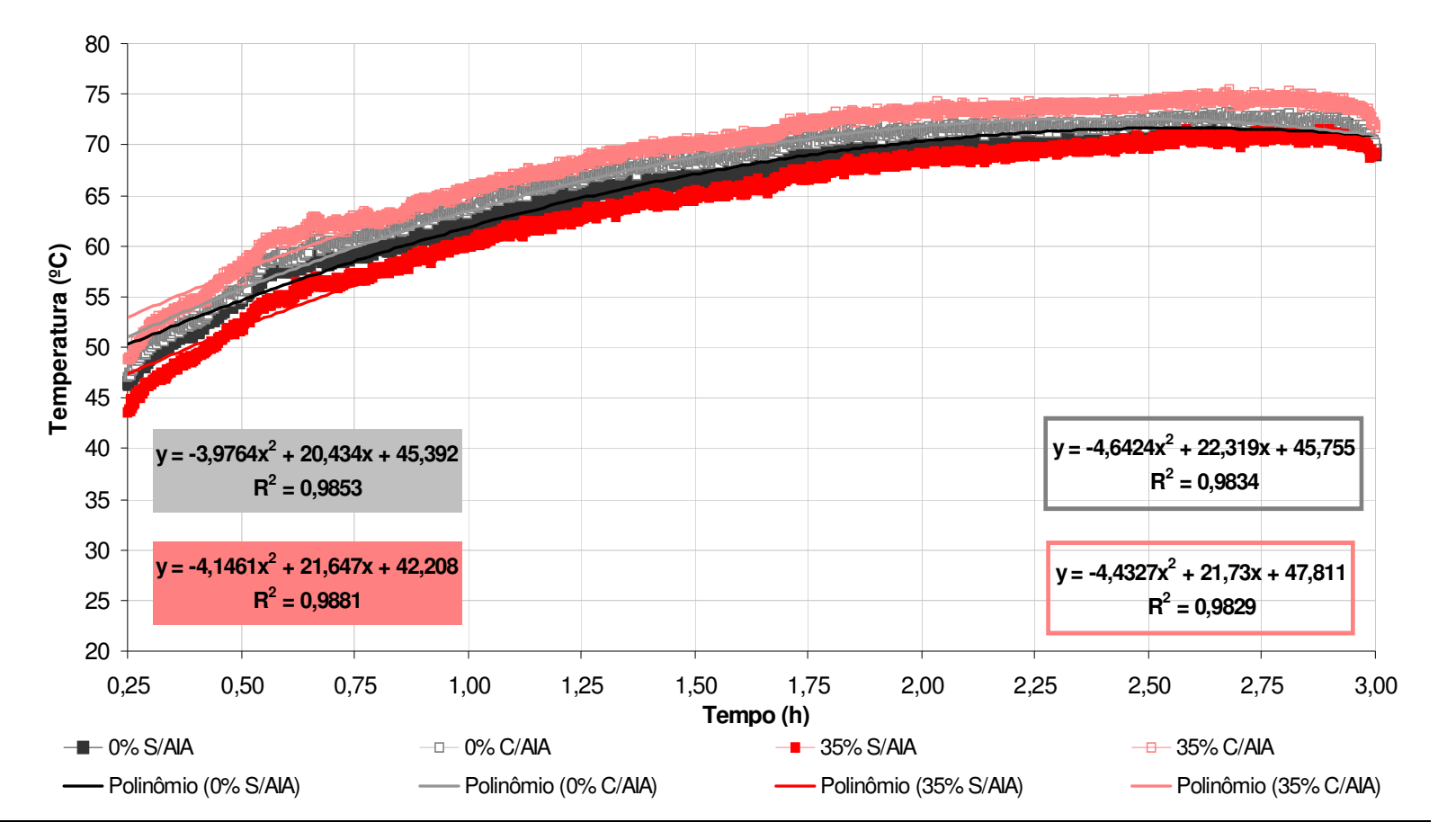

Figura 6-30: Temperaturas superficiais para as 4 combinações entre os $15 \mathrm{~min}$ e $3 \mathrm{~h}$ do aquecimento

De acordo com Kingery (1960) devido ao efeito da maior porosidade dos revestimentos C/AIA, esperava-se que a inclusão do incorporador de ar interferisse na temperatura superficial dos corpos de prova promovendo um grau de isolamento térmico maior devido a diminuição da condutividade térmica do revestimento C/AIA, em função da baixíssima condutividade térmica do ar que segundo Incropera e DeWitt (1990) é de 0,026 W/mºK. Porém o comportamento observado mostra uma melhor absorção do calor na superfície nos revestimentos 35\% C/AIA e 0\% C/AIA.

A Figura 6-31 apresenta a distribuição de temperaturas superficiais para as quatro combinações no período do resfriamento da superfície, ou seja, entre a terceira e quarta hora do ensaio.

Verifica-se também neste trecho que os revestimentos menos densos $(0 \% \mathrm{C} / \mathrm{AIA}$ e $35 \% \mathrm{C} / \mathrm{AIA}$ ) perdem calor mais rapidamente que os revestimentos S/AIA.

Para os corpos de prova em que não foram provocados macro-defeitos de interface $(0 \%)$ a máxima diferença de temperaturas superficiais entre os corpos de prova 
S/AIA e C/AIA foi de $2,94^{\circ} \mathrm{C}$. E para os corpos de prova com $35 \%$ de macro-defeitos de interface, essa diferença atingiu $6,81^{\circ} \mathrm{C}$.

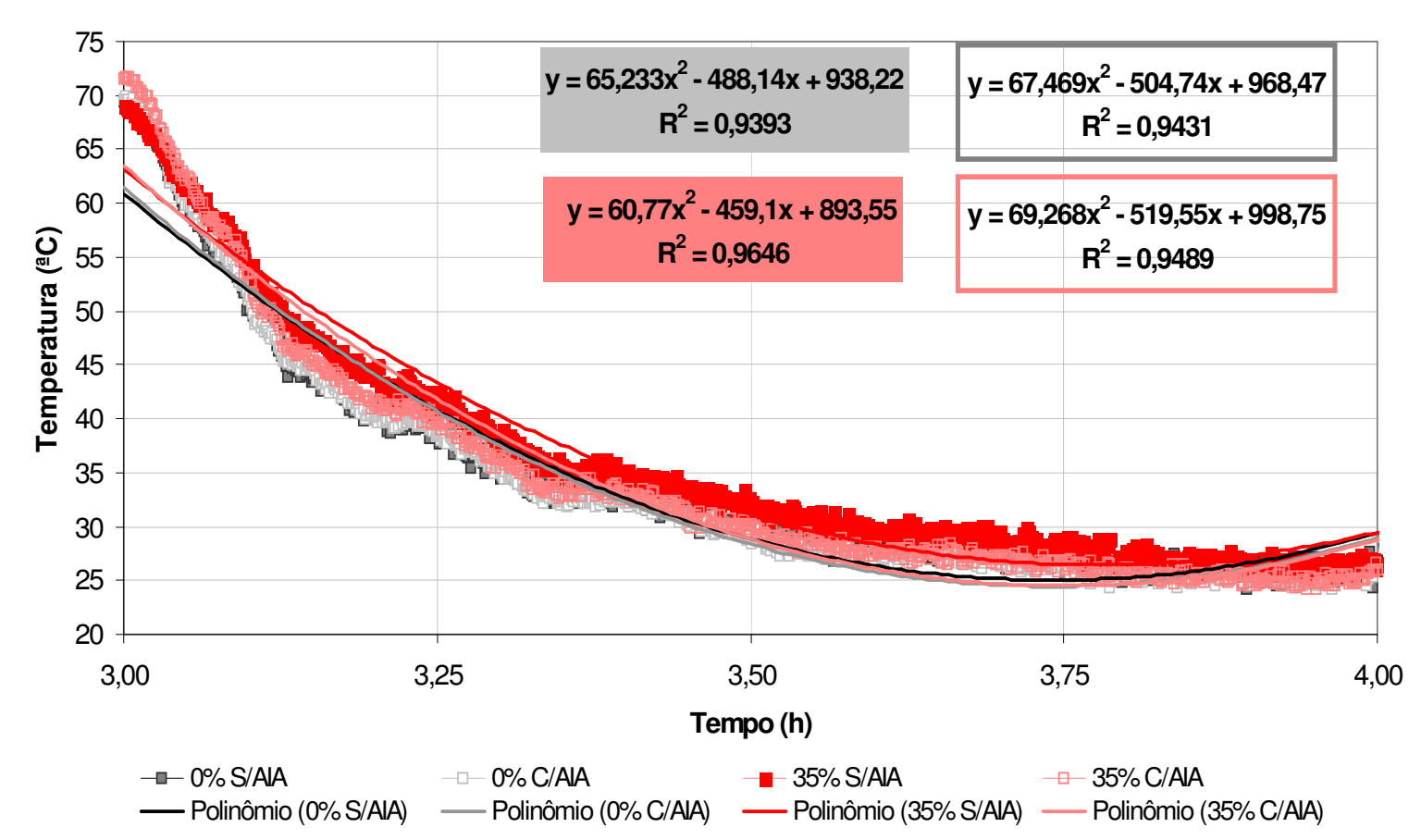

Figura 6-31: Temperaturas superficiais para as 4 combinações no período do choque térmico entre as $3 \mathrm{~h}$ e $4 \mathrm{~h}$ do ensaio

Observa-se que a semelhança do período de aquecimento, a taxa de diminuição de temperatura é maior para o revestimento da combinação 35\% de macro-defeitos de interface C/AIA, ou seja, a perda de calor superficial é mais rápida para esses revestimentos, principalmente nos 15 minutos iniciais do resfriamento.

Analisando os perfis de temperatura obtidos no aquecimento (Figura 6-29 e Figura 6-30) e os fatores determinantes no maior ou menor ganho de temperatura superficial atingida pelos revestimentos de cada combinação, verificou-se que foram tomados os cuidados para que a quantidade de calor emitido pelo painel e a parcela absorvida pela superfície dos corpos de prova, ou seja, sua absortividade térmica foram mantidos constantes em todos os ensaios.

Por outro lado, analisando a forma em que é realizado o resfriamento no ensaio com a aplicação de água na superfície, pode-se deduzir que o aumento da condutividade térmica no revestimento e, portanto sua taxa de absorção de calor pode estar relacionada com o conteúdo de água residual no revestimento no início do período seguinte de aquecimento. 
O tempo de espera entre um ciclo e outro nos ensaios do programa experimental piloto em que era realizado um ensaio por dia, deixando secar os corpos de prova até o dia seguinte, foi de no máximo 20 horas. Porém esse tempo foi reduzido no programa experimental definitivo a uma hora e meia por questões relativas ao cronograma do trabalho, sendo realizados até três ciclos por dia.

Esta situação pode ter provocado um acúmulo maior de água residual nos revestimentos mais porosos (C/AIA) e com isto o aumento da sua condutividade térmica, provocando maiores taxas de aquecimento e resfriamento na superfície dos revestimentos.

Para confirmar estas hipóteses foram analisadas as curvas de distribuição de temperaturas superficiais em cada combinação no primeiro choque térmico (Figura 6-32), período em que as superfícies de todos os corpos de prova encontravam-se "secas", já que ainda não tinha sido promovido o resfriamento com água.
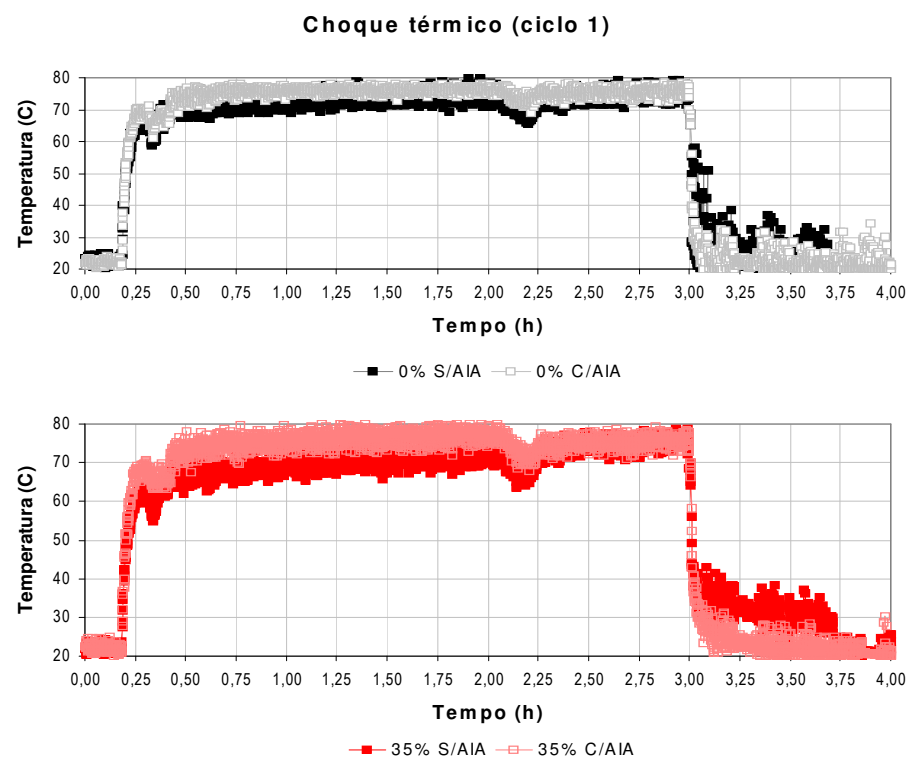

Figura 6-32: Distribuição de temperaturas superficiais para as 4 combinações no primeiro ciclo de choque térmico

De acordo com a Figura 6-32 quando não se tinha a interferência da água (período do primeiro aquecimento) as temperaturas superficiais nos corpos de prova não experimentaram de forma geral variação significativa devido à maior porosidade gerada pelo incorporador de ar nos revestimentos C/AIA. Porém, observa-se na 
mesma figura que a presença dos macro-defeitos de interface gera uma certa perturbação na estabilização das temperaturas superficiais.

Quando, iniciado o primeiro período de resfriamento com água, surge a influência da porosidade na absorção de água e no aumento da condutividade térmica.

Desta forma os períodos de secagem dos corpos de prova no ambiente do laboratório certamente não permitiram a diminuição da umidade nos revestimentos.

\subsubsection{Temperatura na interface base-revestimento}

As temperaturas na interface durante a execução dos ensaios também foram registradas para cada um dos dois corpos de prova submetidos aos 30 ciclos de choque térmico.

A Figura 6-33 apresenta a distribuição das temperaturas médias (dos 30 ciclos) na interface dos corpos de prova para cada combinação.

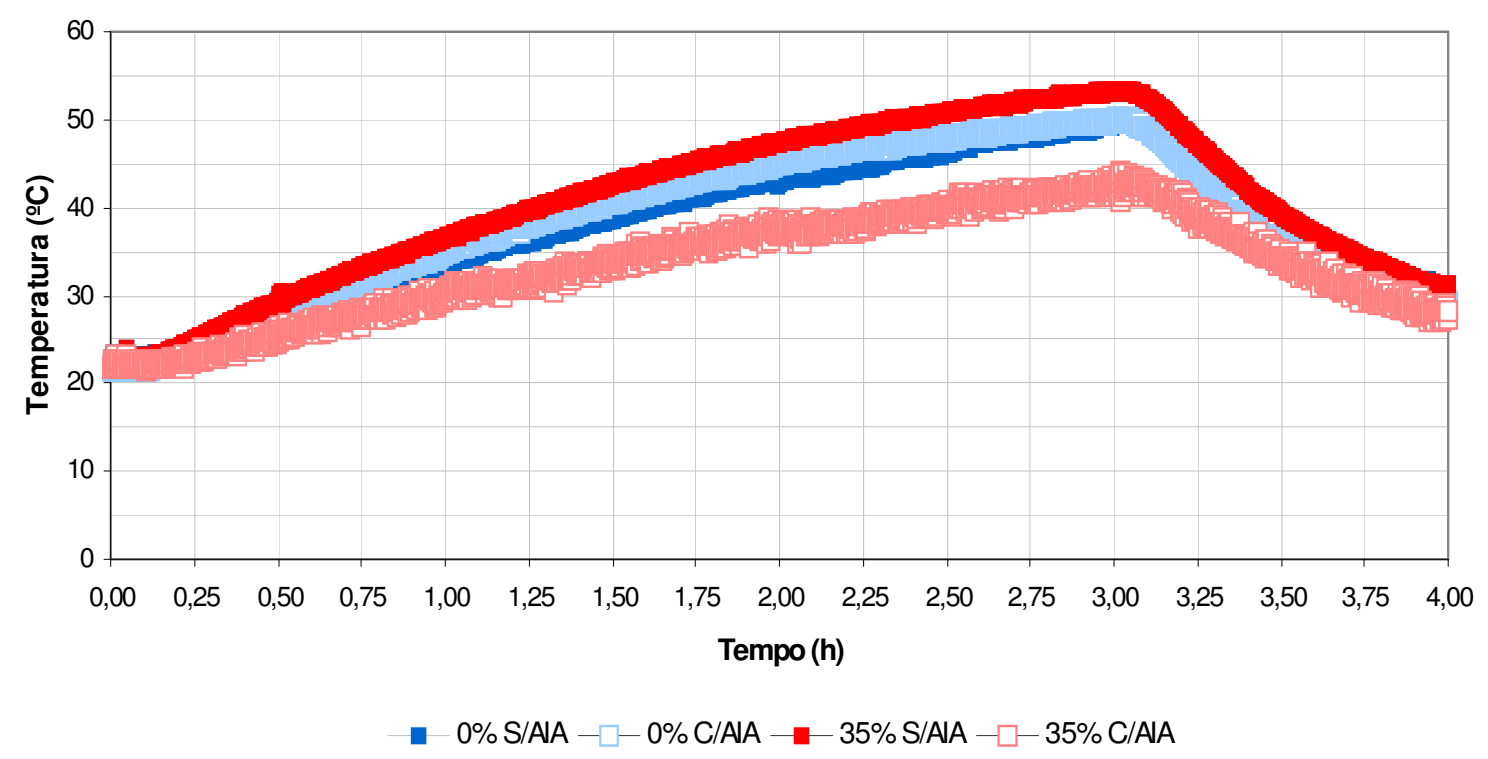

Figura 6-33: Temperaturas médias nas interfaces base-revestimento dos corpos de prova no período de aquecimento e resfriamento para as combinações 0\% S/AIA, 0\% C/AIA, 35\% S/AIA e 35\% C/AIA.

De maneira semelhante aos perfis de temperatura obtidos na superfície, observouse na interface base-revestimento perfis de temperatura com três regiões coincidentes no tempo com aquelas observadas no perfil das temperaturas superficiais (Figura 6-28).

A primeira região em que não há praticamente alteração da temperatura na interface, que mostra o tempo que foi necessário para que o ganho de calor 
produzido na superfície do revestimento atingisse a região da interface, o qual não ultrapassou os 15 minutos iniciais do ensaio. Já na segunda região observa-se um incremento quase linear da temperatura na interface até chegar na terceira hora, momento em que é produzido o choque térmico, alterando o perfil das curvas.

Os corpos de prova em que não foram provocados macro-defeitos de interface $(0 \%$ na cor azul) não apresentaram diferença de comportamento em função da inclusão ou não do aditivo incorporador de ar. A diferença média de temperaturas entre uma combinação e outra foi de $1,4^{\circ} \mathrm{C}$ e o máximo valor dessa diferença foi de $2,95^{\circ} \mathrm{C}$.

Já para os corpos de prova em que foram provocados macro-defeitos de interface (cor vermelha) a diferença média da temperatura atingida na interface foi de $7,5^{\circ} \mathrm{C}$, sendo atingida uma diferença máxima de $12,52^{\circ} \mathrm{C}$.

Analisando os períodos identificados na Figura 6-33 para as quatro combinações avaliadas no ensaio foi possível associar a distribuição das temperaturas da interface a determinadas funções.

A Figura 6-34 apresenta a distribuição de temperaturas para todas as combinações nos 15 minutos iniciais do aquecimento e as funções lineares associadas.

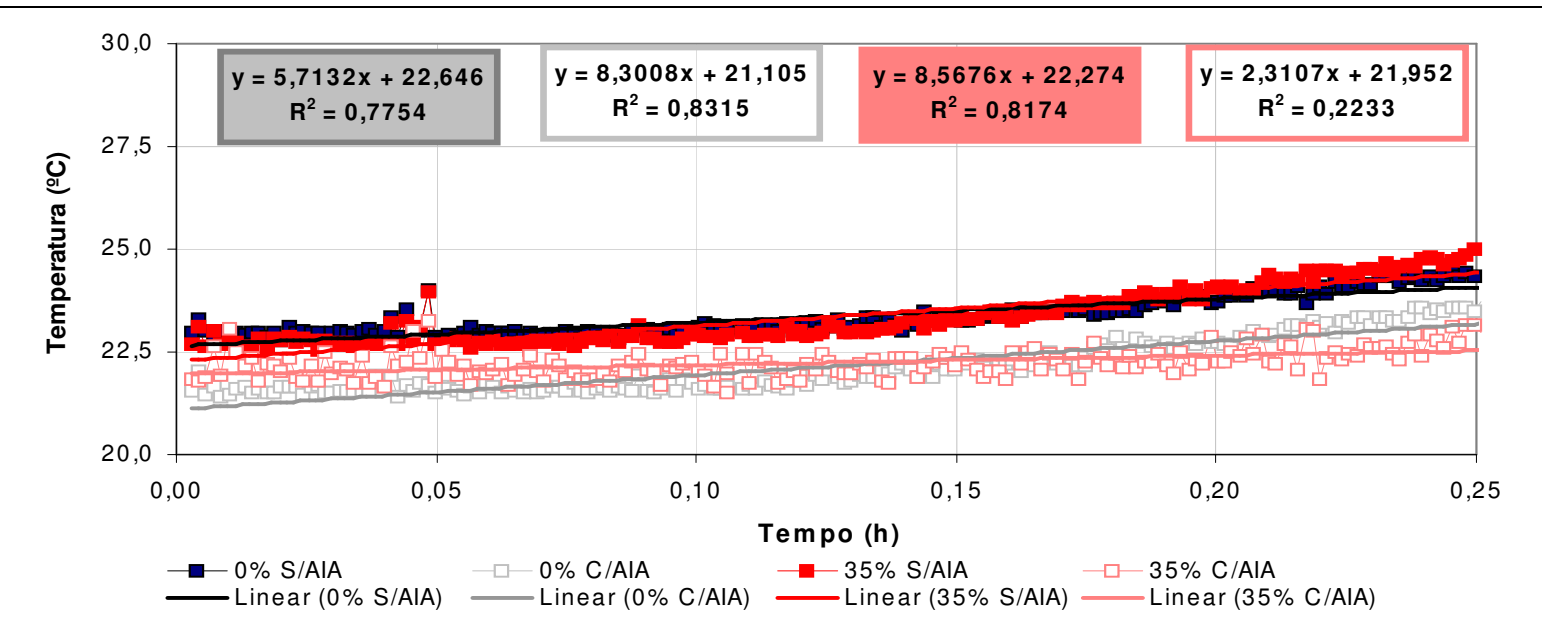

Figura 6-34: Temperaturas nas interfaces base-revestimento dos corpos de prova no período inicial de aquecimento até os 15 minutos $0 \%$ S/AIA,e $0 \%$ C/AIA, 35\% S/AIA e 35\%C/AIA

Analisando o trecho inicial na interface base-revestimento em que a alteração de temperatura é lenta (até os 15 minutos) observa-se taxas de aquecimento bastante próximas nos revestimentos (aproximadamente de 0,1 ${ }^{\circ} \mathrm{C}$ ) $0 \% \mathrm{~S} / \mathrm{AIA}, 0 \% \mathrm{C} / \mathrm{AIA}$ e $35 \%$ S/AIA. Por outro lado nota-se que a introdução dos macro-defeitos de interface 
causa uma perturbação maior na distribuição das temperaturas no revestimento em que foi adicionado o incorporador de ar, provocando uma taxa de aquecimento bastante menor, em torno de $0,04^{\circ} \mathrm{C} / \mathrm{min}$. Nesse caso a distribuição de temperaturas não pode ser associada a uma função linear.

Na Figura 6-35 são apresentados os perfis de temperatura na interface entre os 15 minutos iniciais e 3 horas de aquecimento, sendo possível associar as distribuições de temperaturas a funções lineais.

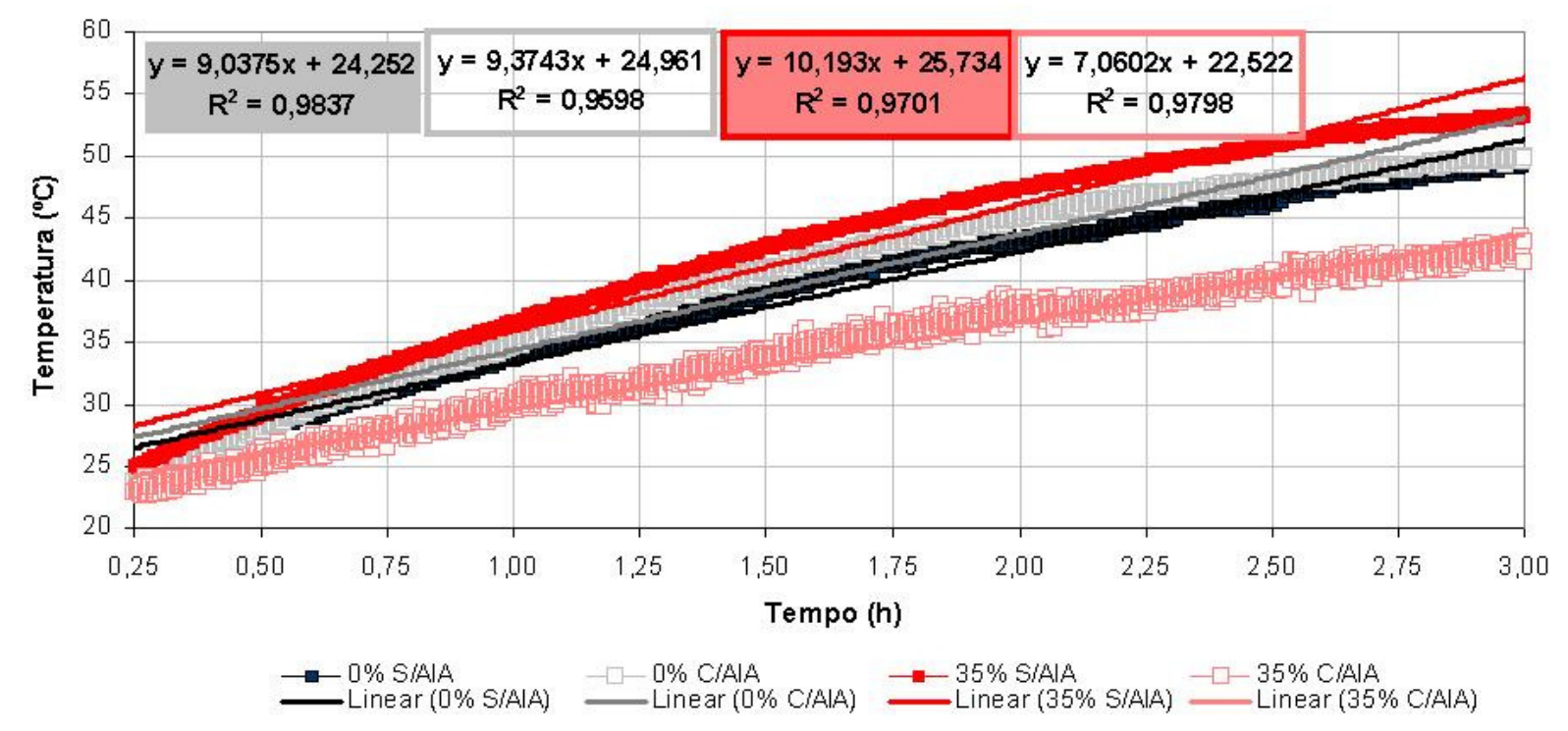

Figura 6-35: Temperaturas nas interfaces base-revestimento dos corpos de prova no período dedos 15 minutos até $3 \mathrm{~h}$ de aquecimento para as combinações: 0\% S/AIA, 0\% C/AIA, 35\% S/AIA e $35 \%$ C/AIA.

Observa-se que para o trecho analisado nos revestimentos sem macro-defeitos de interface o efeito da incorporação de ar na distribuição de temperaturas na interface é mínimo com curvas semelhantes e taxas de aquecimento de $0,08^{\circ} \mathrm{C} / \mathrm{min}$ para ambas combinações.

Com a introdução dos macro-defeitos na interface observa-se uma interferência maior da incorporação de ar no revestimento. Na combinação 35\% S/AIA, a taxa de aquecimento $\left(0,085^{\circ} \mathrm{C} / \mathrm{min}\right)$ é ligeiramente maior do que no caso dos revestimentos com $0 \%$ S/AIA e 0\% C/AIA. Porém, o efeito conjunto da inclusão dos macro-defeitos e do incorporador de ar promove um isolamento maior no revestimento (35\% C/AIA) cuja temperatura na interface aumenta com uma taxa de aquecimento $\left(0,05^{\circ} \mathrm{C} / \mathrm{min}\right)$ $30 \%$ menor do que no revestimento mais denso (35\% S/AIA). 
Na Figura 6-36 são apresentadas as distribuições de temperatura na interface entre a terceira e quarta hora (período de resfriamento).

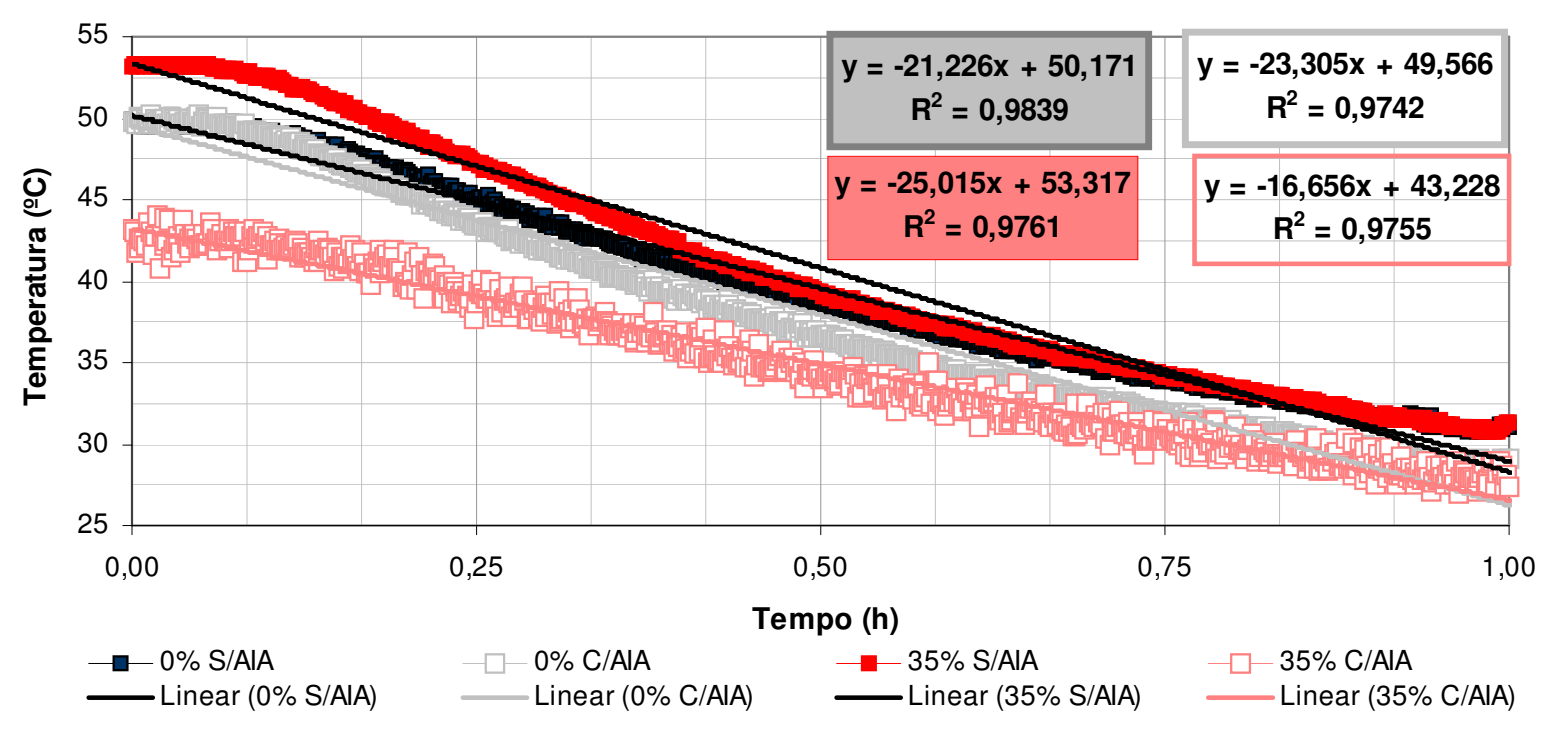

Figura 6-36: Temperaturas nas interfaces base-revestimento dos corpos de prova no período de aquecimento e resfriamento para as combinações 35\% S/AIA e 35\% C/AIA.

Observa-se que o efeito produzido pelo choque térmico na superfície do revestimento é atenuado através da sua espessura até atingir a interface durante os cinco primeiros minutos do início do resfriamento (inércia térmica do revestimento). O revestimento da combinação 35\% C/AIA inicia o período de resfriamento com uma temperatura média na interface $10^{\circ} \mathrm{C}$ menor do que o revestimento da combinação $35 \%$ S/AIA e com taxas de resfriamento também diferenciadas: 0,42 ${ }^{\circ} \mathrm{C} / \mathrm{min}$ para a combinação $35 \%$ S/AIA e $0,28^{\circ} \mathrm{C} / \mathrm{min}$ no revestimento da combinação $35 \% \mathrm{C} / \mathrm{AIA}$, aparecendo neste caso a influência do ar incorporado no revestimento.

\subsubsection{Gradientes de temperatura}

Um dos fatores que condiciona o nível de tensões nos revestimentos de argamassa é o gradiente de temperatura gerado entre as camadas constituintes. Com os dados de temperatura coletados durante o ensaio foram obtidos os gradientes gerados entre a superfície do revestimento e sua interface com a base ao longo de todo o período do ensaio para cada uma das combinações avaliadas no programa experimental. Em todos os casos as temperaturas foram medidas no centro do corpo de prova. 
Na Figura 6-37 a são mostrados os gradientes para a combinação 0\% S/AIA. O valor médio do gradiente foi $20,97^{\circ} \mathrm{C}$ e o gradiente máximo foi de $29,7^{\circ} \mathrm{C}$. Na Figura $6-37$ b são mostrados os gradientes para a combinação $0 \%$ C/AIA. O valor médio do gradiente foi $20,7^{\circ} \mathrm{C}$ e o gradiente máximo foi de $30,3^{\circ} \mathrm{C}$.

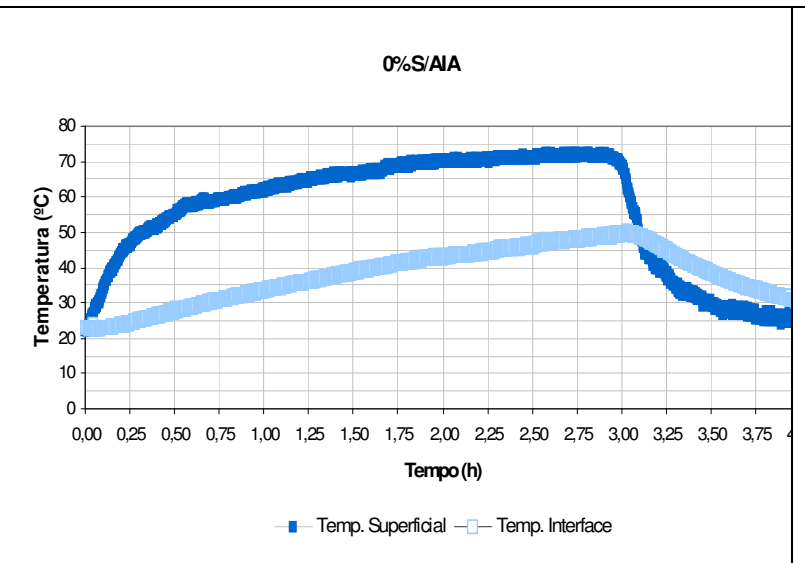

a)

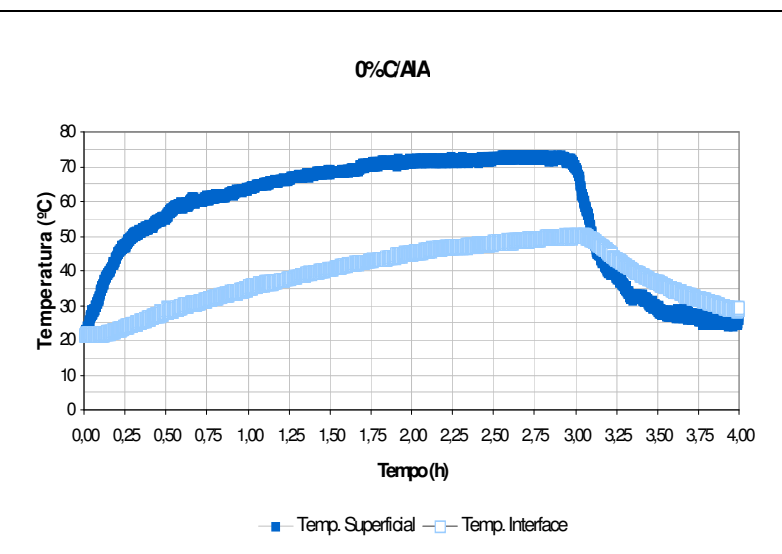

b)

Figura 6-37:Gradientes de temperatura entre a superfície e interface do corpo de prova das combinações a) $0 \%$ S/AIA e b) $0 \%$ C/AIA

Os gradientes para as combinações 35\% S/AIA e 35\% C/AIA são apresentados na Figura 6-38 a e Figura 6-38 b.

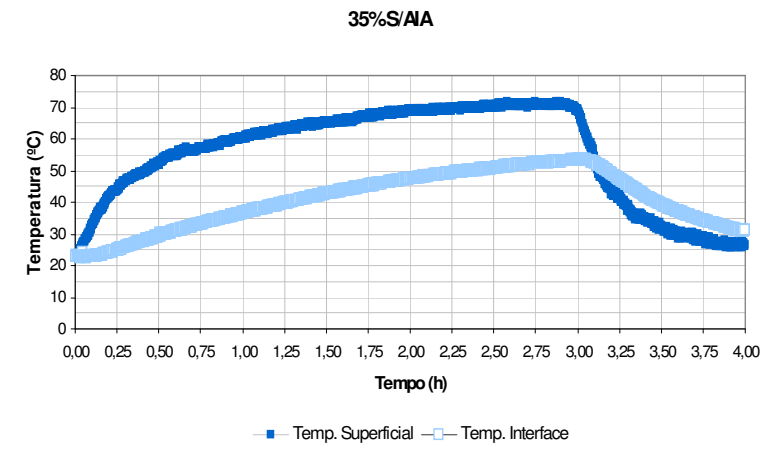

a)

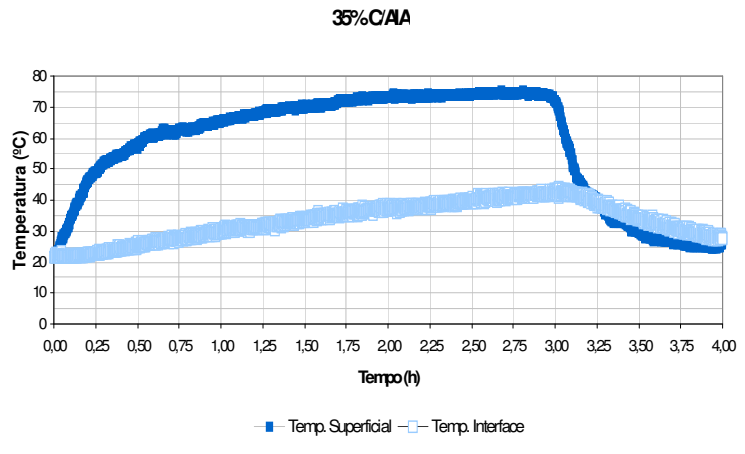

b)

Figura 6-38: Gradientes de temperatura entre a superfície e interface do corpo de prova da combinação $35 \%$ S/AIA

Para a combinação $35 \%$ S/AIA, o valor médio do gradiente foi $17,1^{\circ} \mathrm{C}$ atingindo seu maior valor $\left(25,3^{\circ} \mathrm{C}\right)$ no período de aquecimento ficando anulado aos 6 minutos do início do resfriamento e crescendo ligeiramente novamente até desaparecer no fim dos ciclos do ensaio. Para a combinação 35\% C/AIA o valor médio do gradiente foi $26^{\circ} \mathrm{C}$, sendo o maior dentre todas as combinações, da mesma forma que o valor máximo atingido durante o período do aquecimento $\left(38,3^{\circ} \mathrm{C}\right)$. Esse gradiente ficou 
anulado após 10 minutos do início do resfriamento para aumentar novamente ligeiramente até o fim do período do resfriamento

Analisando as quatro curvas dos gradientes produzidos entre a superfície e a interface dos corpos de prova verifica-se que os maiores gradientes, e conseqüentemente as maiores tensões ocorrem durante o período inicial do aquecimento principalmente devido às taxas de aquecimento superficial provocadas no ensaio e esse gradiente em nenhum dos casos supera os $40^{\circ} \mathrm{C}$. Além disso, uma vez que a temperatura superficial dos corpos de prova fica estabilizada no valor máximo definido $\left(70^{\circ} \mathrm{C}\right)$, a temperatura na interface continua a aumentar diminuindo o gradiente inicial. No início do choque térmico, devido ao resfriamento promovido na superfície o gradiente diminui rapidamente ficando anulado em menos de 10 minutos para depois inverter seu valor tornando a temperatura da interface maior do que a superficial. Isto gera também uma inversão nas tensões na interface e ao longo da espessura do revestimento.

\subsubsection{Resistência de aderência}

Os valores das determinações da resistência de aderência à tração normal foram submetidos a uma análise de variâncias (ANOVA) a qual é apresentada em detalhe no Anexo B. Na Tabela 6-6 são apresentados os valores médios das resistências de aderência com seus intervalos de confiança para cada uma das combinações após a análise.

Tabela 6-6: Valores médios de resistência de aderência à tração (MPa)

\begin{tabular}{|c|c|c|c|c|c|c|}
\hline \multirow{2}{*}{$\begin{array}{c}\text { Taxa de macro- } \\
\text { defeitos na } \\
\text { interface }\end{array}$} & \multirow[t]{2}{*}{$\begin{array}{l}\text { Tipo de } \\
\text { argamassa }\end{array}$} & \multicolumn{2}{|c|}{ Sem choque térmico } & \multicolumn{2}{|c|}{$\begin{array}{c}\text { Após } 30 \text { ciclos de choque } \\
\text { térmico }\end{array}$} & \multirow[t]{2}{*}{$\begin{array}{c}\text { Variação } \\
(\%)\end{array}$} \\
\hline & & Média & $\begin{array}{c}\text { Intervalo de } \\
\text { confiança }\end{array}$ & Média & Intervalo de confiança & \\
\hline \multirow{2}{*}{$\begin{array}{l}0 \% \text { macro- } \\
\text { defeitos }\end{array}$} & Sem AIA & 1,09 & $\pm 0,093$ & 0,40 & $\pm 0,099$ & $-63,3$ \\
\hline & Com AIA & 0,79 & $\pm 0,082$ & 0,43 & $\pm 0,105$ & $-45,6$ \\
\hline \multirow{2}{*}{$\begin{array}{l}\text { 35\% macro- } \\
\text { defeitos }\end{array}$} & Sem AIA & 0,32 & $\pm 0,080$ & 0,21 & $\pm 0,102$ & $-34,4$ \\
\hline & Com AIA & 0,30 & $\pm 0,080$ & 0,20 & $\pm 0,082$ & $-33,3$ \\
\hline
\end{tabular}

A Figura 6-39 apresenta graficamente o comparativo dos resultados da resistência de aderência, com seus respectivos intervalos de confiança para cada uma das situações analisadas comparando os valores entre os corpos de prova submetidos a choque térmico e aqueles de referência. Esta figura mostra também a variação dos 
valores de resistência de aderência em função dos outros efeitos avaliados no experimento.

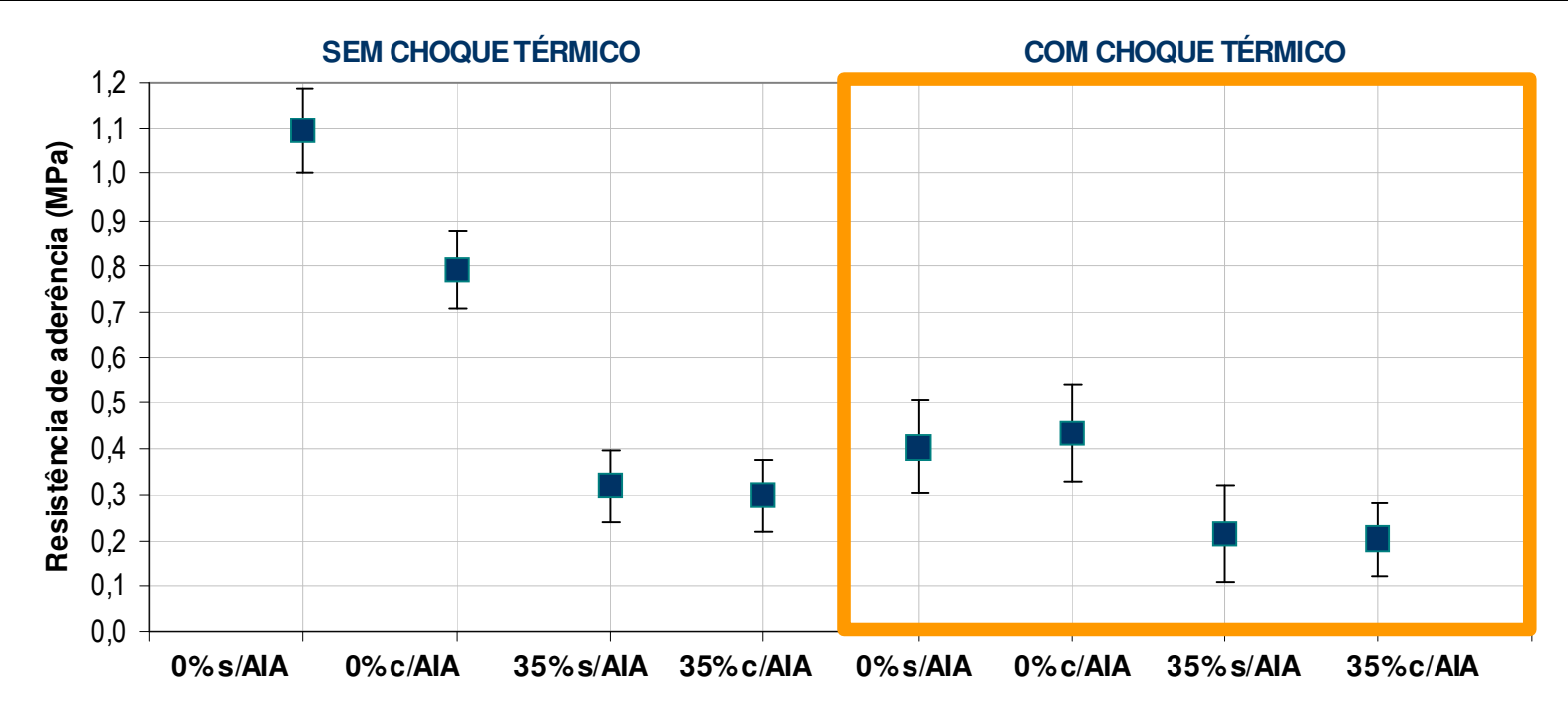

Figura 6-39: Comparativo dos valores médios de resistência de aderência de todos os fatores analisados.

Em primeiro lugar é possível constatar com os resultados que o choque térmico promove uma diminuição na resistência de aderência em todas as combinações sendo mais pronunciada no revestimento sem macro-defeitos de interface e sem aditivo incorporador de ar atingindo uma redução da aderência de 63,1\%.

Para o revestimento com menor rigidez (C/AIA) e sem macro-defeitos de interface a redução da resistência de aderência promovida pelo choque térmico sem macrodefeitos na interface é de $45,3 \%$.

Desta forma, tem-se um indicativo percentualmente falando de que as argamassas mais rígidas sofrem uma degradação 17,7\% maior do que as argamassas de menor rigidez devido aos ciclos de choque térmico.

Para os revestimentos em que a extensão de aderência foi prejudicada (35\% de taxa de macro-defeitos), o choque térmico também provocou uma queda da resistência de aderência com intensidade semelhante - em torno de 33\% - para as duas argamassas, sendo diminuído neste caso o efeito da rigidez do revestimento avaliado.

Esta constatação fica evidente quando avaliado isoladamente o efeito da inclusão dos macro-defeitos de interface. 
Para os revestimentos mais rígidos (S/AIA) a inclusão de 35\% de macro-defeitos na interface base-revestimento provoca uma queda na resistência de aderência de $70,6 \%$ e para os menos rígidos (C/AIA) a inclusão dos macro-defeitos de interface representa uma queda de $62 \%$, sem considerar em ambas as situações o choque térmico.

Quando é considerado o efeito do choque térmico a diminuição da resistência de aderência nos revestimentos é maior para o revestimento de menor rigidez $(-53,5 \%)$ e de $47,5 \%$ para o revestimento mais rígido (S/AIA).

Finalmente, quando avaliado o efeito da maior ou menor rigidez (módulo de elasticidade) percebe-se que a máxima diminuição causada na resistência de aderência atinge 27,5\% e ocorre quando não há interferência dos macro-defeitos de interface nem do efeito do choque térmico. Quando os outros fatores são combinados a diminuição na resistência de aderência não ultrapassa 7,5\%. Esses efeitos podem ser observados na Figura 6-40.

Aqui é possível observar graficamente a variação da resistência de aderência em função do efeito principal: choque térmico, taxa de macro-defeitos de interface e incorporação de ar.

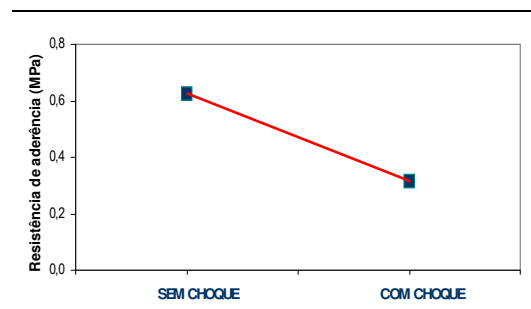

a)

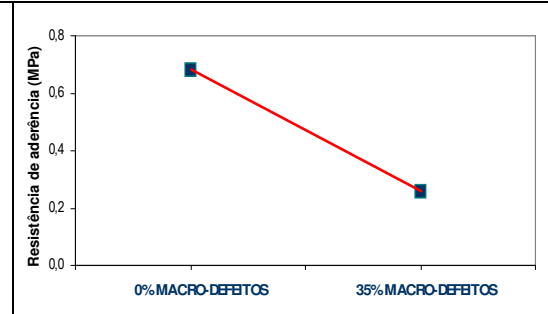

b)

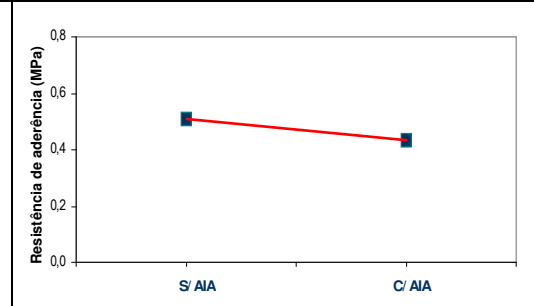

c)

Figura 6-40:Variação da resistência de aderência em função do efeito principal: (a) choque térmico, (b) $0 \%$ taxa de macro-defeitos e (c) incorporação de ar.

Para testar o efeito dos três fatores foi realizado um arranjo fatorial. No ANOVA foram comparados os efeitos dos fatores (efeitos principais e as interações dentre os fatores), confrontando duas hipóteses:

$\mathrm{H}_{0}$ : Não há diferença nas médias

$\mathrm{H}_{1}$ : Há pelo menos uma diferença. 
Para aceitar o rejeitar as hipóteses $f$ oi utilizado $P$-Value $(P)$. Se $P>\alpha H_{0}$ era aceita e se $P \leq \alpha$, a $H_{0}$ era rejeitada, sendo $\alpha=0$ nível de significância do teste definido em 0,05. Os resultados do ANOVA são mostrados na Tabela 6-7.

Tabela 6-7: Resultados obtidos da análise de variância ANOVA das resistências de aderência.

\begin{tabular}{l|l|l|l|l|l|l}
\hline Dependente & \multicolumn{1}{|c|}{ Efeito } & $\begin{array}{c}\text { Grau de } \\
\text { liberdade } \\
\text { (G.L.) }\end{array}$ & $\begin{array}{c}\text { Soma dos } \\
\text { Quadrados } \\
\text { (S.Q.) }\end{array}$ & $\begin{array}{c}\text { Média dos } \\
\text { Quadrados } \\
\text { (M.Q.) }\end{array}$ & F calculado & P-value \\
\hline $\begin{array}{l}\text { Resistencia } \\
\text { de aderência }\end{array}$ & Modelo & 7 & 17,06641 & 2,43806 & 47,69987 & $<0,0001$ \\
\hline & Erro & 192 & 9,8136 & 0,05111 & & \\
\hline & Total corrigido & 199 & 26,88001 & & & \\
\hline
\end{tabular}

A análise ANOVA mostrou - a um nível de significância de 0,05 - que todos os fatores estudados tiveram efeitos significativos na resistência de aderência dos revestimentos avaliados. Foi verificada também a existência de interações significativas entre o efeito do choque térmico e os efeitos da taxa de macro-defeitos e a utilização de aditivo incorporador de ar.

A interação entre a existência de macro-defeitos de interface e a incorporação de ar na argamassa de revestimento não se mostrou significativa.

Tabela 6-8: Analise de variância ANOVA para avaliar o efeito dos fatores e as interações entre fatores.

\begin{tabular}{l|l|l|l|l|l|l|l}
\hline Dependente & \multicolumn{1}{|c|}{ Efeito } & G.L & \multicolumn{1}{c|}{ S. Q. } & \multicolumn{1}{c|}{ M.Q } & F calc & \multicolumn{1}{c|}{ P } & Resultado \\
\hline \multirow{2}{*}{$\begin{array}{l}\text { Resistência } \\
\text { de }\end{array}$} & Choque térmico & 1 & 4,66161 & 4,66161 & 91,20297 & $<0,0001$ & Significativo \\
\cline { 2 - 8 } aderência & $\begin{array}{l}\text { Taxa de macro- } \\
\text { defeitos }\end{array}$ & 1 & 8,56158 & 8,56158 & 167,50473 & $<0,0001$ & Significativo \\
\cline { 2 - 8 } & AIA & 1 & 0,27918 & 0,27918 & 5,46204 & 0,020461 & Significativo \\
\cline { 2 - 8 } & $\begin{array}{l}\text { Choque*Macro- } \\
\text { defeitos }\end{array}$ & 1 & 2,1466 & 2,1466 & 41,99761 & $<0,0001$ & Significativo \\
\cline { 2 - 8 } & Choque*AIA & 1 & 0,34245 & 0,34245 & 6,69983 & 0,01038 & Significativo \\
\cline { 2 - 8 } & $\begin{array}{l}\text { Macro- } \\
\text { defeitos*AIA }\end{array}$ & 1 & 0,1712 & 0,1712 & 3,34942 & 0,06878 & $\begin{array}{l}\text { Não } \\
\text { significativo }\end{array}$ \\
\cline { 2 - 8 } & $\begin{array}{l}\text { Choque*Macro- } \\
\text { defeitos*AIA }\end{array}$ & 1 & 0,31121 & 0,31121 & 6,08864 & $<0,01448$ & Significativo \\
\hline
\end{tabular}

\subsubsection{Forma de ruptura nos ensaios de resistência de aderência}

A forma de ruptura do revestimento nos arrancamentos é uma característica importante a ser avaliada. Os tipos de ruptura que ocorreram com mais freqüência nos ensaios foram as rupturas na interface base-revestimento, denominadas de 
rupturas adesivas. O segundo tipo de ruptura mais freqüente foi a ruptura superficial, a qual era esperada principalmente na superfície do revestimentos submetidos ao choque térmico. Entretanto esse tipo de ruptura ocorreu também com os revestimentos que não foram submetidos ao choque térmico como mostrado no resumo geral do tipo de rupturas apresentados na Tabela 6-9:

Tabela 6-9: Tipos de ruptura produzidas nos ensaios de resistência de aderência.

\begin{tabular}{|c|c|c|c|c|c|}
\hline \multirow{2}{*}{$\begin{array}{c}\text { Taxa de macro-defeitos } \\
\text { na interface }\end{array}$} & \multirow{2}{*}{$\begin{array}{c}\text { Tipo de } \\
\text { argamassa }\end{array}$} & \multicolumn{2}{|c|}{ Sem choque térmico } & \multicolumn{2}{|c|}{ Após 30 ciclos de choque térmico } \\
\hline & & $\begin{array}{l}\text { Tipo de } \\
\text { ruptura }\end{array}$ & $\%$ & $\begin{array}{l}\text { Tipo de } \\
\text { ruptura }\end{array}$ & $\%$ \\
\hline \multirow[t]{4}{*}{$0 \%$ macro-defeitos } & \multirow[t]{2}{*}{ Sem AIA } & adesiva & 30,0 & adesiva & 57,1 \\
\hline & & superficial & 70,0 & superficial & 42,9 \\
\hline & \multirow[t]{2}{*}{ Com AIA } & adesiva & 25,0 & adesiva & 60,0 \\
\hline & & superficial & 75,0 & superficial & 40,0 \\
\hline \multirow[t]{3}{*}{$35 \%$ macro-defeitos } & Sem AIA & adesiva & 100,0 & adesiva & 100,0 \\
\hline & \multirow[t]{2}{*}{ Com AIA } & \multirow[t]{2}{*}{ adesiva } & \multirow[t]{2}{*}{100,0} & adesiva & 92,9 \\
\hline & & & & superficial & 7,1 \\
\hline
\end{tabular}

Quando as rupturas produzidas eram superficiais era colada a pastilha novamente na superfície do revestimento para realizar novamente o ensaio. As porcentagems mostradas na Tabela acima referem-se aos arrancamentos realizados sempre na primeira tentativa.

Nos revestimentos em que não se tinha macro-defeitos e que foram submetidos ao choque térmico produziu-se uma debilitação da superfície causando ruptura superficial em cerca de $40 \%$ dos casos. Por outro lado, a alta porcentagem de ruptura superficial nos revestimentos não expostos ao choque térmico pode ser atribuída a um desempenamento deficiente.

\subsubsection{Influência do conteúdo de umidade}

Isto foi confirmado com corpos de prova resultantes dos ensaios de resistência de aderência dos dois tipos de revestimento (S/AIA e C/AIA) que foram secos em estufa a $40^{\circ} \mathrm{C}$ por um período de 24 horas. Com este procedimento, pôde-se determinar a diminuição de massa do corpo de prova e, por conseguinte, o nível de perda de umidade. Nos ensaios realizados, atingiu-se uma diminuição máxima de 0,01\% em relação à massa inicial dos corpos de prova, o que demonstra que a perda de umidade é muito lenta 


\subsection{Influência das características do choque térmico na resistência de aderência do revestimento.}

De acordo com os modelos numéricos de choque térmico, os fatores determinantes no incremento das tensões térmicas são o módulo de elasticidade, o coeficiente de dilatação térmica, a diferença de temperatura provocada entre a superfície do revestimento e sua interface (gradiente) e a taxa de resfriamento caracterizada pelo número de Biot.

Como na avaliação experimental a espessura do revestimento, a forma de aquecimento e o resfriamento foram mantidos constantes, a alteração do número de Biot (função da espessura, h e k) só poderia ocorrer em função da variação da condutividade térmica dos revestimentos diferentes, devido à variação das densidades das argamassas utilizadas (C/AIA e S/AIA). Essa variação foi observada determinando-se os valores médios de taxa de resfriamento ( $\left.{ }^{\circ} \mathrm{C} / \mathrm{min}\right)$ na superfície dos revestimentos para cada combinação submetida ao choque térmico: $0 \% \mathrm{~S} / \mathrm{AIA}=$

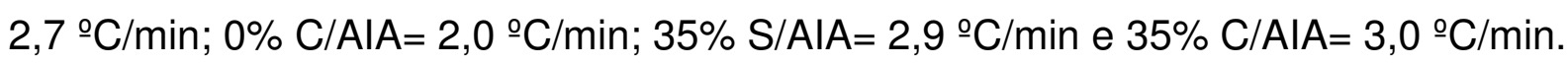
Da mesma forma foram obtidos os valores da taxa de resfriamento na interface base-revestimento. Ambos valores de taxa de resfriamento para cada combinação foram comparados com os da resistência de aderência (Figura 6-41) verificando-se a correlação entre a taxa de resfriamento na superfície e a resistência de aderência
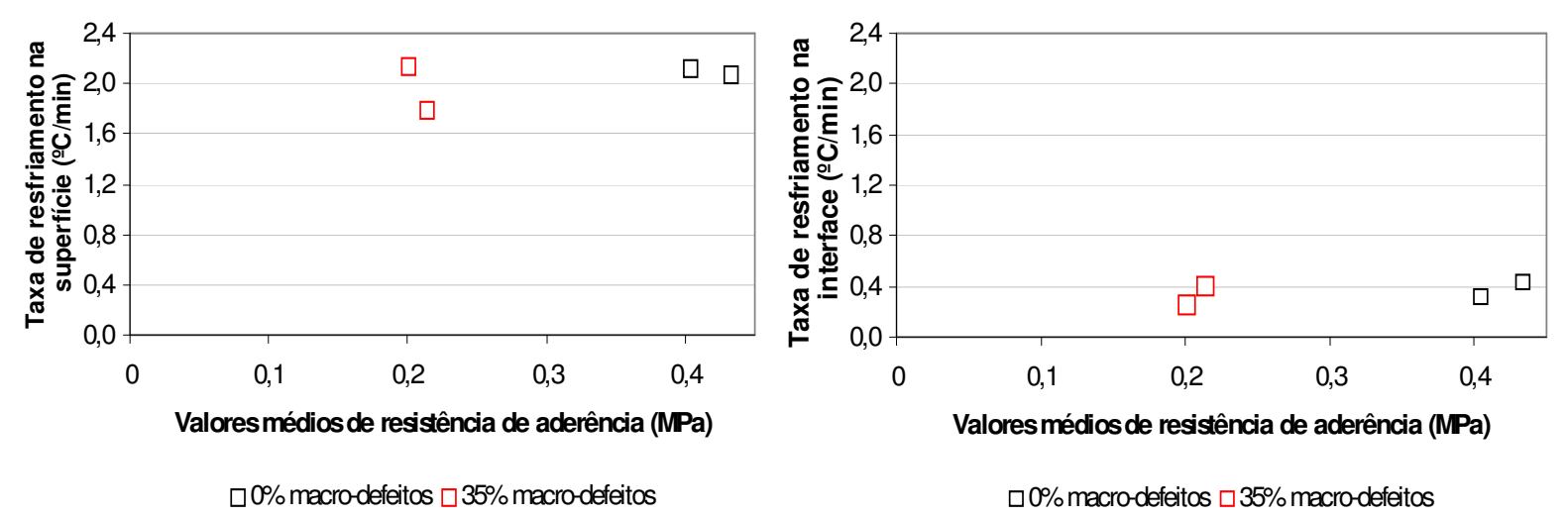

Figura 6-41: Resistência de aderência em função da taxa de resfriamento na superfície e interface dos corpos de prova 


\subsection{Influência das propriedades mecânicas da argamassa para revestimento na resistência de aderência}

De acordo com Jin e Mai (1995) o efeito do choque térmico é dependente da associação de várias propriedades do material e não somente de uma. Desta forma buscou-se encontrar uma relação indiretamente entre o parâmetro $\left(E \times \alpha^{-1}\right)$ e os valores de resistência de aderência para os revestimentos que foram submetidos ao choque térmico.

A Figura 6-42 apresenta a relação entre a resistência de aderência e o parâmetro (E $\mathrm{x} \alpha^{-1}$ ), proporcional ao nível de tensões por choque térmico, de acordo com a Equação 3-1.

Destaca-se que para obter os valores de módulo de elasticidade para as quatro combinações submetidas ao choque térmico (0\% S/AIA; 0\% C/AIA; 35\% S/AIA e 35 $\mathrm{C} / \mathrm{AIA}$ ) foram extraídos corpos de prova do revestimento após os ensaios de choque térmico e foi medido o módulo pelo método de ultra-som. Os valores do coeficiente de dilatação térmica foram apresentados na Tabela 6-4.

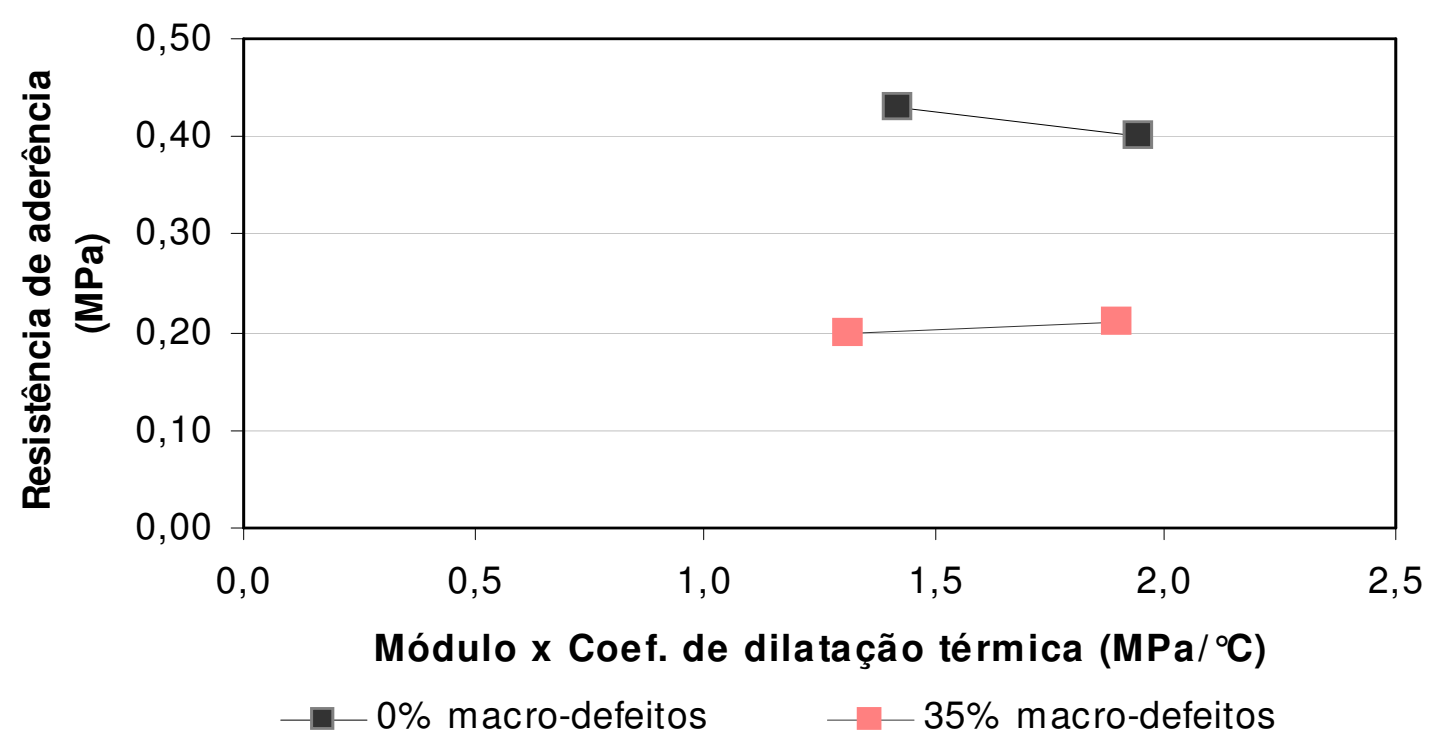

Figura 6-42: Relação entre os valores de resistência de aderência dos revestimentos submetidos ao choque térmico e o produto do valor do módulo de elasticidade e do coeficiente de dilatação térmica do revestimento.

Pode ser observado na Figura 6-42 que o aumento do parâmetro $\left(\mathrm{E} \times \alpha^{-1}\right)$, promove uma ligeira diminuição dos valores de resistência de aderência nos revestimentos em que não se tem macro-defeitos de interface. Essa influência é dissipada quando são incluídos na analise os referidos macro-defeitos. 


\subsubsection{Variação das propriedades mecânicas dos revestimentos em função do choque térmico}

Com o propósito de avaliar o efeito dos trinta ciclos de choque térmico nas propriedades mecânicas da argamassa de revestimento foram extraídos dos corpos de prova de revestimento prismas com dimensões semelhantes aos dos ensaios de resistência à tração e compressão $(4 \times 4 \times 16) \mathrm{cm}$, como mostrado na Figura 6-26.

A Figura 6-43 mostra a variação produzida no módulo de elasticidade de prismas de revestimento extraídos tanto dos corpos de prova de referencia como os que foram submetidos ao choque térmico.

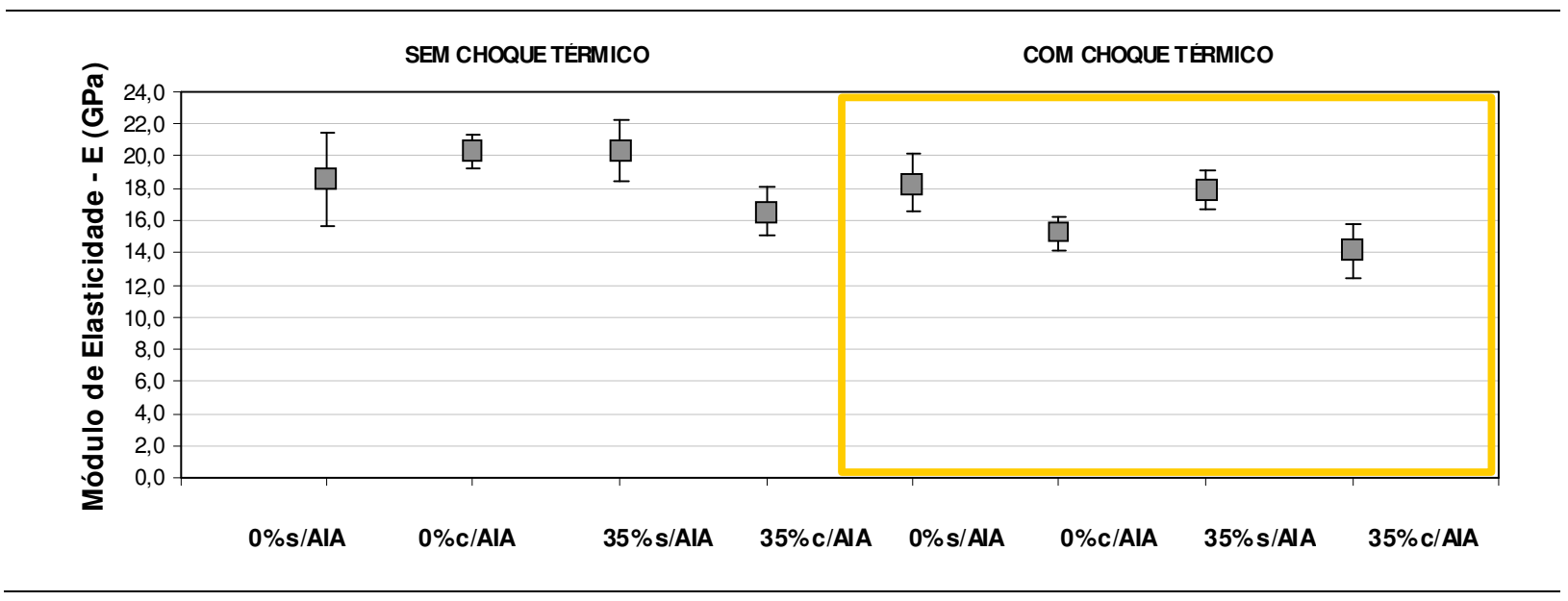

Figura 6-43: Variação do módulo de elasticidade dos prismas de revestimento extraídos dos corpos de prova ensaiados.

Observa-se na Figura 6-43 que ocorre uma diminuição dos valores de módulo de elasticidade devido aos ciclos de choque térmico principalmente para a combinação $0 \%$ C/AIA que atinge uma diminuição máxima de $25 \%$.

Uma avaliação semelhante foi realizada para verificar a variação da resistência à compressão dos prismas de revestimento extraídos dos corpos de prova. A Figura 6-44 apresenta a variação produzida após o choque térmico. 


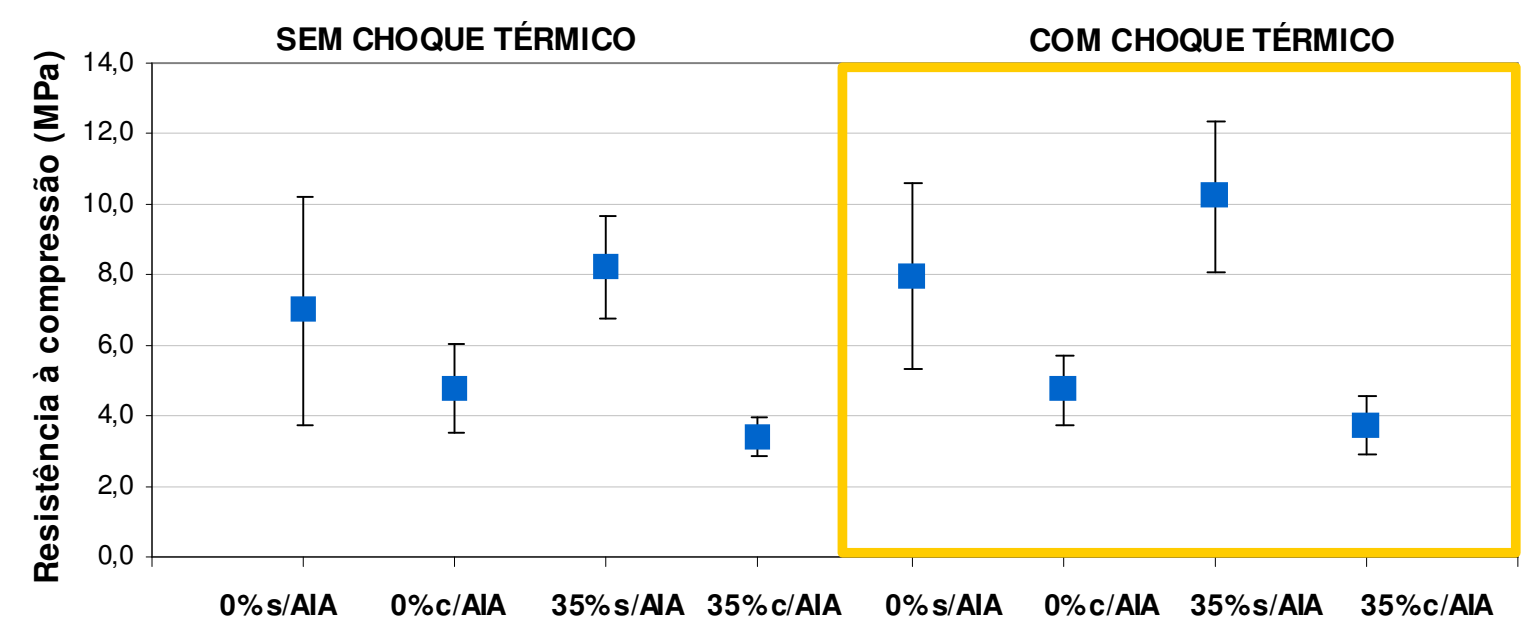

Figura 6-44: Variação da resistência à compressão dos prismas de revestimento extraídos dos corpos de prova ensaiados.

A diferença do efeito produzido pelo choque térmico no módulo de elasticidade dos prismas de revestimento observa-se na Figura 6-44 que ocorre um aumento dos valores de resistência à compressão dos revestimentos submetidos ao choque térmico em três das quatro combinações. A única combinação em que o valor da resistência à compressão decresce ligeiramente (1\%) é $0 \%$ C/AIA. Nos demais revestimentos há um ganho de resistência atingindo até em torno de $25 \%$ na combinação $35 \%$ S/AIA. Esse ganho de resistência pode ter ocorrido devido à cura térmica produzida com os ciclos de aquecimento e resfriamento e é semelhante ao obtido nos trabalhos experimentais de Geyer e Greven (1994) e Crescêncio e Barros (2003) em que após o choque térmico obteve-se ganho na resistência de aderência dos revestimentos ensaiados.

Finalmente a Figura 6-45 apresenta o efeito do choque térmico na resistência à tração na flexão dos prismas extraídos dos revestimentos ensaiados. 


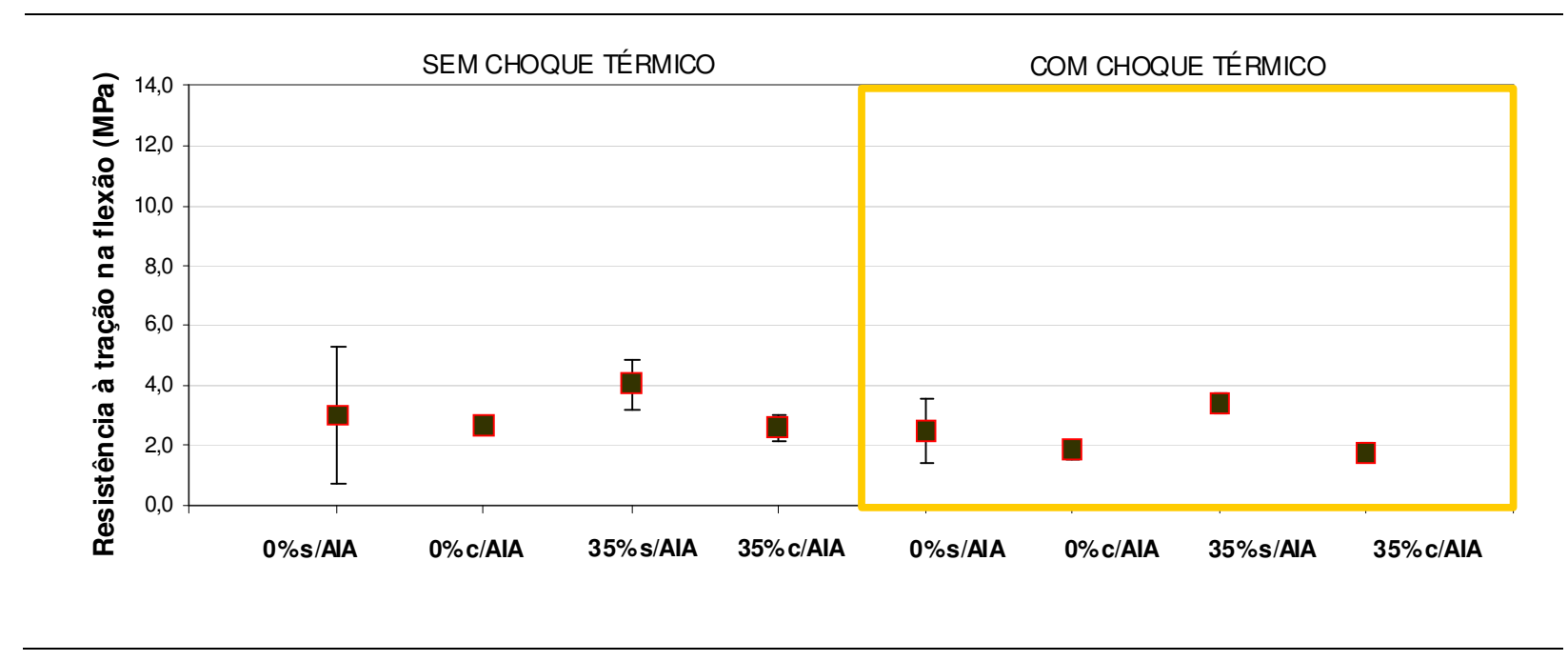

Figura 6-45: Variação da resistência à tração na flexão dos prismas de revestimento extraídos dos corpos de prova ensaiados.

Observa-se uma diminuição dos valores de resistência à tração na flexão de todas as combinações seguindo a tendência apresentada pelos valores de resistência de aderência. O maior decréscimo na resistência a tração ocorre nos prismas dos revestimentos de menor rigidez (C/AIA) 


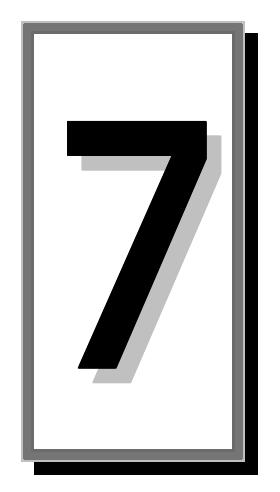

\section{CONCLUSÕES E SUGESTÕES PARA TRABALHOS FUTUROS}

De acordo com o objetivo deste trabalho foi realizada uma avaliação experimental do efeito de sucessivos ciclos de choque térmico na resistência de aderência do revestimento de argamassa, para determinadas condições de contorno fixadas e dentro das condições possíveis com a infra-estrutura laboratorial com que se contou. A análise dos resultados obtidos no trabalho experimental bem como o resultado das simulações computacionais permitiu tecer algumas considerações relativas aos seguintes aspectos:

\subsection{Validação da hipótese}

Com os resultados obtidos foi possível confirmar a hipótese de que a degradação da aderência dos revestimentos, avaliada através da diminuição da resistência de aderência é potencializada pelo efeito da exposição a choques térmicos que no caso desta tese foi de 30 ciclos. Com base na revisão da bibliografia foi possível definir dois cenários críticos: no primeiro trabalhou-se com a hipótese de que o módulo de elasticidade das argamassas é um fator determinante no desenvolvimento das tensões térmicas, sendo selecionados para o trabalho dois valores extremos (alto e baixo módulo de elasticidade); e no segundo cenário crítico a hipótese testada foi que uma elevada taxa de macro-defeitos provocados na interface base-revestimento soma-se aos macro-defeitos inerentes à produção do revestimento e provoca também uma redução na aderência dos revestimentos de argamassa.

Para a validação dessas hipóteses foi necessário manter constantes as características da sua base, o processo de produção do revestimento e as tensões 
originadas pela movimentação da base. Para obtenção dos valores diferenciados do módulo de elasticidade, na composição de uma das argamassas para produção do revestimento foi acrescentado um aditivo incorporador de ar.

\subsection{Considerações sobre a metodologia experimental.}

O desenvolvimento do programa experimental teve como suporte uma etapa inicial de modelagem computacional sobre a qual são apresentadas algumas considerações finais.

\subsubsection{Modelagem computacional}

A utilização da modelagem computacional mostrou-se uma ferramenta de grande utilidade na etapa de tomada de decisões do programa experimental.

A avaliação numérica de fenômenos físicos complexos como transferência de calor e comportamento mecânico de forma simultânea demanda um amplo domínio de ferramentas matemáticas para utilização dos modelos mais atuais, ainda mais quando esta avaliação é realizada de forma transiente, com a consideração da variação das propriedades térmicas e mecânicas em função da variação da temperatura.

Sendo este um trabalho experimental o auxílio da modelagem computacional permitiu desenvolver um modelo estático para o momento da máxima temperatura na superfície externa do revestimento e as tensões resultantes desse carregamento térmico. Para a simulação do choque térmico não se obteve um modelo satisfatório, principalmente pela limitação quanto ao domínio de todos os recursos que a ferramenta fornece.

Uma dificuldade que se teve no desenvolvimento das simulações foi necessidade de equipamentos com alta capacidade de processamento uma vez que com um maior refinamento da malha de análise o número de elementos finitos aumentava também.

Apesar das limitações que ainda existem quanto aos resultados das simulações com elementos finitos, fruto das hipóteses simplificadoras adotadas e da falta da validação experimental dos modelos é possível se obterem resultados que indiquem tendências sobre o comportamento mecânico dos revestimentos de argamassa.

O modelo numérico biaxial mostrou uma esperada tendência de concentração de tensões nas bordas do corpo de prova, tanto para os modelos em que não foram 
considerados os macro-defeitos de interface como os modelos em que foram. Além disso, foi possível verificar que o aumento no nível de tensões ocorre até uma distância mínima independentemente do comprimento do modelo. Embora esses resultados numéricos não tenham sido validados experimentalmente, estiveram em coincidência com modelos numéricos semelhantes encontrados na bibliografia como o de Bortoluzzo (2000); Saraiva (1998) e Silva et al. (1999).

Os resultados dos modelos confirmam que o módulo de elasticidade do revestimento exerce uma influência considerável no nível de tensões atingidas no revestimento quando considerados fatores como da espessura do revestimento e a taxa de macro-defeitos de interface no conjunto. Porém na avaliação experimental não foi avaliado o nível de tensões atingido e sim seu efeito na degradação do mecanismo de aderência do revestimento. Pelos resultados do ensaio de aderência do revestimento, a máxima influência do módulo de elasticidade do revestimento na diminuição da resistência de aderência (-27,5\%) resultou menor do que a máxima influência da existência de macro-defeitos de interface $(-70,6 \%)$ e que do efeito do choque térmico $(-63,3 \%)$, percentualmente falando, como mostrado na Tabela 6-6.

As simulações realizadas na definição dos parâmetros dos corpos de prova para o programa experimental forneceram um indicativo de que uma distribuição homogênea de macro-defeitos com geometria regular na interface baserevestimento produzia um aumento nas tensões máximas na interface, principalmente nas de cisalhamento, em função da sua proximidade à borda do modelo, resultado que não foi comprovado experimentalmente.

Dentre as limitações quanto à utilização do modelo computacional desenvolvido nesta tese podem ser destacadas as seguintes:

a) a modelagem para distribuição de temperaturas foi realizada em regime permanente e considerando uma distribuição linear da temperatura consideração que somente seria válida para as temperaturas na interface base-revestimento no período de aquecimento, fato que ficou evidenciado no registro das temperaturas durante o ensaio de choque térmico.

b) a utilização do o modelo bidimensional obrigou a simular o macro-defeito constante em toda a seção transversal, apesar de serem descontínuos, de 
geometria irregular e aleatórios ao longo da espessura do revestimento nas condições reais

c) a consideração do defeito como vazio dentro do revestimento de argamassa sem nenhuma propriedade física fato que pode ter repercutido nos resultados.

Os resultados das simulações numéricas relativas à concentração das maiores tensões normais e de cisalhamento em regiões muito próximas às bordas do pano do revestimento, a pesar de não terem sido validados experimentalmente, mostraram-se coerentes com observações de autores como autores como Veiga (2003) e Pagnussat et al. (2003) que referenciam a maior intensidade de fissuração e/ou desplacamento do revestimento junto de uma borda livre ou próximo às juntas do revestimento.

\subsubsection{Ensaios de choque térmico}

Considerando a quantidade de variáveis envolvidas e a aleatoriedade com que ocorrem os fenômenos climáticos para simular o choque térmico foram tomados todos os cuidados possíveis para evitar na medição e controle de temperatura o acúmulo de erro experimental.

Pelos resultados obtidos na medição das temperaturas tanto superficiais como na interface observou-se que as características dos corpos de prova obtidos permitiram homogeneidade nas temperaturas atingidas em corpos de prova da mesma família.

Por outro lado, quanto as condições do ensaio e equipamentos disponíveis foram tomadas algumas medidas para melhorar a realização do ensaio, analisando os resultados do programa experimental piloto:

a) Houve a necessidade de produzir um suporte específico para posicionamento dos corpos de prova para diminuir a dissipação de calor pelas bordas da superfície de aquecimento.

b) Para evitar os erros de leitura gerados pelo sistema de fornecimento de energia no laboratório foi necessário o aterramento individual do sistema de aquisição de sinais.

c) Foi produzido um sistema de controle automático para comandar o funcionamento do painel de aquecimento. O sistema de controle do ensaio para o aquecimento (sistema automático liga/desliga) era controlado 
unicamente por um sensor de temperatura. Para obtenção de um aquecimento mais homogêneo seria necessária a utilização de mais sensores e adaptação do sistema de controle por setores.

d) Para garantir o gradiente de temperatura entre a superfície aquecida e a face posterior dos corpos de prova foi produzida uma câmara conectada a um sistema de ar condicionado. Este sistema se mostrou útil durante as duas primeira horas do aquecimento uma vez que na terceira hora a temperatura da face oposta aumentou cerca de 14\%, dificuldade que pode ser superada com o aumento da potência do equipamento de ar condicionado.

Ao longo dos ensaios do programa experimental piloto percebeu-se a influência do conteúdo de umidade no revestimento na distribuição de temperaturas, fato que se procurou atenuar no programa experimental definitivo.

A distribuição da temperatura através da espessura do revestimento pode ser analisada com uma distribuição parabólica de acordo com aproximações realizadas.

Os resultados obtidos para os revestimentos de argamassa submetidos a choque térmico mostraram que existe uma degradação na aderência que é influenciada também por outros fatores como a extensão de aderência na interface baserevestimento.

Entretanto, praticamente não foram encontradas fissuras superficiais visíveis a olho nu que indicassem tensões de tração na superfície superiores à resistência à tração do revestimento durante os ensaios.

Mas a superfície dos revestimentos de maior módulo foram afetados severamente, fato constatado pelas rupturas superficiais no ensaio de resistência de aderência à tração normal naquelas placas de maior rigidez.

\subsubsection{Resistência de aderência}

A resistência de aderência do revestimento, conforme exposto anteriormente, sofreu degradação devido aos sucessivos choques térmicos e ao efeito combinado principalmente dos macro-defeitos de interface.

Os resultados obtidos mostraram que a resistência de aderência na presença de macro-defeitos de interface é governada pela taxa de defeitos mais do que pelo carregamento térmico. 
A necessidade dos cortes dos corpos de prova para realização dos ensaios de resistência de aderência pode ser um fator indutor da variabilidade nos resultados e em situações em que o revestimento encontra-se já degradado pode levar a perda de corpos de prova.

A utilização do procedimento de aspiração dos resíduos de argamassa na hora da realização dos cortes com a serra copo mostrou ser adequado para evitar a perda de corpos de prova para o ensaio de resistência de aderência.

Quanto à influência do tipo de argamassa como fator isolado verificou-se que a resistência de aderência média foi significativamente maior para as argamassas em que não foi utilizado o aditivo incorporador de ar (S/AIA) em relação a aquelas com aditivo (C/AIA). Porém quando considerada a interação com os outros fatores essa diferença foi reduzida.

Cabe destacar que a introdução de ar incorporado apesar ter apresentado uma diferença clara na argamassa no estado fresco foi dissipada na hora da aplicação da argamassa por projeção o que da um indicativo que essa forma de aplicação pode diminuir o teor de ar considerado no início.

A incorporação de ar, apesar da atenuação produzida pela projeção da argamassa mostrou não somente sua influência na redução das propriedades mecânicas da argamassa, mas também uma redução na aderência.

\subsection{Considerações sobre aplicações práticas para projetos de revestimento de fachadas}

A partir dos resultados das simulações é importante insistir nas recomendações sobre os cuidados necessários na produção do revestimento nas regiões das bordas na etapa de aplicação do revestimento principalmente quanto à obtenção de uma maior extensão de aderência (mínima taxa de macro-defeitos) e uma compactação do revestimento adequado, para atenuar o posterior efeito das tensões de origem térmica.

Tendo em vista a maior extensão de aderência é recomendável especificar nos projetos de revestimento de argamassa para fachada o emprego de uma argamassa com adequada reologia em função das condições de aplicação e das próprias características da base, e com técnicas de execução do revestimento que garantam o máximo da compactação, principalmente nas bordas, encontros de paredes e na 
execução de juntas no revestimento, etapa que pode vir a debilitar o revestimento ainda no estado plástico na etapa do corte e na posterior dificuldade de compactação no interior da junta. Pequenos macro-defeitos no contato argamassa base podem resultar em elevação das tensões decorrentes da variação de temperatura.

Por outro lado, a concentração das máximas tensões devidas à variação de temperatura nas bordas dos painéis de revestimento pode indicar a necessidade de utilizar reforços nessas bordas.

Outro aspecto a ser considerado na produção dos revestimentos externos é a avaliação da resistência de aderência nas bordas dos painéis que são produzidos em obra para controle de produção de revestimento.

\subsection{Sugestões para trabalhos futuros}

Ao longo do trabalho foram identificadas outras opções de abordagem do problema proposto, as quais são destacadas aqui como possíveis temas para futuras pesquisas que podem abordar:

A utilização da simulação computacional em análise transiente para atingir um maior grau de aproximação com os resultados experimentais do modelo experimental proposto.

O estudo da influência do grau de saturação do revestimento na aceleração da degradação do mesmo e da sua aderência à base, ocasionada pela exposição a repetidos choques térmicos.

O estudo de diferentes números de ciclos de choque térmico em revestimentos para entender a evolução do processo de degradação da aderência.

A utilização das ferramentas da mecânica da fratura para entender os mecanismos de degradação devidos a tensões térmicas em materiais cimenticios, abordagem que é utilizada amplamente na ciência dos materiais.

O estudo da fadiga das ligações entre o revestimento e a base devido às deformações cíclicas de origem térmica, sejam elas devido ao choque térmico ou devido à variação sazonal da temperatura ambiente nos revestimentos de fachada. 


\section{REFERÊNCIAS BIBLIOGRÁFICAS}

ABREU, M. M. M. Modelação do comportamento de revestimentos cerâmicos.Lisboa, 2001, 194 p. + anexos. Dissertação (Mestrado) - Instituto Superior Técnico. Universidade Técnica de Lisboa, 2001.

ADDLESON, L. Building failures: a guide to diagnosis, remedy, and prevention. Oxford: Boston: Butterworth Architecture, 1992. 167 p.

AGENCE QUALITÉ CONSTRUCTION. L'étanchéité des façades 1: exigences et moyens. Paris: EG, 1995. 72 p.

REBOCO do teto do Maracanã cai, mas ninguém se fere". Jornal do Brasil, Rio de Janeiro 19 jul. 2007.

AMERICAN SOCIETY FOR TESTING AND MATERIALS - ASTM C38 - 49: standard method for basic procedure in panel spalling test for refractory brick. West Conshohocken, ASTM, 1949.

ASTM C531-00: standard test method for linear shrinkage and coefficient of thermal expansion of chemical-resistant mortars, grouts, monolithic surfacings, and polymer concretes. West Conshohocken, ASTM, 2000.

ASTM C1472-06: guide for calculating movement and other effects when establishing sealant joint width. West Conshohocken, ASTM, 2006.

ASTM D1079-02: standard terminology relating to roofing, waterproofing, and bituminous materials. West Conshohocken, ASTM, 2002.

ASTM E132-04: standard test method for poisson's ratio at room temperature. West Conshohocken, ASTM, 2004.

ASTM E514 -06: standard test method for water penetration and leakage through masonry. West Conshohocken, ASTM, 2006.

ASTM G147-96: standard practice for conditioning and handling of nonmetallic materials for natural and artificial weathering tests. West Conshohocken, ASTM, 1996

AMERICAN SOCIETY OF HEATING, REFRIGERATING AND AIR CONDIOTIONING ENGINEERS. ASHRAE Handbook - Fundamentals. Atlanta: ASHRAE, 2001.

ANDEREGG, F. O. The effect of brick absorption characteristics upon mortar properties. Proceedings on the American Society for Testing and Materials, Philadelphia, v. 42, p. 821-836, 1942. 
ANDERSSON, T; ROWCLIFFE, D. J. Indentation thermal shock test for ceramics. Journal of the American Ceramic Society, Easton, v. 79,n. 6, p. 1509-1514, 1996.

ANDERSSON, T; ROWCLIFFE, D. J. Thermal cycling of indented ceramic materials. Journal of the European Ceramic Society, Oxford, v.18, p. 2065-2071, 1998.

ANSYS (R) Mechanical Toolbar. Versão 10.0. Ansys Inc. 2005 - USA.

ANTUNES, Rubiane $P$. N. Influência da reologia e da energia de impacto na resistência de aderência de revestimentos de argamassa. 2005. 156 p. Tese (Doutorado) - Escola Politécnica, Universidade de São Paulo. São Paulo, 2005.

ANTUNES, R. P. N.; JOHN, V. M.; PILEGGI, R. G. Influência da seqüência de mistura nas propriedades reológicas de argamassas avaliada por squeeze-flow. In: Simpósio Brasileiro de Tecnologia de Argamassas, 6. 2005, Florianópois. Anais do VI SBTA. Florianópolis: ANTAC, 2005. p. 158-179.

ARAÚJO JR., J. M. Contribuição ao Estudo das Propriedades Físico-Mecânicas das Argamassas de Revestimento. 2004. 175 p. Dissertação (Mestrado) Faculdade de Tecnologia, Universidade de Brasília, 2004.

ASSOCIAÇÃO BRASILEIRA DE NORMAS TÉCNICAS. NBR7200: Execução de revestimento de paredes e tetos de argamassas inorgânicas - procedimento. Rio de Janeiro, 1998. 13 p.

$11 \mathrm{p}$.

NBR7211: agregado para concreto - especificação. Rio de Janeiro, 2005.

NBR13276: argamassa para assentamento e revestimento de paredes e tetos - preparo da mistura e determinação do índice de consistência. Rio de Janeiro, 2005. 3 p.

. NBR13277: argamassa para assentamento e revestimento de paredes e tetos - determinação da retenção de água. Rio de Janeiro. 2005. 3 p.

NBR13278: argamassa para assentamento e revestimento de paredes e tetos - determinação da densidade de massa e do teor de ar incorporado. . Rio de Janeiro. 2005. 4 p.

NBR13279: argamassa para assentamento e revestimento de paredes e tetos - determinação da resistência à tração na flexão e à compressão. Rio de Janeiro, 2005. 9 p.

NBR13280: argamassa para assentamento e revestimento de paredes e tetos - determinação da densidade de massa aparente no estado endurecido. Rio de Janeiro, 2005. 2 p. 
NBR13281: argamassa para assentamento e revestimento de paredes e tetos - requisitos. Rio de Janeiro, 2005. 7 p.

NBR13528: revestimento de paredes e tetos de argamassas inorgânicas determinação da resistência de aderência à tração. Rio de Janeiro, 1995. 4 p.

NBR13749: revestimento de paredes e tetos de argamassas inorgânicas especificação. Rio de Janeiro. 1996. 6 p.

NBR14082: argamassa colante industrializada para assentamento de placas cerâmicas - execução do substrato-padrão e aplicação de argamassa para ensaios Rio de Janeiro, 1998. 8 p.

NBR15258: argamassa para revestimento de paredes e tetos Determinação da resistência potencial de aderência à tração. Rio de Janeiro, 2005. $5 \mathrm{p}$.

NBR15261: argamassa para assentamento e revestimento de paredes e tetos - determinação da variação dimensional (retração ou expansão linear). Rio de Janeiro, 2005. 6 p.

NBR15575-1: edifícios habitacionais de até cinco pavimentos desempenho - Parte 1: requisitos gerais. Rio de Janeiro, 2008. 52 p.

NBR15575-4: edifícios habitacionais de até cinco pavimentos desempenho - Parte 4: sistemas de vedações verticais externas e internas. Rio de Janeiro, 2008. $51 \mathrm{p}$.

NBRNM 248: agregados - determinação da composição granulométrica. Rio de Janeiro, 2003. 6 p.

BANSAL, N. K.; GARG, S. N.; KOTHARI, S. Effect of exterior surface colour on the thermal performance of buildings. Building and Environment, Oxford, v. 27, n. 1, p. 31-37,1992.

BAROODY, E. M.; SIMONS, E. M.; DUCKWORTH W. H. Effect of shape on thermal fracture. Journal of the American Ceramic Society. Easton, v. 38 N. 1 (1955) 3843.

BASTOS, P. K. X. Retração e desenvolvimento de propriedades mecânicas de argamassas mistas de revestimento. São Paulo, 2001. Tese (Doutorado) $172 \mathrm{p}$. Escola Politécnica, Universidade de São Paulo.

BASTOS, P. K. X. Módulo de elasticidade de argamassas - conceitos e métodos de determinação. In: SIMPOSIO BRASILEIRO DE TECNOLOGIA DE ARGAMASSAS, 5., 2003, São Paulo. Anais. Porto Alegre: ANTAC, 2003. v. 1. p. $27-40$. 
BAUER, E. Revestimentos de argamassa: características e peculiaridades. Disponível em: < http://www.comunidadedaconstrucao.com.br/ativos/ativos.php> . Acesso em 8 jul. 2008.

BAZANT, Z.; CHERN, J; THONGUTHAI, W. Finite element program for moisture and heat transfer in heated concrete. Nuclear Engineering and Design, Amsterdam, v.68, p 61-70, 1981.

BAZANT, Z.; KAPLAN, M. Concrete at high temperatures : material properties and mathematical models. Harlow : Longman, 1996. 412 p.

BECHER, P. Effect of water bath temperature on the thermal shock of Al2O3. Communications of the American Ceramic Society. C-17. January 1981.

BEM AMOR, CH. Comportement mécanique d'un carrelage collé sur sol em betón. In Cahiers du CSTB No. 2916. 1996

BENHAM; HOYLE. Thermal stress. London : I. Pitman, 1964. 382 p.

BISWAS, D.R. Thermal shock resistance in glass-nickel composites. In: BRADT. R. $\mathrm{C}>$ et al. Fracture Mechanics of ceramics: Measurements, transformations, and high-temperature fracture. NewYork: Plenum, 1983. v. 6.

BLANCHARD, N. La classification françaiese dês enduits monocouches d'impermeabilisation. In: SIMPOSIO BRASILEIRO DE TECNOLOGIA DE ARGAMASSAS, 5., 2003, São Paulo. Anais. Porto Alegre: ANTAC, 2003. v. 1. p. 13-25.

BOLEY, B. A.; WEINER, J. H. Theory of thermal stresses. New York: Wiley, 1960. $586 \mathrm{p}$.

BORTOLUZZO, W. C. Contribuição ao estudo do comportamento mecânico dos revestimentos de argamassa. São Carlos, 2000. 190 p. + anexos. Dissertação (Mestrado) - Escola de Engenharia de São Carlos, Universidade de São Paulo. São Carlos, 2000.

BOWMAN, R. G.; BANKS, P. J. the crucial need for computer modelling of tiling systems. In Qualicer 96, IV World Congress on ceramic tile quality, 1996, Castellón. Anais. Castellón, Cámara Oficial de Comercio, Industria y Navegación, 1996.

BOWMAN, R. G.; BANKS, P. J. Theoretical modeling of external wall tiling systems. Disponível na internet in: <http://www.infotile.com.au/services/techpapers/33icbest.shtml>. Acesso em 2003

BOYTON, R. S.; GUTSCHICK, K. A. Aderência de argamassas a elementos de alvenaria. Fatores que influenciam a resistência, extensão e durabilidade da 
aderência. São Paulo: IPT/ABCP, 1964. (Notas técnicas n. 3 sobre argamassa de assentamento de componentes de alvenaria da National Lime Association)

ESTIMATION of thermal and moisture movements and stresses: Part 1, Part 2, Part 3. BRE Digest, Garston, n.227/229, 1979.

BREA, F. Desenvolvimento de formulações de argamassa para aplicação manual. In Simpósio Brasileiro de Tecnologia de Argamassas, 3, Vitória. Anais. Vitória, ANTAC, 1999.

BRETON, D.; CARLES-GIBERGUES, A; BALLIVY, G.; GRANDET, J. Contribution to the formation mechanism of the transition zone between rock-cement paste. Cement and Concrete Research, Oxford, v.23, p. 335-346, 1993.

BRITISH STANDARD INSTITUTION. BS 1881-209: Testing concrete. Recommendations for the measurement of dynamic modulus of elasticity. London, 1990. 8 p.

BROWN, E. J.; ERDOGAN, F. Thermal stresses in bonded materials containing cuts on the interface. International Journal of Engineering Science, New York, v.6, n 9, p. 517-529, 1968.

BUESSEM, W. R. Thermal shock testing. Journal of the American Ceramic Society, Easton, v. 38, n. 1, p. 15-17, 1955.

CALLISTER, W. Materials science and engineering: an introduction. New York: John Wiley, 2000. $871 \mathrm{p}$.

CAMARINI, G.; CINCOTTO, M. A. Efeito da cura térmica na resistência de argamassas de cimento Portland comum e de alto forno - São Paulo: EPUSP, 1995. $20 p$

CAMPANTE, E. Metodologia para diagnostico e prevenção de problemas patológicos de revestimentos cerâmicos de fachada. São Paulo, 2001. Tese (Doutorado) - Escola Politécnica, Universidade de São Paulo.

CANDIA, M. C. Contribuição ao estudo das técnicas de preparo da base no desempenho dos revestimentos de argamassa. 1998. 198 p. Tese (Doutorado) Escola Politécnica, Universidade de São Paulo. São Paulo, 1998.

CANDIA, M. C. Avaliação da durabilidade de revestimentos externos com argamassa. São Paulo: Escola Politécnica, Universidade de São Paulo, 2001. 198 p. (Relatório FAPESP proc 1999/02081-9 Pós-Doutorado).

CARASEK, H. Aderência de argamassas à base de cimento portland a substratos porosos: avaliação dos fatores intervenientes e contribuição ao estudo 
do mecanismo de ligação. 1996. 285 p. Tese (Doutorado) - Escola Politécnica, Universidade de São Paulo. São Paulo, 1996.

CARDOSO, F.A., PILEGGI, R.G., JOHN, V.M. Caracterização reológica de argamassas através do método de squeeze-flow. In: Simpósio Brasileiro de Tecnologia de Argamassas, 6, , 2005. Anais, Florianópolis: ANTAC, 2005. p 121143.

CARINO, N.J.; TANK, R.C. Maturity functions for concrete made with various cements and admixtures. ACI Materials Journal, Farmington Hills, v. 89, n. 2, p. 188-196, Mar/Apr. 1992.

CASTILLO, C; DURRANI, A. J. Effect of transient high temperature on high-strength concrete. ACI Materials Journal, Farmington Hills, v. 87, n. 1, p. 47-53, Jan/Feb. 1990.

CENTRE SCIENTIFIQUE ET TECHNIQUE DE LA CONSTRUTION (CSTC). Guide des performances du bâtiment: façades 2. Bruxelles, 1980.

CHAO, C.K.; CHEN, F. M. Thermal stresses in an isotropic trimaterial interacted with a pair of point heat source and heat sink. International Journal of solids and structures, New York, v.41, p. 6233-6247, 2004.

CHAPULIOT, S.; LACIRE, M. H.; MARIE, S.; NÉDÉLEC, M. Thermomechanical analysis of thermal shock fracture in the brittle/ductile transition zone. Part I: description of tests. Engineering Fracture Mechanics, New York, v.72, p. 661-673, 2005.

CHILDS, P.; WONG, A.C. L.; GOWRIPALAN, N; PENG, G. D. Measurement of the coefficient of thermal expansion of ultra-high strength cementitious composites using fibre optic sensors. Cement and Concrete Research, Oxford, v. 37 p. 789-795, 2007.

CIB W080/RILEM 175-SLM. Prediction of Service Life of Building Materials and Components - Guide and Bibliography to Service Life and Durability Research for Buildings and Components - PART II - Factors Causing Degradation - Norwegian Institute for Air Research. 1980

COBLE, R. L.; KINGERY, W. D. Effect of porosity on thermal stress fracture. Journal of the American Ceramic Society. Easton, v. 38, n. 1, p. 33-37, 1955.

COLLANTES, M., FRANCO, L. S. Desenvolvimento de um método de ensaio de resistência de aderência ao cisalhamento. In: Encontro Nacional de Tecnologia do Ambiente Construído, 8, 2000. Anais, Salvador: ANTAC, 2000, v. 2, p 1994-1001.

COLLINS, J. A. Failure of materials in mechanical design: analysis - prediction prevention. New York: John Wiley, 1980. 628 p. 
COLLIN, M.; ROWCLIFFE, D. Analysis and prediction of thermal shock in brittle materials. Acta Materialia, Vol 48, p. 1655-1665, 2000

COMUNIDADE DA CONSTRUÇÃO, Quem somos. Disponível em: < http://www.comunidadedaconstrucao.com.br/interna.php?polo=1\&pagina=quemsom os> . Acesso em 7 jan. 2008.

CONSITRA - CONSORCIO SETORIAL PARA INOVAÇÃO EM TECNOLOGIA DE REVESTIMENTOS DE ARGAMASSAS -. Projeto apresentado para Finep.. 2003. Não publicado.

COUTINHO, A. A fissurabilidade dos cimentos, argamassas e betões por efeito da sua contracção. LNEC, Lisboa, 1954. (Publicação, 57)

CRESCENCIO, R. M.; PARSEKIAN, G. A.; BARROS, M. M. S. B.; SABBATINI, F. Execução de revestimentos com argamassa projetada. In: ENCONTRO NACIONAL DE TECNOLOGIA DO AMBIENTE CONSTRUÍDO, 8, Salvador, 2000. Anais. Salvador: ENTAC, 2000. v. 2 p.1067-1074.

CRESCENCIO, R.; BARROS, M. A influência do choque térmico na resistência à tração do revestimento decorativo monocamada. In: Simpósio brasileiro de tecnologia de argamassas, 5, São Paulo, 2003. Anais. São Paulo: ANTAC, 2003. p. 631-642.

CRESCENCIO, R. Avaliação de desempenho do revestimentos decorativo monocamada. 170 p. Dissertação (Mestrado) - Escola Politécnica, Universidade de São Paulo. São Paulo, 2003.

CULLEN, W C; BOONE, T. H. Thermal- Shock Resistance for Built-Up Membranes. Washington: Building Research Division. Institute for Applied Technology, 1967. (Building Science Series 9)

DEPARTAMENTO DE ÁGUAS E ENERGIA ELÉTRICA (DAEE). Banco de dados pluviométricos do Estado de São Paulo. Disponível em <http://www.sigrh.sp.gov.br/cgi-bin/bdhm.exe/plu>. Acesso 12 jan. 2004

DÉTRICHÉ, C.H.; GALLIAS, J.L.; GRANDET, J.; MASO, J.C. Mouvements d'eau, hydratation et comportement mécanique des mortiers d'enduit. Matériaux et Constructions, Paris, v.17, n.100, p.297-302.1984.

DÉTRICHÉ, C.H.; GRANDET, J. Influence de la succion des supports poreux sur la prise et la résistance au cisaillement des mortiers moulés à leur contact. Matériaux et Constructions, Paris. v.14, n.80,p. 91-102, 1981. 
DÉTRICHÉ, C.H.; MASO, J.C. Differential hydration in rendering mortars. Cement and Concrete Research, Oxford, v.16, p. 429-439, 1986.

DIAMOND, S.; KJELLSEN, K.O. Scanning electron microscopic investigations of fresh mortars: Well-defined water-filled layers adjacent to sand grains. Cement and Concrete Research, Oxford, v.38, p. 530-537, 2008.

DUAILIBE, R. P.; CAVANI, G. R.; OLIVEIRA, M. C. B.Influência do tipo de projeção da argamassa na resistência de aderência à tração e permeabilidade à água. In: Simpósio brasileiro de tecnologia de argamassa, 6, Florianópolis, 2005. Anais. Florianópolis: ANTAC, 2005. p. 508-517.

DUFFIE, J. A.; BECKMAN, J. Solar engineering of thermal processes. 2.ed. New York, John Wiley, 1991.

DUMÊT, T. B. (Org.). Levantamento das Principais Patologias de Revestimentos de Fachada de Edifícios na Cidade de Salvador. RA045. Salvador, UFBA, Comunidade da Construção, 2006. Disponível em:

< http://www.abcp.org.br/comunidade/ativos/ativos.php>. Acesso em: 07 jan. 2008

DUPIN, I.; DÉTRICHÉ, C.H.; MASO, J.C. Accrochage direct d'un enduit sur un isolant par une liaison de type mécanique dans le cadre d'un procédé d'isolation par l'extérieur. Matériaux et Constructions, Paris, v.21, n.125, p. 370-378, 1988.

ELGAALY, M. Thermal gradients in Beams, Walls, and Slabs. ACI Structural Journal, Farmington Hills, v. 85-S9, p. 76-81, 1988.

EMANUEL, J H.; HULSEY, J. L. Prediction of the Thermal Coefficient of Expansion of Concrete. Journal Proceedings, v. $74-4$, p 149-155, 1977.

EUROPEAN ORGANISATION FOR TECHNICAL APPROVALS (EOTA). Assessment of working life of products: Guidance Document 003. Bruxelles: EOTA, 1999.

2000.

. Exposure procedure for artificial weathering. TR 010. Bruxelles: EOTA,

. Exposure procedure for accelerated ageing by heat. TR 011. Bruxelles: EOTA, 2003.

EUROPEAN STANDARD. EN 1367-5: Tests for thermal and weathering properties of aggregates. Determination of resistance to thermal shock. 2002. 8 p.

EN 13687-2: Products and systems for the protection and repair of concrete structures - Test methods - Determination of thermal compatibility - Part 2: Thundershower cycling (thermal shock). 2002. $12 \mathrm{p}$. 
EN 60068-1: Environmental testing - Part 1: general and guidance (IEC 60068-1:1988 + Corrigendum $1988+$ A1:1992). 1995.

. EN 60068-2-14: Environmental testing - Part 2: Tests; test N: Change of temperature (IEC 60068-2-14:1984 + A1:1986). 2000

. EN 60068-2-38: Environmental testing - Part 2: Tests; test Z/AD: Composite temperature/humidity cyclic test (IEC 60068-2-38:1974).1999

FIORITTO A. J. S. I. Manual de Argamassas e Revestimentos: Estudos e procedimentos de execução. São Paulo: Pini, 1994.

FOLHA ONLINE, Entenda como aconteceu o desabamento nas obras do metrô em SP, Folha Online, São Paulo 14 Jan, 2007. Disponível em:

<http://www1.folha.uol.com.br/folha/cotidiano/ult95u130487.shtml>. Acesso em 20 Jan, 2007.

FONTENELLE, M. A. M.; MOURA, Y. M. Revestimento cerâmico em fachadas estudo das causas das patologias. RA03. Fortaleza, Comunidade da Construção, 2004. Disponível em: < http://www.abcp.org.br/comunidade/ativos/ativos.php $>$. Acesso em 7 jan. 2008.

FU, YU-FANG. Thermal stresses and associated damage in concrete at elevated temperatures. Hong Kong. 2003. Doctoral Thesis - The Hong Kong Polytechnic University. Department of Civil \& Structural Engineering.

FU, Y-F; WONG, Y-L.; POON, C.-S.; TANG, C.-A.; LUO, P. L.; SUN, W.; CHAN, S. $Y$. N. Experimental study of micro/macro crack development and stress-strain relations of cement-based composite materials at elevated temperatures. Cement and Concrete research, Oxford, v.34, n. 5, p. 789-797. 2004.

GAJANAN, M. S. Structural modeling and experimental techniques. Englewood Cliffs, N.J. : Prentice-Hall, c1983. 585 p.

GANJIAN, E.; TINKER, J. A.; CABRERA, J. G. Predicting the thermal conductivity of concrete using density and porosity. In: International Conference on Building Envelope Systems and Technology (ICBEST - 94). ISBN 981-00-6001-7, pp 330 335

GATEWOOD, B. E. Thermal stresses. New York, Toronto e London: McGraw-Hill Book Company, 1957.

GEYER, R. M. T. Influência do choque térmico na aderência de azulejos ao substrato. Porto Alegre. 1994. 104 p. Dissertação (Mestrado) - Escola de Engenharia, Universidade Federal do Rio Grande do Sul. Porto Alegre, 1994. 
GODOY, E. H. P.; BARROS, M. M. S. B. Contribuição ao estudo da influência do teor de polímero nas propriedades das argamassas de cimento Portland.. In: Simpósio Brasileiro de Tecnologia das Argamassas, 3, Vitória, 1999. Anais. Vitória: PPGEC/ANTAC, 1999. v. 1, p. 249-265.

GOLDBERG, R. P. Revestimientos exteriores con adherencia directa de azulejos cerámicos, piedra y ladrillos caravista. Manual de diseño técnico. Bethany, CT 1998. Laticrete International. 200 p.

GOULART, S.; LAMBERTS, R.; FIRMINO, S. Dados climáticos para projeto e avaliação energética de edificações para 14 cidades brasileiras. 2. Ed./ Florianópolis: Núcleo de Pesquisa em Construção / UFSC, 1998. 345 p.: il.

GRANDET, J. Physico chemical mechanisms of the bond between clay products and cement. Third International Brick Masonry Conference, april, 1973.

GRIFFITH, A. A. The phenomena of rupture and flow in solids. Philosophical Transactions of the Royal Society of London, Oxford, A 221, p. 163-198. 1921

GUAN, W., ALUM, J. External Wall Tiling in the Tropical City of Singapore. Monograph. Singapore: Centre for Advanced Construction Studies, 1997.

HAAGENRUD, S.E. Guide and Bibliography to Service Life and Durability Research for Buildings and Components. PART II - Factors Causing Degradation. In: Joint CIB W080 / RILEM TC 140 - Prediction of Service Life of Building Materials and Components, 2004.

HASSELMANN, D.P.H. Elastic energy at fracture and surface energy as design criteria for thermal shock. Journal of the American Ceramic Society, Easton, v. 46 n. 11, p. 535-541. 1963a.

HASSELMANN, D.P.H. Theory of thermal shock resistance of semitransparent ceramics under radiation heating. Journal of the American Ceramic Society, Easton. Discussions and Notes, v. 49, n. 2, p. 103-104. $1963 \mathrm{~b}$.

HASSELMANN, D.P.H. Approximate theory of thermal stress resistance of brittle ceramics involving creep. Journal of the American Ceramic Society, Easton, v. 50 n. 9, p. 454-457.1963c

HASSELMANN, D.P.H. Unified theory of thermal shock fracture initiation and crack propagation in brittle materials. Journal of the American Ceramic Society. Easton, v. 52 , n. 11 , p. $600-604.1969$.

HASSELMANN, D.P.H. Strength behavior of polycrystalline alumina subjected to thermal shock. Journal of the American Ceramic Society. Easton, v. 53 n. 9 , p. 490-495. 1970a. 
HASSELMAN, D.P.H. Thermal stress resistance parameter for brittle refractory ceramics: A compendium. Ceramic Bulletin, v. 49, n. 12, p. 1033-1037, 1970b.

HASSELMANN, D.P.H. Thermal stress resistance of engineering ceramics. Materials Science and Engineering, Lausanne, v. 71, p. 251-264, 1985.

HAYASHI, Y., AOYAMA, T., MATSUYAMA, M. Technique of application of fiber materials to exterior ceramic wall tiling. In: Durability of building materials and components. 1993

HILLERBORG, A. The theoretical basis of a method to determine the fracture energy $\mathrm{G}_{\mathrm{f}}$ of concrete. Journal Materials and Structures. v.18, n. 4, p. 1871-6873. 1985

HILleRBORG, A.; MODÉER, M; PETERSON, P. E. Analysis of crack formation and crack growth in concrete by means of fractures mechanics. Cement and concrete research, Oxford, v. 6, p. 773-782, 1976.

HIRSCHBERGER, C.B.; RICKER, S.; STEINMANN, P.; SUKUMAR, N. Computational multiscale modelling of heterogeneous material layers. Engineering Fracture Mechanics, Amsterdam, nov. 2008. No prelo.

HOBBS, D. W. Expansion and shrinkage of oversulphated Portland cements. Cement \& Concrete Composites, Essex, n. 8, p. 211-222, 1978.

HOLMAN, J. P. Transferência de calor. Trad. Luiz Fernando Milanez. São Paulo; New York : McGraw-Hill, 1983.

HSUEH, C. H. Thermal stresses in elastic multilayer systems. Thin Solid Films. Lausanne, n. 418, p. 182-188, 2002.

HSUEH, C. H.; EVANS, A. G. Residual Stresses in Metal/Ceramic Bonded Strips. Journal of the American Ceramic Society, Easton, v. 68, p. 241-248, 1985.

HSUEH, C. H.; LUTTRELL, C. R.; LEE, S.; WU, T. C.; LIN, H. Y. Interfacial peeling moments and shear forces at free edges of multilayers subjected to thermal stresses. Journal of the American Ceramic Society, Easton, v. 89 [5], p. 1632-1638, 2006.

IGNATIEV, N.; CHATTERJI, S. On the mutual compatibility of mortar an concrete in composite members. Cement \& Concrete Composites, Essex, n. 14, p 179-183, 1992.

INCROPERA, F. P.; DEWITT, D. Fundamentos de transferência de calor, 4a. ed. Tradução Ricardo Cruz. México, Prentice Hall. 1999. 912 p.

INSTITUTO NACIONAL DE METEOROLOGIA. INMET. Gráficos climatológico: Porto Alegre no período 1931-1960. Disponível na internet em: 
<http://www.inmet.gov.br/html/clima/graficos/plotGraf.php?chklist=7\%2C8\%2C\&capit a=saopaulo\%2C\&peri=99\%2C\&per6190=99\&tempmaxabs=7\&tempminabs=8\&saopa ulo=37\&Enviar=> Acesso em junho 2003.

INSTITUTO DE PESQUISAS TECNOLOGICAS - IPT. Critérios mínimos de desempenho para habitações térreas de interesse social. São Paulo: IPT 1998.

INTERNATIONAL ORGANIZATION FOR STANDARDIZATION (1984) Performance Standards in Buildings - Principles for Their Preparation and Factors to be Considered, ISO, Geneva, ISO 6241-1984 (E).

JIN, ZHI-HE; MAI, YIU-WING. Effects of damage on thermal shock strength behavior of ceramics. Journal of the American Ceramic Society, Easton, v. 78 n. 7, p. 18731881. 1995.

JINGYAO, C; CHUNG, D.D. L. Damage evolution during freeze-thaw cycling of cement mortar, studied by electrical resistivity measurement. Cement and concrete research, Oxford, v. 32, p. 167-1661, 2002

JOISEL, A. Les fissures du ciment: causes et remèdes. Paris : Ciment et Betons, 1961.

JOHN, V. M. Repensando o papel da cal nas argamassas. In: Simpósio BRASILEIRO DE TECNOLOGIA DE ARGAMASSAS - VSBTA, 2003, São Paulo. Anais Simpósio Brasileiro de Tecnologia das Argamassas,V. PORTO ALEGRE : ANTAC, 2003. v. 1. p. 47-63.

KACZYNSKI, A. Stress intensity factors for an interface crack in a periodic twolayered composite under the action of heat sources. International Journal of Fracture, Alphen aan den Rijn, v. 62, p. 183-202, 1993.

KARIHALOO, B. L.; CARPINTERI, A.; ELICES, M. Fracture Mechanics of cement mortar and plain concrete. Advanced Cement based materials, 1, 92-105,1993.

KEREZSI, B. B.; KOTOUSOV, A. G.; PRICE, J. W. H. Experimental apparatus for thermal shock fatigue investigations. International Journal of Pressure Vessels and Piping, v. 77, p 425-434, 2000.

KEREZSI, B; PRICE, J. W. H. Using the ASME and BSI codes to predict crack growth due to repeated thermal shock. International Journal of Pressure Vessels and Piping, v. 79, p. 361-371, 2002.

KIM, K.; JEON, S.; KIM, J.; YANG, S. An experimental study on thermal conductivity of concrete. Cement \& Concrete Composites, Essex, n. 33, p 363-371, 2003.

KINGERY, W. D. Factors affecting thermal stress resistance of ceramic materials. Journal of the American Ceramic Society. Easton, v. 38, n. 1, p. 3-15, 1955. 
KINGERY, W.D. Introduction to ceramics. New. York: 1960. J. Wiley \& Sons, Inc. $781 \mathrm{p}$.

KOPSCHITZ, P.; FRANCINETE Jr., P.; CINCOTTO, M. A.; JOHN, V. M. Estudo da retração e do desenvolvimento de propriedades mecânicas de argamassas mistas para revestimento. In: II Simpósio Brasileiro de Tecnologia das Argamassas, 1997, Salvador. Anais. II SBTA. Salvador : Antac, 1997. p. 120-132.

KOVLER, K.; FROSTIG, Y. On the problem of cracking in plaster layers. Construction and building materials. n. 12, p. 251-258, 1998.

KREITH, F. Princípios da transmissão de calor. Tradução Yamane, Pêra, Amorelli. São Paulo: Edgard Blücher Ltda.,1965. 650 p.

KRISTENSEN, L.;HANSEN, T. C. Cracks in concrete core due to fire or thermal heating shock. ACI materials Journal. v. 91, № 5 p. 453-459, 1994.

KÜNZEL, H. M. Simultaneous Heat and Moisture Transport in Building Components. IRB-Verlag. Stuttgart

LAMBERTS, R, DUTRA, L., PEREIRA, F. Eficiência energética na arquitetura. São Paulo: ProLivros, 2004. 192 p.

LEJEUNE, C. Les enduits d'impermeabilisation à base de liants hydrauliques. Revue Technique du Bâtiment et des Constructions Industrielles, n.88, Janvier-fevrier, 1985.

LION, M; SKOCZYLAS, F.; LAFHAJ, M.; SERSAR, Z. Experimental study on a mortar. Temperature effects on porosity and permeability. Residual properties or direct measurements under temperature. Cement and Concrete research, Oxford, v. 35 , p. 1937-1942. 2005.

LU, T. J., FLECK, N. A. The thermal shock resistance of solids. Acta Materialia, v. 46, n. 13, pp 4755-4768, 1998.

LUO, X.; SUN, W.; CHAN, S. Y. N. Effect of heating and cooling regimes on residual strength and microstructure of normal strength and high-performance concrete. Cement and Concrete research, Oxford, v. 30, p. 379-383. 2000.

MABROUK, R.;ISHIDA, T.; MAEKAWA, K. A unified solidification model of hardening concrete composite for predicting the young age behavior of concrete. Cement and Concrete Composites, 26 (2004) 453-461.

MAEKAWA, K; ISHIDA, T.; KISHI, T. Multi-scale modeling of concrete performance Integrated material and structural mechanics. Journal of advanced concrete technology, vol 1, no 2, p. 91-126, July 2003. 
MANSON, S. S. Thermal Stress and low-cycle fatigue. McGraw-Hill. New York, 1966, $404 \mathrm{p}$.

MANSON, S. S.; SMITH, R. W. Theory of thermal shock resistance of brittle materials based on Weilbull's statistical theory of strength. Journal of the American Ceramic Society. Easton, v. 38, n. 1, p. 18-27. 1955

MARSHALL, A. L. The thermal properties of concrete. Build. Sci, v. 7, p. 167-174, 1972.

MATYSIAK, S. J. Thermal stresses in a periodic two-layered composite weakened by an interface crack. Acta Mechanica, v. 78, p. 95-108, 1989.

MEDEIROS, Jonas S., Tecnologia e projeto de revestimentos cerâmicos de fachadas de edifícios. São Paulo, 1999 (Tese - Doutorado) - Escola Politécnica, Universidade de São Paulo.

MEHTA, P. K., MONTEIRO, P. Concreto - Estrutura, propriedades e materiais. São Paulo: PINI, 1994.

MELO A. A. Influência do teor de ativador e da idade de exposição na retração por secagem de argamassas com cimentos de escória ativada com silicato de sódio. São Paulo, 2002. Dissertação (Mestrado). Escola Politécnica, Universidade de São Paulo.

MENOU, A.; MOUNAJED, G; BOUSSA H.; PINEAUD A.; CARRE, H. Residual fracture energy of cement paste, mortar and concrete subject to high temperature. Theoretical and Applied Fracture Mechanics 45 (2006) 64-71

MOHD ZAIN, M.F.; YUSOF, K. M.; MATSUFUJI, Y. The influence of medium temperature environments on the water permeability of high performance mortar. Cement and Concrete research, Oxford, v.29, p. 785-788. 1999.

NIED, H. F. Thermal shock in an edge-cracked plate subjected to uniform surface heating. Engineering Fracture Mechanics, v. 26, No 2 p 239-246, 1987.

MIRANDA, L.; SELMO, S. Efeito de choques térmicos na fissuração de revestimentos de argamassa com RCD. In: Simpósio brasileiro de tecnologia de argamassas, 5, São Paulo, 2003. Anais. São Paulo: ANTAC, 2003. p. 583-594.

NEVILLE, A. M. Properties of concrete. London: Pitman, [1965, c1963]

OBEID, W.; MOUNAJED, G.; ABDENOUR, A. Etude du couplage thermo-hygromécanique en milieux poreux non satures. In Cahiers du CSTB n. 3200. 2000. 
O DIA ONLINE. Motorista sai ilesa após reboco atingir seu carro. O DIAONLINE, Rio de Janeiro, Jan. 18, 2006. Disponível em: http://odia.terra.com.br/rio/htm/geral 20558.asp . Acesso em 24 out., 2007.

O DIA ONLINE. Pedaço de reboco cai de prédio no Centro e atinge carro. 0 DIAONLINE, Rio de Janeiro, Abril 27, 2008. Disponível em: Acesso em 2 maio, 2008.

OLSEN, G. H.; ETTENBERG, M. Calculated stresses in multilayered heteroepitaxial structures. Journal of Applied Physics, v. 48 n. 6 (1977) 2543 - 2547.

PAES, Influência da junta de assentamento no comportamento térmico do sistema de revestimento cerâmico. Goiânia, 2000 (Dissertação - Mestrado) Escola de Engenharia Civil da Universidade Federal de Goiás.

PAGNUSSAT, D. T.; PAULETTI, C.; POSSER, N. D.; MASUERO, A. B. Avaliação das manifestações patológicas em fachadas de prédio histórico na cidade de Porto Alegre. In: V SIMPOSIO BRASILEIRO DE TECNOLOGIA DE ARGAMASSAS VSBTA, 2003, São Paulo. Anais Simpósio Brasileiro de Tecnologia das Argamassas,V. PORTO ALEGRE : ANTAC, 2003. v. 1. p. 573-582.

PALIARI, J. C.;.SOUZA, U. E. L.; ANDRADE, A. C. Estudo sobre consumo de argamassa de revestimentos interno e externo nos canteiros de obras. Brasil Fortaleza, CE. 2001. 12p. Simpósio Brasileiro de Gestão da Qualidade e Organização do Trabalho no Ambiente Construído, 2º , Fortaleza, CE, 2001. Artigo técnico

PCA - Portland Cement Association. Building movements and joints. Illinois PCA 1982.

PICKLES, C.S.J.; FIELD, J.E. The laboratory simulation of thermal shock failure. J. Phys. D: Appl. Phys. , 29, 436-441, 1996.

RAMAZAN, D. Thermal conductivity and compressive strength of expanded perlite aggregate concrete with mineral admixtures. Energy and Buildings 35 (2003) 1155-1159

REYTIER, M.; CHAPULIOT, S.; MARIE, S.; NÉDÉLEC, M. Thermomechanical analysis of thermal shock fracture in the brittle/ductile transition zone. Part II: Numerical calculations and interpretation of the test results. Engineering Fracture Mechanics, 73, p. 283-295, 2006.

ROMAN, L.; SAGAVE, A.; ROMAN, H.; ALARCON O. Análise da resistência de aderência em sistemas de revestimento cerâmico submetidos a ciclos higrotérmicos. In: Encontro Nacional de Tecnologia do Ambiente Construído, 8, 2000. Anais, Salvador: ANTAC, 2000, v. 2, p. 862-868. 
ROMAN, H. R.; ALARCON, O.; SILVA, D. A.; ROMAN, L.; SEGAVE, A. Desenvolvimento de técnicas de avaliação e critérios de desempenho de materiais e componentes da construção. Porto Alegre, RS. 2003. p. 110-133, il. ROMAN, Humberto Ramos; BONIN, Luis Carlos. Normalização e certificação na construção habitacional. Editores da Coletânea Roberto Lamberts e Maria Lúcia Horta de Almeida. Porto Alegre, RS: ANTAC, 2003. cap. 7.

ROSSELLO, M.T.V. Morteros de cemento para albañileria. Madrid, Instituto Eduardo Torroja, 1976. 55p.

SABBATINI, Fernando H. O processo construtivo de edifícios de alvenaria estrutural sílico-calcária. São Paulo, 1984. Dissertação (Mestrado). Escola Politécnica, Universidade de São Paulo.

SABNIS, GAJANAN. M. Structural modeling and experimental techniques. Englewood Cliffs, N.J. : Prentice-Hall, c1983. 585 p

SAEMANN, J.C.; WASHA, G. W. Variation of mortar and concrete properties with temperature. ACI Journal Proceedings, V 54, № 11, November, 1957, p. 385-395.

SALVINI, V. R.; INNOCENTINI, M. D. M; PANDOLFELLI, V. C. Choque térmico em filtros cerâmicos do sistema Al2O3-SiC. Cerâmica 48 (305) 2002, p 22-28.

SARAIVA, A. G. Contribuição ao estudo de tensões de natureza térmica em sistemas de revestimento cerâmico de fachada. Brasília, 1998 (Dissertação Mestrado) - Faculdade de Tecnologia da Universidade de Brasília.

SARAIVA, A. G., BAUER, E., BEZERRA, L. M. Efeito da temperatura nas tensões em sistemas de revestimento cerâmico de fachada. In: Simpósio Brasileiro de Tecnologia de Argamassas, 6, 1999. Anais, Vitória: ANTAC, 1999. p. 553-565.

SAUL, R. H. Effect of a GaAs ${ }_{x} P_{1-x}$ Transition Zone on the perfection of GaP crystals grown by deposition onto GaAs substrates. Journal of Applied Physics, v. 40 n. 8 (1969) 3273 - 3279.

SELMO, S.M.S. Dosagem de argamassas de cimento portland e cal para revestimento externo dos edifícios. São Paulo, 1989. Dissertação (Mestrado) Escola Politécnica da Universidade de São Paulo.

SILVA, A. J. C. Descolamentos dos revestimentos cerâmicos de fachada na cidade do Recife. São Paulo, 2001. Dissertação (Mestrado) Escola Politécnica da Universidade de São Paulo.

SILVA, D. A.; ROMAN, L.M.F; FREDEL, M. C.; ROMAN, H.R. Theoretical analysis on the thermal stresses of ceramic tile coating systems. In oth International Conference on Durability of Building Materials and Components, Volume 1, p.603-612. Vancouver (Canadá):1999. 
SILVA, F. B.; BARROS, M. M. S. B.; MONTE, R. Determinação do módulo de deformação de argamassas: avaliação dos métodos de ensaio e formatos de corpode-prova. In: XII Encontro Nacional de Tecnologia do Ambiente Construído, 2008. Anais Fortaleza. Geração de Valor no Ambiente construído: inovação e sustentabilidade, 2008. p. 1-10.

SIMPÓSIO BRASILEIRO DE TECNOLOGIA, 5, V SBTA 2003, São Paulo: Antac, 2003

SIMPÓSIO BRASILEIRO DE TECNOLOGIA, 6, VI SBTA 2005, Florianópolis: Antac, 2005

SINGH, J. P.; SATYAMURTHY, K.; THOMAS, J. R.;; HASSELMAN, D. P. H. Analysis of thermal stress resistance of partially absorbing ceramic plate subjected to asymmetric radiation, II: Convective cooling at front surface. Journal of the American Ceramic Society. Easton, v. 64, n. 3, p. 169-173. 1981.

SIQUEIRA, N. M. Influencia da fração carbonática da cal hidratada no desempenho de revestimentos em argamassas inorgânicas. São Paulo, 1995. 202 p. Dissertação (Mestrado) - Escola Politécnica, Universidade de São Paulo.

SIQUEIRA, N., M.; CINCOTTO, M. A.; JOHN, V.M..Influência da fração carbonática da cal hidratada no desempenho de rebocos. São Paulo, SP. 1993. v.1, p. 241-260. In: ENCONTRO NACIONAL DE TECNOLOGIA DO AMBIENTE CONSTRUÍDO, 1993, São Paulo. Artigo técnico.

SOUZA, U.E.L; AGOPYAN, V.; PALIARI, J. C.; ANDRADE, A. C. Simpósio Nacional Desperdício de Materiais nos Canteiros de obras: A quebra do Mito. São Paulo: PCC/EPUSP, 1999. 48 p.

STOECKER, W. F.; JONES, J. W. Refrigeração e ar condicionado. Trad. José S. Jabardo. São Paulo: McGraw-Hill, 1985. 481 p.

STRATFORD, T; CADEI, J. Elastic analysis of adhesion stresses for the design of a strengthening plate bonded to a beam. Construction and Building Materials, Vol 20 , p. 30-45, 2006.

SUMARAC, D.; KRASULJA, M. Damage of plain concrete due to thermal incompatibility of its phases. International Journal of Damage Mechanics, V 7 , April, 1998, p. 129-142.

TAM, C-T., LOO, Y-H, QUEK, S-T, SAW, W-H. Simulated thermal fatigue testing of wall-to-tile bond. In: Durability of building materials and components 6, 1993.

TEMOCHE-ESQUIVEL, J. F. Avaliação do uso de revestimentos cerâmicos de fachada em edifícios residenciais multifamiliares em São Paulo: estudo de caso 
Região Sul - 1994 1998. São Paulo, 2002 (Dissertação - Mestrado) - Faculdade de Arquitetura e Urbanismo da Universidade de São Paulo.

TEMOCHE-ESQUIVEL, J. F.; DEIFELD, T.; BARROS, M. M. S. B. ; JOHN, V. M.; FRANCA, R. Influência da taxa de defeitos de interface nas tensões de origem térmica em revestimentos de argamassa. In: Simpósio Brasileiro de Tecnologia das Argamassas, 7, 2007, Recife. Anais VII SBTA. Recife : Antac, 2007. p. 1-13.

TIMOSHENKO, S.; GOODIER, J.N. Teoria de la elasticidad. Bilbao, Urmo. 1968. $549 \mathrm{p}$.

THOMAS, J. R.; SINGH, J. P.; HASSELMAN, D. P. H. Analysis of thermal stress resistance of partially absorbing ceramic plate subjected to asymmetric radiation, I: Convective cooling at rear surface. Journal of the American Ceramic Society, Easton, v. 64, n. 3, p. 163- 169. 1981.

TOAKLEY, A. R.; WATERS, E. H. Stresses in ceramic tiling due to expansion and shrinkage effects. Building Science, v. 8, n. 3, p. 269-281, September 1973.

UEAtc (Union europeenne pour l'agrement technique dans la contruction). Guide technique UEAtc pour l'agrément des systèmes d'isolation extérieure des façades avec enduits minéraux. Avril 1992, UEAtc.

VECCHIO, F. J.; SATO, J. A. Thermal gradient effects in reinforced concrete frame structures. ACI Structural Journal. v. 87, no 3, p. 262-275, 1990.

VEIGA, M. R. da S. Comportamento de argamassas de revestimento de paredes. Contribuição para o estudo da sua resistência à fendilhação. Porto 2001 (Dissertação de doutorado). Laboratório Nacional de Engenharia Civil e Faculdade de Engenharia da Universidade do Porto.

VEIGA, M. R. Comportamento de argamassas de revestimentos de paredes. Susceptibilidade à fendilhação, capacidade de impermeabilização e aderência ao suporte. Influencia de parâmetros de constituição e de aplicação e avaliação de desempenho. In: V SIMPOSIO BRASILEIRO DE TECNOLOGIA DE ARGAMASSAS - V SBTA, 2003, São Paulo. Anais V SBTA. PORTO ALEGRE : ANTAC, 2003. v. 1. p. 63-93.

VENECANIN, S. D. Durability of composite materials as influenced by different coefficients of thermal expansion of components. In: Durability of Building Materials and Components. ASTM, STP 691. Sereda and Litvan Eds., 1980, p 179192

VENECANIN, S. Thermal incompatibility of concrete components and thermal properties of carbonate rocks. ACI Materials Journal, v. 87, n. 6, p. 602-607, 1990 
VILATÓ, R. R. Efeito do preenchimento das juntas verticais entre componentes no comportamento da alvenaria estrutural. São Paulo, 2004. Tese (Doutorado) 165 p. Escola Politécnica, Universidade de São Paulo.

WEIDLINGER, P. Thermal stresses in high concrete buildings. Civil Engineering, 1964.

WILLAM, K.; RHEE, I.; XI, Y. Thermal Degradation of Heterogeneous Concrete Materials. Journal of materials in civil engineering - ASCE / may/june 2005

WITTMANN, F. H. Fracture mechanics of concrete. Amsterdam; New York : Elsevier, 1983.

ZAITSEV, Y. B., 'Crack propagation in a composite material', In Fracture Mechanics of Concrete, Ed. Wittmann, F. H. (Elsevier, 1983) 251-299.

ZHOU, B.; KOKINI, K. Effect of preexisting surface cracks on the interfacial thermal fracture of thermal barrier coatings: an experimental study. Surface \& Coatings Technology, 187 (2004) 17-25. 


\section{APÊNDICE A - CONCEITOS BÁSICOS SOBRE TRANSFERÊNCIA DE CALOR}

\section{Introdução}

Em geral, os processos de transferência de calor baseiam-se em dois princípios fundamentais derivados da termodinâmica: a conservação de energia e o fluxo de calor da temperatura mais alta para a mais baixa.

Segundo o principio geral da conservação de energia, aplicado a um volume de controle, para um intervalo de tempo $(\Delta t)$, conforme descrevem Incropera; Dewitt (1999), o balanço de energia pode ser expresso segundo a Equação A 1:

$$
\mathrm{E}_{\text {ent }}+\mathrm{E}_{g}-\mathrm{E}_{s a i}=\Delta \mathrm{E}_{a r m}
$$

Onde:

$E_{\text {ent }}=$ Energia que ingressa no sistema;

$\mathrm{E}_{\mathrm{g}}$ = Energia gerada no sistema;

$E_{\text {sai }}=$ Energia que sai do sistema;

$\Delta \mathrm{E}_{\mathrm{arm}}=$ Variação da energia armazenada no sistema

Para resolver essa equação é necessário determinar os fluxos de entrada e saída de energia, que podem ser expressos como fluxos de calor (q), governados por processos de transferência de calor, além da energia gerada no interior do volume de controle. Em conseqüência, tem-se a variação da energia nele armazenada.

No caso do revestimento de argamassa, o termo relativo à geração de energia no sistema, que estaria associado à conversão de outro tipo de energia em energia térmica (calor de hidratação, por exemplo), será desconsiderado, já que sua parcela mais importante ocorre com a argamassa ainda úmida, em função do calor de hidratação do cimento.

A variação da energia armazenada no volume de controle depende da taxa de variação da sua energia térmica interna ao longo do tempo, já que no caso do revestimento analisado, não há mudança de fase e, portanto, os efeitos da energia latente não existem. Logo, $E_{\text {arm }}$ pode ser expressa, segundo Incropera; DeWitt (1990) como na Equação A 2 
$\mathrm{E}_{\mathrm{arm}}=\varrho \mathrm{c} \frac{\partial T}{\partial t} \mathrm{dx} \cdot \mathrm{dy} \cdot \mathrm{dz}$

Equação A 2

Onde:

$\mathrm{E}_{\mathrm{arm}}=$ Energia armazenada no sistema;

$\rho=$ densidade do meio contínuo;

c = calor específico do meio contínuo;

$\partial \mathrm{T} / \partial \mathrm{t}=$ taxa de variação da temperatura no tempo

$\mathrm{dx} . \mathrm{dy} \cdot \mathrm{dz}=$ unidade de volume

Por fim, os termos relativos aos fluxos de entrada e saída de energia em forma calor podem ser obtidos das expressões da transferência de calor entre materiais que são três: condução, convecção e radiação, abordados sinteticamente na seqüência.

\section{Condução}

Esta forma de transferência de calor refere-se ao transporte de energia através de um meio por difusão de elétrons ou vibração de fônons devido a um gradiente de temperatura (KREITH, 1965; INCROPERA, DeWITT, 1990). Essa transferência de calor pode ocorrer no meio considerando-se uma única coordenada, ou seja, de maneira unidimensional, duas ou três coordenadas, sendo este último o caso mais geral para o qual é aplicável a Equação A 3, denominada equação de Fourier, na qual é desconsiderada a geração de energia interna:

$$
\frac{\partial^{2} T}{\partial x^{2}}+\frac{\partial^{2} T}{\partial y^{2}}+\frac{\partial^{2} T}{\partial z^{2}}=\frac{\rho . c . \partial T}{k . \partial t}
$$

Onde:

Earm = Energia armazenada no sistema;

$\rho=$ densidade do meio contínuo $\left(\mathrm{Kg} / \mathrm{m}^{3}\right)$;

$c=$ calor específico do meio contínuo;

$\mathrm{k}=$ condutividade térmica $\left(\mathrm{W} / \mathrm{m} .{ }^{\circ} \mathrm{K}\right)$

$\partial \mathrm{T} / \partial \mathrm{t}=$ taxa de variação da temperatura no tempo.

O fluxo de calor pode ser considerado em regime permanente quando o fluxo por condução permanece inalterado com o tempo. Porém, se o fluxo variar com o tempo, a análise deve ser realizada em regime transiente, que é considerado na Equação $A$ 3. 
No caso do revestimento externo de argamassa, a abordagem que considera o regime permanente é válida para avaliação das tensões térmicas no instante em que é atingida a máxima temperatura no revestimento. Entretanto, não é válida para avaliar o perfil de temperaturas no período do aquecimento e do resfriamento do revestimento quando se deve considerar o regime transiente.

\section{Convecção}

Conforme Incropera; DeWitt (1999), o termo convecção descreve a transferência de energia entre uma superfície e o fluido que se movimenta sobre ela. Assim, a convecção não é um fenômeno independente mas a combinação de condução de calor devido ao mecanismo de difusão (movimento aleatório das moléculas do fluido) e do fluxo das partículas do fluido.

A equação básica que descreve a transferência de calor por convecção é dada pela Equação A 4:

$q=h A\left(T_{s}-T_{f}\right)$

Equação A 4

Onde:

$q=$ Fluxo de calor por convecção (W);

$\mathrm{h}=$ Coeficiente de convecção $\left(\mathrm{W} / \mathrm{m}^{2} .{ }^{\circ} \mathrm{C}\right)$;

A = Superficie em contato com o fluido $\left(\mathrm{m}^{2}\right)$;

$\mathrm{T}_{\mathrm{s}}=$ Temperatura na superficie $\left({ }^{\circ} \mathrm{C}\right)$;

$\mathrm{T}_{\mathrm{f}}=$ Temperatura do fluido $\left({ }^{\circ} \mathrm{C}\right)$

A principal dificuldade com a Equação A 4 é que o coeficiente $h$ não é constante mas é função de diferentes variáveis associadas ao fluxo e à condução de calor no fluido. Desta forma, o valor da temperatura do fluido (Tf) que deve ser considerado na equação também é variável e dependente da distancia à superfície (camada limite) e do tipo de fluxo (laminar ou turbulento), sendo tais conceitos amplamente discutidos por Kreith (1965), Incropera, DeWitt (1990) e ASHRAE (2001), dentre outros autores.

Existem diferentes relações para calcular o coeficiente $h$, dependendo do fluido considerado, do regime do fluxo e das condições termodinâmicas.

O fenômeno da convecção nos revestimentos externos no período diurno (aquecimento do revestimento) ocorre por etapas. Inicialmente o calor ganho pela 
superfície do revestimento (radiação) flui por condução para as partículas adjacentes do fluido envolvente (ar). Essas, ao se aquecerem (elevação da sua energia interna), diminuem sua densidade e se movem para a região de menor temperaturas do fluido, onde se misturam e transferem parte de sua energia para outras partículas fluidas (movimento macroscópico). Os gradientes de temperatura assim gerados no fluido (ar) provocam o movimento cíclico da sua massa. O fluxo é, portanto, de fluido e de energia e ocorre na direção do gradiente de temperatura.

Existem na literatura correlações empíricas em termos de parâmetros adimensionais apresentadas por diversos autores como Kreith, 1965; Stoecker e Jones (1985); Incropera e DeWitt, 1990 e ASHRAE (2001) para o cálculo de "h". Entretanto, Stoecker e Jones (1982); Incropera e DeWitt, 1990 apresentam alguns valores típicos para o coeficiente " $h$ ", mostrados na Tabela A 1:

Tabela A 1: Valores típicos do coeficiente de transferência de calor por convecção

\begin{tabular}{|c|c|c|}
\hline \multirow[t]{2}{*}{ Processo de transferência de calor } & \multicolumn{2}{|l|}{$\begin{array}{l}\mathrm{h} \\
\left(\mathrm{W} / \mathrm{m}^{2} \cdot \mathrm{K}\right)\end{array}$} \\
\hline & Incropera e DeWitt, 1990 & Stoecker e Jones (1985) \\
\hline \multicolumn{3}{|l|}{ Convecção livre } \\
\hline Gases & $2-25$ & Com ar $\quad 5-25$ \\
\hline Líquidos & $50-1000$ & Com água $20-100$ \\
\hline \multicolumn{3}{|l|}{ Convecção forçada } \\
\hline Gases & $25-250$ & $10-200$ \\
\hline Líquidos & $50-20000$ & Com água $50-10.000$ \\
\hline \multicolumn{3}{|l|}{ Convecção com mudança de fase } \\
\hline Ebulição & $2500-100.000$ & $3000-100.000$ \\
\hline Condensação & $2500-100.000$ & $5000-100.000$ \\
\hline
\end{tabular}

\section{Radiação}

A radiação é o processo de transferência de energia entre dois corpos por ondas eletromagnéticas sem que o espaço intermediário entre eles altere seu estado térmico e pode ocorrer também no vácuo (INCROPERA, DeWITT, 1990; KREITH, 1965).

O estudo da radiação do calor se baseia na definição do "corpo negro" e de leis físicas que regem o fenômeno. O corpo negro é definido como sendo uma superfície onde a absortividade $(\alpha)$ é unitária e a refletividade $\left(\rho_{r}\right)$ e a transmissividade $(\tau)$ são nulas. Estes índices representam, respectivamente, a relação entre o fluxo de calor absorvido, refletido e transmitido e a radiação total incidente em uma superfície. 
Uma superfície real sempre irradia menos radiação que um corpo negro na mesma temperatura. Se a superfície ou corpo tiver emissividade monocromática igual em todos os comprimentos de onda, esta é denominada de "superfície ou corpo cinzento" e a potência emissiva é dada, segundo Holman (1983), por:

$E=\varepsilon_{\mathrm{s}} \cdot \sigma_{\mathrm{b}} \cdot T^{4}$

Equação A 5

Onde:

$E$ = poder emissivo;

$\varepsilon_{\mathrm{s}}=$ emissividade ou poder de emissão no equilíbrio térmico;

$\sigma_{b}=$ constante de Stefan-Bolztmann;

$\mathrm{T}=$ temperatura

O fluxo de calor " $q_{1-2}$ " recebido por uma área $A_{2}$ com temperatura $T_{2}$, oriunda de uma área $A_{1}$, com temperatura $T_{1}$ é:

$q_{1-2}=\sigma_{\mathrm{b}} \cdot A_{1} \cdot F_{1-2}\left(T_{1}^{4}-T_{2}^{4}\right)$

Equação A 6

Onde:

$\sigma_{b}$ é a constante de proporcionalidade de Stephan-Boltzmann, cujo valor é de $4,92.10^{-8} \mathrm{Kcal} / \mathrm{m}^{2} . \mathrm{h}$ $\left({ }^{(\mathrm{o} K}\right)^{4}$;

$F_{1-2}$ é o fator de configuração e está relacionado com a posição, a forma geométrica das áreas e a emissividade dos corpos cinzentos.

A principal fonte de calor por radiação no revestimento externo é a energia solar, que é absorvida na superfície, durante o período de exposição; porém, trocas de calor por radiação também ocorrem entre o revestimento e os corpos ao redor dele.

Da mesma forma, no interior do substrato quando não é um material contínuo como, por exemplo, no caso da vedação de alvenaria de blocos vazados, ocorrerão trocas de calor por radiação entre as paredes do bloco e a argamassa de assentamento.

A distribuição de temperaturas em um meio geralmente é resultado do efeito combinado dos três modos de transferência de calor, de tal forma que não se pode isolar totalmente um dos outros. Em análises simplificadas é possível considerar somente os efeitos dominantes, tendo-se em mente que mudanças nas condições externas podem exigir que sejam avaliados os modos desprezados. 


\section{APÊNDICE B: DADOS DE LEVANTAMENTOS DE CAMPO}

A partir de dados climáticos obtidos na Estação Climática da EPUSP e também no Instituto de Astronomia, Geofísica e Ciências Atmosféricas, foram analisados os períodos em que poderiam ter ocorrido choques térmicos.

Alguns dos gráficos analisados são apresentados na seqüência indicando o ano, mês e temperaturas.

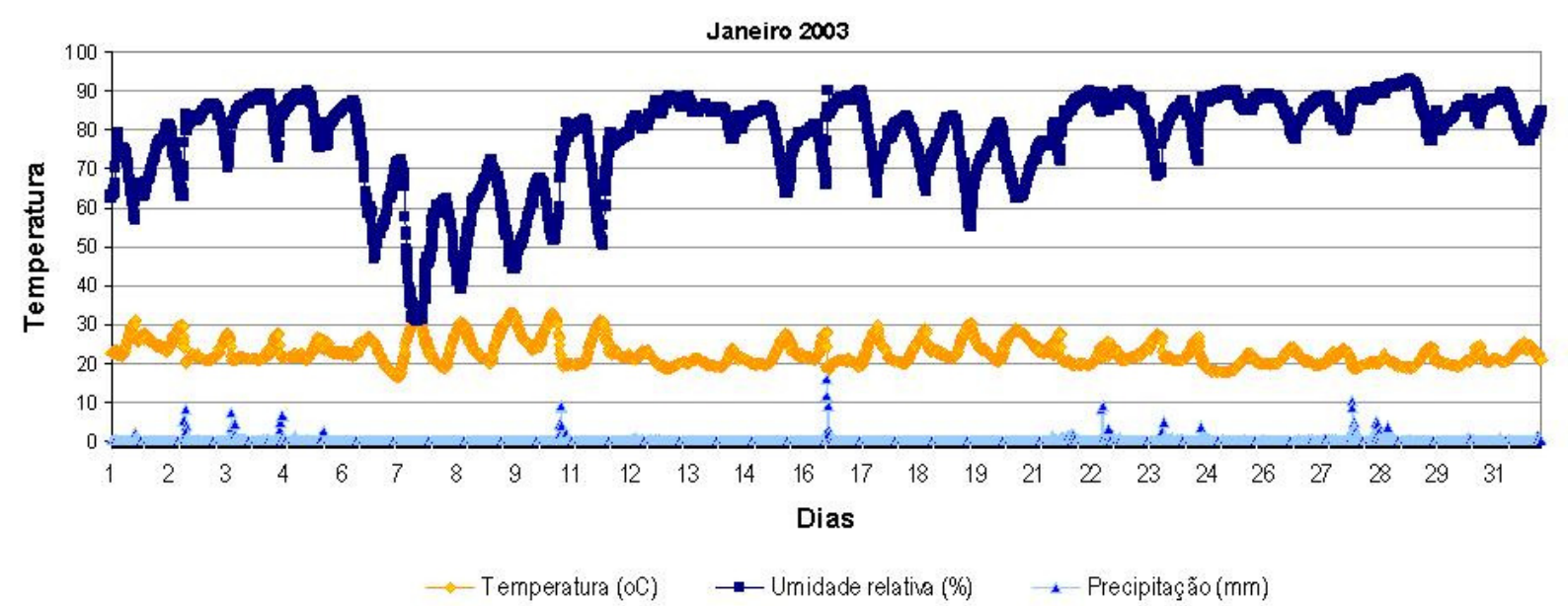

Figura B. 1: Dados de temperatura do ar, precipitação e umidade relativado mês de janeiro de 2003

\section{Variação de Temperatura no dia 16/01/2003}

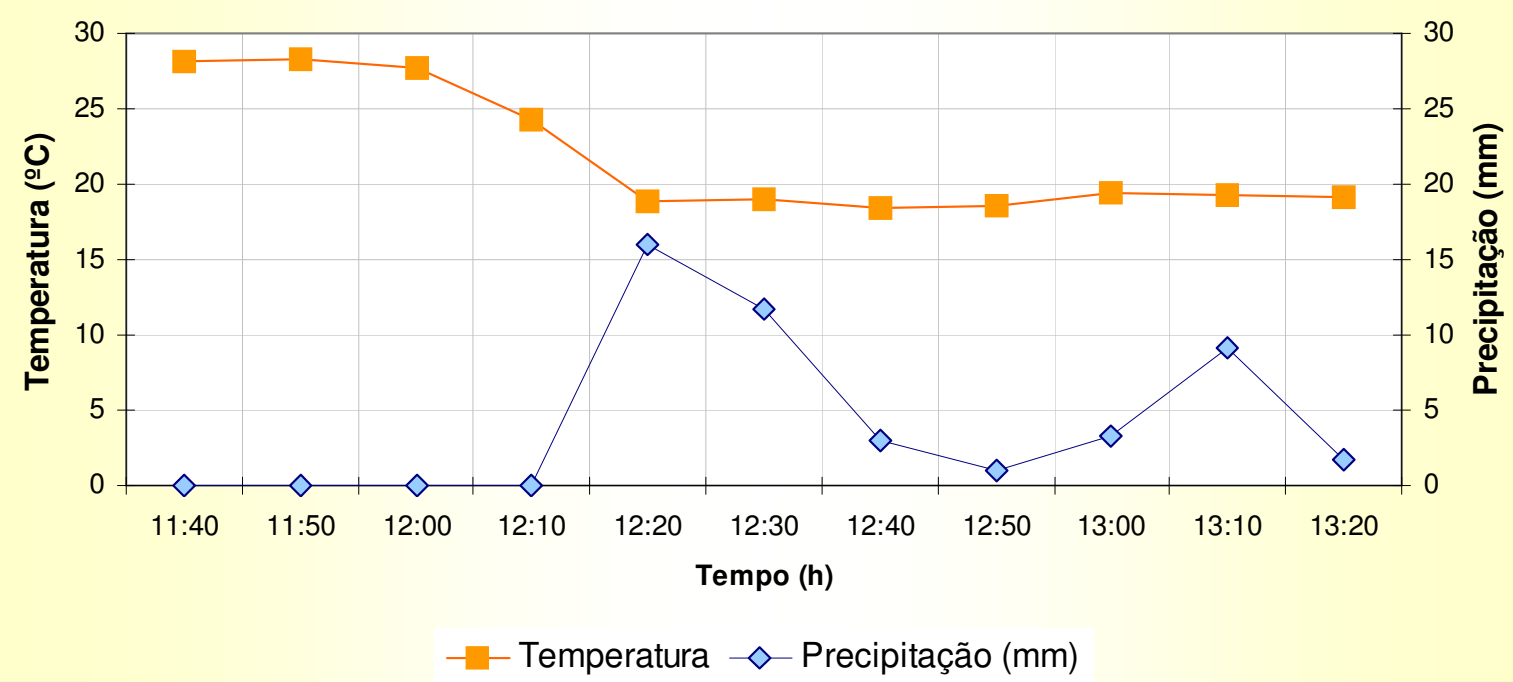

Figura B. 2: Diminuição de temperatura com início de precipitação 


\section{APÊNDICE C - PROGRAMA EXPERIMENTAL PILOTO}

\section{Introdução}

O efeito do choque térmico sobre materiais e/ou componentes construtivos é avaliado experimentalmente submetendo-se corpos de prova a um resfriamento repentino, geralmente com água, após um período de aquecimento. Posteriormente, são avaliadas as modificações geradas pelo choque térmico no corpo de prova, sejam elas fissuras superficiais ou alteração das suas propriedades físicas.

Para os revestimentos de argamassa em fachada os fatores que têm influência no efeito do choque térmico podem ser classificados em dois grupos: aqueles relativos ao processo térmico que produz a variação repentina de temperatura e aqueles relativos às características do revestimento que condicionam sua resposta perante a solicitação térmica.

Quanto aos fatores relativos ao processo térmico, neste trabalho está se fazendo variar repentinamente a temperatura superficial do revestimento, dentro de limites que podem vir a ocorrer nos revestimentos de edifícios, em condições brasileiras.

Quanto às variáveis relativas que condicionam a resposta do revestimento, tendo em vista que não se conseguiria estudar todas elas, estão se enfatizando duas delas: o módulo de deformação da argamassa e as condições iniciais de aderência do revestimento à base.

A ênfase dada a cada um dos fatores ou variáveis neste programa experimental tem o intuito de verificar a hipótese de que sucessivos choques térmicos afetam a durabilidade da aderência revestimento-base dos revestimentos de argamassa, principalmente em função das suas condições iniciais de aderência ao substrato.

As atividades experimentais estão sendo desenvolvidas principalmente nas instalações dos Laboratórios do Departamento de Engenharia de Construção Civil da Escola Politécnica da USP (CPqDCC $\left.{ }^{16}\right)$.

\footnotetext{
${ }^{16}$ CPqDCC é o Centro de Pesquisa e Desenvolvimento da Construção Civil da Escola Politécnica da Universidade de São Paulo.
} 


\section{Planejamento do experimento}

Este trabalho está inserido no escopo do conjunto de pesquisas definido pelo CONSITRA - Consórcio Setorial para Inovação Tecnológica de Revestimentos de Argamassa $^{17}$, particularmente no que se refere à durabilidade dos revestimentos.

Estudos sobre as variáveis que influenciam na aderência do revestimento à base foram realizados por Antunes (2005), tendo-se identificado que os macro-defeitos na interface entre a argamassa e o substrato são fundamentais para o desempenho mecânico do revestimento. No presente trabalho associou-se este fator à variação brusca de temperatura e às características da argamassa, buscando-se identificar quanto a durabilidade do revestimento poderá ser comprometida ao longo da vida útil do edifício.

Assim, algumas variáveis foram definidas a partir dos resultados dos trabalhos de Antunes (2005) e Temoche et al. (2007), seguindo-se as atividades mostradas na Figura C 1:

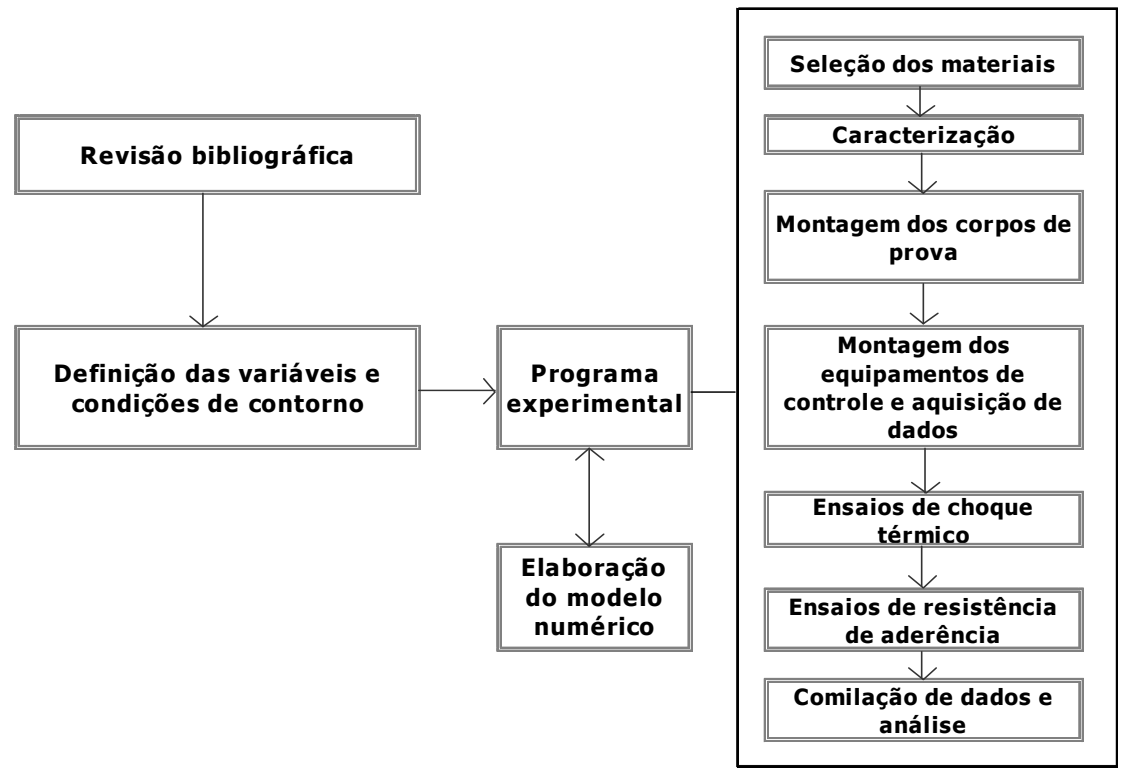

Figura C 1: Atividades Programa Experimental piloto

${ }^{17}$ O Consitra, Consórcio Setorial para Inovação em Tecnologia de Revestimentos de Argamassa, é uma iniciativa inédita, pois integra vários agentes da cadeia produtiva em um projeto com objetivo comum, que é desenvolver, no âmbito dos revestimentos, novas tecnologias pautadas por atributos como: confiabilidade, produtividade, durabilidade e custo compatível com o mercado nacional (COMUNIDADE DA CONSTRUÇÃO, 2004) 


\section{Variáveis e níveis de análise}

Dentro do grupo de variáveis relativas às características do processo térmico que produz a variação repentina de temperatura, foi definida como única variável a ocorrência ou não do choque térmico. Para tanto foi necessário definir os valores da temperatura máxima atingida no aquecimento e a temperatura mínima no resfriamento; o tempo de aquecimento e o tempo de permanência na temperatura máxima e da mesma forma para o resfriamento; o número de ciclos de ensaio; as características dos equipamentos utilizados no ensaio; a forma de avaliação do grau de degradação causado pelo choque térmico, dentre outros aspectos.

Da analise dos trabalhos nacionais dentre eles os de Geyer; Greven (1994), Siqueira; Cincotto; John (1995), Candia (2001), Miranda; Selmo (2003) e, Crescêncio; Barros (2003), observou-se a utilização do procedimento de ensaio especificado pelo IPT (1998), com algumas variantes no caso de Collantes (1999) e a utilização de câmara climática no caso de Roman et al. (2000).

Para as variáveis dependentes do revestimento de argamassa foram selecionadas para o programa experimental: a densidade do revestimento através do teor de ar incorporado que permitiu controlar o módulo de deformação e a condutividade térmica do revestimento e, a taxa de macro-defeitos de interface existente no revestimento aderido, utilizando também como base os resultados dos modelos numéricos desenvolvidos.

Desta forma são apresentadas na Tabela C. 1 as variáveis do programa experimental e seus níveis.

Tabela C. 1: Variáveis do arranjo experimental

\begin{tabular}{l|l|l|l}
\hline \multirow{2}{*}{ Tipo de argamassa } & $\begin{array}{l}\text { Taxa de macro- } \\
\text { defeitos de } \\
\text { Interface provocados }\end{array}$ & Sem choque térmico & 30 ciclos de choque térmico \\
\cline { 2 - 4 } & $\mathrm{e}=30 \mathrm{~mm}$ & $\mathrm{e}=30 \mathrm{~mm}$ \\
\hline Argamassa sem AIA & $0 \%$ & $1 \ldots$ & 5 \\
\cline { 2 - 4 } & $35 \%$ & 2 & 6 \\
\hline Argamassa com AIA & $0 \%$ & 3 & 7 \\
\cline { 2 - 4 } & $35 \%$ & 4 & 8 \\
\hline
\end{tabular}

Desenvolvimento do modelo numérico

O objetivo do modelo numérico foi determinar a distribuição de temperaturas, e o respectivo campo de tensões, em um bloco formado por uma base de concreto ou 
substrato, sob uma camada de revestimento de argamassa, submetido a uma variação de temperatura em uma das faces. Para isto foi utilizada a Análise com Elementos Finitos.

Para realização dessa análise buscou-se a parceria de um especialista do Departamento de Estruturas e Fundações da EPUSP, sendo viabilizada a utilização do software Ansys ${ }^{\circledR}$ através do Laboratório de Mecânica Computacional (LMC).

Inicialmente considerou-se o bloco submetido a uma temperatura inicial, aplicandose na fase externa do revestimento um acréscimo na temperatura. Os efeitos são verificados considerando análises estáticas e transiente.

Como variável adicional às propriedades dos materiais estudou-se também a influência de falhas na interface entre o substrato e o revestimento. As falhas foram introduzidas pela supressão dos elementos finitos na região do modelo.

Foram desenvolvidos modelos bidimensionais (2D) e posteriormente modelos tridimensionais (3D) para confirmação dos resultados.

Modelos em 2D

Os modelos considerados preliminarmente têm a forma da Figura C 2. As espessuras do substrato e do revestimento são de $2,5 \mathrm{~cm}$ (semelhante a do substrato padrão) e $3 \mathrm{~cm}$ (espessura média do revestimento). O comprimento é igual a $50 \mathrm{~cm}$. Essas dimensões foram redefinidas posteriormente.

Foi criada uma camada intermediária, com as propriedades do revestimento, para que se possa considerar a ocorrência de falhas na interface.

\section{Revestim ento}

\section{B a s e}

Figura C 2: Geometria do modelo em 2D

Usa-se, nesta simulação numérica, os elementos finitos PLANE13 (análise estática) e PLANE55 (análise transiente) do ANSYS. A Figura C 3 mostra as geometrias destes elementos. 
Figure 13.1 PLANE13 Geometry

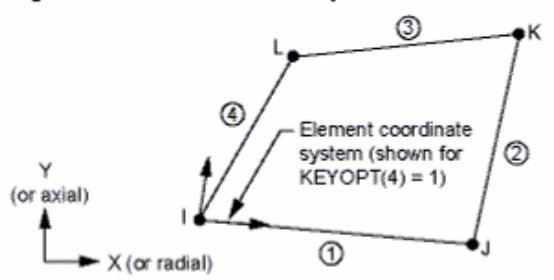

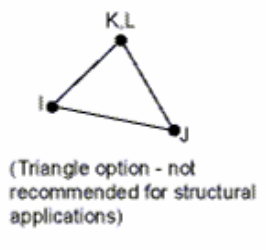

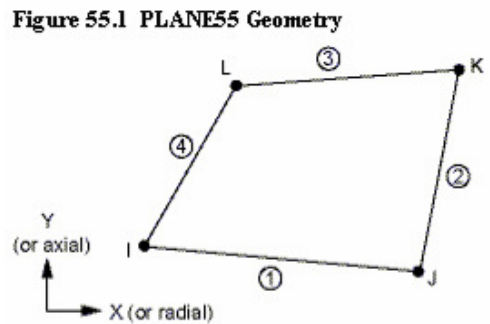

Figura C 3: Geometria dos elementos PLANE13 e PLANE55 do Ansys

A Figura C 4 mostra a malha de elementos finitos considerada e as condições de contorno.

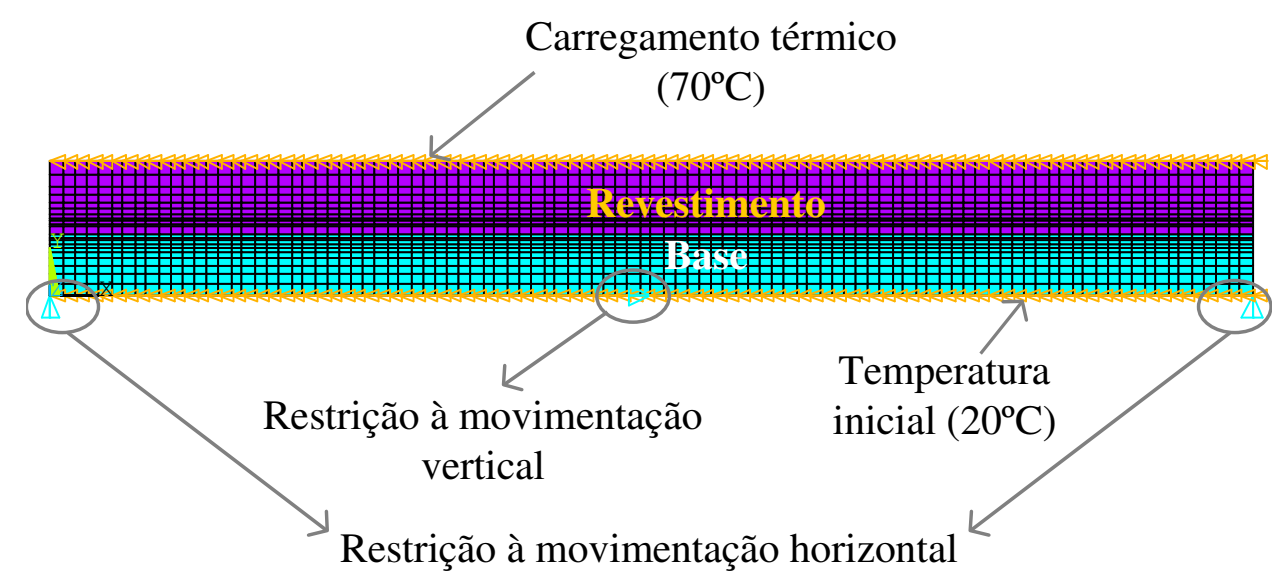

Figura C 4: Malha e condições de contorno

A dimensão dos elementos definidos pela malha foi variada com a altura, em cada uma das camadas, de forma a apresentar elementos menores nas proximidades da interface.

As vinculações foram definidas para impedir apenas os movimentos de corpo rígido do modelo deixando-o livre para quaisquer deformações que viessem ocorrer. Nos extremos inferiores foi impedida a movimentação no eixo $Y$ o no centro foi impedida a movimentação no eixo $X$.

\section{Modelos em 3D}

Os modelos considerados têm a forma da Figura C 5. As espessuras do substrato e do revestimento são de 2,5 e $3 \mathrm{~cm}$ respectivamente. Os comprimentos Ix e ly foram definidos nesta análise iguais a $50 \mathrm{~cm}$, simulando o lado maior de um substrato padrão de concreto. 


\section{Revestimento}

Base

Figura C 5: Modelo 3D

Foi criada uma camada intermediária entre o revestimento e a base, com as mesmas propriedades do revestimento, para que se pudesse considerar a ocorrência dos macro-defeitos na interface.

Usaram-se, nesta simulação numérica, os elementos finitos SOLID226 (análise estática) do ANSYS, mostrados na Figura C 6:
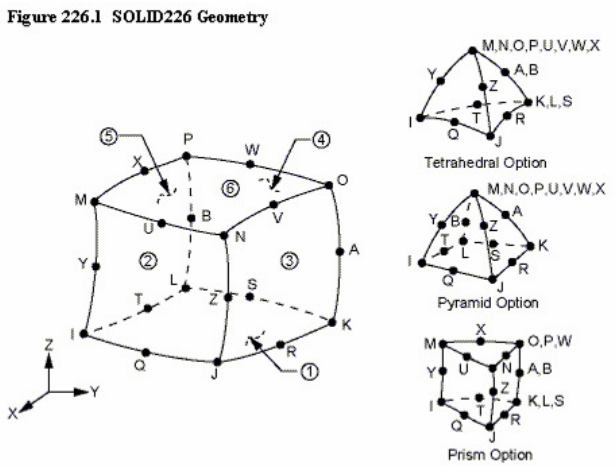

Figura C 6: Geometria dos elementos finitos usado Geometria do elementos utilizados

A análise estática consistiu da aplicação de uma temperatura de $20 \stackrel{\circ}{C}$ na face inferior (face externa do substrato) e de uma temperatura de $70^{\circ} \mathrm{C}$ na face superior (face externa do revestimento) do modelo, considerando-se que a temperatura inicial do modelo era a mesma aplicada na face inferior.

Escolha da variável de resposta

A avaliação da aderência de revestimentos em geral é realizada comumente com o ensaio denominado resistência de aderência à tração normal, cuja descrição é apresentada na NBR 13528 (ABNT, 1995). Este parâmetro de resposta possibilita avaliar o efeito de tensões térmicas devido ao choque térmico na resistência de aderência do revestimento, comparando os corpos de prova de referência, isto é, não submetidos ao choque térmico, com aqueles que foram submetidos. 


\section{Geometria dos corpos de prova}

Nos modelos posteriores, tanto a geometria como as dimensões dos corpos de prova foram definidas utilizando simulação numérica de forma a se obter uma base suficientemente rígida para minimizar os deslocamentos verticais no seu centro quando aplicada a carga térmica, e de forma a se obter uma área suficiente para realizar os ensaios de aderência. Para isto, os requisitos utilizados para definição das dimensões dos corpos de prova foram: a) o corpo de prova deveria proporcionar uma área mínima livre de perturbações nas tensões térmicas devido a efeitos de borda e; b) na área definida deveria ser possível extrair pelo menos seis corpos de prova de forma cilíndrica para ensaios de resistência de aderência. Com isto, 0 corpo de prova foi definido com as características geométricas mostradas na Tabela C. 2:

Tabela C. 2: Dimensões dos corpos de prova

\begin{tabular}{l|l|l|l|l}
\hline Componente & Espessura $(\mathrm{mm})$ & Largura $(\mathrm{mm})$ & $\begin{array}{l}\text { Comprimento } \\
(\mathrm{mm})\end{array}$ & Referência \\
\hline Substrato & 100 & 30 & 40 & \\
\hline $\begin{array}{l}\text { Argamassa de } \\
\text { revestimento }\end{array}$ & 30 (mínima) & 30 & 40 & \\
\hline
\end{tabular}

Materiais e equipamentos utilizados

\section{Base ou substrato}

Como o substrato de aplicação do revestimento não deveria ser uma variável, optouse pela sua produção junto a um especialista, no caso, a Associação Brasileira de Cimento Portland (ABCP) que produz costumeiramente as bases de substrato padrão para ensaios de argamassas colantes. As características definidas para esses substratos, são apresentadas na Tabela C. 3:

Tabela C. 3: Características da base ou substrato

\begin{tabular}{|c|c|c|c|c|}
\hline Material & Dimensões (m) & $\begin{array}{c}\text { Módulo de } \\
\text { deformação - E } \\
(\mathrm{GPa})\end{array}$ & $\begin{array}{c}\text { Densidade } \\
\left(\mathrm{kg} / \mathrm{cm}^{3}\right)\end{array}$ & Características superficiais \\
\hline Concreto & $\begin{array}{l}0,30 \times 0,40 \times \\
0,10\end{array}$ & 25 & 2.400 & $\begin{array}{l}\text { características superficiais } \\
\text { semelhantes às do substrato padrão } \\
\text { da norma NBR } 14082^{18} \text {. }\end{array}$ \\
\hline
\end{tabular}

${ }^{18} \mathrm{O}$ concreto para o substrato-padrão deve ser executado com cimento Portland, areia e pedrisco, com relação água:cimento de 0,45 a 0,50 e consumo mínimo de cimento de $400 \mathrm{~kg} / \mathrm{m} 3$. Como traço indicativo (em massa), sugere-se 1:2,58:1,26. Os agregados devem ser ensaiados e cumprir as 
Os materiais utilizados na produção dos substratos de concreto foram: cimento Portland CP II E (NBR 11578); brita № 1 e aditivo dispersante para concreto.

O equipamento utilizado para mistura do concreto foi uma betoneira de 120 I e na moldagem dos substratos foram utilizadas fôrmas de madeira compensada, conforme mostrado na Figura C 7:

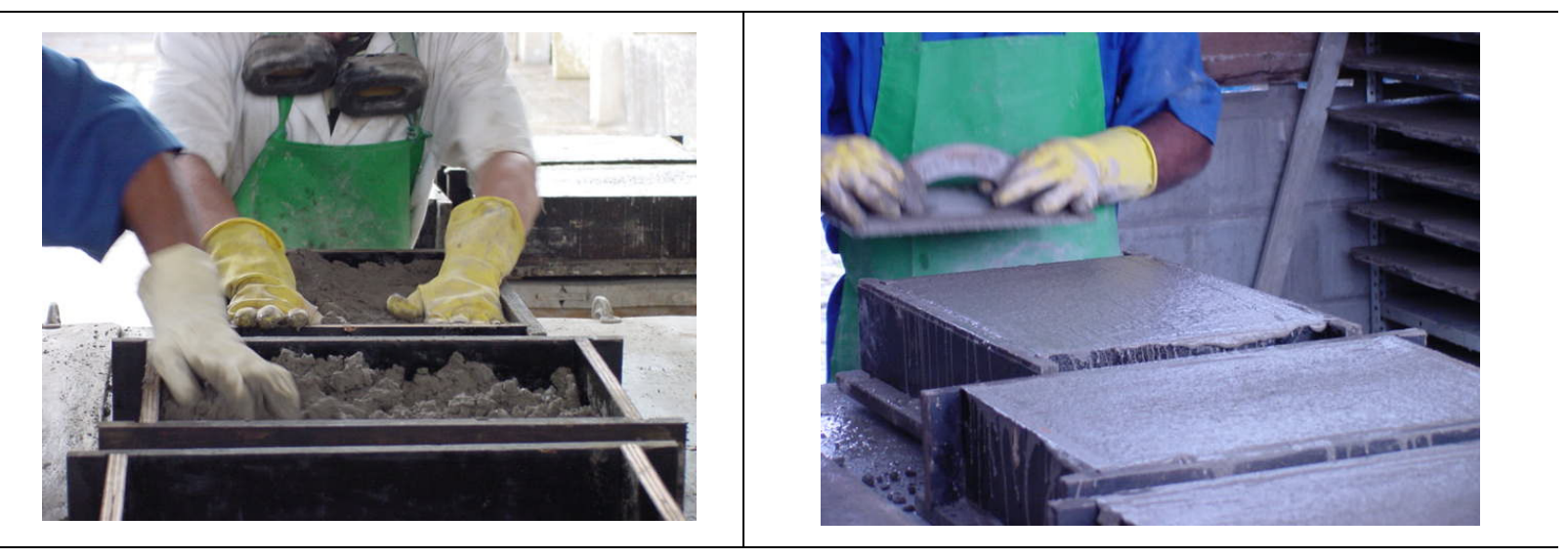

Figura C 7: Produção dos substratos de concreto

A cura foi realizada durante 28 dias sendo o primeiro dia no molde, seis dias imerso na água e 21 dias ao abrigo das intempéries.

Na Figura C 8 é mostrado o período de cura em que a base ficou imersa na água.

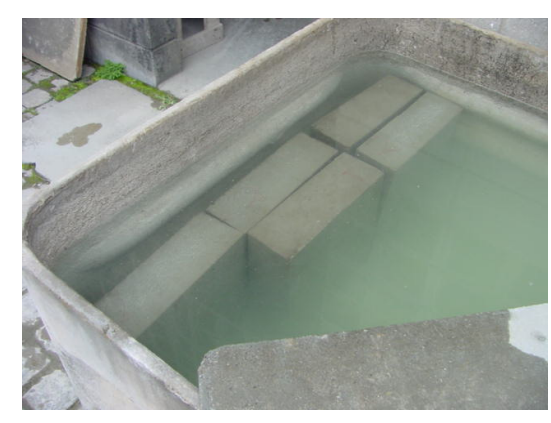

Figura C 8: Cura das bases de concreto

\section{Revestimento de argamassa}

Como uma das variáveis consideradas no experimento refere-se a uma das propriedades mecânicas do revestimento, seu módulo de deformação, sua variação

prescrições da NBR 7211 (areia da zona 3 e agregado graúdo de graduação 0). A mistura deve ser em betoneira, adensado mediante vibração, e regularizado com régua metálica. $\mathrm{O}$ acabamento final deve ser feito com desempenadeira de madeira após a evaporação de eventual água de exsudação. A cura deve ser feita durante 28 dias, sendo o primeiro dia no molde, seis dias imerso na água e 21 dias ao abrigo das intempéries. 
foi controlada unicamente pelo uso de aditivo incorporador de ar na dosagem da argamassa.

A espessura do revestimento tem influência no seu comportamento mecânico, uma vez que o aumento da espessura do revestimento diminui o nível de tensões na interface base-revestimento, fato que foi confirmado também pelo modelo numérico em coincidência com trabalhos como o de Bortoluzzo (2000). Entretanto, neste trabalho optou-se pelo cenário mais crítico, ou seja, aquele do revestimento com a menor espessura média que representasse o valor mais freqüente em obra.

Assim a espessura do revestimento foi definida em $30 \mathrm{~mm}$, que é um valor acima do mínimo recomendado pela norma ABNT, NBR 7200 (1998) e que foi registrado pelo pesquisador em diversas visitas a obras na cidade de São Paulo. Da mesma forma, esse valor coincide o citado por Souza et al. (1999) e o utilizado no trabalho de Antunes (2005).

O módulo de deformação é uma propriedade que indica a capacidade de deformação que o revestimento pode apresentar. Sua influência no desempenho do revestimento é destacada em trabalhos experimentais como os de Godoy e Barros (1999) e Bastos (2003). Também, Collantes (2001) identificou em ensaios de choque térmico sobre revestimentos de argamassa que o aumento do módulo de deformação das argamassas de revestimento influi negativamente na resistência de aderência após o choque térmico. Todos esses resultados experimentais são coerentes com os modelos teóricos para choque térmico apresentados no capítulo 3. Portanto, foram escolhidos dois valores extremos de módulo de deformação da argamassa, a partir dos trabalhos de Temoche et al. (2007); Silva; Monte, Barros (2008).

No programa experimental foram utilizadas duas argamassas para revestimento. A primeira dosada na proporção 1:4, em volume de materiais secos sem aditivos e a segunda com adição de incorporador de ar. $O$ teor de aglomerante e do agregado (em massa) e o teor de água ( $16 \%$ da massa dos materiais secos) foram mantidos constantes.

A adição de incorporador de ar teve por objetivo provocar a diminuição da a condutividade térmica do revestimento, devido à baixa condutividade térmica do ar $\left(0,025 \mathrm{~W} / \mathrm{m}^{\circ} \mathrm{K}\right)$. Outra propriedade modificada com a variação da densidade da 
argamassa foi o módulo de elasticidade, obtendo-se uma variação da rigidez do revestimento.

Os materiais utilizados para produção do revestimento de argamassa são apresentados na Tabela C. 4

Tabela C. 4:Traço da argamassa para revestimento

\begin{tabular}{l|l|l}
\hline \multicolumn{1}{c|}{ Materiais } & $\begin{array}{l}\text { Massa dos materiais secos utilizados por } \\
\text { batelada (20 litros de argamassa) em Kg }\end{array}$ & Traço em massa \\
\hline $\begin{array}{l}\text { Cimento Portland CP II F (NBR } \\
\text { 11578) }\end{array}$ & 5,177 & 1 \\
\hline $\begin{array}{l}\text { areia quartzosa proveniente de leito de } \\
\text { rio, }\end{array}$ & 29,818 & 5,759 \\
\hline $\begin{array}{l}\text { aditivo incorporador de ar a base de } \\
\text { laurilsulfato de sódio }(0,00125 \% \mathrm{da} \\
\text { massa de materiais secos) }\end{array}$ & $0,437 \mathrm{~g}$ & \\
\hline água & & 1,08 \\
\hline
\end{tabular}

O equipamento utilizado para produção e homogeneização da argamassa para revestimento foi uma argamassadeira de eixo horizontal marca Consolid modelo $\mathrm{MH}$ 80 com capacidade de 50 litros, equipamentos comumente utilizados em obras na cidade de São Paulo. Para produção do revestimento foi utilizado um projetor de argamassa marca ANVI (tipo caneca) conectado a um sistema de ar comprimido. Ambos os equipamentos são mostrados na Figura $C 9$
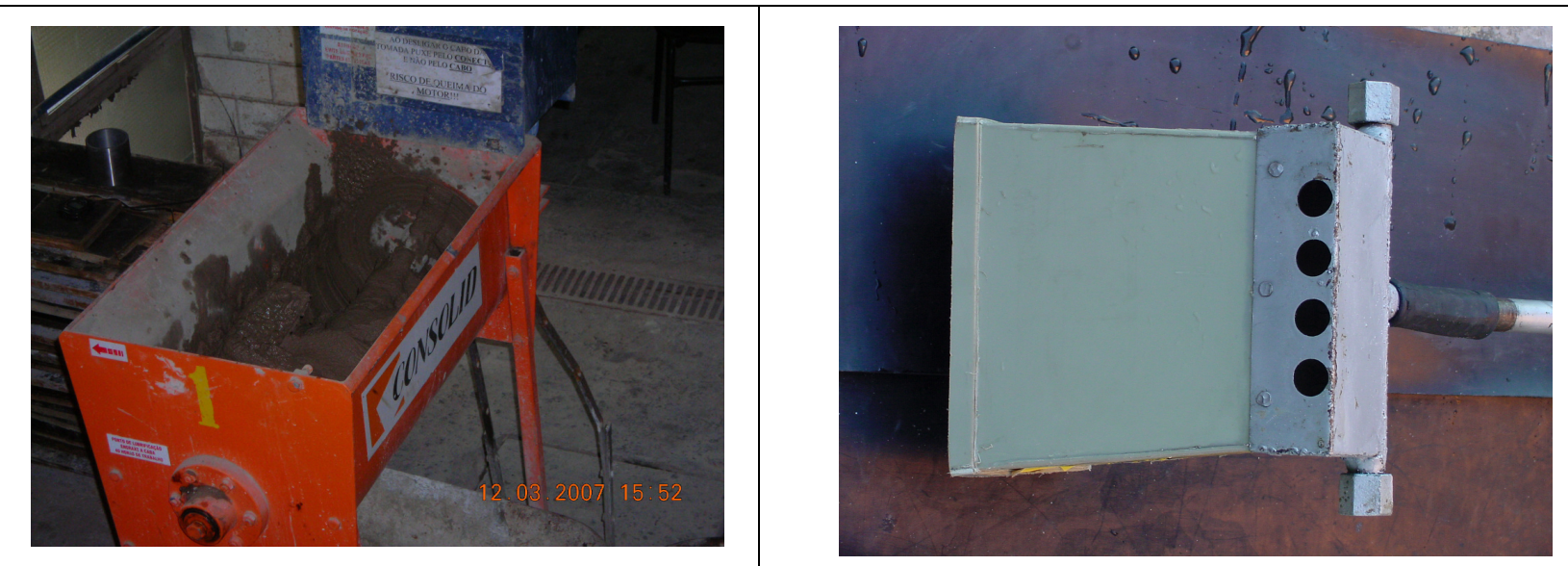

Figura C 9: Argamassadeira de eixo horizontal e projetor de argamassa tipo "caneca"

Simulação de macro-defeitos de interface base-revestimento

A taxa de defeitos na interface base-revestimento é determinante na aderência do revestimento como discutido por Antunes (2005). Com o intuito de trabalhar com o cenário extremo selecionou-se inicialmente para efeitos da modelagem o maior e 0 
menor valor de taxa de macro-defeitos encontrada por essa autora, que resultaram em $7 \%$ e $42 \%$.

Para simulação dos macro-defeitos de aderência na interface base-revestimento foi definida inicialmente a geometria e as dimensões do defeito típico para realizar sua reprodução. Isto foi realizado a partir das análises de imagem de macro-defeitos apresentadas por Antunes (2005) como mostrado na Figura C 10:

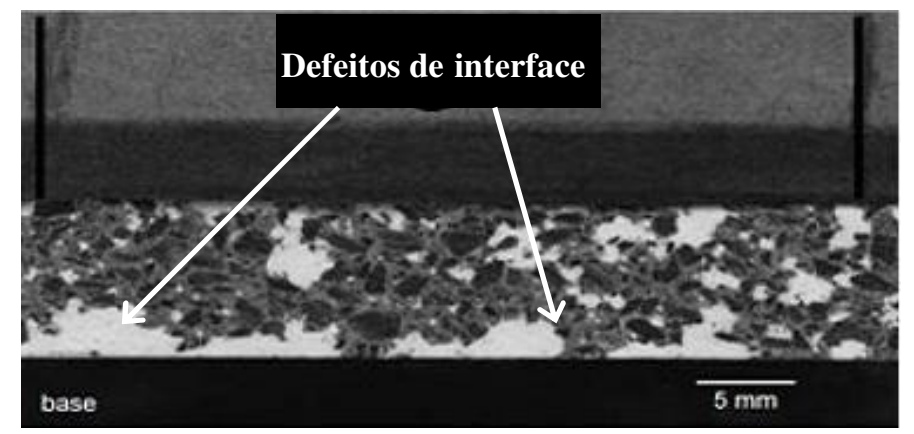

Fonte: Antunes (2005)

Figura C 10: Análise de macro-defeitos de interface base-revestimento de argamassa

Utilizando a escala gráfica nas imagens foi definido um defeito com formato de calota circular com $8 \mathrm{~mm}$ de diâmetro e $1 \mathrm{~mm}$ de altura, imersa no revestimento e aderida ao substrato. A Figura C 11 (a) mostra o volume correspondente as falhas que estão sobre a superfície do substrato correspondentes a 7\% e na Figura C 11 (b) é mostrado volume ocupado pelas falhas na camada de revestimento e o afastamento entre si, no caso em que se considera que a área das falhas corresponde a $42 \%$ da área da interface entre os materiais.

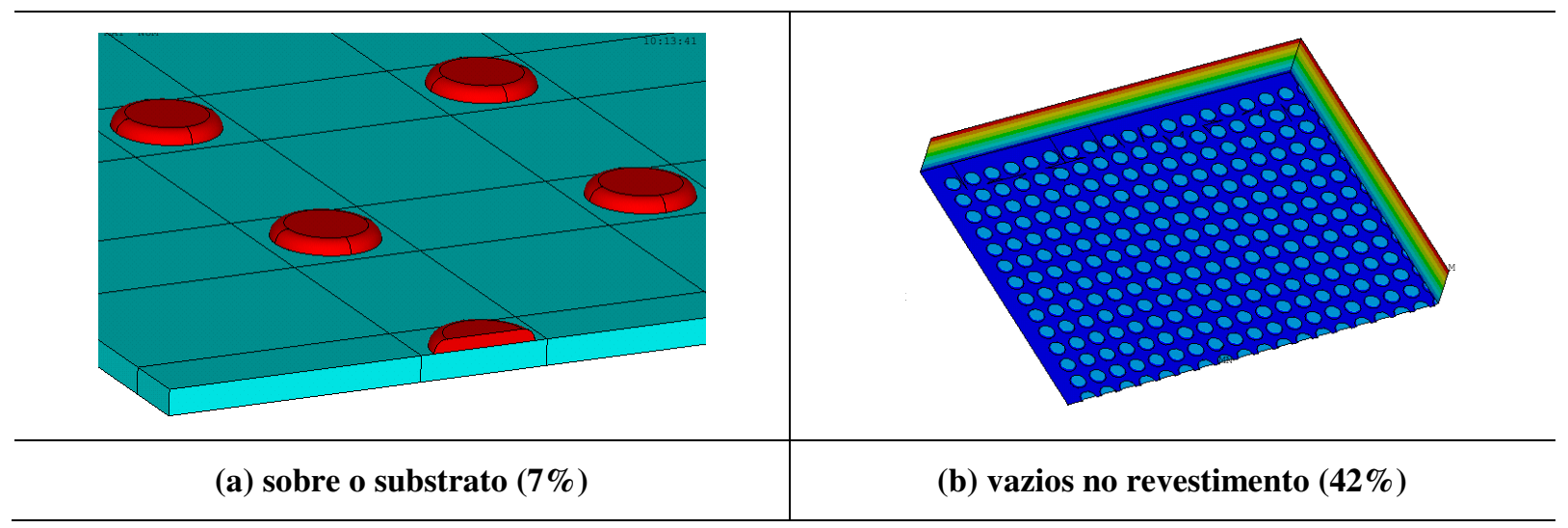

Figura C 11: Geometria e distribuição de macro-defeitos (7\% e 42\%) no modelo tridimensional

Desta forma partiu-se para simulação dos macro-defeitos sobre a superfície rugosa e porosa dos substratos produzidos. Foi utilizada para isto uma tinta à base de emulsão acrílica expansível usada para impressão serigráfica (geralmente sobre 
tecidos de algodão ou mistos) e que expande com calor formando acabamento alto relevo.

Para aplicação da serigrafia foi utilizada uma tela com o desenho dos macro-defeitos distribuídos em filas e colunas, de acordo com a Figura C 12a. O resultado da aplicação da tinta sobre a base não foi satisfatório devido à rugosidade da superfície que não permitia um acabamento homogêneo e no caso da maior taxa (42\%) a proximidade dos macro-defeitos simulados entre si provocava o junção entre um defeito e outro após a segunda e terceira aplicações da serigrafia. A solução para este problema foi a redução da taxa de macro-defeitos ao valor de 35\% da superfície da interface, valor que também foi analisado no modelo computacional e, paralelamente a produção de um gabarito (Figura C 12b) em chapa de aço de $1 \mathrm{~mm}$ de altura perfurada de acordo com a distribuição dos macro-defeitos que permitiu, apoiado na superfície da base ou substrato corrigir as imperfeições da aplicação com serigrafia.

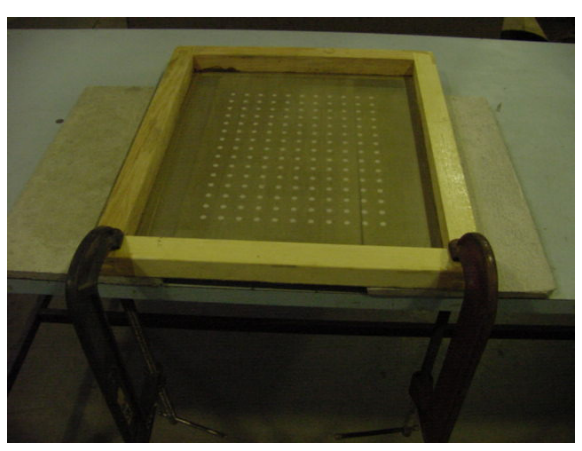

a)

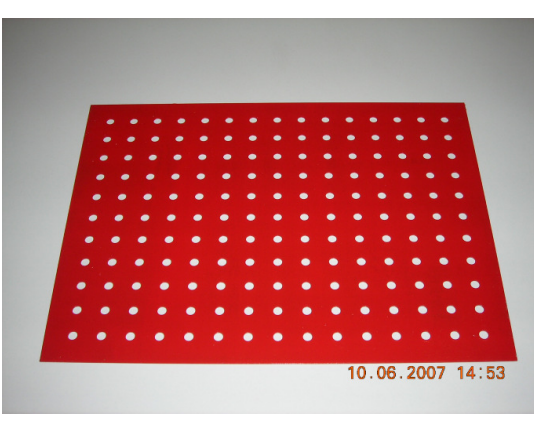

b)

Figura C 12: Tela para impressão de macro-defeitos e gabarito metálica

O resultado da impressão dos macro-defeitos é mostrado para a taxa de $35 \%$ na Figura 5-9. O uso da tinta expansível com aumento de temperatura ajudou a obter o volume com a espessura aproximada de $1 \mathrm{~mm}$ definida anteriormente. 


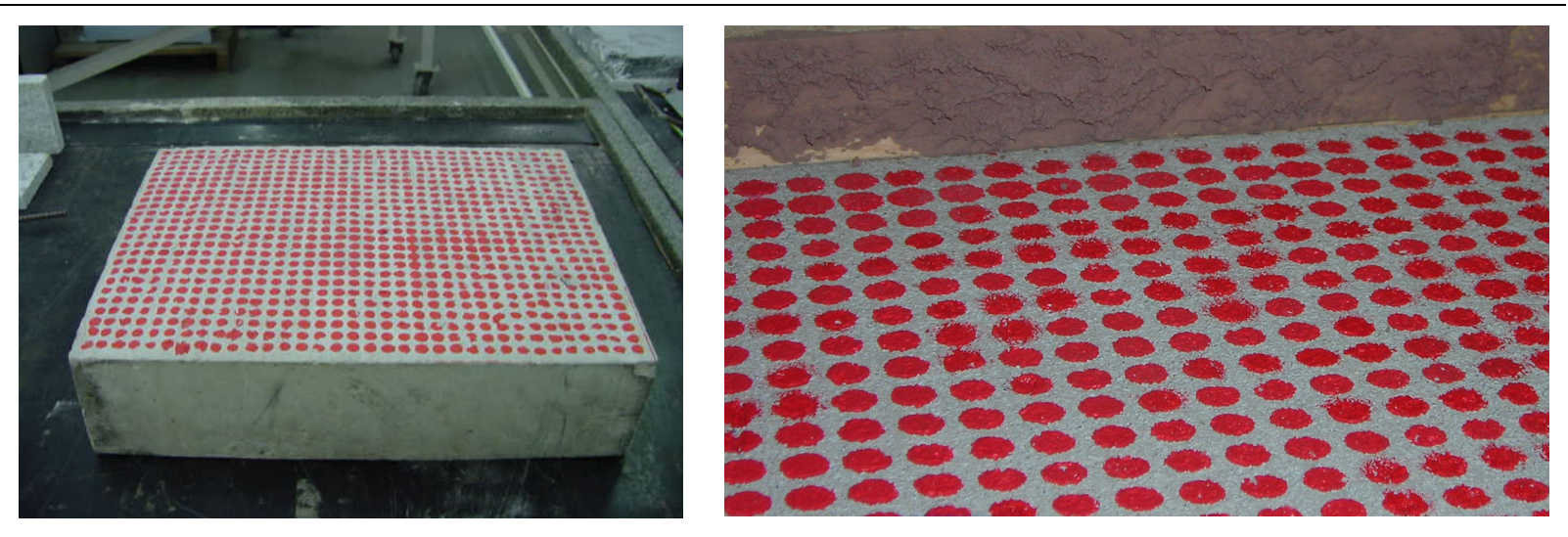

Figura C 13: Reprodução dos macro-defeitos sobre a superfície do substrato

Parâmetros dos ensaios de choque térmico

A partir dos métodos de ensaio reunidos na Tabela 2.1, foram selecionados aqueles possíveis de serem realizados com os equipamentos disponíveis, dentre eles os métodos especificados pelo CSTC (CSTC, 1980), UEAtc (UEAtc, 1992), pelo IPT (IPT,1998) e pela norma EN 13687-2 (EN, 2002). Da análise desses métodos e dos trabalhos citados na bibliografia com destaque para os citados em 5.2 foram escolhidos os parâmetros apresentados na Tabela C. 5

Tabela C. 5: Parâmetros para o ensaio de choque térmico

\begin{tabular}{l|l|l}
\hline \multicolumn{1}{c|}{ Parâmetro de ensaio } & \multicolumn{1}{|c}{ Valores definidos no ensaio } & \multicolumn{1}{c}{ Referência } \\
\hline Temperatura superficial máxima & $70^{\circ} \mathrm{C}$ UEAtc 1999 \\
\hline Temperatura superficial mínima & $23^{\circ} \mathrm{C}$ (ambiente) & UEAtc 1999 \\
\hline Tempo de aquecimento & $3 \mathrm{~h}$ & IPT (1998) \\
\hline $\begin{array}{l}\text { Tempo de permanencia na } \\
\text { temperatura máxima }\end{array}$ & $1,5 \mathrm{~h}$ & \\
\hline Tempo de resfriamento & $1 \mathrm{~h}$ & IPT (1998) \\
\hline Forma de aquecimento & $\begin{array}{l}\text { Painel radiante com 96 lampadas } \\
\text { incandescentes com potencia de 150 W }\end{array}$ & IPT (1998) \\
\hline Forma de resfriamento & $\begin{array}{l}\text { Espelho de água na superfície do } \\
\text { revestimento }\end{array}$ & EN 13687-2 \\
\hline Número de ciclos & 30 & IPT (1998) \\
\hline Duração do ciclo & $4 \mathrm{~h}$ & \\
\hline Controle de temperatura & $\begin{array}{l}\text { Controlador automático liga/desliga } \\
\text { montado neste trabalho }\end{array}$ \\
\hline Registro de temperaturas & Termopares tipo "t" & \\
\hline
\end{tabular}

Para o cenário considerado neste trabalho adotou-se a temperatura superficial máxima de $70^{\circ} \mathrm{C}$ provocada por um aquecimento por radiação. Este valor foi escolhido a partir de valores extremos citados Goldberg (1998) e medições de temperatura superficial realizadas em revestimentos expostos na quatro orientações 
na Torre do Laboratório de Sistemas Prediais da EPUSP durante os meses de janeiro e fevereiro de 2005.

Quanto ao valor da temperatura de resfriamento do revestimento esta foi definida de acordo com os valores das referências normativas para testes de choque térmico, considerando que o choque seria produzido com água a temperatura ambiente, que segundo Hasselman (1969), é o mais freqüente nestes testes. Assim o valor definido foi de $23^{\circ} \mathrm{C}$.

Esses parâmetros foram comparados também com medições realizadas pelo autor em levantamento de campo e na Estação climática da EPUSP.

Equipamento para o ensaio de choque térmico

Para simulação da variação de temperatura foi utilizado um equipamento de aquecimento (painel radiante) constituído por um painel de 1,30 m x 2,30 m. com suporte móvel, composto por 98 lâmpadas incandescentes de $150 \mathrm{~W}$ cada uma conforme mostrado na Figura C 14:
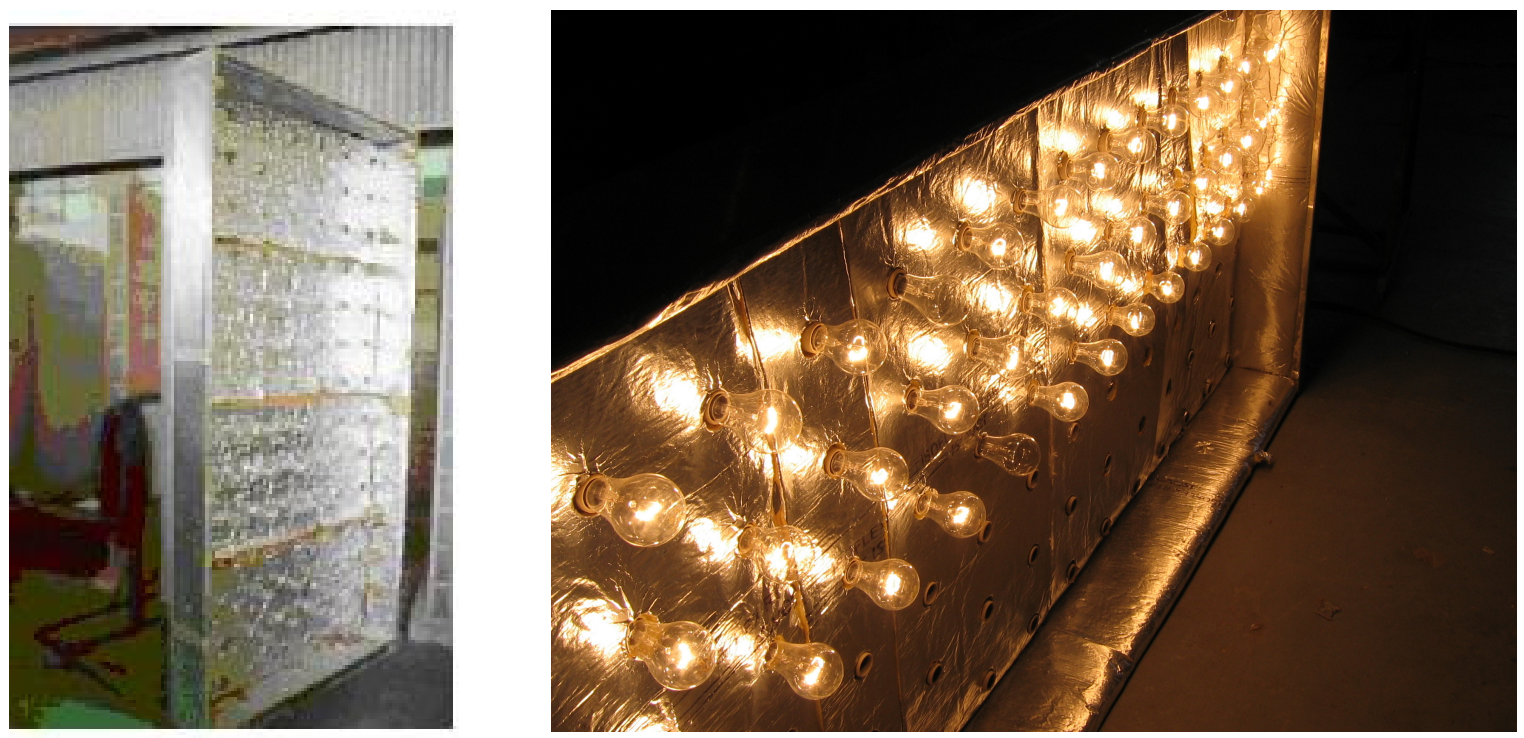

Figura C 14: Equipamento para simulação do choque térmico em posição vertical e horizontal

Materiais e equipamentos para registro e controle do ensaio de choque térmico

Para o sistema de aquisição de temperaturas durante os ensaios de choque térmico foram utilizados: 
a) Cabo de compensação para termopar tipo $T$

b) Equipamento de aquisição de sinais marca National, conforme mostrado na Figura C 15. O equipamento consta de um módulo de amplificação de sinais (Módulo SCXI 1000) e um bloco terminal SCXI 1300 com 32 canais de leitura para medição das temperaturas.

Este equipamento possui também um sistema de medição de deformações a partir de sensores denominados extensômetros elétricos (strain gage). Estes sensores foram utilizados para determinação de outras propriedades dos materiais utilizados como o coeficiente de Poisson e o coeficiente de dilatação térmica.

O programa de interface utilizado é Labview, versão 8,0 com uma rotina especificamente desenvolvida para leitura simultânea de temperaturas e deformações.
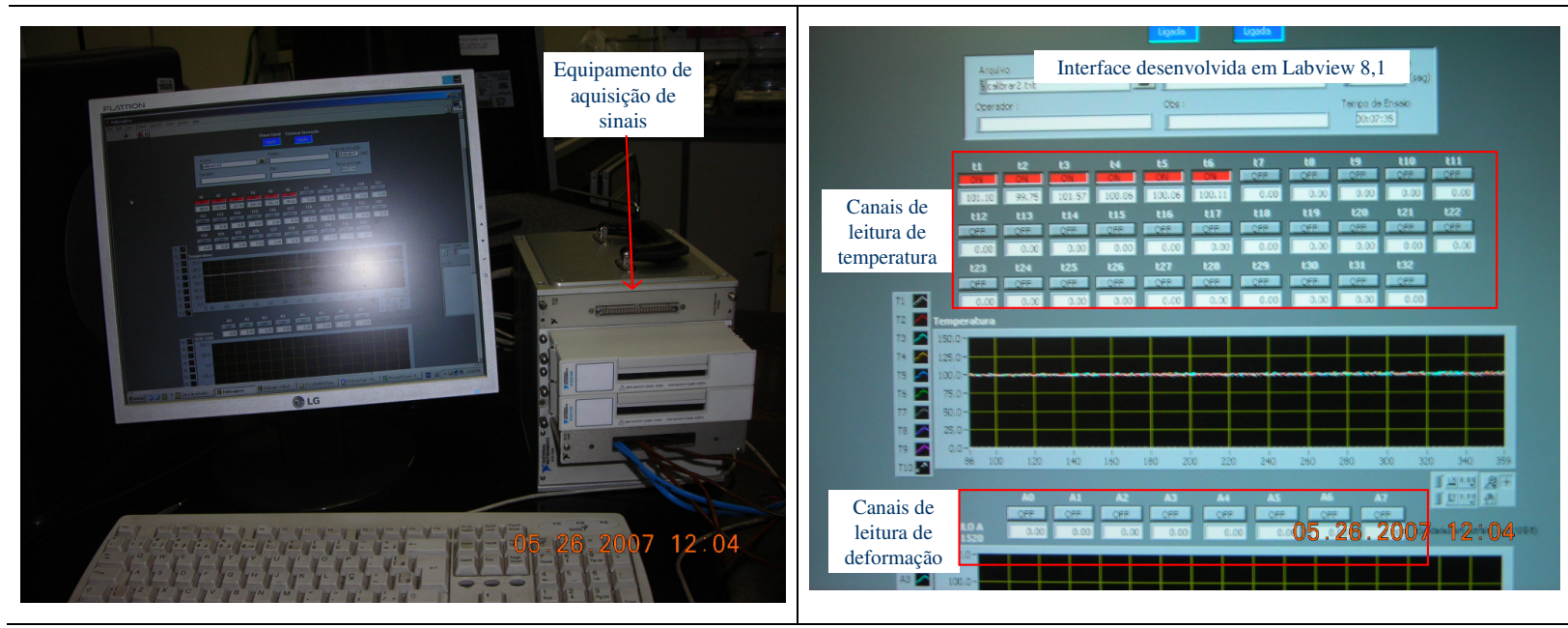

Figura C 15: Equipamento e programa de aquisição de sinais

Produção dos corpos de prova do revestimento

Instrumentação dos corpos de prova

Antes da aplicação do revestimento foram colados termopares tipo "T" na interface substrato/argamassa de revestimento, conforme mostrado na Figura C 16: 


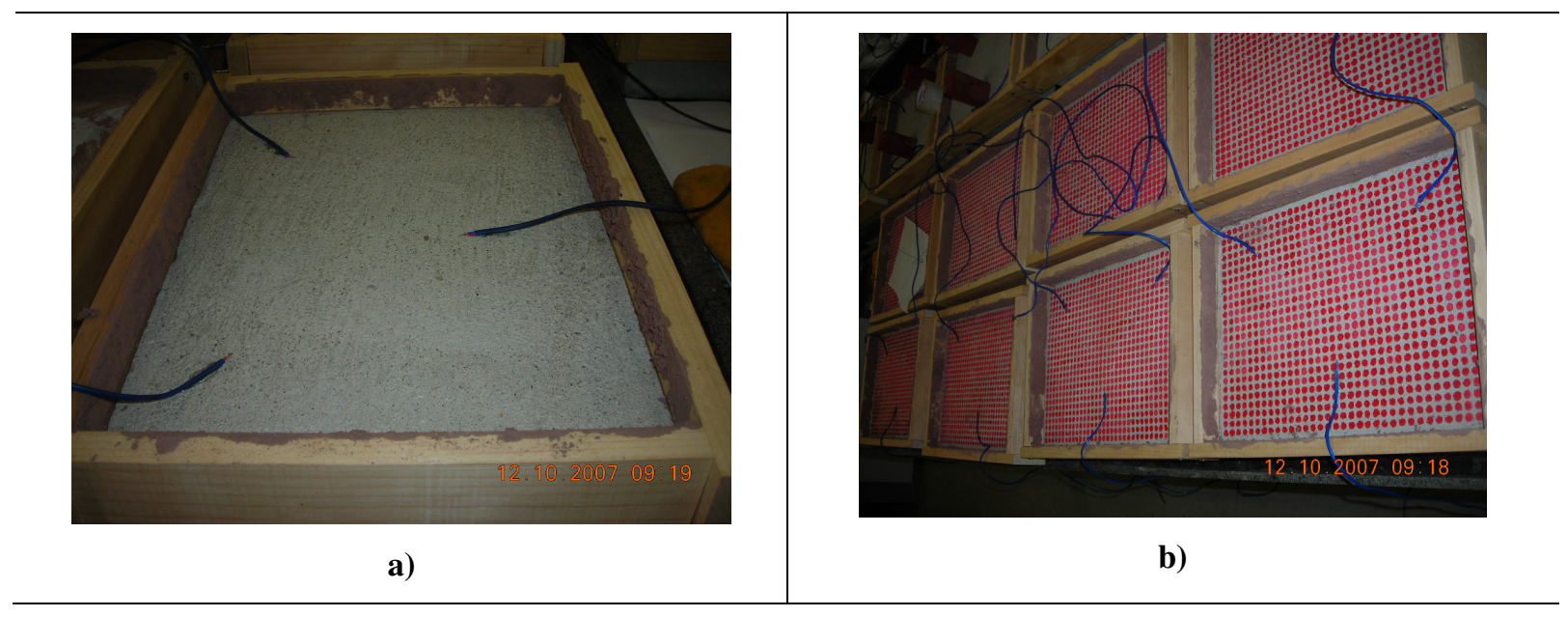

Figura C 16: Termopares colados na interface base-revestimento previamente à moldagem do revestimento para o substrato sem macro-defeitos provocados (a) e para o substratos com $35 \%$ de macro-defeitos provocados

No programa experimental piloto, para os ensaios de choque térmico foram utilizados unicamente termopares para coleta das temperaturas na superfície do revestimento, na sua interface com a base e na face posterior do substrato.

Moldagem da camada de revestimento

O processo de mistura das argamassas de revestimento produzidas em obra não é pautado na maioria dos casos por um processo padronizado, e fatores que exercem influência nas propriedades da argamassa resultante e conseqüentemente na sua aderência à base, tais como a forma de mistura, a energia utilizada na mistura, a quantidade de água adicionada e o tempo de mistura, não são totalmente controlados, conforme é destacado por Antunes (2005).

Assim, com o propósito de diminuir a introdução de mais variáveis no estudo, a mistura da argamassa foi realizada com controle da seqüência e tempo de mistura, bem como da quantidade de água utilizada. De acordo com as recomendações de Antunes (2005) para a seqüência de mistura foram colocados em primeiro lugar os materiais secos (Figura C 17a), e posteriormente o teor de água definido (Figura C 17c). 


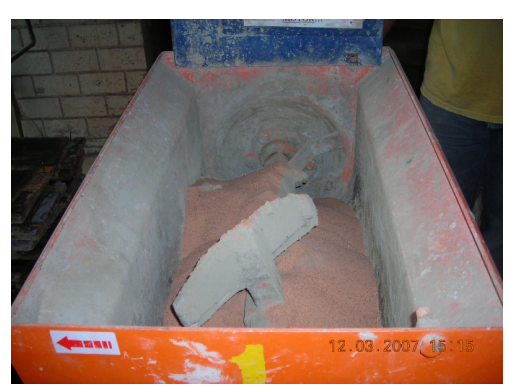

a)

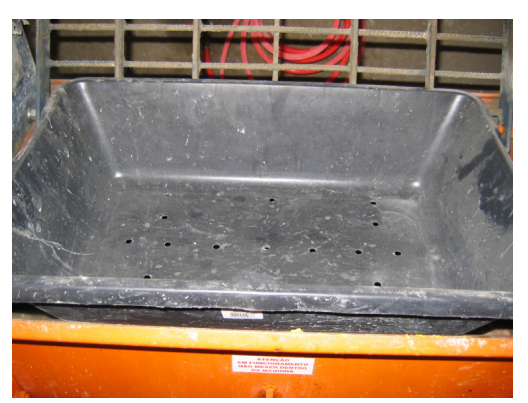

b)

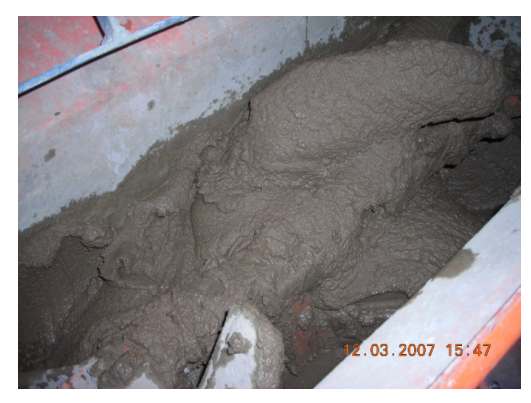

c)

Figura C 17: Seqüência de mistura das argamassa.

Para manter uma vazão constante foi utilizada uma bandeja furada (Figura C 17b) durante a adição da água, resultando em uma vazão de 74,3 gr/s

Para definição do teor de água foram realizados testes preliminares com o propósito de avaliar as características reológicas da argamassa resultante com o ensaio de squeeze-flow, descrito por Cardoso, Pileggi e John (2005).

A seqüência de mistura e o tempo utilizado são mostrados na Figura C 18:

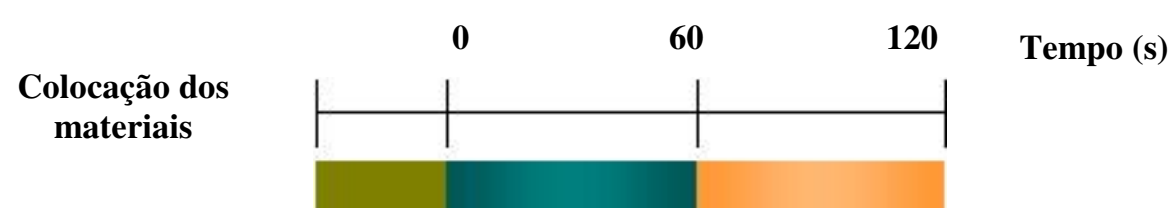

Adição da água Mistura

Figura C 18: Tempo utilizado na seqüência de mistura da argamassa

O processo de aplicação também é um fator condicionante na obtenção da máxima aderência, portanto a escolha do procedimento de aplicação evitou à aplicação manual para não introduzir variáveis fora do controle na produção dos corpos de prova. De forma a padronizar a aplicação da argamassa foi selecionada a com projeção mecânica com spray a ar comprimido que alem de compatível com as praticas utilizadas em boa parte dos canteiros de obra atualmente permite um melhor controle da energia de aplicação e aumento da produtividade, com resultados favoráveis na resistência de aderência em relação à aplicação manual.

A argamassa foi projetada sobre os substratos com equipamento de projeção ("canequinha") marca Anvi a ar comprimido com pressão constante de 100 psi, com 
o intuito de atingir uma ótima extensão de aderência, conforme exemplificado na Figura C 19:
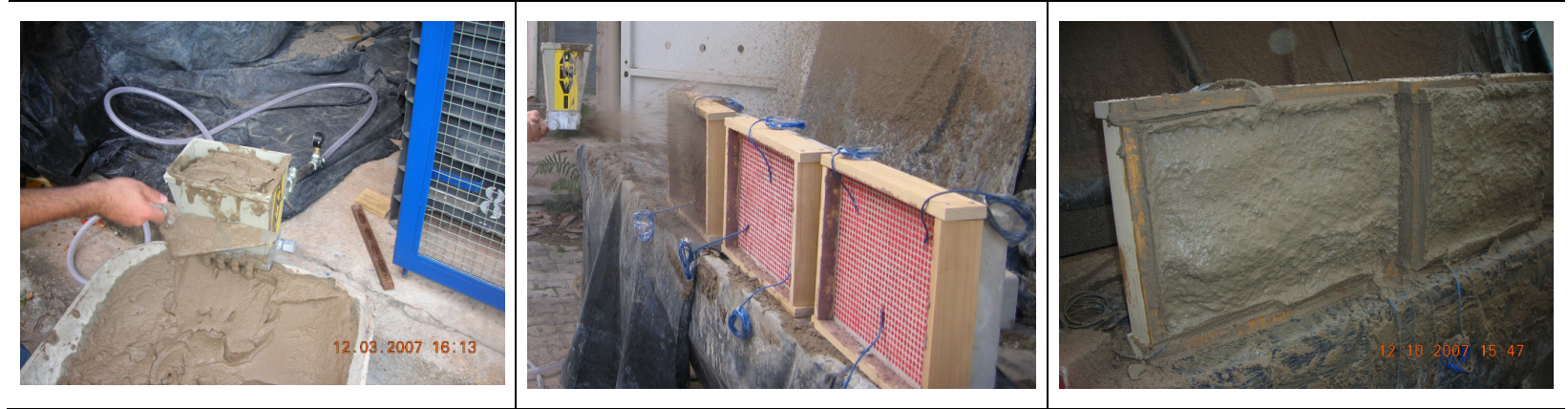

Figura C 19: Transporte e projeção de argamassa

Finalmente no processo de secagem da argamassa foram tomados os seguintes cuidados:

Para melhor reproduzir as características de restrição à livre movimentação do pano de revestimento moldado, foi aplicado nas formas de todos os corpos de prova chapisco industrializado para promover a aderência do revestimento às laterais, como poder ser observado na Figura C 20:

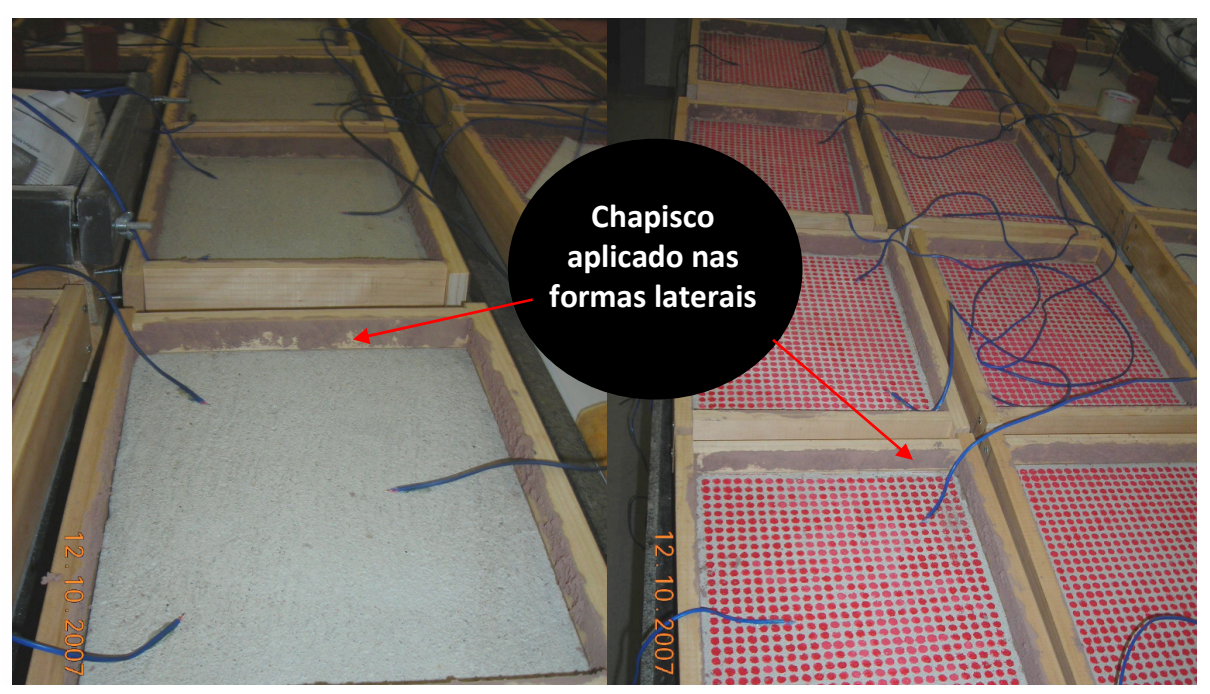

Figura C 20: Aplicação de chapisco nas formas laterais.

Para otimizar as condições ambientais durante a secagem do revestimento, os corpos de prova foram forrados com plástico (Figura C 21) para evitar perda de água e levados à câmara úmida durante 28 dias. 

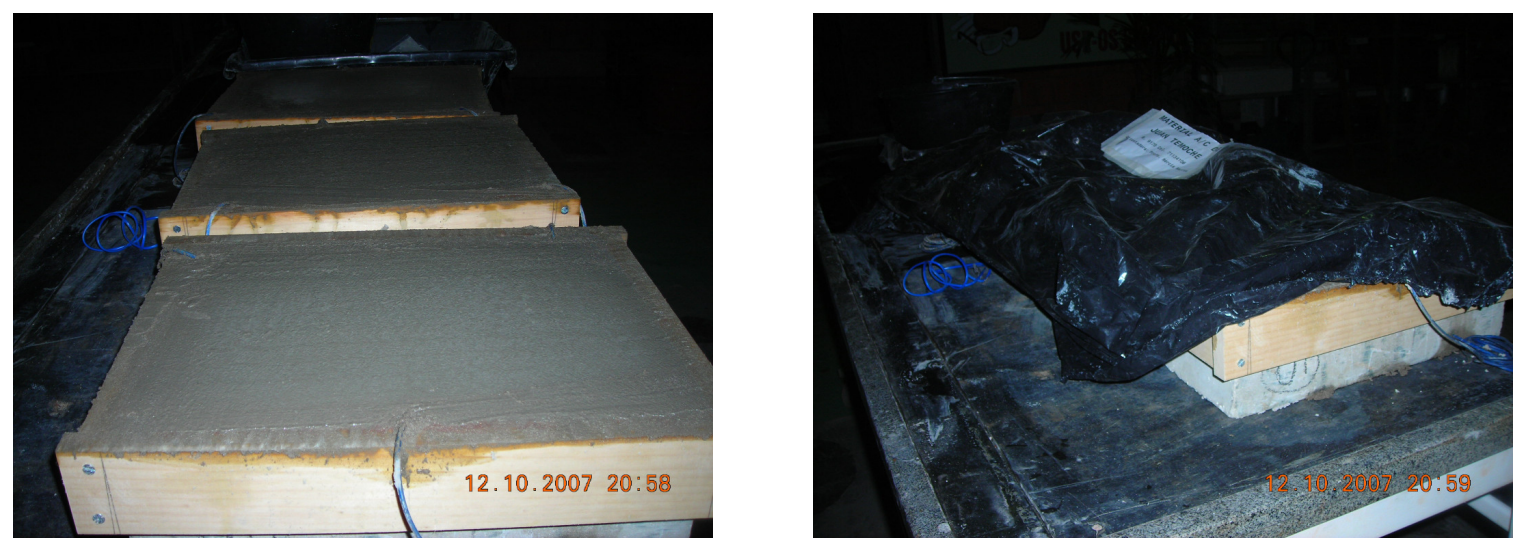

Figura C 21: Condições de secagem dos corpos de prova

\section{Métodos de ensaios selecionados}

\section{Caracterização dos materiais}

Os materiais constituintes da argamassa foram caracterizados no estado anidro, fresco e no estado endurecido conforme é mostrado na Tabela C. 6 apresenta o resumo dos ensaios de caracterização das argamassas a serem utilizados.

Tabela C. 6: Ensaios de caracterização e de avaliação dos materiais utilizados, argamassa e revestimento propostos no trabalho

\begin{tabular}{|c|c|c|c|}
\hline Material & Ensaio & № de repetições & Referência normativa \\
\hline & Estado anidro & & \\
\hline \multirow{2}{*}{ Cimento } & Massa específica & 3 & NBR NM 23/01 \\
\hline & Granulometria a laser & & \\
\hline \multirow{4}{*}{ Areia } & Massa unitária & 3 & NBR7251 ABNT, 1982) \\
\hline & Massa específica & 3 & Picnometria \\
\hline & Granulometria a laser & & \\
\hline & Estado Fresco & & \\
\hline \multirow{5}{*}{ Argamassa } & Squeeze flow & 1 & (MIN; ERWIN, JENNINGS, 1994) \\
\hline & Densidade de massa & 3 & NBR 13278 (ABNT, 2005) \\
\hline & Retenção de água - & & NBR 13277 (ABNT, 2005) \\
\hline & $\begin{array}{l}\text { Determinação do teor de ar } \\
\text { incorporado - }\end{array}$ & 3 & NBR 13278 (ABNT, 2005) \\
\hline & Estado endurecido & & \\
\hline \multirow{7}{*}{$\begin{array}{l}\text { Argamassa de } \\
\text { revestimento }\end{array}$} & Resistência à tração na flexão & 6 & NBR 13279 (ABNT, 2005) \\
\hline & Resistência à compressão & 6 & NBR 13279 (ABNT, 2005) \\
\hline & $\begin{array}{l}\text { Módulo de Elasticidade - Método } \\
\text { do ultrasom - }\end{array}$ & 6 & BS 1881 Part:209 (BSI, 1990) \\
\hline & $\begin{array}{l}\text { Densidade de massa aparente no } \\
\text { estado endurecido - }\end{array}$ & 3 & NBR 13280 (ABNT, 2005) \\
\hline & Coeficiente de dilatação térmica & 3 & (ASTM C531, 2000) \\
\hline & \begin{tabular}{|l|} 
Coeficiente de poisson - \\
\end{tabular} & 3 & ASTM E132 (ASTM 2004) \\
\hline & Termogravimetria & 1 & \\
\hline \multirow{2}{*}{ Revestimento } & Resistencia de aderência à tração & 6 & NBR15258 (ABNT, 2005) \\
\hline & Choque térmico & 30 & \\
\hline
\end{tabular}


O ensaio de termogravimetria (TG) ${ }^{9}$ permitiu obter informações sobre a composição e estabilidade da argamassa endurecida comparando as amostras que foram submetidas ao choque térmico com as amostras de referência após a elevação de temperatura. Procura-se verificar se na faixa de temperatura em que se produz o choque térmico ocorre dissociação térmica de alguma espécie química dentro das argamassas.

Ensaios preliminares de choque térmico

Para realização dos ensaios de choque térmico do programa experimental piloto houve necessidade de algumas atividades de preparo prévias ao início do ensaio propriamente dito.

Atividades de montagem

Para o posicionamento dos corpos de prova frente ao painel de aquecimento (rolante) foi montado um suporte em forma de bancada que permitisse a colocação dos quatro corpos de prova a serem submetidos ao choque térmico.

Esta bancada devia permitir a aproximação do painel de aquecimento até a superfície dos revestimentos e também a instalação de um depósito para coleta da água utilizada na etapa de resfriamento, como é mostrado na Figura C 22:
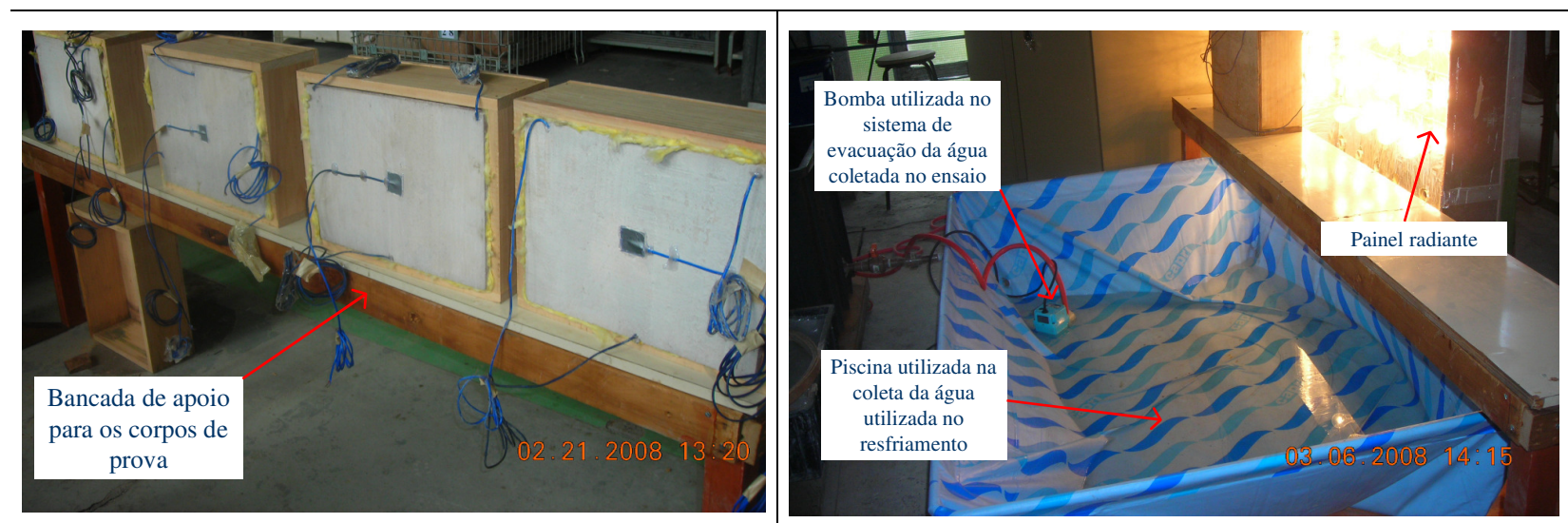

Figura C 22: Montagem de bancada para colocação dos corpos de prova

De acordo as condições de contorno estabelecidas para o ensaio o choque térmico deve ocorrer unicamente na face externa do revestimento mantendo isoladas as laterais e a fase posterior da base. Com tal propósito foram fabricadas umas caixas

\footnotetext{
${ }^{9}$ A termogravimetria (TG) é uma técnica de análise térmica bastante empregada que consiste em aquecer (ou resfriar) uma amostra a uma taxa geralmente constante, e medir a variação de sua massa. No experimento proposto será utilizada uma termobalança Nezstch TG 209 (LM).
} 
com material de baixa condutividade térmica com dimensões tais que o corpo de prova coubesse dentro deixando exposta unicamente a face do revestimento. Para melhor isolar as laterais foi colocado material isolante térmico no fundo das caixas e nas laterais em contato com os corpos de prova, como pode ser apreciado também na Figura 5-13.

Para promover o resfriamento com água na superfície do revestimento foi necessário montar um pequeno sistema de fornecimento, circulação e evacuação de água. Utilizando quatro reservatórios de aproximadamente $1 \mathrm{~m}^{3}$ cada foi possível manter o fornecimento água constante durante todo o período do ensaio, sendo essa água coletada novamente nos reservatórios com ajuda de duas bombas.

Outra atividade de montagem foi necessária para instalação do sistema de aquisição de dados com seu respectivo aterramento. Uma vez instalado esse sistema foi possível realizar a conexão de cada um dos sensores utilizados para coleta de dados de temperatura, como mostrado na Figura C 23.

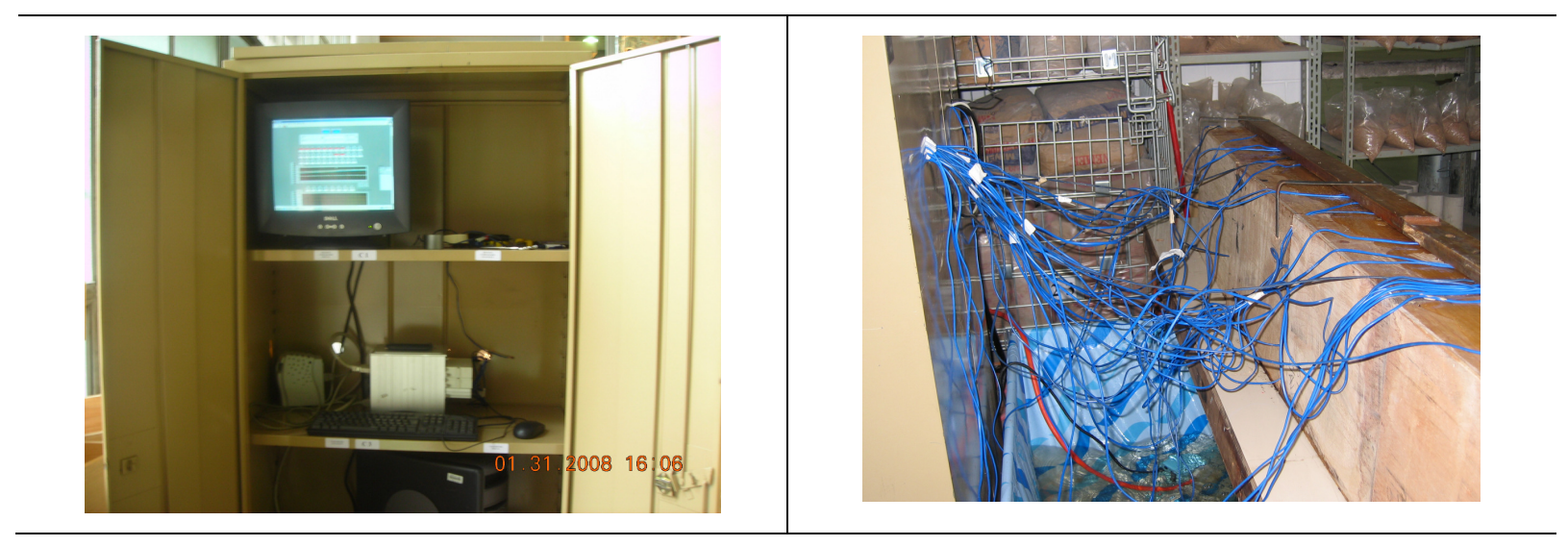

Figura C 23: Montagem de sistema de aquisição de temperaturas e instalação dos sensores nos corpos de prova

Atividades de calibração

Com o propósito de identificar fontes de erro experimental e buscar formas de atenuá-lo, antes de iniciar os ensaios foram realizados testes de calibração dos equipamentos utilizados na medição de temperaturas identificando-se a necessidade de realizar algumas correções nas leituras de alguns dos canais do equipamento de aquisição. 
Uma das fontes de erro identificada foi a própria rede de alimentação de energia que apresentava continuas oscilações, pelo que foi necessário ligar os sistema individualmente um ponto de aterramento atenuando as flutuações nas leituras.

Outra fonte de erro nas leituras era provocada por diferença de leituras entre os próprios canais do equipamento pelo que no programa de interface com o equipamento de aquisição (Labview) foram realizadas as correções.

Da mesma forma foram realizados testes de aquecimento e corpos de prova semelhantes aos do ensaio de choque térmico para identificar a homogeneidade na forma de aquecimento promovida pelo painel.

A Figura C 24 mostra como no estado de equilíbrio a temperatura ambiente a variação da temperatura superficial para o corpo de prova é mínima, aumentando no momento do aquecimento $\left(4^{\circ} \mathrm{C}\right)$, ficando evidentes as perdas de calor pelas bordas. Já no momento do resfriamento a variação promovida foi maior nos primeiros minutos do resfriamento tendendo a diminuir e se estabilizar no tempo.

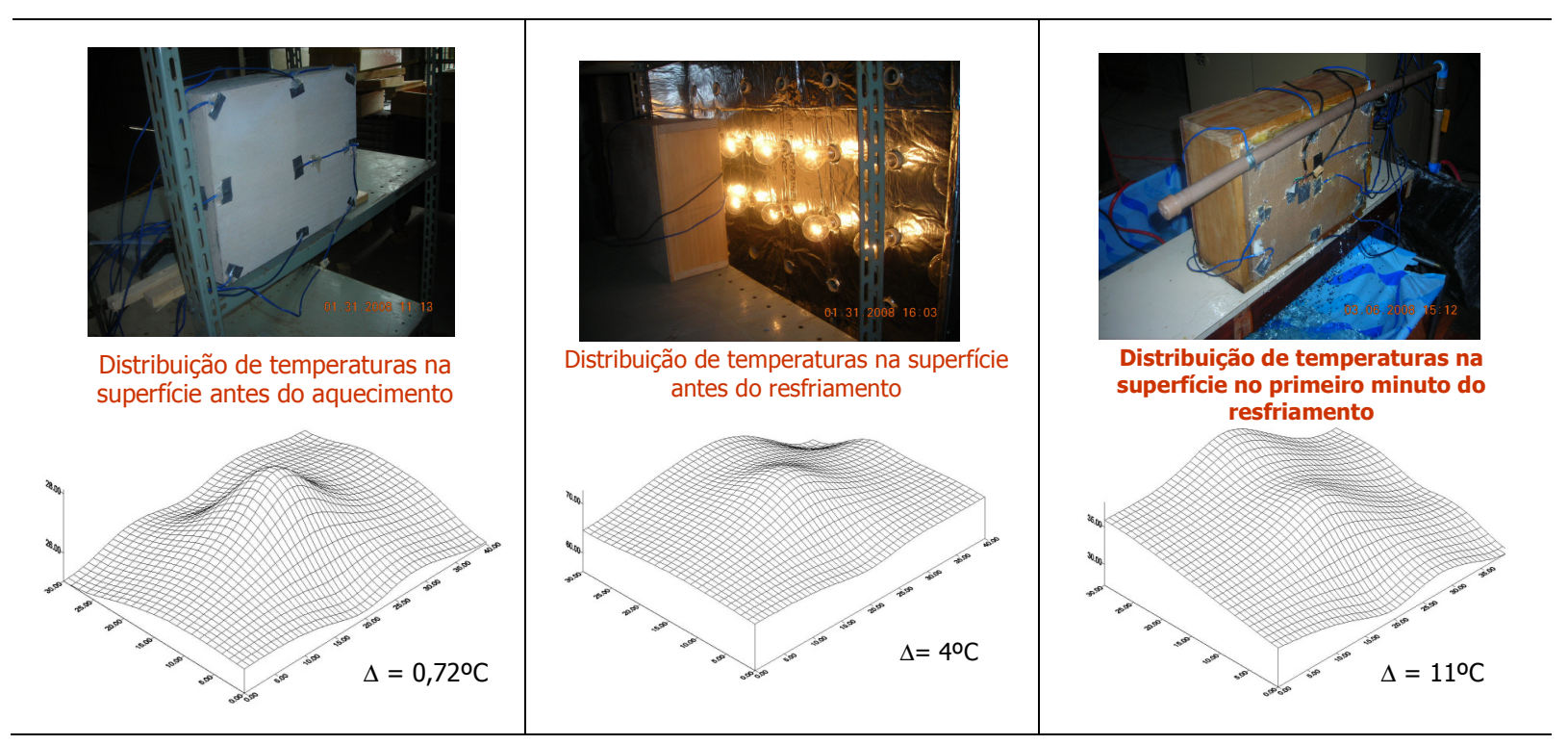

Figura C 24: Diferenças de temperatura superficial do corpo de prova a temperatura ambiente, no momento do aquecimento e após um minuto do resfriamento

Forma de aquecimento nos ensaios

Com a disposição adotada para os corpos de prova foi necessário utilizar o painel deitado de forma tal que a superfície de fonte de calor fosse maior do que a superfície dos corpos de prova para poder compensar o efeito de perda de calor pelas bordas dos corpos de prova. 


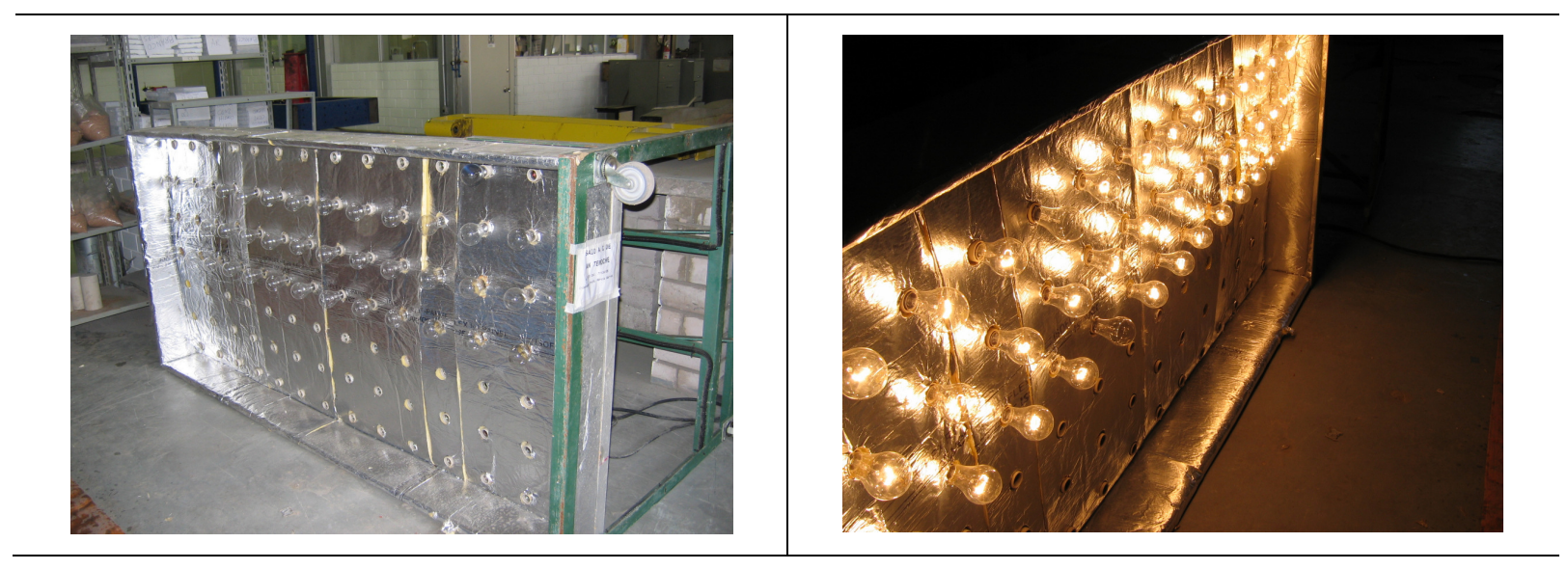

Figura C 25: Posicionamento do painel radiante para o aquecimento dos corpos de prova

Para evitar as eventuais perdas de calor no período do aquecimento foram utilizadas placas isolantes nas laterais entre os corpos de prova e o painel radiante. $O$ aquecimento foi realizado com lâmpadas incandescentes sobre os corpos de prova até atingir a temperatura superficial especificada nos parâmetros do ensaio $\left(70^{\circ} \mathrm{C}\right)$.

Forma de resfriamento nos ensaios

Para o início do resfriamento após a terceira hora de aquecimento o procedimento adotado foi manual.

Faltando cinco minutos para o fim do período de aquecimento, no reservatório principal a bomba era ligada mantendo a recirculação de água dentro dele. Posteriormente era colocado na parte superior dos corpos de prova um tubo conectado por mangueira aos reservatórios de água. Neste tubo de PVC foram realizados furos a cada $25 \mathrm{~mm}$ de distancia seguindo um mesmo alinhamento para coincidir com a superfície de cada corpo de prova alinhados sobre a bancada de apoio.

Após os desligamento das lâmpadas, o painel radiante era afastado da superfície dos corpos de prova e simultaneamente era aberta a válvula de controle para a passagem de água no sistema, como é apresentado na Figura C 26: 


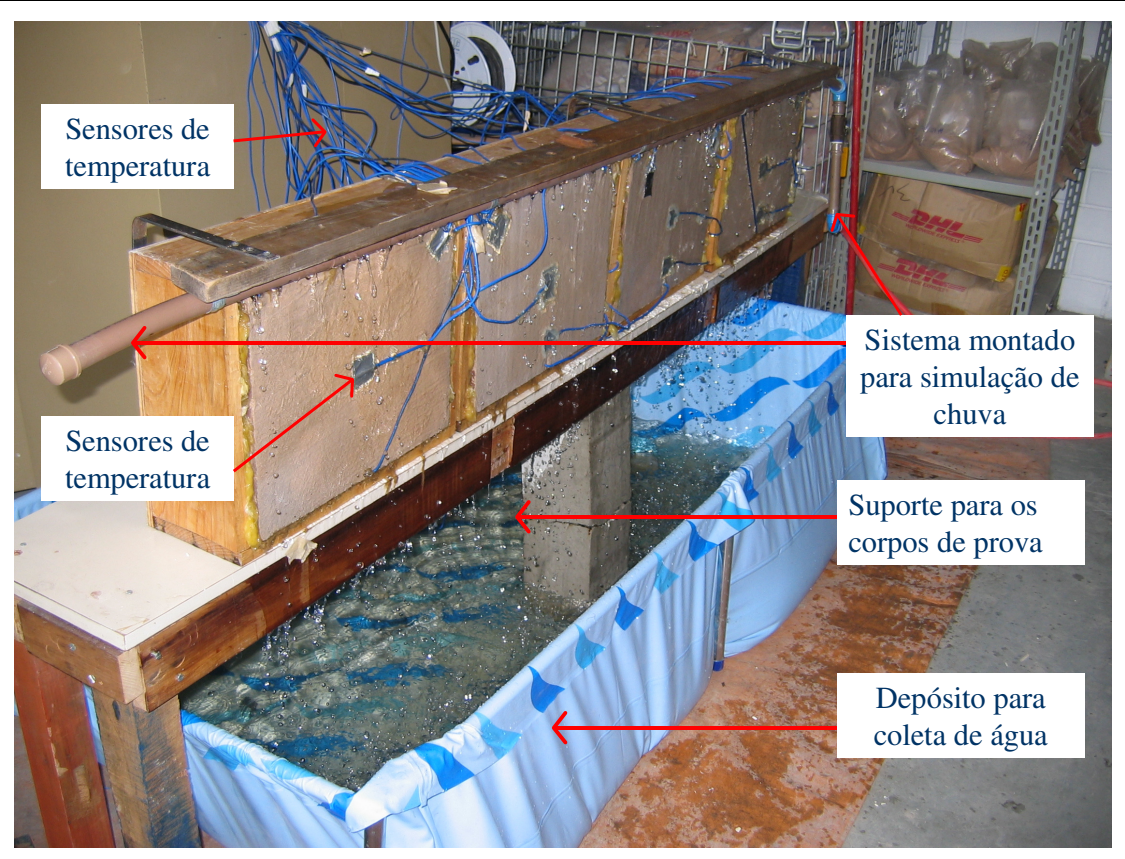

Figura C 26: Estrutura montada para realização dos ensaios de choque térmico mostrando o período de resfriamento dos corpos de prova

O resfriamento dos corpos de prova com água, simulando chuva, era mantido durante uma hora para cada um dos ciclos de ensaio.

Controle do ensaio

Neste programa experimental piloto o controle de temperatura máxima foi realizado com um termopar de referência pintado na cor preta colocado na parte central da bancada, colado na superfície de um dos corpos de prova. Observou-se que a diferença de temperaturas entre os termopares na superfície do revestimento e o de referência era aproximadamente de $10^{\circ} \mathrm{C}$.

Assim o controle da temperatura máxima na superfície do revestimento era realizado manualmente. Quando a temperatura no termopar de referência atingia $85^{\circ} \mathrm{C}$, 0 sistema de aquecimento era desligado e ligado novamente quando a leitura nesse termopar diminuía até $75^{\circ} \mathrm{C}$.

Da mesma forma o controle da temperatura da água de resfriamento foi realizado somente nos primeiros ensaios no reservatório, porém ela não foi constante ao longo dos trinta ciclos de ensaio devido a que dependia da temperatura ambiente variando dos $21^{\circ} \mathrm{C}$ até os $24^{\circ} \mathrm{C}$. 
Esse sistema de controle mostrou-se ineficiente pelo que foi desenvolvido para a seguinte etapa de ensaios um sistema de controle automático com controle liga/desliga das lâmpadas e com um temporizador mostrado na Figura C 27

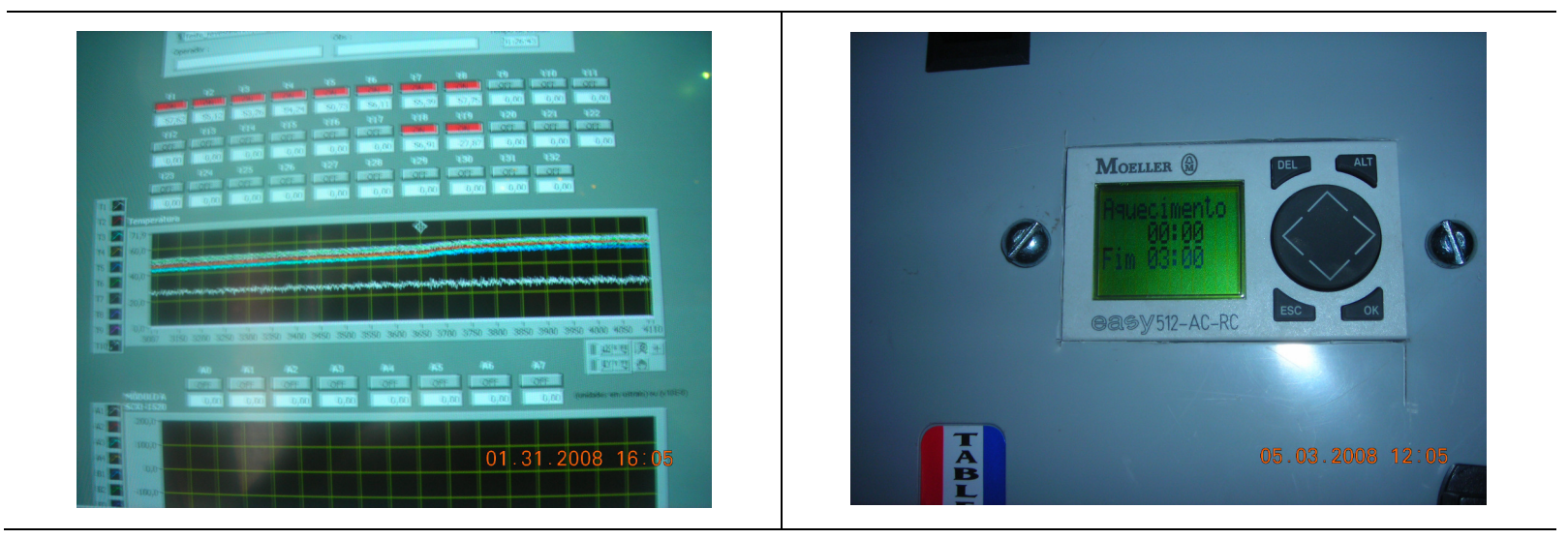

Figura C 27: Controle da temperatura na interface base-revestimento

\section{Ensaios cíclicos de choque térmico}

O número de ciclos definido para os ensaios de choque térmico foi de 30 , em coincidência com a recomendação normativa da EN 13687-2.

O procedimento adotado para cada ciclo foi realização do aquecimento no período da manhã e na seqüência o período de aquecimento, deixando os corpos de prova atingirem o equilíbrio térmico até o dia seguinte, dando aproximadamente intervalos de 20 horas entre um ciclo e outro.

Ensaios de avaliação da resistência de aderência

A influência dos ciclos de choque térmico na aderência do revestimento tem sido avaliada através de ensaios de resistência de aderência à tração normal de acordo com a NBR 13528 (ABNT, 1995) após cada conjunto de ensaios cíclicos, isto é, após os 30 ciclos, deixando em repouso os corpos de prova mais um dia antes do inicio dos ensaios de resistência de aderência.

Cabe destacar que nos corpos de prova de referencia (não submetidos ao choque térmico), em mesmo número que os corpos de prova ensaiados, são realizados os ensaios de resistência de aderência na mesma data.

Para verificar a influência da taxa de macro-defeitos na interface do revestimento serão analisadas imagens da interface para as duas situações extremas de taxa de 
macro-defeitos com imagens antes e depois da aplicação dos ciclos de choque térmico.

Considerações estatísticas

Tendo em vista que o processo experimental em geral está sujeito a ocorrência certo grau de variabilidade e erro, os procedimentos adotados no programa experimental estão pautados pelos conceitos de repetição e aleatorização para poder posteriormente se ter uma estimativa do erro experimental e o grau de variabilidade pode ser minimizado.

O emprego de ferramentas estatísticas aplicadas aos dados resultantes dos ensaios objetiva dar consistência a análise.

Serão realizados testes de hipóteses paramétricos, para determinar o grau de influência de cada um dos fatores nos fenômenos analisados. 


\section{ANEXO A - MODELO PARA CALCULO DE TENSÕES TÉRMICAS EM SISTEMAS MULTICAMADAS}

Cálculo de tensões térmicas em sistemas multicamadas

$\mathrm{Na}$ Figura A. 1-a é mostrado esquematicamente o modelo proposto por Hsueh (2002) como um sistema com " $n$ " camadas com espessuras individuais " $t$ " que estão aderidos a um substrato com espessura " $t_{s}$ " expostos a alta temperatura. $O$ índice " $\vec{l}$ refere-se ao número da camada e varia de 1 até " $n$ ", sendo que a camada 1 está em contato direto com o substrato. O sistema de coordenadas está definido para que a interface entre a camada 1 e o substrato corresponda a $z=0$ e a superfície livre do substrato corresponda a $z=-t_{s}$. A superfície da mais externa das camadas estará em $z=h_{n}$ e a interface entre as camadas $i$ e $i+1$ está na coordenada $z=h_{i}$.

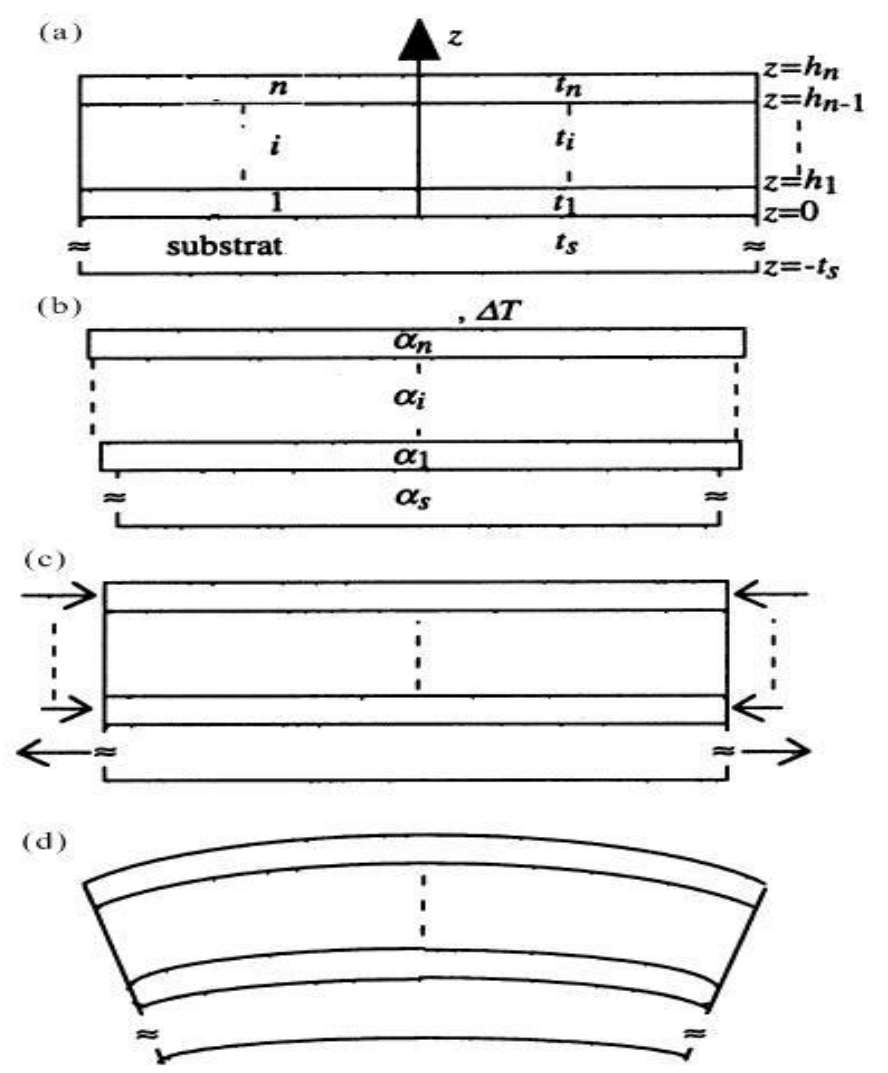

Figura A. 1: Sistema multicamada submetido a tensões por variação de temperatura, segundo modelo proposto por Hsueh (2002).

$\mathrm{Na}$ Figura $\mathrm{A}$. 1-b é mostrada a variação de temperatura $(\Delta \mathrm{T})$ produzida pelo resfriamento aplicado na camada externa resultando em deformações diferenciais 
entre as camadas devido aos diferentes coeficientes de dilatação térmica $\alpha_{s}, \alpha_{1}, \alpha_{i}$ respectivamente.

Tensões de tração e compressão são impostas em cada uma das camadas para atingir a compatibilidade de deslocamentos, de tal forma que a deformação no sistema é " $c$ " como é mostrado na Figura 2.8-c e, finalmente, é produzida flexão no sistema uma vez que a variação de temperatura é assimétrica, como indicado na Figura 2.8-d.

De acordo com o modelo proposto por Hsueh (2002), a deformação do sistema $(\varepsilon)$ pode ser descomposta na componente de deformação " $c$ " e a componente resultante da flexão. Desta forma a deformação total pode ser expressa pela Equação 0-1:

$$
\varepsilon=c+\frac{z-t_{b}}{r} \quad\left(\text { para }-\mathrm{t}_{\mathrm{s}} \leq \mathrm{z} \leq \mathrm{h}_{\mathrm{n}}\right)
$$

\section{Onde:}

$\varepsilon=$ deformação total do sistema;

$c=$ resultante da restrição às deformações entre camadas;

$z=t_{b}$ define a posição do eixo de flexão;

$r=$ raio de curvatura do sistema

As expressões derivadas por Hsueh (2002) para calcular as tensões normais resultantes no substrato e em cada uma das camadas são apresentadas na Equação 0-2 e na Equação 0-3:

$$
\sigma_{s}=E_{s}\left(c+\frac{z-t_{b}}{r}-\alpha_{s} \Delta T\right) \quad\left(\text { para }-\mathrm{t}_{\mathrm{s}} \leq \mathrm{z} \leq \mathrm{h}_{\mathrm{n}}\right) \quad \text { Equação 0-2 }
$$

Onde: 
$\sigma_{\mathrm{s}}=$ Tensão normal no substrato para a coordenada $z$;

$E_{s}=$ módulo de elasticidade do substrato;

$c=$ resultante da restrição às deformações entre camadas;

$z=t_{b}$ define a posição do eixo de flexão;

$r=$ raio de curvatura do sistema.

$\sigma_{i}=E_{i}\left(c+\frac{z-t_{b}}{r}-\alpha_{i} \Delta T\right) \quad($ para $\mathrm{i}=1$ até $\mathrm{n})$

Equação 0-3

Onde:

$\sigma_{\mathrm{s}}=$ Tensão normal no substrato para a coordenada $\mathrm{z}$;

$\mathrm{E}_{\mathrm{s}}=$ módulo de elasticidade do substrato;

$c=$ resultante da restrição às deformações entre camadas;

$z=t_{b}$ define a posição do eixo de flexão;

$r=$ raio de curvatura do sistema.

Solução das equações precedentes depende dos valores dos parâmetros indicados por Hsueh (2002) como condições de contorno c, $r$ e tque são expressos nas seguintes equações:

$$
c=\frac{\left(E_{s} t_{s} \alpha_{s}+\sum_{i=1}^{n} E_{i} t_{i} \alpha_{i}\right) \cdot \Delta T}{E_{s} t_{s}+\sum_{i=1}^{n} E_{i} t_{i}}
$$

Equação 0-4

$t_{b}=\frac{-E_{s} t_{s}^{2}+\sum_{i=1}^{n} E_{i} t_{i}\left(2 h_{i-1}+t_{i}\right)}{2\left(E_{s} t_{s}+\sum_{i=1}^{n} E_{i} t_{i}\right)}$

Equação 0-5

$\frac{1}{r}=\frac{3 \cdot\left[E_{s}\left(c-\alpha_{s} \Delta T\right) t_{s}^{2}-\sum_{i=1}^{n} E_{i} t_{i}\left(c-\alpha_{i} \Delta T\right)\left(2 h_{i-1}+t_{i}\right)\right]}{E_{s} t_{s}^{2}\left(2 t_{s}+3 t_{b}\right)+\sum_{i=1}^{n} E_{i} t_{i}\left[6 h_{i-1}^{2}+6 h_{i-1} t_{i}+2 t_{i}^{2}-3 t_{b}\left(2 h_{i-1}+t_{i}\right)\right]} \quad$ Equação 0-6 
Onde:

$E_{s}$ e $E_{i}=$ módulos de elasticidade do substrato e da camada i respectivamente;

$t_{s}$ e $t_{i}=$ espessuras do substrato e da camada i respectivamente;

$\alpha_{s}$ e $\alpha_{i}=$ coeficientes de dilatação térmica do substrato e da camada i respectivamente;

$\Delta \mathrm{T}=$ variação de temperatura;

$t_{b}=$ posição do eixo de flexão

$c=$ resultante da restrição às deformações entre camadas;

$\mathrm{h}_{\mathrm{i}-1}=0$ quando $\mathrm{i}=1$;

$r=$ raio de curvatura do sistema.

Nas equações precedentes para o cálculo das tensões biaxiais o módulo de elasticidade $E$ deve ser substituído por E/(1-v), onde v é coeficiente de Poisson. Por fim, Hsueh e Luttrell (2006) ressaltam que no modelo de Hsueh (2002) é utilizada a teoria de placas finas sem considerar o efeito das tensões de cisalhamento. 


\section{ANEXO B: ANÁLISE ESTATÍSTICA \\ PLANEJAMENTO DO EXPERIMENTO \\ Foi estudado o efeito de três variáveis na resistência de aderência a tração do revestimento: \\ Processo térmico (Sem choque, Com choque)}

Taxa de macro-defeitos de interface $(0 \%, 35 \%)$

Adição de incorporador de ar (S/ AIA, C/ AIA).

A combinação dos fatores pode ser vista na Tabela.B-1

Tabela B-1. Combinação dos fatores

\begin{tabular}{l|l|l|l}
\hline \multicolumn{2}{c|}{ COMBINAÇ̃̃O } & \multicolumn{2}{c}{ CHOQUE } \\
\hline \multirow{2}{*}{ Taxa de macro-defeitos } & AIA & SEM CHOQUE & COM CHOQUE \\
\hline \multirow{2}{*}{$0 \%$} & S/ AIA & 1 & 5 \\
\cline { 2 - 4 } & C/ AIA & 2 & 6 \\
\hline \multirow{2}{*}{$35 \%$} & S/ AIA & 3 & 7 \\
\cline { 2 - 4 } & C/ AIA & 4 & 8 \\
\hline
\end{tabular}

Para cada combinação dos fatores (8 em total), ensaiadas 4 placas por combinação.

A avaliação do efeito dos fatores foi realizada mediante a análise de variância (ANOVA ) de um arranjo fatorial de três fatores, comparando os efeitos dos fatores (efeitos principais, interações de $1^{\circ}$ ordem, interações de $2^{\circ}$ ordem, etc.). Basicamente são confrontadas duas hipóteses:

$\mathrm{H}_{0}$ : Não há diferença nas médias

$\mathrm{H}_{1}$ : Há pelo menos uma diferença.

Para aceitar o rejeitar as hipóteses foi usado o $\mathrm{P}$-Value $(\mathrm{P})$. Se $\mathrm{P}>\alpha$ aceitamos $\mathrm{H}_{0}$,

Se $P \leq \alpha$ rejeitamos $H_{0}$. Sendo $\alpha=0,05$ (nível de significância do teste).

Eliminação de dados espúrios

Um suposto do ANOVA é a homogeneidade das variâncias dos fatores. Assim, para garantir a homogeneidade de variâncias, foi feita a eliminação das observações espúrias que pudessem estar alterando a análise. A eliminação das observações foi realizada em duas partes: 
Foi realizado um ANOVA considerando a placa como fator e o teste de Levene de homogeneidade de variâncias, ambos com $\alpha=0,05$. Se no ANOVA se aceitava que as placas tinham a mesma média, e no teste de Levene se aceitava que as placas tem variância comum, todas as observações das placas seriam incluídas na análise . Se o ANOVA ou o teste de Levene dava diferenças, se procedeu a eliminar as observações atípicas até obter homogeneidade de variâncias das placas, e se for possível média comum. A análise estatística será realizada usando o software SAS 9.1 .

\section{Combinação 1: Sem choque , 0\% macro-defeitos, sem AIA}

Tabela B-2: The ANOVA Procedure

\begin{tabular}{l|l|l|l|l|l|l}
\hline Dependent & Source & DF & $\begin{array}{l}\text { Sum of } \\
\text { Squares }\end{array}$ & $\begin{array}{l}\text { Mean } \\
\text { Square }\end{array}$ & F Value & Pr $>$ F \\
\hline $\begin{array}{l}\text { Resistência } \\
\text { de aderência }\end{array}$ & Model & 3 & 3,44622 & 1,14874 & 12,87638 & 0,00003 \\
\hline & Error & 24 & 2,14111 & 0,08921 & & \\
\hline & $\begin{array}{l}\text { Corrected } \\
\text { Total }\end{array}$ & 27 & 5,58733 & & & \\
\hline
\end{tabular}

Tabela B-3: Levene's Test for Homogeneity of TENSAO Variance ANOVA of Squared Deviations for Group Means

\begin{tabular}{l|l|l|l|l|l|l|l}
\hline Dependent & Method & Source & DF & $\begin{array}{c}\text { Sum of } \\
\text { Squares }\end{array}$ & $\begin{array}{c}\text { Mean } \\
\text { Square }\end{array}$ & $\begin{array}{c}\mathbf{F} \\
\text { Value }\end{array}$ & Pr $>$ F \\
\hline TENSAO & LV & REP & 3 & 0,08993 & 0,02998 & 1,6225 & 0,2104 \\
\hline & & Error & 24 & 0,44339 & 0,01847 & & \\
\hline
\end{tabular}

ANOVA: Como $\mathrm{P}<0,05$ rejeitamos $\mathrm{H}_{0}$, isto é as placas da combinação 1 tem médias diferentes.

Teste de Levene: Como $\mathrm{P}=0,2104>0,05$ aceitamos que as quatro placas tem a mesma variabilidade.

Excluindo as observações com valores influentes (atípicas): Tensão < 0,33 temos:

Tabela B-4: The ANOVA Procedure

\begin{tabular}{l|c|c|c|c|c|c}
\hline Dependent & Source & DF & $\begin{array}{c}\text { Sum of } \\
\text { Squares }\end{array}$ & $\begin{array}{c}\text { Mean } \\
\text { Square }\end{array}$ & $\begin{array}{c}\mathbf{F} \\
\text { Value }\end{array}$ & Pr $>$ F \\
\hline TENSAO & Model & 3 & 0,84901 & 0,283 & 5,36181 & 0,0076 \\
\hline & Error & 19 & 1,00284 & 0,05278 & & \\
\hline & Corrected Total & 22 & 1,85185 & & & \\
\hline
\end{tabular}


Tabela B-5: Levene's Test for Homogeneity of TENSAO Variance ANOVA of Squared Deviations for Group Means

\begin{tabular}{l|l|l|l|l|l|c|c}
\hline Dependent & Method & Source & DF & $\begin{array}{c}\text { Sum of } \\
\text { Squares }\end{array}$ & $\begin{array}{c}\text { Mean } \\
\text { Square }\end{array}$ & $\begin{array}{c}\text { F } \\
\text { Value }\end{array}$ & Pr $>$ F \\
\hline TENSAO & LV & REP & 2 & 0,0064 & 0,0032 & 2,87805 & 0,08231 \\
\hline & & Error & 18 & 0,02002 & 0,00111 & & \\
\hline
\end{tabular}

ANOVA: Como $\mathrm{P}<0,05$ rejeitamos $\mathrm{H}_{0}$, isto é as placas da combinação 1 tem médias diferentes.

Teste de Levene: Como $\mathrm{P}=0,08231>0,05$ aceitamos que as quatro placas tem a mesma variabilidade.

Para esta combinação não foi possível conseguir a igualdade de médias para as quatro placas, para diminuir a variabilidade, foram retiradas as tensões menores a 0,33 .

Combinação 2: Sem choque , 0\% concentração, com AlA

Tabela B-6: The ANOVA Procedure

\begin{tabular}{l|l|l|l|l|l|l}
\hline Dependent & \multicolumn{1}{|c|}{ Source } & DF & \multicolumn{1}{|c|}{$\begin{array}{c}\text { Sum of } \\
\text { Squares }\end{array}$} & $\begin{array}{c}\text { Mean } \\
\text { Square }\end{array}$ & $\begin{array}{c}\text { F } \\
\text { Value }\end{array}$ & \multicolumn{1}{|c}{ Pr $>$ F } \\
\hline TENSAO & Model & 3 & 0,75926 & 0,25309 & 2,37323 & 0,09429 \\
\hline & Error & 25 & 2,66606 & 0,10664 & & \\
\hline & $\begin{array}{l}\text { Corrected } \\
\text { Total }\end{array}$ & 28 & 3,42532 & & & \\
\hline
\end{tabular}

Tabela B-7: Levene's Test for Homogeneity of TENSAO Variance ANOVA of Squared Deviations for Group Means

\begin{tabular}{l|l|l|l|l|l|l|l}
\hline Dependent & Method & Source & DF & $\begin{array}{l}\text { Sum of } \\
\text { Squares }\end{array}$ & $\begin{array}{l}\text { Mean } \\
\text { Square }\end{array}$ & F Value & Pr $>$ F \\
\hline TENSAO & LV & REP & 3 & 0,08882 & 0,02961 & 1,44932 & 0,25228 \\
\hline & & Error & 25 & 0,51071 & 0,02043 & & \\
\hline
\end{tabular}

ANOVA: Como $\mathrm{P}=0,09429>0,05$ aceitamos $\mathrm{H}_{0}$, isto é, não existem diferenças significativas entre as médias das placas da combinação 2.

Teste de Levene: Como $\mathrm{P}=0,2104>0,05$ aceitamos que as quatro placas tem a mesma variabilidade.

Para esta combinação, todas as observações das placas serão incluídas na análise. 


\section{Combinação 3: Sem choque , 35\% concentração, sem AIA}

Tabela B-8: The ANOVA Procedure

\begin{tabular}{l|l|l|l|l|l|l}
\hline Dependent & Source & DF & $\begin{array}{l}\text { Sum of } \\
\text { Squares }\end{array}$ & Mean Square & $\begin{array}{l}\text { F } \\
\text { Value }\end{array}$ & Pr $>$ F \\
\hline TENSAO & Model & 3 & 0,15178 & 0,05059 & 1,3369 & 0,2831 \\
\hline & Error & 27 & 1,02182 & 0,03785 & & \\
\hline & $\begin{array}{l}\text { Corrected } \\
\text { Total }\end{array}$ & 30 & 1,1736 & & & \\
\hline
\end{tabular}

Tabela B-9: Levene's Test for Homogeneity of TENSAO Variance. ANOVA of Squared Deviations for Group Means

\begin{tabular}{l|l|l|l|l|l|l|l}
\hline Dependent & Method & Source & DF & $\begin{array}{l}\text { Sum of } \\
\text { Squares }\end{array}$ & $\begin{array}{l}\text { Mean } \\
\text { Square }\end{array}$ & F Value & Pr $>$ F \\
\hline TENSAO & LV & REP & 3 & 0,00939 & 0,00313 & 1,34792 & 0,27972 \\
\hline & & Error & 27 & 0,0627 & 0,00232 & & \\
\hline
\end{tabular}

ANOVA: Como $P=0,2831>0,05$ aceitamos $H_{0}$, isto é, não existem diferenças significativas entre as médias das placas da combinação 3 .

Teste de Levene: Como $\mathrm{P}=0,27972>0,05$ aceitamos que as quatro placas tem a mesma variabilidade.

Para esta combinação, todas as observações das placas serão incluídas na análise.

Combinação 4: Sem choque , $35 \%$ concentração, com AlA

Tabela B-10: The ANOVA Procedure

\begin{tabular}{l|l|l|l|l|l|l}
\hline Dependent & Source & DF & $\begin{array}{l}\text { Sum of } \\
\text { Squares }\end{array}$ & $\begin{array}{l}\text { Mean } \\
\text { Square }\end{array}$ & F Value & Pr $>$ F \\
\hline TENSAO & Model & 3 & 0,15713 & 0,05238 & 1,72123 & 0,18626 \\
\hline & Error & 27 & 0,82163 & 0,03043 & & \\
\hline & $\begin{array}{l}\text { Corrected } \\
\text { Total }\end{array}$ & 30 & 0,97876 & & & \\
\hline
\end{tabular}

Tabela B-11: Levene's Test for Homogeneity of TENSAO Variance ANOVA of Squared Deviations for Group Means

\begin{tabular}{l|l|l|l|l|l|l|l}
\hline Dependent & Method & Source & DF & $\begin{array}{l}\text { Sum of } \\
\text { Squares }\end{array}$ & $\begin{array}{l}\text { Mean } \\
\text { Square }\end{array}$ & F Value & Pr F \\
\hline TENSAO & LV & REP & 3 & 0,00702 & 0,00234 & 0,79352 & 0,50819 \\
\hline & & Error & 27 & 0,07956 & 0,00295 & & \\
\hline
\end{tabular}

ANOVA: Como $\mathrm{P}=0,18626>0,05$ aceitamos $\mathrm{H} 0$, isto é, não existem diferenças significativas entre as médias das placas da combinação 4.

Teste de Levene: Como $\mathrm{P}=0,50819>0,05$ aceitamos que as quatro placas tem a mesma variabilidade. 
Para esta combinação, todas as observações das placas serão incluídas na análise.

Combinação 5: Com choque , $0 \%$ concentração, sem AlA

Tabela B-12: The ANOVA Procedure

\begin{tabular}{l|l|l|l|l|l|l}
\hline Dependent & Source & DF & $\begin{array}{l}\text { Sum of } \\
\text { Squares }\end{array}$ & $\begin{array}{l}\text { Mean } \\
\text { Square }\end{array}$ & F Value & Pr $>$ F \\
\hline TENSAO & Model & 3 & 1,68269 & 0,5609 & 4,74057 & 0,00943 \\
\hline & Error & 25 & 2,95795 & 0,11832 & & \\
\hline & $\begin{array}{l}\text { Corrected } \\
\text { Total }\end{array}$ & 28 & 4,64064 & & & \\
\hline
\end{tabular}

Tabela B-13: Levene's Test for Homogeneity of TENSAO Variance. ANOVA of Squared Deviations for Group Means

\begin{tabular}{l|l|l|l|l|l|l|l}
\hline Dependent & Method & Source & DF & $\begin{array}{l}\text { Sum of } \\
\text { Squares }\end{array}$ & $\begin{array}{l}\text { Mean } \\
\text { Square }\end{array}$ & F Value & Pr $>$ F \\
\hline TENSAO & LV & REP & 3 & 0,24062 & 0,08021 & 3,84047 & 0,02173 \\
\hline & & Error & 25 & 0,52212 & 0,02088 & & \\
\hline
\end{tabular}

ANOVA: Como $\mathrm{P}<0,05$ rejeitamos $\mathrm{H} 0$, isto é as placas da combinação 5 tem médias diferentes.

Teste de Levene: Como $\mathrm{P}=0,02173<0,05$ temos que as quatro placas tem variâncias diferentes.

Excluindo as observações com valores influentes (atípicas) : Tensão $\leq 0,12$ e Tensão $\geq 0,85$, temos:

Tabela B-14: The ANOVA Procedure

\begin{tabular}{l|l|l|l|l|l|l}
\hline Dependent & Source & DF & Sum of Squares & Mean Square & F Value & Pr $>$ F \\
\hline TENSAO & Model & 3 & 0,1282 & 0,04273 & 1,00514 & 0,41607 \\
\hline & Error & 16 & 0,68026 & 0,04252 & & \\
\hline & Corrected Total & 19 & 0,80847 & & & \\
\hline
\end{tabular}

Tabela B-15: Levene's Test for Homogeneity of TENSAO Variance. ANOVA of Squared Deviations for Group Means

\begin{tabular}{l|l|l|l|l|l|l|l}
\hline Dependent & Method & Source & DF & Sum of Squares & Mean Square & F Value & $\operatorname{Pr}>$ F \\
\hline TENSAO & LV & REP & 3 & 0,01036 & 0,00345 & 3,38305 & 0,04421 \\
\hline & & Error & 16 & 0,01634 & 0,00102 & & \\
\hline
\end{tabular}

ANOVA: Como $\mathrm{P}=0,41607>0,05$ aceitamos $\mathrm{H}_{0}$, isto é, não existem diferenças significativas entre as médias das placas da combinação 5 .

Teste de Levene: Como $\mathrm{P}=0,04421<0,05$ temos que as quatro placas tem variâncias diferentes. 
Para esta combinação, considerando tensões entre 0,12 e 0,85 , conseguimos que todas as placas tenham a mesma média, porem as variâncias entre as placas são ligeiramente diferentes.

\section{Combinação 6: Com choque , $0 \%$ concentração, com AIA}

Tabela B-16: The ANOVA Procedure

\begin{tabular}{l|l|l|l|l|l|l}
\hline Dependent & Source & DF & Sum of Squares & Mean Square & F Value & $\operatorname{Pr}>$ F \\
\hline TENSAO & Model & 2 & 1,50774 & 0,75387 & 8,13071 & 0,00261 \\
\hline & Error & 20 & 1,85438 & 0,09272 & & \\
\hline & Corrected Total & 22 & 3,36212 & & & \\
\hline
\end{tabular}

Tabela B-17: Levene's Test for Homogeneity of TENSAO Variance. ANOVA of Squared Deviations for Group Means

\begin{tabular}{l|l|l|l|l|l|l|l}
\hline Dependent & Method & Source & DF & $\begin{array}{l}\text { Sum of } \\
\text { Squares }\end{array}$ & Mean Square & F Value & $\operatorname{Pr}>$ F \\
\hline TENSAO & LV & REP & 2 & 0,05252 & 0,02626 & 2,50582 & 0,10688 \\
\hline & & Error & 20 & 0,20958 & 0,01048 & & \\
\hline
\end{tabular}

ANOVA: Como $\mathrm{P}<0,05$ rejeitamos $\mathrm{H}_{0}$, isto é as placas da combinação 6 tem médias diferentes.

Teste de Levene: Como $\mathrm{P}=0,10688>0,05$ temos que as quatro placas tem placas tem a mesma variabilidade.

Excluindo as observações com valores influentes (atípicas): Tensão $\leq 0,1$ e Tensão $\geq 1,1$, temos:

Tabela B-18: The ANOVA Procedure

\begin{tabular}{l|l|l|l|l|l|l}
\hline Dependent & Source & DF & Sum of Squares & Mean Square & F Value & Pr $>$ F \\
\hline TENSAO & Model & 2 & 0,18634 & 0,09317 & 1,35555 & 0,28764 \\
\hline & Error & 15 & 1,03098 & 0,06873 & & \\
\hline & Corrected Total & 17 & 1,21731 & & & \\
\hline
\end{tabular}

Tabela B-19: Levene's Test for Homogeneity of TENSAO Variance. ANOVA of Squared Deviations for Group Means

\begin{tabular}{l|l|l|l|l|l|l|l}
\hline Dependent & Method & Source & DF & Sum of Squares & Mean Square & F Value & $\operatorname{Pr}>$ F \\
\hline TENSAO & LV & REP & 2 & 0,00537 & 0,00269 & 0,67996 & 0,52159 \\
\hline TENSAO & & Error & 15 & 0,05927 & 0,00395 & & \\
\hline
\end{tabular}

ANOVA: Como $\mathrm{P}=0,28764>0,05$ aceitamos $\mathrm{H}_{0}$, isto é, não existem diferenças significativas entre as médias das placas da combinação 6 .

Teste de Levene: Como $\mathrm{P}=0,52159>0,05$ temos que as quatro placas tem placas tem a mesma variabilidade

Para esta combinação, considerando tensões entre 0,1 e 1,1 , conseguimos que todas as placas tenham a mesma média e a mesma variabilidade. 
Combinação 7: Com choque, $35 \%$ concentração, sem AIA

Tabela B-20: The ANOVA Procedure

\begin{tabular}{l|l|l|l|l|l|l}
\hline Dependent & Source & DF & Sum of Squares & Mean Square & F Value & Pr $>$ F \\
\hline TENSAO & Model & 3 & 0,42062 & 0,14021 & 19,82788 & $<, 0001$ \\
\hline & Error & 27 & 0,19092 & 0,00707 & & \\
\hline & Corrected Total & 30 & 0,61155 & & & \\
\hline
\end{tabular}

Tabela B-21: Levene's Test for Homogeneity of TENSAO Variance. ANOVA of Squared Deviations for Group Means

\begin{tabular}{l|l|l|l|l|l|l|l}
\hline Dependent & Method & Source & DF & Sum of Squares & Mean Square & F Value & Pr $>$ F \\
\hline TENSAO & LV & REP & 3 & 0,00083 & 0,00028 & 1,93472 & 0,14778 \\
\hline & & Error & 27 & 0,00387 & 0,00014 & & \\
\hline
\end{tabular}

ANOVA: Como $\mathrm{P}<0,05$ rejeitamos $\mathrm{H}_{0}$, isto é as placas da combinação 7 tem médias diferentes.

Teste de Levene: Como $\mathrm{P}=0,14778>0,05$ temos que as quatro placas tem placas tem a mesma variabilidade.

Excluindo as observações com valores influentes (atípicas): Tensão $\leq 0,1$ e Tensão $\geq 0,35$, temos:

Tabela B-22: The ANOVA Procedure

\begin{tabular}{l|l|l|l|l|l|l}
\hline Dependent & Source & DF & Sum of Squares & Mean Square & F Value & Pr $>$ F \\
\hline TENSAO & Model & 3 & 0,0804 & 0,0268 & 6,84182 & 0,00399 \\
\hline & Error & 15 & 0,05875 & 0,00392 & & \\
\hline & Corrected Total & 18 & 0,13915 & & & \\
\hline
\end{tabular}

Tabela B-23: Levene's Test for Homogeneity of TENSAO Variance. ANOVA of Squared Deviations for Group Means

\begin{tabular}{l|l|l|l|l|l|l|l}
\hline Dependent & Method & Source & DF & $\begin{array}{l}\text { Sum of } \\
\text { Squares }\end{array}$ & $\begin{array}{l}\text { Mean } \\
\text { Square }\end{array}$ & F Value & Pr $>$ F \\
\hline TENSAO & LV & REP & 3 & 0,00009 & 0,00003 & 1,11751 & 0,37316 \\
\hline & & Error & 15 & 0,00041 & 0,00003 & & \\
\hline
\end{tabular}

ANOVA: Como $\mathrm{P}<0,05$ rejeitamos $\mathrm{H}_{0}$, isto é as placas da combinação 7 tem médias diferentes.

Teste de Levene: Como $\mathrm{P}=0,37316>0,05$ temos que as quatro placas tem placas tem a mesma variabilidade.

Quando consideramos as tensões entre 0,1 e 0,35 , conseguimos que todas as placas tenham a mesma variabilidade, porém ainda existem diferenças entre as médias das placas. 
Combinação 8: Com choque, $35 \%$ concentração, com AIA

Tabela B-24: The ANOVA Procedure

\begin{tabular}{l|l|l|l|l|l|l}
\hline Dependent & Source & DF & Sum of Squares & Mean Square & F Value & $\operatorname{Pr}>$ F \\
\hline TENSAO & Model & 3 & 0,00565 & 0,00188 & 0,22049 & 0,88124 \\
\hline & Error & 25 & 0,21349 & 0,00854 & & \\
\hline & Corrected Total & 28 & 0,21913 & & & \\
\hline
\end{tabular}

Tabela B-25: Levene's Test for Homogeneity of TENSAO Variance. ANOVA of Squared Deviations for Group Means

\begin{tabular}{l|l|l|l|l|l|l|l}
\hline Dependent & Method & Source & DF & Sum of Squares & Mean Square & F Value & Pr $>$ F \\
\hline TENSAO & LV & REP & 3 & 0,0004 & 0,00013 & 1,47538 & 0,24528 \\
\hline & & Error & 25 & 0,00228 & 0,00009 & & \\
\hline
\end{tabular}

ANOVA: Como $\mathrm{P}=0,88124>0,05$ aceitamos $\mathrm{H}_{0}$, isto é, não existem diferenças significativas entre as médias das placas da combinação 8.

Teste de Levene: Como $\mathrm{P}=0,24528>0,05$ temos que as quatro placas tem placas tem a mesma variabilidade.

Para esta combinação, todas as observações das placas serão incluídas na análise.

Na tabela B-26 é apresentado um resumo com os critérios de inclusão das observações para eliminar os dados espúrios.

Tabela B-26 Critérios de inclusão das observações

\begin{tabular}{l|l|l}
\hline & \multicolumn{1}{|c|}{ COMBINAÇÃO } & \multicolumn{1}{c}{ CRITÉRIO DE INCLUSÃO } \\
\hline 1 & Sem choque, $0 \%$ concentração, sem AIA & Tensão $\geq 0,33$ \\
\hline 2 & Sem choque, $0 \%$ concentração, com AIA & Todas as observações \\
\hline 3 & Sem choque, $35 \%$ concentração, sem AIA & Todas as observações \\
\hline 4 & Sem choque, $35 \%$ concentração, com AIA & Todas as observações \\
\hline 6 & Com choque, $0 \%$ concentração, sem AIA & Tensão entre 0,12 e 0,85 \\
\hline 7 & Com choque, $0 \%$ concentração, com AIA & Tensão entre 0,1 e 1,1 \\
\hline 8 & Com choque, $35 \%$ concentração, sem AIA & Tensão entre 0,1 e 0,35 \\
\hline
\end{tabular}




\section{ANÁLISE DOS FATORES CHOQUE TÉRMICO, TAXA DE MACRO-DEFEITOS E INCLUSÃO DE ADITIVO INCORPORADO DE AR}

Foi realizado um arranjo fatorial para testar o efeito do choque térmico, taxa de macrodefeitos e AIA. Os e resultados do ANOVA são mostrados a seguir:

Para cada um dos efeitos significativos foi realizado o Teste de Tukey de comparação de médias para ver quais níveis do fatores apresentavam diferenças no comportamento médio.

\section{AVALIAÇÃO DAS MÉDIAS}

\section{EFEITOS PRINCIPAIS}

Choque Térmico: a resistência de aderência média das placas sem choque térmico foi significativamente maior do que as placas submetidas ao Choque Térmico.

Taxa de macro-defeitos: a resistência de aderência média foi significativamente maior sem macro-defeitos $(0 \%)$ do que com $35 \%$ de macro-defeitos.

Inclusão de AIA: a resistência de aderência média das placas foi significativamente maior para os revestimentos sem AIA que os revestimentos com AIA.

Tabela B-27:. Tensão média para o fator Choque Térmico $(\mathrm{P}<0,0001)$

\begin{tabular}{l|l|l|l}
\hline CHOQUE & MÉDIA & \multicolumn{3}{|l}{ INTERVALO DE CONFIANÇA } \\
\hline Sem Choque Térmico & 0,62554 & 0,58346 & 0,66762 \\
\hline Com Choque Térmico & 0,31306 & 0,26412 & 0,36199 \\
\hline
\end{tabular}

Tabela B-28 . Tensão média para o fator Concentração $(\mathrm{P}<0,0001)$

\begin{tabular}{l|l|l|l}
\hline TAXA DE MACRO-DEFEITOS & MÉDIA & \multicolumn{3}{|l}{ INTERVALO DE CONFIANÇA } \\
\hline Concentração 0\% & 0,68104 & 0,63328 & 0,7288 \\
\hline Concentração 35\% & 0,25756 & 0,21415 & 0,30097 \\
\hline
\end{tabular}

Tabela B-29. Tensão média para o fator AIA $(\mathrm{P}-$ Value $=0,0205)$

\begin{tabular}{l|l|l|l}
\hline AIA & MÉDIA & INTERVALO DE CONFIANÇA \\
\hline Sem AIA & 0,50753 & 0,46045 & 0,55462 \\
\hline Com AIA & 0,43106 & 0,38692 & 0,4752 \\
\hline
\end{tabular}

\section{INTERAÇÕES DE ORDEM 2:}

\section{Choque Térmico vs. Concentração:}

A maior a resistência de aderência foi registrada para as placas sem Choque Térmico sem macro-defeitos $(0 \%)$, a menor foi observada nas placas com Choque Térmico e com taxa de macro-defeitos de $35 \%$.

Não existem diferenças significativas entre as resistências de aderência médias das placas sem choque térmico com $35 \%$ de taxa de macro-defeitos, e as placas com choque térmico sem macro-defeitos $(0 \%)$. 
Não existem diferenças significativas entre as tensões médias das placas sem Choque Térmico com concentração de $35 \%$, e as placas com choque térmico com concentração de $35 \%$. Isto é, para uma concentração de $35 \%$ não há diferenças significativas para as tensões médias da placas sem Choque Térmico e com Choque Térmico.

Todas as outras interações do Choque Térmico vs Concentração, tiveram médias estatisticamente diferentes.

Tabela B-30: Tensões médias para as interações dos fatores Choque Térmico vs.

Concentração

\begin{tabular}{l|l|l|l|l}
\hline INTERAÇÕES & $\begin{array}{l}\text { LSMEAN } \\
\text { Number }\end{array}$ & MÉDIA & \multicolumn{2}{l}{$\begin{array}{l}\text { INTERVALO DE } \\
\text { CONFIANÇA }\end{array}$} \\
\hline SEM CHOQUE SEM CONCENTRACAO & 1 & 0,9433 & 0,88105 & 1,00556 \\
\hline SEM CHOQUE CONCENTRACAO 35\% & 2 & 0,30777 & 0,25114 & 0,36441 \\
\hline COM CHOQUE SEM CONCENTRACAO & 3 & 0,41877 & 0,34633 & 0,49121 \\
\hline COM CHOQUE CONCENTRACAO 35\% & 4 & 0,20734 & 0,14153 & 0,27315 \\
\hline
\end{tabular}

Tabela B-31: P-VALUES para as diferenças de médias da interação Choque Térmico vs. Concentração.

\begin{tabular}{ll|l|l|l|l|l}
\hline \multicolumn{2}{c}{ P-VALUE } \\
\hline INTERAÇÕES & $\mathrm{i} / \mathrm{j}$ & 1 & 2 & 3 & 4 \\
\hline SEM CHOQUE SEM CONCENTRACAO & 1 & & $<, 0001$ & $<, 0001$ & $<, 0001$ \\
\hline SEM CHOQUE CONCENTRACAO 35\% & 2 & $<, 0001$ & & 0,0842 & 0,1059 \\
\hline COM CHOQUE SEM CONCENTRACAO & 3 & $<, 0001$ & 0,0842 & & 0,0002 \\
\hline COM CHOQUE CONCENTRACAO 35\% & 4 & $<, 0001$ & 0,1059 & 0,0002 & \\
\hline
\end{tabular}

\section{Choque Térmico vs. AIA:}

A maior tensão foi registrada para as placas sem Choque Térmico sem AIA.

Não existem diferenças significativas das tensões médias das placas sem choque térmico sem AIA, e as placas com choque térmico com AIA. Isto é, diante do Choque Térmico, não existem diferenças significativas nas tensões médias das placas sem AIA e com AIA.

Tabela B-32: Tensões médias para as interações dos fatores Choque Térmico vs. AIA

\begin{tabular}{l|l|l|l|l}
\hline INTERAÇÕES & $\begin{array}{l}\text { LSMEAN } \\
\text { Number }\end{array}$ & MÉDIA & \multicolumn{2}{l}{$\begin{array}{l}\text { INTERVALO DE } \\
\text { CONFIANCA }\end{array}$} \\
\hline SEM CHOQUE SEM AIA & 1 & 0,70612 & 0,64476 & 0,76748 \\
\hline SEM CHOQUE COM AIA & 2 & 0,54496 & 0,48736 & 0,60256 \\
\hline COM CHOQUE SEM AIA & 3 & 0,30894 & 0,23752 & 0,38037 \\
\hline COM CHOQUE COM AIA & 4 & 0,31717 & 0,25027 & 0,38407 \\
\hline
\end{tabular}


Tabela B-33: P-VALUES para as diferenças de médias das interações Choque Térmico vs. Concentração.

\begin{tabular}{l|l|l|l|l|l}
\hline INTERAÇÕES & $\mathrm{i} / \mathrm{j}$ & 1 & 2 & 3 & 4 \\
\hline SEM CHOQUE SEM AIA & 1 & & 0,0012 & $<, 0001$ & $<, 0001$ \\
\hline SEM CHOQUE COM AIA & 2 & 0,0012 & & $<, 0001$ & $<, 0001$ \\
\hline COM CHOQUE SEM AIA & 3 & $<, 0001$ & $<, 0001$ & & 0,9984 \\
\hline COM CHOQUE COM AIA & 4 & $<, 0001$ & $<, 0001$ & 0,9984 & \\
\hline
\end{tabular}

\section{INTERAÇÕES DE ORDEM 3: Choque Térmico vs . concentração vs. AIA}

A maior tensão foi registrada para as placas sem Choque Térmico sem concentração e sem AIA.

Observando a tabela com os P-VALUES, notamos que a interação Choque Térmico vs . concentração vs. AIA resultou significativa principalmente pelas interações: sem Choque Térmico - sem Concentração - sem AIA e sem Choque Térmico - sem Concentração - com AIA, que tem medias significativamente diferentes as demais.

Tabela B-34:Tensões médias para as interações dos fatores Choque Térmico vs. Concentração vs. AIA

\begin{tabular}{l|l|l|l|l}
\hline INTERAÇÕES & $\begin{array}{l}\text { LSMEAN } \\
\text { Number }\end{array}$ & \multicolumn{2}{l}{ MÉDIA } & \multicolumn{2}{l}{$\begin{array}{l}\text { INTERVALO DE } \\
\text { CONFIANÇA }\end{array}$} \\
\hline SEM CHOQUE SEM CONCENTRACAO SEM AIA & 1 & 1,0942 & 1,00122 & 1,18718 \\
\hline SEM CHOQUE SEM CONCENTRACAO COM AIA & 2 & 0,79241 & 0,7096 & 0,87521 \\
\hline SEM CHOQUE CONCENTRACAO 35\% SEM AIA & 3 & 0,31805 & 0,23796 & 0,39814 \\
\hline SEM CHOQUE CONCENTRACAO 35\% COM AIA & 4 & 0,2975 & 0,21741 & 0,37759 \\
\hline COM CHOQUE SEM CONCENTRACAO SEM AIA & 5 & 0,40423 & 0,30452 & 0,50395 \\
\hline COM CHOQUE SEM CONCENTRACAO COM AIA & 6 & 0,43331 & 0,32821 & 0,53842 \\
\hline COM CHOQUE CONCENTRACAO 35\% SEM AIA & 7 & 0,21366 & 0,11135 & 0,31596 \\
\hline COM CHOQUE CONCENTRACAO 35\% COM AIA & 8 & 0,20102 & 0,11822 & 0,28383 \\
\hline
\end{tabular}


Tabela B-35: P-VALUES para as diferenças de médias das interações Choque Térmico vs.

Concentração vs AIA.

\begin{tabular}{l|l|c|c|c|c|c|c|c|c}
\hline \multicolumn{1}{c|}{ INTERAÇÕES } & $\mathbf{i} / \mathbf{j}$ & $\mathbf{1}$ & $\mathbf{2}$ & $\mathbf{3}$ & $\mathbf{4}$ & $\mathbf{5}$ & $\mathbf{6}$ & $\mathbf{7}$ & $\mathbf{8}$ \\
\hline $\begin{array}{l}\text { SEM CHOQUE SEM } \\
\text { CONCENTRACAO SEM AIA }\end{array}$ & 1 & & $<, 0001$ & $<, 0001$ & $<, 0001$ & $<, 0001$ & $<, 0001$ & $<, 0001$ & $<, 0001$ \\
\hline $\begin{array}{l}\text { SEM CHOQUE SEM } \\
\text { CONCENTRACAO COM AIA }\end{array}$ & 2 & $<, 0001$ & & $<, 0001$ & $<, 0001$ & $<, 0001$ & $<, 0001$ & $<, 0001$ & $<, 0001$ \\
\hline $\begin{array}{l}\text { SEM CHOQUE } \\
\text { CONCENTRACAO 35\% SEM AIA }\end{array}$ & 3 & $<, 0001$ & $<, 0001$ & & 1 & 0,8867 & 0,6739 & 0,7589 & 0,4822 \\
\hline $\begin{array}{l}\text { SEM CHOQUE } \\
\text { CONCENTRACAO 35\% COM } \\
\text { AIA }\end{array}$ & 4 & $<, 0001$ & $<, 0001$ & 1 & & 0,7216 & 0,4664 & 0,9078 & 0,718 \\
\hline $\begin{array}{l}\text { COM CHOQUE SEM } \\
\text { CONCENTRACAO SEM AIA }\end{array}$ & 5 & $<, 0001$ & $<, 0001$ & 0,8867 & 0,7216 & & 0,9999 & 0,1513 & 0,0462 \\
\hline $\begin{array}{l}\text { COM CHOQUE SEM } \\
\text { CONCENTRACAO COM AIA }\end{array}$ & 6 & $<, 0001$ & $<, 0001$ & 0,6739 & 0,4664 & 0,9999 & & 0,0678 & 0,0169 \\
\hline $\begin{array}{l}\text { COM CHOQUE } \\
\text { CONCENTRACAO 35\% SEM AIA }\end{array}$ & 7 & $<, 0001$ & $<, 0001$ & 0,7589 & 0,9078 & 0,1513 & 0,0678 & & 1 \\
\hline $\begin{array}{l}\text { COM CHOQUE } \\
\text { CONCENTRACAO 35\% COM } \\
\text { AIA }\end{array}$ & 8 & $<, 0001$ & $<, 0001$ & 0,4822 & 0,718 & 0,0462 & 0,0169 & 1 & \\
\hline
\end{tabular}




\section{ANEXO C: ANÁLISE GRANULOMÉTRICA DA AREIA}

RESULTADOS DE ANÁLISE DE TAMANHO DE PARTÍCULAS

\begin{tabular}{|c|c|}
\hline 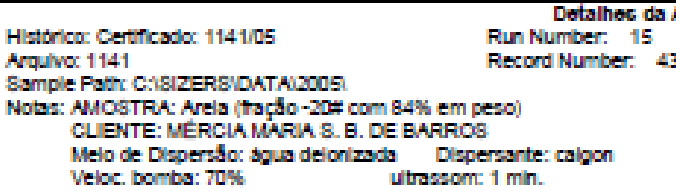 & $\begin{array}{l}\text { Medida: } \\
\text { Antilse: } 13 \text { Dec } 2005 \text { 15:11PM } \\
\text { Fonte de Reaulador: Medls }\end{array}$ \\
\hline
\end{tabular}

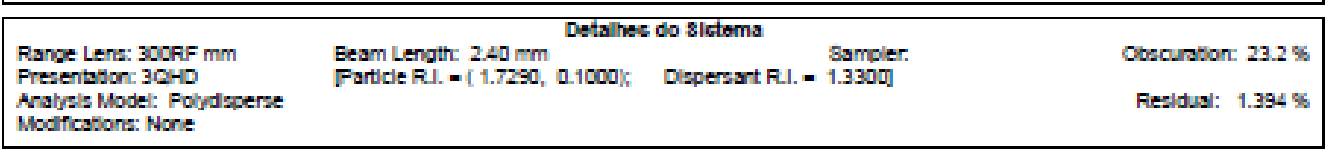

\begin{tabular}{|c|c|c|c|}
\hline \multicolumn{4}{|c|}{$\begin{array}{c}\text { Rosultsdoc Ectatictioce } \\
\end{array}$} \\
\hline $\begin{array}{l}\text { Tlpo de Dietroulęfo: Volume } \\
\text { Dismetros Medica: } \\
\text { D [4, 3] - } 134.65 \mathrm{um}\end{array}$ & $\begin{array}{l}\text { Concentroç5o- } 0.2871 \% \mathrm{Wo}) \\
D(v, 0.1)=58.33 \mathrm{um} \\
D[3,2]=101.53 \mathrm{um}\end{array}$ & $\begin{array}{l}\text { Densidade- } 2.650 \mathrm{~g} / \mathrm{cub} . \mathrm{cm} \\
D(\mathrm{v}, 0.5)=125.89 \mathrm{um} \\
\text { Span }=1.319 \mathrm{E}+00\end{array}$ & $\begin{array}{l}\text { Avea Supert Eepec. } 0.022394 \mathrm{~m} / \mathrm{g} \\
\text { D (v, 0.9) }=224.38 \mathrm{um} \\
\text { Uniformidade }=4.080 \mathrm{E}-01\end{array}$ \\
\hline
\end{tabular}

\begin{tabular}{|c|c|c|c|c|c|c|c|}
\hline Dism.inferior (um & No Intervaio \% & Ism. Superior fum & Acum Abgiro\% & pism.inferior (um & No Intervalo \% & bism. Superior lum & Acum Aba $x 0 \%$ \\
\hline 0.05 & 0.00 & 0.06 & 0.00 & 6.63 & 0.00 & 7.72 & 0.01 \\
\hline 0.05 & 0.00 & 0.07 & 0.00 & 7.72 & 0.01 & 9.00 & 0.01 \\
\hline 0.07 & 0.00 & 0.08 & 0.00 & 900 & 0.02 & 10.48 & 0.03 \\
\hline 0.08 & 0.00 & 0.09 & 0.00 & 10.48 & 0.02 & 1221 & 0.05 \\
\hline 0.09 & 0.00 & 0.11 & 0.00 & 12.21 & 0.04 & 1422 & 0.09 \\
\hline 0.11 & 0.00 & 0.13 & 0.00 & 14.22 & 0.06 & 15.57 & 0.15 \\
\hline 0.13 & 0.00 & 0.15 & 0.00 & 16.57 & 0.10 & 19.31 & 0.25 \\
\hline 0.15 & 000 & 0.17 & 0.00 & 19.31 & 0.18 & 2249 & 0.43 \\
\hline 0.17 & 0.00 & 0.20 & 0.00 & 22.49 & 0.32 & 26.20 & 0.75 \\
\hline 0.20 & 0.00 & 0.23 & 0.00 & 25.20 & 0.54 & 3053 & 1.29 \\
\hline 0.23 & 0.00 & 0.27 & 0.00 & 30.53 & 0.90 & 35.56 & 2.19 \\
\hline 0.27 & 0.00 & 0.31 & 0.00 & 35.56 & 1.43 & 41.43 & 3.62 \\
\hline 0.31 & 0.00 & 0.36 & 0.00 & 41.43 & 2.20 & 48.27 & 5.82 \\
\hline 0.36 & 0.00 & 0.42 & 0.00 & 48.27 & 3.22 & 56.23 & 904 \\
\hline 0.42 & 0.00 & 0.49 & 0.00 & 56.23 & 4.50 & 65.51 & 13.53 \\
\hline 0.49 & 0.00 & 0.58 & 0.00 & 65.51 & 5.97 & 76.32 & 19.50 \\
\hline 0.58 & 0.00 & 0.67 & 0.00 & 76.32 & 7.55 & 88.91 & 27.05 \\
\hline 0.67 & 0.00 & 0.78 & 0.00 & 88.91 & 9.13 & 10358 & 36.19 \\
\hline 0.78 & 0.00 & 0.91 & 0.00 & 103.58 & 10.60 & 120.67 & 46.79 \\
\hline 0.91 & 0.00 & 1.06 & 0.00 & 120.67 & 11.90 & 140.58 & 58.69 \\
\hline 1.05 & 0.00 & 1.24 & 0.00 & 140.58 & 11.90 & 163.77 & 70.59 \\
\hline 1.24 & 0.00 & 1.44 & 0.00 & 163.77 & 10.58 & 190.80 & B1.18 \\
\hline 1.44 & 0.00 & 1.68 & 0.00 & 190.80 & 8.40 & 22228 & 89.57 \\
\hline 1.68 & 0.00 & 1.95 & 0.00 & 222.28 & 5.87 & 25895 & 95.44 \\
\hline 1.95 & 0.00 & 2.28 & 0.00 & 258.95 & 3.34 & 301.68 & 98.78 \\
\hline 2.28 & 0.00 & 265 & 0.00 & 301.68 & 1.03 & 351.46 & 99.81 \\
\hline 2.65 & 0.00 & 3.09 & 0.00 & 351.46 & 0.19 & 409.45 & 100.00 \\
\hline 3.09 & 0.00 & 3.60 & 0.00 & 409.45 & 0.00 & 477.01 & 100.00 \\
\hline 3.60 & 0.00 & 4.19 & 0.00 & 477.01 & 0.00 & 555.71 & 100.00 \\
\hline 4.19 & 0.00 & 4.88 & 0.00 & 555.71 & 0.00 & 647.41 & 100.00 \\
\hline 4.88 & 0.00 & 5.69 & 0.00 & 547.41 & 0.00 & 75423 & 100.00 \\
\hline 5.69 & 0.00 & 6.63 & 0.00 & 754.23 & 0.00 & 878.67 & 100.00 \\
\hline
\end{tabular}

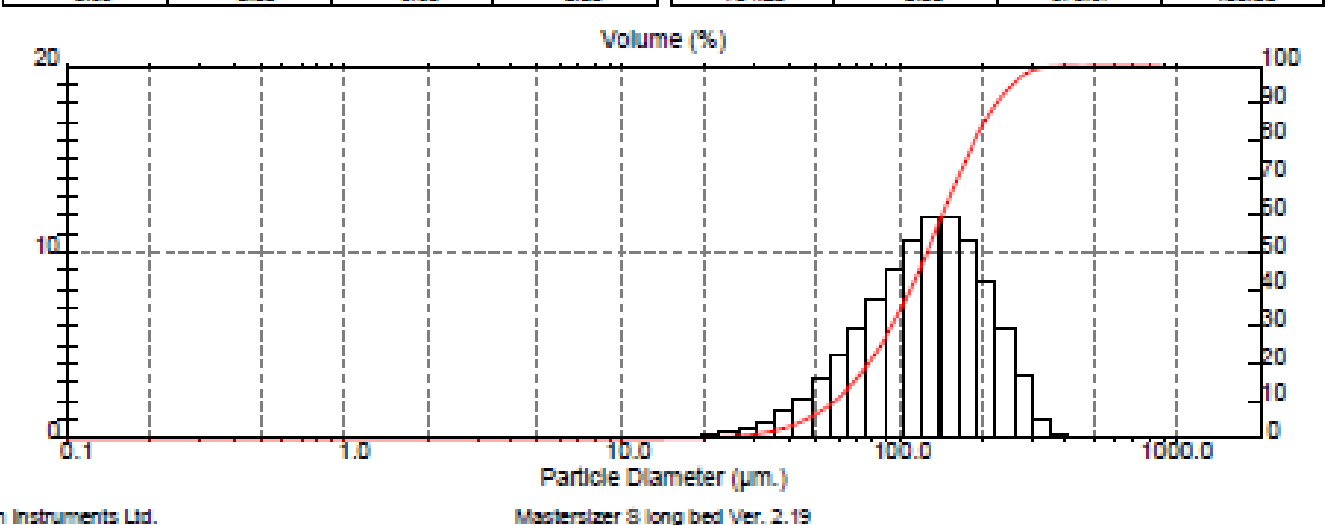

